Prepared for the U.S. Department of Energy

under Contract DE-AC05-76RL01830

\title{
Evaluation of Representative Smart Grid Investment Grant Project Technologies: Demand Response
}

JC Fuller

N Prakash Kumar

CA Bonebrake

February 2012

Pacific Northwest

NATIONAL LABORATORY

Proudly Operated by Battelle Since 1965 


\title{
DISCLAIMER
}

This report was prepared as an account of work sponsored by an agency of the United States Government. Neither the United States Government nor any agency thereof, nor Battelle Memorial Institute, nor any of their employees, makes any warranty, express or implied, or assumes any legal liability or responsibility for the accuracy, completeness, or usefulness of any information, apparatus, product, or process disclosed, or represents that its use would not infringe privately owned rights. Reference herein to any specific commercial product, process, or service by trade name, trademark, manufacturer, or otherwise does not necessarily constitute or imply its endorsement, recommendation, or favoring by the United States Government or any agency thereof, or Battelle Memorial Institute. The views and opinions of authors expressed herein do not necessarily state or reflect those of the United States Government or any agency thereof.

\author{
PACIFIC NORTHWEST NATIONAL LABORATORY \\ operated by \\ BATTELLE \\ for the \\ UNITED STATES DEPARTMENT OF ENERGY \\ under Contract DE-AC05-76RL01830
}

Printed in the United States of America
Available to DOE and DOE contractors from the Office of Scientific and Technical Information,
P.O. Box 62, Oak Ridge, TN 37831-0062;
ph: (865) 576-8401
fax: $(865)$ 576-5728
email: reports@adonis.osti.gov

\begin{abstract}
Available to the public from the National Technical Information Service, U.S. Department of Commerce, 5285 Port Royal Rd., Springfield, VA 22161 ph: (800) 553-6847 fax: $(703) 605-6900$ email: orders@ntis.fedworld.gov online ordering: http://www.ntis.gov/ordering.htm
\end{abstract}

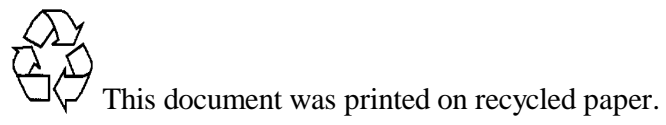




\title{
Evaluation of Representative Smart Grid Investment Grant Project Technologies: Demand Response
}

\author{
JC Fuller \\ N Prakash Kumar \\ CA Bonebrake
}

February 2012

Prepared for the U.S. Department of Energy under Contract DE-AC05-76RL01830

Pacific Northwest National Laboratory

Richland, Washington 99352 
Table of Contents

TABLE OF FIGURE

TABLE OF TABLES

XIV

SUMMARY.

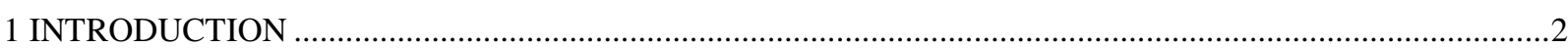

1.1 REPORT SCOPE.

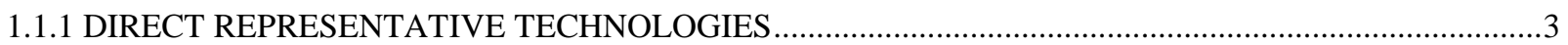

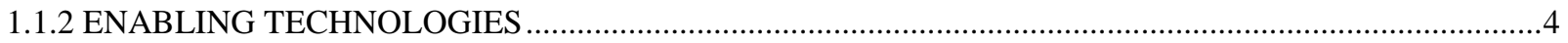

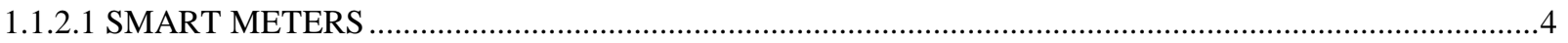

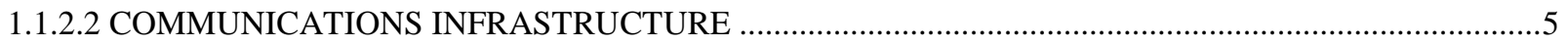

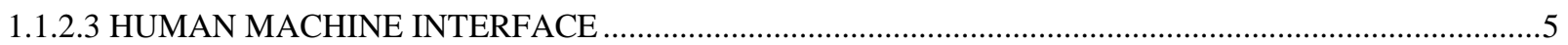

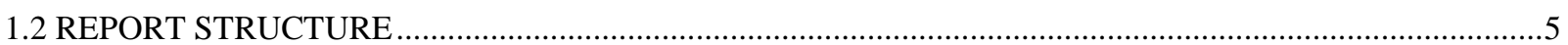

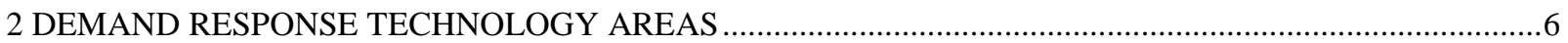

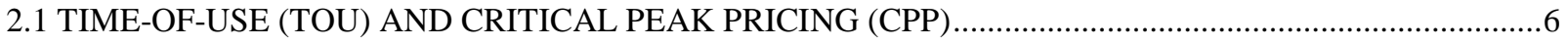

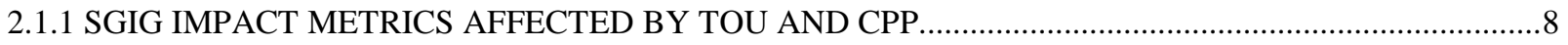

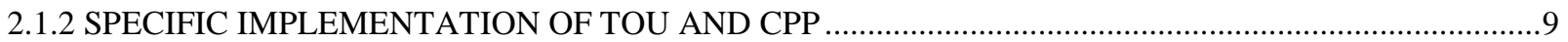

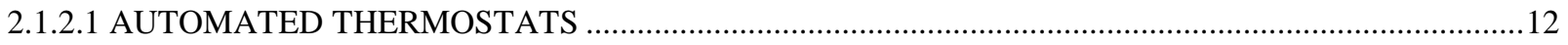

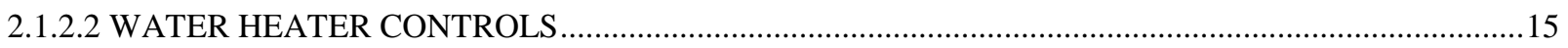

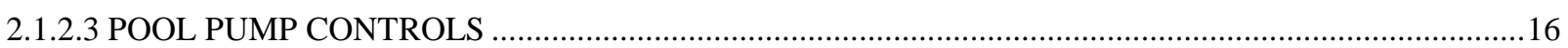

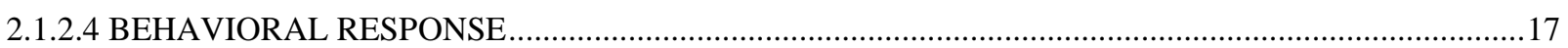

2.1.3 HIGH LEVEL TOU AND CPP SIMULATION RESULTS .......................................................................24

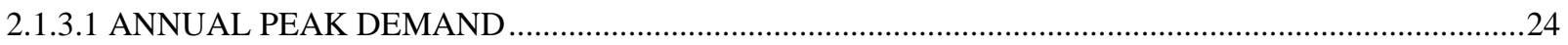

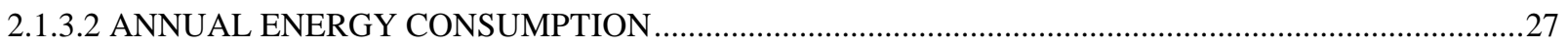

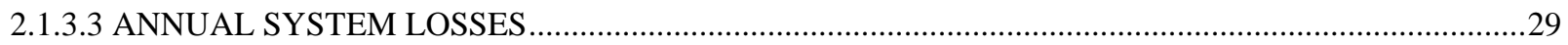

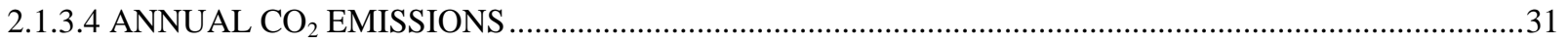

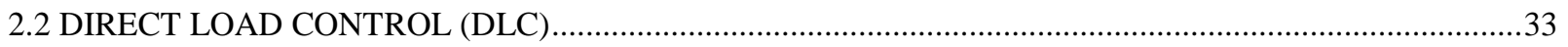

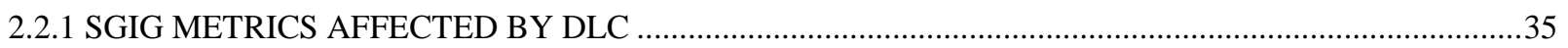

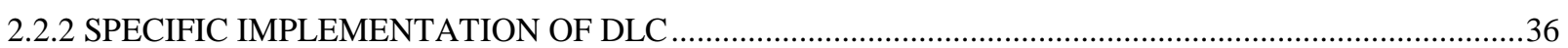

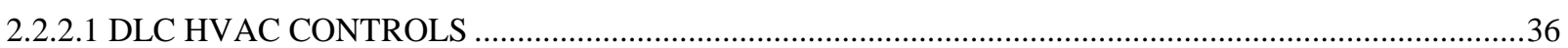

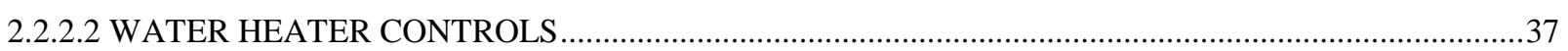

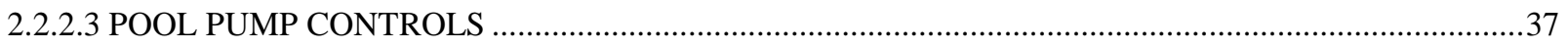

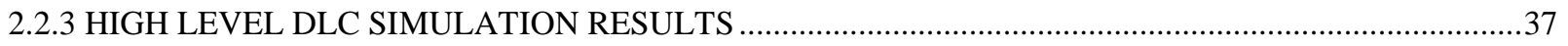

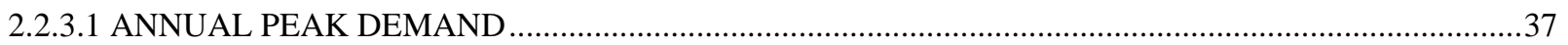

2.2.3.2 ANNUAL ENERGY CONSUMPTION

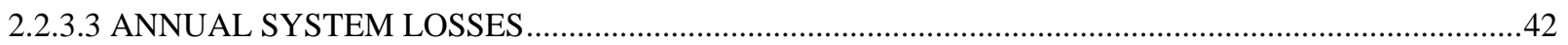

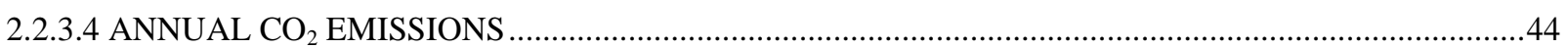

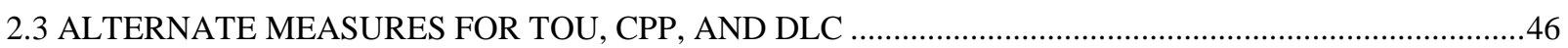

2.4 ALTERNATE PEAK METRICS FOR TOU, CPP, AND DLC ………………….............................................. 


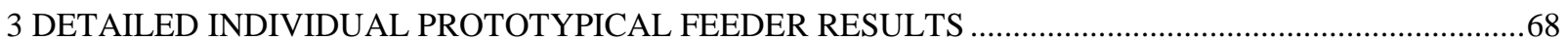

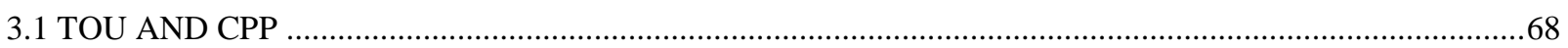

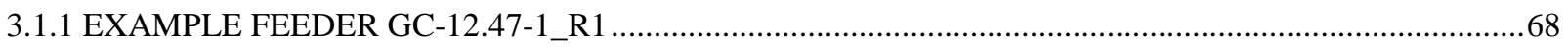

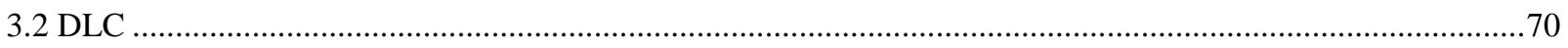

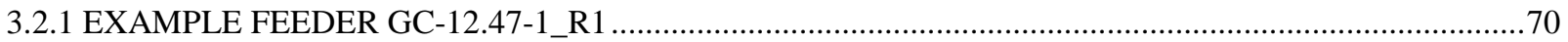

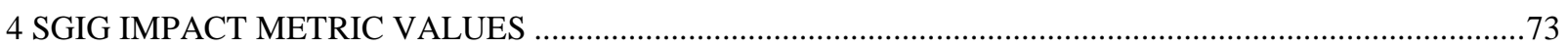

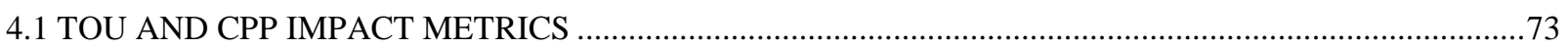

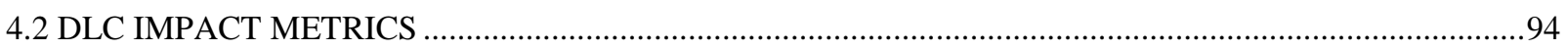

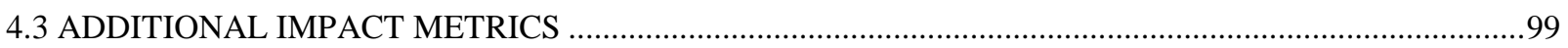

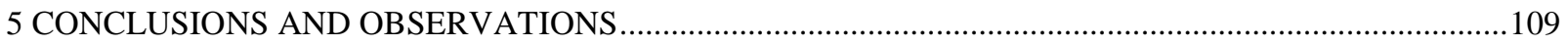

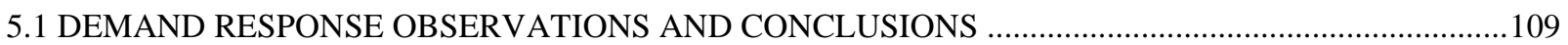

5.2 DEMAND RESPONSE OBSERVATIONS AND CONCLUSIONS SUMMARY …..................................111

5.3 CONCLUSIONS AND OBSERVATIONS FOR SPECIFIC TECHNOLOGIES …........................................111

5.3.1 CONCLUSIONS AND OBSERVATIONS FOR TOU AND TOU/CPP ..................................................111

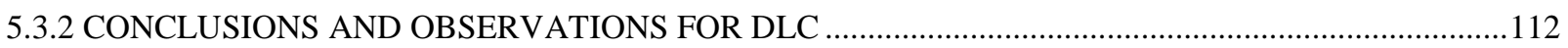

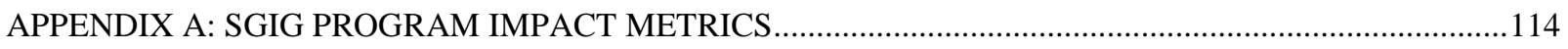

APPENDIX B: TAXONOMY OF PROTOTYPICAL DISTRIBUTION FEEDERS .....................................123

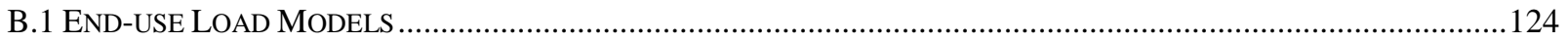

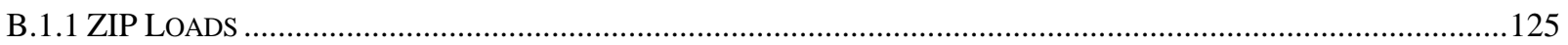

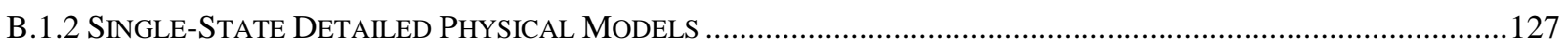

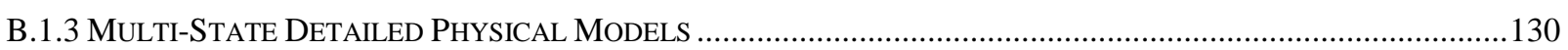

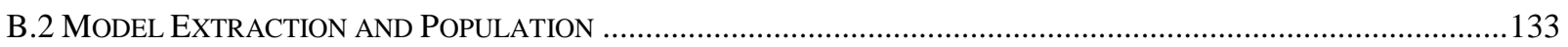

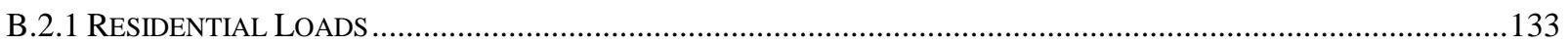

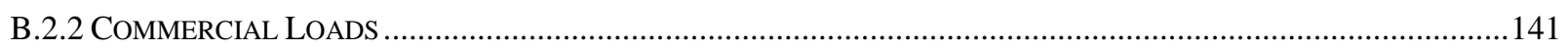

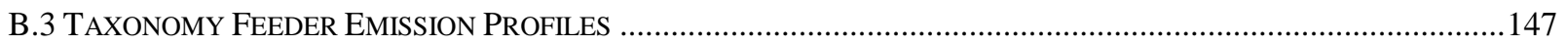

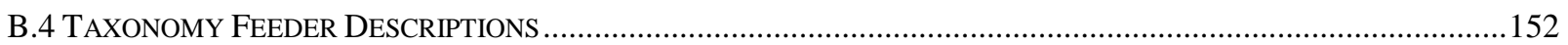

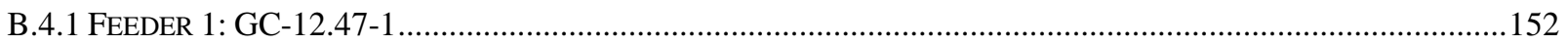

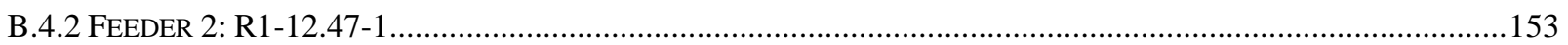

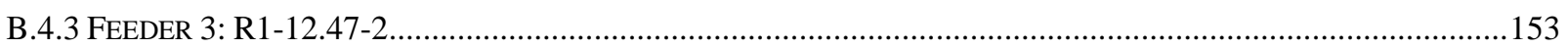

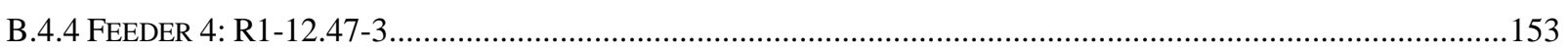

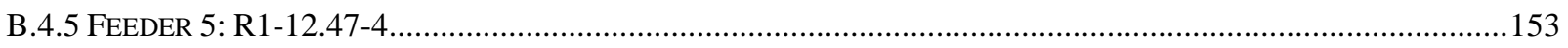

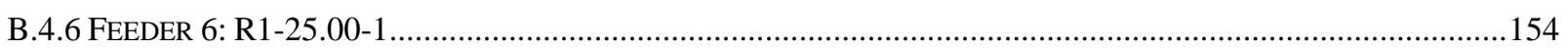

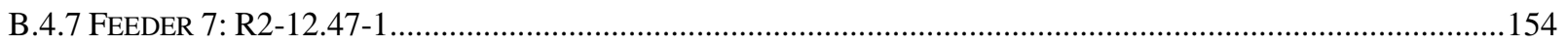

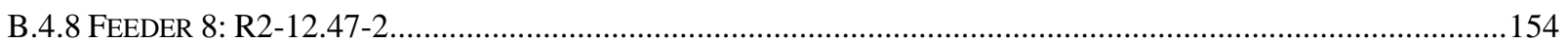

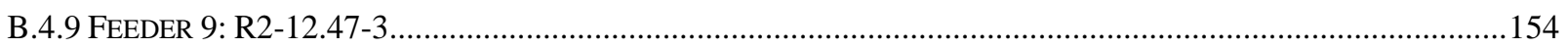

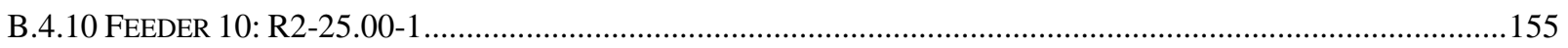

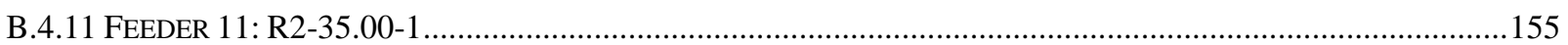

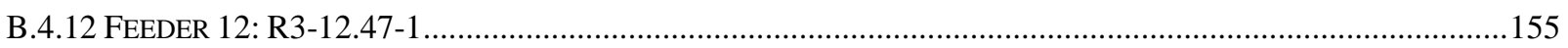

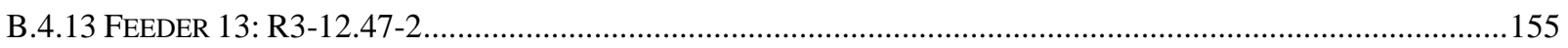

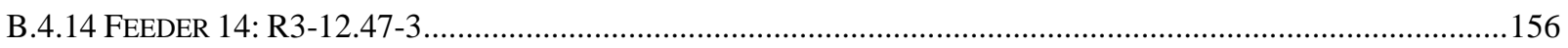




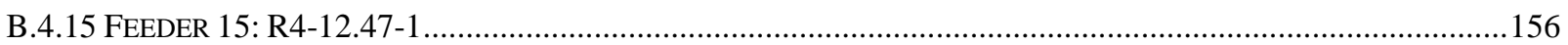

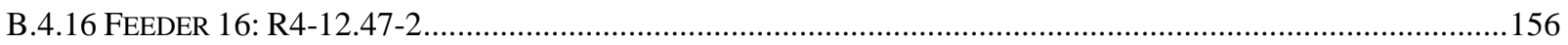

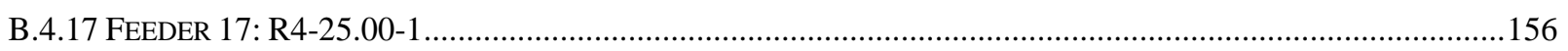

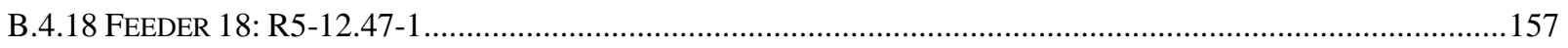

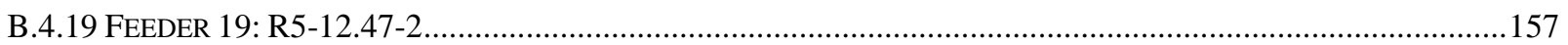

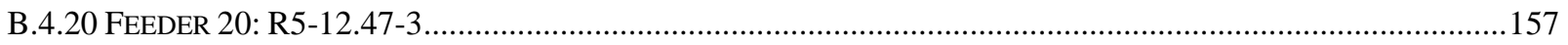

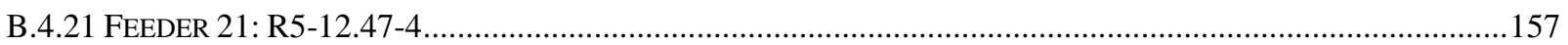

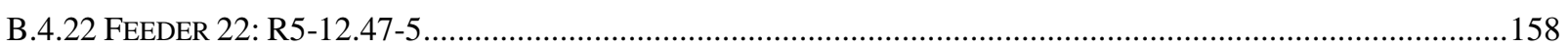

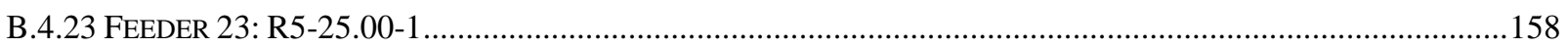

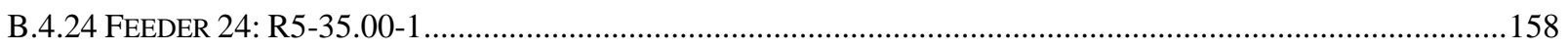

APPENDIX C: SIMULATION TECHNOLOGY AND METHODOLOGY ....................................................159

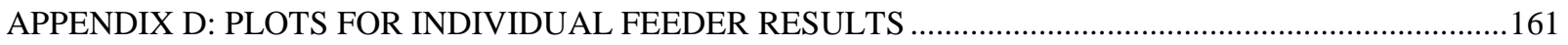

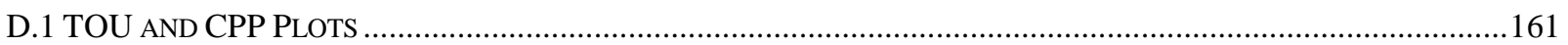

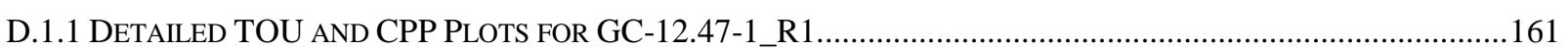

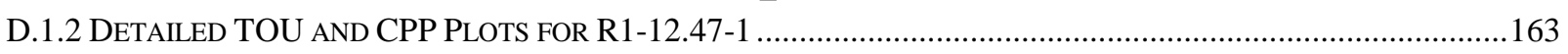

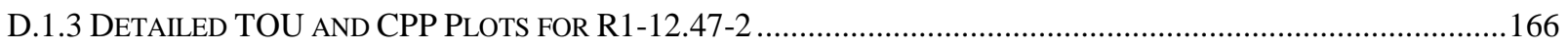

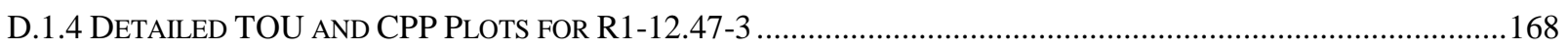

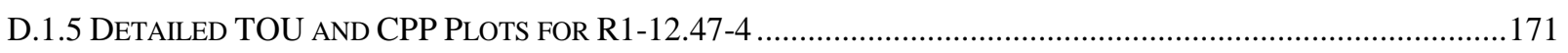

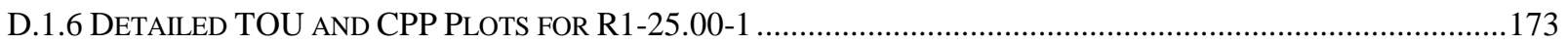

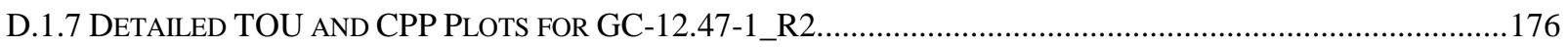

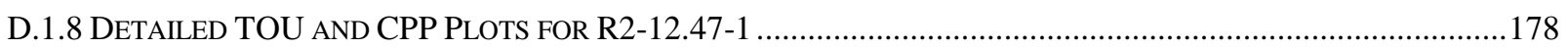

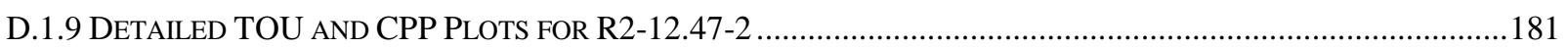

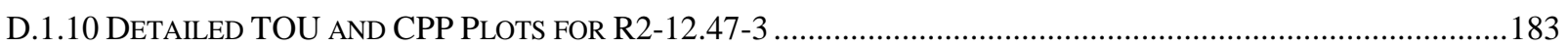

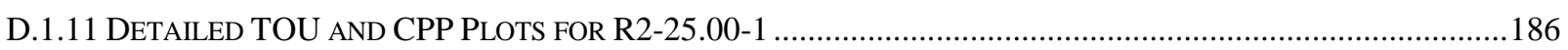

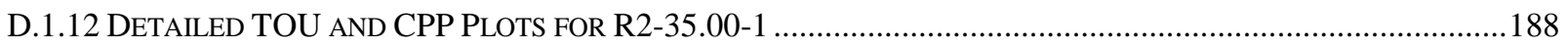

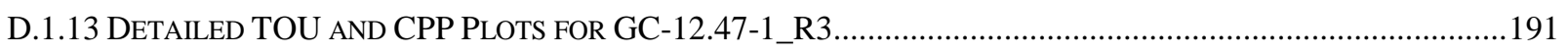

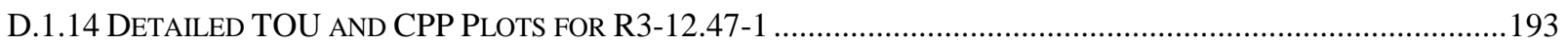

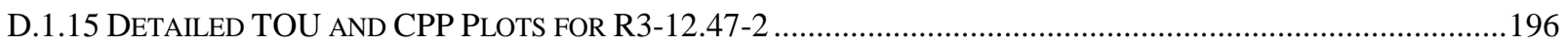

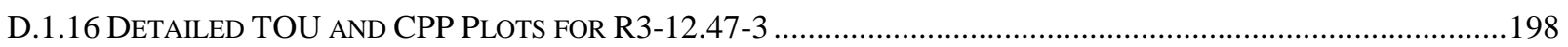

D.1.17 DETAILED TOU AND CPP PLOTS FOR GC-12.47-1_R4 _............................................................................201

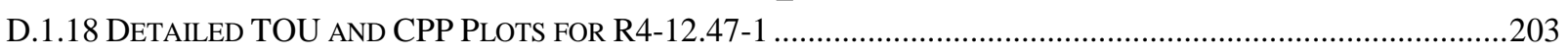

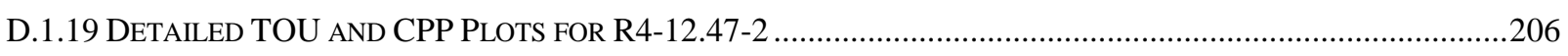

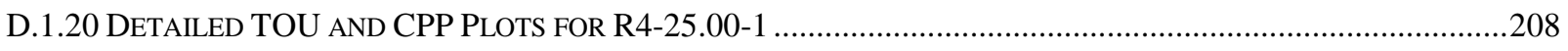

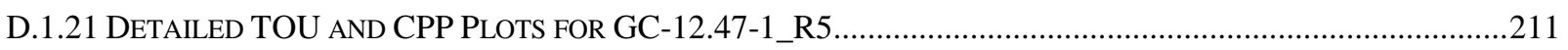

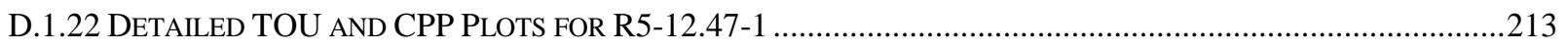

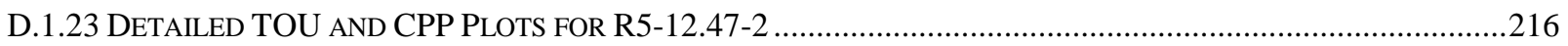

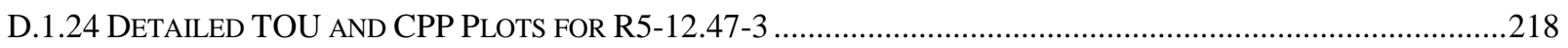

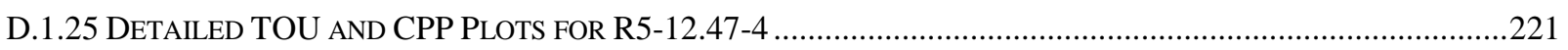

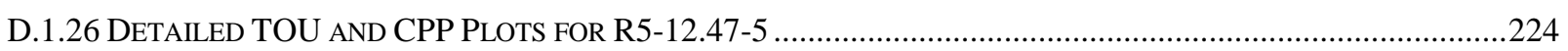

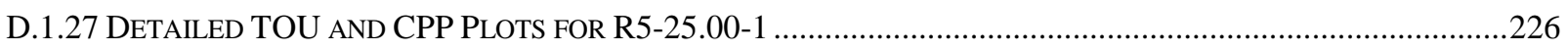

D.1.28 DETAILED TOU AND CPP PLOTS FOR R5-35.00-1 ….........................................................................228

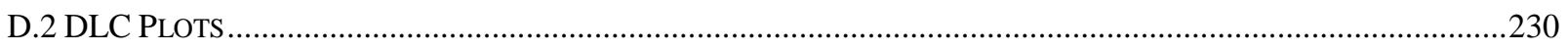

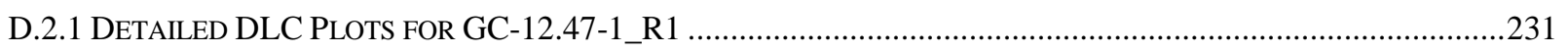

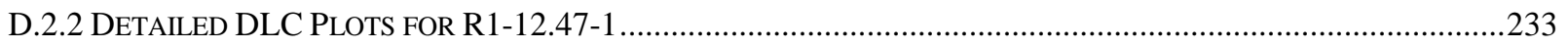




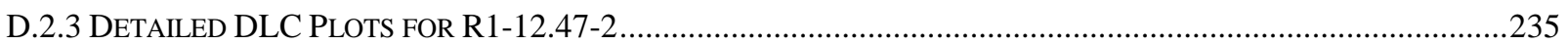

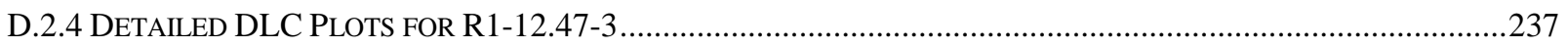

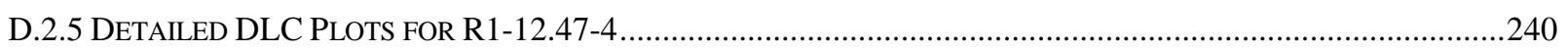

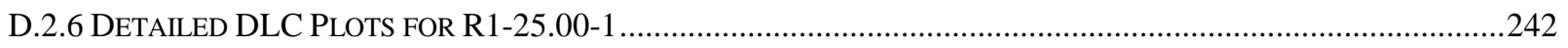

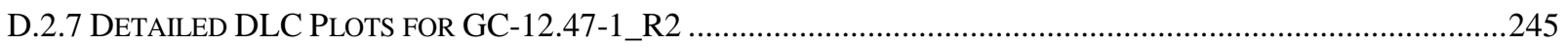

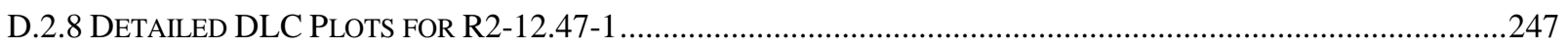

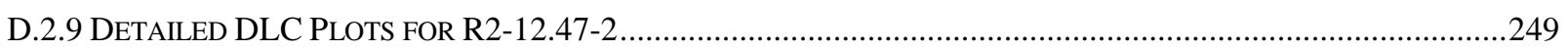

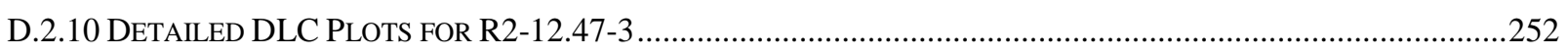

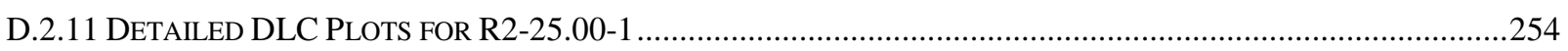

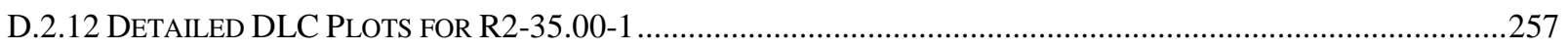

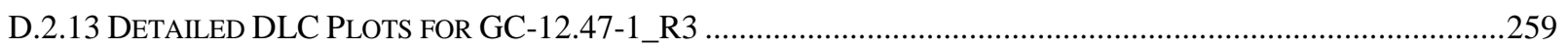

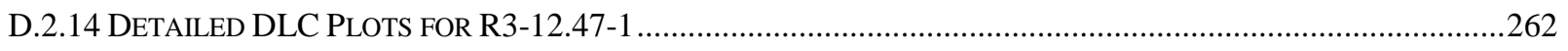

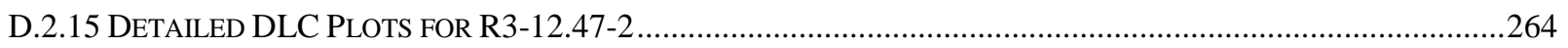

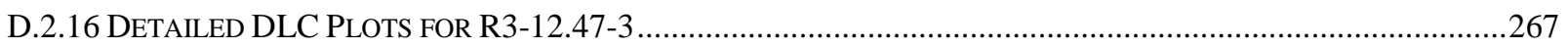

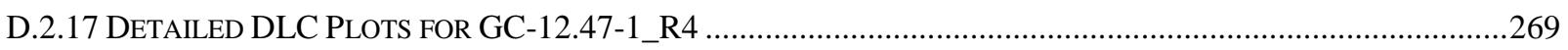

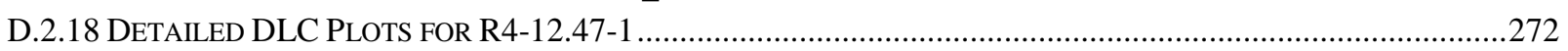

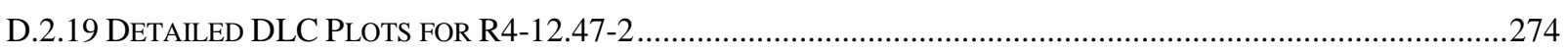

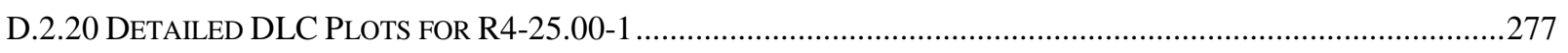

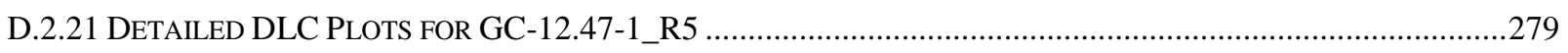

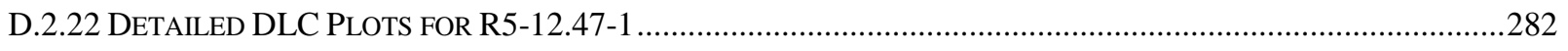

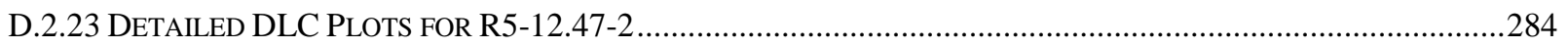

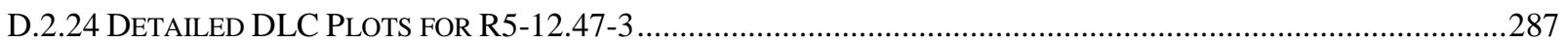

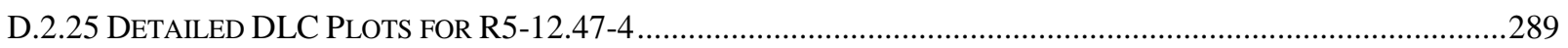

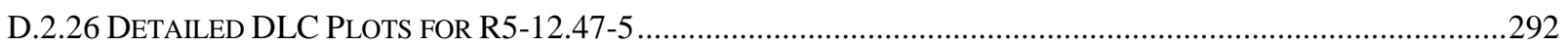

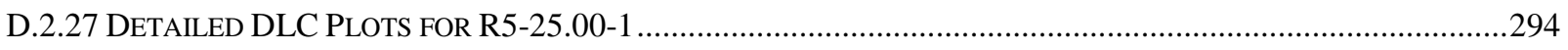

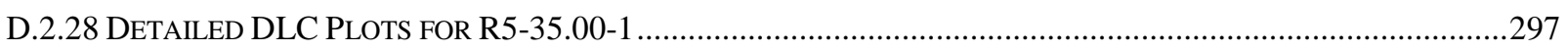

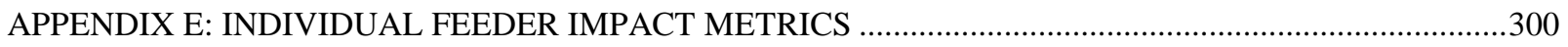

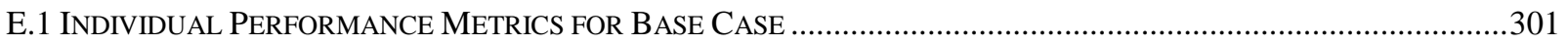

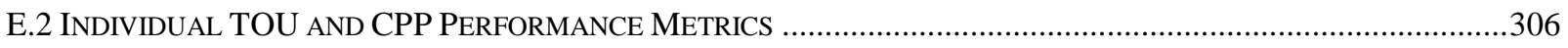

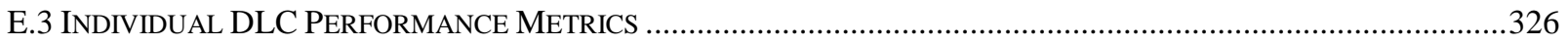

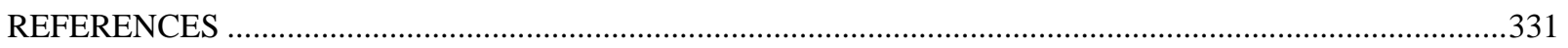




\section{Table of Figure}

Figure 2.1: Graphical representation of automated thermostat response …....................................................14

Figure 2.2: Distribution of customer response slider settings ........................................................................

Figure 2.3: Example of time series change in $\mathrm{Q}$ when changing from fixed to TOU rate structure ........................22

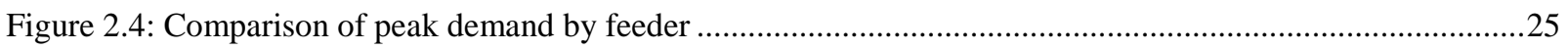

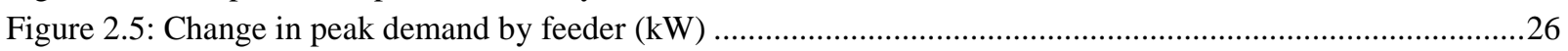

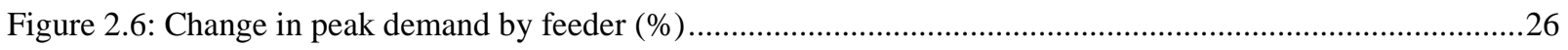

Figure 2.7: Comparison of annual energy consumption by feeder (MWh) .......................................................22

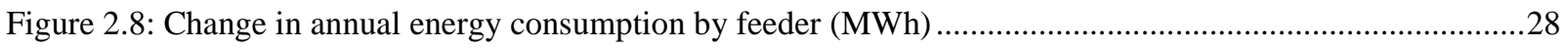

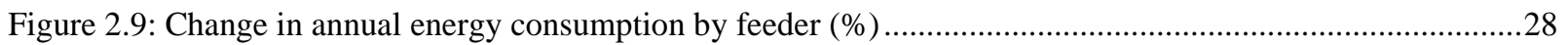

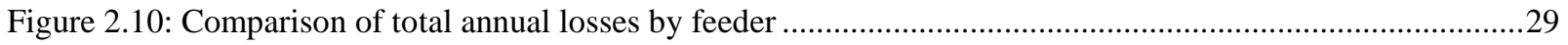

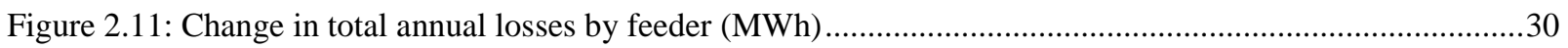

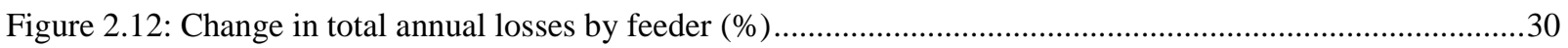

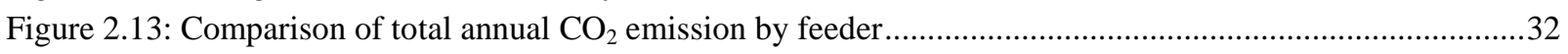

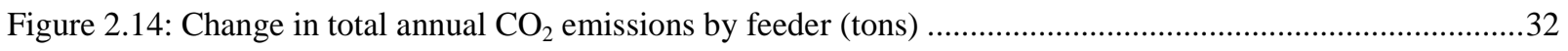

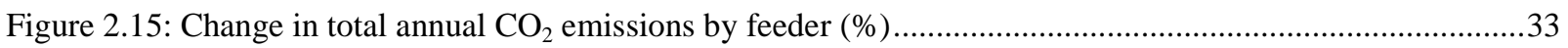

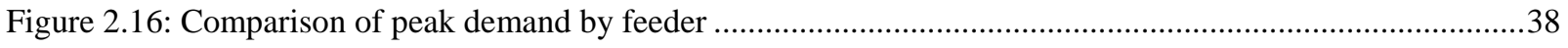

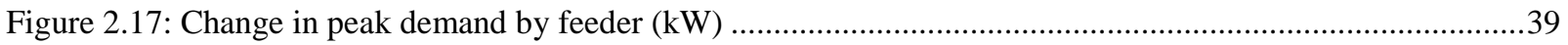

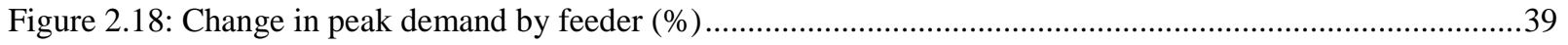

Figure 2.19: Comparison of annual energy consumption by feeder (MWh) .......................................................40

Figure 2.20: Change in annual energy consumption by feeder (MWh) ..........................................................

Figure 2.21: Change in annual energy consumption by feeder $(\%)$...................................................................4

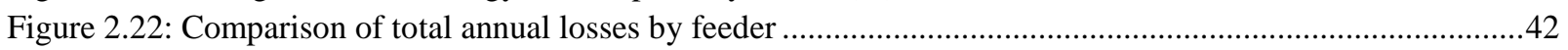

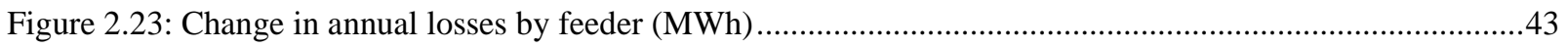

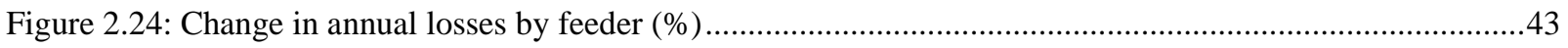

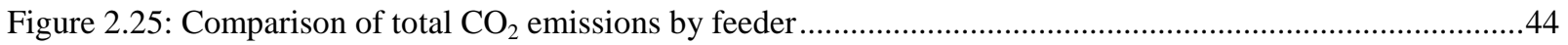

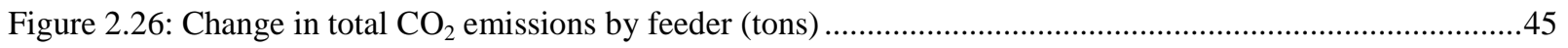

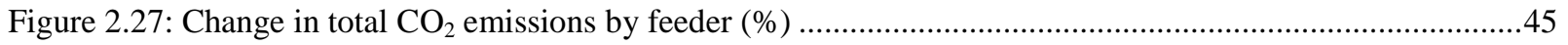

Figure 2.28: Times series comparison of TOU/CPP with enabling technologies on a peak day............................46

Figure 2.29: Times series comparison of TOU/CPP without enabling technologies on a peak day.......................47

Figure 2.30: Times series comparison of TOU with enabling technologies on a peak day. .....................................47

Figure 2.31: Times series comparison of TOU/CPP without enabling technologies on a peak day......................48

Figure 2.32: Times series comparison of DLC on a peak day. .......................................................................4

Figure 2.33: Differential equation solution to the ETP equation. ...................................................................50

Figure 2.34: Times series comparison of diversified controls on a peak day $(33 / 33 / 33) \ldots \ldots \ldots \ldots \ldots \ldots \ldots \ldots \ldots \ldots \ldots \ldots \ldots . . .52$

Figure 2.35: Times series comparison of diversified controls on a peak day $(20 / 40 / 20 / 20) \ldots \ldots \ldots \ldots \ldots \ldots \ldots \ldots \ldots \ldots \ldots . . .53$

Figure 2.36: Comparison of demand for a sample base case and a CPP signal at $12 \mathrm{pm}$...................................54

Figure 2.37: Comparison of demand for CPP signal starting at 6 different times. ...................................................54

Figure 2.38: Comparison of demand for a base case and with blended CPP start times........................................55

Figure 2.39: Times series example illustrating instantaneous peak reduction........................................................57

Figure 2.40: Times series example illustrating the one hour peak reduction.......................................................58

Figure 2.41: Times series example illustrating the six hour peak reduction........................................................59

Figure 2.42: Times series example illustrating the flattened peak load reduction................................................60

Figure 2.43: Times series example illustrating the flattened peak load including rebound....................................61

Figure 2.44: Comparison of load reduction for R3-12.47-3 CPP in kW.........................................................62

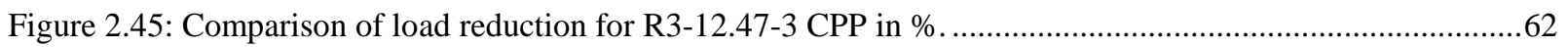

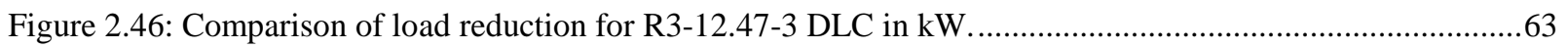




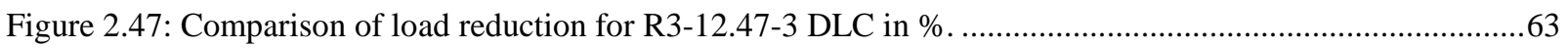

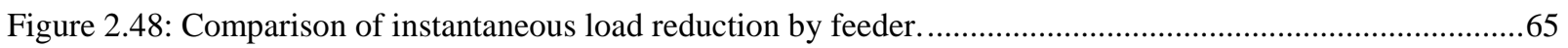

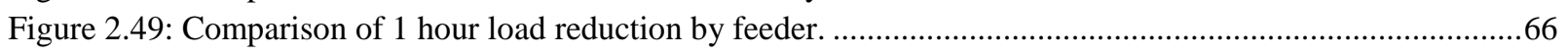

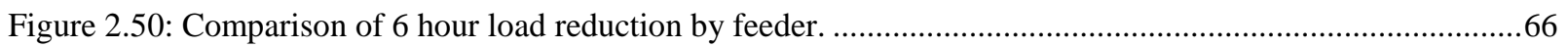

Figure 2.51: Comparison of average load reduction by feeder. …...................................................................67

Figure 2.52: Comparison of average load reduction while accounting for the rebound by feeder. ........................67

Figure B.1: Climate Zones Used for Development of Prototypical Feeders......................................................123

Figure B.2: Voltage dependent energy consumption of 13W CFL .....................................................................127

Figure B.3: The ETP mode of a residential heating/cooling system ...............................................................128

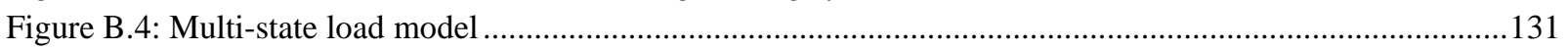

Figure B.5: Exemplary cooling set points diversified with time and daytime and nighttime offsets....................138

Figure B.6: Average cooling set points of entire population of R1-1247-2 ….............................................138

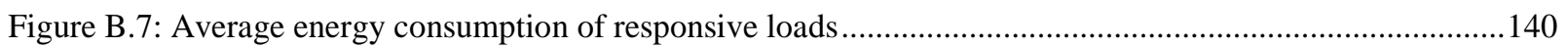

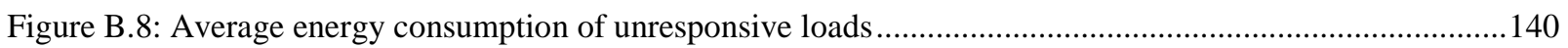

Figure B.9: Office zonal floor plan representing 1 of 3 identical floors ............................................................142

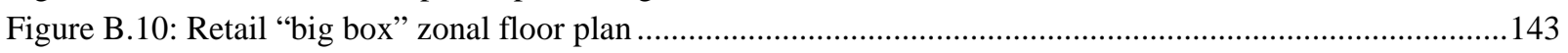

Figure B.11: Retail strip mall zonal floor plan with $\mathrm{N}$ zones depending upon scaling factor..............................144

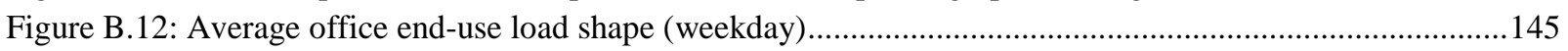

Figure B.13: Average office end-use load shape (weekend) ...........................................................................145

Figure B.14: Average big box and strip mall end-use load shape (weekday) .................................................146

Figure B.15: Average big box and strip mall end-use load shape (weekend) ................................................146

Figure B.16: Exemplary 15-minute interval comparing fuel dispatch for the peak load versus the base case load

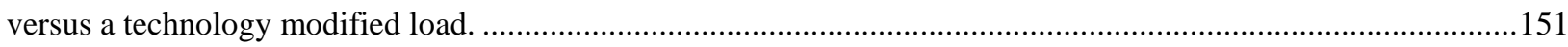

Figure D.1: Comparison of peak demand by month for GC-12.47-1_R1 ........................................................161

Figure D.2: Comparison of energy consumption by month for GC-12.47-1_R1 ................................................162

Figure D.3: Comparison of losses by month for GC-12.47-1_R1 ...................................................................162

Figure D.4: Comparison of $\mathrm{CO}_{2}$ emissions by month for GC-12.47-1_R1 …..............................................163

Figure D.5: Comparison of peak demand by month for R1-12.47-1 …...................................................... 164

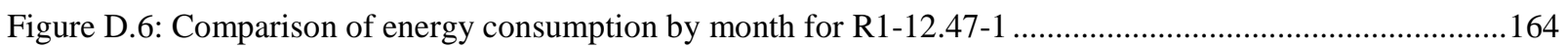

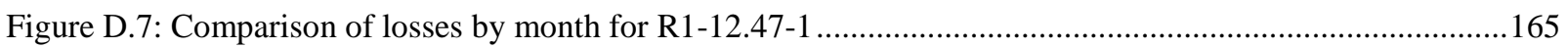

Figure D.8: Comparison of $\mathrm{CO}_{2}$ emissions by month for R1-12.47-1 …......................................................165

Figure D.9: Comparison of peak demand by month for R1-12.47-2 .............................................................166

Figure D.10: Comparison of energy consumption by month for R1-12.47-2 …..............................................167

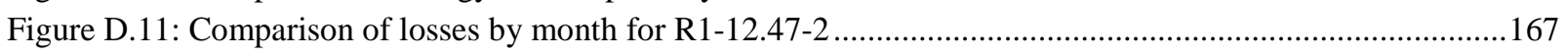

Figure D.12: Comparison of $\mathrm{CO}_{2}$ emissions by month for R1-12.47-2 .....................................................168

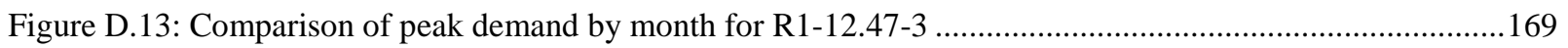

Figure D.14: Comparison of energy consumption by month for R1-12.47-3 ……..........................................169

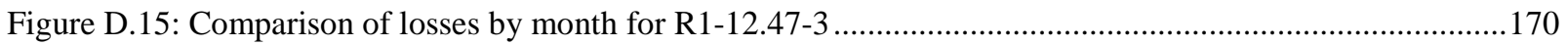

Figure D.16: Comparison of $\mathrm{CO}_{2}$ emissions by month for R1-12.47-3 ….......................................................170

Figure D.17: Comparison of peak demand by month for R1-12.47-4 .........................................................171

Figure D.18: Comparison of energy consumption by month for R1-12.47-4 …...............................................172

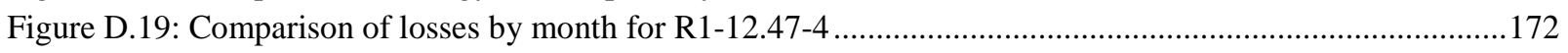

Figure D.20: Comparison of $\mathrm{CO}_{2}$ emissions by month for R1-12.47-4 ........................................................173

Figure D. 21: Comparison of peak demand by month for R1-25.00-1 ...........................................................174

Figure D. 22: Comparison of energy consumption by month for R1-25.00-1 ……...........................................174 
Figure D. 23: Comparison of losses by month for R1-25.00-1 ...................................................................175

Figure D. 24: Comparison of $\mathrm{CO}_{2}$ emissions by month for R1-25.00-1 .....................................................175

Figure D.25: Comparison of peak demand by month for GC-12.47-1_R2 .......................................................176

Figure D.26: Comparison of energy consumption by month for GC-12.47-1_R2 ……......................................177

Figure D.27: Comparison of losses by month for GC-12.47-1_R2 …..........................................................177

Figure D.28: Comparison of $\mathrm{CO}_{2}$ emissions by month for GC-12.47-1_R2 ……........................................178

Figure D.29: Comparison of peak demand by month for R2-12.47-1 ............................................................179

Figure D.30: Comparison of energy consumption by month for R2-12.47-1 …................................................179

Figure D.31: Comparison of losses by month for R2-12.47-1 ......................................................................180

Figure D.32: Comparison of $\mathrm{CO}_{2}$ emissions by month for R2-12.47-1 ........................................................180

Figure D.33: Comparison of peak demand by month for R2-12.47-2 ….................................................... 181

Figure D.34: Comparison of energy consumption by month for R2-12.47-2 ….............................................182

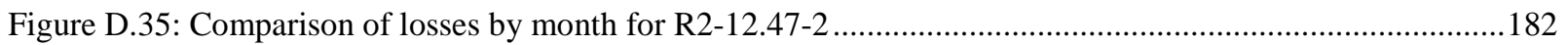

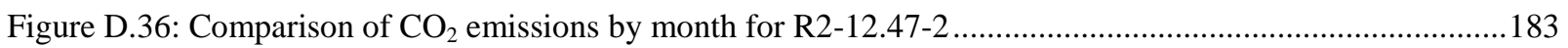

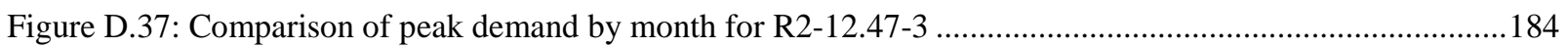

Figure D.38: Comparison of energy consumption by month for R2-12.47-3 ….................................................184

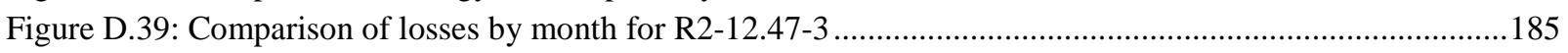

Figure D.40: Comparison of $\mathrm{CO}_{2}$ emissions by month for R2-12.47-3 …..................................................185

Figure D.41: Comparison of peak demand by month for R2-25.00-1 …....................................................186

Figure D.42: Comparison of energy consumption by month for R2-25.00-1 ....................................................187

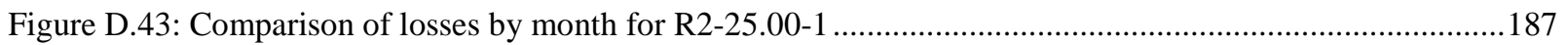

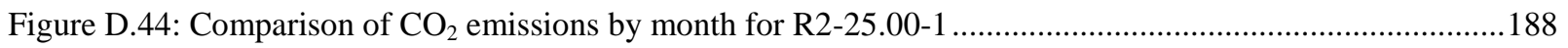

Figure D.45: Comparison of peak demand by month for R2-35.00-1 .......................................................... 189

Figure D.46: Comparison of energy consumption by month for R2-35.00-1 …...................................................189

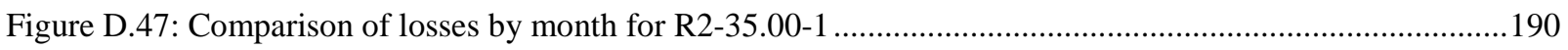

Figure D.48: Comparison of $\mathrm{CO}_{2}$ emissions by month for R2-35.00-1 ............................................................190

Figure D.49: Comparison of peak demand by month for GC-12.47-1_R3 ..........................................................191

Figure D.50: Comparison of energy consumption by month for GC-12.47-1_R3 ............................................192

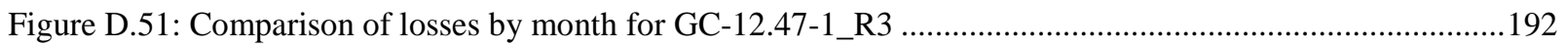

Figure D.52: Comparison of $\mathrm{CO}_{2}$ emissions by month for GC-12.47-1_R3 …….........................................193

Figure D.53: Comparison of peak demand by month for R3-12.47-1 ........................................................... 194

Figure D.54: Comparison of energy consumption by month for R3-12.47-1 …..................................................194

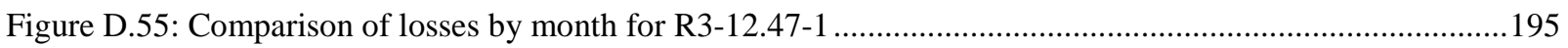

Figure D.56: Comparison of $\mathrm{CO}_{2}$ emissions by month for R3-12.47-1 ...........................................................195

Figure D.57: Comparison of peak demand by month for R3-12.47-2 ….....................................................196

Figure D.58: Comparison of energy consumption by month for R3-12.47-2 …..........................................197

Figure D.59: Comparison of losses by month for R3-12.47-2 ..............................................................197

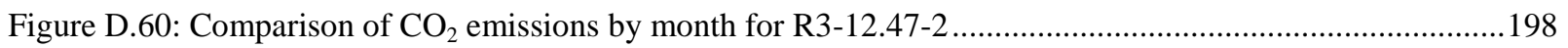

Figure D.61: Comparison of peak demand by month for R3-12.47-3 ….....................................................199

Figure D.62: Comparison of energy consumption by month for R3-12.47-3 ……..........................................199

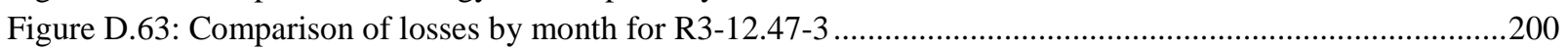

Figure D.64: Comparison of $\mathrm{CO}_{2}$ emissions by month for R3-12.47-3 ...........................................................200

Figure D.65: Comparison of peak demand by month for GC-12.47-1_R4 …...................................................201

Figure D.66: Comparison of energy consumption by month for GC-12.47-1_R4 …………………................202

Figure D.67: Comparison of losses by month for GC-12.47-1_R4 …….....................................................202

Figure D.68: Comparison of $\mathrm{CO}_{2}$ emissions by month for GC-12.47-1_R4 …………...................................203

Figure D.69: Comparison of peak demand by month for R4-12.47-1 ….........................................................204 
Figure D.70: Comparison of energy consumption by month for R4-12.47-1 …............................................204

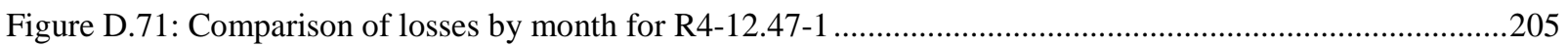

Figure D.72: Comparison of $\mathrm{CO}_{2}$ emissions by month for R4-12.47-1 …......................................................205

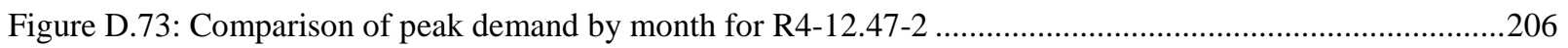

Figure D.74: Comparison of energy consumption by month for R4-12.47-2 ................................................207

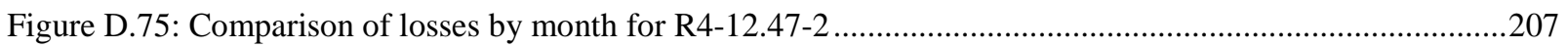

Figure D.76: Comparison of $\mathrm{CO}_{2}$ emissions by month for R4-12.47-2 ….........................................................208

Figure D.77: Comparison of peak demand by month for R4-25.00-1 ............................................................209

Figure D.78: Comparison of energy consumption by month for R4-25.00-1 .....................................................209

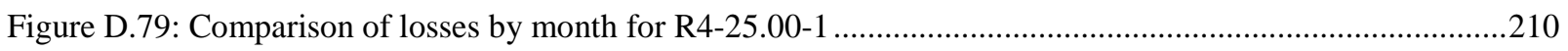

Figure D.80: Comparison of $\mathrm{CO}_{2}$ emissions by month for R4-25.00-1 .......................................................210

Figure D.81: Comparison of peak demand by month for GC-12.47-1_R5 ......................................................211

Figure D.82: Comparison of energy consumption by month for GC-12.47-1_R5 ...........................................212

Figure D.83: Comparison of losses by month for GC-12.47-1_R5 …......................................................212

Figure D.84: Comparison of $\mathrm{CO}_{2}$ emissions by month for GC-12.47-1_R5 …................................................213

Figure D.85: Comparison of peak demand by month for R5-12.47-1 ….....................................................214

Figure D.86: Comparison of energy consumption by month for R5-12.47-1 .................................................214

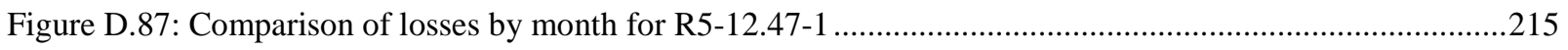

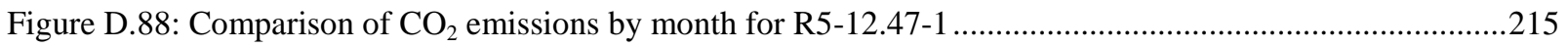

Figure D.89: Comparison of peak demand by month for R5-12.47-2 …......................................................216

Figure D.90: Comparison of energy consumption by month for R5-12.47-2 …...........................................217

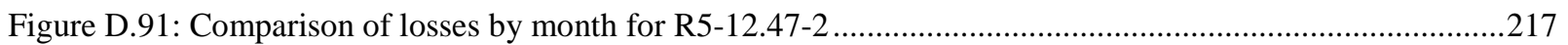

Figure D.92: Comparison of $\mathrm{CO}_{2}$ emissions by month for R5-12.47-2 ….......................................................218

Figure D.93: Comparison of peak demand by month for R5-12.47-3 ….........................................................219

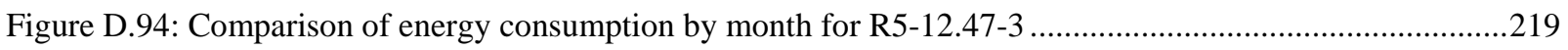

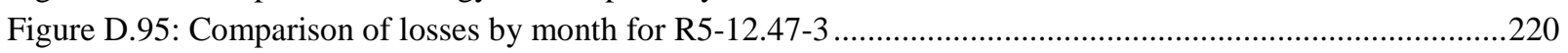

Figure D.96: Comparison of $\mathrm{CO}_{2}$ emissions by month for R5-12.47-3 ..........................................................220

Figure D.97: Comparison of peak demand by month for R5-12.47-4 .........................................................221

Figure D.98: Comparison of energy consumption by month for R5-12.47-4 ...............................................222

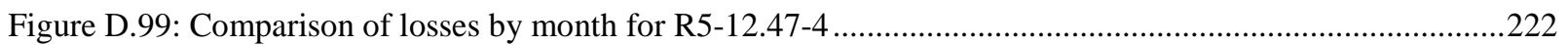

Figure D.100: Comparison of $\mathrm{CO}_{2}$ emissions by month for R5-12.47-4 ........................................................223

Figure D.101: Comparison of peak demand by month for R5-12.47-5 ……....................................................224

Figure D.102: Comparison of energy consumption by month for R5-12.47-5 …...............................................224

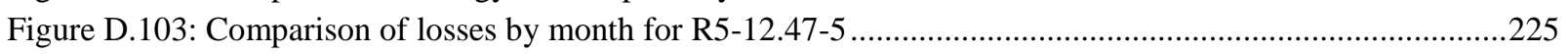

Figure D.104: Comparison of $\mathrm{CO}_{2}$ emissions by month for R5-12.47-5 …..................................................225

Figure D.105: Comparison of peak demand by month for R5-25.00-1 .........................................................226

Figure D.106: Comparison of energy consumption by month for R5-25.00-1 …............................................227

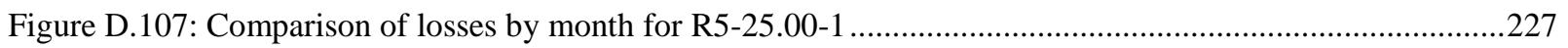

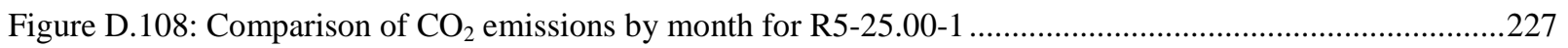

Figure D.109: Comparison of peak demand by month for R5-35.00-1 …....................................................228

Figure D.110: Comparison of energy consumption by month for R5-35.00-1 …................................................229

Figure D.111: Comparison of losses by month for R5-35.00-1 ….............................................................229

Figure D.112: Comparison of $\mathrm{CO}_{2}$ emissions by month for R5-35.00-1 ….....................................................230

Figure D.113: Comparison of peak demand by month for GC-12.47-1_R1 ......................................................231

Figure D.114: Comparison of energy consumption by month for GC-12.47-1_R1 ..........................................2231

Figure D.115: Comparison of losses by month for GC-12.47-1_R1 ….......................................................232

Figure D.116: Comparison of $\mathrm{CO}_{2}$ emissions by month for GC-12.47-1_R1 ………......................................2232 


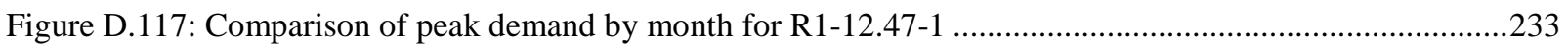

Figure D.118: Comparison of energy consumption by month for R1-12.47-1 ….........................................234

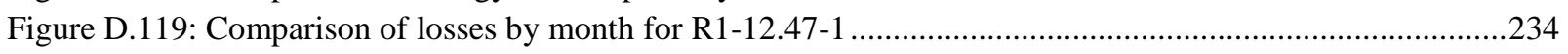

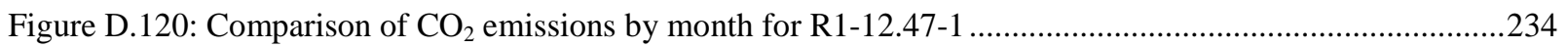

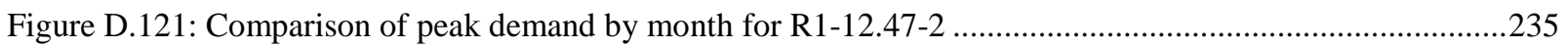

Figure D.122: Comparison of energy consumption by month for R1-12.47-2 ............................................236

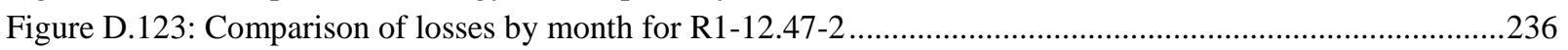

Figure D.124: Comparison of $\mathrm{CO}_{2}$ emissions by month for R1-12.47-2 ..........................................................237

Figure D.125: Comparison of peak demand by month for R1-12.47-3 .............................................................238

Figure D.126: Comparison of energy consumption by month for R1-12.47-3 …............................................23

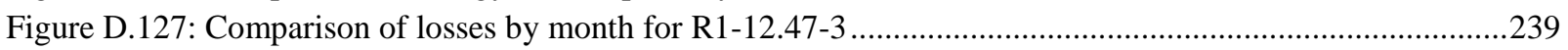

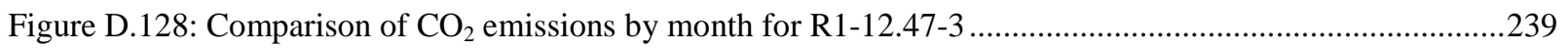

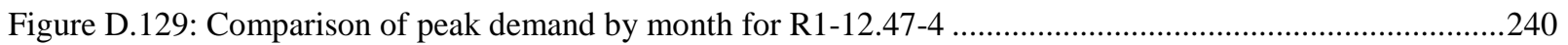

Figure D.130: Comparison of energy consumption by month for R1-12.47-4 …............................................241

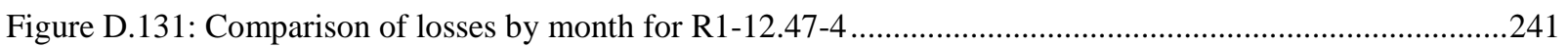

Figure D.132: Comparison of $\mathrm{CO}_{2}$ emissions by month for R1-12.47-4 ...........................................................242

Figure D.133: Comparison of peak demand by month for R1-25.00-1 ........................................................243

Figure D.134: Comparison of energy consumption by month for R1-25.00-1 .................................................243

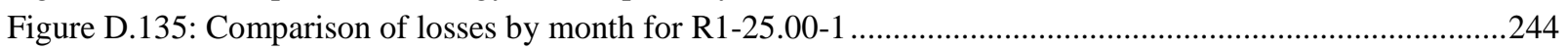

Figure D.136: Comparison of $\mathrm{CO}_{2}$ emissions by month for R1-25.00-1 .........................................................244

Figure D. 137: Comparison of peak demand by month for GC-12.47-1_R2 ……........................................245

Figure D. 138: Comparison of energy consumption by month for GC-12.47-1_R2 .........................................246

Figure D. 139: Comparison of losses by month for GC-12.47-1_R2 .........................................................246

Figure D. 140: Comparison of $\mathrm{CO}_{2}$ emissions by month for GC-12.47-1_R2 ….................................................246

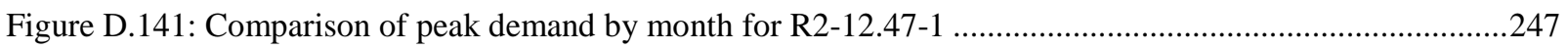

Figure D.142: Comparison of energy consumption by month for R2-12.47-1 ..................................................248

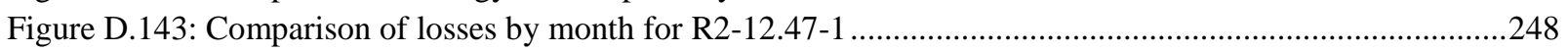

Figure D.144: Comparison of $\mathrm{CO}_{2}$ emissions by month for R2-12.47-1 …......................................................249

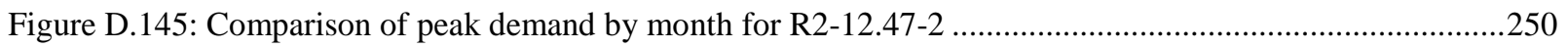

Figure D.146: Comparison of energy consumption by month for R2-12.47-2 .............................................250

Figure D.147: Comparison of losses by month for R2-12.47-2 ….............................................................251

Figure D.148: Comparison of $\mathrm{CO}_{2}$ emissions by month for R2-12.47-2 ….....................................................251

Figure D.149: Comparison of peak demand by month for R2-12.47-3 ......................................................252

Figure D.150: Comparison of energy consumption by month for R2-12.47-3 .................................................253

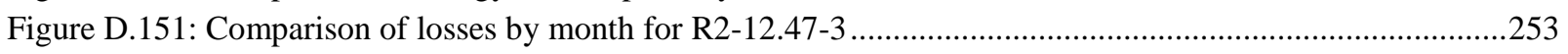

Figure D.152: Comparison of $\mathrm{CO}_{2}$ emissions by month for R2-12.47-3 ......................................................254

Figure D.153: Comparison of peak demand by month for R2-25.00-1 .......................................................255

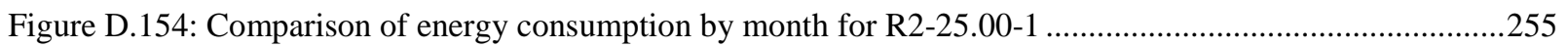

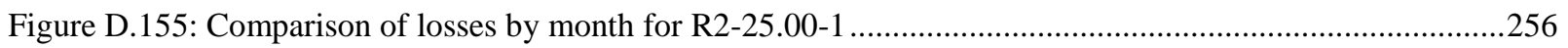

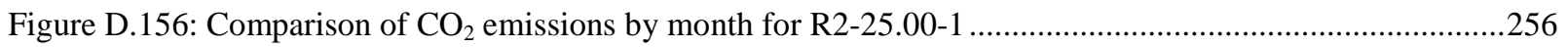

Figure D.157: Comparison of peak demand by month for R2-35.00-1 …........................................................257

Figure D.158: Comparison of energy consumption by month for R2-35.00-1 .................................................258

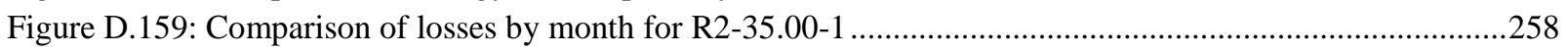

Figure D.160: Comparison of $\mathrm{CO}_{2}$ emissions by month for R2-35.00-1 ….......................................................259

Figure D.161: Comparison of peak demand by month for GC-12.47-1_R3 …..................................................260

Figure D.162: Comparison of energy consumption by month for GC-12.47-1_R3 ............................................260

Figure D.163: Comparison of losses by month for GC-12.47-1_R3 …………………………….....................261 
Figure D.164: Comparison of $\mathrm{CO}_{2}$ emissions by month for GC-12.47-1_R3 ……………………………......261

Figure D.165: Comparison of peak demand by month for R3-12.47-1 ........................................................262

Figure D.166: Comparison of energy consumption by month for R3-12.47-1 ..................................................263

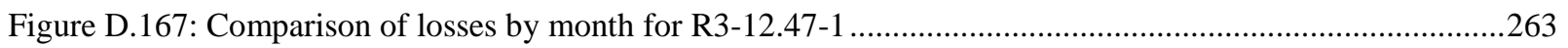

Figure D.168: Comparison of $\mathrm{CO}_{2}$ emissions by month for R3-12.47-1 ........................................................264

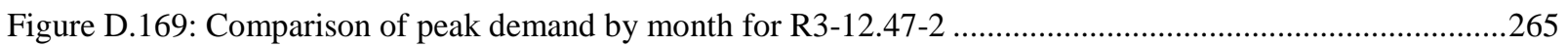

Figure D.170: Comparison of energy consumption by month for R3-12.47-2 ….................................................265

Figure D.171: Comparison of losses by month for R3-12.47-2 …..............................................................26

Figure D.172: Comparison of $\mathrm{CO}_{2}$ emissions by month for R3-12.47-2 .............................................................266

Figure D.173: Comparison of peak demand by month for R3-12.47-3 .......................................................267

Figure D.174: Comparison of energy consumption by month for R3-12.47-3 …............................................268

Figure D.175: Comparison of losses by month for R3-12.47-3 …..............................................................268

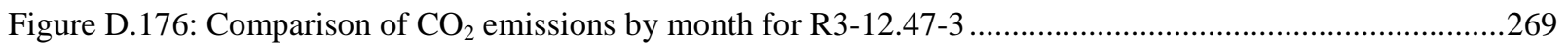

Figure D.177: Comparison of peak demand by month for GC-12.47-1_R4 …................................................270

Figure D.178: Comparison of energy consumption by month for GC-12.47-1_R4 ….........................................2270

Figure D.179: Comparison of losses by month for GC-12.47-1_R4 ……..................................................271

Figure D.180: Comparison of $\mathrm{CO}_{2}$ emissions by month for GC-12.47-1_R4 .................................................271

Figure D.181: Comparison of peak demand by month for R4-12.47-1 ............................................................272

Figure D.182: Comparison of energy consumption by month for R4-12.47-1 ...............................................273

Figure D.183: Comparison of losses by month for R4-12.47-1 ...................................................................273

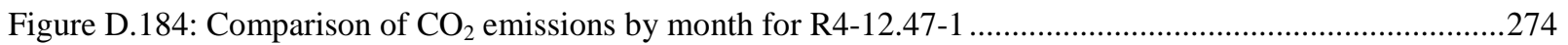

Figure D.185: Comparison of peak demand by month for R4-12.47-2 ….................................................275

Figure D.186: Comparison of energy consumption by month for R4-12.47-2 …...........................................275

Figure D.187: Comparison of losses by month for R4-12.47-2 ….................................................................276

Figure D.188: Comparison of $\mathrm{CO}_{2}$ emissions by month for R4-12.47-2 …......................................................276

Figure D.189: Comparison of peak demand by month for R4-25.00-1 ............................................................277

Figure D.190: Comparison of energy consumption by month for R4-25.00-1 .....................................................278

Figure D.191: Comparison of losses by month for R4-25.00-1 ….................................................................278

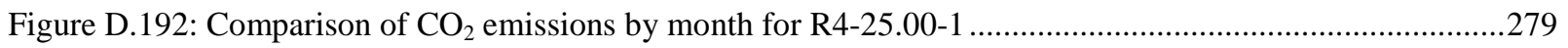

Figure D.193: Comparison of peak demand by month for GC-12.47-1_R5 …...................................................280

Figure D.194: Comparison of energy consumption by month for GC-12.47-1_R5 ..............................................280

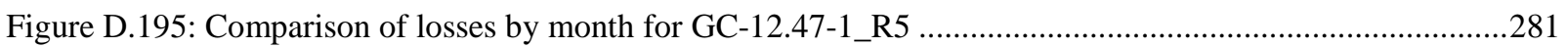

Figure D.196: Comparison of $\mathrm{CO}_{2}$ emissions by month for GC-12.47-1_R5 …….............................................281

Figure D.197: Comparison of peak demand by month for R5-12.47-1 ..........................................................282

Figure D.198: Comparison of energy consumption by month for R5-12.47-1 .................................................283

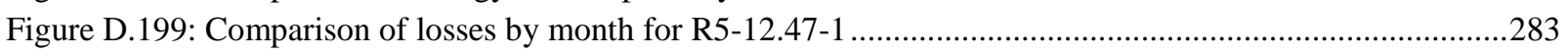

Figure D.200: Comparison of $\mathrm{CO}_{2}$ emissions by month for R5-12.47-1 .....................................................284

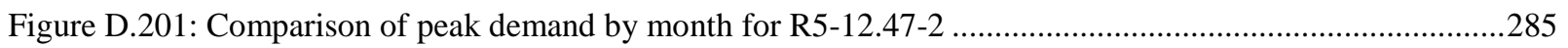

Figure D.202: Comparison of energy consumption by month for R5-12.47-2 …...........................................285

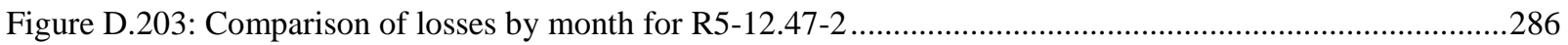

Figure D.204: Comparison of $\mathrm{CO}_{2}$ emissions by month for R5-12.47-2 ….....................................................286

Figure D.205: Comparison of peak demand by month for R5-12.47-3 .......................................................28

Figure D.206: Comparison of energy consumption by month for R5-12.47-3 ….............................................28

Figure D.207: Comparison of losses by month for R5-12.47-3 …...............................................................28

Figure D.208: Comparison of $\mathrm{CO}_{2}$ emissions by month for R5-12.47-3 …....................................................289

Figure D.209: Comparison of peak demand by month for R5-12.47-4 …....................................................290

Figure D.210: Comparison of energy consumption by month for R5-12.47-4 .................................................290 
Figure D.211: Comparison of losses by month for R5-12.47-4 .............................................................291

Figure D.212: Comparison of $\mathrm{CO}_{2}$ emissions by month for R5-12.47-4 .................................................291

Figure D.213: Comparison of peak demand by month for R5-12.47-5 ..............................................292

Figure D.214: Comparison of energy consumption by month for R5-12.47-5 ............................................293

Figure D.215: Comparison of losses by month for R5-12.47-5 ...............................................................293

Figure D.216: Comparison of $\mathrm{CO}_{2}$ emissions by month for R5-12.47-5 ...................................................294

Figure D.217: Comparison of peak demand by month for R5-25.00-1 ....................................................295

Figure D.218: Comparison of energy consumption by month for R5-25.00-1 ..........................................295

Figure D.219: Comparison of losses by month for R5-25.00-1 …..............................................................296

Figure D.220: Comparison of $\mathrm{CO}_{2}$ emissions by month for R5-25.00-1 ..................................................296

Figure D.221: Comparison of peak demand by month for R5-35.00-1 ….............................................297

Figure D.222: Comparison of energy consumption by month for R5-35.00-1 ...........................................298

Figure D.223: Comparison of losses by month for R5-35.00-1 .........................................................298

Figure D.224: Comparison of $\mathrm{CO}_{2}$ emissions by month for R5-35.00-1 .............................................299 


\section{Table of Tables}

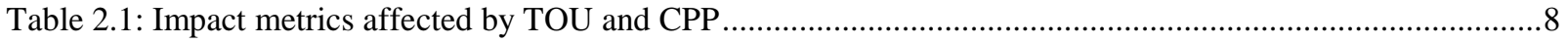

Table 2.2: Periods of low, high, and critical prices for each region.............................................................. 10

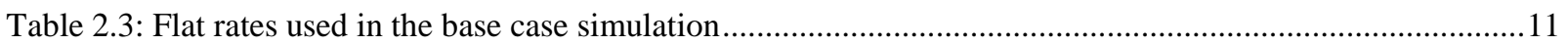

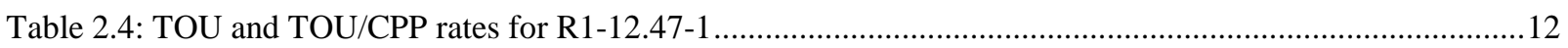

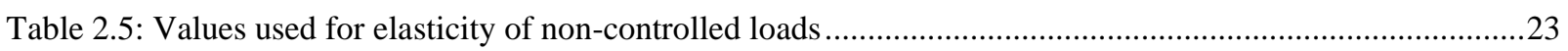

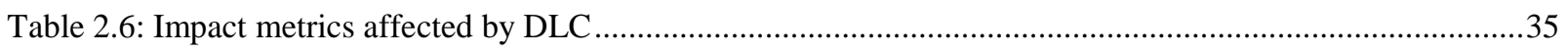

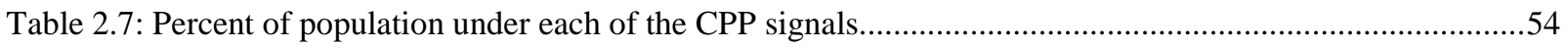

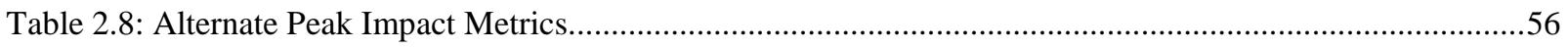

Table 4.1: TOU without enabling technologies impact metrics for region 1 ........................................................74

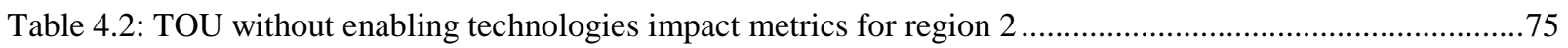

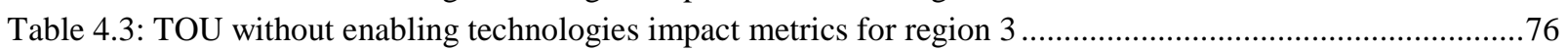

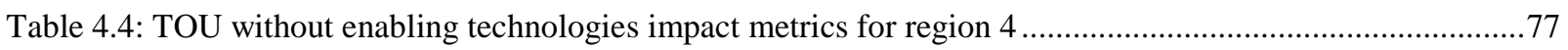

Table 4.5: TOU without enabling technologies impact metrics for region 5 ........................................................78

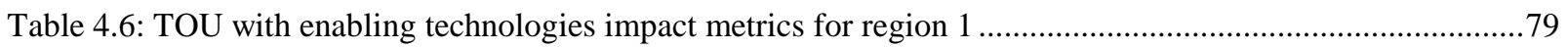

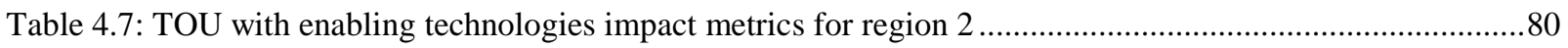

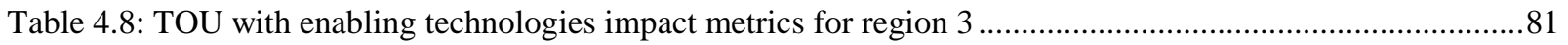

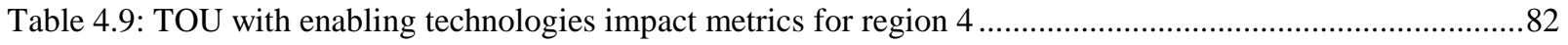

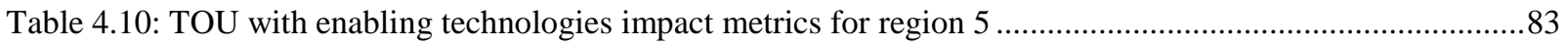

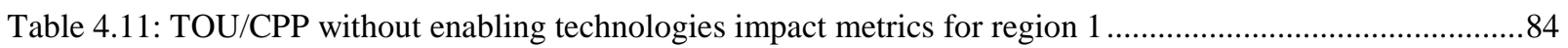

Table 4.12: TOU/CPP without enabling technologies impact metrics for region 2 .............................................85

Table 4.13: TOU/CPP without enabling technologies impact metrics for region 3 ...............................................86

Table 4.14: TOU/CPP without enabling technologies impact metrics for region 4 ...............................................87

Table 4.15: TOU/CPP without enabling technologies impact metrics for region 5 ............................................8

Table 4.16: TOU/CPP with enabling technologies impact metrics for region 1 ...................................................89

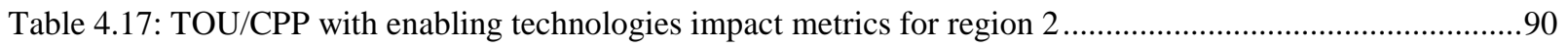

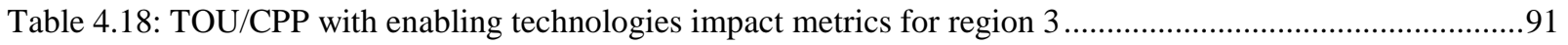

Table 4.19: TOU/CPP with enabling technologies impact metrics for region 4 ................................................92

Table 4.20: TOU/CPP with enabling technologies impact metrics for region 5 .................................................93

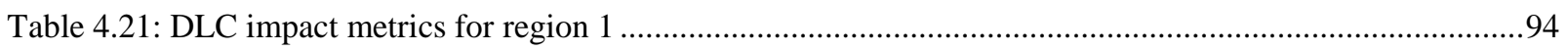

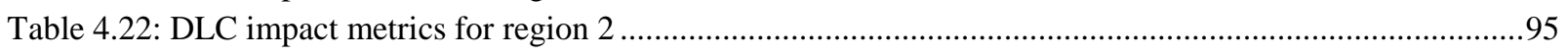

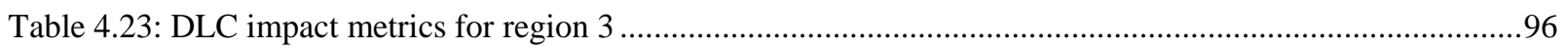

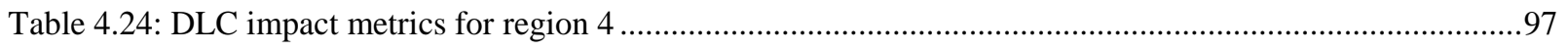

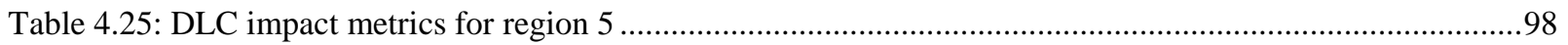

Table 4.26: Additional TOU/CPP with technology impact metrics for region 1 ...............................................99

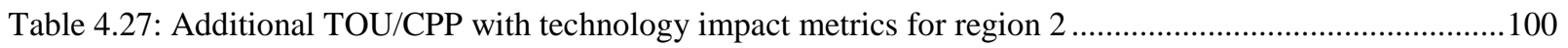

Table 4.28: Additional TOU/CPP with technology impact metrics for region 3 ..................................................101

Table 4.29: Additional TOU/CPP with technology impact metrics for region 4 .................................................102

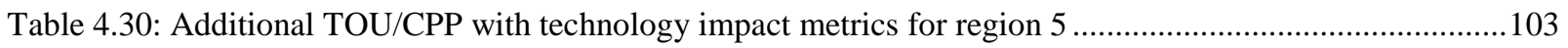

Table 4.31: Additional DLC with technology impact metrics for region 1 ........................................................ 104

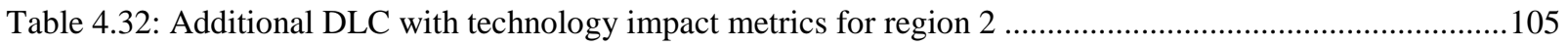

Table 4.33: Additional DLC with technology impact metrics for region 3 .......................................................106

Table 4.34: Additional DLC with technology impact metrics for region 4 ....................................................... 107

Table 4.35: Additional DLC with technology impact metrics for region 5 ........................................................108

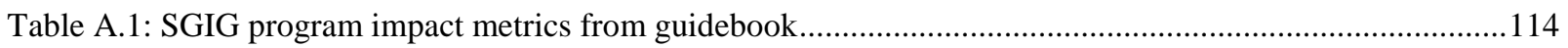




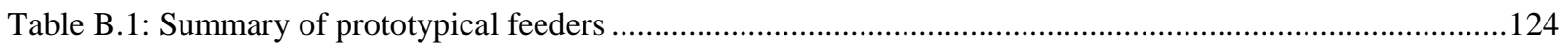

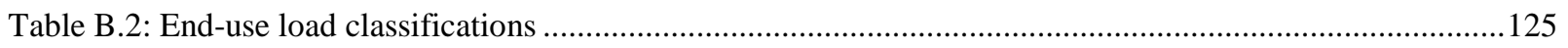

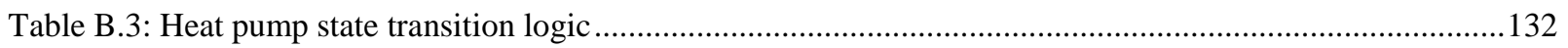

Table B.4: Table of weighting factors for mapping regional parameters...........................................................134

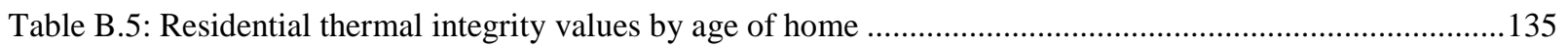

Table B.6: Percentage of single family homes in total population by age and region ..........................................135

Table B.7: Percentage of apartments in total population by age and region ........................................................136

Table B.8: Percentage of mobile homes in total population by age and region .....................................................136

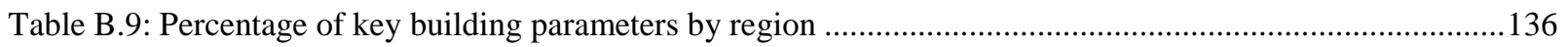

Table B.10: Percentage of nighttime heating and cooling set points by housing type ........................................137

Table B.11: Average square footage by building type and region ................................................................137

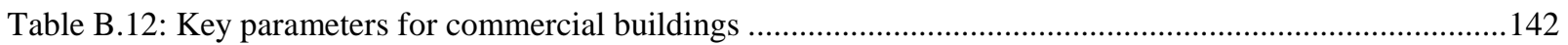

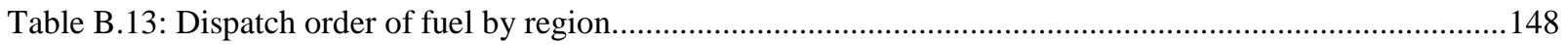

Table B.14: Percent of energy consumed, broken down by fuel type and month in region 1...............................148

Table B.15: Percent of energy consumed, broken down by fuel type and month in region 2...............................149

Table B.16: Percent of energy consumed, broken down by fuel type and month in region 3 ...............................149

Table B.17: Percent of energy consumed, broken down by fuel type and month in region 4..............................149

Table B.18: Percent of energy consumed, broken down by fuel type and month in region 5...............................150

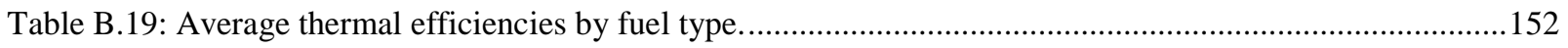

Table B.20: Pollutant production per BTU of fuel (lbs./MBTU) ..................................................................152

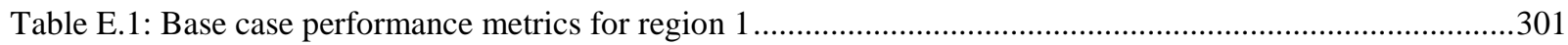

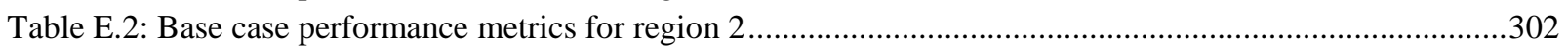

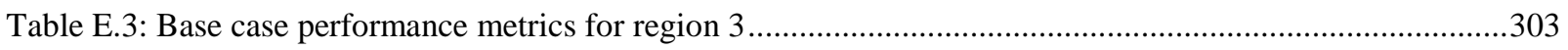

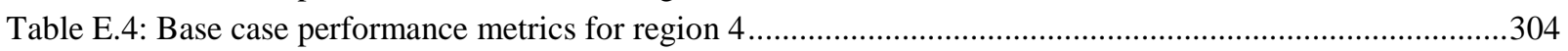

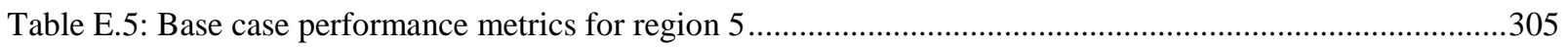

Table E.6: TOU without enabling technologies performance metrics for region 1 ............................................306

Table E.7: TOU without enabling technologies performance metrics for region 2 ...........................................307

Table E.8: TOU without enabling technologies performance metrics for region 3 ..........................................308

Table E.9: TOU without enabling technologies performance metrics for region 4 ............................................309

Table E.10: TOU without enabling technologies performance metrics for region 5 .............................................310

Table E.11: TOU with enabling technologies performance metrics for region 1 ...............................................311

Table E.12: TOU with enabling technologies performance metrics for region 2 ...............................................312

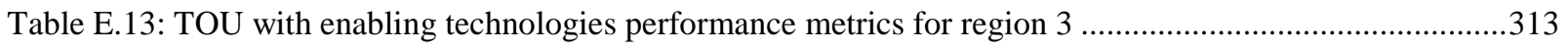

Table E.14: TOU with enabling technologies performance metrics for region 4 .............................................314

Table E.15: TOU with enabling technologies performance metrics for region 5 .............................................315

Table E.16: TOU/CPP without enabling technologies performance metrics for region 1 ..................................316

Table E.17: TOU/CPP without enabling technologies performance metrics for region 2 ..................................317

Table E.18: TOU/CPP without enabling technologies performance metrics for region 3 ...................................318

Table E.19: TOU/CPP without enabling technologies performance metrics for region 4 .....................................319

Table E.20: TOU/CPP without enabling technologies performance metrics for region 5 ....................................320

Table E.21: TOU/CPP with enabling technologies performance metrics for region 1 ........................................321

Table E.22: TOU/CPP with enabling technologies performance metrics for region 2 ........................................322

Table E.23: TOU/CPP with enabling technologies performance metrics for region 3 .......................................323

Table E.24: TOU/CPP with enabling technologies performance metrics for region 4 ........................................324

Table E.25: TOU/CPP with enabling technologies performance metrics for region 5 .......................................325 
Table E.26: DLC performance metrics for region 1 326

Table E.27: DLC performance metrics for region 2

Table E.28: DLC performance metrics for region 3

Table E.29: DLC performance metrics for region 4

Table E.30: DLC performance metrics for region 5 


\section{Summary}

This document is one of a series of five reports commissioned by the United States Department of Energy, Office of Electricity Delivery and Energy Reliability. The purpose of these reports is to estimate some of the benefits of deploying technologies similar to those implemented on the Smart Grid Investment Grant (SGIG) projects. Four technical reports cover the various types of technologies deployed in the SGIG projects: distribution automation, demand response, energy storage, and distributed generation. While the results of these reports provide insight into the variation of impacts by technology, feeder composition and region, it should be noted that the actual impacts and benefits of employing specific technologies in individual SGIG projects may vary from these projections. A fifth report in the series examines the benefits of deploying these technologies on a national level. This technical report examines the impacts of distribution automation technologies deployed in the SGIG projects. 


\section{Introduction}

As part of the American Recovery and Reinvestment Act of 2009, the U.S. Department of Energy (DOE) Office of Electricity Delivery and Energy Reliability (OE) provided Smart Grid Investment Grant (SGIG) funding to 99 award recipients totaling \$3.4 Billion [1]. Coupled with matching funds of $\$ 4.6$ Billion from industry, the SGIG projects are intended to accelerate the modernization of the nation's electricity infrastructure. To help evaluate the effect of these projects, a set of impact metrics has been developed by the DOE [2]. Once the SGIG projects are complete, it will be possible to analyze collected field measurements and determine the exact benefit from each of the various technologies within each of the projects. OE has several initiatives operating in current and near-term time frames to assess impacts and disseminate information as data becomes available. These initiatives include analysis partnerships with individual SGIG recipients, specific technology assessments, stakeholder briefings, and improvements to existing algorithms and tools.

In order to examine the SGIG project benefits, the Pacific Northwest National Laboratory (PNNL) utilized the GridLAB-D simulation environment to conduct extensive simulations on representative technologies. GridLAB-D was originally developed at PNNL, via DOE OE funding, to provide an open source simulation environment to evaluate the impacts of emerging technologies on the nation's electricity infrastructure. The unique multi-disciplinary agent based structure of GridLAB-D allows for the effective evaluation of complex emerging technologies such as voltage optimization and demand response. These are the same technologies that being deployed as part of the SGIG projects.

The impact of these technologies, at the distribution feeder level across various climate regions of the United States [3], is presented in a series of 4 technical reports, of which this report is the first. Each of the 4 technical reports examines a class of technologies deployed in the SGIG projects. The 4 technical reports examine distribution automation, demand response, energy storage, and renewable integration. A $5^{\text {th }}$ report uses the results of the four technical reports to generate a policy level examination of the various technologies. The final report includes extrapolation to a national level deployment at various penetration levels.

To ensure that the results of this report can be reproduced by other researchers, all of the tools, models, and materials used are openly available at [3]. Through detailed time-series simulations conducted in GridLAB-D, the impact of adding demand response capabilities to the grid can be examined on the relevant prototypical feeders. Utilities, regulators, vendors and other stakeholders interested in analyses more specific to their systems, goals, and conditions may make use of these open tools for their own purposes. 


\subsection{Report Scope}

Due to the large number of SGIG projects and the wide range of specific implementations, it is not feasible to simulate each of the specific SGIG projects. In addition to the numerous implementations, it would be necessary to model the electrical infrastructure of each of the projects. To address these issues, the technical reports will model a selection of technologies that are representative of those seen in the SGIG projects, and it will examine their impact on a set of prototypical distribution feeders that are representative of those seen in the various climate regions of North America [3]. By utilizing representative technologies and prototypical distribution feeders, it will be possible for this report to estimate the feeder level impact of each technology. Once the impact of the technologies has been evaluated on the prototypical feeders, the results will be extrapolated to explore the impacts and considerations associated with deploying the technology on a national level.

The technologies deployed as part of the SGIG projects can be placed in one of two categories: direct and enabling. Direct technologies are those that provide direct benefit to the system. Enabling technologies are those that may not provide a direct benefit to the system, but they enable other beneficial technologies. As an example, a communications network does not provide any reduction in energy consumption, but it does enable demand response systems that create reductions in energy consumption.

The technical reports focus on the benefits obtained from the deployment of direct technologies when supported with the necessary enabling technologies.

\subsubsection{Direct Representative Technologies}

These are the 15 technologies that will be specifically analyzed using GridLAB-D simulations. Within each of the 4 technical reports there are one or more specific direct technologies that are examined.

Distribution Automation (DA)

- $\quad$ t1: Volt-VAR Optimization (VVO)

- $\quad$ 2: Capacitor Automation (CA)

- $\quad$ t3: Reclosers and Sectionalizers $(\mathrm{R} \& S)$

- $\quad$ t4: Distribution Management and Outage Management Systems (DMS\&OMS)

- t5: Fault Detection Identification and Reconfiguration (FDIR)

Demand Response (DR) 
- t6: TOU/CPP with enabling technologies

- $\quad$ 7: TOU/CPP without enabling technologies

- t8: TOU with enabling technologies

- t9: TOU without enabling technologies

- t10: Direct Load Control (DLC)

Energy Storage (ES)

- t11: Thermal Energy Storage (TES)

Distributed Generation (DG)

- t12: Solar residential

- t13: Solar commercial

- t14: Solar combined

- t15: Wind commercial

\subsubsection{Enabling Technologies}

In addition to technologies that provide direct benefits to the system, there are those that enable other technologies to benefit the system, but themselves may not provide a direct benefit. The majority of the projects in the SGIG program have committed to deploying a large number of enabling technologies that do not provide any direct measurable benefit. Despite the lack of a direct benefit, these technologies form the foundation needed for the technologies that do provide direct benefits to the system.

\subsubsection{Smart Meters}

Traditional electromechanical metering devices have proven to be accurate and reliable over multiple decades, but have the significant disadvantage of requiring manual data collection; there is no network connectivity. The deployment of new "smart meters" is the largest common element to the SGIG projects, ranging from projects with a few thousand, to projects with multiple millions. These new meters are able to bi-directionally communicate information via a wired or wireless communications network. Communications to the customer can now include time-based electricity rates or event-triggered signals. Communications from the customer allow remote meter reading, as well as usage patterns. 


\subsubsection{Communications Infrastructure}

Communications infrastructure, both wireless and wired, is an excellent example of an enabling technology. A communications infrastructure in an isolated environment does not provide any direct benefit to the system. However, direct technologies and capabilities, such as demand response, would not be possible without a supporting communications infrastructure. For the purposes of the conducted analysis, it is assumed that the required communications infrastructure is available, but it will not be simulated. Zero latency and infinite bandwidth is assumed. While an explicit communications system model is not used in this analysis, there are issues outside the scope of this work where a communications system model would be essential.

\subsubsection{Human Machine Interface}

Human Machine Interfaces (HMI) can exist in many forms. In a single family residence, the HMI can range from a simple thermostat to a fully functional Home Energy Management System (HEMS). An HMI can allow a residential user to see the current price of electricity, interact with their heating and cooling system, or with an energy storage system. By providing an end-user with more information about the current price of electricity and the state of their consumption, the effectiveness of demand response opportunities can be increased.

\subsection{Report Structure}

The structures of the four technical reports follow a similar design. The four reports share a common introduction in Section 1 with Section 2, discussing the representative technologies to be examined in each report. Section 3 contains the detailed feeder level examination of the impact of each technology, while Section 4 examines the change in the impact metrics between the base case and the case with various technologies. It should be noted that the base case is a representative simulation without new technologies; it is not representative of the operation of any actual SGIG project. Section 5 contains the concluding comments. Additionally, there are multiple appendices. Appendices A, B, and C are common to all 4 reports with Appendix A giving a detailed description of the SGIG impact metrics, Appendix B detailing the taxonomy of prototypical distribution feeders, and Appendix C discussing GridLAB-D and the simulation methodology. Appendix D is specific to each report and contains the plots produced for individual feeders from the simulations. Appendix E contains the impact metric values for each technology and is the basis for the differential impact metrics in Section 4.

The fifth report has a structure independent of the four technical reports. 


\section{Demand Response Technology Areas}

Demand Response (DR) can be defined as changes in electric usage by consumers in response to changes in electricity prices or incentive payments designed to induce changes in consumer consumption patterns. In general, this includes a broad range of pricing programs and technologies that are focused on shifting end-use load in response to various external control signals, whether price, frequency, voltage, or combined signals. A review of the SGIG projects indicated that many of the DR projects were deploying Advanced Metering Infrastructure (AMI) mainly in preparation for future DR rate structures. Those that are currently deploying DR programs included various combinations of alternate rate structures and enabling technologies. Alternate rate structures included Time-of-Use (TOU), Critical Peak Pricing (CPP), and Critical Peak Rebates (CPR) or Peak Time Rebates (PTR). Enabling technologies range from those that increase customer awareness of current energy consumption and pricing rates, such as In-Home Displays (IHDs), web portals, or programmable thermostats, to technologies aimed at automating customer response, such as smart thermostats or direct equipment control. Additionally, Direct Load Control (DLC) was often mentioned.

Based on a review of the SGIG project proposals, five forms of demand response were selected as being appropriate for simulation in GridLAB-D. These included Time-of-Use with and without enabling technologies, Time-of-Use with a Critical Peak Pricing overlay, again with and without enabling technologies, and Direct Load Control. As there are a relatively large number of available rate programs, technologies, and all of the combination of each, simulating all of them would be cost and time prohibitive. These five DR schemes were selected to define the lower and upper limits of the capabilities of DR programs, and what impacts could be seen by the utility. Additionally, it should be noted, that at the time this analysis was undertaken, very little information was available about the specific technologies to be employed by the grant recipients. The technologies chosen for simulation are meant to be representative of the possibilities when using these technologies, but may not represent any actual technology used by the grant recipients. The following sections will examine the approaches, the specific implementation of technologies used in this analysis, and examples from the analysis.

\subsection{Time-of-Use (TOU) and Critical Peak Pricing (CPP)}

DR programs have been used by utilities for well over 30 years [4]; however, the widespread introduction of AMI increases the opportunity for utilities to implement TOU and CPP rates at the residential level by taking advantage of the communication infrastructure and the capabilities of newer meters. In general, TOU programs charge higher rates for electricity during peak consumption hours, and lower rates during low consumption, or off-peak hours. TOU programs may also include a third period (i.e. shoulder hours), where the price for electricity is in between the peak and off-peak prices. These programs rely on consumers changing their consumption habits, especially during peak load periods, to reduce overall system consumption during peak 
periods. The number of periods, the difference in prices between periods, and the hours covered by each period is highly dependent upon the utility's technical needs and ratemaking goals.

Typical TOU programs will include two or three price periods, where the peak period often has a price on the order of two to five times higher than the off-peak period. The hours covered by each period commonly vary from four to eighteen hours with varying start and end times, often with seasonal shifts. CPP programs charge a substantially higher price during a set number of hours with limited annual frequency, based on critical system conditions, such as high demand or high prices. The higher prices can be overlaid on flat, tiered pricing, or TOU rates. The critical peak price is often on the order of five to twenty times higher than the off-peak rate, but a critical event can typically only be declared 10-15 times per year. The customer is typically notified 24 hours prior to a CPP event being declared. More advanced programs may also provide automated controls on consumer devices, such as water heaters and air conditioning units to enhance customer responsiveness to price changes. With the advent of smart appliances and home energy management units, additional automation can be obtained.

To ensure that the results of this report can be reproduced by other researchers, all of the tools, models, and materials used are openly available at [3]. To estimate the potential of rate programs and automated response controls to reduce peak demand, detailed time series simulations were conducted in GridLAB-D [3] on each of the Prototypical Feeders [5], both developed at PNNL by DOE OE and freely available for public use. Openly available automated controls and consumer interfaces were used. Sections 2.1.2 and 2.2.2 will discuss the specific technologies modeled and simulated, while Appendix B discusses the creation and calibration of the base feeder models used in the analysis. 


\subsubsection{SGIG Impact Metrics Affected by TOU and CPP}

A detailed list of the SGIG impact metrics can be found in Appendix A. These metrics are for all of the SGIG projects, and reflect annual values. The following SGIG metrics are affected by TOU and TOU/CPP and will be tracked in this analysis:

Table 2.1: Impact metrics affected by TOU and CPP

\begin{tabular}{|c|c|c|}
\hline Index & Metric & Units \\
\hline 1 & Hourly Customer Electricity Usage & $\mathrm{kWh}$ \\
\hline 2 & Monthly Customer Electricity Usage & MWh \\
\hline \multirow{10}{*}{3} & Peak Generation & $\mathrm{kW}$ \\
\hline & Nuclear & $\%$ \\
\hline & Solar & $\%$ \\
\hline & Bio & $\%$ \\
\hline & Wind & $\%$ \\
\hline & Coal & $\%$ \\
\hline & Hydroelectric & $\%$ \\
\hline & Natural Gas & $\%$ \\
\hline & Geothermal & $\%$ \\
\hline & Petroleum & $\%$ \\
\hline 4 & Peak Load & $\mathrm{kW}$ \\
\hline 7 & Annual Electricity Production & MWh \\
\hline 12 & $\mathrm{CO}_{2}$ Emissions & Tons \\
\hline \multirow{3}{*}{13} & SOx Emissions & Tons \\
\hline & NOx Emissions & Tons \\
\hline & PM-10 Emissions & Tons \\
\hline \multirow{2}{*}{21} & Feeder Real Load & $\mathrm{kW}$ \\
\hline & Feeder Reactive Load & kVAR \\
\hline 29 & Distribution Losses & $\%$ \\
\hline 30 & Distribution Power Factor & $\mathrm{pf}$ \\
\hline 39 & $\mathrm{CO}_{2}$ Emissions & Tons \\
\hline \multirow{3}{*}{40} & SOx Emissions & Tons \\
\hline & NOx Emissions & Tons \\
\hline & PM-10 Emissions & Tons \\
\hline
\end{tabular}




\subsubsection{Specific Implementation of TOU and CPP}

A review of the SGIG grants showed a large number of utilities engaging in, or preparing for, the use of TOU or TOU/CPP price structures, enabled by the AMI and communication infrastructure needed for such implementation. Some utilities went as far as proposing the desired rate structure, often based on DOE guidelines for TOU and TOU/CPP programs [1]. Additionally, a number of utilities planned technology deployments to complement the timebased pricing programs. In-home displays and web portal access to customer energy consumption were the most noted. However, a few grant proposals indicated the use of advanced controls, such as responsive or programmable thermostats, hot water heater controls, and pool pump controllers in conjunction with time-based rates. While a few programs also included home area networks (HAN) for engaging smart appliances, it was found that investment in the smart appliances was minor. In addition, a number of price programs beyond TOU and TOU/CPP were proposed, however there were relative few such cases. From this, it was determined that four cases would be investigated:

1) TOU/CPP with enabling technologies

2) TOU/CPP without enabling technologies

3) TOU with enabling technologies

4) TOU without enabling technologies.

Enabling technologies were considered to be responsive thermostats for HVACs, hot water heater controls, pool pump controls, and various forms of IHDs and web portals. Cases without enabling technologies were assumed to be equipped with programmable thermostats, and relied mainly upon direct consumer reaction to rate changes. The assumptions and controls used in this analysis will be described in more detail later in this section. Additionally, it was assumed that a communications infrastructure was in place for the communication of price and event signals.

The first step in this analysis was to design time-based rates appropriate for each of the simulated feeders. Two rate structures, TOU and TOU/CPP, were created for each climate region. A relative price pattern was designed using a two-period TOU and a two-period CPP program. The TOU/CPP program used a TOU rate throughout the year, and then applied a 6hour critical price period 15 days per year which replaced the high TOU rate. These were declared with perfect knowledge from the base case by determining the 15 days with the highest peaks in each region. The second period rate for both programs was defined to be two times larger than the first period, and the critical period rate was ten times larger than the first period. A relative price pattern was determined for each region by aggregating all of the feeder circuit loads from each region. This was then coupled with general engineering knowledge to develop a schedule to best reduce peak energy and load consumption within each region, and not feeder by 
feeder. Price signals for TOU and CPP are rarely designed with particular feeder circuits in mind, but rather coincident system peak demands, shifting power at the system level from peak to off-peak. For this analysis, it has the effect that the price signal will not be optimized for a particular feeder. Different TOU patterns were developed for winter and summer because of a shift in the end-use behaviors between the two seasons. Because of the high penetration of nonelectric heating devices, all CPP days fell within the summer time frame. Table 2.2 shows the TOU and CPP periods used for each region.

Table 2.2: Periods of low, high, and critical prices for each region

\begin{tabular}{|c|c|c|c|c|c|c|}
\hline & \multicolumn{2}{|c|}{ TOU Summer } & \multicolumn{2}{|c|}{ TOU Winter } & \multicolumn{2}{|c|}{ CPP Summer } \\
\hline $\begin{array}{l}\text { Region } 1 \\
\text { West Coast }\end{array}$ & $\begin{array}{l}\text { Low: } \\
\text { High: }\end{array}$ & $\begin{array}{l}0: 00-9: 00 \\
21: 00-24: 00 \\
9: 00-21: 00\end{array}$ & $\begin{array}{l}\text { Low: } \\
\text { High: }\end{array}$ & $\begin{array}{l}0: 00-9: 00 \\
21: 00-24: 00 \\
9: 00-21: 00\end{array}$ & $\begin{array}{l}\text { Low: } \\
\text { Critical: }\end{array}$ & $\begin{array}{l}0: 00-11: 00 \\
17: 00-24: 00 \\
11: 00-17: 00\end{array}$ \\
\hline $\begin{array}{l}\text { Region } 2 \\
\text { N. Central and Northeast }\end{array}$ & $\begin{array}{l}\text { Low: } \\
\text { High: }\end{array}$ & $\begin{array}{l}0: 00-10: 00 \\
18: 00-24: 00 \\
10: 00-18: 00\end{array}$ & $\begin{array}{l}\text { Low: } \\
\text { High: }\end{array}$ & $\begin{array}{l}0: 00-9: 00 \\
21: 00-24: 00 \\
9: 00-21: 00\end{array}$ & $\begin{array}{l}\text { Low: } \\
\text { Critical: }\end{array}$ & $\begin{array}{l}0: 00-11: 00 \\
17: 00-24: 00 \\
11: 00-17: 00\end{array}$ \\
\hline $\begin{array}{l}\text { Region } 3 \\
\text { Non-Coastal Southwest }\end{array}$ & $\begin{array}{l}\text { Low: } \\
\text { High: }\end{array}$ & $\begin{array}{l}0: 00-10: 00 \\
19: 00-24: 00 \\
10: 00-19: 00\end{array}$ & $\begin{array}{l}\text { Low: } \\
\text { High: }\end{array}$ & $\begin{array}{l}0: 00-9: 00 \\
21: 00-24: 00 \\
9: 00-21: 00\end{array}$ & $\begin{array}{l}\text { Low: } \\
\text { Critical: }\end{array}$ & $\begin{array}{l}0: 00-13: 00 \\
19: 00-24: 00 \\
13: 00-19: 00\end{array}$ \\
\hline $\begin{array}{l}\text { Region } 4 \\
\text { Non-Coastal Southeast } \\
\text { and Central }\end{array}$ & $\begin{array}{l}\text { Low: } \\
\text { High: }\end{array}$ & $\begin{array}{l}0: 00-10: 00 \\
20: 00-24: 00 \\
10: 00-20: 00\end{array}$ & $\begin{array}{l}\text { Low: } \\
\text { High: }\end{array}$ & $\begin{array}{l}0: 00-9: 00 \\
21: 00-24: 00 \\
9: 00-21: 00\end{array}$ & $\begin{array}{l}\text { Low: } \\
\text { Critical: }\end{array}$ & $\begin{array}{l}0: 00-10: 00 \\
16: 00-24: 00 \\
10: 00-16: 00\end{array}$ \\
\hline $\begin{array}{l}\text { Region } 5 \\
\text { Southeast }\end{array}$ & $\begin{array}{l}\text { Low: } \\
\text { High: }\end{array}$ & $\begin{array}{l}0: 00-10: 00 \\
19: 00-24: 00 \\
10: 00-19: 00\end{array}$ & $\begin{array}{l}\text { Low: } \\
\text { High: }\end{array}$ & $\begin{array}{l}0: 00-9: 00 \\
21: 00-24: 00 \\
9: 00-21: 00\end{array}$ & $\begin{array}{l}\text { Low: } \\
\text { Critical: }\end{array}$ & $\begin{array}{l}0: 00-10: 00 \\
16: 00-24: 00 \\
10: 00-16: 00\end{array}$ \\
\hline
\end{tabular}

For each customer simulated, including residential and commercial customers, a monthly electric bill was collected. In the base case simulation, this included a flat monthly connection fee and a flat energy rate that varied between region and customer type. The values used are shown in Table 2.3. They were obtained from the EIA website and represent the regional average rate for electricity in dollars per kilowatt-hour for each region by customer type [6]. 
Table 2.3: Flat rates used in the base case simulation

\begin{tabular}{|l|c|c|}
\hline & Residential (\$/kWh) & Commercial (\$/kWh) \\
\hline $\begin{array}{l}\text { Region 1 } \\
\text { West Coast }\end{array}$ & 0.1243 & 0.1142 \\
\hline $\begin{array}{l}\text { Region 2 } \\
\text { N. Central and Northeast }\end{array}$ & 0.1294 & 0.1112 \\
\hline $\begin{array}{l}\text { Region 3 } \\
\text { Non-Coastal Southwest }\end{array}$ & 0.1012 & 0.0843 \\
\hline $\begin{array}{l}\text { Region 4 } \\
\text { Non-Coastal Southeast and Central }\end{array}$ & 0.1064 & 0.0923 \\
\hline $\begin{array}{l}\text { Region 5 } \\
\text { Southeast }\end{array}$ & 0.1064 & 0.0923 \\
\hline
\end{tabular}

Regulators require that all retails rates collect sufficient revenue from the various billing determinants of all customers exposed to the rate in order to cover the costs of serving this group. As such, all rates are designed to be "revenue neutral" with respect to the billing determinants of the "average" customer. If a new rate (e.g. TOU or TOU/CPP) is introduced, it will be designed to collect the same amount of revenue from the group being served as was collected under the old rate or a flat rate in this case. While individual customers may experience differences in their bills depending upon their specific load shape when exposed to the new rate versus the old rate, the total annual revenue collected by the utility from all customers should be constant, assuming that the customers do not change their load patterns in respond to the new rate. The incentive for customers to join the new time-based rate is for the potential monetary benefit of modifying their electricity consumption in response to the new rate. For example, customers on a TOU rate are incentivized to shift their demand away from the more expensive on-peak period to the less expensive off-peak period. The GridLAB-D simulation environment is well suited for studying the exact effects of rate structures on revenue neutrality as the base case simulations provide an ideal reference point to develop the revenue neutral rate.

A revenue neutral rate structure was designed for the TOU and TOU/CPP rates for each feeder in each region, based on the base case simulation results. Data on customer billing and energy consumption was collected on fifteen minute intervals. Monthly and annual bills were also calculated at the end of the simulation. To design a new revenue neutral rate structure, a pattern of relative prices for each hour of was assumed. Time intervals are described in Table 2.2. Relative rates were $1 \mathrm{x}, 2 \mathrm{x}$, and 10x for the low TOU, high TOU, and CPP periods. Using the time series loads from the base case, the energy consumption at each hour was multiplied by the relative price for that hour and summed for each simulated customer and in total for all customers to form the total relative revenue. To ensure that the total revenue is the same between the original fixed-price rate structure and the new time-based structure assuming no 
price response, a revenue scaling factor is used to multiply the pattern of relative prices to form the actual revenue required. Thus, the revenue scaling factor is:

$$
\text { Revenue Scaling Factor }=\frac{\text { Total Base Case Revenue }}{\text { Total Relative Revenue }}
$$

and the retail price at any given time $t$ is:

$$
\text { Retail Price }(t)=\text { Revenue Scaling Factor } * \text { Relative Price Pattern }(t)
$$

The TOU and TOU/CPP rates created allow the utility to collect the same amount of revenue from each group of customers, assuming that the customers do not to respond to the new rate structure. The rates designed for residential customers in feeder R1-12.47-1 (West Coast region) are shown as an example in Table 2.4. Note that the addition of the CPP period in the TOU/CPP rate slightly reduces the TOU rates in comparison to the TOU only rates to maintain revenue neutrality. These rate values are used to determine the level of customer responsiveness to the new price, as discussed in Section 2.1.2.4. While the effects on the customer bill were captured during the simulations, detailed analysis was not performed here, as it was outside the scope of this analysis.

Table 2.4: TOU and TOU/CPP rates for R1-12.47-1

\begin{tabular}{|l|l|c|c|c|}
\hline & \multicolumn{1}{|c|}{ Period } & TOU & TOU/CPP & Fixed \\
\hline & Low & 0.0764 & 0.0705 & \\
R1-12.47-1 & High & 0.1527 & 0.1410 & 0.1243 \\
& Critical & & 0.7049 & \\
\hline
\end{tabular}

\subsubsection{Automated Thermostats}

The thermal energy within a population of buildings can be utilized to provide peak shifting by adjusting the thermostat set points during key periods. While consumers may manually alter their set points as a function of time and price, programmable communicating thermostats (PCTs) provide a more automated method for customers to adjust their temperature set points to changing prices, thereby increasing customer participation and response to price changes. Because of the continual operation of PCTs, there is the potential for greater peak reduction and greater savings to the customer. The functionality of automated thermostats can range anywhere from scheduled time blocks such as AWAY, HOME, and SLEEP settings, to those that respond directly to changes in price through complex predictive algorithms. The PCT design used in the DOE supported Pacific Northwest GridWise ${ }^{\mathrm{TM}}$ Test bed Demonstration Project was used in this analysis [7]. A more detailed description of its capabilities is provided below. It should be noted that none of the SGIG projects were planning to deploy 2-way communicating thermostats, but the automated controls discussed below can be mapped to a simple setback program, i.e. the 
customer can program the thermostat to shift 2 degrees between TOU low and high periods. This is also used to represent the potential of demand response, utilizing the most advanced technology available. While this implementation is well understood by the authors and is currently being deployed in the gridSMART Demonstration Project, there are a number of other commercially available price-responsive thermostats that may also be used. This model was chosen due to an understanding of the distribution of customer responsiveness found during the field experiments in the GridWise Demonstration Project [7].

Figure 2.1 graphically illustrates the behavior of the PCT implemented in this analysis. Cooling response is used as an illustration but the same effects can be achieved with heating. Essentially, the thermostat translates the current price of electricity into a change in the temperature set point. If price is relatively high, the cooling set point is adjusted upward. Conversely, if the price is relatively low, the cooling set point is adjusted downward. Customers have full control over the level of responsiveness of their individual system, defining the maximum downward and upward deviations $\left(T_{\min }\right.$ and $\left.T_{\max }\right)$ from their desired set point $(\Delta T=0)$, the rate at which they respond (the slope of the line), and whether they wish to pre-cool the home. For simplicity, all of these parameters are mapped to a "slider setting". Customers can choose a value between $0 \%$ and $100 \%$, where $0 \%$ equates to "maximum comfort" (or standard, non-price response thermostat operation) and $100 \%$ equates to a pre-defined "maximum savings". For this analysis a distribution of typical customer participation levels or slider settings was determined from the Pacific Northwest GridWise Demonstration [7]. This distribution was found to be a best fit by a normal distribution centered on $45 \%$ with a standard deviation of $20 \%$ participation. Values below $0 \%$ were set to $0 \%$, while values chosen above $100 \%$ were re-chosen. This led to a distribution with an approximate mean of $45 \%$ tailing off to $100 \%$, but with a large population of customers who did not participate at all (0\% setting). A plot of this distribution is shown in Figure 2.2. This was similar to results from the Pacific Northwest GridWise Demonstration Project. More detailed descriptions about the operation of the automated thermostat can be found in [7]-[9]. Additionally, pre-cooling and pre-heating was excluded from use in this analysis. While some customers are inclined to use this feature, especially when presented with advanced notice of a price change (such as a scheduled CPP event), limited information is available as to the number of customers who would participate. Due to a lack of detailed information about participation, pre-heating and pre-cooling modes were excluded from this analysis.

It is important to note that when prices are continuous, such as those found in retail real-time pricing programs, the mapped response of set points to price is a continuous function. However, in the case of TOU and TOU/CPP, there are only two or three discrete prices which map to two or three discrete set point deviations. This is analogous to a customer scheduling their programmable thermostat to change their set point during low versus high versus critical peak periods. For this analysis critical prices resulted in customers responding at their maximum 
allowable deviation $\left(\mathrm{T}_{\max }\right)$. High period TOU prices resulted in customers responding at a lesser deviation related to their slider setting. Low period TOU prices resulted in normal thermostat operation.

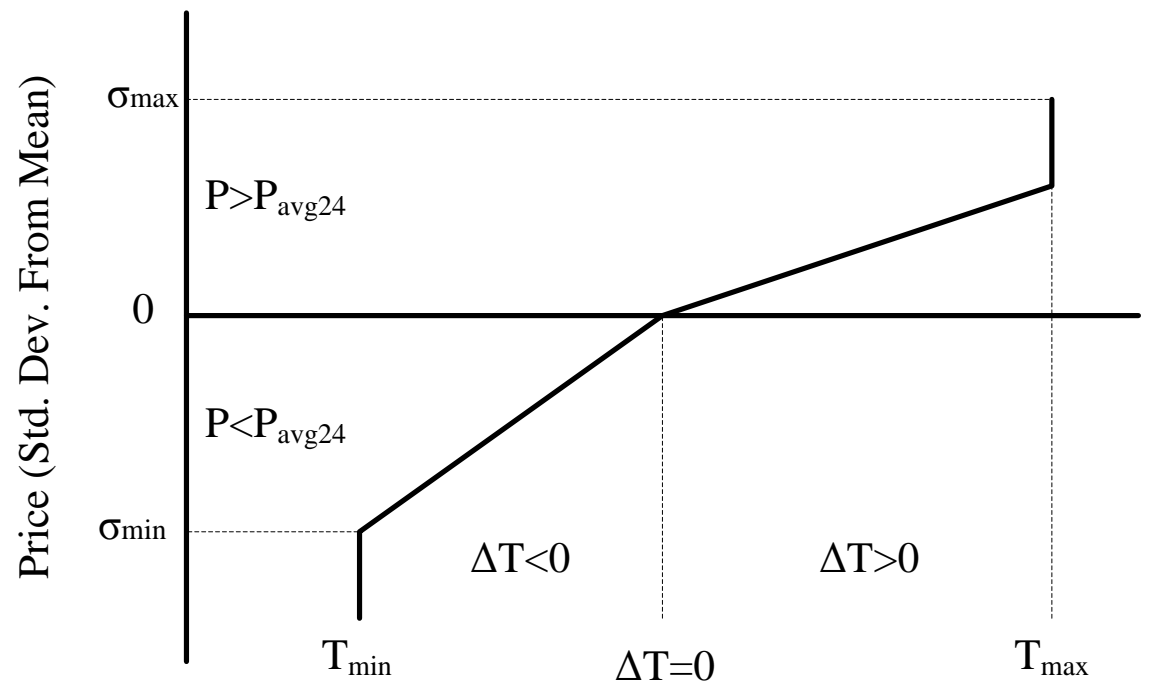

Temperature $\left({ }^{\circ} \mathrm{F}\right)$

Figure 2.1: Graphical representation of automated thermostat response

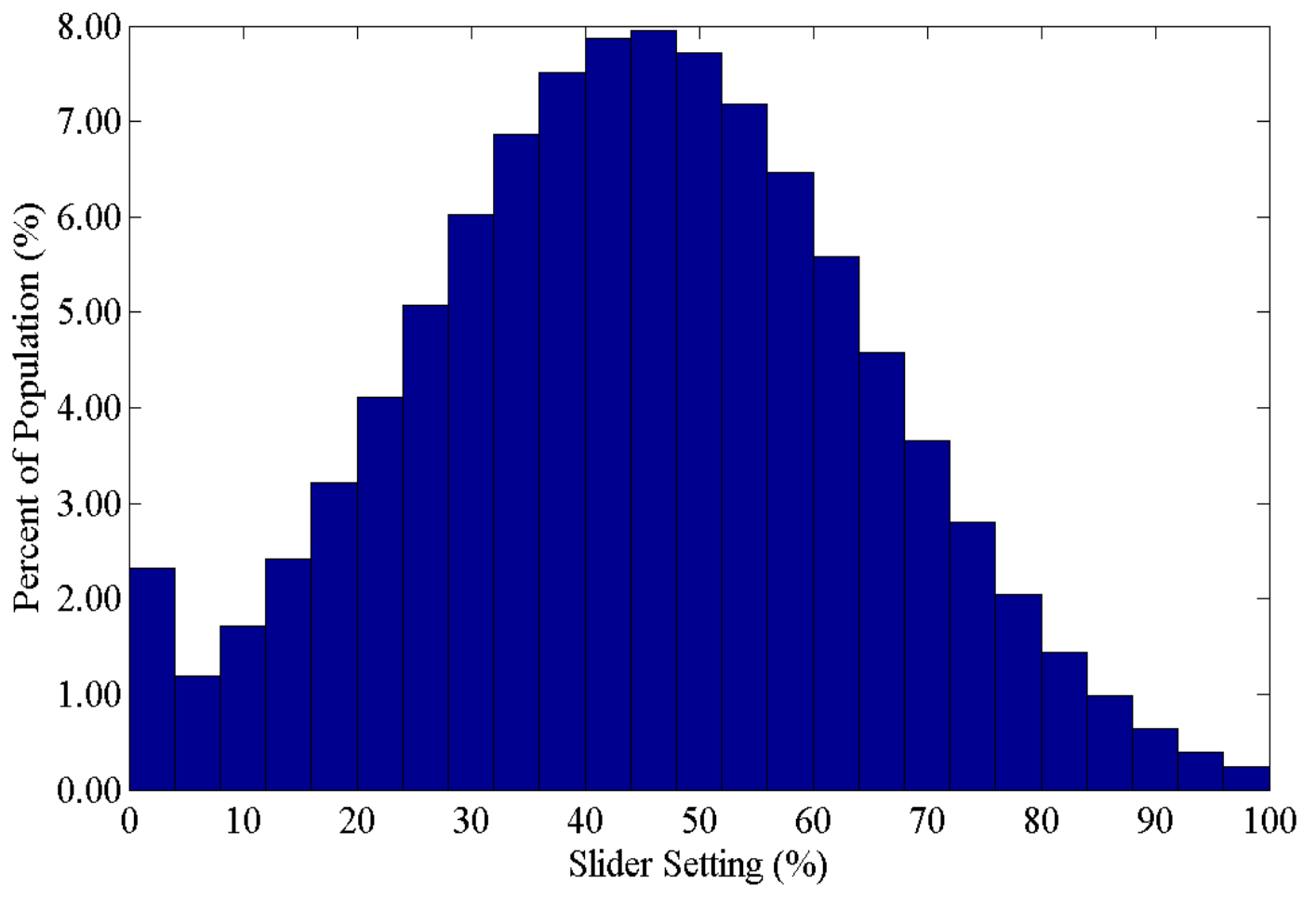

Figure 2.2: Distribution of customer response slider settings 


\subsubsection{Water Heater Controls}

Electric hot water heaters are a readily controllable and a relatively unobtrusive load to manage in areas where residential electric hot water heaters are prevalent. Because of the stored thermal energy within the water, most consumers do not notice short term changes in water heater behavior, similar to automated thermostat and the HVAC systems. These characteristics make electric hot water heating an ideal candidate for DR programs. Again, automated water heater controls designed for the DOE supported Pacific Northwest GridWise ${ }^{\mathrm{TM}}$ Testbed Demonstration Project [7] were used in this analysis. The goal of this control is to allow the water heater to opportunistically respond to changing prices without having to formulate any additional value information. Again, it should be noted that none of the SGIG projects indicated the use of automated water heater controls coupled with time-based rates, but these controls (along with advanced HVAC and pool pump controls) were used to illustrate the potential of demand response programs coupled with advanced technologies.

In the demonstration project, a probabilistic opportunity function was designed to increase the likelihood that the water heater would disconnect during a high price signal. Essentially, as prices become very high, a circuit breaker opens to turn off the water heater with increasing probability. As prices approach average or below average levels, the probability of a disconnect goes to zero. The probability function is defined as:

$$
r=k_{w}\left[\frac{1}{\sqrt{2 \pi} \sigma} \int_{-\infty}^{P_{\text {clear }}} e^{\frac{(\bar{P}-x)^{2}}{2 \sigma^{2}}} d x-\frac{1}{2}\right] ; \quad r \geq 0
$$

where:

$\begin{array}{ll}k_{w} & \text { is the customer's comfort level or slider setting } \\ P_{\text {clear }} & \text { is the current market price } \\ P & \text { is the average price of electricity for the previous } 24 \text { hours } \\ \sigma & \text { is the standard deviation of the current market price for previous } 24 \text { hours } \\ r & \text { is a parameter used for comparison against a uniformly generated number }\end{array}$

The parameter $r$ is used to compare against a uniformly generated number between 0 and 1 every fifteen minutes [7]. If the chosen $r$ is greater than the random number, the water heater is turned to the inoperative state whether or not demand requires that the water heater run. Again, in a continuous real-time pricing program, this is a continuous function with an infinite number of probability states. In the case of a TOU or TOU/CPP program, these translate to discrete price levels that are only affected by the customer's willingness to participate. For this analysis, during low a TOU price period, no response is expected. The response rate was set so that 
during a high TOU price period approximately $80 \%$ of customers $(\sigma=2)$ would respond if all of the customers selected maximum savings. However, since most customers choose a much lower level of participation, the level of response is much lower. During a CPP period, approximately $95 \%$ of customers $(\sigma=3)$ would respond at any given time, if all customers selected maximum savings. In this case, response means the water heater would be disconnected whether or not demand was required. Of course, not all customers were defined as having full response. The same slider setting distribution used in the HVAC controls was used, where a $0 \%$ slider setting $\left(k_{w}=0\right)$ meant no response and a $100 \%$ slider setting $\left(k_{w}=3\right)$ commanded maximum response.

\subsubsection{Pool Pump Controls}

Swimming pool filter pumps can be a significant portion of the system load in some areas. A 1993 Southern California Edison report showed that pool pumps were the third largest consumer of residential energy in the Southern California Edison service territory [10]. Pool pump motors consume an average of $1.36 \mathrm{~kW}$ while running [11], commonly making them the third largest instantaneous load in a typical home after the HVAC system and the electric hot water heater. Pool pumps are often controlled by a manually set, constant duty cycle timer, where the run-time is often decreased during winter months. Pool pumps typically run for a period of two to four hours at a time, and on average four to twelve hours per day [10]. These values were used in this analysis to diversify the population of pool pumps on each feeder during normal operation. While in many areas pool pumps are operated year round with a decreased duty cycle during the winter, for this analysis it was assumed that pool pumps only operated 6-8 months out of the year and were turned off during the remaining time, depending upon the region. Again, it should be noted that none of the SGIG projects indicated the use of automated pool pump controls coupled with time-based rates, but these controls (along with advanced HVAC and water heater controls) were used to illustrate the potential of demand response programs coupled with advanced technologies.

While it is possible for customers to adjust their timers to respond to TOU and TOU/CPP prices manually, this is not a practical solution. A number of commercial strategies exist for automating pool pump controls, but these are often proprietary control functions. For this analysis, an automated pool pump control strategy was designed which increased the duty cycle during low price times and decreased the duty cycle during high price times, while conserving the overall run-time and energy consumption of the unit. The customer sets the base run-time and duty cycle of the pool pump. Depending upon the ratio of low price to high price, and the ratio of low price duration to high price duration, the duty cycle during each of the periods is adjusted. The adjusted duty cycles during TOU pricing can be described as:

$$
D C_{\text {high }}=D C_{\text {base }} \frac{P_{\text {low }}}{P_{\text {low }}+P_{\text {high }}} \frac{t_{\text {low }}+t_{\text {high }}}{t_{\text {high }}}
$$


and:

$$
D C_{\text {low }}=D C_{\text {base }} \frac{P_{\text {high }}}{P_{\text {low }}+P_{\text {high }}} \frac{t_{\text {low }}+t_{\text {high }}}{t_{\text {low }}}
$$

where:

$\begin{array}{ll}D C_{\text {base }} & \text { is the duty cycle before applying a TOU program } \\ D C_{\text {high }} & \text { is the duty cycle during the high price period } \\ D C_{\text {low }} & \text { is the duty cycle during the low price period } \\ P_{\text {high }} & \text { is the price during the high price period } \\ P_{\text {low }} & \text { is the price during the low price period } \\ t_{\text {high }} & \text { is the length of time at the high price tier } \\ t_{\text {low }} & \text { is the length of time at the low price tier. }\end{array}$

This has the effect of decreasing energy consumption during high price periods and increasing energy consumption during low price periods, but effectively conserving energy consumption across the entire operational cycle of the pool pump. For CPP, the response is similar except $D C_{\text {high }}$ is reduced to zero while $D C_{\text {low }}$ is still calculated in the same way. This results in a slight drop in energy consumption over the 24 hour period, but effectively shuts he pool pump off during the critical time period.

\subsubsection{Behavioral Response}

Aside from automated controls, there are manual controls, which are essentially the actions of people, responding to supplied inputs and observations. In this case, the inputs are the price of electricity at a given time. These actions can be treated as a behavioral response of the end-use load. Basic economics suggests that changing the price of electricity will affect the demand for electricity. Increasing the price of electricity will cause the demand to decrease, while decreasing the price of electricity will cause the demand to increase. The relationship between a change in electrical demand and a change in price is known as the price elasticity. Traditionally, utilities have charged residential consumers a fixed price for electricity at any given time of the day and any given time of the year, with some variations based on season. When alternate pricing strategies, such as TOU or CPP rate structures are implemented, it is important to analyze and understand the change in load response to the new pricing strategy. When there is a load response, or change in the consumer demand due to a change in the price of electricity, electricity consumption will no longer appear to be price inelastic as it had previously; the load shape of the customer will be altered. Thus, it is essential to study the degree of such load response, or the price elasticity of electricity usage for a particular deployment.

In general, system operators would like to have the ability to shift some portion of the consumption of electricity from peak periods to the off-peak periods. Conceptually, consumers 
would be presented with a higher cost of electricity during the peak period and a lower cost during the off-peak period, shifting consumption from the peak period to the off-peak period, thereby improving the load factor of the system. One of the important points to note is that, CPP is mostly used for curtailing loads during extremely high peak power periods. However, the high pricing is mostly used as a methodology for load shifting and/or load leveling. Additionally, utilities and system operators are in most cases restricted in the number of days and hours that a critical signal (CPP pricing) can be imposed; however, the same restriction does not apply to a high pricing signal.

System operators may combine a two period pricing scheme with the CPP pricing to obtain the benefits of both. This can be done in two ways. System operators can choose to have dual period pricing during all days of the year, except for a few peak days, when the CPP price could be imposed. Alternatively, system operators could have a three tier pricing for certain high peak days of the year. The system operators could impose the CPP for a few hours of the high peak days, have the two period pricing for the other hours of the same peak days and a two tier pricing for all the other days of the year. This three tier pricing scheme for certain peak days of the year is commonly used to curtail load during extremely high peak power periods and helps shift the load away from peak periods to the off -peak periods during all days of the year. Studies have shown that a combination of two signals, a CPP or a TOU/CPP (3 period) price combination for certain critical (CPP) days of the year and a TOU (2 period) price for other (non-CPP) days of the year, is the most effective at affecting consumer behavior to changes in electricity price [12].

Studies have also shown that an incremental increase in the price of electricity between the peak and off-peak period is an important deciding factor in determining if consumers will react to the changes in electricity pricing [12]. The degree of such consumer response is important for multiple reasons, including planning and revenue studies. Load forecasting is an important component for electricity providers in planning studies; hence, being able to predict the changes in the load given a change in the price of electricity becomes important. It is thus important to have a model that can predict the changes in consumer behavior and demand given a new pricing structure.

A number of the SGIG proposals plan to implement some form of automated controls for the thermostat, hot water heater and/or pool pump, but other appliances may also be price elastic while not designed to automatically respond to price signals. Appliances like refrigerators and freezers, unless specially designed to respond to price signals, will remain price inelastic. Without considerable upgrades to the equipment to include DR equipped logic, users will not change the usage of such appliances in response to price signals. However, consumers are known to change their usage habits for appliances such as clothes washers, dryers, dishwashers, etc., where consumers can easily modify their behavior given a TOU pricing program, and postpone using these appliances until off-peak pricing periods even if the appliances themselves have not been designed to automatically respond to price. The elasticity model, which was built 
into GridLAB-D for this project and will be described in detail later in this section, helps simulate such changes in appliance usage, either due to human factors or due to external technology (i.e. technology not related to the appliance design itself). Such appliances include, but are not limited to, cooking ranges, cooking ovens, microwaves, dryers, dishwashers and clothes washers. Studies also show, that appliances in conjunction with external technology respond more to changes in price signals, than when only human behavior is involved without any user interface or external control technology [13]-[14].

In economic terms, elasticity of a variable with relation to another variable is defined as the percentage change in the first variable for a one percentage change in the second variable. Price elasticity of the demand of a commodity is defined as the percentage change in the demand of the commodity given a one percent change in the price of the commodity. The price elasticity of substitution of a commodity is defined as the percentage change in the ratio of the demand for the two different commodities (e.g., peak and off-peak period electricity) for a one percent change in the price ratio of the two commodities. When combined, a comprehensive consumer demand elasticity model can be constructed that aims to predict the change in the demand for electricity given a change in the price of electricity throughout the day base on historic load usage patterns and elasticity parameters based on previous studies.

The methodology adopted to design the elasticity model in GridLAB-D is based on the Brattle Group's Price Impact Simulation Model (PRISM). The PRISM model includes two substitution elasticity estimates (one for CPP days and one for non-CPP days) and two daily price elasticity estimates (one for CPP days and one for non-CPP days) [13].

The substitution elasticity parameter $(\sigma)$ captures the shift in electricity from the peak to offpeak period, or the degree by which people will postpone using their appliances until the offpeak price periods. This can be thought of as deferred energy usage, as it has a zero net energy change. As defined previously, the elasticity of substitution for electricity is defined as the percentage change in the ratio of the peak to off-peak electricity usage, given a one percent change in the ratio of the peak to off-peak electricity prices. These can be described by:

$$
\frac{\left(\frac{Q_{\text {Peak }}^{\text {New }}}{Q_{\text {OffPeak }}^{\text {New }}}\right)-\left(\frac{Q_{\text {Peak }}^{\text {old }}}{Q_{\text {OffPeak }}^{\text {Old }}}\right)}{\left(\frac{Q_{\text {Peak }}^{\text {Old }}}{Q_{\text {OffPeak }}^{\text {Old }}}\right)}=\sigma^{p} \frac{\left(\frac{P_{\text {Peak }}^{\text {New }}}{P_{\text {OffPeak }}^{\text {New }}}\right)-\left(\frac{P_{\text {Peak }}^{\text {Old }}}{P_{\text {OffPeak }}^{\text {Old }}}\right)}{\left(\frac{P_{\text {Peak }}^{\text {Old }}}{P_{\text {OffPeak }}^{\text {Old }}}\right)}
$$

where:

$$
\begin{array}{ll}
Q_{P e a k}^{\text {new }} & \text { is the new electricity usage in the peak period }(\mathrm{kWh}) \\
Q_{O f \text { ef }}^{\text {neeak }} & \text { is the new electricity usage in the off-peak period }(\mathrm{kWh}) \\
Q_{\text {Peak }}^{\text {old }} & \text { is the old electricity usage in the peak period }(\mathrm{kWh})
\end{array}
$$


$Q_{\text {OffPeak }}^{\text {old }} \quad$ is the old electricity usage in the off-peak period (kWh)

$\sigma^{p} \quad$ is the substitution elasticity between the peak and off-peak periods (-)

$P_{P e a k}^{n e w} \quad$ is the new peak period price of electricity $(\$ / \mathrm{kWh})$

$P_{\text {OffPeak }}^{\text {new }} \quad$ is the new off-peak period price of electricity $(\$ / \mathrm{kWh})$

$P_{\text {Peak }}^{\text {old }} \quad$ is the old peak period price of electricity $(\$ / \mathrm{kWh})$

PoffPeak

is the old off-peak period price of electricity $(\$ / \mathrm{kWh})$

For example, if the ratio of the peak to off-peak electricity price changes from 1 to 2 , then the change in the ratio of the peak to off-peak electricity prices is $100 \%$. If the substitution electricity parameter is -0.11 , then the change in the ratio of the peak to off-peak energy usage is $-11 \%$. In this model, two substitution elasticity values were considered. The first substitution elasticity parameter relates to the substitution of peak price energy usage with off-peak energy usage and is applied only on non-critical peak price days. The second elasticity parameter relates to the substitution of critical price energy usage with off-peak energy usage and is applied on critical price days. The value of the two substitution elasticity parameters depends upon whether the day is a CPP or TOU day, and whether customers had access to enabling technologies.

The daily elasticity parameter $(\eta)$ captures the change in daily energy usage, or the degree by which people will change their overall daily energy usage given a change in electricity price. This can be thought of as unused energy, as it is the amount of energy customers will not "make up" at a later time. The daily elasticity of electricity is defined as the percentage change in the daily average electricity usage given a one percent change in the daily average price of electricity and can be described by:

$$
\frac{Q_{\text {daily }}^{\text {new }}-Q_{\text {daily }}^{\text {old }}}{Q_{\text {daily }}^{\text {old }}}=\eta \frac{P_{\text {ave daily }}^{\text {new }}-P_{\text {ave daily }}^{\text {old }}}{P_{\text {ave daily }}^{\text {old }}}
$$

where,

$\begin{array}{ll}Q_{\text {daily }}^{\text {new }} & \text { is the new daily electricity energy usage }(\mathrm{kWh}) \\ Q_{\text {daily }}^{\text {old }} & \text { is the old daily electricity energy usage }(\mathrm{kWh}) \\ \eta & \text { is the daily elasticity of electricity }(-) \\ P_{\text {avg daily }}^{\text {new }} & \text { is the new load-weighted daily average price of electricity }(\$ / \mathrm{kWh}) \\ P_{\text {avg daily }}^{\text {old }} & \text { is the old load-weighted daily average price of electricity }(\$ / \mathrm{kWh})\end{array}$

For example, if the calculated new daily average price is two times that of the previous calculated daily average price and the daily elasticity parameter is -0.042 , then the daily average energy is said to decrease by $4.2 \%$. The daily elasticity parameter depends upon the day of the week (weekend versus weekday), whether it was a CPP or TOU day, and whether customers had access to enabling technologies. 
The load-weighted average price used in Equations 2.6 and 2.7 is defined as:

$$
P_{\text {avg daily }}=\frac{\sum_{t} P_{t} Q_{t}}{\sum_{t} Q_{t}}
$$

where $t$ is the number of time periods throughout the day with different price levels, $P$ is the price during that time period, and $Q$ is the electricity usage during that time period. The specific equations used to calculate the values in Equations 2.6 and 2.7 are dependent upon the pricing structure currently in use on a particular day, whether a three period TOU/CPP, a two period TOU, or a two period CPP. For a three period TOU/CPP price structure, the load-weighted average price is calculated by:

$$
P_{\text {avg daily }}=\frac{\left(P_{\text {CriticalPeak }} * Q_{\text {CriticalPeak }}\right)+\left(P_{\text {Peak }} * Q_{\text {Peak }}\right)+\left(P_{\text {OffPeak }} * Q_{\text {offPeak }}\right)}{Q_{\text {CriticalPeak }}+Q_{\text {Peak }}+Q_{\text {OffPeak }}}
$$

where:

$Q_{\text {CriticalPeak }}$ is the electricity usage during the critical peak period (kWh)

$Q_{\text {Peak }} \quad$ is the electricity usage during the peak period $(\mathrm{kWh})$

$Q_{\text {OffPeak }} \quad$ is the electricity usage during the off-peak period (kWh)

$P_{\text {CriticalPeak }}$ is the critical peak period price of electricity $(\$ / \mathrm{kWh})$

$P_{\text {Peak }} \quad$ is the peak period price of electricity $(\$ / \mathrm{kWh})$

$P_{\text {OffPeak }} \quad$ is the off-peak period price of electricity $(\$ / \mathrm{kWh})$

A two period TOU pricing structure utilizes peak and off-peak pricing, so the load-weighted average price is calculated as:

$$
P_{\text {avg daily }}=\frac{\left(P_{\text {Peak }} * Q_{\text {Peak }}\right)+\left(P_{\text {OffPeak }} * Q_{\text {OffPeak }}\right)}{Q_{\text {Peak }}+Q_{\text {OffPeak }}}
$$

And when a two period CPP pricing structure is used with a critical peak price and an off-peak price, the load-weighted average price is calculated as:

$$
P_{\text {avg daily }}=\frac{\left(P_{\text {CriticalPeak }} * Q_{\text {CriticalPeak }}\right)+\left(P_{\text {OffPeak }} * Q_{\text {OffPeak }}\right)}{Q_{\text {CriticalPeak }}+Q_{\text {OffPeak }}}
$$

In this model, both the substitution and daily elasticity parameters are used simultaneously to predict the change in the current load of the appliances in the residence due to a change in price. The appliance load shape of the previous 24 hours of the base case simulation, when the price signal was a flat rate, is used as a starting point. The change in price is determined from the customer's previous pricing structure (flat rate in this analysis) as compared to the new pricing structure, whether TOU or CPP. These are used together to predict the new load under the new 
pricing structure at any given hour. Two sets of equations are simultaneously solved; the first equation calculates the change in the overall daily usage given a change in the daily price of electricity, while the second equation calculates the change in the peak (or critical peak) to offpeak ratio of electricity usage, given a change in the ratio of the peak (or critical peak) to offpeak prices of electricity. Using the two equations, the change in electricity demand of any given hour is calculated. When incorporating the load shape from the base case simulation with the two solved equations, the load shape under the new pricing structure is obtained. Figure 2.3 demonstrates this by applying the daily elasticity and substitution elasticity separately, then combining both equations into a new load.

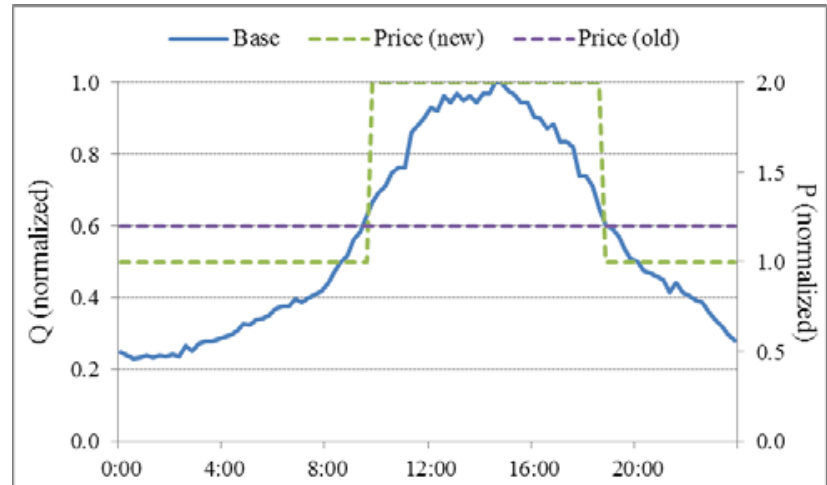

(a) Base Case

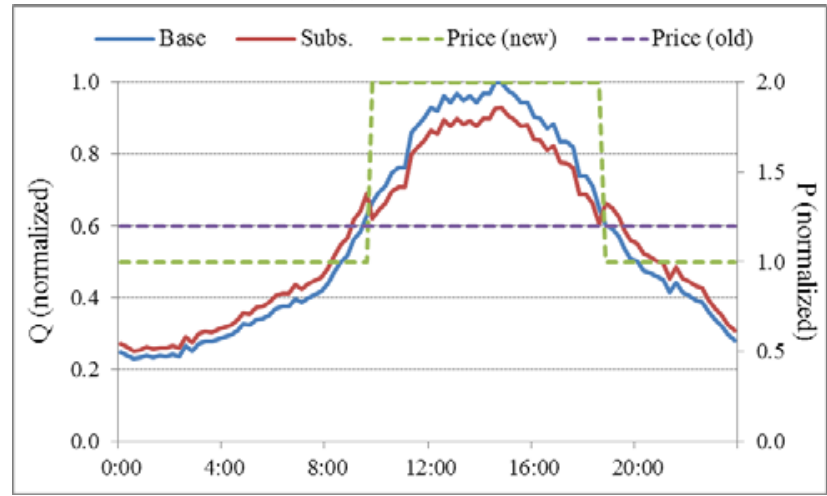

(c) Substitution Elasticity

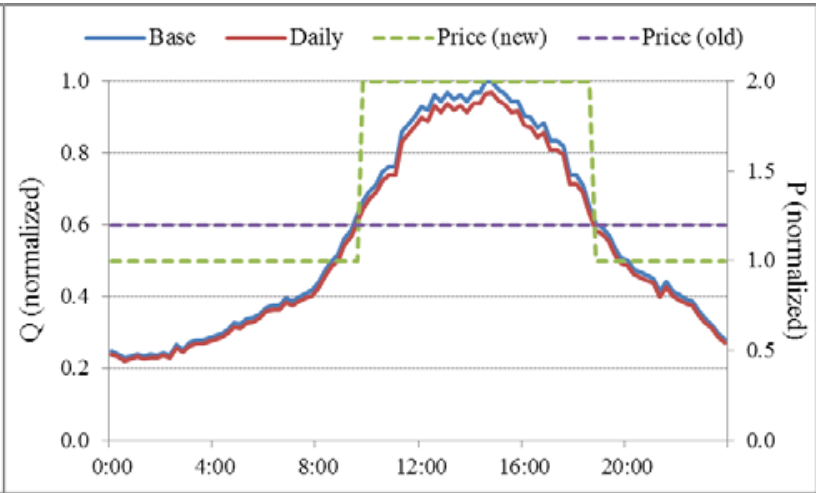

(b) Daily Elasticity

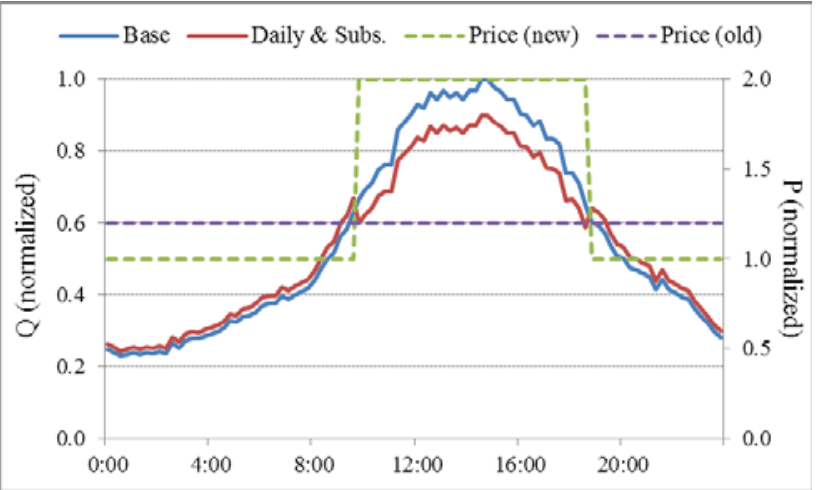

(d) Both Elasticity Values

Figure 2.3: Example of time series change in $\mathrm{Q}$ when changing from fixed to TOU rate structure

Figure 2.3 uses example elasticity and price values on a peak summer day applied to the normalized load of an entire feeder. In fact, most of the values are exaggerated to help show the effects on the demand over time. Notice that the daily elasticity reduces demand in relation to the base case at all times as a function of the total load, while the substitution elasticity shifts demand from the peak to the off-peak period, consuming the same amount of energy throughout the day as is used in the base case. It should be noted, that in the case of revenue neutrality, where the load-weighted price average is the same in both the fixed price and a two rate TOU 
case, the right-hand side of Equation 2.7 goes to zero, and there is no net reduction in daily energy consumption.

Of course, to apply this in an analysis, actual values for each of the elasticity values must be applied. The elasticity values used in the analysis were derived from the elasticity values obtained in the California Statewide Pricing Pilot [15]. The model was developed in GridLAB$\mathrm{D}$ to cater to the rate structures being simulated, or a two period TOU rate designed both with and without a CPP overlay. Therefore, the choice of elasticity values was limited to studies which had used similar pricing structures. The data from the California Statewide Pricing Pilot (California SPP) has been widely cited and is also the basis for the elasticity parameters in studies using the PRISM model [15]. The PRISM model has also been widely used in many other studies and its results have been widely used and referenced [16]. Hence, values derived from a widely acknowledged model and pricing pilot were chosen for this model. The model was also designed to simulate how enabling technologies such as IHDs, HEMs, and web portals affect the elasticity, and therefore, customer response to a change in price. Note, that since loads such as air conditioners, water heaters, and pool pumps are already being controlled by technologies in the enabling technology cases, the elasticity values only apply to the other loads in the home. Hence, elasticity values from studies which made this distinction were needed. Both the PRISM model and the California SPP take into account Central Air Conditioning (CAC) or Heating, Ventilation, and Air Conditioning (HVAC) saturation values and account for the effects of weather using the Cooling Degree Hours $(\mathrm{CDH})$ values. These factors are taken into account by these studies when calculating the elasticity values. For the various scenarios, the elasticity parameters determined for the purpose of this analysis are listed in Table 2.5.

Table 2.5: Values used for elasticity of non-controlled loads

\begin{tabular}{|c|c|c|}
\hline & Non-Critical Days & Critical Peak Days \\
\hline $\begin{array}{c}\text { Substitution Elasticity } \\
\text { (without enabling technology) }\end{array}$ & -0.076 & -0.111 \\
\hline $\begin{array}{c}\text { Substitution Elasticity } \\
\text { (with enabling technology) }\end{array}$ & -0.152 & -0.222 \\
\hline $\begin{array}{c}\text { Daily Elasticity } \\
\text { (without enabling technology) }\end{array}$ & -0.041 & -0.027 \\
\hline $\begin{array}{c}\text { Daily Elasticity } \\
\text { (with enabling technology) }\end{array}$ & -0.051 & -0.052 \\
\hline $\begin{array}{c}\text { Daily Elasticity } \\
\text { (weekends - with \& without) }\end{array}$ & -0.043 & -0.043 \\
\hline
\end{tabular}

The elasticity parameters in Table 2.5 represent the average of the total population of consumers for the various scenarios. However, to represent the elasticity values of each individual customer and simulate a diverse set of customer responses, a log-normal distribution of elasticity parameters was developed using the values in Table 2.5 as the average for the given 
scenario. This provided for a population of consumers who each responded a different amount to a price change, while still preserving the average response seen in previous studies. This means that when the daily elasticity is applied to the population of customers (as seen in Figure 2.4), the average customer has no net change in energy consumption; individual customers, however, may experience changes in their daily energy consumption, depending upon the random elasticity value assigned to that particular customer.

\subsubsection{High Level TOU and CPP Simulation Results}

In this section the high level results of TOU and TOU/CPP will be examined. At this level of examination the reporting of the impact metrics will not be divided into monthly values, but rather annual values will be examined. This section will provide a summary of the four test case results compared against the base case simulation. The high level examination will include a summary of the ability of the implemented TOU and TOU/CPP (with and without enabling technologies) programs to reduce peak load, annual energy consumption, system losses, and carbon emissions. Additional impact metrics affected by these technologies can be found in Appendix E.

\subsubsection{Annual Peak Demand}

Peak reduction is the most commonly claimed benefit of implementing a TOU/CPP DR program. Figure 2.4 compares peak demand for the five cases on each feeder, while Figure 2.5 and Figure 2.6 show the change in peak demand from the base case to the current technology case, first in terms of $\mathrm{kW}$, then in terms of percent of peak demand. As can be seen from Figure 2.4 to Figure 2.6, peak reduction is not always a benefit of TOU and TOU/CPP, especially when automated controls are used. The price signal can act as a synchronizing signal, temporarily reducing load diversity throughout the system and causing a "rebound" during the recovery time. At times, the rebound peak can be significantly greater than the original peak, but typically for only a short period of time. While most utilities actively manage the rebound (when necessary), the addition of automated technologies exacerbates the rebound problem. In fact, it should be noted that feeder R5-12.47-3 does not show results for the "with technology" cases, as the rebound was so large it caused voltage collapse on the system. As technologies begin to further automate the process of demand response, the magnitude of the rebound may become a greater concern. Section 2.3 will discuss these issues in more detail.

It should be noted that in this case, the definition of annual peak demand may be misleading. For example, while the individual feeder circuits may experience an increase in peak demand, this peak demand may be offset temporally by as much as a few hours. If the rebound peak is non-coincidental with the system peak, then this may result in an overall system level peak reduction. This illustrates one of the difficulties in describing the benefits of DR through a simple metric; the benefits of DR cannot be described by a simple peak demand reduction 
metric, but requires one to ask a multitude of questions like how much can demand be reduced and for how long, at what return cost (i.e. the rebound), and who receives the benefits (e.g. transmission system peak reduction versus a local reduction in peak). Some of these questions, including the temporal offset of the peak, peak reductions within a certain time window, and the effects of the rebound will be further discussed in Sections 2.3 and 2.4, including alternate impact metrics for evaluating the performance of the demand response program.

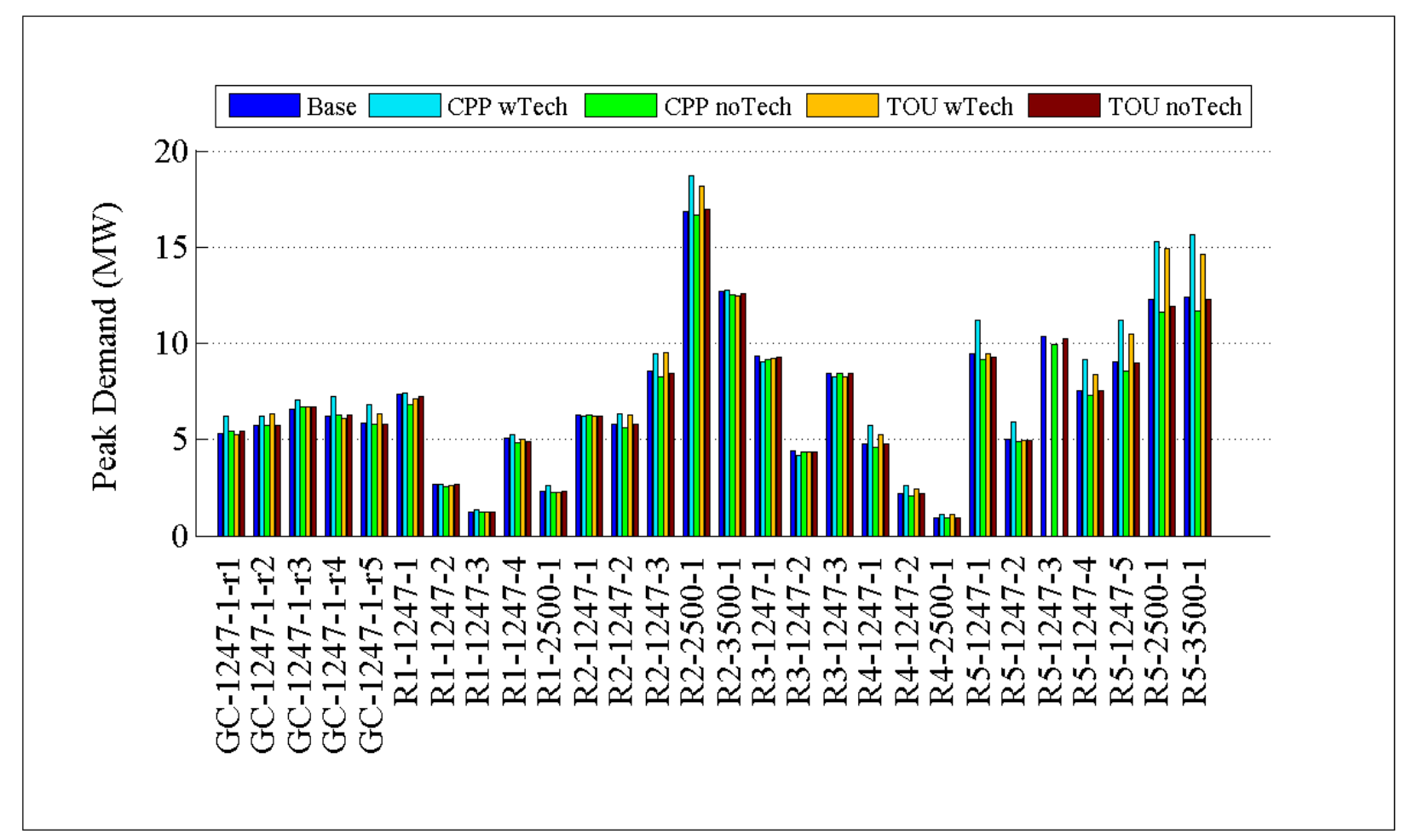

Figure 2.4: Comparison of peak demand by feeder 


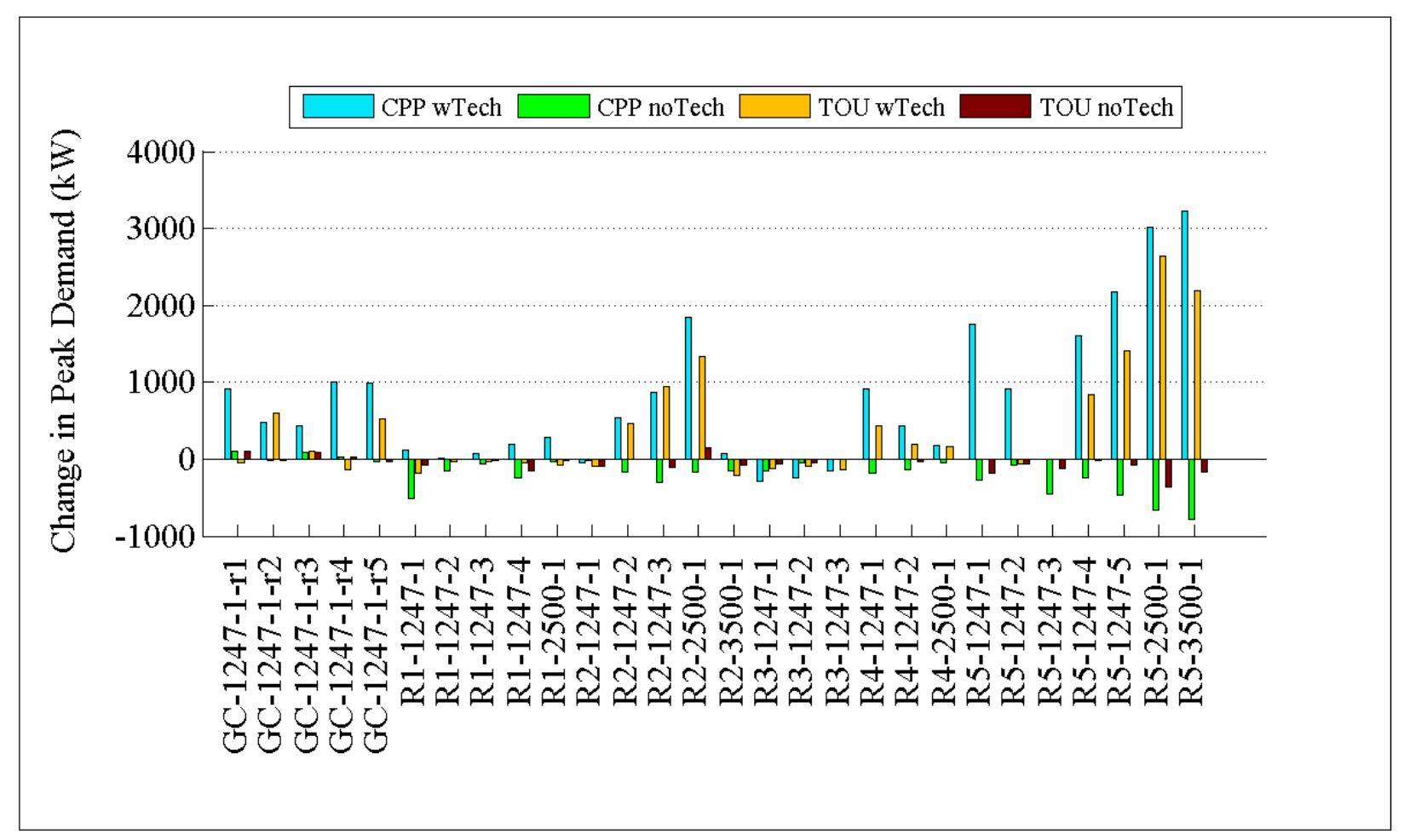

Figure 2.5: Change in peak demand by feeder $(\mathrm{kW})$

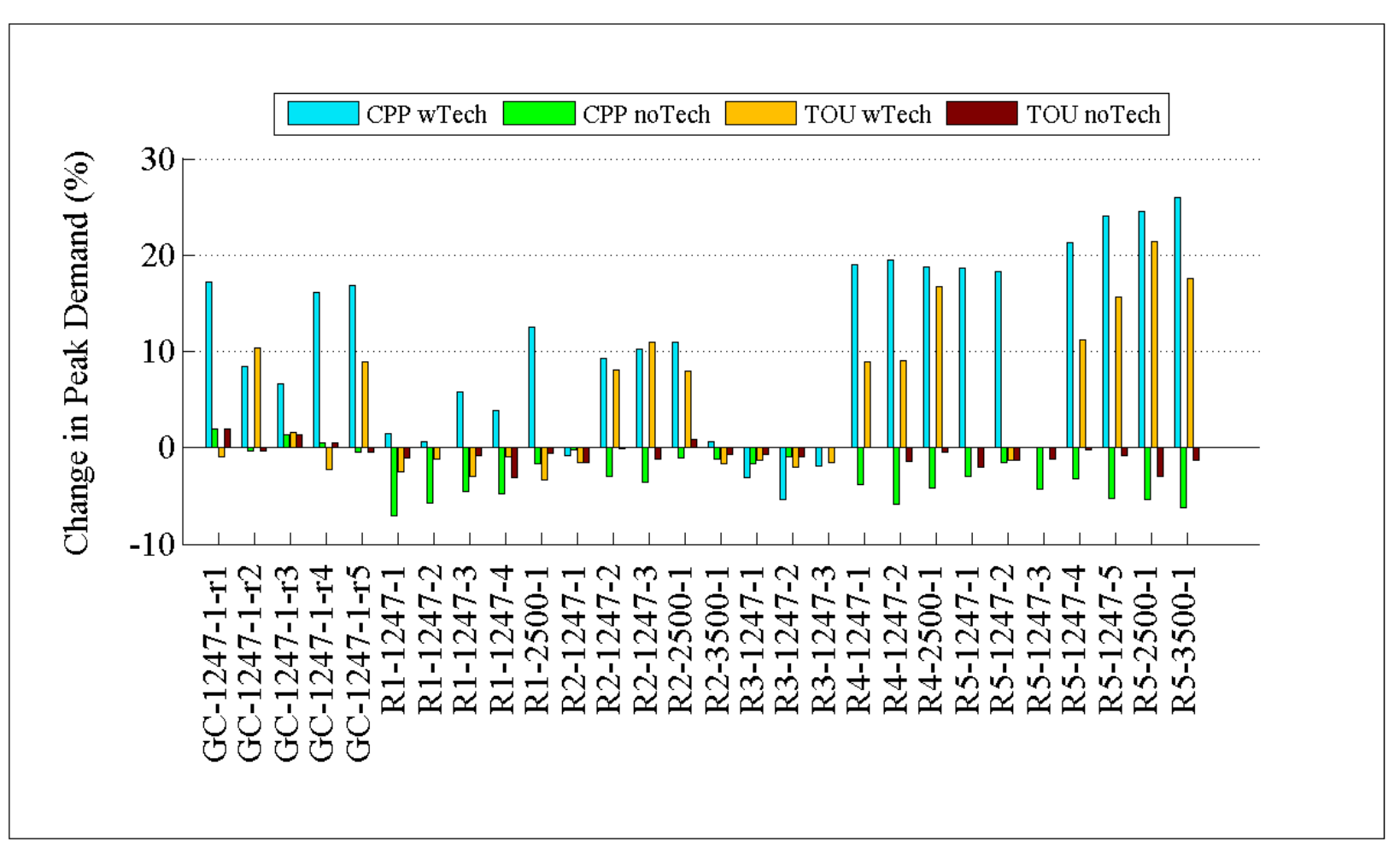

Figure 2.6: Change in peak demand by feeder (\%) 


\subsubsection{Annual Energy Consumption}

Reduction of annual energy consumption is not typically considered a primary impact of TOU or TOU/CPP programs, as they are typically designed to temporally shift energy consumption or reduce peak demand. Often, the recovery period may require as much or more energy than that deferred in the peak period. The benefits seen are typically second order effects, such as the slight increase in efficiency seen by shifting the cooling load to a later time of day after the outside air temperature has decreased, and do not significantly contribute to energy reduction.

As can be seen from Figure 2.7 to Figure 2.9, annual energy consumption is reduced or increased depending upon the feeder studied across all cases, but in general reductions of less than $1 \%$ in annual energy consumption are seen. Another issue that can be seen in Figure 2.7 to Figure 2.9 is that the reductions in annual energy consumption have a strong regional correlation. The regional correlation can be attributed to the second order effects, such as the recovery period, that are primarily affected by climate.

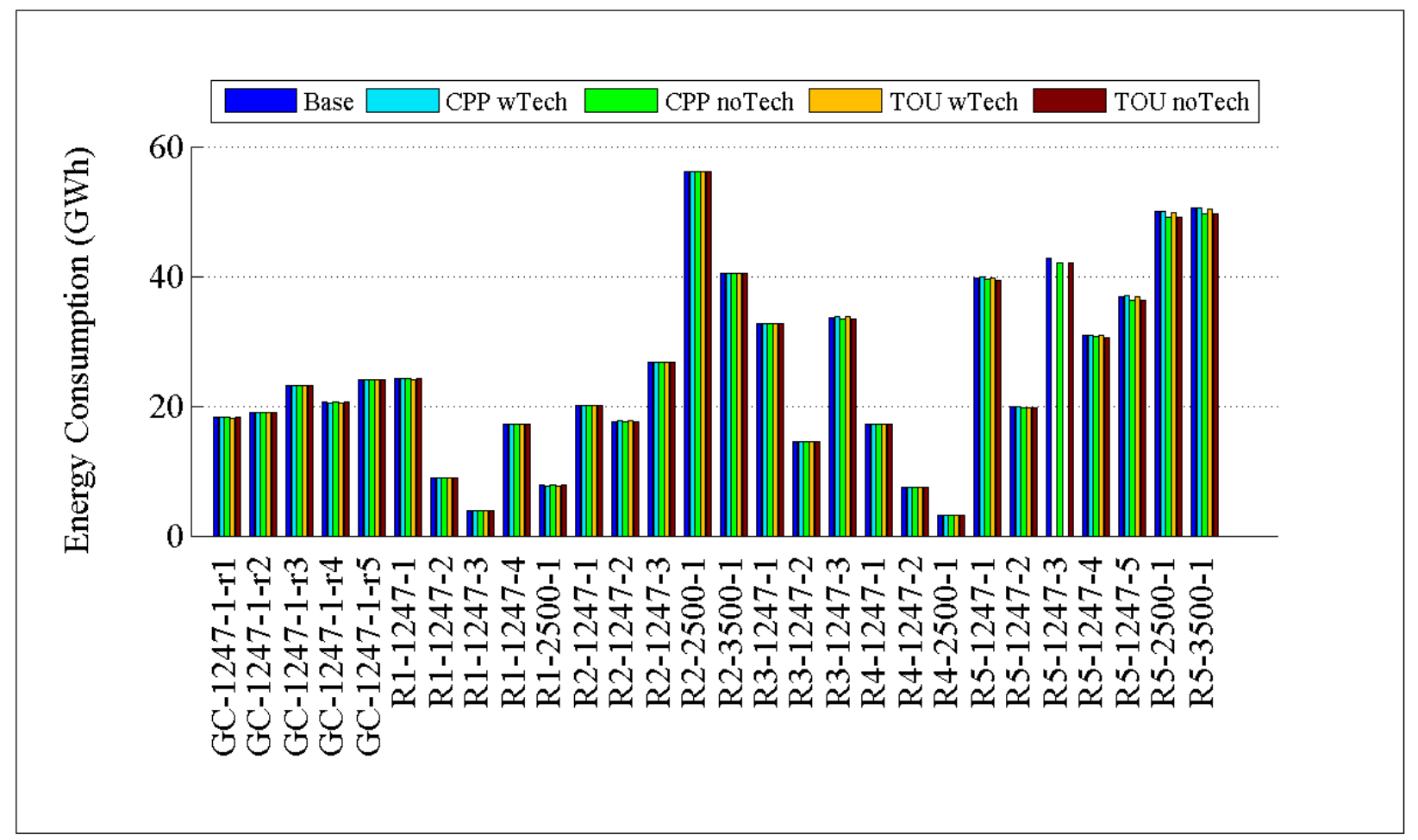

Figure 2.7: Comparison of annual energy consumption by feeder (MWh) 


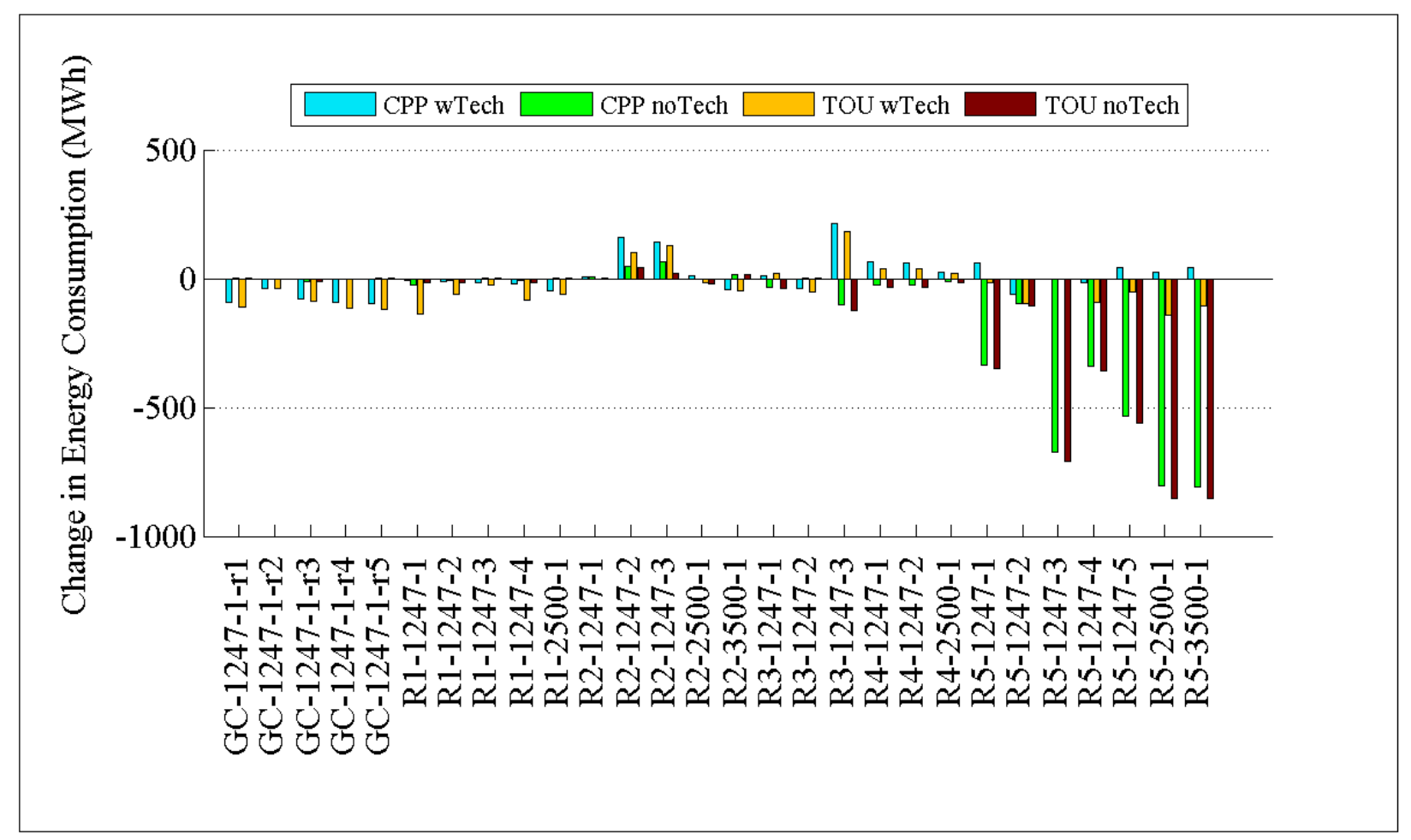

Figure 2.8: Change in annual energy consumption by feeder (MWh)

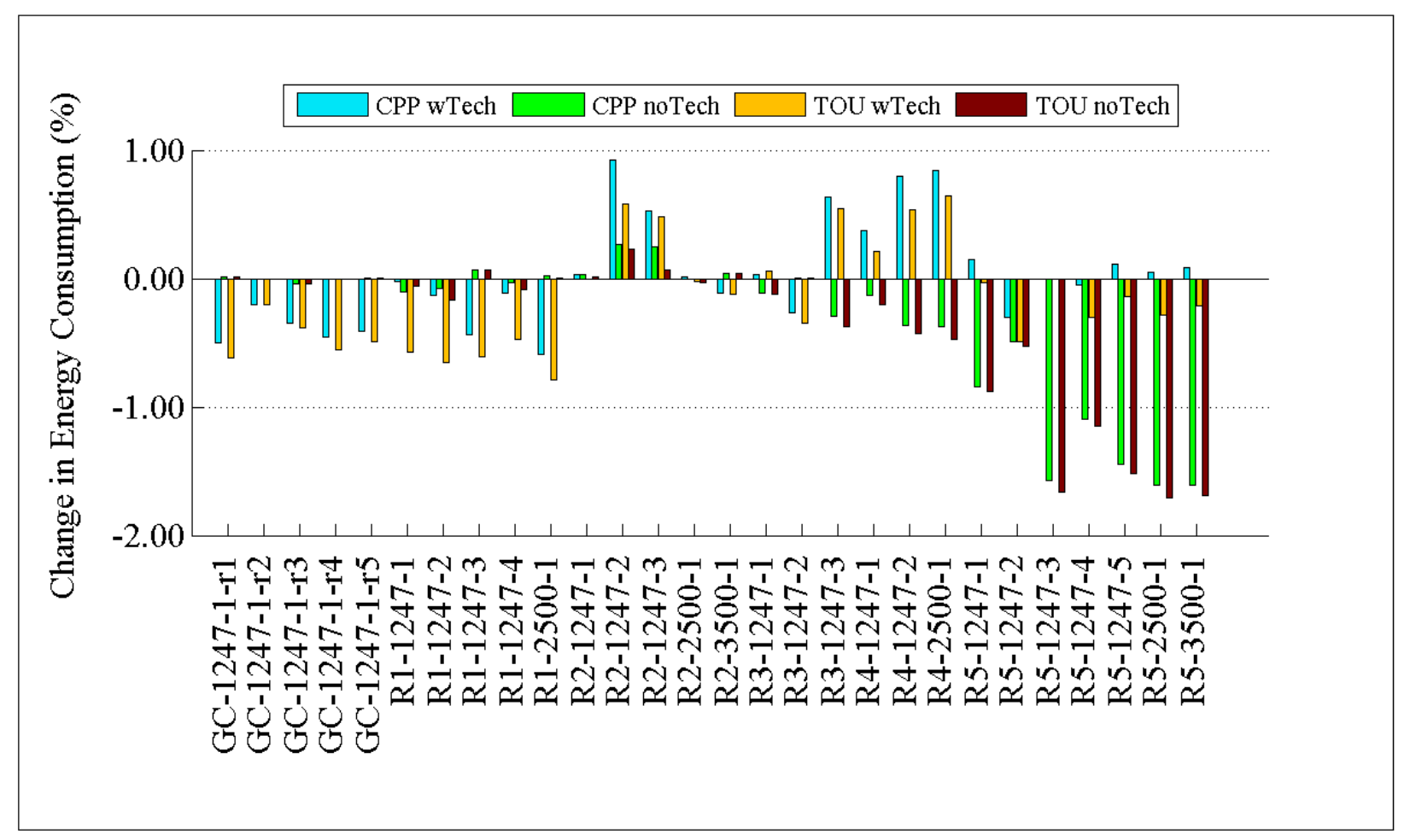

Figure 2.9: Change in annual energy consumption by feeder (\%) 


\subsubsection{Annual System Losses}

Loss reduction is often described as an impact peak reduction in response to time-based pricing. However, it can be seen from Figure 2.10 to Figure 2.12 that the change in losses varies from increased losses to decreased losses depending upon the feeder investigated. Feeder losses include those accumulated from distribution transformers, overhead and underground lines, and triplex cabling, and do not address transmission or sub-transmission losses. Additionally, the annual system losses change by less than 3\% between the five cases, except on feeder R5-12.473. Losses are affected by a number of different factors, from feeder topology to load composition, and represent less than $5 \%$ of the total annual energy consumption.

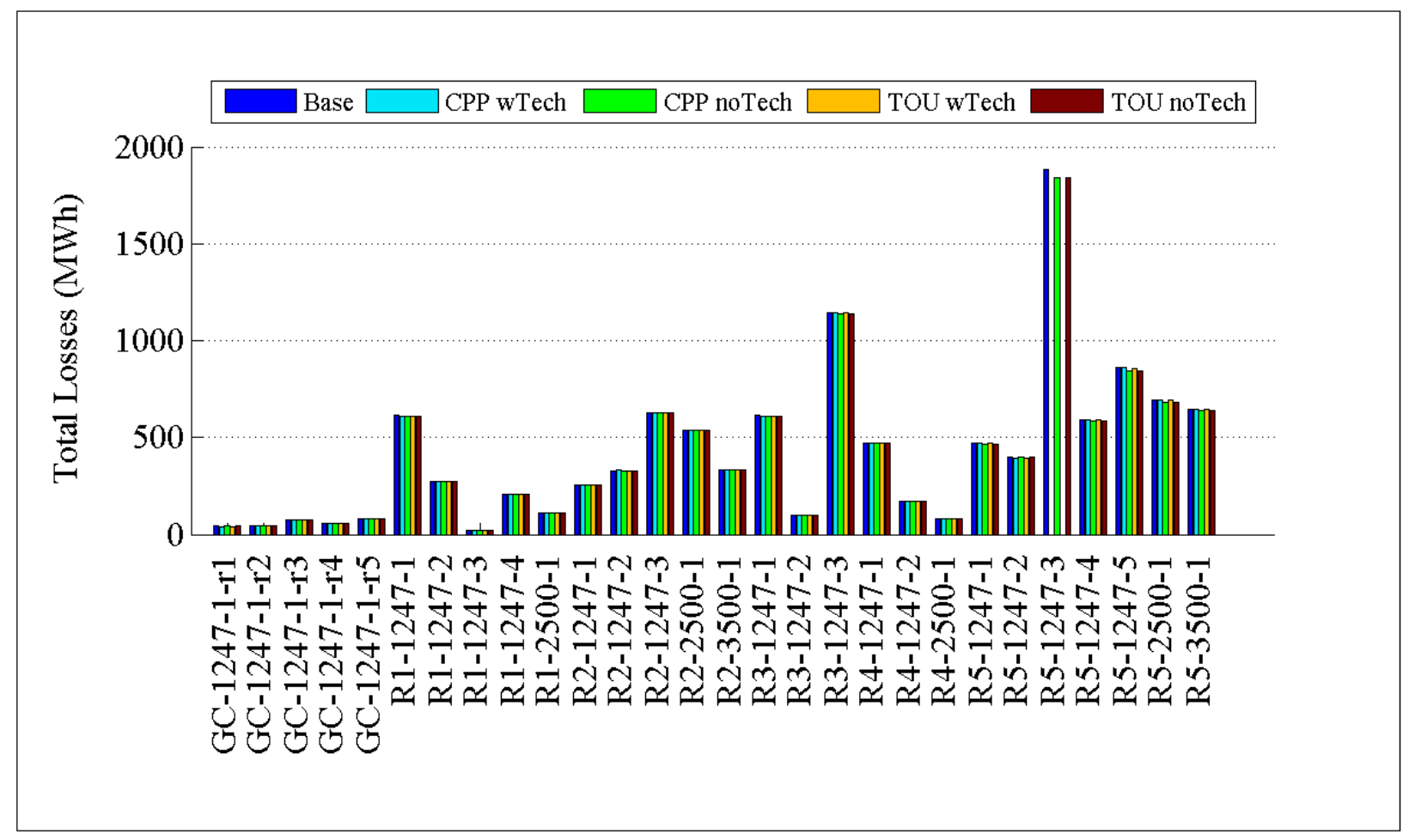

Figure 2.10: Comparison of total annual losses by feeder 


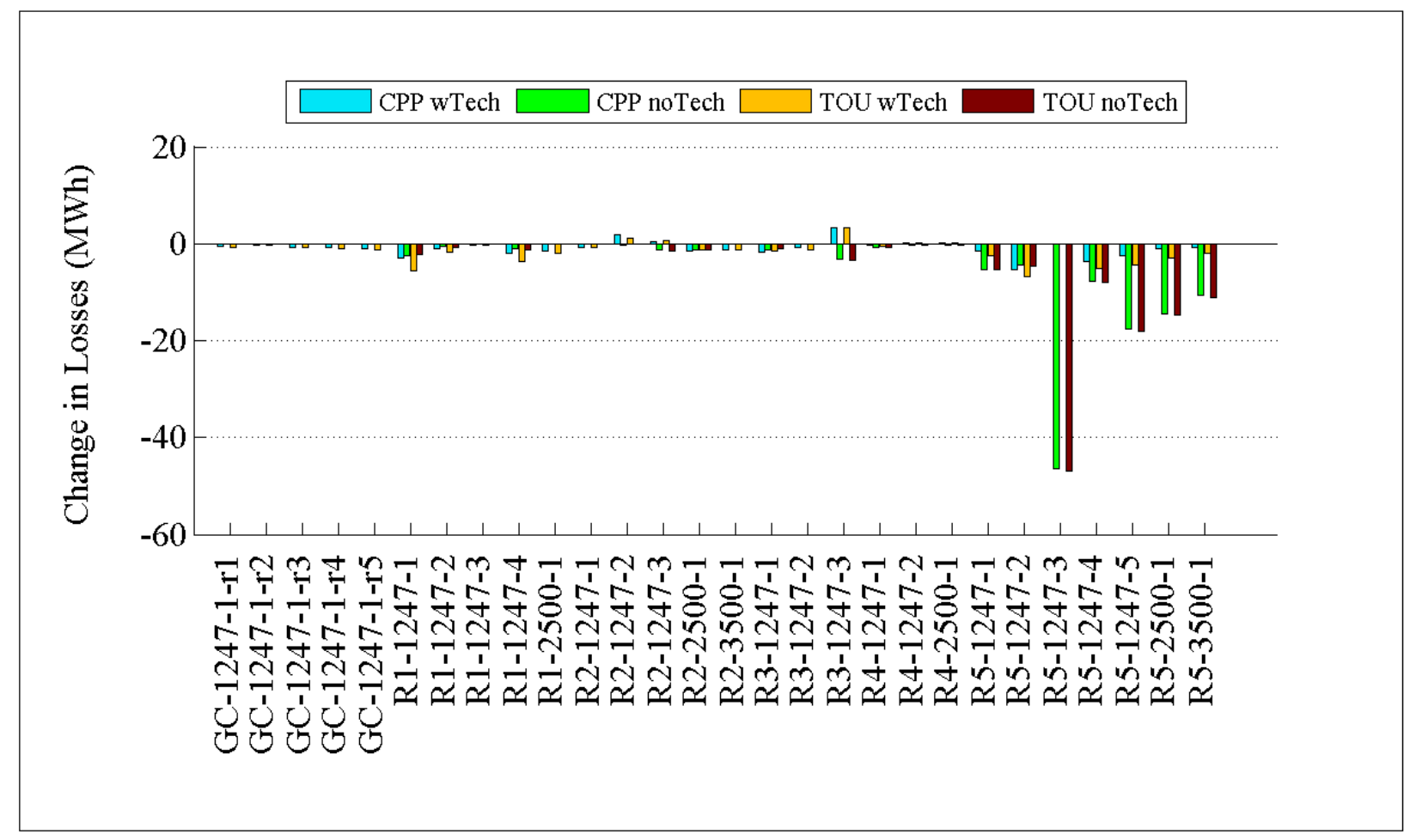

Figure 2.11: Change in total annual losses by feeder (MWh)

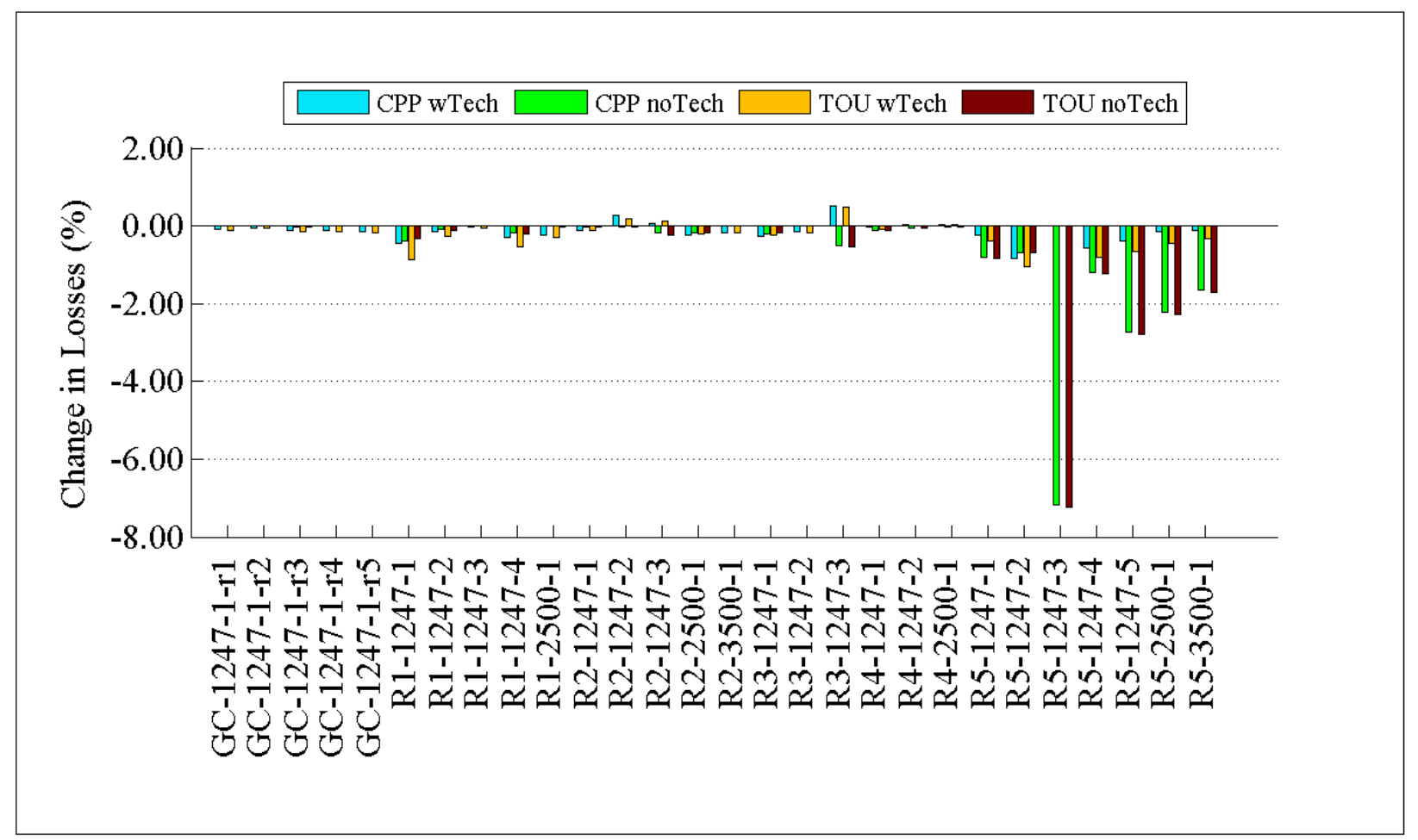

Figure 2.12: Change in total annual losses by feeder (\%) 


\subsubsection{Annual $\mathrm{CO}_{2}$ Emissions}

Environmental emissions for each feeder were estimated using a simple dispatch algorithm. Generation sources were sized by the regional generator types, and ranked to dispatch in an appropriate order. Full commitments were achieved before proceeding to the next generator. For example, consider a region where natural gas turbines dispatch first and support $250 \mathrm{MW}$ of load, followed by $400 \mathrm{MW}$ of petroleum-fired generation. To support $300 \mathrm{MW}$ of load, the natural gas is fully dispatched then the remaining $50 \mathrm{MW}$ is attributed to petroleum-fired generation. Representative heat rates and emission rates are then applied to these power outputs to determine the overall environmental impacts. The details of these rates, along with the dispatch orders and amounts for each region, are explained in Appendix B.3.

Figure 2.13 to Figure 2.15 compare annual $\mathrm{CO}_{2}$ emissions between the base case and the four technology cases. Again, results are mixed depending on the feeder studied. However, results are often consistent within each region, indicating that generation mix plays a strong role in determining the effects on $\mathrm{CO}_{2}$ emissions. While reduced energy consumption will generally reduce $\mathrm{CO}_{2}$ emissions, in the case of DR, load is often shifted temporally but not reduced, moving it from one generation source to another. Depending on what prime mover is being utilized during the peak period versus the off-peak period, $\mathrm{CO}_{2}$ emissions can either decrease or increase. As can easily be seen in Figure 2.15, regions 1 and 5 (West Coast and Southern regions) show a greater reduction in $\mathrm{CO}_{2}$ emissions than other regions. This is mainly due to the reduced energy consumption seen in those regions. 


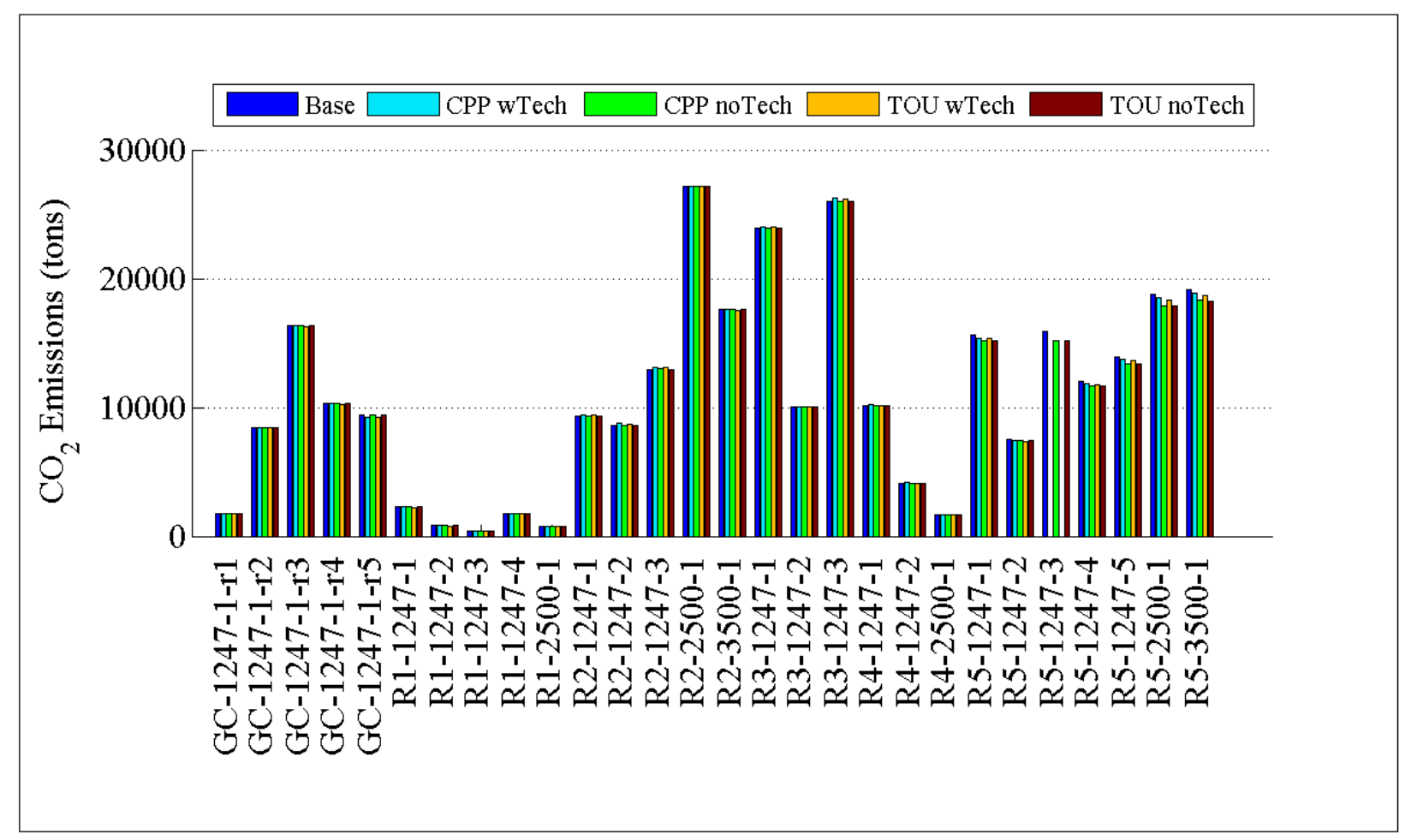

Figure 2.13: Comparison of total annual $\mathrm{CO}_{2}$ emission by feeder

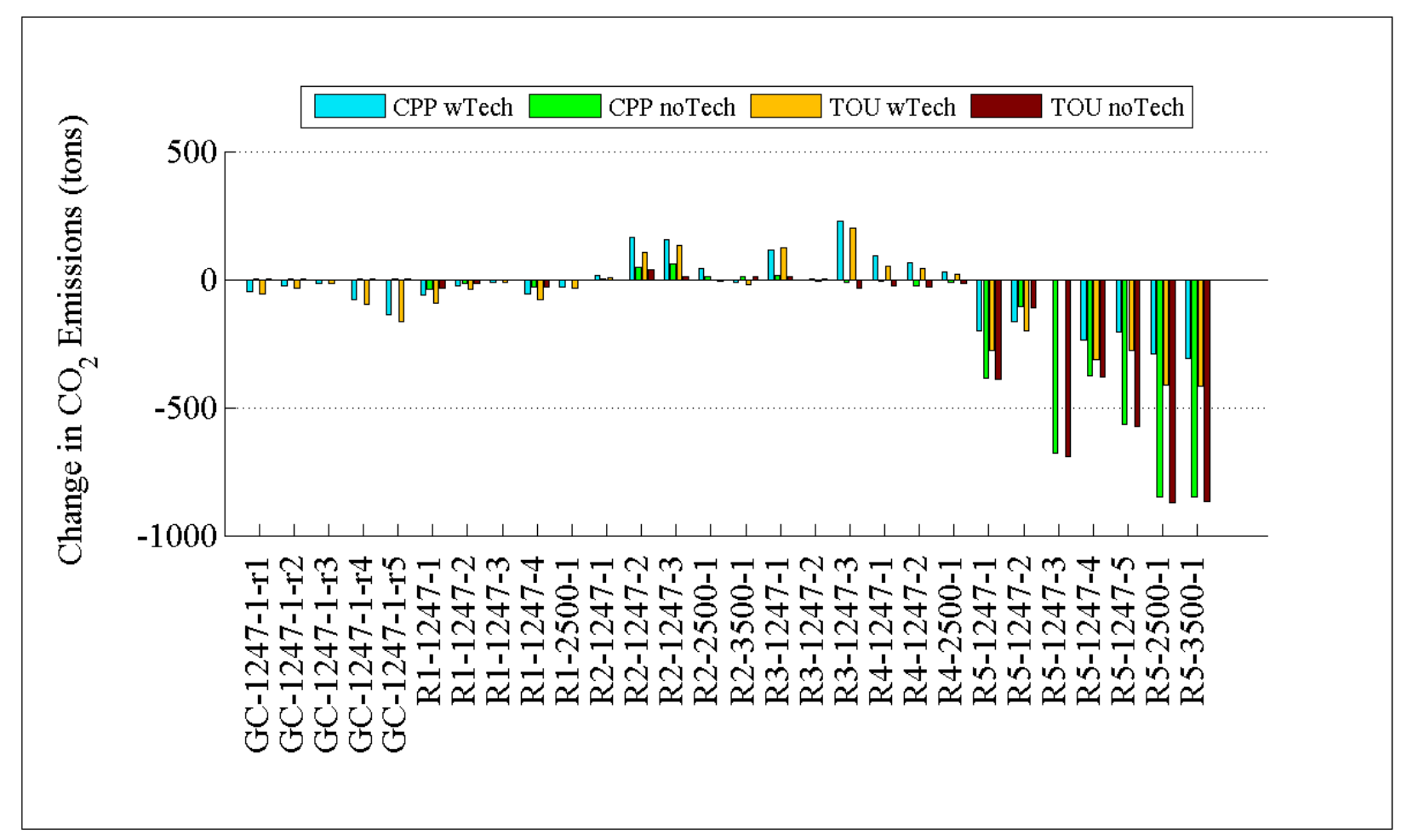

Figure 2.14: Change in total annual $\mathrm{CO}_{2}$ emissions by feeder (tons) 


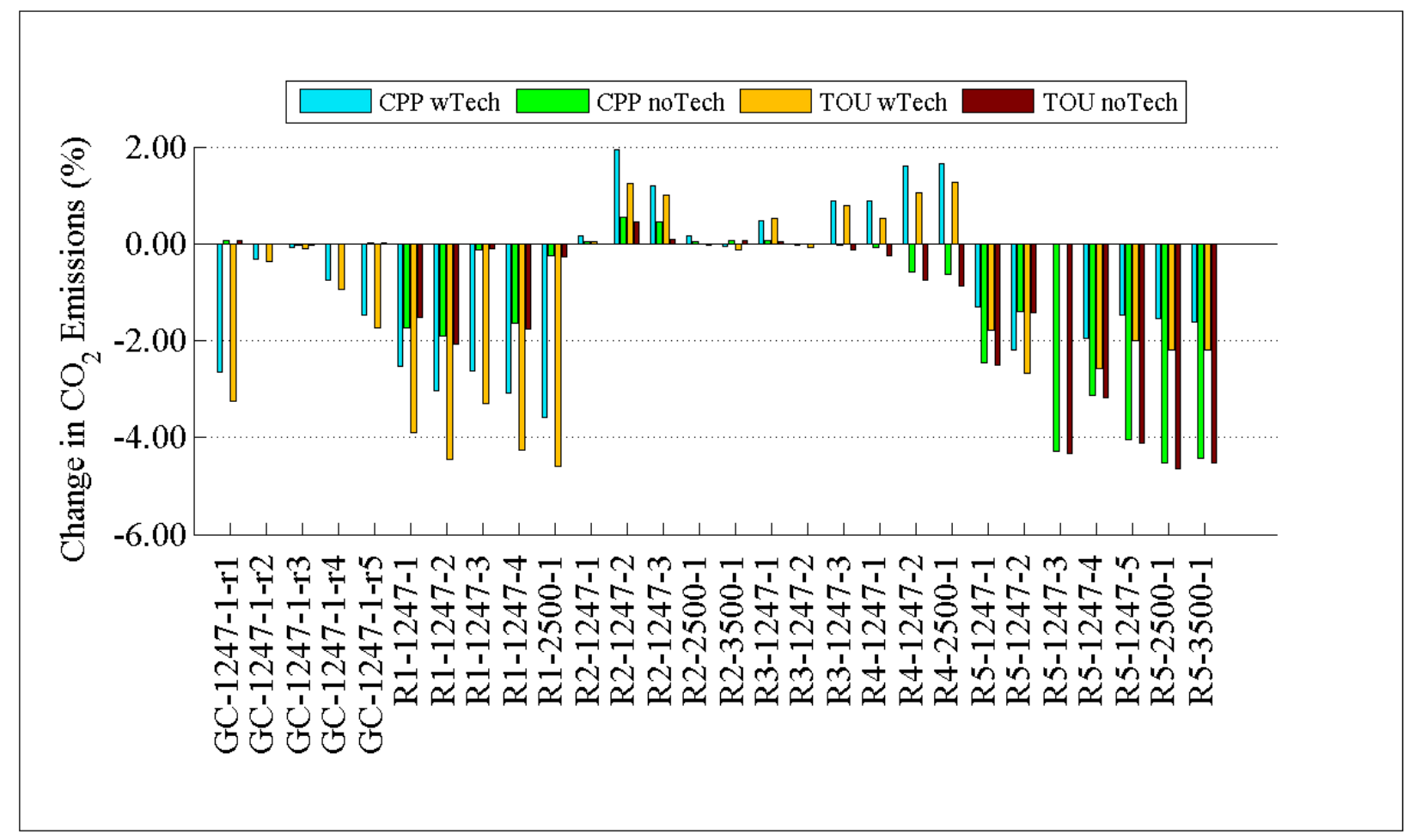

Figure 2.15: Change in total annual $\mathrm{CO}_{2}$ emissions by feeder $(\%)$

\subsection{Direct Load Control (DLC)}

Direct load control has been used by utilities for a number of decades. This type of demand response allows utilities to take control of specific residential customer end-uses directly (i.e. air conditioners, pool pumps, and hot water heaters), and manipulate the load in a limited way that benefits the distribution or bulk power system. This can range anywhere from a percentage reduction of load by altering the behavior of the load to a complete disconnecting of all loads. These are typically voluntary programs, and customers are often incentivized with a reduced rate for electricity or a flat rebate in exchange for providing the service. Proponents of DLC like it because the response of the load is very predictable and quantifiable, as customers have given over almost all control to the utility. Additionally, only 1-way communication is usually required, reducing the cost of deployment, but also reducing the observability of the system, as information about how the load behaves is not directly transmitted to the utility. Retention in DLC programs can often be a difficult and costly problem for the utility, and if the program is underutilized (i.e. all of the days contracted by the utility and customer agreement are not used every year), a "free rider" effect is often seen, where customers are receiving an incentive without having to change their behavior. 
To ensure that the results of this report can be reproduced by other researchers, all of the tools, models, and materials used are openly available at [3]. To estimate the potential of DLC in reducing peak demand, detailed time series simulations were conducted in GridLAB-D [3] on each of the 28 Prototypical Feeders [5]. Openly available automated controls were included to determine the impact of technologies in utilizing DLC programs. 


\subsubsection{SGIG Metrics Affected by DLC}

The following SGIG metrics are affected by DLC and will be tracked in this analysis:

Table 2.6: Impact metrics affected by DLC

\begin{tabular}{|c|c|c|}
\hline Index & Metric & Units \\
\hline 1 & Hourly Customer Electricity Usage & $\mathrm{kWh}$ \\
\hline 2 & Monthly Customer Electricity Usage & MWh \\
\hline \multirow{10}{*}{3} & Peak Generation & $\mathrm{kW}$ \\
\hline & Nuclear & $\%$ \\
\hline & Solar & $\%$ \\
\hline & Bio & $\%$ \\
\hline & Wind & $\%$ \\
\hline & Coal & $\%$ \\
\hline & Hydroelectric & $\%$ \\
\hline & Natural Gas & $\%$ \\
\hline & Geothermal & $\%$ \\
\hline & Petroleum & $\%$ \\
\hline 4 & Peak Load & $\mathrm{kW}$ \\
\hline 7 & Annual Electricity Production & MWh \\
\hline 12 & $\mathrm{CO}_{2}$ Emissions & Tons \\
\hline \multirow{3}{*}{13} & SOx Emissions & Tons \\
\hline & NOx Emissions & Tons \\
\hline & PM-10 Emissions & Tons \\
\hline \multirow{2}{*}{21} & Feeder Real Load & $\mathrm{kW}$ \\
\hline & Feeder Reactive Load & kVAR \\
\hline 29 & Distribution Losses & $\%$ \\
\hline 30 & Distribution Power Factor & $\mathrm{pf}$ \\
\hline 39 & $\mathrm{CO}_{2}$ Emissions & Tons \\
\hline \multirow{3}{*}{40} & SOx Emissions & Tons \\
\hline & NOx Emissions & Tons \\
\hline & PM-10 Emissions & Tons \\
\hline
\end{tabular}




\subsubsection{Specific Implementation of DLC}

In this analysis, DLC was applied in a similar manner to the CPP signal. The six hour windows used for the CPP signal on each of the feeders was also applied the same 15 times per year for DLC, as it is common for DLC events to be used by utilities 10-15 times per year. These signals were applied to the HVAC system, hot water heaters, and pool pumps. In the DLC analysis, the price of electricity was a fixed rate so the elasticity model was not used, as it is a customer behavior model and not a direct load control device. The following sections will describe the specific DLC controls used for each appliance.

\subsubsection{DLC HVAC Controls}

As DLC is a mature technology, a number of control strategies for HVAC systems already exist. A common method of DLC for HVAC systems involves modifying the natural duty cycle of the HVAC system to consume less energy during a given time period. In some programs this requires monitoring of the current duty cycle, then decreasing the duty cycle by $20-50 \%$ during the specified time period. This requires additional monitoring and control devices at the residence to process the utility request for a certain percentage of reduction. Other programs provide a scheduled time frame during which the HVAC is allowed to operate, and an additional time frame for which it is shut off. This has the effect of enforcing a duty cycle and period of operation. For example, the HVAC may be allowed to operate normally during the first 15 minutes of the hour, but then be shut off during the remaining 45 minutes of the hour. Common strategies consider a forced duty cycle anywhere from 30-70\% for residential buildings, and 50$70 \%$ for commercial buildings. A third method allows the utility to directly modify the customer's set point (thermostat setback program), e.g. increase the cooling set point by five degrees for four hours. The first method provides more controllability over the amount of load reduction provided, but requires more equipment and additional expenditures. The second is easier and less expensive to implement, but also provides less control over the amount of load reduction and when the HVAC system is greatly oversized, it can provide little to no reduction. The third requires access to the thermostat only and is usually better understood by customers, but does not provide a constant load reduction; as time progresses, the response diminishes as customers reach a saturation point, and the internal air temperature climbs to the new set point (in a cooling example). None of the SGIG proposals specified which (if any) of these control methods was to be used.

For the current analysis, the second methodology, using fixed duty time frames, was chosen. A duty cycle within defined ranges (30-70\% duty cycle for residential customers and 50-70\% for commercial customers) was randomly chosen for each residence. The actual value depended upon the normal duty cycle of the residence, and tried to reduce the duty cycle by approximately $50 \%$ for residential customers and 30\% for commercial customers. During the 6-hour DLC period, HVAC operation would be limited to the "on" period of the duty cycle, then forced to 
"off" during the rest. Periods for applying the duty cycle ranged from 10-30 minutes. Additionally, to decrease customer discomfort, maximum temperature deviations were provided. Internal air temperature was not allowed to deviate more than 5-10 degrees above the desired set point. If the internal air temperature exceeded this range, the DLC was deactivated until the internal air temperature returned to within the allowed deviation range. This can be thought of as a hybrid DLC system, utilizing both a thermostat setback (maximum deviation) and a duty cycle restriction with fixed duty cycle time frames.

\subsubsection{Water Heater Controls}

The DLC for the hot water heater was relatively simple. During the DLC signal, the hot water heater was switched to off whether there was demand or not. When the DLC signal was released, the hot water heater re-entered normal operation. The advantage of this system is the simplicity of implementation. The disadvantage is that during those 15 days a year when a DLC event is declared, customers may run out of hot water as the customers use hot water during the DLC period. Additionally, because the internal water temperature drifts lower than its normal setting during the DLC event, when the DLC signal is turned off, the hot water heater will immediately begin heating the water back to its original set point. When a number of appliances do this at once, it can result in a significant rebound as the loads are temporarily less diversified.

\subsubsection{Pool Pump Controls}

Similar to the hot water heater DLC, the pool pump was deactivated during the DLC time period. However, when the DLC signal was released, the pool pumps re-started their cycle, and turned on at the same time they would have normally. This is analogous to a pool pump running on a timer, with an additional DLC switch delivering power to the pool pump that opens due to DLC signal.

\subsubsection{High Level DLC Simulation Results}

In this section the high level results of DLC will be examined. At this level of examination the data will not be divided into monthly values and instead annual values will be observed. Simulation results for each of the prototypical distribution feeders will be shown. The high level simulation results will help examine the impact of DLC on peak demand, annual energy consumption, system losses and $\mathrm{CO}_{2}$ emissions.

\subsubsection{Annual Peak Demand}

The primary objective of DLC is to reduce peak demand during critical periods. Figure 2.16 to Figure 2.18 show the peak demand of the base case versus the DLC case on each of the prototypical feeders. Figure 2.16 shows the actual peak demand of both cases, while Figure 2.17 and Figure 2.18 show the change in peak demand in power and percent of peak respectively. 
Similar to the results from the TOU and TOU/CPP cases, it can be seen that due to the rebound from the control signal, in most cases DLC actually increases peak demand. This will be discussed in more detail in section 2.3. Notice again that results for R5-12.47-3 were not shown, as the rebound caused a voltage collapse on the distribution system. The rebound effect, and how it can be mitigated, will be further discussed in Sections 2.3 and 2.4.

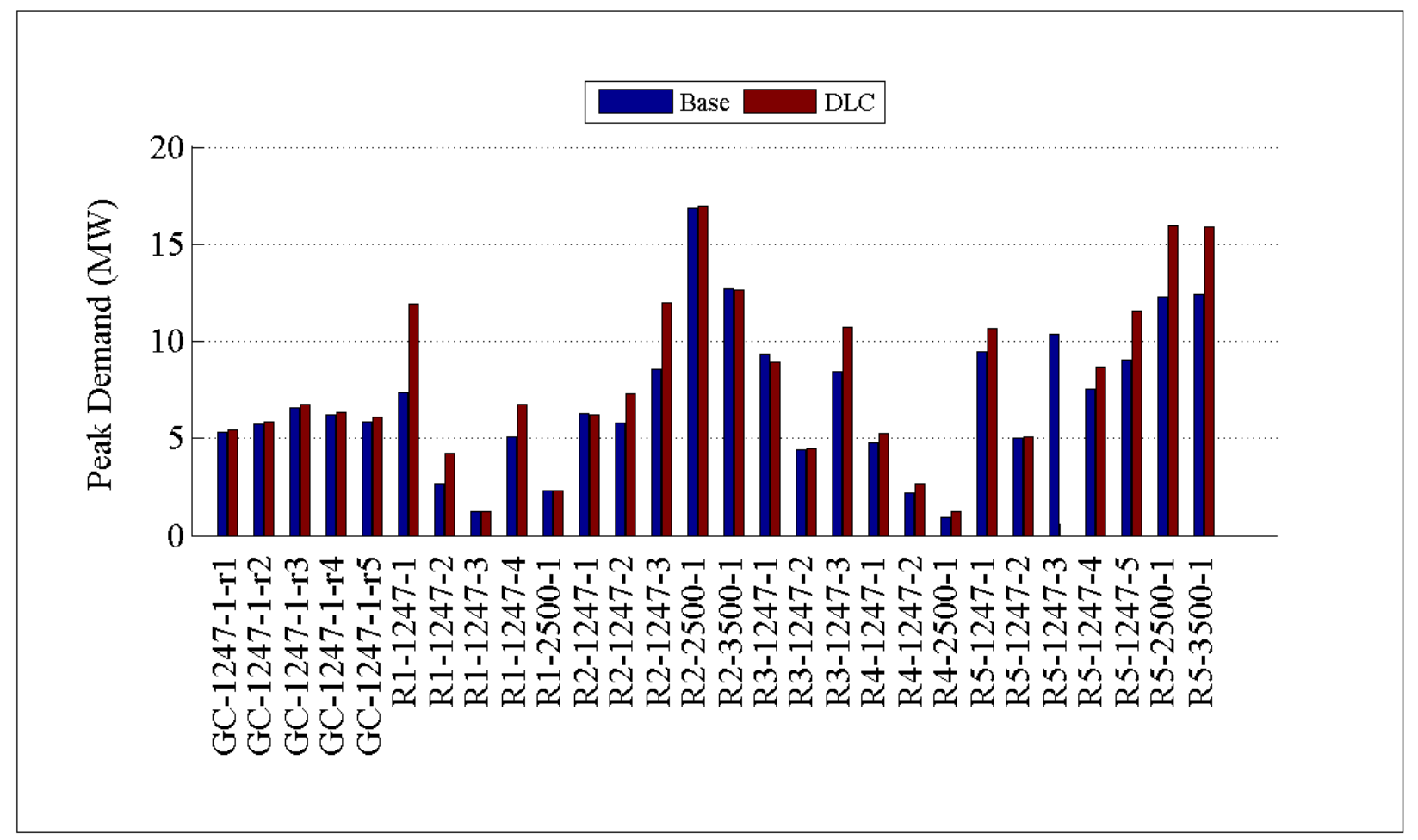

Figure 2.16: Comparison of peak demand by feeder 


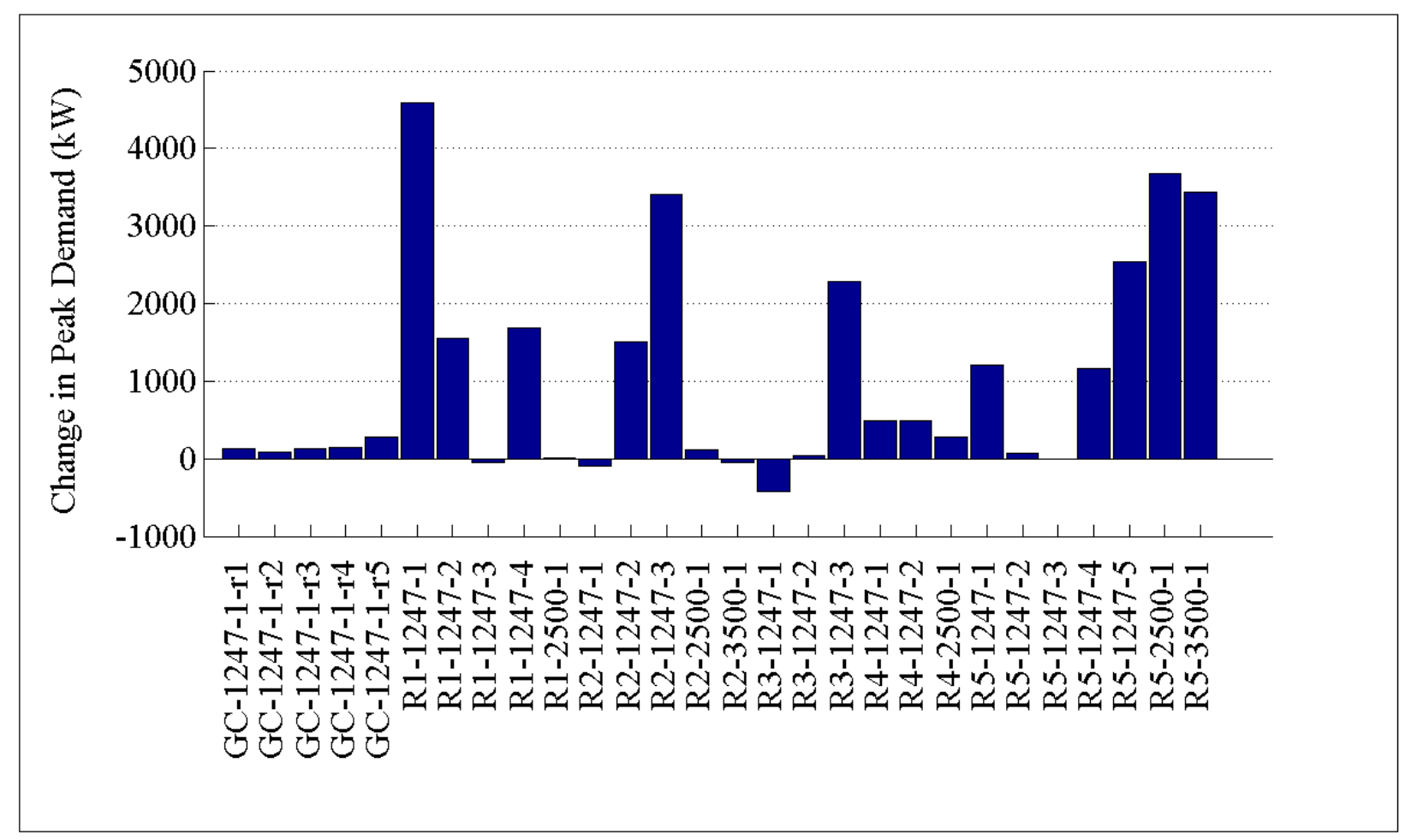

Figure 2.17: Change in peak demand by feeder $(\mathrm{kW})$

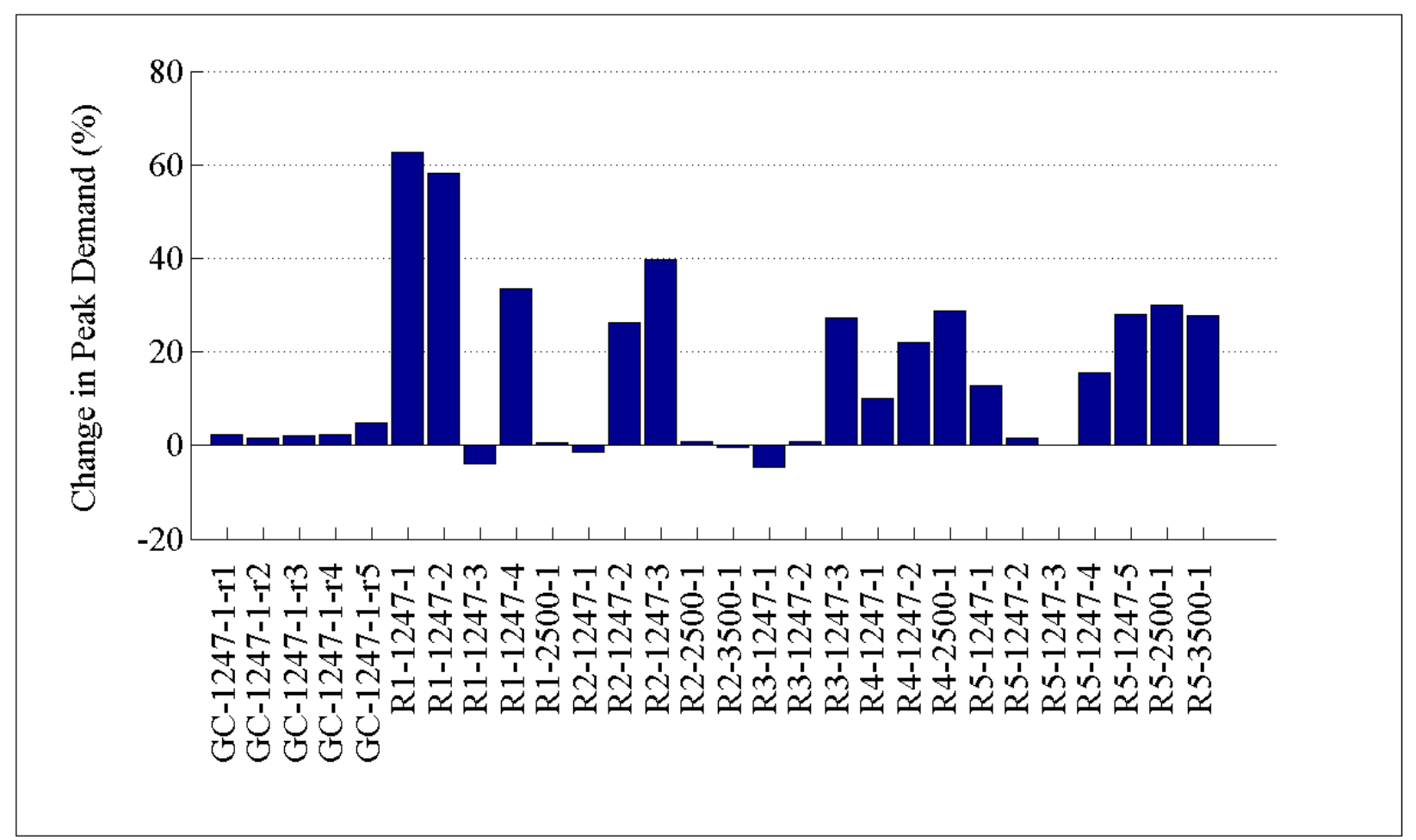

Figure 2.18: Change in peak demand by feeder (\%) 


\subsubsection{Annual Energy Consumption}

Figure 2.19 to Figure 2.21 compare the annual energy consumption of the base case versus the DLC case. Figure 2.19 displays total energy consumption of both cases, while Figure 2.20 and Figure 2.21 show the change in energy consumption in terms of energy and percentage of total energy respectively. In all cases, DLC decreases or does not affect annual energy consumption. This is due to the fact that the implemented DLC shuts off load during critical peak periods. During the recovery period, the instantaneous demand increases to move the customers' appliances back to their desired set points, but does not increase overall energy consumption. However, it should be noted that this is not necessarily a method of energy reduction or conservation, as the DLC signal is turning off or modulating the appliance specifically to reduce peak demand. The side effect is that energy consumption is reduced by inconveniencing the customer.

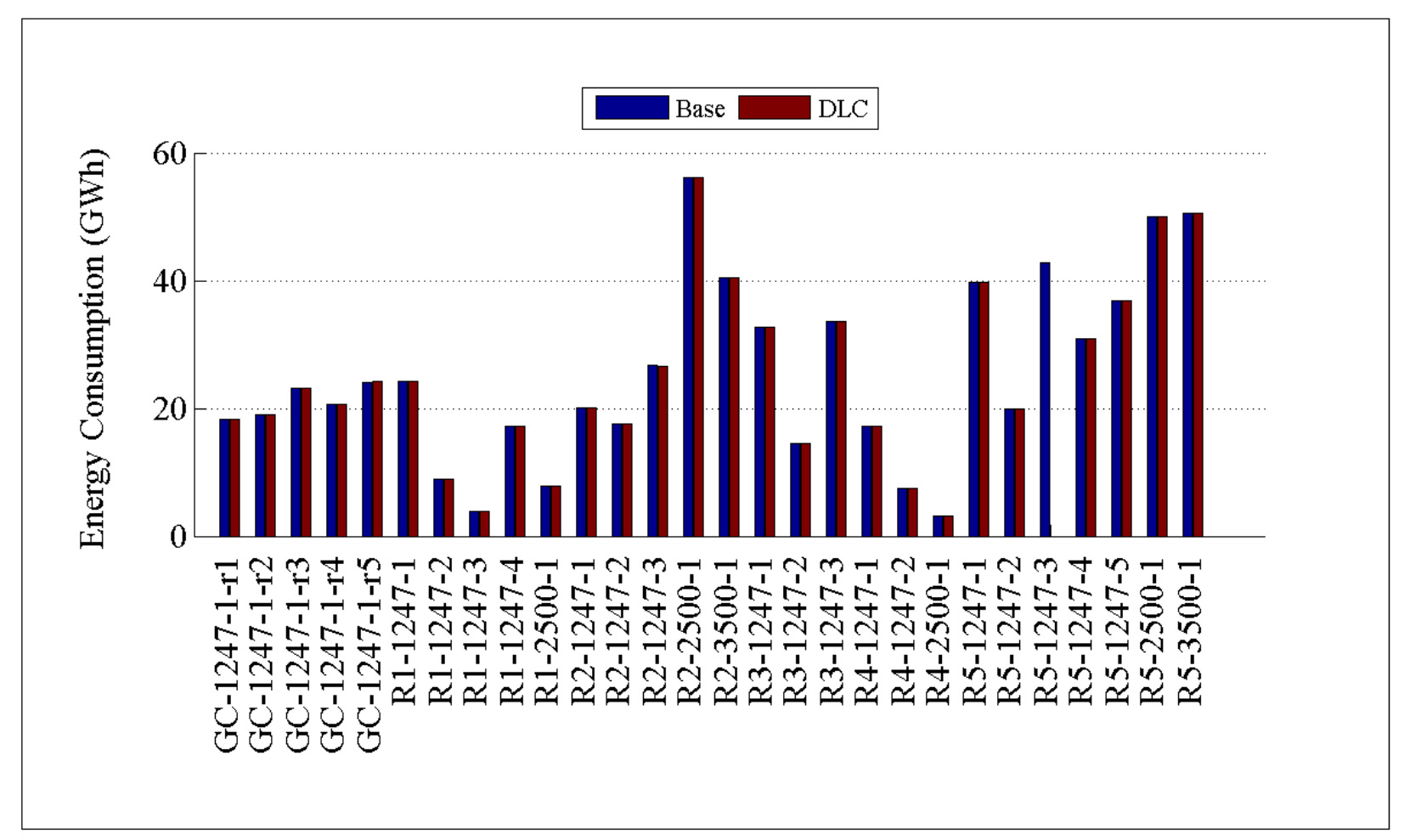

Figure 2.19: Comparison of annual energy consumption by feeder (MWh) 


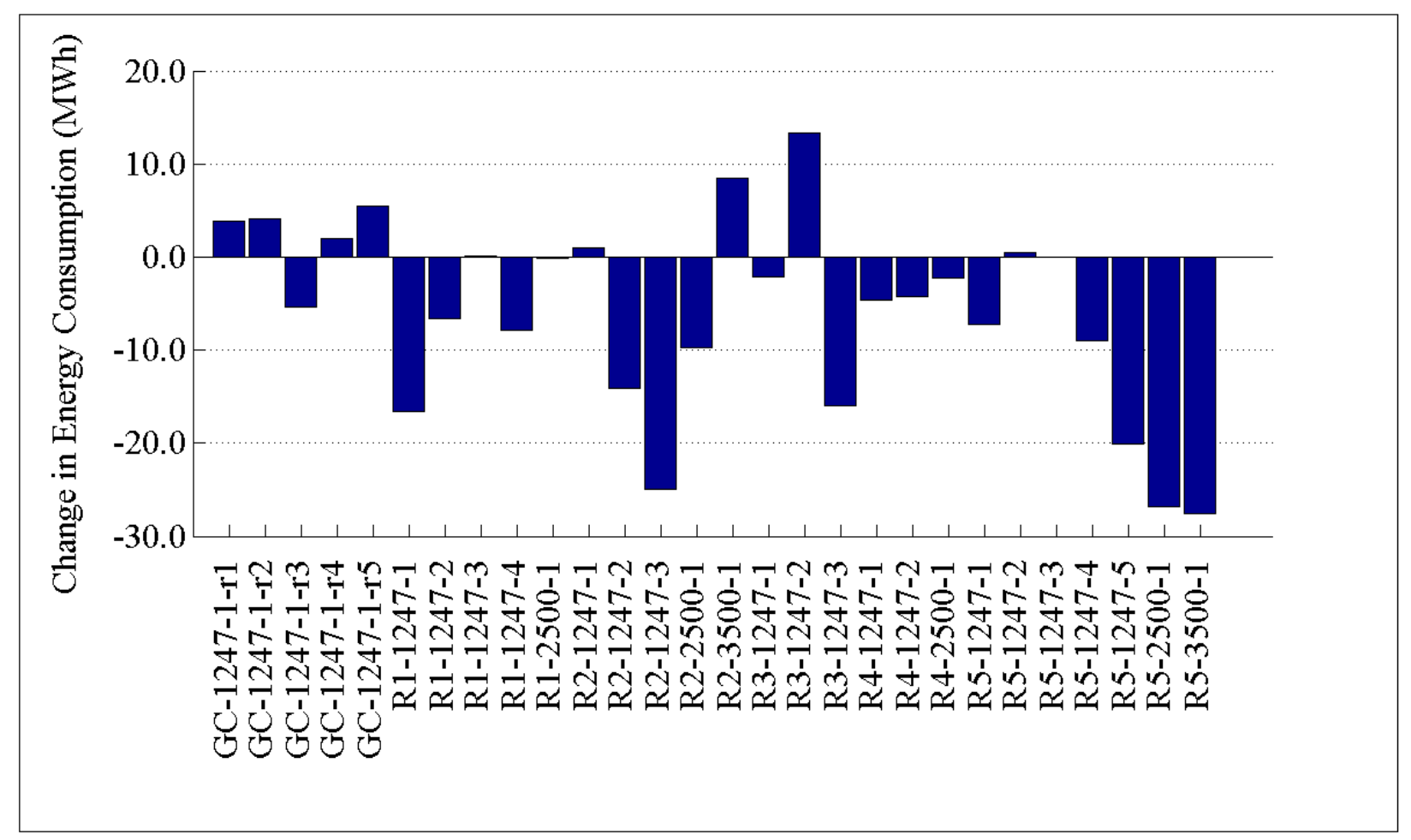

Figure 2.20: Change in annual energy consumption by feeder (MWh)

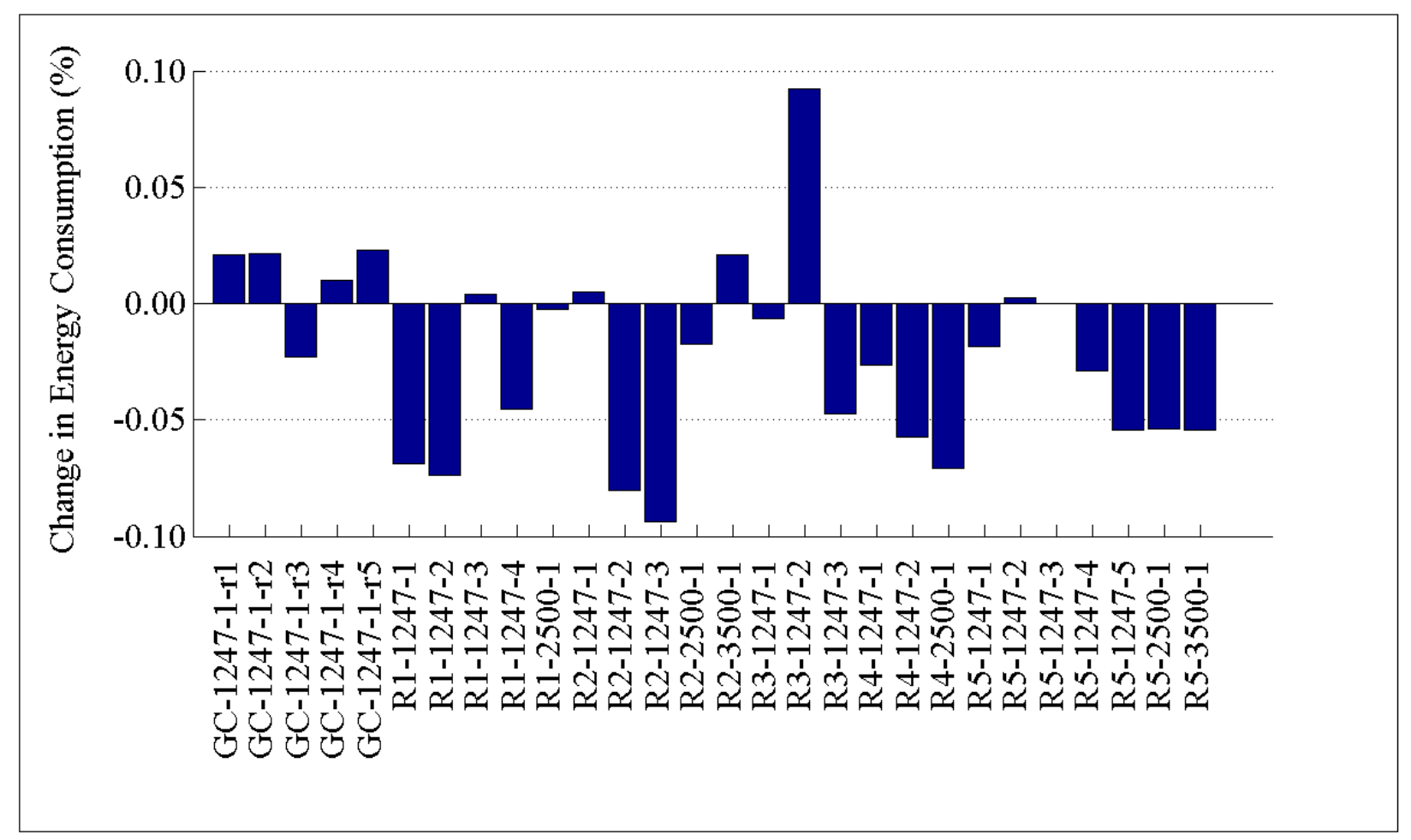

Figure 2.21: Change in annual energy consumption by feeder (\%) 


\subsubsection{Annual System Losses}

Figure 2.22 to Figure 2.24 compare the annual system losses of the base case versus the DLC case for each of the prototypical feeders. In all cases, system losses are decreased as overall demand is decreased during critical peak periods. However, it should be noted that while losses can decrease by as much as 5\%, annual system losses amount to less than $4 \%$ of total energy consumption. For example, R1-12.47-3 decreases losses by approximately 5\% or $32 \mathrm{MWh}$, while the overall energy consumption for the circuit was approximately 32,000 MWh. This results in a $0.1 \%$ reduction in energy consumption due to reduction in losses.

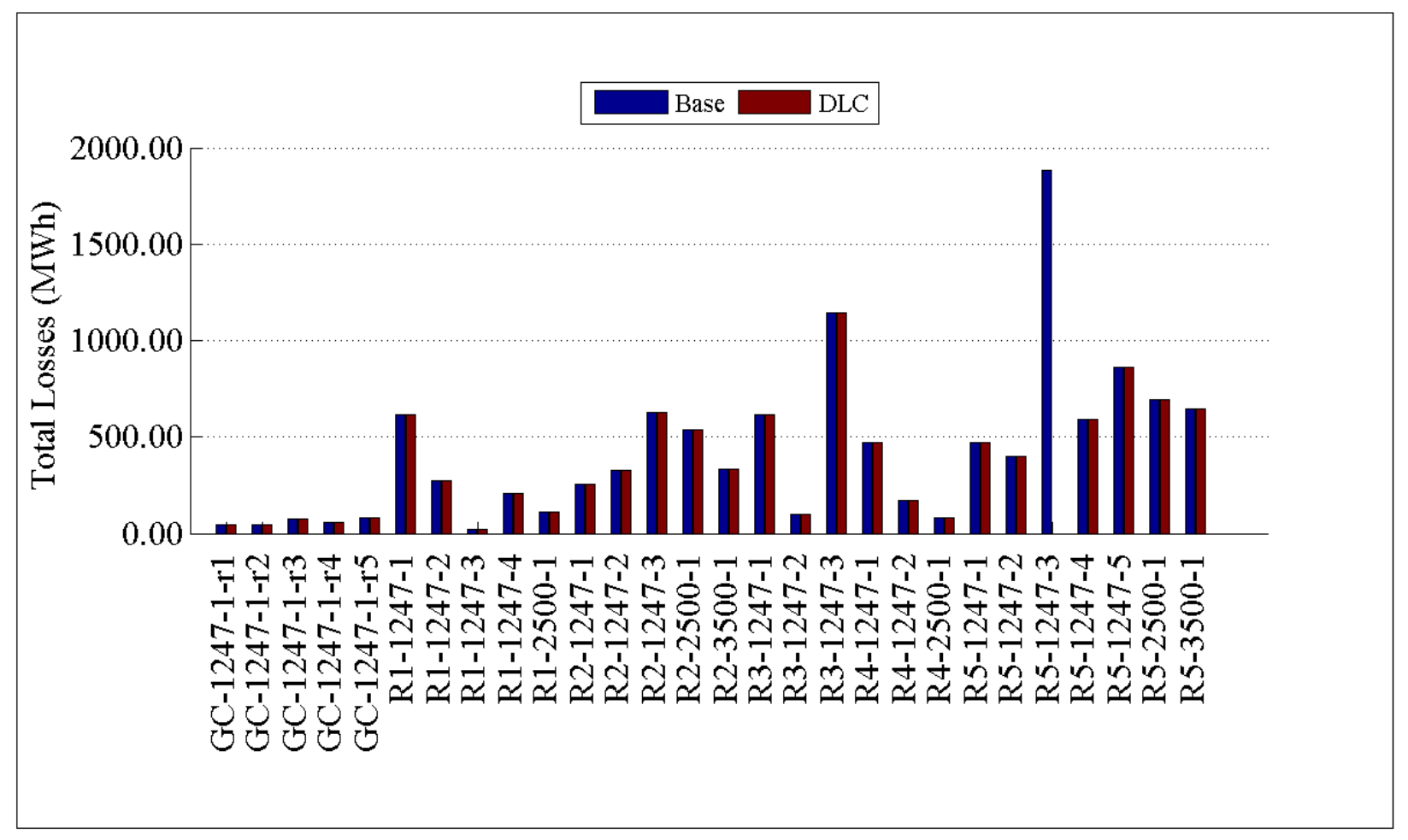

Figure 2.22: Comparison of total annual losses by feeder 


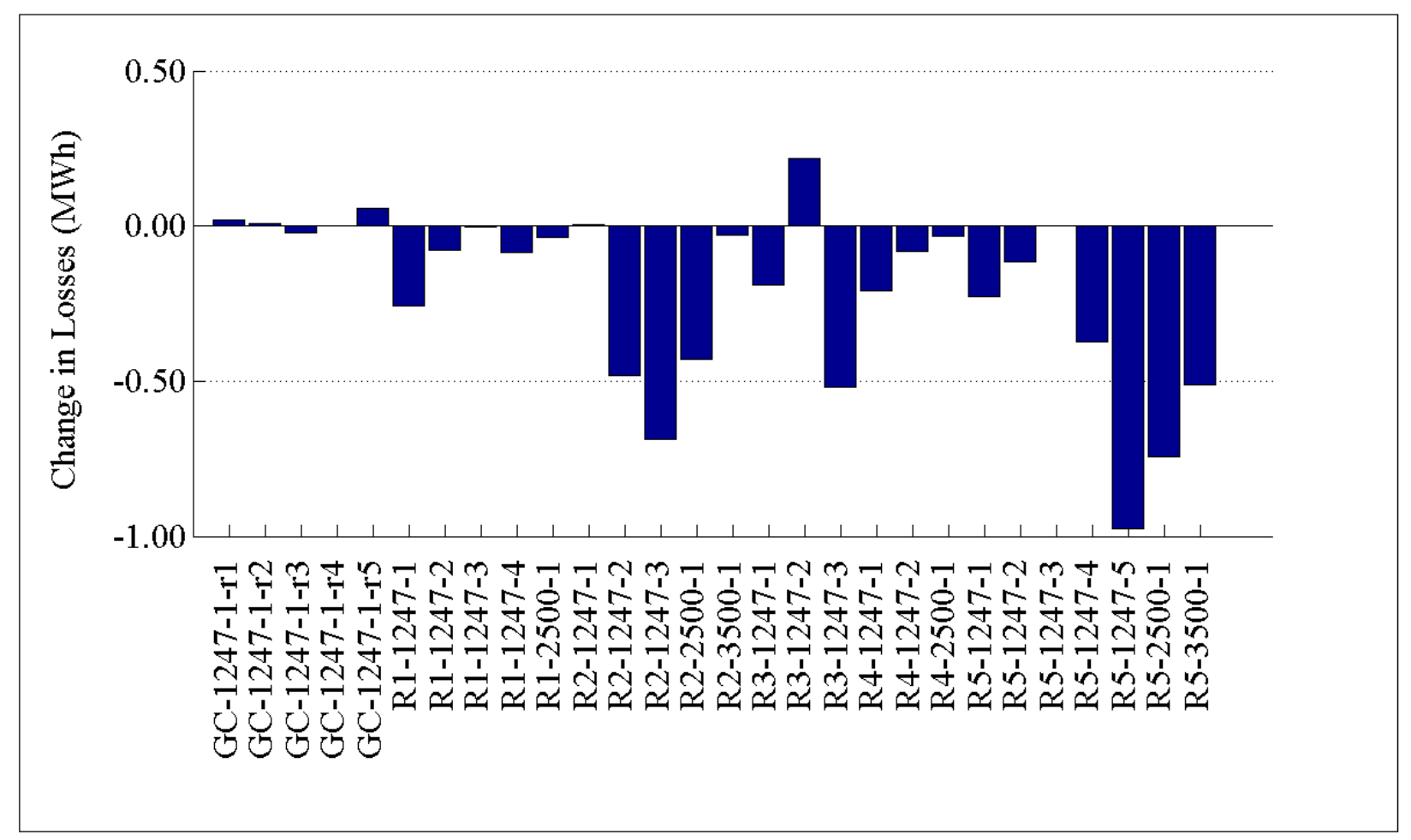

Figure 2.23: Change in annual losses by feeder (MWh)

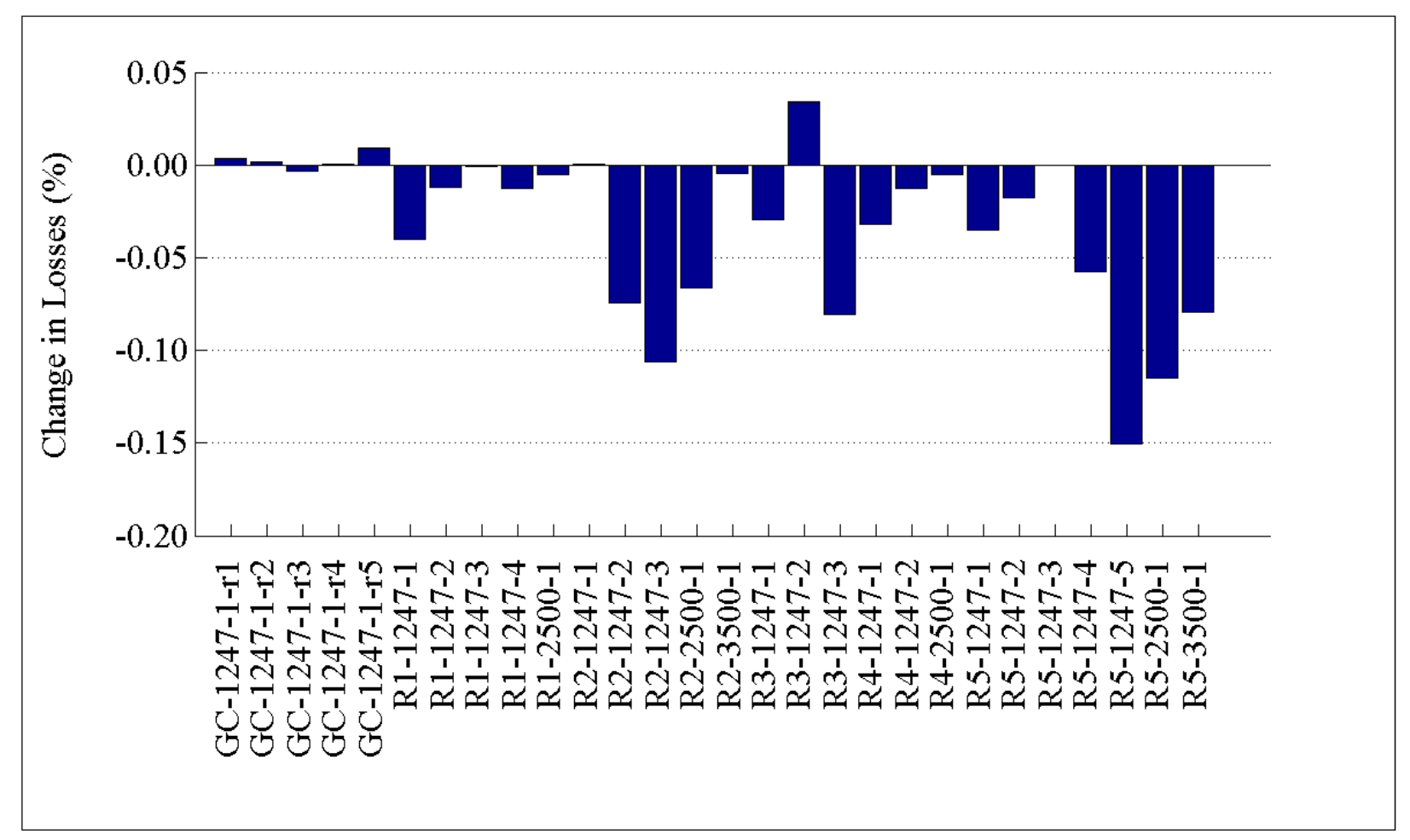

Figure 2.24: Change in annual losses by feeder (\%) 


\subsubsection{Annual $\mathrm{CO}_{2}$ Emissions}

Figure 2.25 to Figure 2.27 show the effects of DLC on $\mathrm{CO}_{2}$ emissions. Emissions were calculated using a simplified dispatch algorithm outlined earlier, which is described in detail in Appendix B.3. Figure 2.25 shows the total $\mathrm{CO}_{2}$ generated by the base case and the DLC case, while Figures 2.26 and Figure 2.27 show the change in $\mathrm{CO}_{2}$ generated in terms of tons and percentage respectively. In most of the feeder cases studied, DLC had little to no impact on $\mathrm{CO}_{2}$ emissions. Most of the feeders showed a change of less than $0.1 \%$ in their $\mathrm{CO}_{2}$ emissions output. Two Region 1 feeders showed noticeable increased in $\mathrm{CO}_{2}$ emissions, but even this increase was only $0.75 \%$. This is due to the designed dispatch order of Region 1 (West Coast) and the high penetration of hydroelectric, which makes the $\mathrm{CO}_{2}$ emissions of the base case relatively small. In this case, the shift in peak demand causes the used generation to shift from a low $\mathrm{CO}_{2}$ emission generating station (hydroelectric and geothermal) to a higher $\mathrm{CO}_{2}$ emission plant (natural gas). While DLC has the potential to move the load to off-peak conditions, since this only occurs a limited number of days per year, the overall benefit is relatively small.

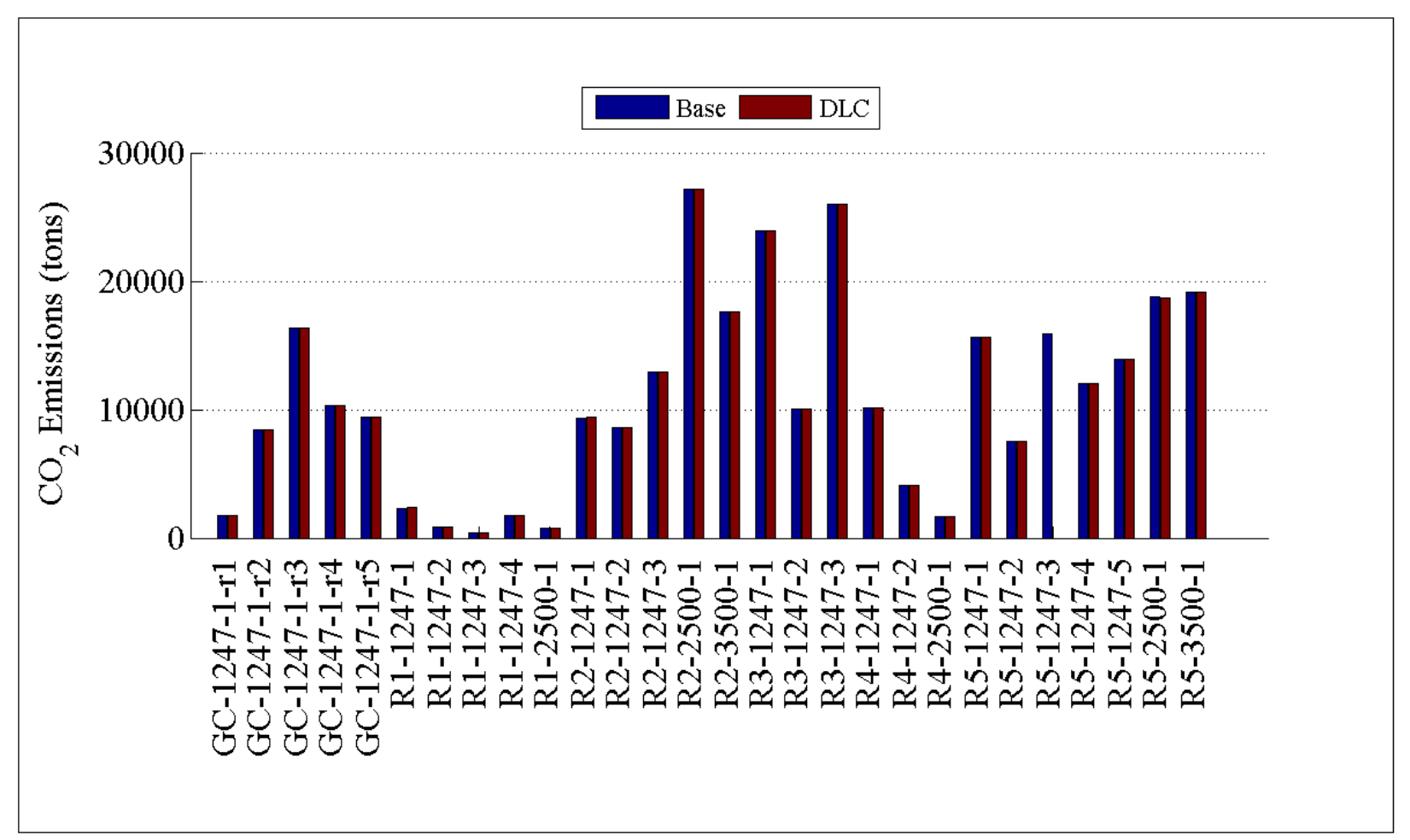

Figure 2.25: Comparison of total $\mathrm{CO}_{2}$ emissions by feeder 


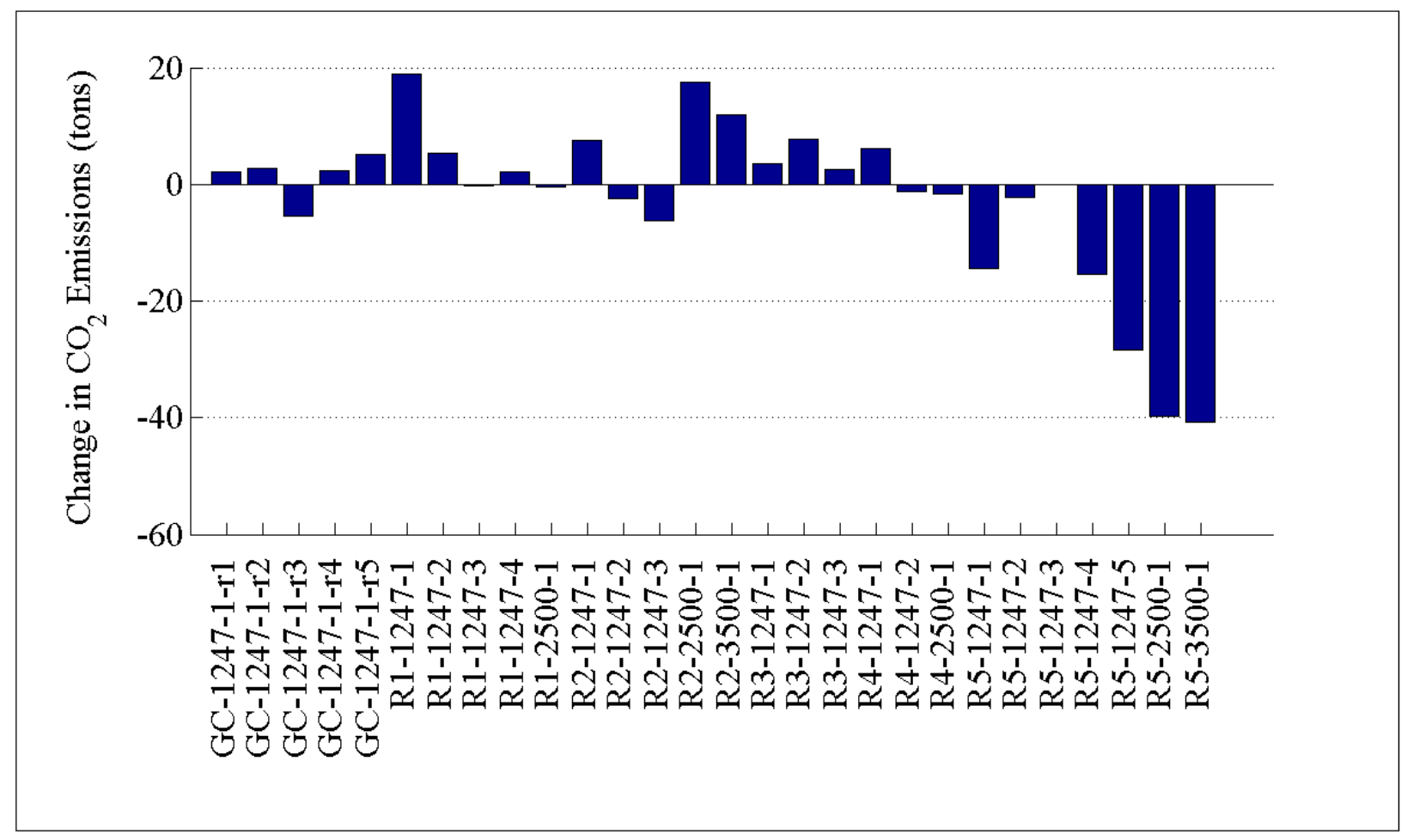

Figure 2.26: Change in total $\mathrm{CO}_{2}$ emissions by feeder (tons)

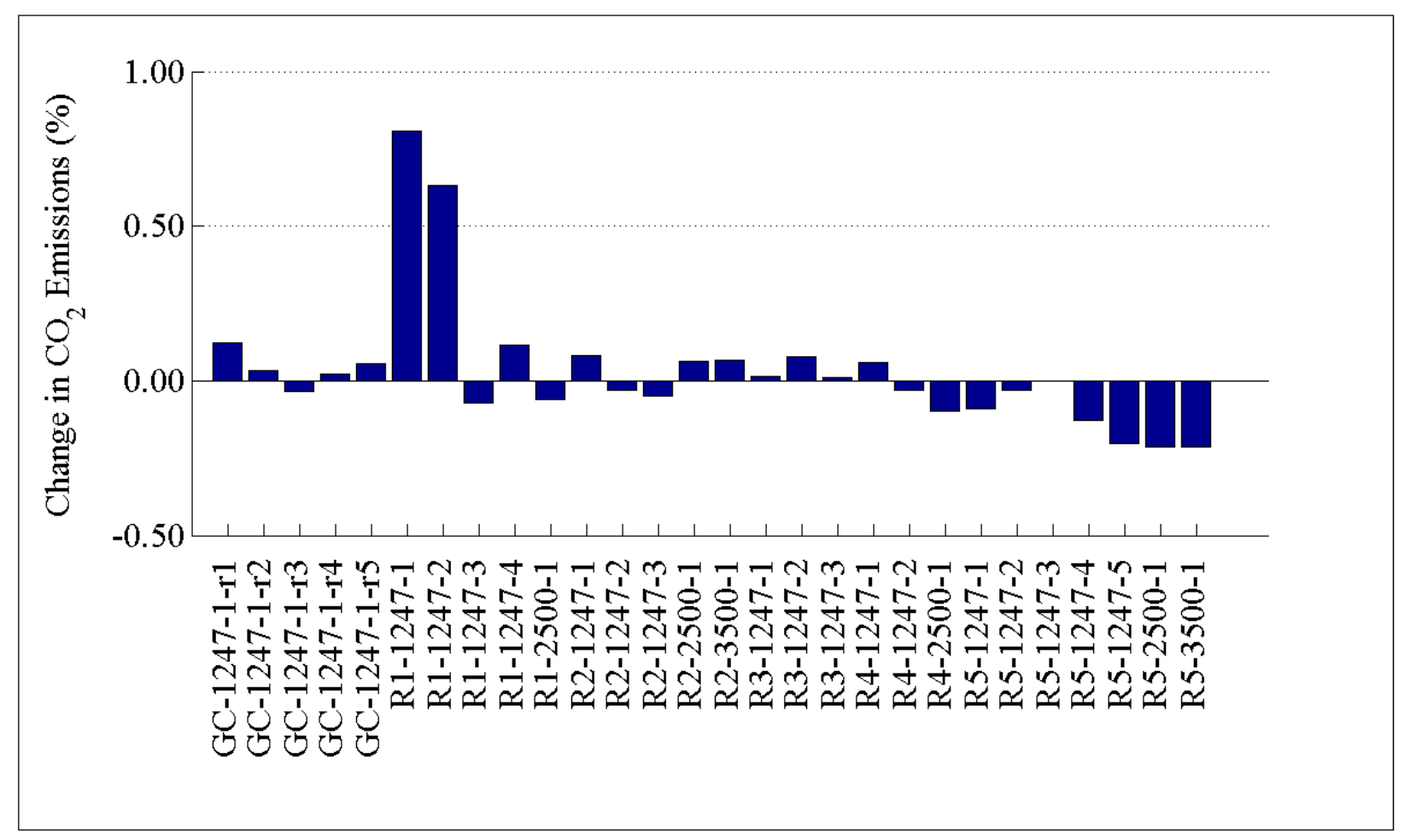

Figure 2.27: Change in total $\mathrm{CO}_{2}$ emissions by feeder (\%) 
True economic dispatch and optimal powerflow solutions might deviate from this result to a certain degree. However, unless DLC results in a significant shift in the demand time, the $\mathrm{CO}_{2}$ emissions impact is expected to be minimal. If the shift occurred such that load dropped into a less carbon-intensive generation source, or a much lower demand period, then $\mathrm{CO}_{2}$ impacts may be more significant.

\subsection{Alternate Measures for TOU, CPP, and DLC}

The previously results have shown that TOU, CPP, and DLC programs may actually increase peak demand. This is counter-intuitive, and in disagreement with the majority of available literature. In fact, the apparently negative impacts of DR that have been shown are a result of poor implementation rather than a deficiency of the technology itself. This section will be devoted to explaining the shortcomings of the proposed implementations, and to provide a framework for discussions on how to improve the performance of "simple" demand response programs. The following section will present a set of alternative metrics for capturing the potential benefits of DR systems.

It is first important to discuss why the increased demand occurs, and how to better operate and measure performance of DR systems. This is most easily shown with a plot of total load as a time series on a peak day, comparing the base case to the various DR cases. Figure 2.28 to Figure 2.32 demonstrate this for each of the technologies on feeder R3-12.47-3.

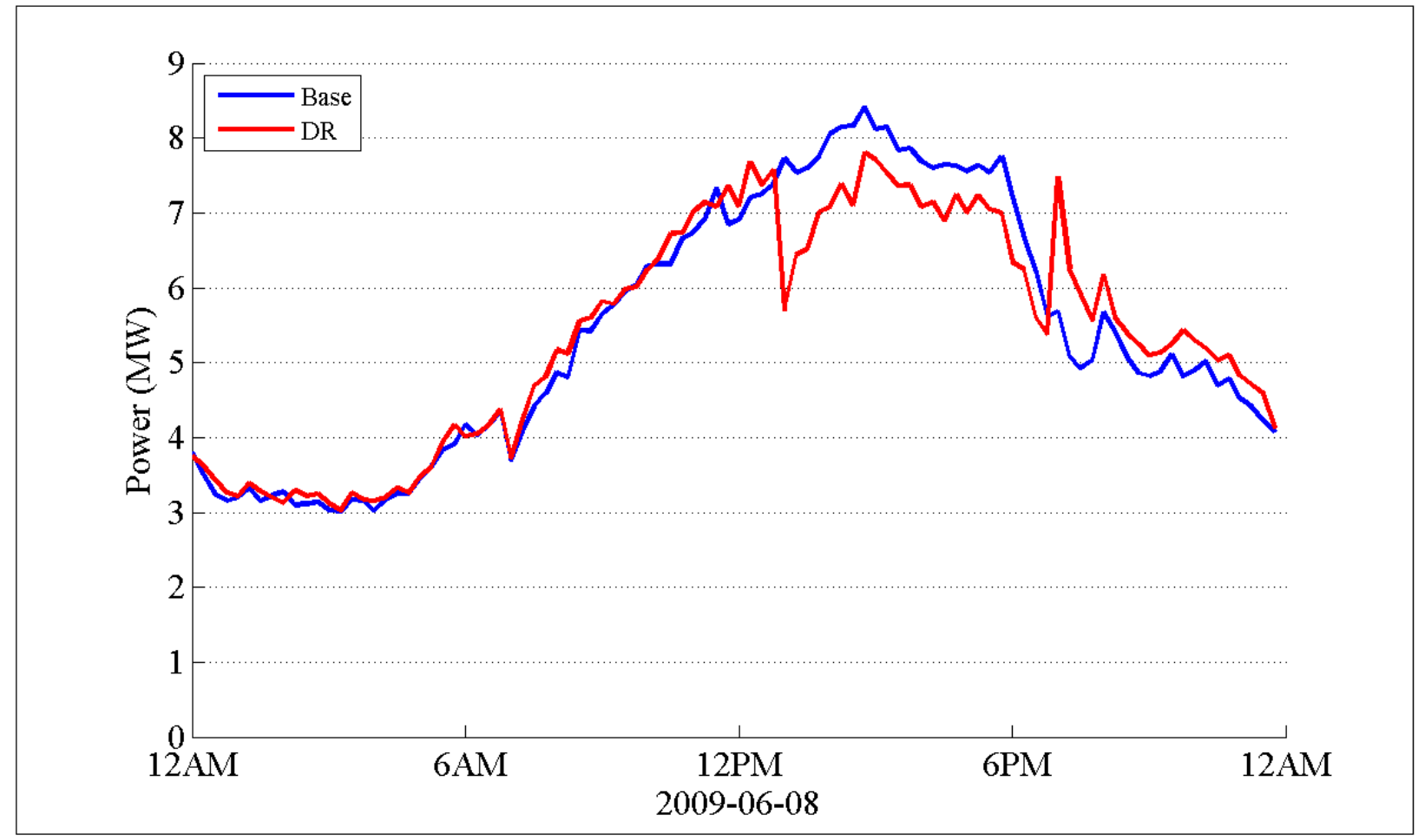

Figure 2.28: Times series comparison of TOU/CPP with enabling technologies on a peak day. 


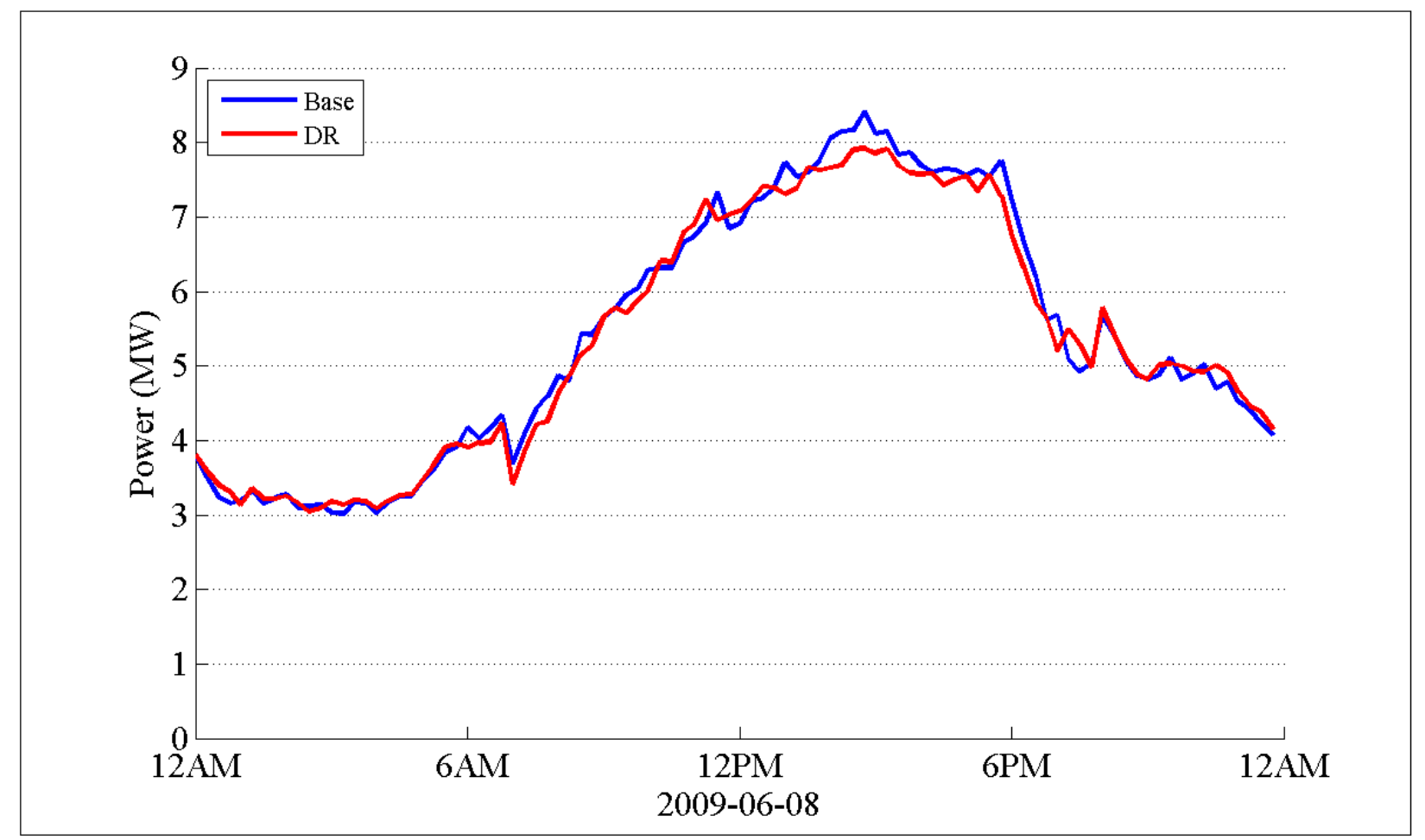

Figure 2.29: Times series comparison of TOU/CPP without enabling technologies on a peak day.

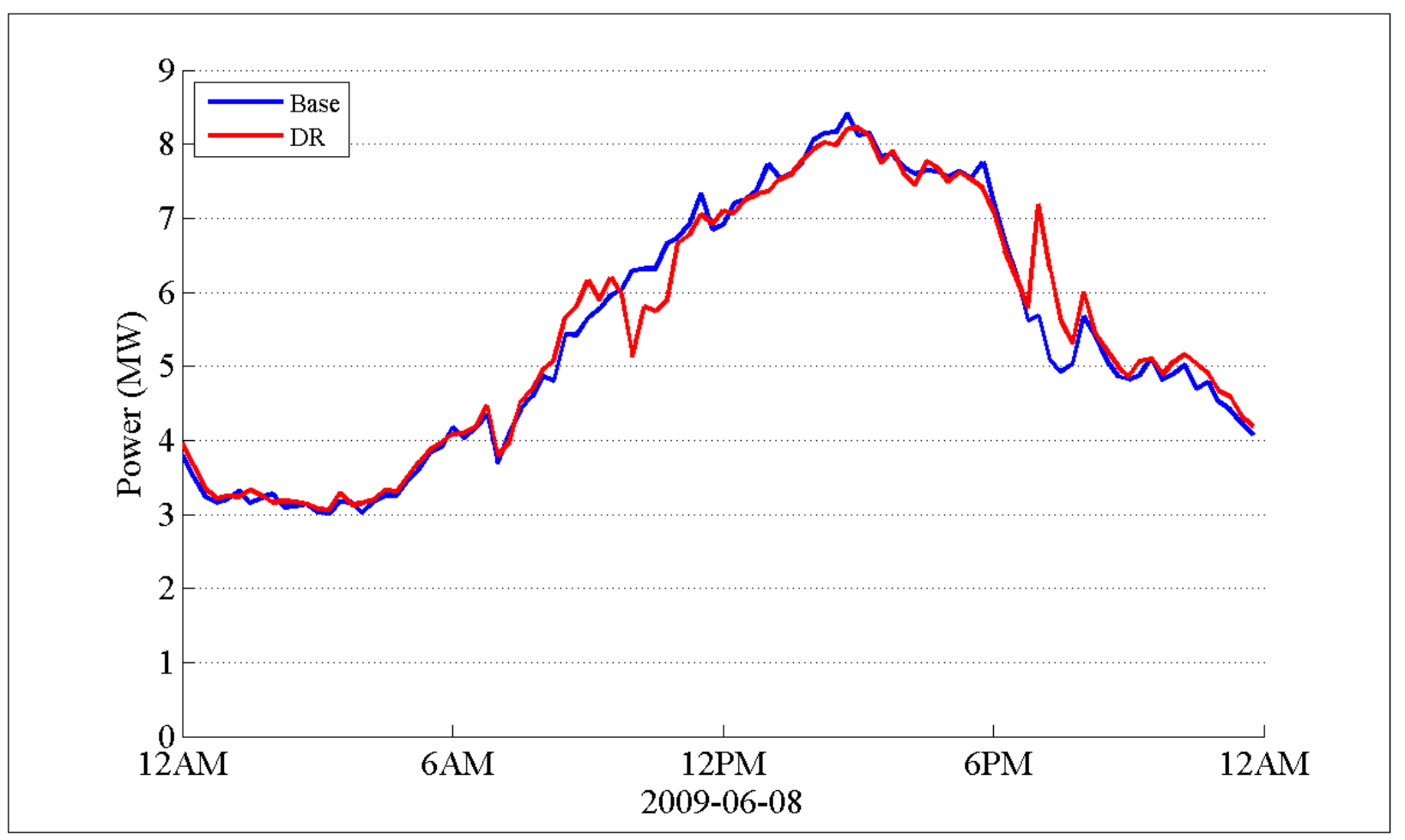

Figure 2.30: Times series comparison of TOU with enabling technologies on a peak day. 


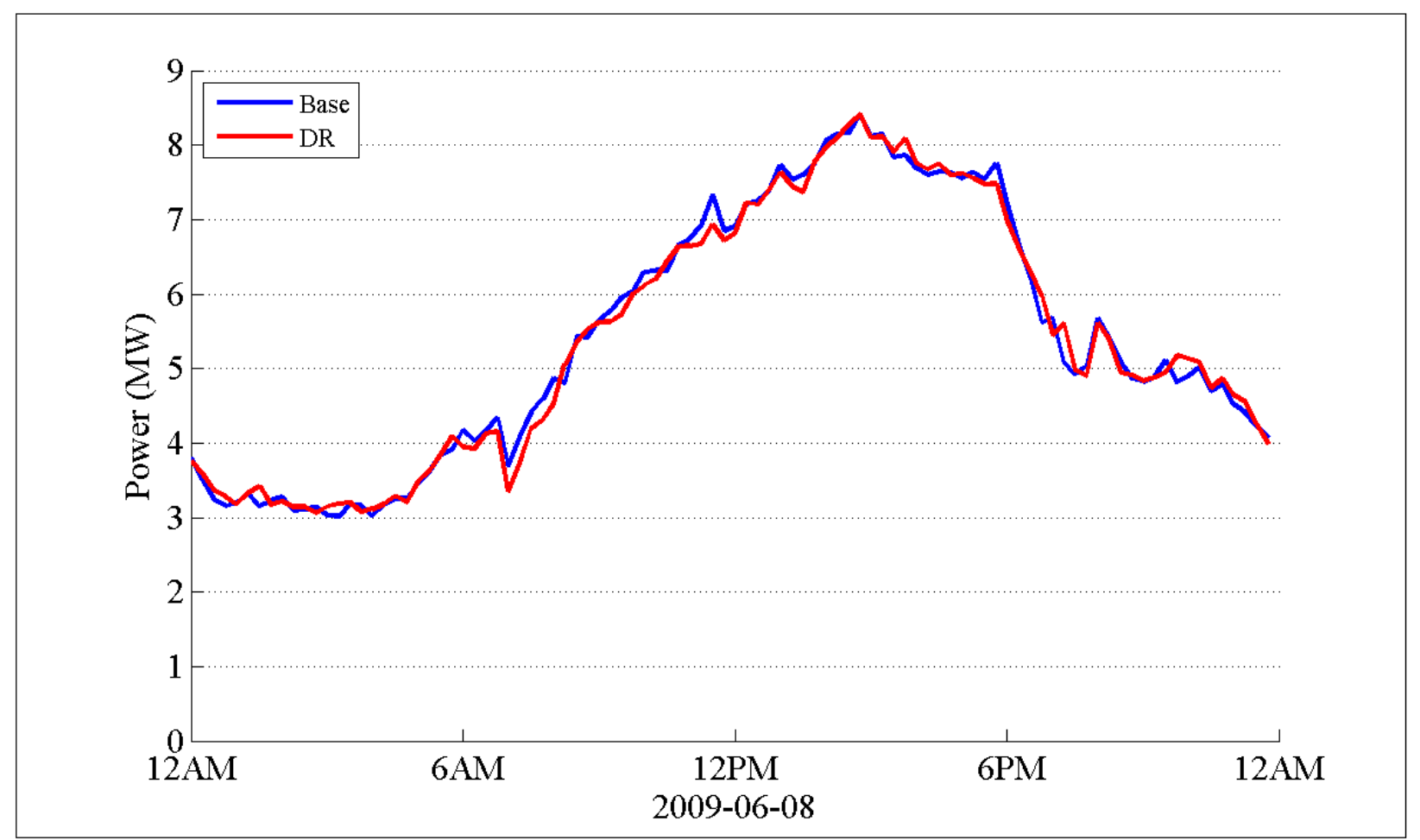

Figure 2.31: Times series comparison of TOU/CPP without enabling technologies on a peak day.

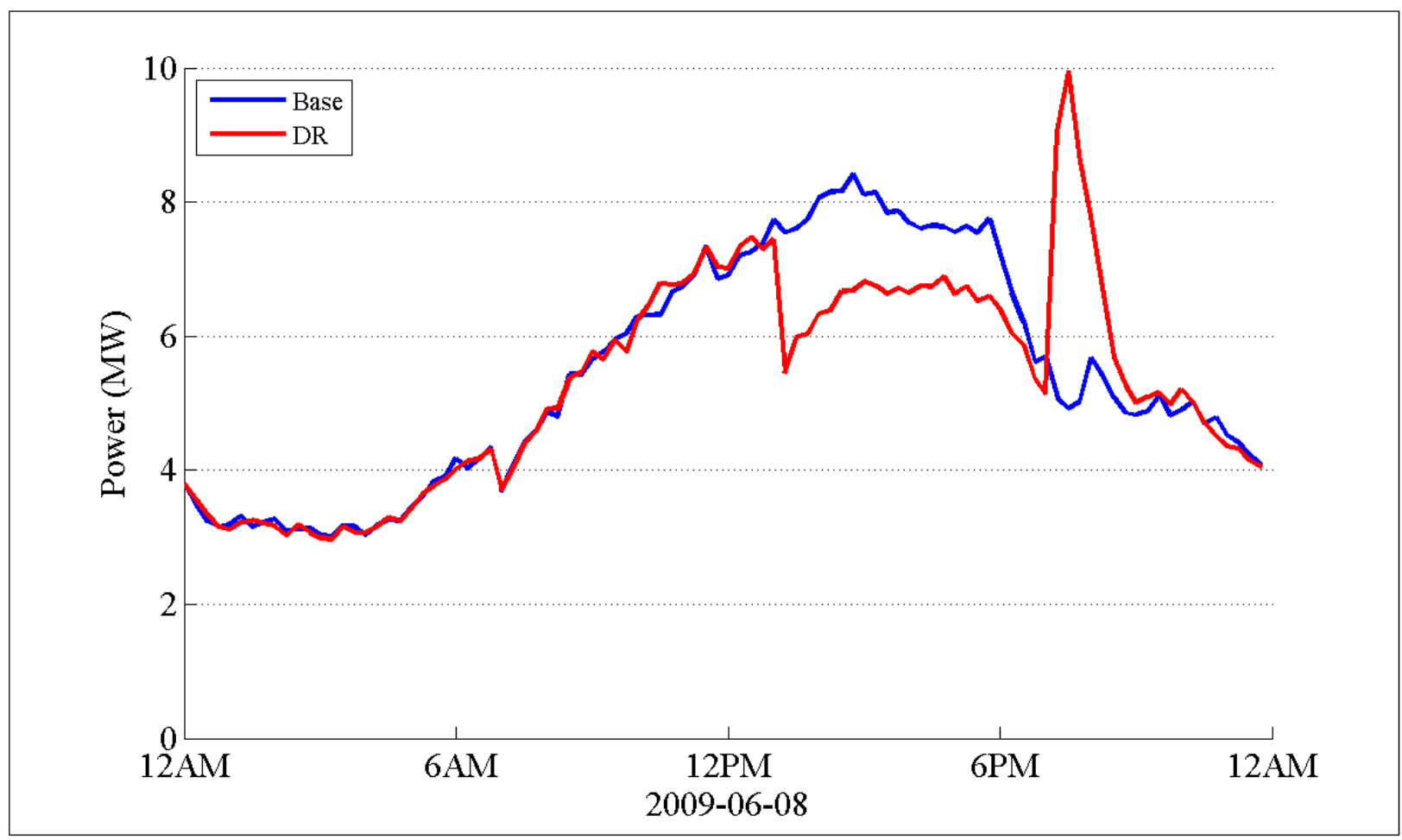

Figure 2.32: Times series comparison of DLC on a peak day. 
Notice that each of the three cases that use enabling technologies, such as automated thermostats or direct air conditioning control, initially shows a significant reduction in demand. DLC shows the largest initial reduction with CPP a close second, while TOU, even with automated equipment, shows far less reduction. As time proceeds and the HVAC systems return to new equilibrium operating points, the reduction in demand is less pronounced. At the end of the peak period, when the CPP or TOU signal is released to a lower price level or the DLC command is discontinued, a significant rebound in the demand can be seen as the air conditioning systems simultaneously react to move the internal house air temperatures back to their normal settings. The CPP (or TOU or DLC) signal not only acts in concert with the automated equipment to reduce the peak demand, but also has the effect of synchronizing the load during the release, diminishing diversity within the system. Until diversity can be restored, the total load increases, often creating a new, larger peak than was previously seen. This is not seen with the cases without enabling technologies. The enabling technologies that interpret the control signal (whether CPP, TOU, or DLC) into a change in load behavior (e.g. a thermostat setback) tend to synchronize the response of all the units on the system, and the change happens at the same time. Without the automated controllers, the change in demand relies upon the way people respond to the change in price, and people do not necessarily synchronize with a control signal. In a way, the non-automated system relies on human interaction to maintain diversity.

Figure 2.33 illustrates this movement to a new equilibrium point, by demonstrating a typical cooling load response to a change in thermostat settings for a population of homes. These are modeled as a sequence of differential equation solutions of the ETP heat balance equation described in Appendix B. As might be seen on a typical peak day, the outdoor air temperature is assumed to be $100^{\circ} \mathrm{F}$, while the solar gains and internal heat gains are consistent with a late afternoon. The thermostat settings for the population of homes are changed from $70^{\circ} \mathrm{F}$ to $75^{\circ} \mathrm{F}$ at Hour 0 . The initial cooling load is approximately $62 \%$ of total capacity, as it is assumed that all of the HVACs are oversized in this example. 


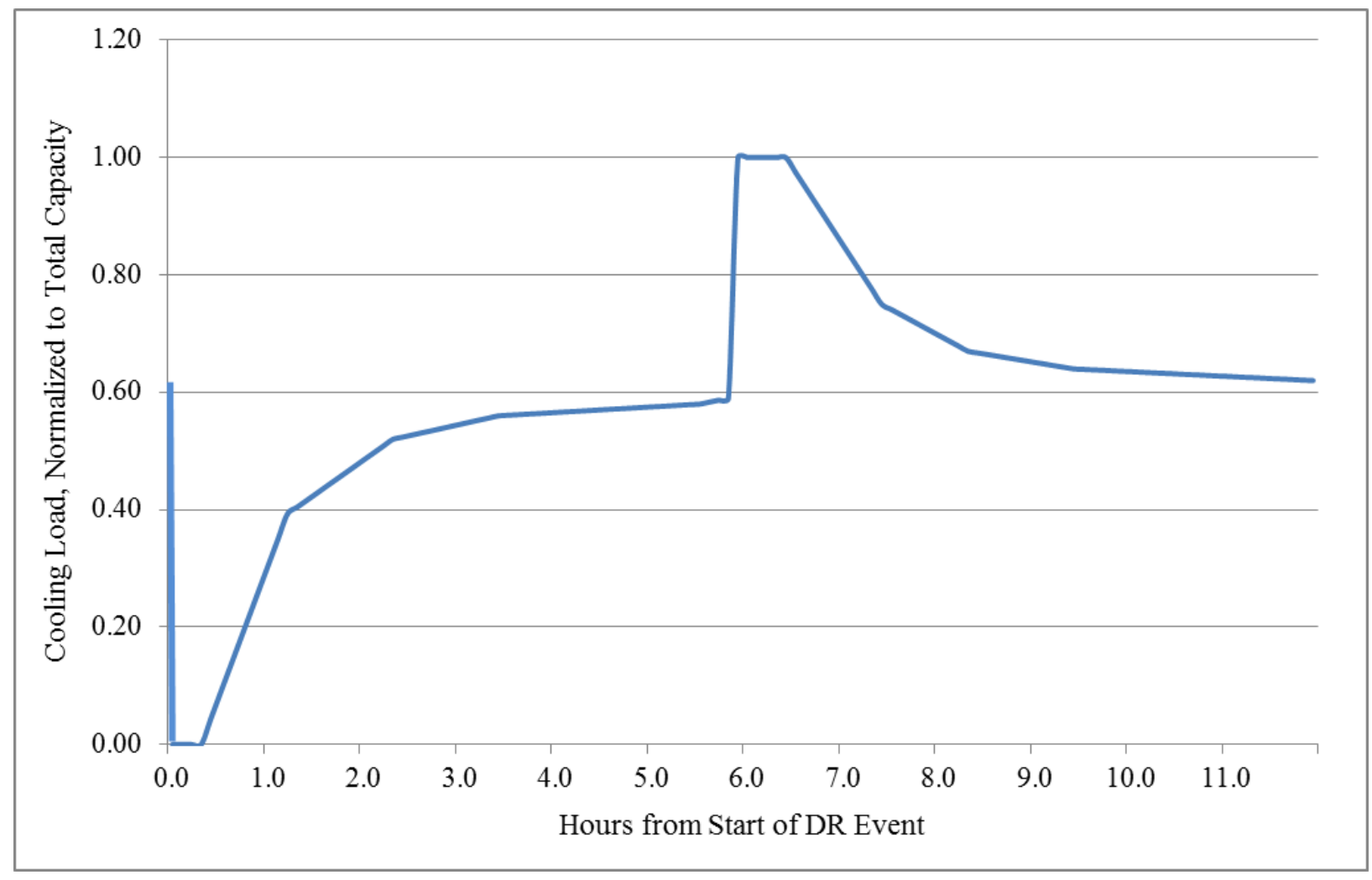

Figure 2.33: Differential equation solution to the ETP equation.

The cooling demand responds to the change in thermostat set point by immediately turning off and remains off for about 15 minutes until the buildings have warmed up to $75^{\circ} \mathrm{F}$. During this time period, the cooling "load" is entirely made up by the heat being absorbed by the thermal masses (primarily by the capacitance of the thermal mass $-\mathrm{C}_{\mathrm{m}}$ ). At this point, the indoor air temperatures reach $75^{\circ} \mathrm{F}$, the cooling systems begin to turn on again, and the average diversified cooling load for the population begins to rise. Of course, the load in any specific building is either fully on or fully off, but here the plot indicates the average load of a population, assuming the on-off cycles are uniformly distributed.

The thermal mass is still somewhat cooler than $75^{\circ} \mathrm{F}$, so it continues to reduce the cooling load below the eventual steady state level as it warms up. Also at that point, the air conditioning loads begin to steadily rises, exponentially approaching the eventual steady-state level. At the end of the first hour, the diversified load has reached about $80 \%$ of initial load. The new steadystate cooling load is about $93 \%$ of the original load, only slightly less than the original load, because the homes are warmer inside and so less heat is conducted through the envelope. The specific results will vary depending on the characteristics of the buildings, the weather, and the thermostat set points, but generally will behave in a similar manner. 
It is very important that system planners and operators understand this fundamental effect: turning up thermostats eliminates the cooling load entirely for a short period, dramatically reducing the total system load. But, the load returns after this short period is over and returns to nearly the same level over the course of an hour or two. It also suggests that quantifying demand response as a percentage reduction in the original load is not meaningful without also identifying the time period over which the reduction was sustained.

Continuing with the illustration, at some subsequent point in time the thermostat is restored to its initial set point (Hour 6 in this example). The thermostats immediately respond by turning on cooling systems and operating them at full capacity until the original set point is reached. This effect, known as rebound, can have a dramatic impact on the defined metrics. In this illustration, it creates a new peak load, much higher than the original load, which lasts for roughly 30 minutes, that is dependent upon the level of participation of each of the individual homes and the oversizing factor of the HVAC units. Once the indoor air temperatures reach the original set point the thermal mass still remains slightly warmer. It continues to increase the cooling load above its original steady-state level for an hour or two, absorbing cooling energy as it cools off. The diversified cooling load reaches $125 \%$ of its initial steady-state value after about an hour (again, depending on conditions).

It is equally important that system planners and operators understand the rebound effect: restoring thermostats to their original temperature causes the cooling system to run flat out at rated capacity for a short period, followed by a slow exponential decay that eventually results in the original diversified load. This importance of the effects of a rebound is illustrated by the simulation of feeder R5-12.47-3. The rebound was so great during the TOU/CPP and TOU with enabling technologies and DLC cases that the power system was unable to support the rapid change in load, and the system went into voltage collapse. The implication is that it is not only important to consider the start and operation of the DR program, but also how to release it back to normal operation.

One key to understanding how loads are shifted by demand response signals is the principle of diversity. Most end-uses are not continuous functions over the course of time. In an individual home, end-use power consumption is comprised of a series of discrete events, such as an air conditioner cycling on and off, or drying a load of clothes, etc. In a population of homes, when the demand of the population is increasing, these discrete events are more likely in any given home, i.e. they are packed more densely, and vice versa as demand decreases. But, at any given time period where load is reasonably steady (like an hour), the discrete events are evenly distributed throughout the population and throughout the time period, i.e. they are random or diversified. This is what prevents large spikes and dips in the load, unless there is some coincidental simultaneous event (like a DR signal) that changes this random behavior and removes the inherent diversity. The initiation of a demand response event and the restoration of thermostat settings after such an event, are exactly the type of triggers that synchronize end-uses 
and diminish the natural diversity. While this example illustrates the response of an HVAC system under relatively steady state conditions (e.g. constant outdoor temperatures, constant internal heat gains, etc.), similar conclusions can be drawn from hot water heaters, or other thermostatically driven loads. It should also be noted that while this example demonstrates the ideal response and describes the general behavior, it is much more complicated in a real system as steady state does not really exist as set points, outdoor conditions, appliance usage, and etc. change constantly.

Fortunately, there are ways to operate programs that compensate for these problems. However, they typically increase the complexity of the system at the same time. One example, demonstrated in Figure 2.34 and Figure 2.35, relies upon maintaining a certain degree of diversity within the population of homes and end-use loads. This is accomplished by giving certain segments of the population on a feeder different control signals, by varying the penetration levels of the different pricing programs. Figure 2.34 demonstrates this by again using R3-12.47-3 on the same peak day shown before, but now leaving $33 \%$ of the population at the normal fixed price (base), 33\% of the population with CPP and enabling technologies and $33 \%$ TOU without enabling technologies. Figure 2.35 similarly demonstrates the results with $20 \%$ at a fixed price, $40 \%$ CPP with enabling technologies, 20\% CPP without enabling technologies, and 20\% DLC.

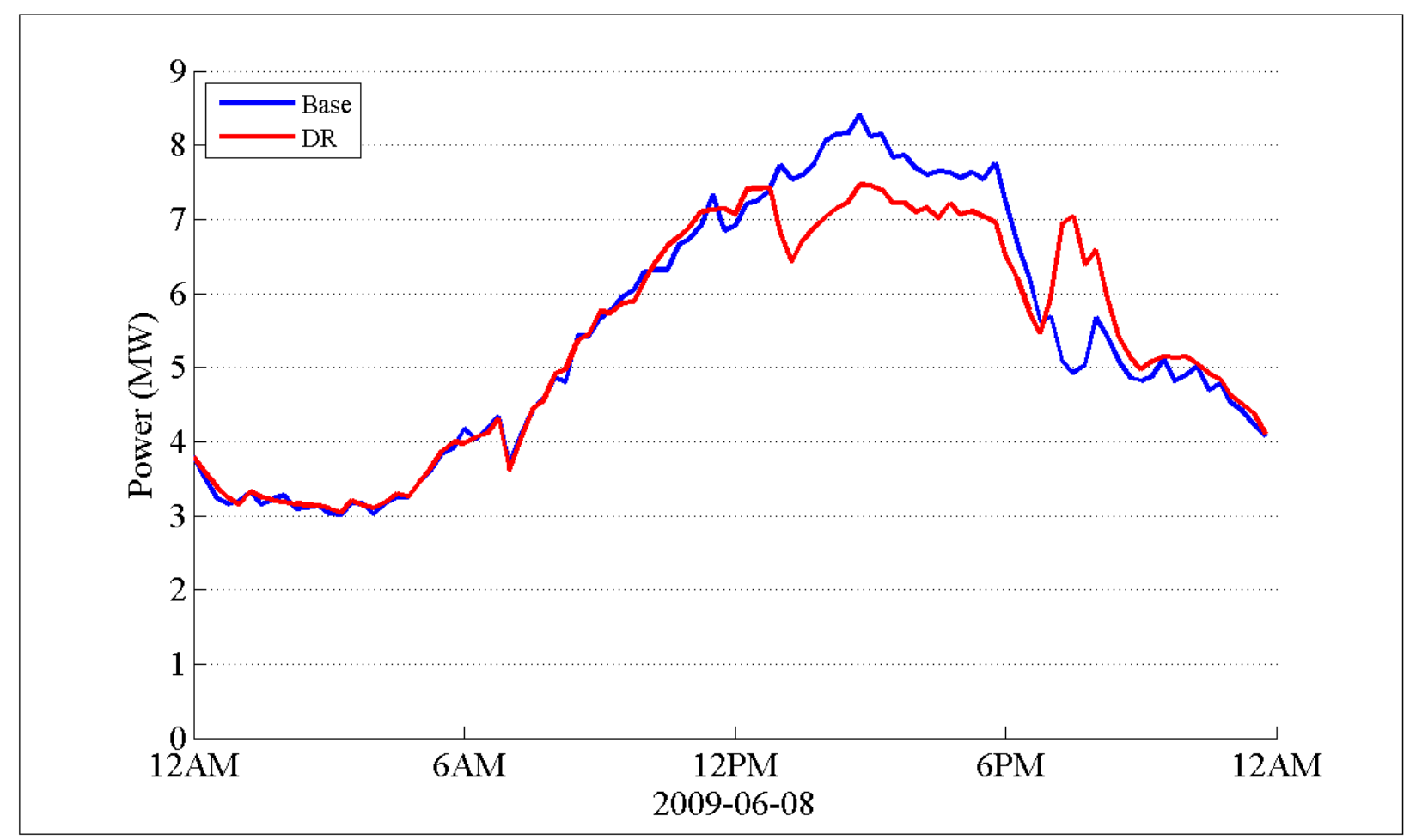

Figure 2.34: Times series comparison of diversified controls on a peak day (33/33/33). 


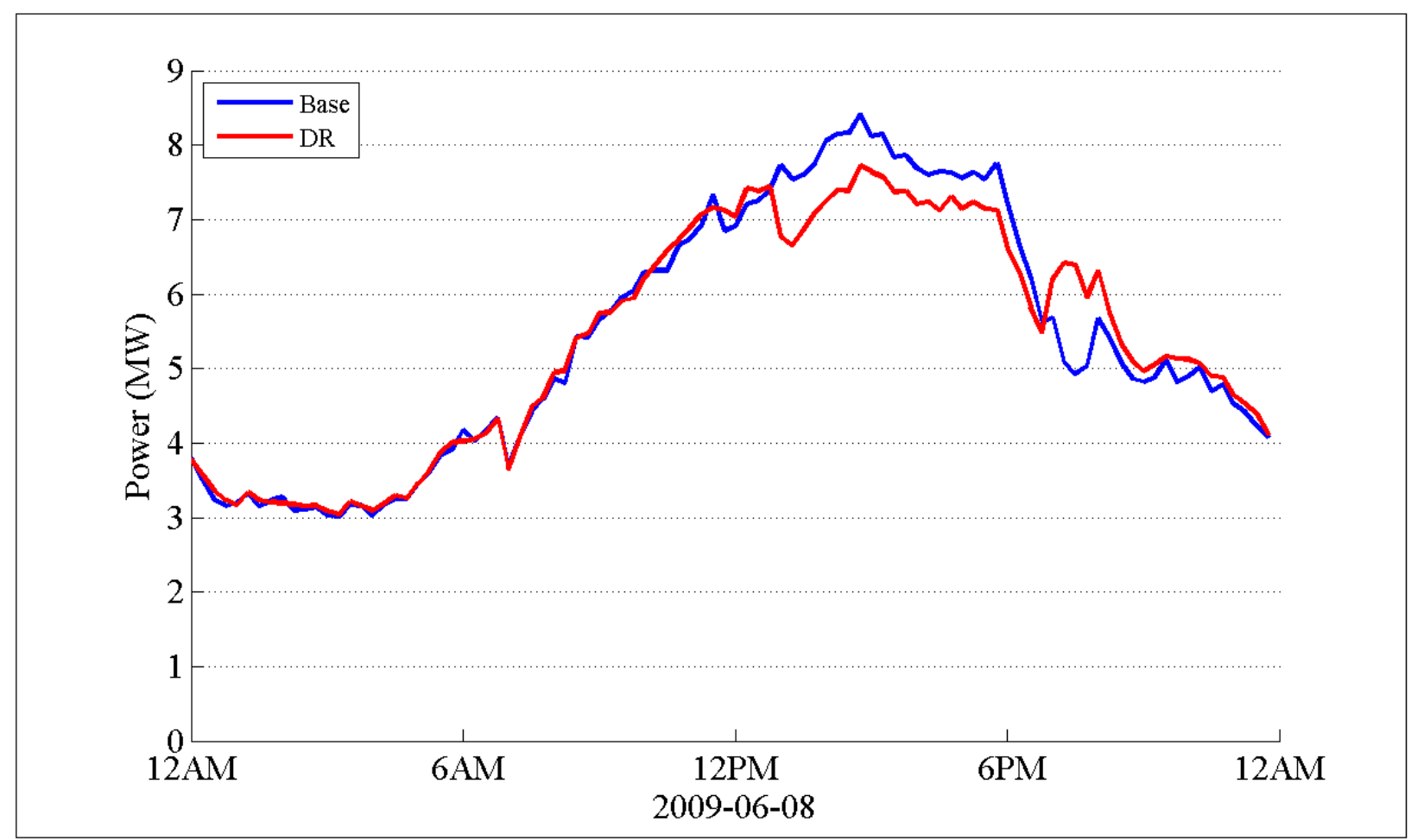

Figure 2.35: Times series comparison of diversified controls on a peak day (20/40/20/20).

While the rebound effect is still noticeable, it is now a manageable phenomenon and includes significant peak reductions. Another solution may be to rotate the timing of the CPP or DLC control signal. For example, one-sixth of the feeder customers could each start at each hour from $1 \mathrm{pm}$ to $6 \mathrm{pm}$, and then proceed for 6 hours before being released back to normal operation. Figure 2.36 to Figure 2.38 demonstrate this idea with a set of demand data which is normalized to the base demand peak, where CPP 1 indicates that the CPP signal starts at $12 \mathrm{pm}, \mathrm{CPP} 2$ at 1 pm, etc. Notice in Figure 2.41 and Figure 2.42 that the CPP signal creates a rebound greater than the original peak for both CPP 1 and CPP 2. CPP signals 3-6 create rebounds that are less than the original peak, but in general reduce the peak by less than $5 \%$. Figure 2.38 demonstrates the demand if the population of homes is assigned one of the six CPP signals, using the distribution shown in Table 2.7. While the demand in Figure 2.43 has been reduced by nearly $12 \%$, the level of complexity in the control is much higher, and it is not guaranteed that this mix is ideal on all 15 of the peak days. All of these exemplary solutions (and any other similar solution) work by maintaining a certain degree of diversity. Other even more complicated solutions (but often more controllable), include real time pricing with closed loop controls and other feedback orientated controls. 


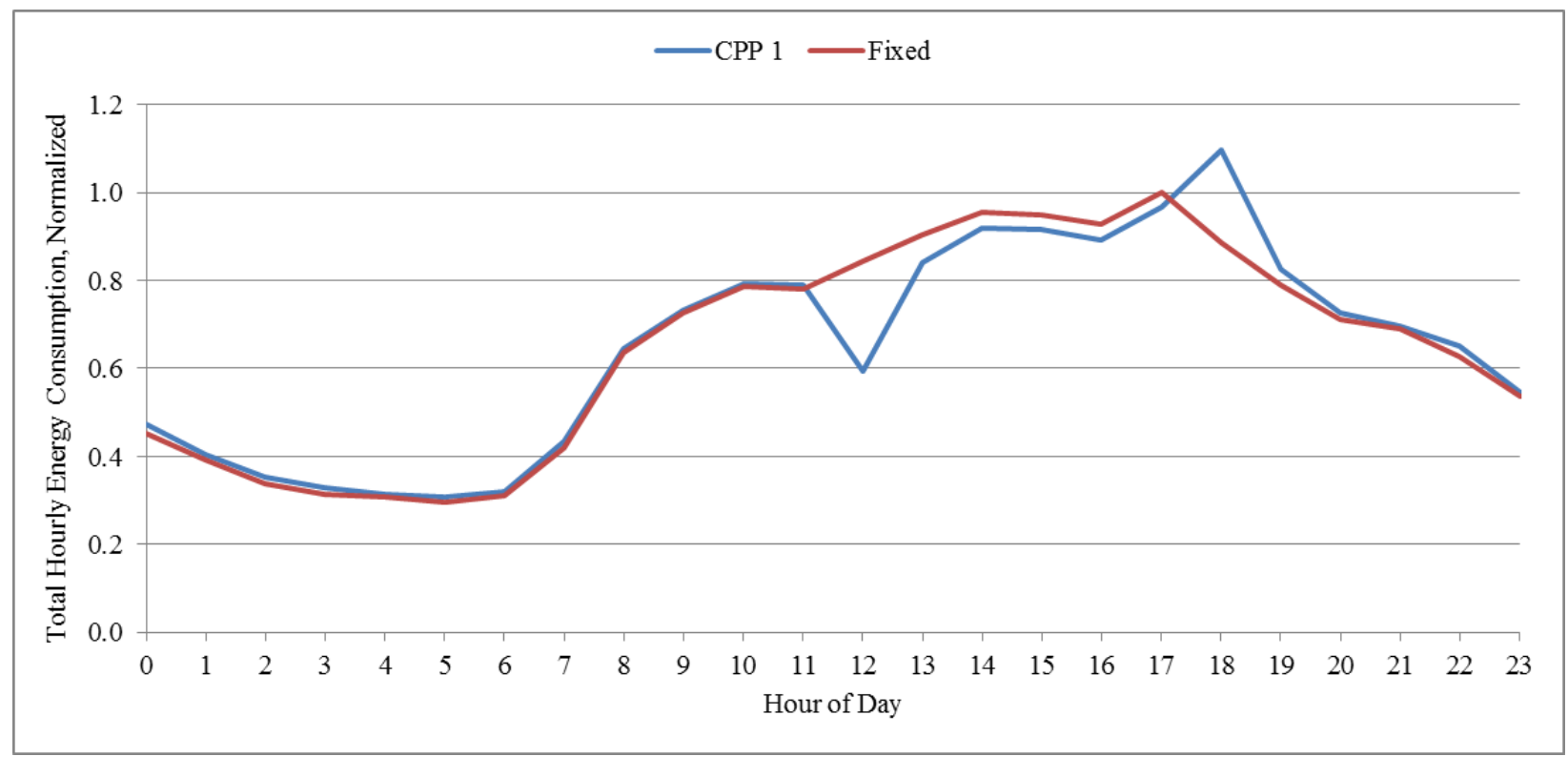

Figure 2.36: Comparison of demand for a sample base case and a CPP signal at $12 \mathrm{pm}$.

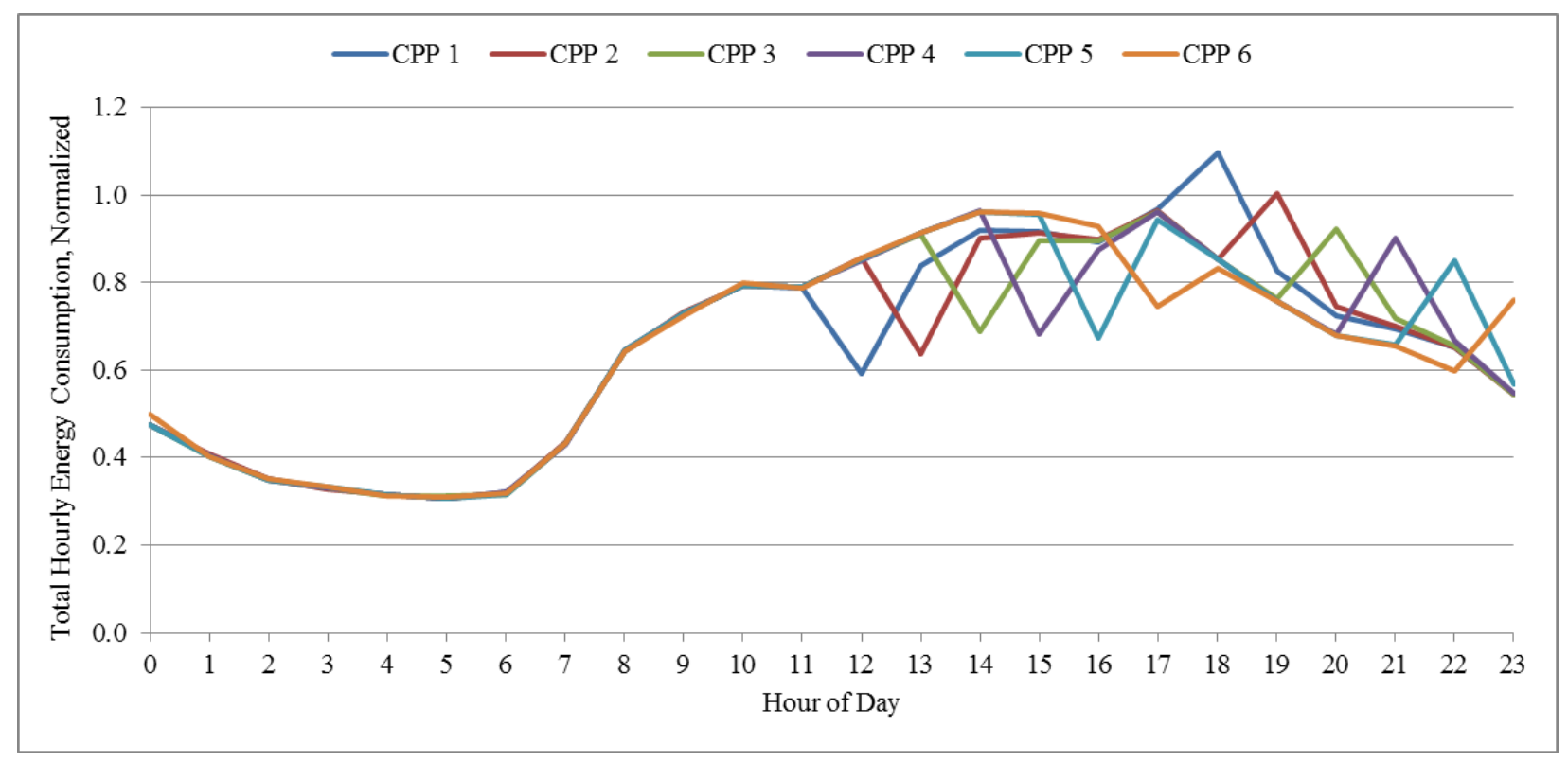

Figure 2.37: Comparison of demand for CPP signal starting at 6 different times.

Table 2.7: Percent of population under each of the CPP signals.

\begin{tabular}{|l|c|c|c|c|c|c|}
\hline & CPP 1 & CPP 2 & CPP 3 & CPP 4 & CPP 5 & CPP 6 \\
\hline Percent of Population & $9.4 \%$ & $13.6 \%$ & $21.6 \%$ & $16.5 \%$ & $5.6 \%$ & $33.2 \%$ \\
\hline
\end{tabular}




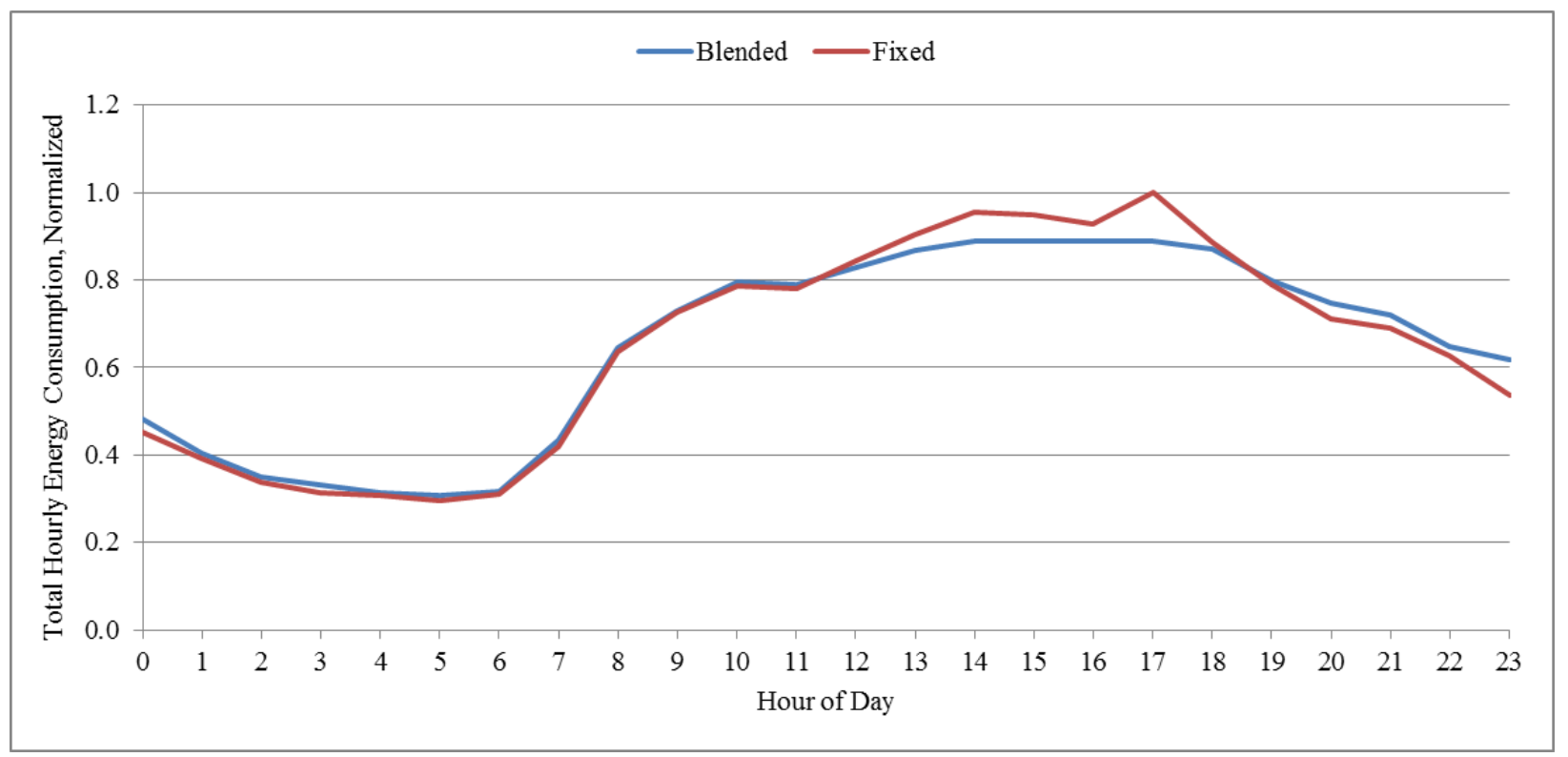

Figure 2.38: Comparison of demand for a base case and with blended CPP start times.

An additional point to consider is whether the rebound effect is even a problem that must be dealt with at the individual feeder level, excepting the cases where voltage collapse or other such problems occurs. The goal of some demand response programs is to eliminate coincidental peaks at the transmission or sub-transmission level. In this case, a single feeder would shift its peak to a different time non-coincidental with the transmission peak, thereby reducing the overall system peak while shifting the rebound response to a system non-peak period. To address these concerns, Section 2.4 will develop an additional set of metrics to describe the potential benefits associated with demand response depending upon the goal of the operator.

\subsection{Alternate Peak Metrics for TOU, CPP, and DLC}

Detailed information about the proposed demand response deployments was limited in the SGIG proposals, with little data pertaining to the operational deployment or acknowledgement of the difficulties that can be associated with DR deployment. The previous section highlighted some of the problems that can occur when DR systems are deployed without proper consideration for the complexities of the system and when secondary effects are not accounted for during more straightforward implementations. These issues cannot be adequately captured with a single peak load reduction value.

Because of the temporal component of a demand response program, a single value for peak load reduction is not sufficient for capturing the benefits it can provide. When a DR signal is sent to a population of automated controllers, there is an instantaneous reduction in load. Over time, this resource is depleted and the load reduction capability is reduced. At some point in 
time, the resource will be nearly depleted and there will only be a small effective reduction in load. In order to capture this temporal component, this section will develop an alternate set of metrics for peak demand that can capture the various goals of demand response programs, from instantaneous peak reduction to sustained feeder level peak reduction, and more properly highlight the potential of DR programs.

The basic premise behind demand response programs is to reduce demand, but the reason for reducing demand varies from utility to utility, and the type of program implemented is highly dependent upon the needs of the system operator. A DR program designed for short-term reduction (i.e. 15-minute) of demand will behave differently than a program designed for longer periods of reduction (i.e. 6-hour), and therefore has different metrics to define success. Table 2.8 shows a set of peak demand metrics that attempt to capture a majority of the often proposed benefits of DR programs. These metrics are intended to complement the original peak load metric in the SGIG impact metrics [2] to provide additional information and insight into the potential of the DR programs and their various purposes.

Table 2.8: Alternate Peak Impact Metrics.

\begin{tabular}{|c|l|c|}
\hline Index & \multicolumn{1}{|c|}{$\Delta$ Metric } & Units \\
\hline \multirow{7}{*}{$7^{*}$} & $\begin{array}{l}\text { Instantaneous Peak } \\
\text { Load }\end{array}$ & $\mathrm{kW}$ \\
\cline { 2 - 3 } & 1 Hour Peak Load & $\mathrm{kW}$ \\
\cline { 2 - 3 } & 6 Hour Peak Load & $\mathrm{kW}$ \\
\cline { 2 - 3 } & Average Peak Load & $\mathrm{kW}$ \\
\hline \multirow{7}{*}{$7^{*}$} & $\begin{array}{l}\text { Average Peak Load } \\
\text { with Rebound }\end{array}$ & $\mathrm{kW}$ \\
\hline \multirow{7}{*}{} & $\begin{array}{l}\text { Instaneous Peak } \\
\text { Load }\end{array}$ & $\%$ \\
\cline { 2 - 3 } & 1 Hour Peak Load & $\%$ \\
\cline { 2 - 3 } & 6 Hour Peak Load & $\%$ \\
\cline { 2 - 3 } & Average Peak Load & $\%$ \\
\cline { 2 - 3 } & $\begin{array}{l}\text { Average Peak Load } \\
\text { with Rebound }\end{array}$ & $\%$ \\
\hline
\end{tabular}

Instantaneous peak load represents the initial response to a DR control signal, and generally represents the maximum achievable reduction of demand. This occurs at the beginning of a DLC or CPP call, when nearly all of the participants are willing to reduce load. It can also be used to 
define the maximum resource potential for a number of short term ancillary services typically provided by generation providers, such as spinning reserves or frequency regulation. Figure 2.39 uses the same example discussed in Section 2.3 to highlight the instantaneous peak reduction, where the green line demonstrates the instantaneous peak load reduction on feeder R3-12.47-3 using the described DLC strategy. It should be noted that the instantaneous peak reduction shown here is the maximum achievable under this particular DLC strategy under the constraints of previous assumptions. It is conceivable that a control signal can be devised which maximizes the potential on a short time scale (e.g. turn off all of the appliances for five minutes), however the greater reduction, the greater the potential for a rebound effect when the load is released back to its normal operation. This should instead be considered an example model that is used to describe the method.

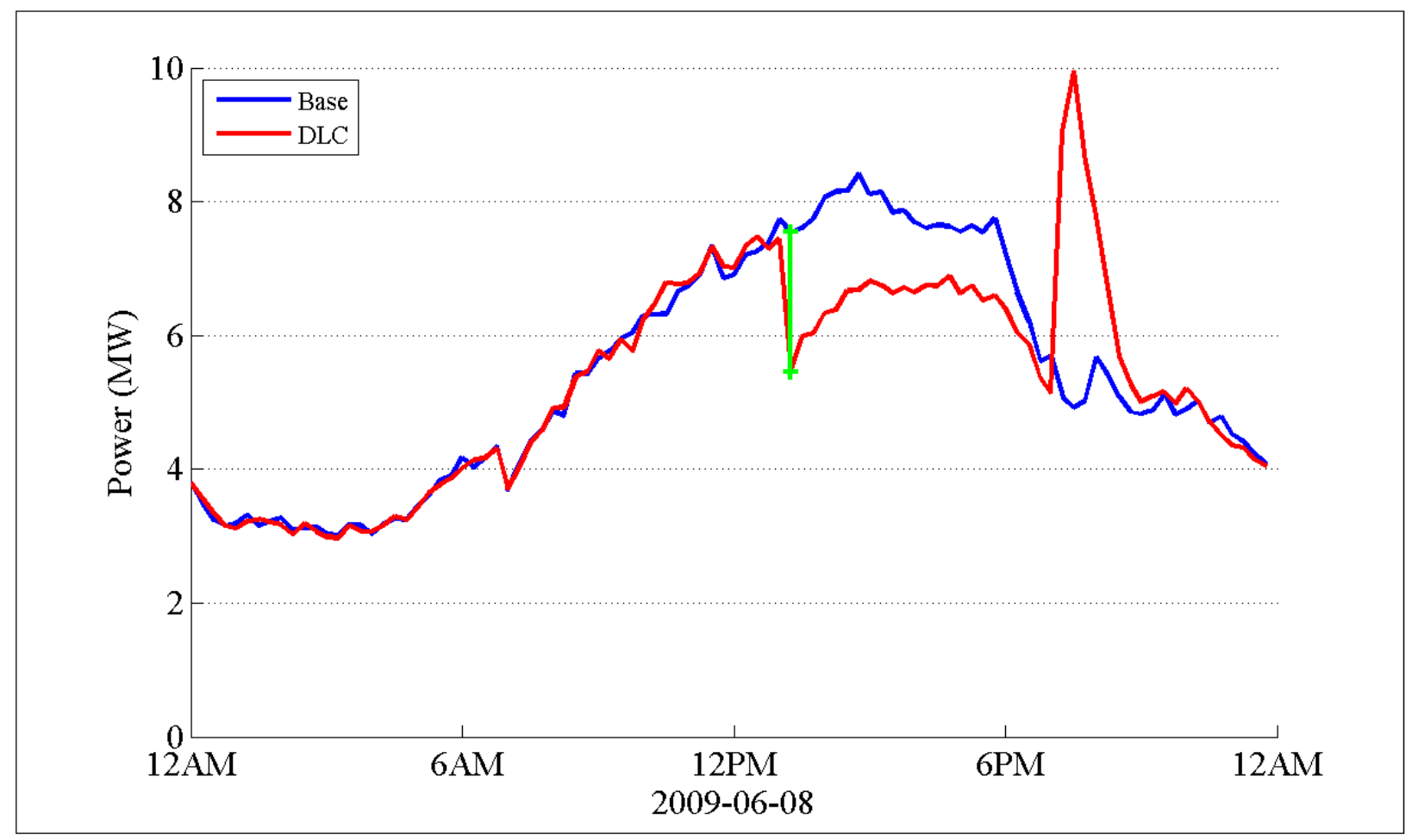

Figure 2.39: Times series example illustrating instantaneous peak reduction.

The metrics one hour and six hour peak load reductions are solely used to demonstrate the decaying response of the load to a static DR control signal, such as those often used in CPP or DLC. These metrics are demonstrated on feeder R3-12.47-3 in Figure 2.40 and Figure 2.41. Notice that the load reduction after one hour is not the same as the load reduction after six hours, and is considerably reduced as time progresses. This highlights the fact that demand response is a finite resource, and should be dispatched at a rate that is designed to meet either the short or long term goals of the program, as necessary. As the load reduction signal is sustained, fewer 
and fewer resources are available, both as customers fatigue from the change in internal set points (e.g. it is seven degrees warmer in their home) and as the resource itself runs out as described in Section 2.3, and the resource reaches a new sustained equilibrium point. This is driven by both the basic thermodynamics of the system and by customer behavior, and while customer behavior can be modified to a certain extent, the basic energy balance of the system cannot.

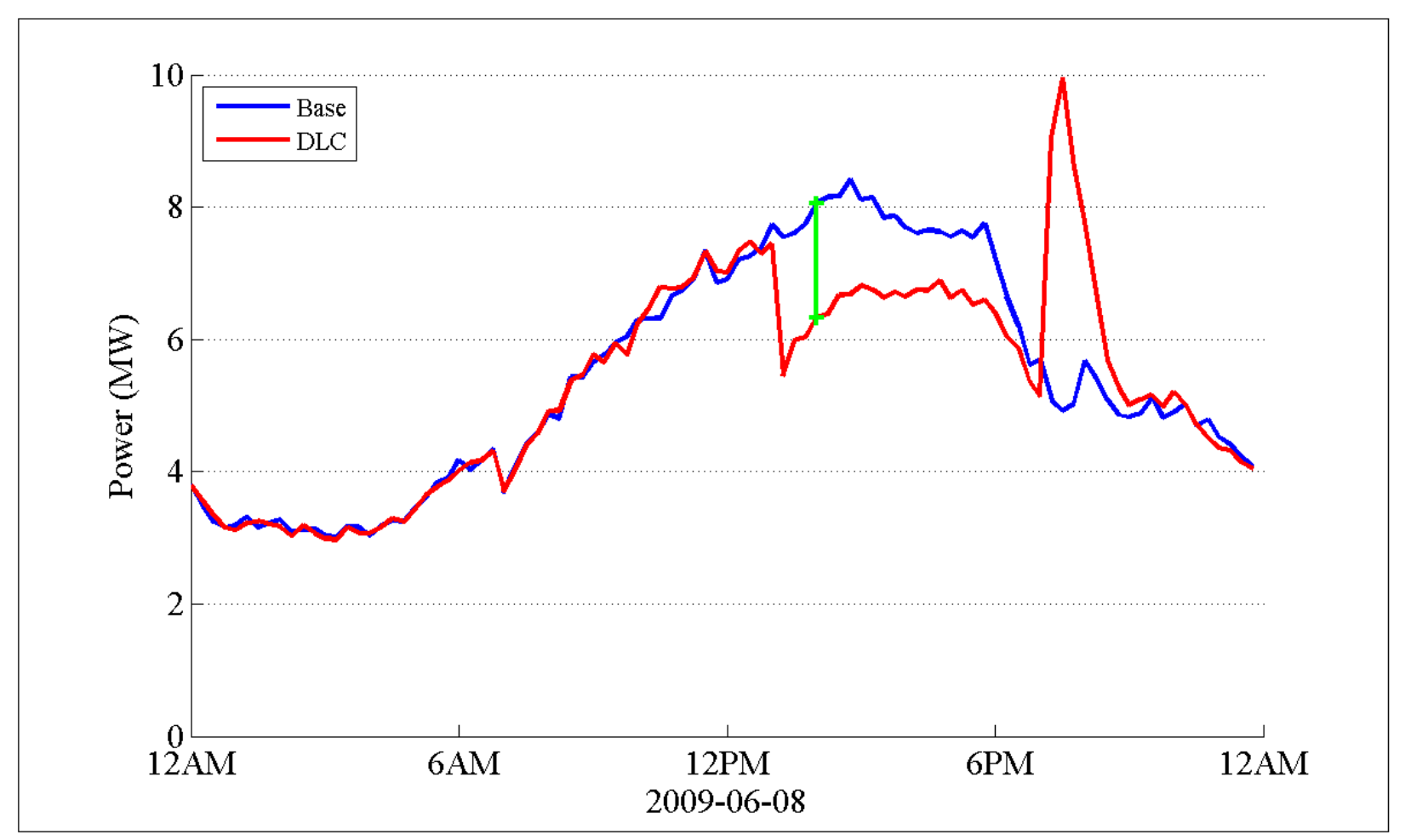

Figure 2.40: Times series example illustrating the one hour peak reduction. 


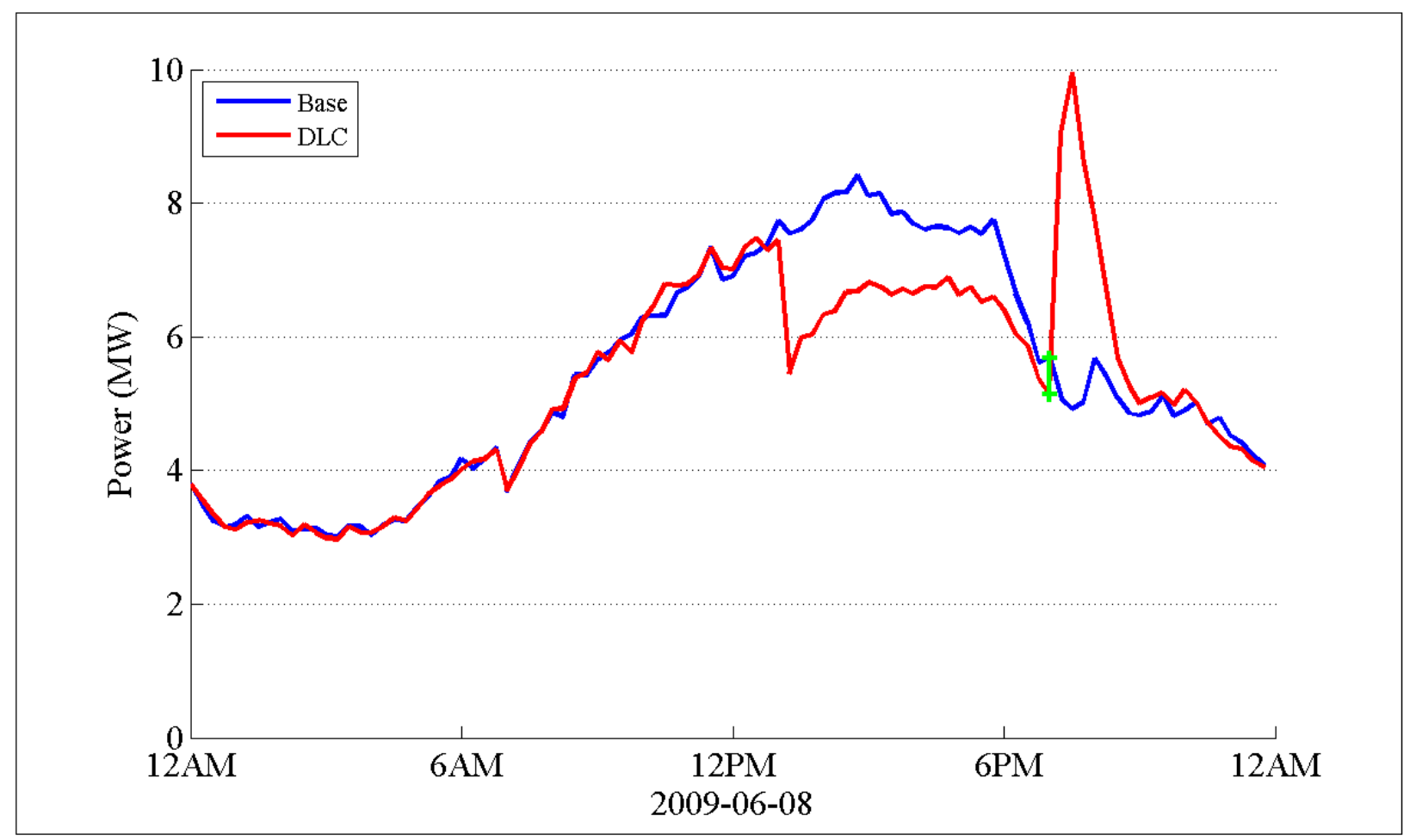

Figure 2.41: Times series example illustrating the six hour peak reduction.

The metrics flattened peak load and flattened peak load including rebound attempt to capture the maximum potential for peak load reduction over extended periods of time. The method used to compute them is described here. In this specific DR implementation, the period of time for which the reduction is to occur is six hours for the former and six hours plus the amount of time the system takes to settle from the rebound for the latter. To a first order approximation, there is a limited amount of energy resources obtained by inducing a change in the thermostat settings or load behavior, representing the change in energy in the thermal mass of the population. Literally, this is the sum of the product of the thermal capacitance and temperature change in each building and hot water heater of the population. Of course, this ignores the second order effect due to the increased indoor air temperatures, which reduce the heat gained through the building envelopes, and any changes in other external parameters, such as external air temperature. This same change in energy then forms an energy debt across the population of buildings that must be repaid eventually to return the load to its original behavior, in this case, the air and water temperatures back to their original set points. This can be thought of as energy balance within the system; the longer or harder you push down the load, the more energy debt is incurred.

The energy resource of a DR event can be dispatched over the six hour (or other length) period as needed. It can also be used to manage the rebound, as necessary, but again takes away from the total available resource. It is up to the system operator to determine how to implement the 
program so as to apportion the energy across the given time frame to obtain the needed load reduction. In the case of a DLC or CPP signal that uses a static control signal, without using a more advanced control schema, the load reduction is inherently greatest at the beginning of the time period and is reduced subsequently over time. These new metrics describe the potential load reduction if the energy were to be apportioned across the time interval using a more advanced control in a way that flattens the load, regardless of the control signal designed to produce the flattened load. If the time interval over which the reduction is required is extended, the peak reduction obtained will be reduced to maintain the maximum peak load reduction possible, given the available energy resource obtained. These metrics look at the potential reduction within the given time window, and ignore the load level outside of the described time window. The metric flattened peak load examines the maximum peak load reduction over the six hour period if the rebound does not matter (e.g. moving local demand off the system peak). The metric flattened peak load including rebound examines the maximum reduction if maintaining the rebound below the reduced peak is also important (e.g. local equipment is overloaded). If the time window were to include times before the six hour window, then this would need to be accounted for also, but was not accounted for in this analysis. Figure 2.42 and Figure 2.43 illustrate the new peak load metric, where the dotted green line represents the new load during the desired time period.

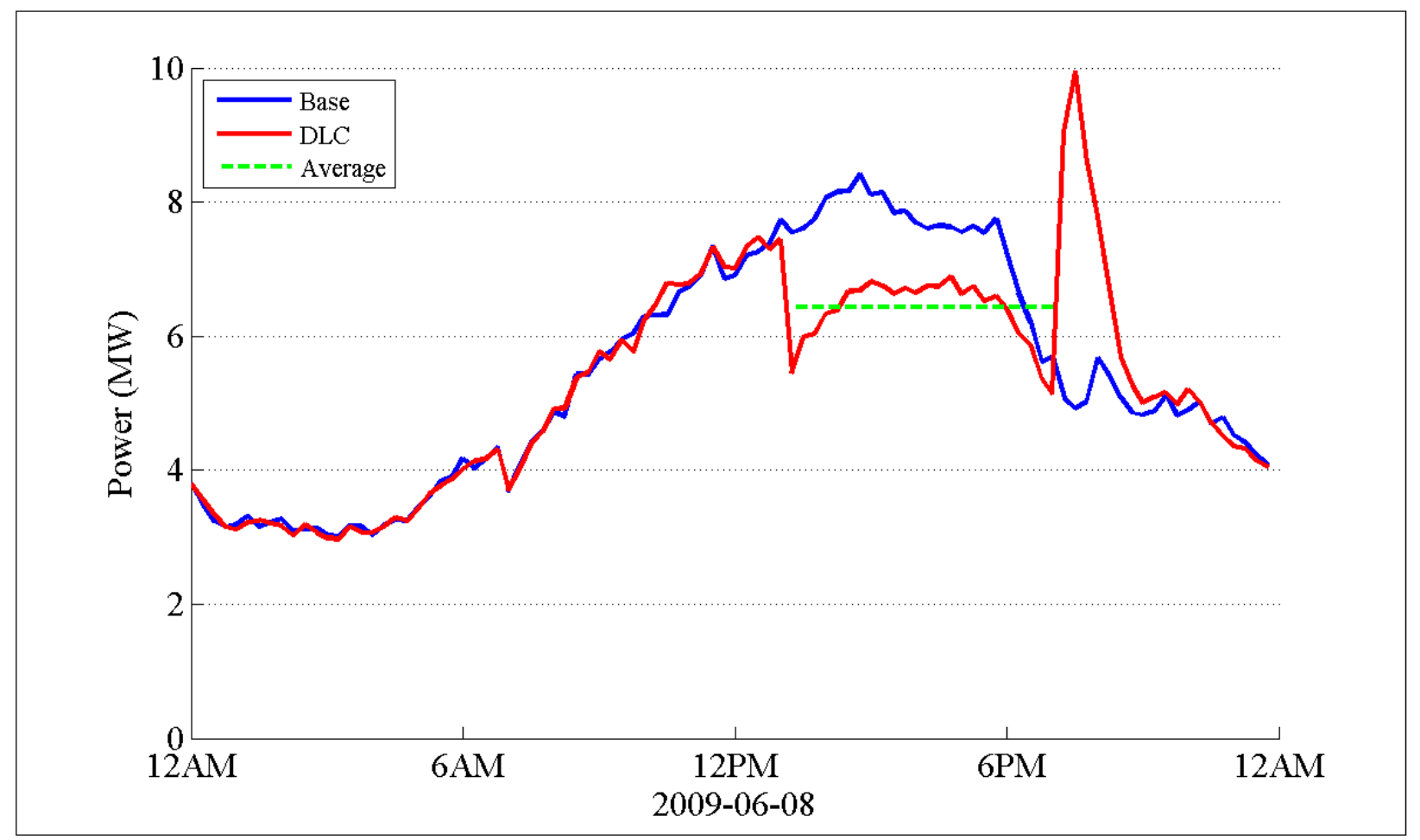

Figure 2.42: Times series example illustrating the flattened peak load reduction. 


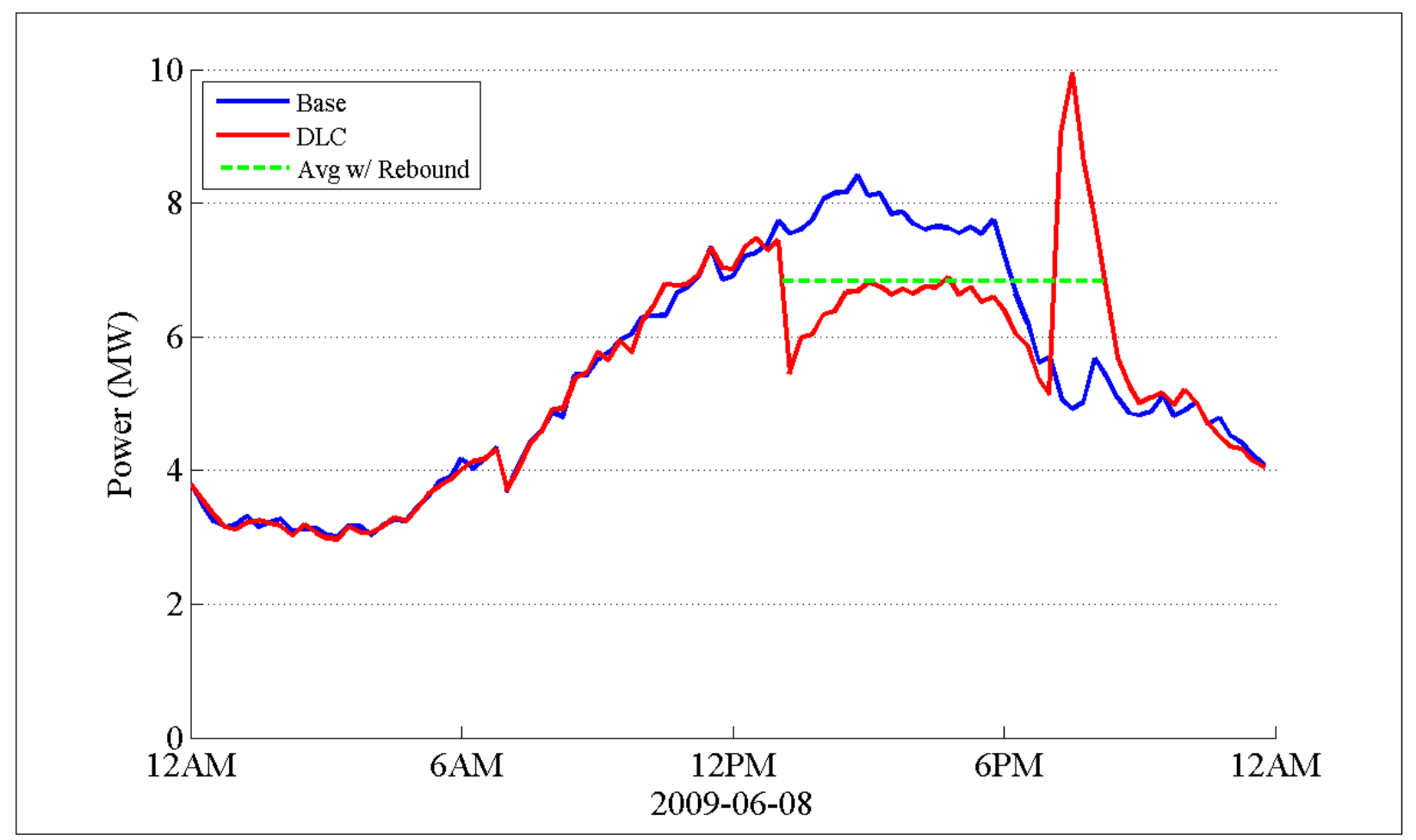

Figure 2.43: Times series example illustrating the flattened peak load including rebound.

Of course, to achieve the flat load reduction over the course of time, the control signal requires a "throttle" or some sort of adaptive control that can modify the control signal over time. This may be as straightforward as creating a number of CPP/DLC bins, where each customer responds at different times, but may be as complicated as a centralized, adaptive control device which modulates the signal over time as necessary. This is an area of open research, and will not be addressed in this report, but this analysis begins to highlight some of the issues that must be addressed during the design of such a controller. And while not explicitly stated in the SGIG project proposals, it is assumed that the proposed deployments of DR will adequately address these issues before deployment.

As an example, comparisons of the load reductions in terms of $\mathrm{kW}$ and percentage for R312.47-3 for both CPP and DLC are shown in Figure 2.44 and Figure 2.45. Of obvious note is the declining reduction over time from instantaneous to six hours in both the CPP and DLC cases. Note that the flattened peak load reduction is approximately $500 \mathrm{~kW}$ (CPP) and $200 \mathrm{~kW}$ (DLC) less than the instantaneous peak load reduction, but in both cases greater than the one hour and six hour peak load reduction. Notice that the flattened peak load including rebound reduction is approximately $400 \mathrm{~kW}$ less than the flattened peak load reduction in the DLC case, while the CPP case shows that they are identical as the rebound was already below the flattened peak load. For each feeder, the ratios between the different reductions is quite different depending upon a 
number of external factors, including load composition, weather conditions on the peak day, and penetration of commercial versus residential customers.

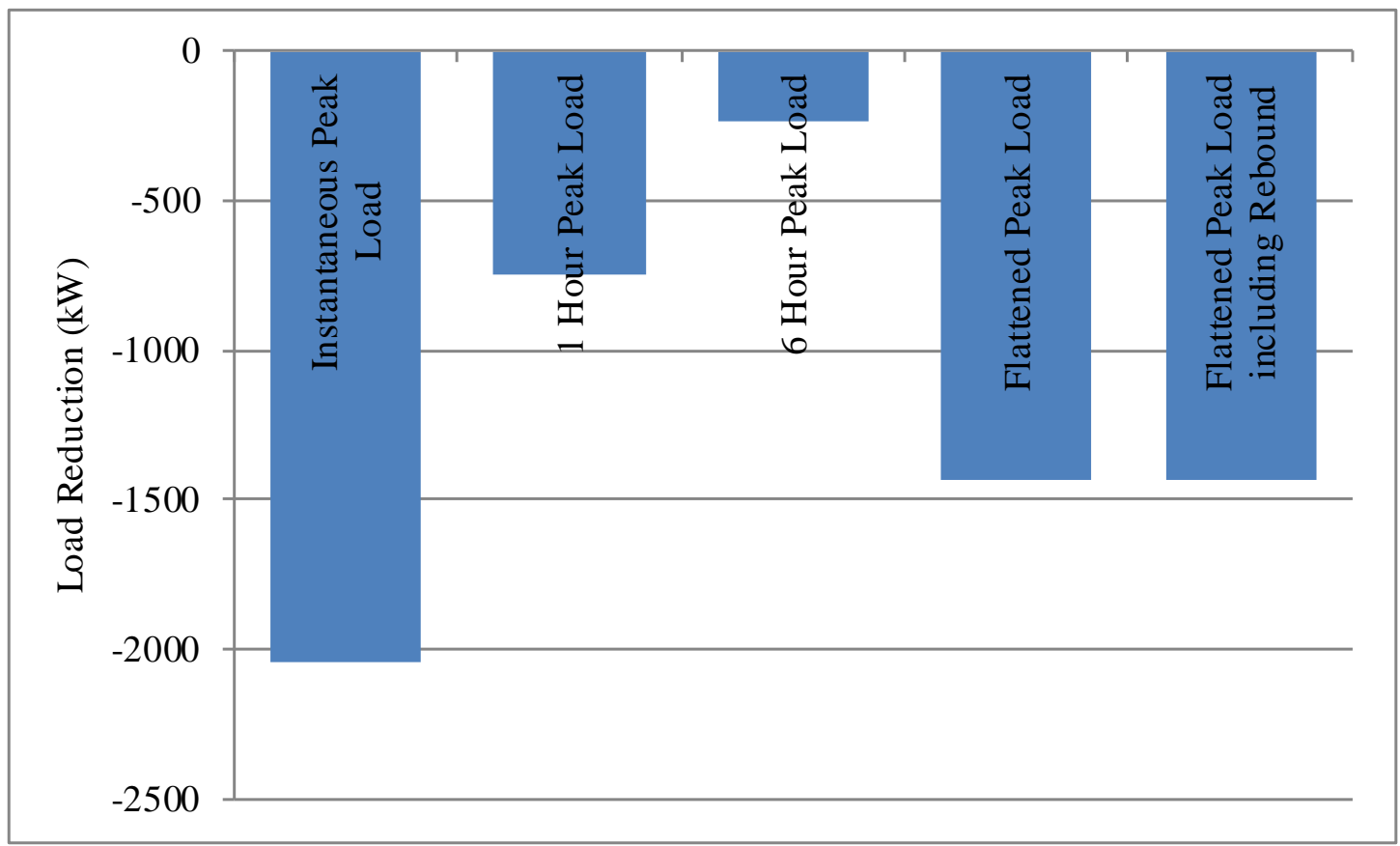

Figure 2.44: Comparison of load reduction for R3-12.47-3 CPP in kW.

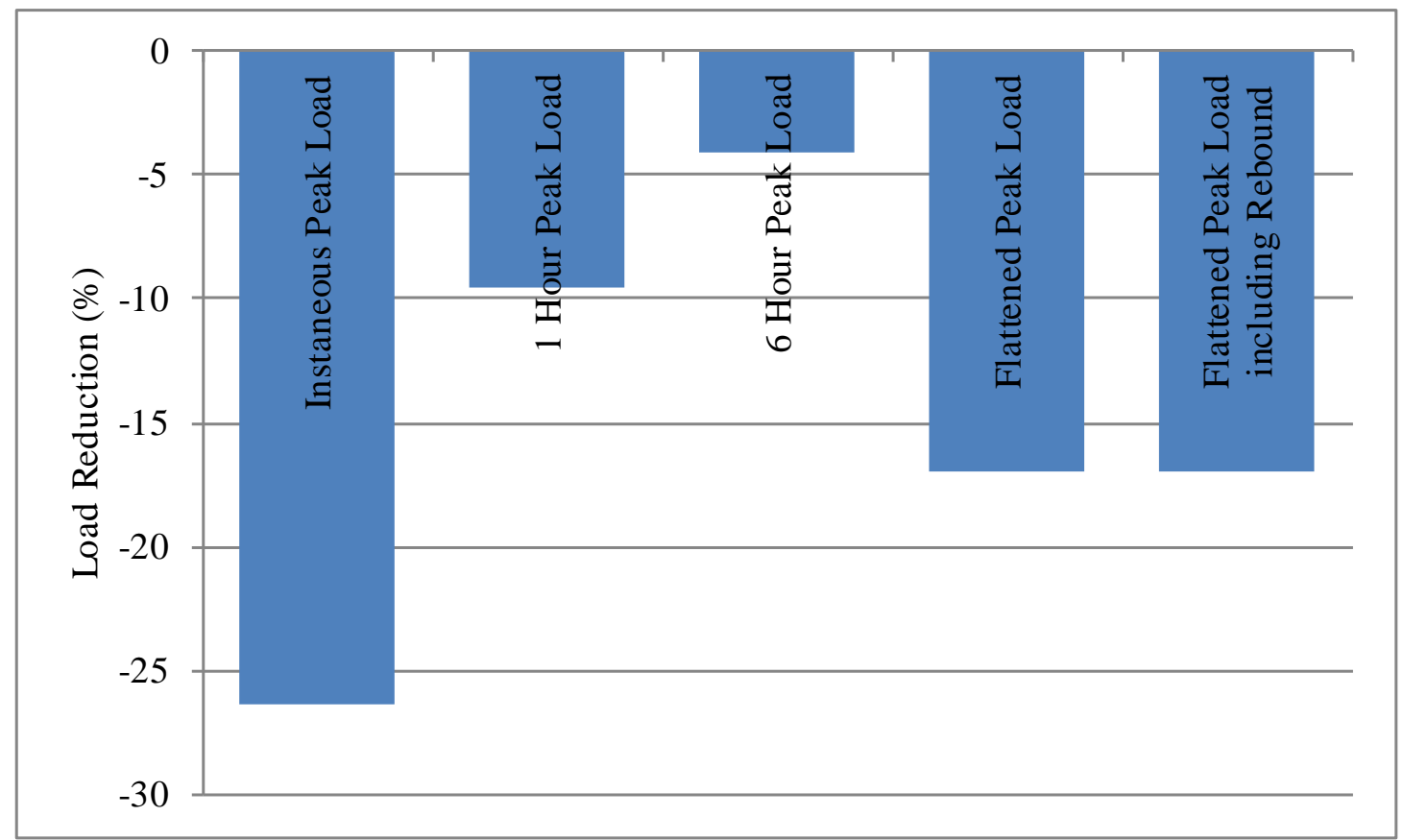

Figure 2.45: Comparison of load reduction for R3-12.47-3 CPP in \%. 


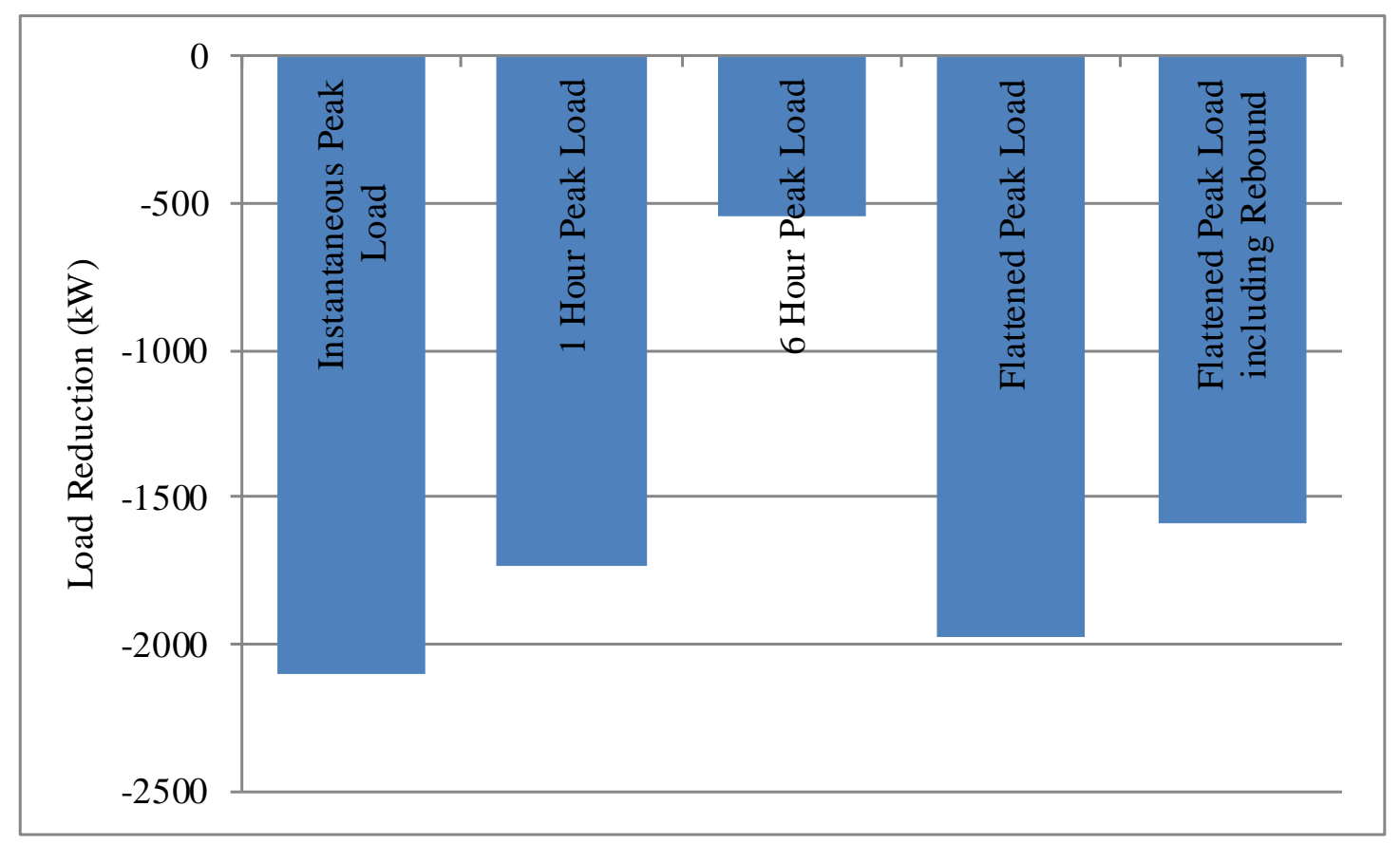

Figure 2.46: Comparison of load reduction for R3-12.47-3 DLC in kW.

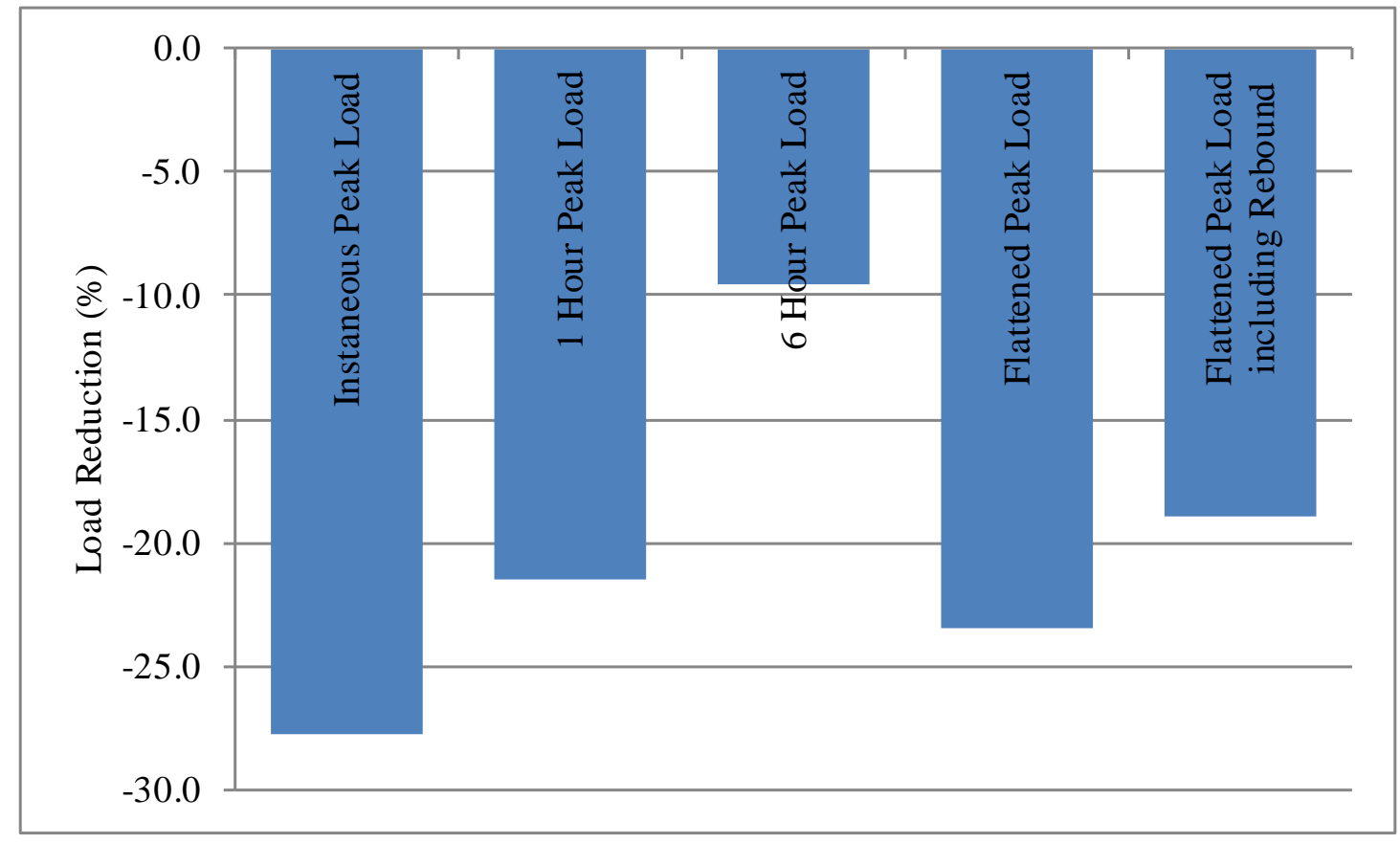

Figure 2.47: Comparison of load reduction for R3-12.47-3 DLC in \%. 
An additional note about the " $16^{\text {th" }}$ day should be made here. In many cases, the average reduction of load resulted in 15 days which had a reduced peak load, but the " $16^{\text {th" }}$ day then became the new peak day. This may or may not matter in a utility deployment, again depending upon the goals of the utility. However, if the " $16^{\text {th" }}$ day is important to the utility, it may be worth redesigning the control signal to reduce load across more days than the aforementioned 15. This leads into a discussion about whether customers would be willing to participate in the load reduction strategy more than 15 days per year. One way to overcome this objection may be to revisit the idea of a "throttle" or closed-loop control on the demand response signal, allowing the utility to ask for "a lot" of response on the highest peak day, while asking for less and less on each successively smaller peak day. Again, this is an area for additional research and will not be addressed further in this report.

The described metrics were applied to the results from the previous simulations, without resimulating the feeders with a control signal designed to meet the individual goals. Graphical results comparing the load reductions across all of the simulated feeders for the additional metrics are shown in Figure 2.49 to Figure 2.52. Tabular results are given in Section 4.3, and can be described as a first order approximation to define the potential peak reduction limits of a DR program, under the assumptions previously described.

In these figures, a few general trends can be seen. First, as time progress from instantaneous to one hour to six hours, the amount of reduction is consistently less, from as much as a 55\% reduction during the first 15 minutes to some cases where the demand actually increases at the six hour mark as resources are exhausted. From a purely thermodynamic point of view, the six hour peak load should be at a slightly lesser equilibrium demand. However, the CPP/DLC programs were mostly designed for use on residential loads; feeders with high penetration of commercial buildings did not perform as well as those of lower commercial building penetration. Additionally, the six hour peak load metric normally fell upon a time when load was naturally decreasing and less resource was available than during the peak. In a few cases, shown in Figure 2.50 , the six hour window was still being applied as the commercial load rapidly decreased (say at $6 \mathrm{pm}$ when smaller shops closed), causing some second order shifting of load reduction.

It should also be noted that with these particular demand response programs, the instantaneous reduction of TOU/CPP is greater than that of DLC. However, this should not be considered typical, as neither of these programs was designed for instantaneous reduction, but rather as a way to manage a six hour peak. It is conceivable that the instantaneous peak reduction could be increased, where the limit would be described as all of the controlled loads being turned off for 15 minutes. In this example, this metric was used to describe the changing response of a flat demand response signal, not to describe the absolute potential of a short term reduction. It also provides an estimate of a lower bound for this particular implementation, and describes the largest possible reduction without redesigning the program. 
Managing the rebound reduces peak reduction is between $0 \%$ and $11.4 \%$ when compared to allowing the rebound to occur, depending upon the magnitude of the rebound. However, the overall potential for sustained peak reduction, even when managing the peak rebound, is between $4 \%$ and $37 \%$ less than the peak load depending upon weather on the peak day, load composition of the feeder, and the type of program applied. In general, this shows that peak demand reduction is a significant benefit that can be derived from demand response programs, assuming that the program is properly designed to meet the utility goals.

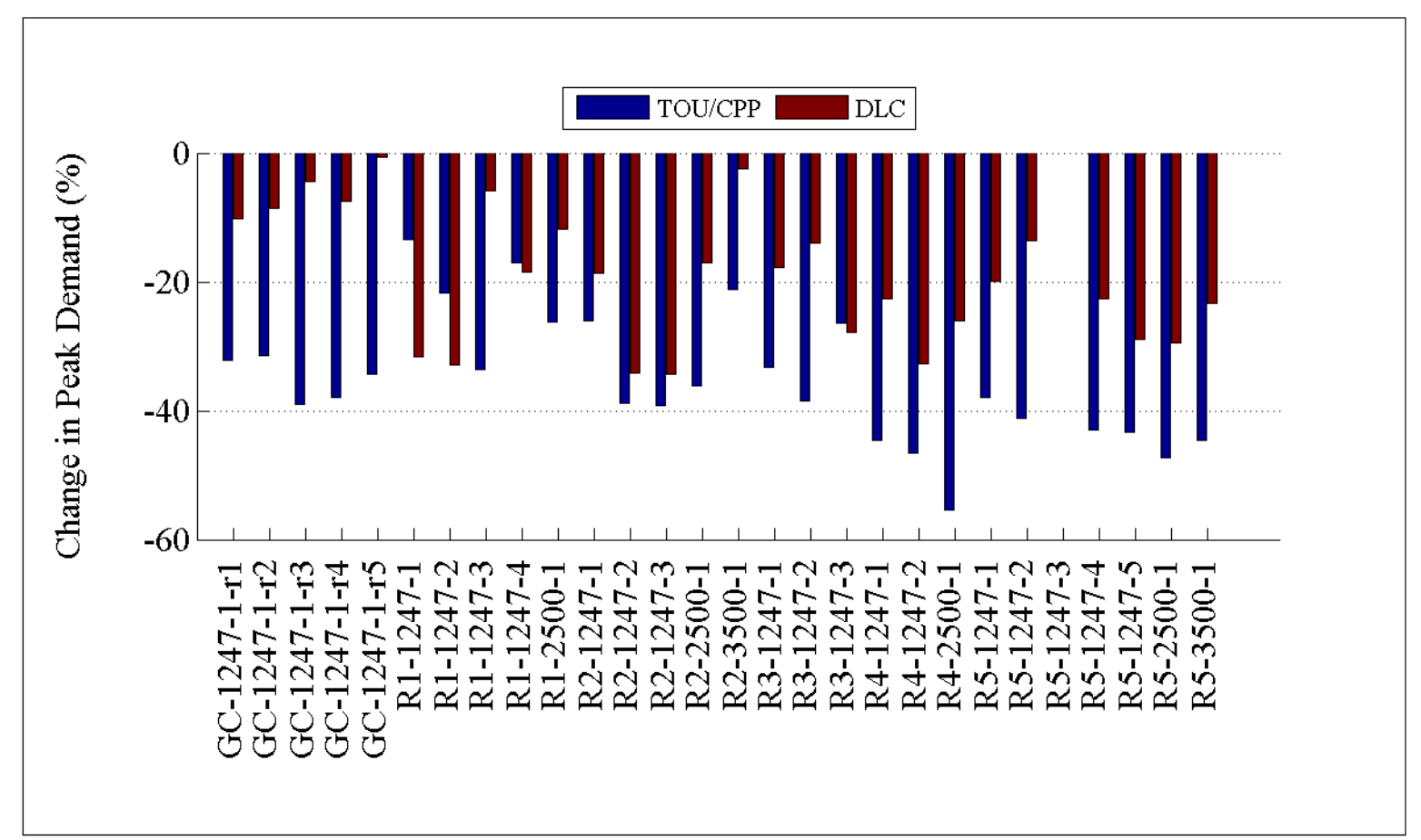

Figure 2.48: Comparison of instantaneous load reduction by feeder. 


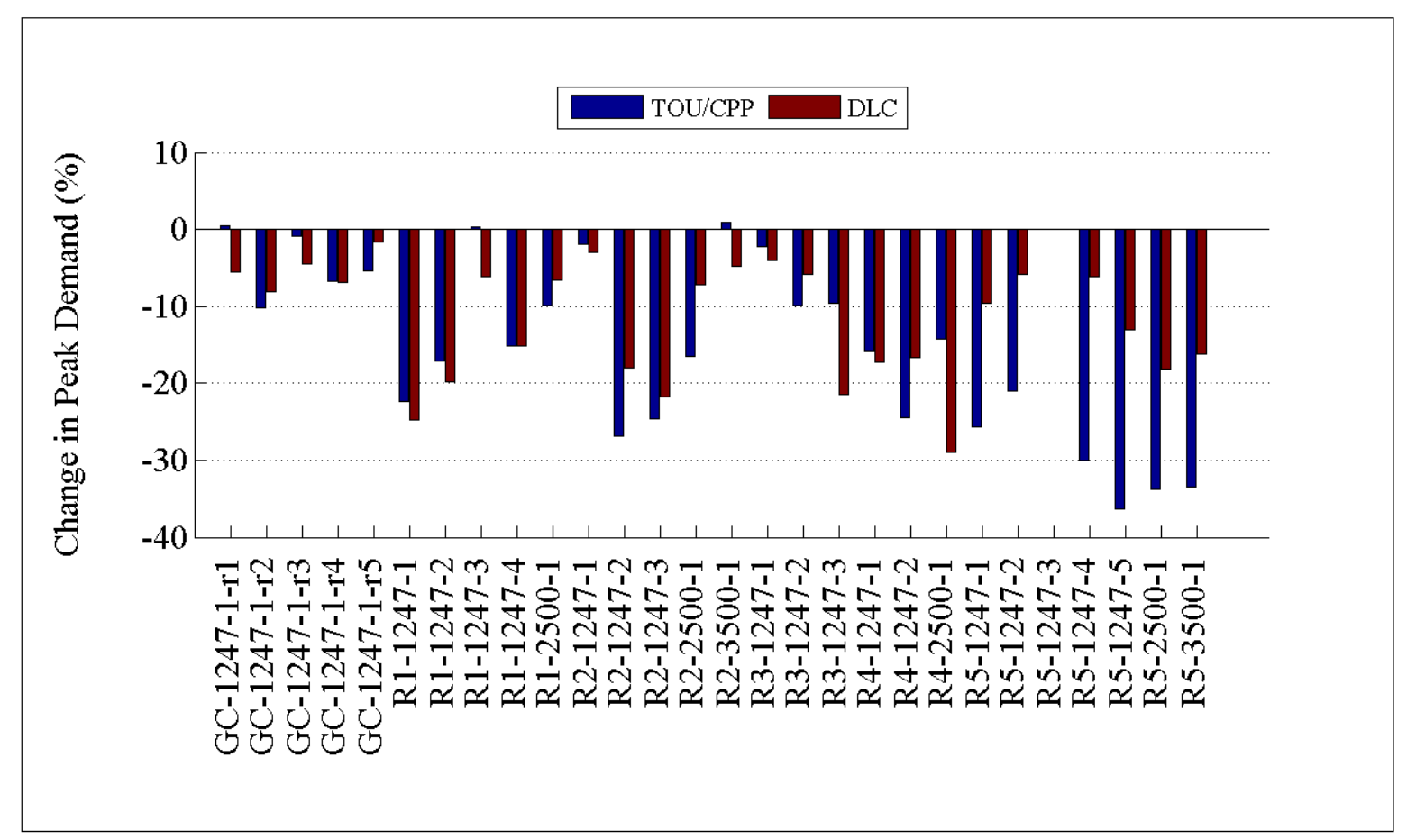

Figure 2.49: Comparison of 1 hour load reduction by feeder.

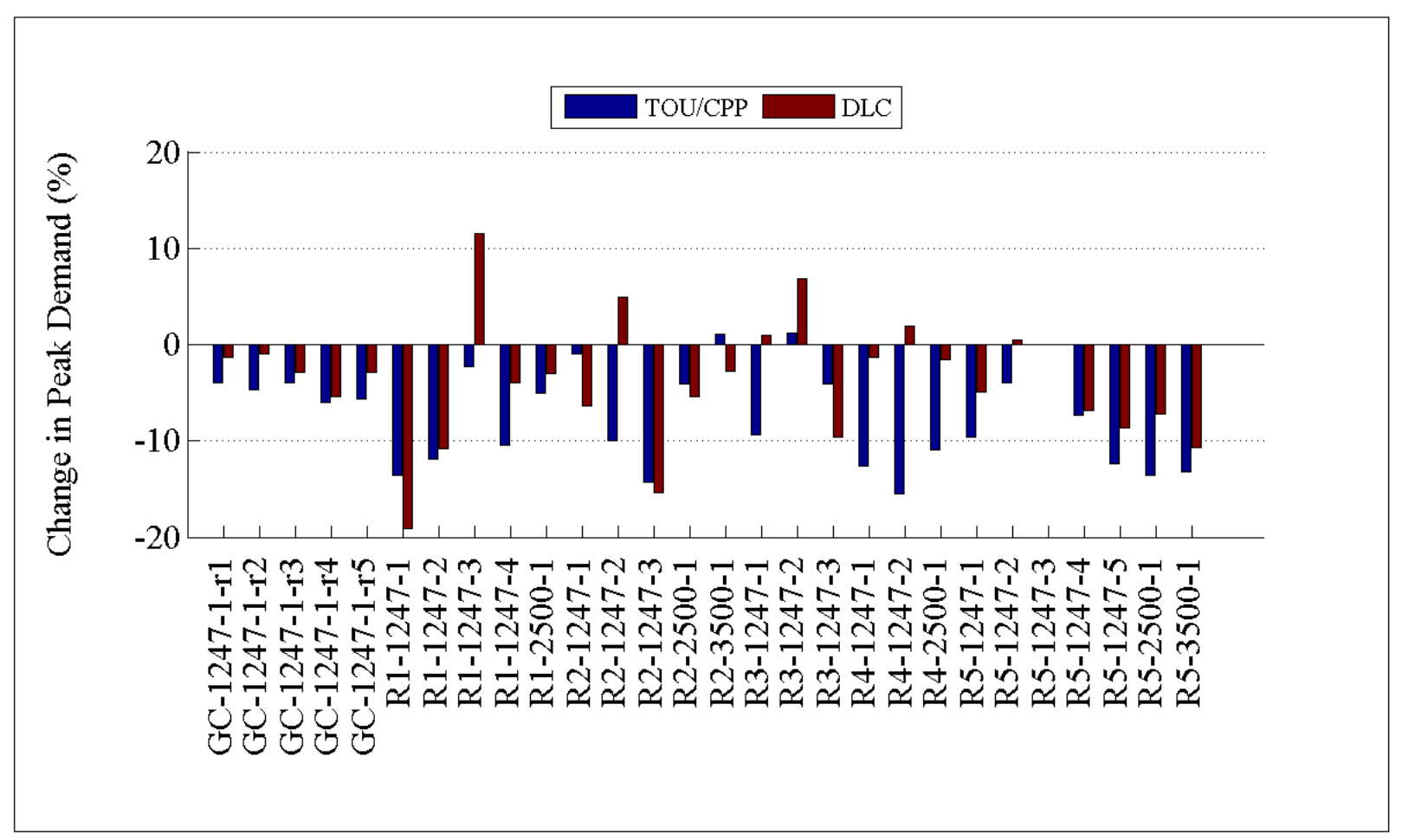

Figure 2.50: Comparison of 6 hour load reduction by feeder. 


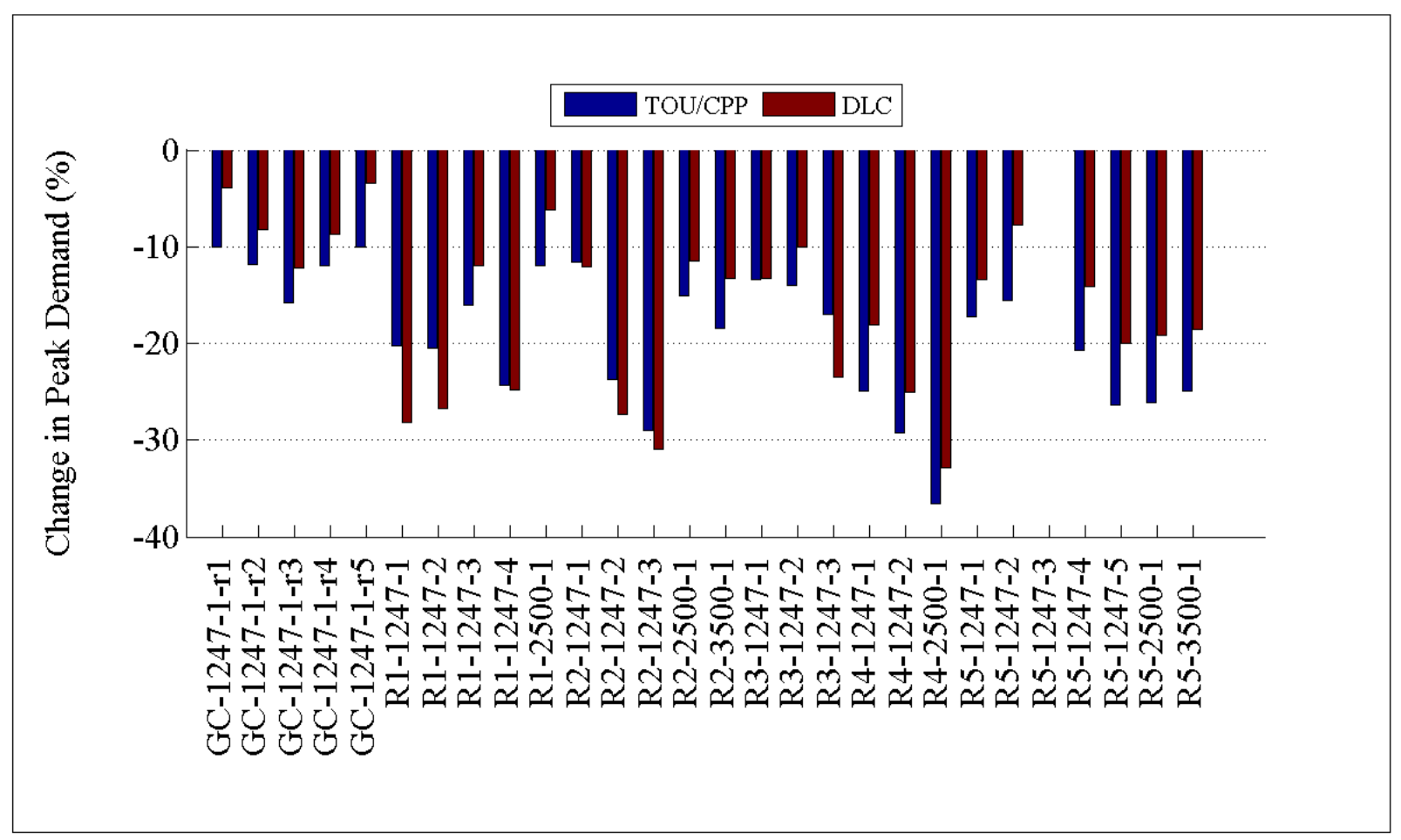

Figure 2.51: Comparison of average load reduction by feeder.

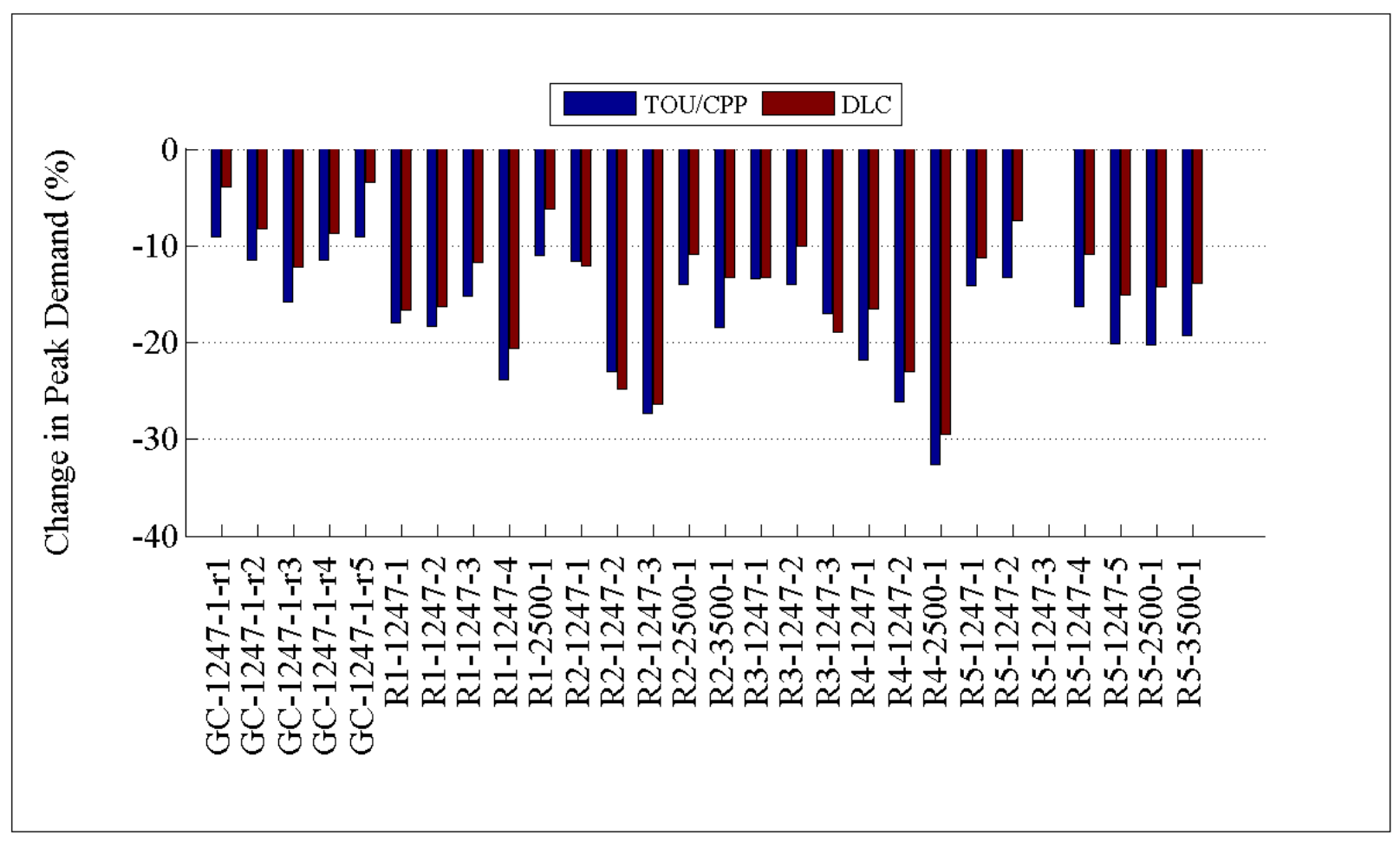

Figure 2.52: Comparison of average load reduction while accounting for the rebound by feeder. 


\section{Detailed Individual Prototypical Feeder Results}

Due to the large number of plots generated by the simulations it is not practical to place all of the results in this section. Section 3 will examine the output results of a single feeder and the output for the remaining feeders will be provided in Appendix D.

\subsection{TOU and CPP}

For TOU and TOU/CPP, four plots will be displayed. For each feeder, peak monthly demand, monthly energy consumption, monthly losses and monthly $\mathrm{CO}_{2}$ emissions will be plotted with data from the base case, TOU/CPP with enabling technology, TOU/CPP without enabling technology, TOU with enabling technology, TOU without enabling technology.

\subsubsection{Example Feeder GC-12.47-1_R1}

Figure 3.1 to Figure 3.4 show the monthly plots that are generated from feeder GC-12.471_R1.

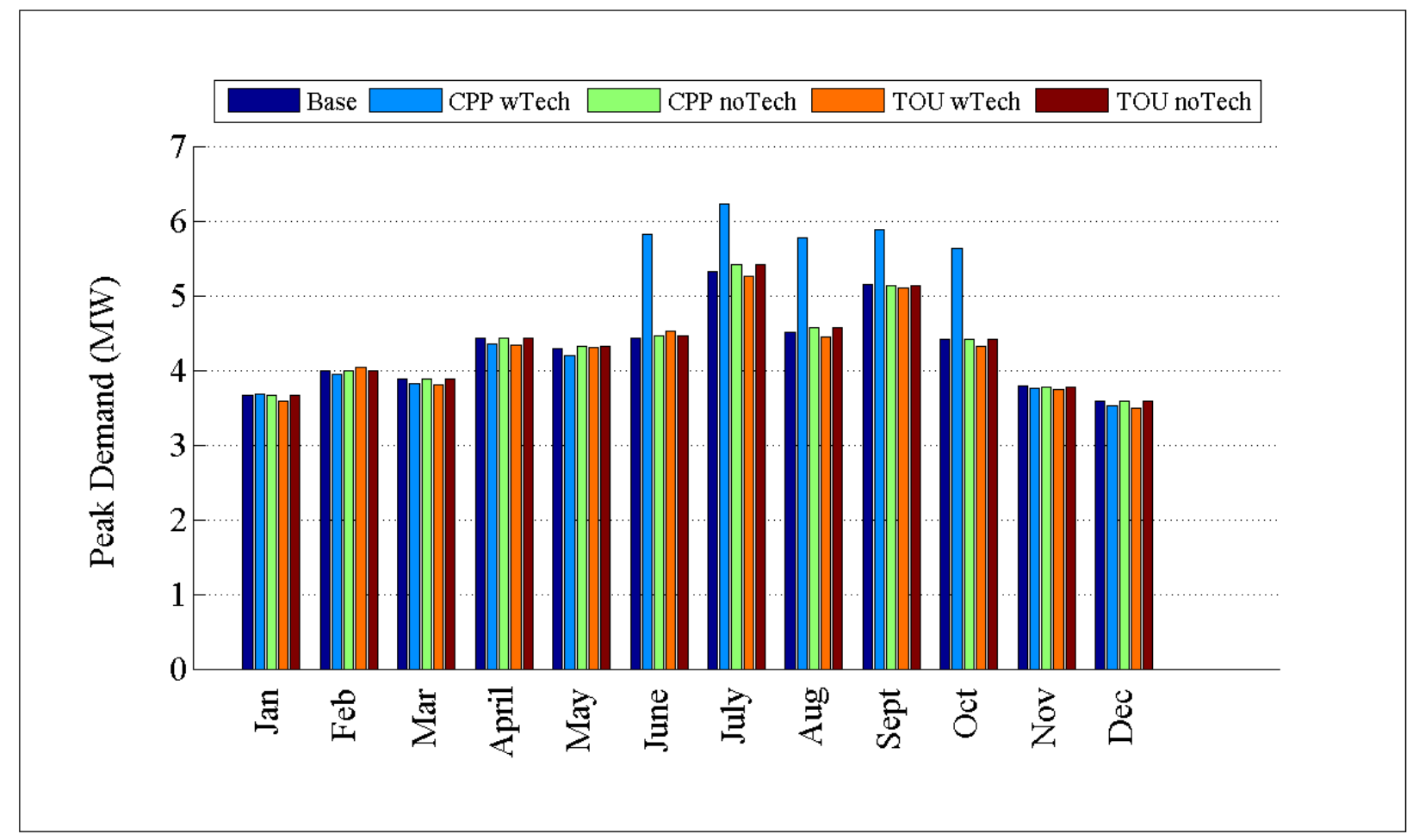

Figure 3.1: Comparison of peak demand by month for GC-12.47-1_R1 


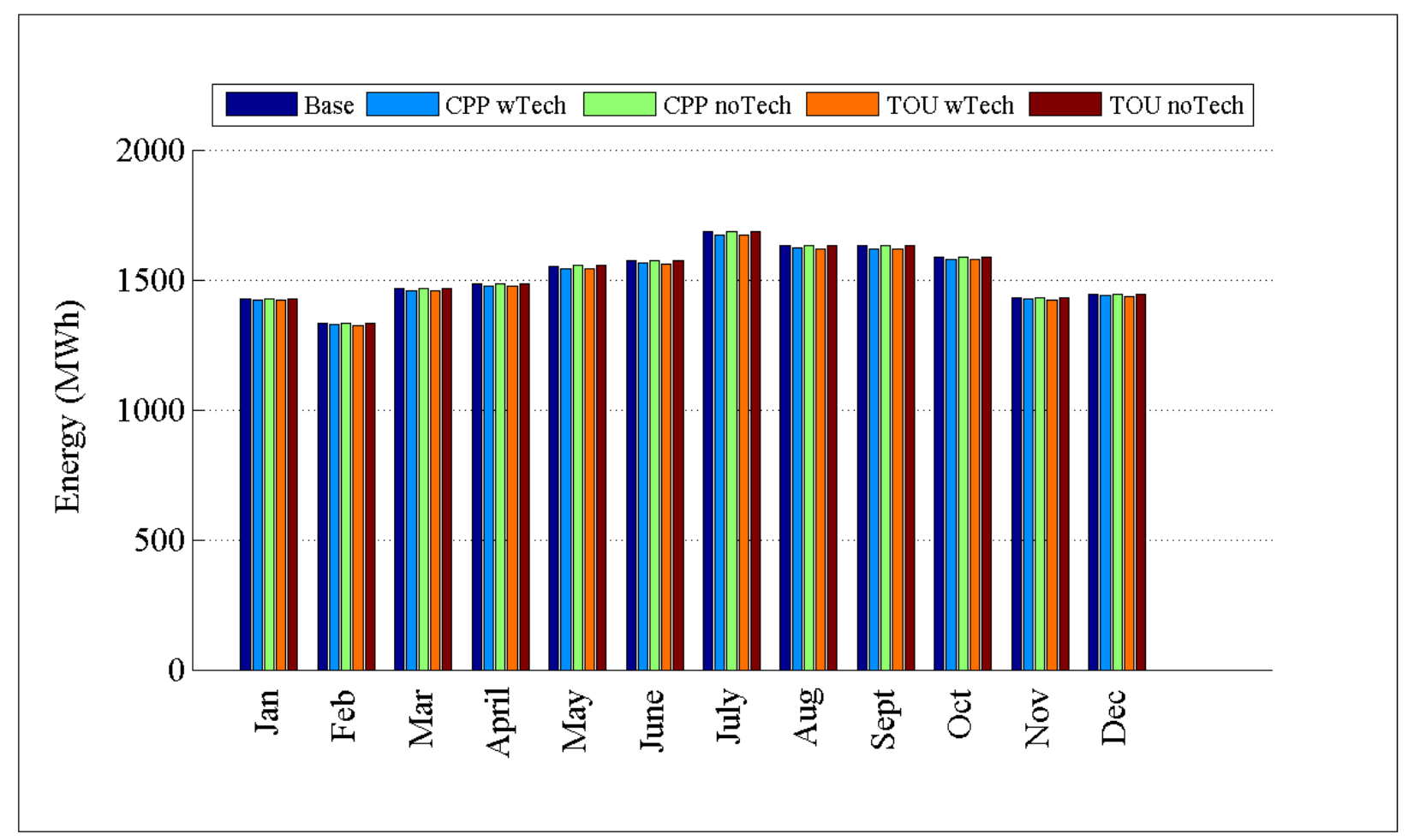

Figure 3.2: Comparison of energy consumption by month for GC-12.47-1_R1

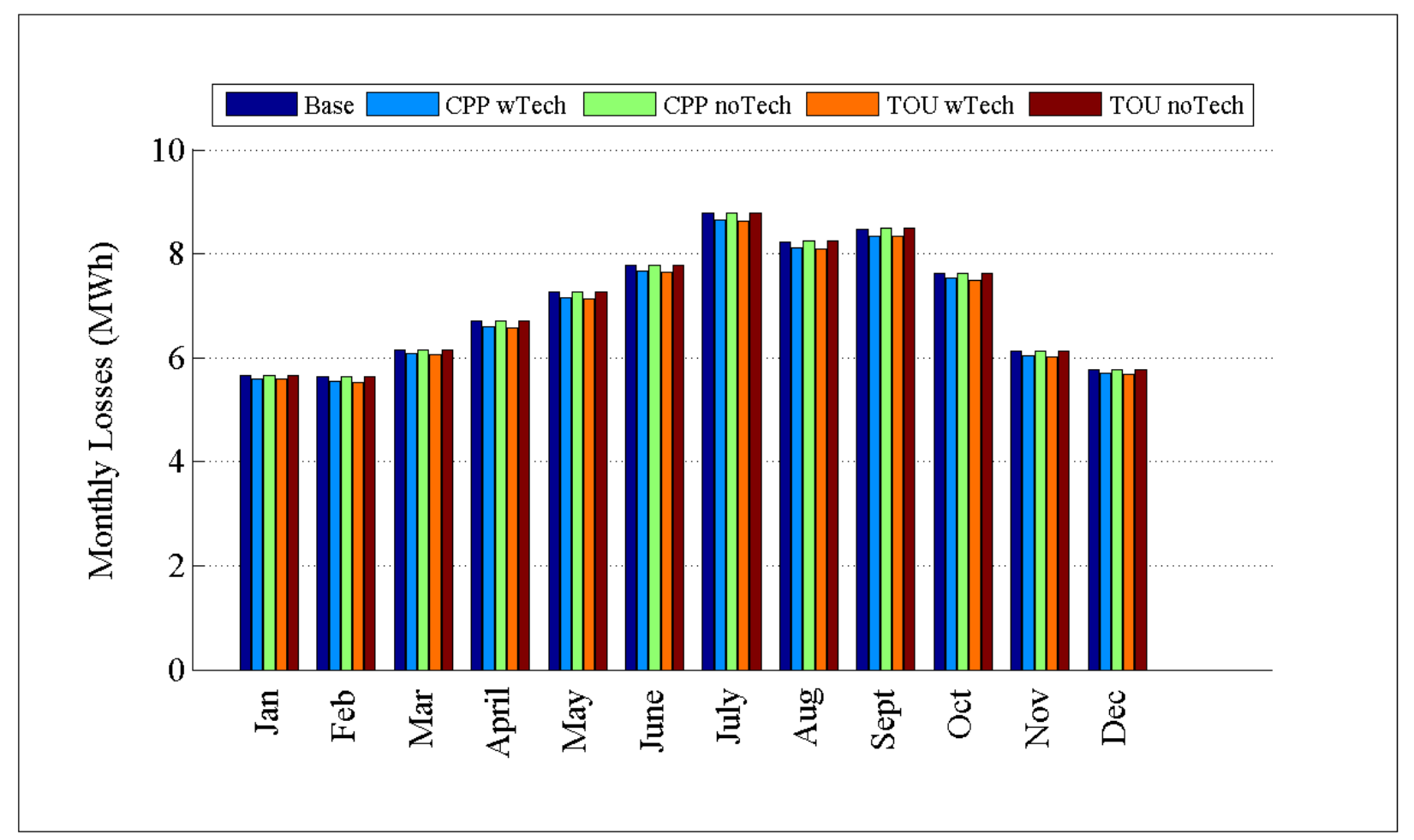

Figure 3.3: Comparison of losses by month for GC-12.47-1_R1 


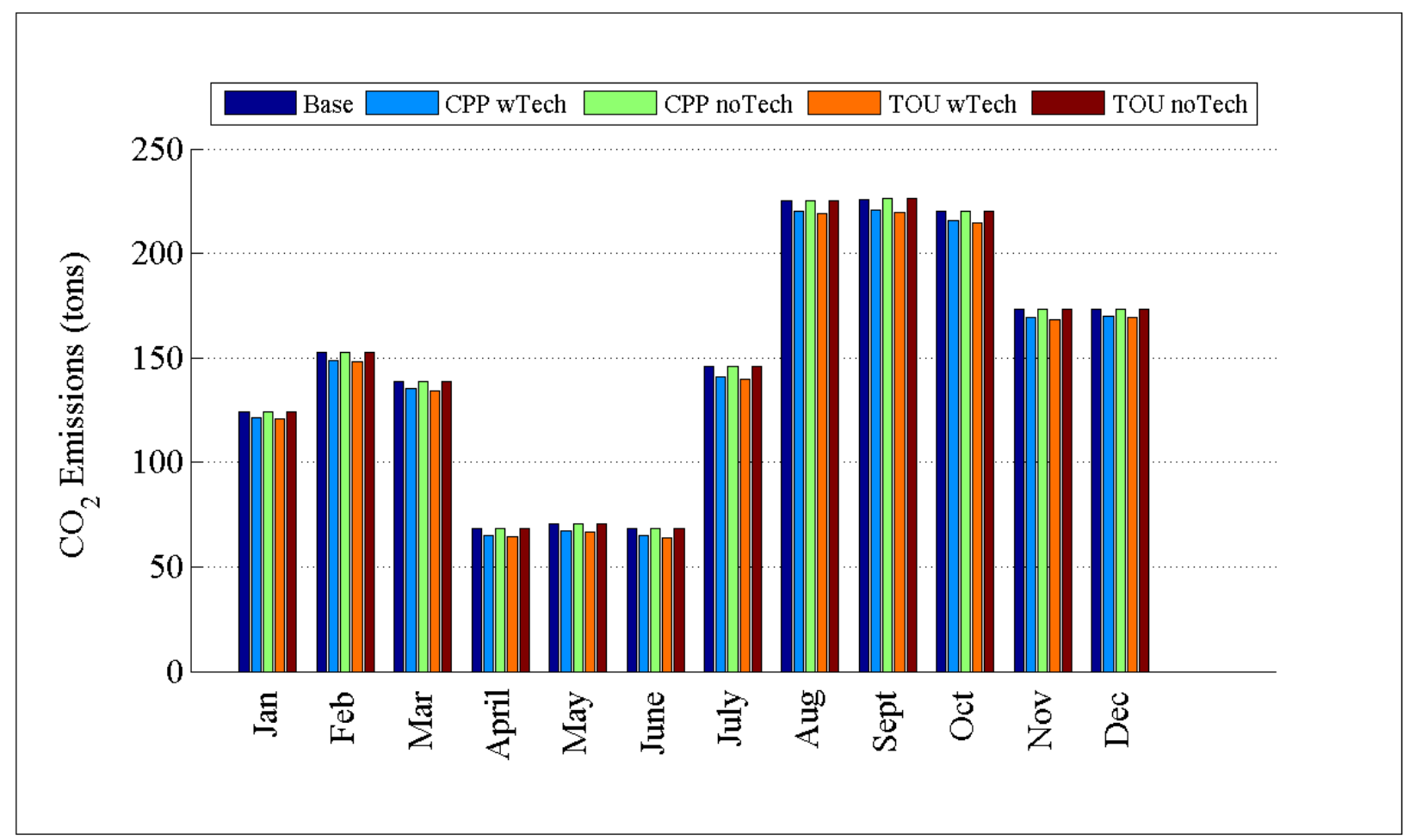

Figure 3.4: Comparison of $\mathrm{CO}_{2}$ emissions by month for GC-12.47-1_R1

\subsection{DLC}

For DLC, four plots will be displayed. For each feeder, peak monthly demand, monthly energy consumption, monthly losses and monthly $\mathrm{CO}_{2}$ emissions will be plotted with data from the base case and the DLC case.

\subsubsection{Example Feeder GC-12.47-1_R1}

Figure 3.5 to Figure 3.8 show the monthly plots that are generated from feeder GC-12.471_R1. 


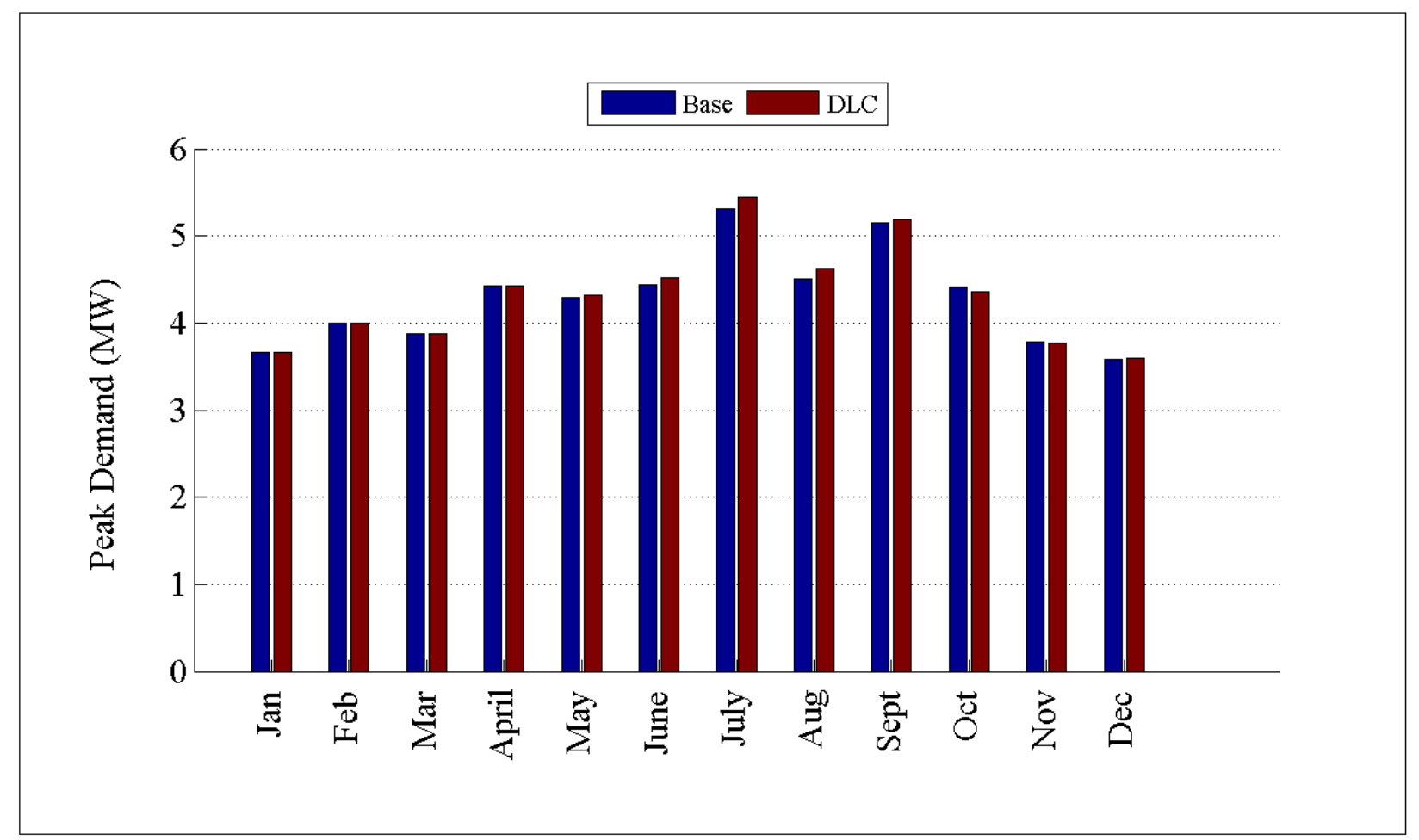

Figure 3.5: Comparison of peak demand by month for GC-12.47-1_R1

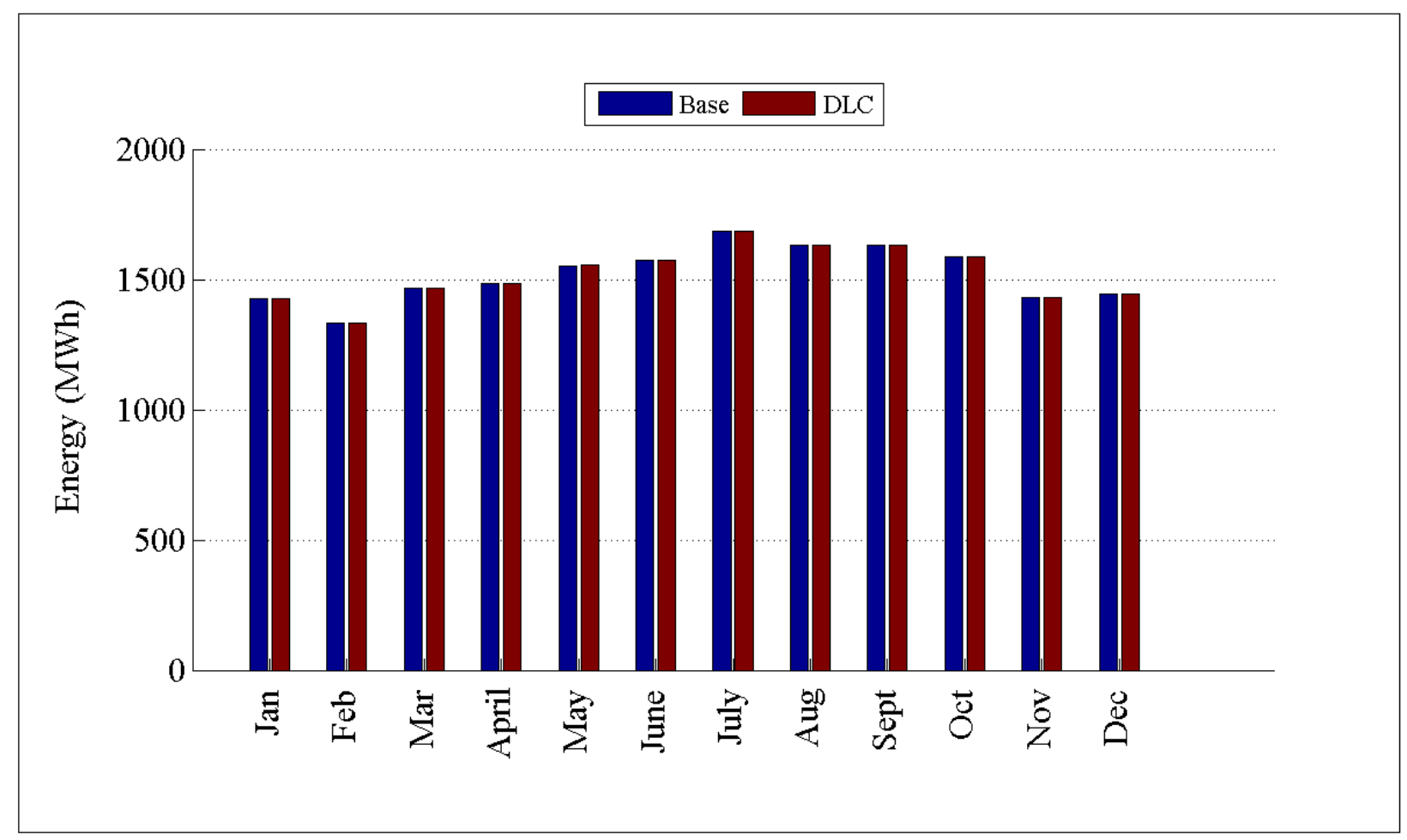

Figure 3.6: Comparison of energy consumption by month for GC-12.47-1_R1 


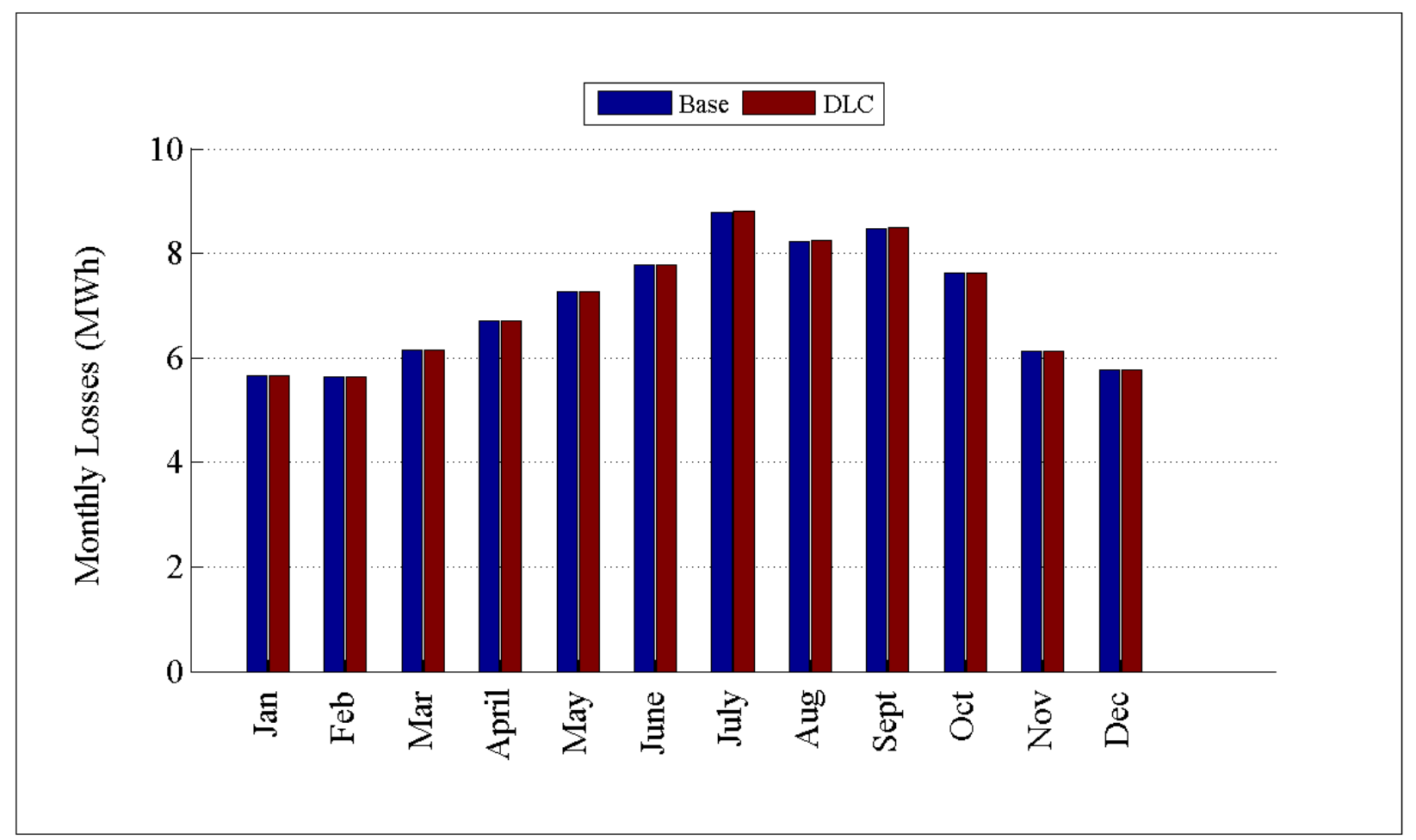

Figure 3.7: Comparison of losses by month for GC-12.47-1_R1

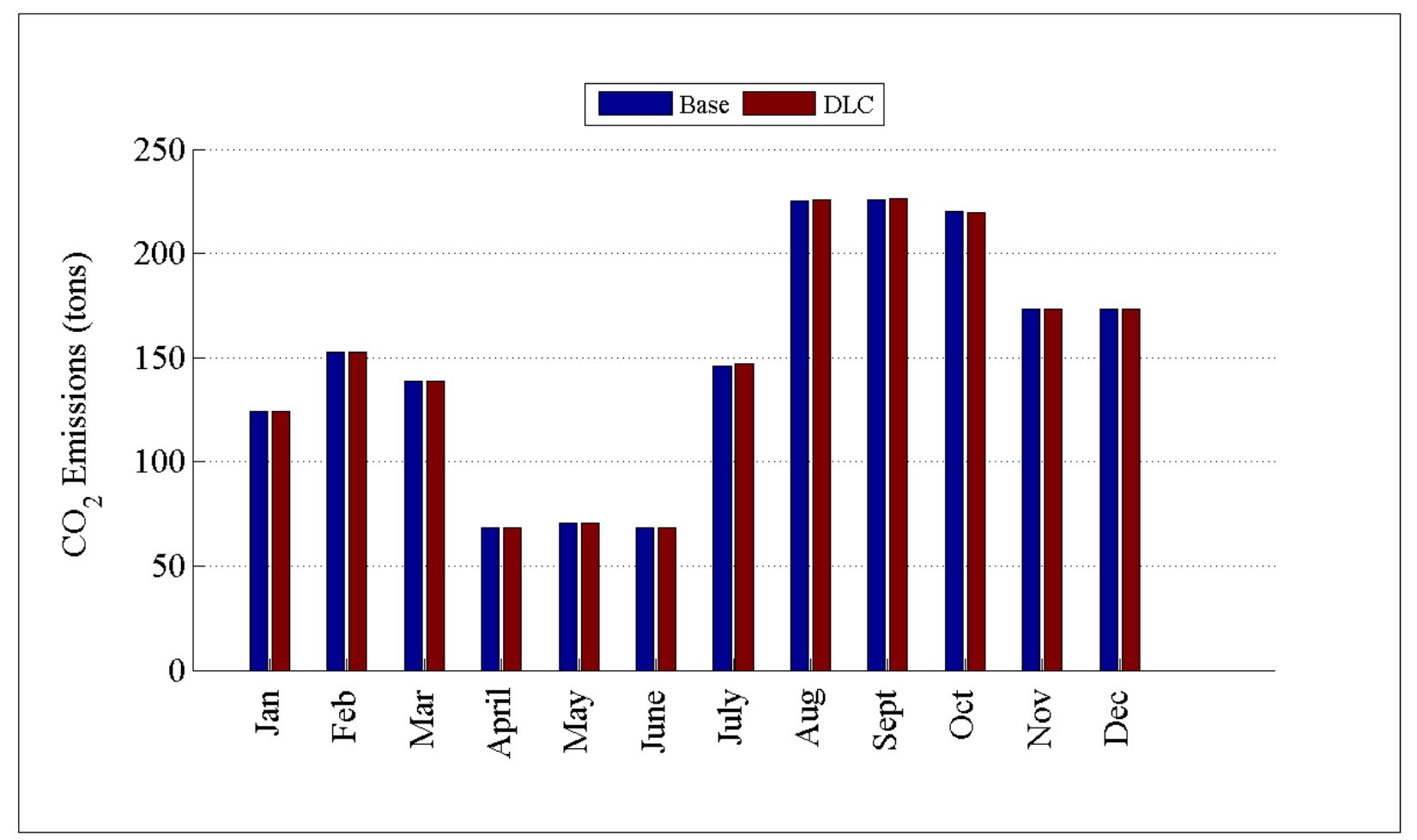

Figure 3.8: Comparison of $\mathrm{CO}_{2}$ emissions by month for GC-12.47_R1 


\section{SGIG Impact Metric Values}

Specific metric impact values are filled in for the metrics identified in sections 2.1.1 and 2.2.1, by feeder. The raw metric values, by technology and region are in Appendix E.

\subsection{TOU and CPP Impact Metrics}


Table 4.1: TOU without enabling technologies impact metrics for region 1

\begin{tabular}{|c|c|c|c|c|c|c|c|c|}
\hline Index & $\Delta$ Metric & Units & 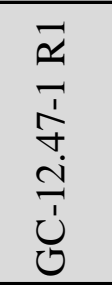 & 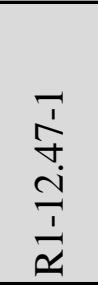 & 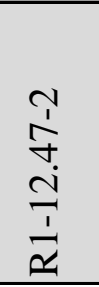 & 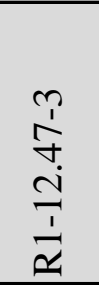 & 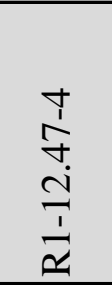 & $\begin{array}{l}7 \\
8 \\
\dot{8} \\
\stackrel{1}{\alpha} \\
\frac{1}{\alpha}\end{array}$ \\
\hline 1 & $\begin{array}{l}\text { Hourly Customer } \\
\text { Electricity Usage }\end{array}$ & $\mathrm{kWh}$ & 0.37 & -1.37 & -1.61 & 0.31 & -1.53 & 0.07 \\
\hline 2 & $\begin{array}{l}\text { Monthly Customer } \\
\text { Electricity Usage }\end{array}$ & MWh & 0.27 & -1.00 & -1.18 & 0.23 & -1.11 & 0.05 \\
\hline \multirow{10}{*}{3} & Peak Generation & $\mathrm{kW}$ & 101.65 & -72.68 & 1.52 & -10.39 & -155.82 & -13.30 \\
\hline & Nuclear & $\%$ & 0.00 & 0.00 & 0.00 & 0.00 & 0.59 & 0.00 \\
\hline & Solar & $\%$ & 0.00 & 0.00 & 0.00 & 0.00 & 0.04 & 0.00 \\
\hline & Bio & $\%$ & 0.00 & 0.00 & 0.00 & 0.00 & -0.05 & 0.00 \\
\hline & Wind & $\%$ & 0.00 & 0.00 & 0.00 & 0.00 & 0.52 & 0.00 \\
\hline & Coal & $\%$ & 0.00 & 0.00 & 0.00 & 0.00 & -1.50 & 0.00 \\
\hline & Hydroelectric & $\%$ & 0.00 & 0.00 & 0.00 & 0.00 & 10.56 & 0.00 \\
\hline & Natural Gas & $\%$ & 0.00 & 0.00 & 0.00 & 0.00 & -9.86 & 0.00 \\
\hline & Geothermal & $\%$ & 0.00 & -0.64 & 0.00 & -0.47 & -2.99 & -0.22 \\
\hline & Petroleum & $\%$ & 1.91 & -0.35 & 0.06 & -0.35 & -0.38 & -0.35 \\
\hline 4 & Peak Load & $\mathrm{kW}$ & 101.65 & -72.68 & 1.52 & -10.39 & -155.82 & -13.30 \\
\hline 7 & $\begin{array}{l}\text { Annual Electricity } \\
\text { Production }\end{array}$ & $\mathrm{MWh}$ & 3.26 & -14.14 & -14.85 & 2.73 & -14.75 & 0.49 \\
\hline 12 & $\mathrm{CO} 2$ Emissions & Tons & 1.00 & -34.42 & -16.83 & -0.42 & -30.92 & -2.00 \\
\hline \multirow{3}{*}{13} & SOx Emissions & Tons & 0.00 & 0.00 & 0.00 & 0.00 & 0.00 & 0.00 \\
\hline & NOx Emissions & Tons & 0.00 & 0.00 & 0.00 & 0.00 & 0.00 & 0.00 \\
\hline & PM-10 Emissions & Tons & 0.00 & 0.00 & 0.00 & 0.00 & 0.00 & 0.00 \\
\hline \multirow{2}{*}{21} & Feeder Real Load & $\mathrm{kW}$ & 0.37 & -1.61 & -1.70 & 0.31 & -1.68 & 0.06 \\
\hline & Feeder Reactive Load & kVAR & 0.27 & 4.48 & 1.52 & 0.26 & 1.90 & 0.33 \\
\hline 29 & Dis tribution Losses & $\%$ & 0.00 & -0.01 & 0.00 & 0.00 & -0.01 & 0.00 \\
\hline 30 & $\begin{array}{l}\text { Distribution Power } \\
\text { Factor }\end{array}$ & $\mathrm{pf}$ & 0.000 & 0.000 & 0.001 & 0.000 & 0.000 & 0.000 \\
\hline 39 & $\mathrm{CO} 2$ Emis sions & Tons & 1.01 & -35.49 & -17.39 & -0.43 & -31.42 & -2.04 \\
\hline \multirow{3}{*}{40} & SOx Emis sions & Tons & 0.00 & 0.00 & 0.00 & 0.00 & 0.00 & 0.00 \\
\hline & NOx Emissions & Tons & 0.00 & 0.00 & 0.00 & 0.00 & 0.00 & 0.00 \\
\hline & PM-10 Emissions & Tons & 0.00 & -0.01 & 0.00 & 0.00 & 0.00 & 0.00 \\
\hline
\end{tabular}


Table 4.2: TOU without enabling technologies impact metrics for region 2

\begin{tabular}{|c|c|c|c|c|c|c|c|c|}
\hline Index & $\Delta$ Metric & Units & 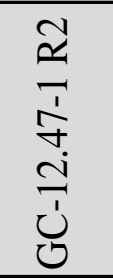 & 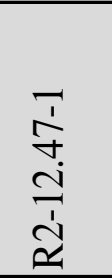 & 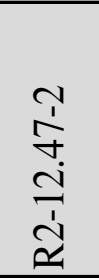 & 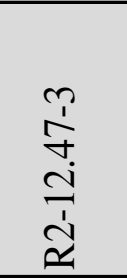 & 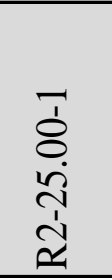 & $\begin{array}{l}7 \\
\delta \\
\ddot{8} \\
\tilde{1} \\
\tilde{d}\end{array}$ \\
\hline 1 & $\begin{array}{l}\text { Hourly Customer } \\
\text { Electricity Usage }\end{array}$ & $\mathrm{kWh}$ & -0.01 & 0.27 & 4.69 & 2.30 & -2.10 & 1.70 \\
\hline 2 & $\begin{array}{l}\text { Monthly Customer } \\
\text { Electricity Usage }\end{array}$ & MWh & 0.00 & 0.19 & 3.42 & 1.68 & -1.53 & 1.24 \\
\hline \multirow{10}{*}{3} & Peak Generation & $\mathrm{kW}$ & -17.11 & -95.34 & -3.68 & -101.81 & 147.00 & -82.60 \\
\hline & Nuclear & $\%$ & 0.00 & 0.00 & 0.00 & -1.62 & 1.62 & 0.00 \\
\hline & Solar & $\%$ & 0.00 & 0.00 & 0.00 & 0.00 & 0.00 & 0.00 \\
\hline & Bio & $\%$ & 0.00 & 0.00 & 0.00 & -0.02 & 0.02 & 0.00 \\
\hline & Wind & $\%$ & 0.00 & 0.00 & 0.00 & -0.29 & 0.29 & 0.00 \\
\hline & Coal & $\%$ & 0.00 & 0.00 & 0.00 & 1.64 & -1.64 & 0.00 \\
\hline & Hydroelectric & $\%$ & 0.00 & -1.02 & 0.00 & -2.07 & 1.63 & -0.15 \\
\hline & Natural Gas & $\%$ & 0.00 & 0.00 & 0.00 & 1.86 & -1.86 & 0.00 \\
\hline & Geothermal & $\%$ & 0.00 & -0.07 & 0.00 & -0.07 & 0.00 & -0.07 \\
\hline & Petroleum & $\%$ & -0.30 & -0.43 & -0.06 & -0.37 & 1.46 & -0.43 \\
\hline 4 & Peak Load & $\mathrm{kW}$ & -17.11 & -95.34 & -3.68 & -101.81 & 147.00 & -82.60 \\
\hline 7 & $\begin{array}{l}\text { Annual Electricity } \\
\text { Production }\end{array}$ & MWh & -0.05 & 2.19 & 40.90 & 18.55 & -19.59 & 14.95 \\
\hline 12 & $\mathrm{CO} 2$ Emis sions & Tons & 0.03 & -0.57 & 37.54 & 12.26 & -7.62 & 9.88 \\
\hline \multirow{3}{*}{13} & SOx Emis sions & Tons & 0.00 & 0.00 & 0.02 & 0.01 & 0.01 & 0.01 \\
\hline & NOx Emis sions & Tons & 0.00 & 0.00 & 0.01 & 0.01 & 0.00 & 0.00 \\
\hline & PM-10 Emis sions & Tons & 0.00 & 0.00 & 0.01 & 0.00 & 0.00 & 0.00 \\
\hline \multirow[b]{2}{*}{21} & Feeder Real Load & $\mathrm{kW}$ & -0.01 & 0.25 & 4.67 & 2.12 & -2.24 & 1.71 \\
\hline & \begin{tabular}{|l} 
Feeder Reactive \\
Load \\
\end{tabular} & kVAR & 0.17 & 0.89 & 1.56 & 2.37 & 2.08 & 2.10 \\
\hline 29 & Distribution Losses & $\%$ & 0.00 & 0.00 & -0.01 & -0.01 & 0.00 & 0.00 \\
\hline 30 & $\begin{array}{l}\text { Distribution Power } \\
\text { Factor }\end{array}$ & $\mathrm{pf}$ & 0.000 & 0.000 & 0.000 & 0.000 & 0.000 & 0.000 \\
\hline 39 & $\mathrm{CO} 2$ Emis sions & Tons & 0.02 & -0.66 & 37.79 & 11.56 & -8.20 & 9.92 \\
\hline \multirow{3}{*}{40} & SOx Emis sions & Tons & 0.00 & 0.00 & 0.02 & 0.01 & 0.01 & 0.01 \\
\hline & NOx Emis sions & Tons & 0.00 & 0.00 & 0.01 & 0.01 & 0.00 & 0.00 \\
\hline & PM-10 Emis sions & Tons & 0.00 & 0.00 & 0.01 & 0.00 & 0.00 & 0.00 \\
\hline
\end{tabular}


Table 4.3: TOU without enabling technologies impact metrics for region 3

\begin{tabular}{|c|c|c|c|c|c|c|}
\hline Index & $\Delta$ Metric & Units & 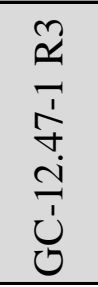 & 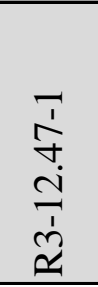 & 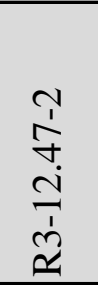 & 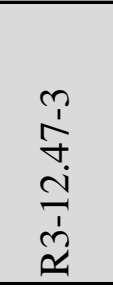 \\
\hline 1 & $\begin{array}{l}\text { Hourly Customer } \\
\text { Electricity Usage }\end{array}$ & $\mathrm{kWh}$ & -1.17 & -4.26 & 0.07 & -13.94 \\
\hline 2 & $\begin{array}{l}\text { Monthly Customer } \\
\text { Electricity Usage }\end{array}$ & MWh & -0.86 & -3.11 & 0.05 & -10.18 \\
\hline \multirow{10}{*}{3} & Peak Generation & $\mathrm{kW}$ & 88.61 & -65.66 & -40.22 & -1.16 \\
\hline & Nuclear & $\%$ & 1.07 & 0.00 & 0.00 & 0.00 \\
\hline & Solar & $\%$ & 0.00 & 0.00 & 0.00 & 0.00 \\
\hline & Bio & $\%$ & 0.02 & 0.00 & 0.00 & 0.00 \\
\hline & Wind & $\%$ & 0.40 & 0.00 & 0.00 & 0.00 \\
\hline & Coal & $\%$ & 1.28 & 0.00 & 0.00 & 0.00 \\
\hline & Hydroelectric & $\%$ & 0.82 & 0.00 & 0.00 & 0.00 \\
\hline & Natural Gas & $\%$ & -3.79 & 0.00 & 0.00 & 0.00 \\
\hline & Geothermal & $\%$ & 0.15 & -0.45 & -0.66 & 0.00 \\
\hline & Petroleum & $\%$ & 1.48 & -0.25 & -0.25 & -0.01 \\
\hline 4 & Peak Load & $\mathrm{kW}$ & 88.61 & -65.66 & -40.22 & -1.16 \\
\hline 7 & $\begin{array}{l}\text { Annual Electricity } \\
\text { Production }\end{array}$ & $\mathrm{MWh}$ & -10.35 & -38.45 & 0.60 & -125.55 \\
\hline 12 & $\mathrm{CO} 2$ Emissions & Tons & -4.36 & 11.04 & 0.34 & -31.35 \\
\hline \multirow{3}{*}{13} & SOx Emis sions & Tons & 0.00 & 0.02 & 0.00 & 0.02 \\
\hline & NOx Emis sions & Tons & 0.00 & 0.01 & 0.00 & 0.01 \\
\hline & PM-10 Emissions & Tons & 0.00 & 0.00 & 0.00 & 0.00 \\
\hline \multirow[b]{2}{*}{21} & Feeder Real Load & $\mathrm{kW}$ & -1.18 & -4.39 & 0.07 & -14.33 \\
\hline & $\begin{array}{l}\text { Feeder Reactive } \\
\text { Load } \\
\end{array}$ & kVAR & -0.16 & -0.08 & 0.29 & -1.15 \\
\hline 29 & Distribution Losses & $\%$ & 0.00 & 0.00 & 0.00 & 0.00 \\
\hline 30 & $\begin{array}{l}\text { Distribution Power } \\
\text { Factor }\end{array}$ & $\mathrm{pf}$ & 0.000 & 0.000 & 0.000 & 0.000 \\
\hline 39 & $\mathrm{CO} 2$ Emissions & Tons & -4.41 & 10.95 & 0.31 & -31.76 \\
\hline \multirow{3}{*}{40} & SOx Emis sions & Tons & 0.00 & 0.02 & 0.00 & 0.02 \\
\hline & NOx Emissions & Tons & 0.00 & 0.01 & 0.00 & 0.01 \\
\hline & PM-10 Emissions & Tons & 0.00 & 0.00 & 0.00 & 0.00 \\
\hline
\end{tabular}


Table 4.4: TOU without enabling technologies impact metrics for region 4

\begin{tabular}{|c|c|c|c|c|c|c|}
\hline Index & $\Delta$ Metric & Units & 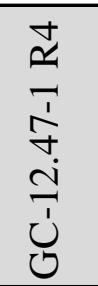 & 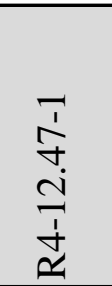 & 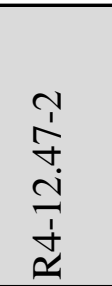 & 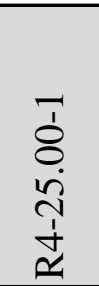 \\
\hline 1 & $\begin{array}{l}\text { Hourly Customer } \\
\text { Electricity Usage }\end{array}$ & $\mathrm{kWh}$ & -0.13 & -3.94 & -3.57 & -1.65 \\
\hline 2 & $\begin{array}{l}\text { Monthly Customer } \\
\text { Electricity Usage } \\
\end{array}$ & $\mathrm{MWh}$ & -0.09 & -2.88 & -2.60 & -1.21 \\
\hline \multirow{10}{*}{3} & Peak Generation & $\mathrm{kW}$ & 31.21 & -0.36 & -30.13 & -3.88 \\
\hline & Nuclear & $\%$ & 0.00 & 0.00 & -1.13 & 0.00 \\
\hline & Solar & $\%$ & 0.00 & 0.00 & 0.00 & 0.00 \\
\hline & Bio & $\%$ & 0.00 & 0.00 & -0.03 & 0.00 \\
\hline & Wind & $\%$ & 0.00 & 0.00 & 0.05 & 0.00 \\
\hline & Coal & $\%$ & 0.00 & 0.00 & 0.86 & 0.00 \\
\hline & Hydroelectric & $\%$ & 0.00 & 0.00 & 0.23 & -0.08 \\
\hline & Natural Gas & $\%$ & 0.00 & 0.00 & -0.10 & 0.00 \\
\hline & Geothermal & $\%$ & 0.00 & 0.00 & 0.00 & 0.00 \\
\hline & Petroleum & $\%$ & 0.50 & -0.01 & 3.77 & -0.33 \\
\hline 4 & Peak Load & $\mathrm{kW}$ & 31.21 & -0.36 & -30.13 & -3.88 \\
\hline 7 & $\begin{array}{l}\text { Annual Electricity } \\
\text { Production }\end{array}$ & $\mathrm{MWh}$ & -1.16 & -35.29 & -31.67 & -14.69 \\
\hline 12 & $\mathrm{CO} 2$ Emissions & Tons & 0.47 & -24.55 & -30.01 & -14.03 \\
\hline \multirow{3}{*}{13} & SOx Emissions & Tons & 0.00 & -0.01 & -0.01 & -0.01 \\
\hline & NOx Emissions & Tons & 0.00 & -0.01 & -0.01 & 0.00 \\
\hline & PM-10 Emissions & Tons & 0.00 & 0.00 & 0.00 & 0.00 \\
\hline \multirow{2}{*}{21} & Feeder Real Load & $\mathrm{kW}$ & -0.13 & -4.03 & -3.62 & -1.68 \\
\hline & Feeder Reactive Load & kVAR & 0.13 & 0.12 & 0.19 & 0.11 \\
\hline 29 & Distribution Losses & $\%$ & 0.00 & 0.00 & 0.00 & 0.01 \\
\hline 30 & $\begin{array}{l}\text { Distribution Power } \\
\text { Factor }\end{array}$ & $\mathrm{pf}$ & 0.000 & 0.000 & 0.000 & 0.000 \\
\hline 39 & $\mathrm{CO} 2$ Emissions & Tons & 0.45 & -25.10 & -30.55 & -14.30 \\
\hline \multirow{3}{*}{40} & SOx Emissions & Tons & 0.00 & -0.01 & -0.01 & -0.01 \\
\hline & NOx Emis sions & Tons & 0.00 & -0.01 & -0.01 & 0.00 \\
\hline & PM-10 Emissions & Tons & 0.00 & 0.00 & 0.00 & 0.00 \\
\hline
\end{tabular}


Table 4.5: TOU without enabling technologies impact metrics for region 5

\begin{tabular}{|c|c|c|c|c|c|c|c|c|c|c|}
\hline Index & $\Delta$ Metric & Units & 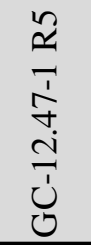 & \begin{tabular}{l}
$\overrightarrow{1}$ \\
\multirow{+}{*}{} \\
$\stackrel{1}{1}$ \\
$\dot{1}$ \\
$\underline{v}$
\end{tabular} & 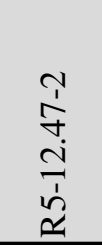 & 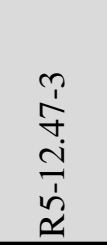 & 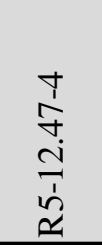 & 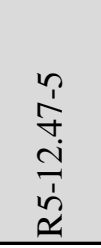 & 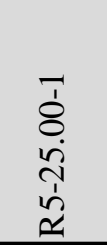 & 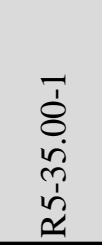 \\
\hline 1 & $\begin{array}{l}\text { Hourly Customer } \\
\text { Electricity Usage }\end{array}$ & $\mathrm{kWh}$ & 0.02 & -39.49 & -11.38 & -75.88 & -39.82 & -62.00 & -95.73 & -96.12 \\
\hline 2 & $\begin{array}{l}\text { Monthly Customer } \\
\text { Electricity Usage }\end{array}$ & MWh & 0.01 & -28.83 & -8.31 & -55.39 & -29.07 & -45.26 & -69.88 & -70.17 \\
\hline \multirow{10}{*}{3} & Peak Generation & $\mathrm{kW}$ & -27.48 & -186.43 & -62.41 & -116.20 & -11.52 & -75.37 & -366.90 & -160.10 \\
\hline & Nuclear & $\%$ & -0.32 & 0.00 & 0.00 & 0.00 & 0.00 & 0.00 & -0.32 & 0.00 \\
\hline & Solar & $\%$ & 0.00 & 0.00 & 0.00 & 0.00 & 0.00 & 0.00 & 0.00 & 0.00 \\
\hline & Bio & $\%$ & -0.02 & 0.00 & 0.00 & 0.00 & 0.00 & 0.00 & -0.02 & 0.00 \\
\hline & Wind & $\%$ & 0.26 & 0.00 & 0.00 & 0.00 & 0.00 & 0.00 & 0.26 & 0.00 \\
\hline & Coal & $\%$ & 0.20 & 0.00 & 0.00 & 0.00 & 0.00 & 0.00 & 0.20 & 0.00 \\
\hline & Hydroelectric & $\%$ & 0.15 & -0.11 & 0.00 & 0.00 & 0.00 & 0.00 & 0.15 & 0.00 \\
\hline & Natural Gas & $\%$ & -0.39 & 0.00 & 0.00 & 0.00 & 0.00 & 0.00 & -0.39 & 0.00 \\
\hline & Geothermal & $\%$ & 0.00 & 0.00 & 0.00 & 0.00 & 0.00 & 0.00 & 0.00 & 0.00 \\
\hline & Petroleum & $\%$ & 2.08 & -1.86 & -1.25 & -1.12 & -0.15 & -0.83 & -1.00 & -1.29 \\
\hline 4 & Peak Load & $\mathrm{kW}$ & -27.48 & -186.43 & -62.41 & -116.20 & -11.52 & -75.37 & -366.90 & -160.10 \\
\hline 7 & $\begin{array}{l}\text { Annual Electricity } \\
\text { Production }\end{array}$ & MWh & 0.16 & -351.35 & -104.21 & -711.58 & -356.70 & -561.15 & -853.38 & -853.10 \\
\hline 12 & $\mathrm{CO} 2$ Emis sions & Tons & 0.83 & -384.49 & -105.51 & -654.09 & -374.46 & -558.86 & -856.80 & -854.41 \\
\hline \multirow{3}{*}{13} & SOx Emissions & Tons & 0.00 & -0.19 & -0.05 & -0.29 & -0.18 & -0.26 & -0.40 & -0.40 \\
\hline & NOx Emis sions & Tons & 0.00 & -0.11 & -0.03 & -0.18 & -0.11 & -0.16 & -0.24 & -0.24 \\
\hline & PM-10 Emis sions & Tons & 0.00 & -0.06 & -0.02 & -0.10 & -0.06 & -0.08 & -0.13 & -0.13 \\
\hline \multirow{2}{*}{21} & Feeder Real Load & $\mathrm{kW}$ & 0.02 & -40.11 & -11.90 & -81.23 & -40.72 & -64.06 & -97.42 & -97.39 \\
\hline & Feeder Reactive Load & kVAR & 0.18 & -9.55 & -2.78 & -29.49 & -9.24 & -17.03 & -20.55 & -19.66 \\
\hline 29 & Distribution Losses & $\%$ & 0.00 & 0.00 & -0.01 & -0.04 & 0.00 & -0.01 & -0.01 & 0.00 \\
\hline 30 & $\begin{array}{l}\text { Distribution Power } \\
\text { Factor }\end{array}$ & $\mathrm{pf}$ & 0.000 & 0.000 & 0.000 & 0.000 & 0.000 & 0.000 & 0.000 & 0.000 \\
\hline 39 & $\mathrm{CO} 2$ Emissions & Tons & 0.83 & -389.59 & -108.61 & -690.10 & -382.19 & -574.08 & -869.99 & -865.58 \\
\hline \multirow{3}{*}{40} & SOx Emis sions & Tons & 0.00 & -0.20 & -0.05 & -0.31 & -0.19 & -0.27 & -0.41 & -0.40 \\
\hline & NOx Emissions & Tons & 0.00 & -0.12 & -0.03 & -0.19 & -0.11 & -0.16 & -0.25 & -0.24 \\
\hline & PM-10 Emis sions & Tons & 0.00 & -0.06 & -0.02 & -0.10 & -0.06 & -0.09 & -0.13 & -0.13 \\
\hline
\end{tabular}


Table 4.6: TOU with enabling technologies impact metrics for region 1

\begin{tabular}{|c|c|c|c|c|c|c|c|c|}
\hline Index & $\Delta$ Metric & Units & 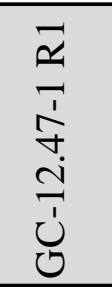 & 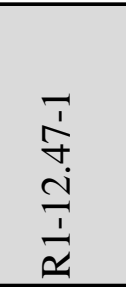 & $\begin{array}{l}\stackrel{N}{\frac{1}{+}} \\
\stackrel{1}{c} \\
\frac{1}{\vec{a}}\end{array}$ & 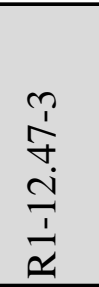 & 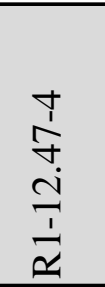 & $\begin{array}{l}F \\
\delta \\
\ddot{d} \\
\hat{i} \\
\frac{a}{\alpha}\end{array}$ \\
\hline 1 & $\begin{array}{l}\text { Hourly Customer } \\
\text { Electricity Usage }\end{array}$ & $\mathrm{kWh}$ & -12.76 & -15.25 & -6.49 & -2.60 & -8.96 & -6.80 \\
\hline 2 & \begin{tabular}{|l|} 
Monthly Customer \\
Electricity Usage \\
\end{tabular} & MWh & -9.32 & -11.13 & -4.74 & -1.90 & -6.54 & -4.96 \\
\hline \multirow{10}{*}{3} & Peak Generation & $\mathrm{kW}$ & -47.64 & -184.78 & -32.29 & -37.72 & -45.70 & -75.87 \\
\hline & Nuclear & $\%$ & 0.00 & -0.59 & 0.00 & -0.59 & 0.59 & 0.00 \\
\hline & Solar & $\%$ & 0.00 & -0.04 & 0.00 & -0.04 & 0.04 & 0.00 \\
\hline & Bio & $\%$ & 0.00 & 0.05 & 0.00 & 0.05 & -0.05 & 0.00 \\
\hline & Wind & $\%$ & 0.00 & -0.52 & 0.00 & -0.52 & 0.52 & 0.00 \\
\hline & Coal & $\%$ & 0.00 & 1.50 & 0.00 & 1.50 & -1.50 & -0.08 \\
\hline & Hydroelectric & $\%$ & 0.00 & -10.56 & 0.00 & -10.56 & 10.56 & 0.00 \\
\hline & Natural Gas & $\%$ & 0.00 & 9.86 & 0.00 & 9.86 & -9.86 & 0.00 \\
\hline & Geothermal & $\%$ & -0.55 & 0.27 & -0.86 & 0.27 & -0.81 & -2.84 \\
\hline & Petroleum & $\%$ & -0.35 & 1.22 & -0.35 & 1.15 & -0.38 & -0.35 \\
\hline 4 & Peak Load & $\mathrm{kW}$ & -47.64 & -184.78 & -32.29 & -37.72 & -45.70 & -75.87 \\
\hline 7 & \begin{tabular}{|l|} 
Annual Electricity \\
Production
\end{tabular} & MWh & -112.53 & -139.27 & -58.70 & -23.13 & -82.03 & -61.54 \\
\hline 12 & $\mathrm{CO} 2$ Emis sions & Tons & -58.04 & -88.63 & -36.35 & -12.89 & -75.47 & -34.40 \\
\hline \multirow{3}{*}{13} & SOx Emissions & Tons & -0.01 & -0.01 & 0.00 & 0.00 & -0.01 & 0.00 \\
\hline & NOx Emis sions & Tons & -0.01 & -0.01 & 0.00 & 0.00 & -0.01 & 0.00 \\
\hline & PM-10 Emissions & Tons & -0.01 & -0.01 & -0.01 & 0.00 & -0.01 & 0.00 \\
\hline \multirow[b]{2}{*}{21} & Feeder Real Load & $\mathrm{kW}$ & -12.85 & -15.90 & -6.70 & -2.64 & -9.36 & -7.03 \\
\hline & \begin{tabular}{|l|} 
Feeder Reactive \\
Load \\
\end{tabular} & kVAR & -3.29 & 4.81 & 1.81 & -0.46 & 1.24 & -1.70 \\
\hline 29 & Distribution Losses & $\%$ & 0.00 & -0.01 & 0.00 & -0.01 & -0.01 & -0.01 \\
\hline 30 & \begin{tabular}{|l|} 
Distribution Power \\
Factor \\
\end{tabular} & $\mathrm{pf}$ & 0.000 & 0.000 & 0.001 & 0.000 & 0.000 & 0.000 \\
\hline 39 & $\mathrm{CO} 2$ Emissions & Tons & -58.21 & -91.15 & -37.50 & -12.99 & -76.65 & -35.01 \\
\hline \multirow{3}{*}{40} & SOx Emissions & Tons & -0.01 & -0.01 & 0.00 & 0.00 & -0.01 & 0.00 \\
\hline & NOx Emissions & Tons & -0.01 & -0.01 & 0.00 & 0.00 & -0.01 & 0.00 \\
\hline & PM-10 Emis sions & Tons & -0.01 & -0.01 & -0.01 & 0.00 & -0.01 & -0.01 \\
\hline
\end{tabular}


Table 4.7: TOU with enabling technologies impact metrics for region 2

\begin{tabular}{|c|c|c|c|c|c|c|c|c|}
\hline Index & $\Delta$ Metric & Units & 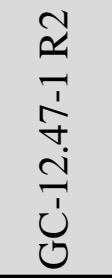 & 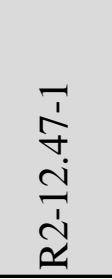 & 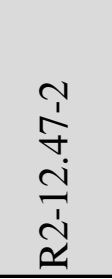 & 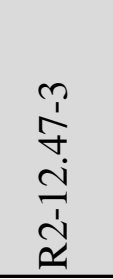 & 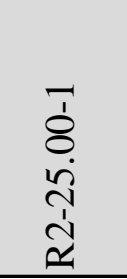 & $\begin{array}{l}7 \\
\delta \\
\dot{\delta} \\
\tilde{d} \\
\dot{1} \\
\alpha\end{array}$ \\
\hline 1 & $\begin{array}{l}\text { Hourly Customer } \\
\text { Electricity Usage }\end{array}$ & $\mathrm{kWh}$ & -4.38 & 0.02 & 11.53 & 14.53 & -1.53 & -5.41 \\
\hline 2 & $\begin{array}{l}\text { Monthly Customer } \\
\text { Electricity Usage }\end{array}$ & MWh & -3.20 & 0.02 & 8.42 & 10.60 & -1.11 & -3.95 \\
\hline \multirow{10}{*}{3} & Peak Generation & $\mathrm{kW}$ & 596.41 & -97.48 & 469.31 & 940.24 & $1,339.60$ & -214.20 \\
\hline & Nuclear & $\%$ & 0.00 & 0.00 & 0.00 & -1.62 & 0.00 & 0.00 \\
\hline & Solar & $\%$ & 0.00 & 0.00 & 0.00 & 0.00 & 0.00 & 0.00 \\
\hline & Bio & $\%$ & 0.00 & 0.00 & 0.00 & -0.02 & 0.00 & 0.00 \\
\hline & Wind & $\%$ & 0.00 & 0.00 & 0.00 & -0.29 & 0.00 & 0.00 \\
\hline & Coal & $\%$ & 0.00 & 0.00 & 0.00 & 1.64 & 0.00 & 0.00 \\
\hline & Hydroelectric & $\%$ & 0.00 & -1.05 & 0.00 & -1.63 & 0.00 & -1.19 \\
\hline & Natural Gas & $\%$ & 0.00 & 0.00 & 0.00 & 1.86 & 0.00 & 0.00 \\
\hline & Geothermal & $\%$ & 0.00 & -0.07 & 0.00 & 0.00 & 0.00 & -0.07 \\
\hline & Petroleum & $\%$ & 10.37 & -0.43 & 8.12 & 11.33 & 7.95 & -0.43 \\
\hline 4 & Peak Load & $\mathrm{kW}$ & 596.41 & -97.48 & 469.31 & 940.24 & $1,339.60$ & -214.20 \\
\hline 7 & $\begin{array}{l}\text { Annual Electricity } \\
\text { Production }\end{array}$ & MWh & -38.72 & -0.58 & 102.15 & 128.00 & -14.69 & -48.60 \\
\hline 12 & $\mathrm{CO} 2$ Emissions & Tons & -31.42 & 5.22 & 104.14 & 129.22 & -1.92 & -19.75 \\
\hline \multirow{3}{*}{13} & SOx Emis sions & Tons & -0.01 & 0.01 & 0.06 & 0.07 & 0.02 & 0.00 \\
\hline & NOx Emissions & Tons & -0.01 & 0.00 & 0.04 & 0.04 & 0.01 & 0.00 \\
\hline & PM-10 Emissions & Tons & -0.01 & 0.00 & 0.01 & 0.02 & 0.00 & 0.00 \\
\hline \multirow[b]{2}{*}{21} & Feeder Real Load & $\mathrm{kW}$ & -4.42 & -0.07 & 11.66 & 14.61 & -1.68 & -5.55 \\
\hline & \begin{tabular}{|l} 
Feeder Reactive \\
Load \\
\end{tabular} & kVAR & -1.04 & 0.86 & 4.58 & 8.93 & 2.63 & -0.17 \\
\hline 29 & Distribution Losses & $\%$ & 0.00 & 0.00 & 0.00 & -0.01 & 0.00 & 0.00 \\
\hline 30 & \begin{tabular}{|l|}
$\begin{array}{l}\text { Distribution Power } \\
\text { Factor }\end{array}$ \\
\end{tabular} & $\mathrm{pf}$ & 0.000 & 0.000 & 0.000 & 0.000 & 0.000 & 0.000 \\
\hline 39 & CO2 Emissions & Tons & -31.59 & 4.92 & 105.73 & 131.21 & -2.51 & -20.26 \\
\hline \multirow{3}{*}{40} & SOx Emissions & Tons & -0.01 & 0.01 & 0.06 & 0.08 & 0.02 & 0.00 \\
\hline & NOx Emis sions & Tons & -0.01 & 0.00 & 0.04 & 0.04 & 0.01 & 0.00 \\
\hline & PM-10 Emissions & Tons & -0.01 & 0.00 & 0.01 & 0.02 & 0.00 & 0.00 \\
\hline
\end{tabular}


Table 4.8: TOU with enabling technologies impact metrics for region 3

\begin{tabular}{|c|c|c|c|c|c|c|}
\hline Index & $\Delta$ Metric & Units & 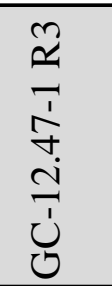 & 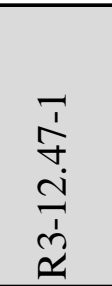 & 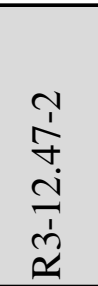 & 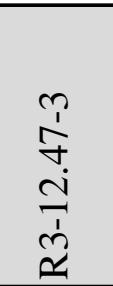 \\
\hline 1 & $\begin{array}{l}\text { Hourly Customer } \\
\text { Electricity Usage }\end{array}$ & $\mathrm{kWh}$ & -10.05 & 2.38 & -5.59 & 20.51 \\
\hline 2 & \begin{tabular}{|l|} 
Monthly Customer \\
Electricity Usage
\end{tabular} & MWh & -7.34 & 1.73 & -4.08 & 14.98 \\
\hline \multirow{10}{*}{3} & Peak Generation & $\mathrm{kW}$ & 106.04 & -117.73 & -88.19 & -132.52 \\
\hline & Nuclear & $\%$ & 0.00 & 0.00 & 0.00 & 0.00 \\
\hline & Solar & $\%$ & 0.00 & 0.00 & 0.00 & 0.00 \\
\hline & Bio & $\%$ & 0.00 & 0.00 & 0.00 & 0.00 \\
\hline & Wind & $\%$ & 0.00 & 0.00 & 0.00 & 0.00 \\
\hline & Coal & $\%$ & 0.00 & 0.00 & 0.00 & 0.00 \\
\hline & Hydroelectric & $\%$ & 0.00 & 0.00 & -0.34 & 0.00 \\
\hline & Natural Gas & $\%$ & 0.00 & 0.00 & 0.00 & 0.00 \\
\hline & Geothermal & $\%$ & 0.00 & -1.01 & -1.40 & -1.32 \\
\hline & Petroleum & $\%$ & 1.61 & -0.25 & -0.25 & -0.25 \\
\hline 4 & Peak Load & $\mathrm{kW}$ & 106.04 & -117.73 & -88.19 & -132.52 \\
\hline 7 & \begin{tabular}{|l|} 
Annual Electricity \\
Production
\end{tabular} & MWh & -88.92 & 19.36 & -50.12 & 182.92 \\
\hline 12 & $\mathrm{CO} 2$ Emissions & Tons & -17.09 & 123.08 & -7.61 & 197.96 \\
\hline \multirow{3}{*}{13} & SOx Emis sions & Tons & 0.02 & 0.10 & 0.01 & 0.10 \\
\hline & NOx Emissions & Tons & 0.01 & 0.05 & 0.01 & 0.06 \\
\hline & PM-10 Emissions & Tons & 0.00 & 0.02 & 0.00 & 0.03 \\
\hline \multirow[b]{2}{*}{21} & Feeder Real Load & $\mathrm{kW}$ & -10.15 & 2.21 & -5.72 & 20.88 \\
\hline & $\begin{array}{l}\text { Feeder Reactive } \\
\text { Load } \\
\end{array}$ & kVAR & -2.66 & 1.11 & -1.50 & 10.35 \\
\hline 29 & Distribution Losses & $\%$ & 0.00 & -0.01 & -0.01 & -0.01 \\
\hline 30 & \begin{tabular}{|l|} 
Distribution Power \\
Factor
\end{tabular} & $\mathrm{pf}$ & 0.000 & 0.000 & 0.000 & 0.000 \\
\hline 39 & $\mathrm{CO} 2$ Emis sions & Tons & -17.57 & 124.07 & -8.23 & 202.53 \\
\hline \multirow{3}{*}{40} & SOx Emis sions & Tons & 0.02 & 0.10 & 0.01 & 0.10 \\
\hline & NOx Emis sions & Tons & 0.01 & 0.05 & 0.01 & 0.06 \\
\hline & PM-10 Emissions & Tons & 0.00 & 0.02 & 0.00 & 0.03 \\
\hline
\end{tabular}


Table 4.9: TOU with enabling technologies impact metrics for region 4

\begin{tabular}{|c|c|c|c|c|c|c|}
\hline Index & $\Delta$ Metric & Units & 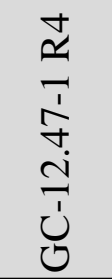 & 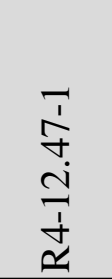 & 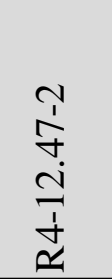 & 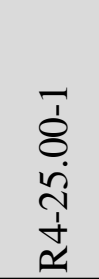 \\
\hline 1 & $\begin{array}{l}\text { Hourly Customer } \\
\text { Electricity Usage }\end{array}$ & $\mathrm{kWh}$ & -12.87 & 4.17 & 4.55 & 2.28 \\
\hline 2 & $\begin{array}{l}\text { Monthly Customer } \\
\text { Electricity Usage }\end{array}$ & MWh & -9.40 & 3.04 & 3.32 & 1.66 \\
\hline \multirow{10}{*}{3} & Peak Generation & $\mathrm{kW}$ & -142.85 & 430.30 & 200.07 & 158.16 \\
\hline & Nuclear & $\%$ & 0.00 & 0.00 & -1.13 & -0.43 \\
\hline & Solar & $\%$ & 0.00 & 0.00 & 0.00 & 0.00 \\
\hline & Bio & $\%$ & 0.00 & 0.00 & -0.03 & -0.03 \\
\hline & Wind & $\%$ & 0.00 & 0.00 & 0.05 & -0.06 \\
\hline & Coal & $\%$ & 0.00 & 0.00 & 0.86 & 0.83 \\
\hline & Hydroelectric & $\%$ & -1.82 & 0.00 & 0.23 & -1.04 \\
\hline & Natural Gas & $\%$ & 0.00 & 0.00 & -0.10 & 0.61 \\
\hline & Geothermal & $\%$ & 0.00 & 0.00 & 0.00 & 0.00 \\
\hline & Petroleum & $\%$ & -0.48 & 8.97 & 14.75 & 34.97 \\
\hline 4 & Peak Load & $\mathrm{kW}$ & -142.85 & 430.30 & 200.07 & 158.16 \\
\hline 7 & $\begin{array}{l}\text { Annual Electricity } \\
\text { Production }\end{array}$ & MWh & -113.75 & 36.05 & 39.99 & 20.13 \\
\hline 12 & $\mathrm{CO} 2$ Emissions & Tons & -97.77 & 53.31 & 42.75 & 20.52 \\
\hline \multirow{3}{*}{13} & SOx Emissions & Tons & -0.04 & 0.03 & 0.02 & 0.01 \\
\hline & \begin{tabular}{|l|} 
NOx Emissions \\
\end{tabular} & Tons & -0.02 & 0.02 & 0.01 & 0.01 \\
\hline & PM-10 Emissions & Tons & -0.01 & 0.01 & 0.01 & 0.00 \\
\hline \multirow{2}{*}{21} & Feeder Real Load & $\mathrm{kW}$ & -12.98 & 4.12 & 4.56 & 2.30 \\
\hline & Feeder Reactive Load & kVAR & -3.42 & 3.07 & 3.00 & 1.44 \\
\hline 29 & Distribution Losses & $\%$ & 0.00 & -0.01 & -0.01 & $\begin{array}{l}-0.01 \\
\end{array}$ \\
\hline 30 & \begin{tabular}{|l} 
Distribution Power \\
Factor
\end{tabular} & $\mathrm{pf}$ & 0.000 & 0.001 & 0.000 & 0.000 \\
\hline 39 & CO2 Emissions & Tons & -98.39 & 53.92 & 43.31 & 20.86 \\
\hline \multirow{3}{*}{40} & SOx Emis sions & Tons & -0.04 & 0.03 & 0.02 & 0.01 \\
\hline & NOx Emis sions & Tons & -0.02 & 0.02 & 0.01 & 0.01 \\
\hline & PM-10 Emissions & Tons & -0.01 & 0.01 & 0.01 & 0.00 \\
\hline
\end{tabular}


Table 4.10: TOU with enabling technologies impact metrics for region 5

\begin{tabular}{|c|c|c|c|c|c|c|c|c|c|c|}
\hline Index & $\Delta$ Metric & Units & 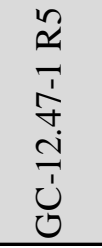 & 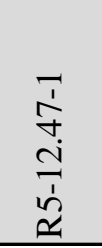 & 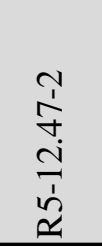 & 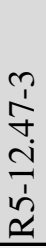 & 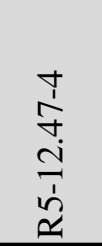 & 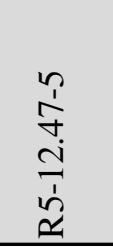 & 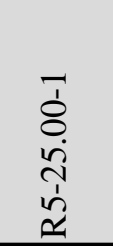 & 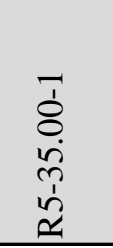 \\
\hline 1 & $\begin{array}{l}\text { Hourly Customer } \\
\text { Electricity Usage }\end{array}$ & $\mathrm{kWh}$ & -13.44 & -1.27 & -10.32 & - & -10.11 & -5.33 & -15.63 & -11.73 \\
\hline 2 & $\begin{array}{l}\text { Monthly Customer } \\
\text { Electricity Usage }\end{array}$ & MWh & -9.81 & -0.93 & -7.53 & - & -7.38 & -3.89 & -11.41 & -8.56 \\
\hline \multirow{10}{*}{3} & Peak Generation & $\mathrm{kW}$ & 517.91 & 4.95 & -63.86 & - & 839.21 & $1,415.00$ & $2,635.00$ & $2,188.80$ \\
\hline & Nuclear & $\%$ & -0.32 & -1.15 & 0.00 & - & -1.15 & -0.83 & -1.15 & -1.15 \\
\hline & Solar & $\%$ & 0.00 & 0.00 & 0.00 & - & 0.00 & 0.00 & 0.00 & 0.00 \\
\hline & Bio & $\%$ & -0.02 & 0.06 & 0.00 & - & 0.06 & 0.08 & 0.06 & 0.06 \\
\hline & Wind & $\%$ & 0.26 & 1.04 & 0.00 & - & 1.04 & 0.78 & 1.04 & 1.04 \\
\hline & Coal & $\%$ & 0.20 & 3.29 & 0.00 & - & 3.29 & 3.09 & 3.29 & 3.29 \\
\hline & Hydroelectric & $\%$ & 0.15 & 1.12 & 0.00 & - & 1.12 & 0.97 & 1.12 & 1.12 \\
\hline & Natural Gas & $\%$ & -0.39 & -4.13 & 0.00 & - & -4.13 & -3.74 & -4.13 & -4.13 \\
\hline & Geothermal & $\%$ & 0.00 & 0.00 & 0.00 & - & 0.00 & 0.00 & 0.00 & 0.00 \\
\hline & Petroleum & $\%$ & 11.65 & 10.39 & -1.28 & - & 23.71 & 28.47 & 36.37 & 34.83 \\
\hline 4 & Peak Load & $\mathrm{kW}$ & 517.91 & 4.95 & -63.86 & - & 839.21 & $1,415.00$ & $2,635.00$ & $2,188.80$ \\
\hline 7 & $\begin{array}{l}\text { Annual Electricity } \\
\text { Production }\end{array}$ & MWh & -118.90 & -13.62 & -97.09 & - & -93.74 & -50.93 & -139.82 & -104.84 \\
\hline 12 & $\mathrm{CO} 2$ Emis sions & Tons & -162.02 & -272.36 & -196.31 & - & -303.91 & -269.17 & -405.82 & -412.39 \\
\hline \multirow{3}{*}{13} & SOx Emissions & Tons & -0.09 & -0.23 & -0.13 & - & -0.23 & -0.22 & -0.32 & -0.33 \\
\hline & NOx Emis sions & Tons & -0.06 & -0.13 & -0.08 & - & -0.13 & -0.13 & -0.20 & -0.20 \\
\hline & PM-10 Emis sions & Tons & -0.03 & -0.04 & -0.03 & - & -0.05 & -0.06 & -0.10 & -0.09 \\
\hline \multirow[b]{2}{*}{21} & Feeder Real Load & $\mathrm{kW}$ & -13.57 & -1.55 & -11.08 & - & -10.70 & -5.81 & -15.96 & -11.97 \\
\hline & $\begin{array}{l}\text { Feeder Reactive } \\
\text { Load }\end{array}$ & kVAR & -3.64 & 3.06 & -2.04 & - & 0.85 & 4.63 & 6.67 & 7.86 \\
\hline 29 & Distribution Losses & $\%$ & 0.00 & -0.01 & -0.02 & - & -0.01 & -0.01 & 0.00 & 0.00 \\
\hline 30 & \begin{tabular}{|l|} 
Distribution Power \\
Factor \\
\end{tabular} & $\mathrm{pf}$ & 0.000 & 0.000 & 0.000 & - & 0.000 & 0.000 & 0.000 & 0.000 \\
\hline 39 & $\mathrm{CO} 2$ Emis sions & Tons & -162.87 & -276.54 & -202.16 & - & -311.17 & -276.77 & -411.91 & -418.02 \\
\hline \multirow{3}{*}{40} & SOx Emissions & Tons & -0.09 & -0.24 & -0.14 & - & -0.24 & -0.23 & -0.32 & -0.34 \\
\hline & NOx Emis sions & Tons & -0.06 & -0.13 & -0.08 & - & -0.14 & -0.14 & -0.20 & -0.21 \\
\hline & PM-10 Emis sions & Tons & -0.03 & -0.04 & -0.03 & - & -0.05 & -0.06 & -0.10 & -0.09 \\
\hline
\end{tabular}


Table 4.11: TOU/CPP without enabling technologies impact metrics for region 1

\begin{tabular}{|c|c|c|c|c|c|c|c|c|}
\hline Index & $\Delta$ Metric & Units & 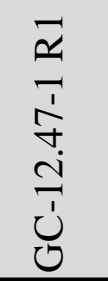 & 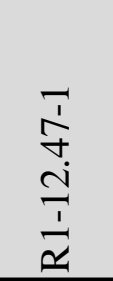 & $\begin{array}{l}\frac{N}{1} \\
\frac{7}{\sim} \\
\frac{1}{\sim} \\
\frac{1}{\alpha}\end{array}$ & $\begin{array}{l}m \\
\frac{1}{7} \\
\stackrel{1}{*} \\
\frac{1}{\alpha}\end{array}$ & $\begin{array}{l}\underset{+}{+} \\
\stackrel{+}{\sim} \\
\stackrel{1}{\sim} \\
\frac{1}{\alpha}\end{array}$ & 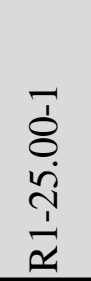 \\
\hline 1 & $\begin{array}{l}\text { Hourly Customer } \\
\text { Electricity Usage }\end{array}$ & $\mathrm{kWh}$ & 0.37 & -2.60 & -0.73 & 0.30 & -0.54 & 0.18 \\
\hline 2 & $\begin{array}{l}\text { Monthly Customer } \\
\text { Electricity Usage }\end{array}$ & MWh & 0.27 & -1.90 & -0.53 & 0.22 & -0.39 & 0.13 \\
\hline \multirow{10}{*}{3} & Peak Generation & $\mathrm{kW}$ & 101.65 & -514.73 & -151.96 & -57.19 & -243.47 & -37.18 \\
\hline & Nuclear & $\%$ & 0.00 & 0.00 & 0.00 & 0.00 & 0.59 & 0.00 \\
\hline & Solar & $\%$ & 0.00 & 0.00 & 0.00 & 0.00 & 0.04 & 0.00 \\
\hline & Bio & $\%$ & 0.00 & 0.00 & 0.00 & 0.00 & -0.05 & 0.00 \\
\hline & Wind & $\%$ & 0.00 & 0.00 & 0.00 & 0.00 & 0.52 & 0.00 \\
\hline & Coal & $\%$ & 0.00 & -2.88 & -2.49 & -1.35 & -3.12 & 0.00 \\
\hline & Hydroelectric & $\%$ & 0.00 & 0.00 & 0.00 & 0.00 & 10.56 & 0.00 \\
\hline & Natural Gas & $\%$ & 0.00 & -0.95 & 0.00 & 0.00 & -9.86 & 0.00 \\
\hline & Geothermal & $\%$ & 0.00 & -2.84 & -2.84 & -2.84 & -3.11 & -1.25 \\
\hline & Petroleum & $\%$ & 1.91 & -0.35 & -0.35 & -0.35 & -0.38 & -0.35 \\
\hline 4 & Peak Load & $\mathrm{kW}$ & 101.65 & -514.73 & -151.96 & -57.19 & -243.47 & -37.18 \\
\hline 7 & $\begin{array}{l}\text { Annual Electricity } \\
\text { Production } \\
\end{array}$ & MWh & 3.26 & -25.22 & -7.03 & 2.64 & -5.79 & 1.47 \\
\hline 12 & CO2 Emis sions & Tons & 1.00 & -39.13 & -15.62 & -0.54 & -28.97 & -1.86 \\
\hline \multirow{3}{*}{13} & SOx Emis sions & Tons & 0.00 & 0.00 & 0.00 & 0.00 & 0.00 & 0.00 \\
\hline & NOx Emis sions & Tons & 0.00 & 0.00 & 0.00 & 0.00 & 0.00 & 0.00 \\
\hline & PM-10 Emis sions & Tons & 0.00 & -0.01 & 0.00 & 0.00 & 0.00 & 0.00 \\
\hline \multirow[b]{2}{*}{21} & Feeder Real Load & $\mathrm{kW}$ & 0.37 & -2.88 & -0.80 & 0.30 & -0.66 & 0.17 \\
\hline & $\begin{array}{l}\text { Feeder Reactive } \\
\text { Load }\end{array}$ & kVAR & 0.27 & 4.29 & 1.51 & 0.25 & 1.86 & 0.35 \\
\hline 29 & Distribution Losses & $\%$ & 0.00 & -0.01 & 0.00 & 0.00 & -0.01 & 0.00 \\
\hline 30 & $\begin{array}{l}\text { Distribution Power } \\
\text { Factor } \\
\end{array}$ & $\mathrm{pf}$ & 0.000 & 0.000 & 0.001 & 0.000 & 0.000 & 0.000 \\
\hline 39 & $\mathrm{CO} 2$ Emis sions & Tons & 1.01 & -40.32 & -16.15 & -0.54 & -29.43 & -1.90 \\
\hline \multirow{3}{*}{40} & SOx Emis sions & Tons & 0.00 & 0.00 & 0.00 & 0.00 & 0.00 & 0.00 \\
\hline & NOx Emis sions & Tons & 0.00 & 0.00 & 0.00 & 0.00 & 0.00 & 0.00 \\
\hline & PM-10 Emis sions & Tons & 0.00 & -0.01 & 0.00 & 0.00 & 0.00 & 0.00 \\
\hline
\end{tabular}


Table 4.12: TOU/CPP without enabling technologies impact metrics for region 2

\begin{tabular}{|c|c|c|c|c|c|c|c|c|}
\hline Index & $\Delta$ Metric & Units & 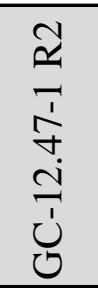 & 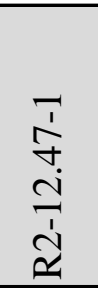 & 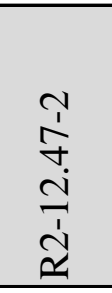 & 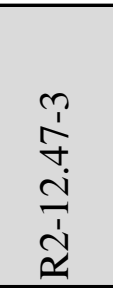 & 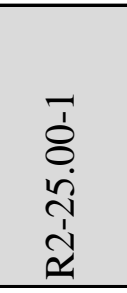 & $\begin{array}{l}\overline{1} \\
\delta \\
\ddot{1} \\
\tilde{1} \\
\tilde{1} \\
\tilde{1}\end{array}$ \\
\hline 1 & $\begin{array}{l}\text { Hourly Customer } \\
\text { Electricity Usage }\end{array}$ & $\mathrm{kWh}$ & -0.01 & 0.66 & 5.39 & 7.57 & 0.00 & 1.78 \\
\hline 2 & \begin{tabular}{|l|} 
Monthly Customer \\
Electricity Usage \\
\end{tabular} & $\mathrm{MWh}$ & 0.00 & 0.48 & 3.94 & 5.52 & 0.00 & 1.30 \\
\hline \multirow{10}{*}{3} & Peak Generation & $\mathrm{kW}$ & -17.11 & -13.22 & -171.03 & -308.27 & -167.70 & -147.30 \\
\hline & Nuclear & $\%$ & 0.00 & 0.00 & 1.62 & -1.62 & 0.00 & 0.00 \\
\hline & Solar & $\%$ & 0.00 & 0.00 & 0.00 & 0.00 & 0.00 & 0.00 \\
\hline & Bio & $\%$ & 0.00 & 0.00 & 0.02 & -0.02 & 0.00 & 0.00 \\
\hline & Wind & $\%$ & 0.00 & 0.00 & 0.29 & -0.29 & 0.00 & 0.00 \\
\hline & Coal & $\%$ & 0.00 & 0.00 & -1.64 & 1.64 & 0.00 & 0.00 \\
\hline & Hydroelectric & $\%$ & 0.00 & 0.00 & 1.63 & -4.49 & -0.50 & -0.66 \\
\hline & Natural Gas & $\%$ & 0.00 & 0.00 & -1.86 & 1.86 & 0.00 & 0.00 \\
\hline & Geothermal & $\%$ & 0.00 & 0.00 & 0.00 & -0.07 & -0.07 & -0.07 \\
\hline & Petroleum & $\%$ & -0.30 & -0.21 & 1.91 & -0.37 & -0.43 & -0.43 \\
\hline 4 & Peak Load & $\mathrm{kW}$ & -17.11 & -13.22 & -171.03 & -308.27 & -167.70 & -147.30 \\
\hline 7 & $\begin{array}{l}\text { Annual Electricity } \\
\text { Production }\end{array}$ & $\mathrm{MWh}$ & -0.05 & 5.70 & 47.02 & 65.13 & -1.21 & 15.62 \\
\hline 12 & $\mathrm{CO} 2$ Emissions & Tons & 0.03 & 2.89 & 46.33 & 58.84 & 13.74 & 11.28 \\
\hline \multirow{3}{*}{13} & SOx Emissions & Tons & 0.00 & 0.00 & 0.03 & 0.04 & 0.02 & 0.01 \\
\hline & NOx Emissions & Tons & 0.00 & 0.00 & 0.02 & 0.02 & 0.01 & 0.00 \\
\hline & PM-10 Emis sions & Tons & 0.00 & 0.00 & 0.01 & 0.01 & 0.00 & 0.00 \\
\hline \multirow[b]{2}{*}{21} & Feeder Real Load & $\mathrm{kW}$ & -0.01 & 0.65 & 5.37 & 7.44 & -0.14 & 1.78 \\
\hline & $\begin{array}{l}\text { Feeder Reactive } \\
\text { Load } \\
\end{array}$ & kVAR & 0.17 & 0.87 & 1.47 & 2.43 & 1.90 & 2.06 \\
\hline 29 & Distribution Losses & $\%$ & 0.00 & 0.00 & -0.01 & -0.01 & 0.00 & 0.00 \\
\hline 30 & \begin{tabular}{|l} 
Distribution Power \\
Factor \\
\end{tabular} & $\mathrm{pf}$ & 0.000 & 0.000 & 0.000 & 0.000 & 0.000 & 0.000 \\
\hline 39 & $\mathrm{CO} 2$ Emissions & Tons & 0.02 & 2.85 & 46.66 & 58.93 & 13.29 & 11.32 \\
\hline \multirow{3}{*}{40} & SOx Emis sions & Tons & 0.00 & 0.00 & 0.03 & 0.04 & 0.02 & 0.01 \\
\hline & NOx Emis sions & Tons & 0.00 & 0.00 & 0.02 & 0.02 & 0.01 & 0.00 \\
\hline & PM-10 Emissions & Tons & 0.00 & 0.00 & 0.01 & 0.01 & 0.00 & 0.00 \\
\hline
\end{tabular}


Table 4.13: TOU/CPP without enabling technologies impact metrics for region 3

\begin{tabular}{|c|c|c|c|c|c|c|}
\hline Index & $\Delta$ Metric & Units & 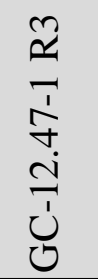 & 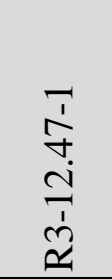 & 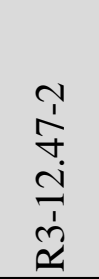 & 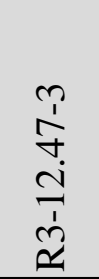 \\
\hline 1 & $\begin{array}{l}\text { Hourly Customer } \\
\text { Electricity Usage }\end{array}$ & $\mathrm{kWh}$ & -1.17 & -3.93 & 0.07 & -11.00 \\
\hline 2 & $\begin{array}{l}\text { Monthly Customer } \\
\text { Electricity Usage }\end{array}$ & MWh & -0.86 & -2.87 & 0.05 & -8.03 \\
\hline \multirow{10}{*}{3} & Peak Generation & $\mathrm{kW}$ & 88.61 & -149.29 & -40.22 & 3.14 \\
\hline & Nuclear & $\%$ & 1.07 & 0.00 & 0.00 & 0.00 \\
\hline & Solar & $\%$ & 0.00 & 0.00 & 0.00 & 0.00 \\
\hline & Bio & $\%$ & 0.02 & 0.00 & 0.00 & 0.00 \\
\hline & Wind & $\%$ & 0.40 & 0.00 & 0.00 & 0.00 \\
\hline & Coal & $\%$ & 1.28 & 0.00 & 0.00 & 0.00 \\
\hline & Hydroelectric & $\%$ & 0.82 & 0.00 & 0.00 & 0.00 \\
\hline & Natural Gas & $\%$ & -3.79 & 0.00 & 0.00 & 0.00 \\
\hline & Geothermal & $\%$ & 0.15 & -1.35 & -0.66 & 0.00 \\
\hline & Petroleum & $\%$ & 1.48 & -0.25 & -0.25 & 0.04 \\
\hline 4 & Peak Load & $\mathrm{kW}$ & 88.61 & -149.29 & -40.22 & 3.14 \\
\hline 7 & $\begin{array}{l}\text { Annual Electricity } \\
\text { Production }\end{array}$ & $\mathrm{MWh}$ & -10.35 & -35.70 & 0.60 & -99.52 \\
\hline 12 & $\mathrm{CO} 2$ Emis sions & Tons & -4.36 & 17.86 & 0.34 & -9.86 \\
\hline \multirow{3}{*}{13} & SOx Emis sions & Tons & 0.00 & 0.03 & 0.00 & 0.03 \\
\hline & NOx Emis sions & Tons & 0.00 & 0.01 & 0.00 & 0.01 \\
\hline & PM-10 Emissions & Tons & 0.00 & 0.00 & 0.00 & 0.00 \\
\hline \multirow[b]{2}{*}{21} & Feeder Real Load & $\mathrm{kW}$ & -1.18 & -4.08 & 0.07 & -11.36 \\
\hline & \begin{tabular}{|l|} 
Feeder Reactive \\
Load
\end{tabular} & kVAR & -0.16 & -0.31 & 0.29 & -0.97 \\
\hline 29 & Distribution Losses & $\%$ & 0.00 & 0.00 & 0.00 & 0.00 \\
\hline 30 & $\begin{array}{l}\text { Distribution Power } \\
\text { Factor }\end{array}$ & $\mathrm{pf}$ & 0.000 & 0.000 & 0.000 & 0.000 \\
\hline 39 & $\mathrm{CO} 2$ Emis sions & Tons & -4.41 & 17.76 & 0.31 & -10.05 \\
\hline \multirow{3}{*}{40} & SOx Emis sions & Tons & 0.00 & 0.03 & 0.00 & 0.03 \\
\hline & NOx Emis sions & Tons & 0.00 & 0.01 & 0.00 & 0.01 \\
\hline & PM-10 Emissions & Tons & 0.00 & 0.00 & 0.00 & 0.00 \\
\hline
\end{tabular}


Table 4.14: TOU/CPP without enabling technologies impact metrics for region 4

\begin{tabular}{|c|c|c|c|c|c|c|}
\hline Index & $\Delta$ Metric & Units & 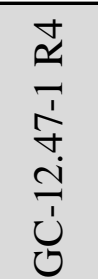 & 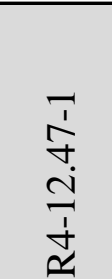 & 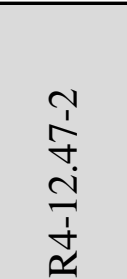 & 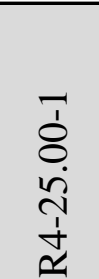 \\
\hline 1 & $\begin{array}{l}\text { Hourly Customer } \\
\text { Electricity Usage }\end{array}$ & $\mathrm{kWh}$ & -0.13 & -2.53 & -3.03 & -1.31 \\
\hline 2 & $\begin{array}{l}\text { Monthly Customer } \\
\text { Electricity Usage }\end{array}$ & MWh & -0.09 & -1.85 & -2.21 & -0.95 \\
\hline \multirow{10}{*}{3} & Peak Generation & $\mathrm{kW}$ & 31.21 & -185.65 & -129.63 & -39.64 \\
\hline & Nuclear & $\%$ & 0.00 & 0.00 & -1.67 & 0.00 \\
\hline & Solar & $\%$ & 0.00 & 0.00 & 0.00 & 0.00 \\
\hline & Bio & $\%$ & 0.00 & 0.00 & -0.03 & 0.00 \\
\hline & Wind & $\%$ & 0.00 & 0.00 & 0.01 & 0.00 \\
\hline & Coal & $\%$ & 0.00 & 0.00 & 1.08 & 0.00 \\
\hline & Hydroelectric & $\%$ & 0.00 & -2.20 & -3.09 & -3.09 \\
\hline & Natural Gas & $\%$ & 0.00 & -1.19 & -0.97 & -0.78 \\
\hline & Geothermal & $\%$ & 0.00 & 0.00 & 0.00 & 0.00 \\
\hline & Petroleum & $\%$ & 0.50 & -0.48 & -0.33 & -0.33 \\
\hline 4 & Peak Load & $\mathrm{kW}$ & 31.21 & -185.65 & -129.63 & -39.64 \\
\hline 7 & $\begin{array}{l}\text { Annual Electricity } \\
\text { Production }\end{array}$ & MWh & -1.16 & -22.87 & -26.99 & -11.62 \\
\hline 12 & $\mathrm{CO} 2$ Emis sions & Tons & 0.47 & -7.42 & -22.94 & -10.28 \\
\hline \multirow{3}{*}{13} & SOx Emissions & Tons & 0.00 & 0.00 & -0.01 & 0.00 \\
\hline & NOx Emis sions & Tons & 0.00 & 0.00 & -0.01 & 0.00 \\
\hline & PM-10 Emissions & Tons & 0.00 & 0.00 & 0.00 & 0.00 \\
\hline \multirow[b]{2}{*}{21} & Feeder Real Load & $\mathrm{kW}$ & -0.13 & -2.61 & -3.08 & -1.33 \\
\hline & $\begin{array}{l}\text { Feeder Reactive } \\
\text { Load }\end{array}$ & kVAR & 0.13 & 0.12 & 0.08 & 0.11 \\
\hline 29 & Distribution Losses & $\%$ & 0.00 & 0.00 & 0.00 & 0.00 \\
\hline 30 & $\begin{array}{l}\text { Distribution Power } \\
\text { Factor }\end{array}$ & $\mathrm{pf}$ & 0.000 & 0.000 & 0.000 & 0.000 \\
\hline 39 & $\mathrm{CO} 2$ Emis sions & Tons & 0.45 & -7.66 & -23.37 & -10.49 \\
\hline \multirow{3}{*}{40} & SOx Emissions & Tons & 0.00 & 0.00 & -0.01 & 0.00 \\
\hline & NOx Emis sions & Tons & 0.00 & 0.00 & -0.01 & 0.00 \\
\hline & PM-10 Emis sions & Tons & 0.00 & 0.00 & 0.00 & 0.00 \\
\hline
\end{tabular}


Table 4.15: TOU/CPP without enabling technologies impact metrics for region 5

\begin{tabular}{|c|c|c|c|c|c|c|c|c|c|c|}
\hline Index & $\Delta$ Metric & Units & 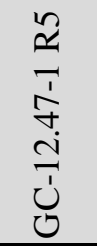 & 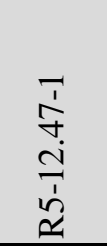 & 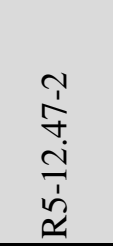 & 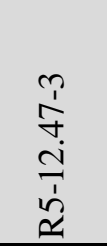 & 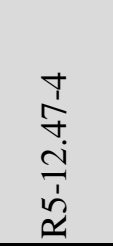 & 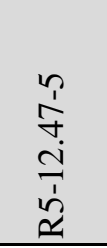 & 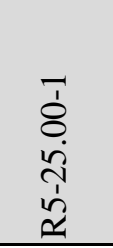 & 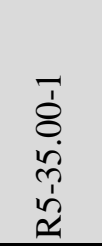 \\
\hline 1 & $\begin{array}{l}\text { Hourly Customer } \\
\text { Electricity Usage }\end{array}$ & $\mathrm{kWh}$ & 0.02 & -37.68 & -10.70 & -71.67 & -37.93 & -58.97 & -90.16 & -91.23 \\
\hline 2 & $\begin{array}{l}\text { Monthly Customer } \\
\text { Electricity Usage }\end{array}$ & $\mathrm{MWh}$ & 0.01 & -27.51 & -7.81 & -52.32 & -27.69 & -43.05 & -65.82 & -66.60 \\
\hline \multirow{10}{*}{3} & Peak Generation & $\mathrm{kW}$ & -27.48 & -275.55 & -76.37 & -445.08 & -244.15 & -472.95 & -659.50 & -775.40 \\
\hline & Nuclear & $\%$ & -0.32 & 0.00 & 0.00 & 1.14 & 0.00 & 0.32 & 0.00 & 0.00 \\
\hline & Solar & $\%$ & 0.00 & 0.00 & 0.00 & 0.00 & 0.00 & 0.00 & 0.00 & 0.00 \\
\hline & Bio & $\%$ & -0.02 & 0.00 & 0.00 & -0.01 & 0.00 & 0.02 & 0.00 & 0.00 \\
\hline & Wind & $\%$ & 0.26 & 0.00 & 0.00 & 0.17 & 0.00 & -0.26 & 0.00 & 0.00 \\
\hline & Coal & $\%$ & 0.20 & -0.43 & 0.00 & 1.67 & -0.75 & -2.65 & -2.88 & -3.75 \\
\hline & Hydroelectric & $\%$ & 0.15 & -0.63 & 0.00 & 0.83 & -0.63 & -0.78 & -0.63 & -0.63 \\
\hline & Natural Gas & $\%$ & -0.39 & 0.00 & 0.00 & -4.03 & 0.00 & 0.39 & 0.00 & 0.00 \\
\hline & Geothermal & $\%$ & 0.00 & 0.00 & 0.00 & 0.00 & 0.00 & 0.00 & 0.00 & 0.00 \\
\hline & Petroleum & $\%$ & 2.08 & -1.86 & -1.53 & -0.39 & -1.86 & -1.98 & -1.86 & -1.86 \\
\hline 4 & Peak Load & $\mathrm{kW}$ & -27.48 & -275.55 & -76.37 & -445.08 & -244.15 & -472.95 & -659.50 & -775.40 \\
\hline 7 & $\begin{array}{l}\text { Annual Electricity } \\
\text { Production }\end{array}$ & $\mathrm{MWh}$ & 0.16 & -335.42 & -98.19 & -674.29 & -340.11 & -534.32 & -804.18 & -809.90 \\
\hline 12 & $\mathrm{CO} 2$ Emis sions & Tons & 0.83 & -379.60 & -103.18 & -643.67 & -368.74 & -548.97 & -836.21 & -838.71 \\
\hline \multirow{3}{*}{13} & SOx Emis sions & Tons & 0.00 & -0.20 & -0.05 & -0.30 & -0.18 & -0.27 & -0.40 & -0.40 \\
\hline & NOx Emissions & Tons & 0.00 & -0.12 & -0.03 & -0.18 & -0.11 & -0.16 & -0.24 & -0.24 \\
\hline & PM-10 Emis sions & Tons & 0.00 & -0.06 & -0.02 & -0.10 & -0.06 & -0.08 & -0.12 & -0.13 \\
\hline \multirow[b]{2}{*}{21} & Feeder Real Load & $\mathrm{kW}$ & 0.02 & -38.29 & -11.21 & -76.97 & -38.82 & -61.00 & -91.80 & -92.45 \\
\hline & $\begin{array}{l}\text { Feeder Reactive } \\
\text { Load }\end{array}$ & kVAR & 0.18 & -9.57 & -2.72 & -29.30 & -9.18 & -16.91 & -20.22 & -19.54 \\
\hline 29 & Distribution Losses & $\%$ & 0.00 & 0.00 & -0.01 & -0.04 & 0.00 & -0.01 & -0.01 & 0.00 \\
\hline 30 & $\begin{array}{l}\text { Distribution Power } \\
\text { Factor }\end{array}$ & $\mathrm{pf}$ & 0.000 & 0.000 & 0.000 & 0.000 & 0.000 & 0.000 & 0.000 & 0.000 \\
\hline 39 & $\mathrm{CO} 2$ Emissions & Tons & 0.83 & -384.69 & -106.26 & -679.67 & -376.44 & -564.07 & -849.19 & -849.72 \\
\hline \multirow{3}{*}{40} & SOx Emis sions & Tons & 0.00 & -0.20 & -0.05 & -0.32 & -0.19 & -0.27 & -0.41 & -0.41 \\
\hline & NOx Emissions & Tons & 0.00 & -0.12 & -0.03 & -0.19 & -0.11 & -0.16 & -0.25 & -0.25 \\
\hline & PM-10 Emissions & Tons & 0.00 & -0.06 & -0.02 & -0.10 & -0.06 & -0.08 & -0.13 & -0.13 \\
\hline
\end{tabular}


Table 4.16: TOU/CPP with enabling technologies impact metrics for region 1

\begin{tabular}{|c|c|c|c|c|c|c|c|c|}
\hline Index & $\Delta$ Metric & Units & 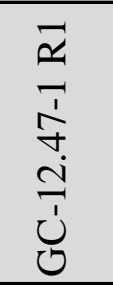 & 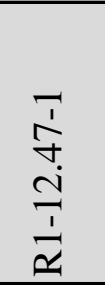 & 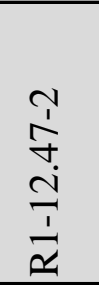 & 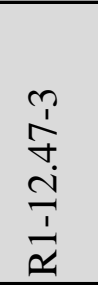 & 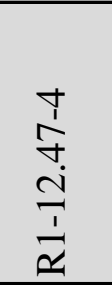 & $\begin{array}{l}\bar{\delta} \\
8 \\
\ddot{n} \\
\frac{1}{\alpha} \\
\end{array}$ \\
\hline 1 & \begin{tabular}{|l} 
Hourly Customer \\
Electricity Usage
\end{tabular} & $\mathrm{kWh}$ & -10.36 & -0.31 & -1.22 & -1.89 & -2.02 & -5.09 \\
\hline 2 & $\begin{array}{l}\text { Monthly Customer } \\
\text { Electricity Usage } \\
\end{array}$ & MWh & -7.56 & -0.23 & -0.89 & -1.38 & -1.48 & -3.71 \\
\hline \multirow{10}{*}{3} & Peak Generation & $\mathrm{kW}$ & 916.00 & 112.07 & 17.19 & 72.33 & 195.87 & 289.86 \\
\hline & Nuclear & $\%$ & 0.00 & 0.00 & 0.00 & 0.00 & 0.59 & 0.00 \\
\hline & Solar & $\%$ & 0.00 & 0.00 & 0.00 & 0.00 & 0.04 & 0.00 \\
\hline & Bio & $\%$ & 0.00 & 0.00 & 0.00 & 0.00 & -0.05 & 0.00 \\
\hline & Wind & $\%$ & 0.00 & 0.00 & 0.00 & 0.00 & 0.52 & 0.00 \\
\hline & Coal & $\%$ & 0.00 & 0.00 & 0.00 & 0.00 & -1.50 & 0.00 \\
\hline & Hydroelectric & $\%$ & 0.00 & 0.00 & 0.00 & 0.00 & 10.56 & 0.00 \\
\hline & Natural Gas & $\%$ & 0.00 & 0.00 & 0.00 & 0.00 & -9.86 & 0.00 \\
\hline & Geothermal & $\%$ & 0.00 & 0.00 & 0.00 & 0.00 & -0.27 & 0.00 \\
\hline & Petroleum & $\%$ & 17.24 & 1.53 & 0.64 & 5.74 & 3.86 & 12.51 \\
\hline 4 & Peak Load & $\mathrm{kW}$ & 916.00 & 112.07 & 17.19 & 72.33 & 195.87 & 289.86 \\
\hline 7 & $\begin{array}{l}\text { Annual Electricity } \\
\text { Production }\end{array}$ & MWh & -91.33 & -5.63 & -11.60 & -16.81 & -19.60 & -46.15 \\
\hline 12 & $\mathrm{CO} 2$ Emissions & Tons & -46.99 & -57.44 & -24.79 & -10.32 & -54.33 & -26.92 \\
\hline \multirow{3}{*}{13} & SOx Emissions & Tons & 0.00 & -0.01 & 0.00 & 0.00 & -0.01 & 0.00 \\
\hline & NOx Emis sions & Tons & 0.00 & -0.01 & 0.00 & 0.00 & -0.01 & 0.00 \\
\hline & PM-10 Emissions & Tons & -0.01 & -0.01 & 0.00 & 0.00 & -0.01 & 0.00 \\
\hline \multirow[b]{2}{*}{21} & Feeder Real Load & $\mathrm{kW}$ & -10.43 & -0.64 & -1.32 & -1.92 & -2.24 & -5.27 \\
\hline & \begin{tabular}{|l} 
Feeder Reactive \\
Load \\
\end{tabular} & kVAR & -2.64 & 5.55 & 1.92 & -0.32 & 1.60 & -1.27 \\
\hline 29 & Distribution Losses & $\%$ & 0.00 & -0.01 & -0.01 & 0.00 & -0.01 & -0.01 \\
\hline 30 & \begin{tabular}{|l} 
Distribution Power \\
Factor
\end{tabular} & $\mathrm{pf}$ & 0.000 & 0.000 & 0.001 & 0.000 & 0.000 & 0.000 \\
\hline 39 & $\mathrm{CO} 2$ Emissions & Tons & -47.14 & -59.20 & -25.63 & -10.39 & -55.16 & -27.40 \\
\hline \multirow{3}{*}{40} & SOx Emissions & Tons & 0.00 & -0.01 & 0.00 & 0.00 & -0.01 & 0.00 \\
\hline & NOx Emis sions & Tons & 0.00 & -0.01 & 0.00 & 0.00 & -0.01 & 0.00 \\
\hline & PM-10 Emissions & Tons & -0.01 & -0.01 & 0.00 & 0.00 & -0.01 & 0.00 \\
\hline
\end{tabular}


Table 4.17: TOU/CPP with enabling technologies impact metrics for region 2

\begin{tabular}{|c|c|c|c|c|c|c|c|c|}
\hline Index & $\Delta$ Metric & Units & 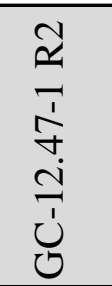 & 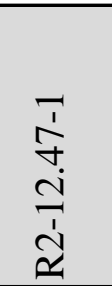 & 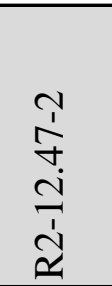 & 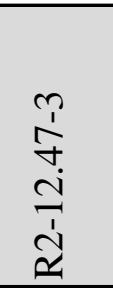 & 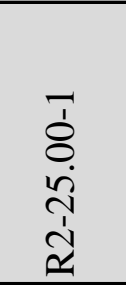 & $\begin{array}{l}7 \\
\delta \\
o \\
\ddot{1} \\
\dot{1} \\
\tilde{1}\end{array}$ \\
\hline 1 & $\begin{array}{l}\text { Hourly Customer } \\
\text { Electricity Usage }\end{array}$ & $\mathrm{kWh}$ & -4.30 & 0.72 & 18.27 & 15.98 & 1.26 & -4.86 \\
\hline 2 & $\begin{array}{l}\text { Monthly Customer } \\
\text { Electricity Usage }\end{array}$ & MWh & -3.14 & 0.53 & 13.34 & 11.67 & 0.92 & -3.55 \\
\hline \multirow{10}{*}{3} & Peak Generation & $\mathrm{kW}$ & 481.93 & -50.39 & 537.43 & 875.02 & $1,852.10$ & 78.00 \\
\hline & Nuclear & $\%$ & 0.00 & 0.00 & 0.00 & -1.62 & 0.00 & 0.00 \\
\hline & Solar & $\%$ & 0.00 & 0.00 & 0.00 & 0.00 & 0.00 & 0.00 \\
\hline & Bio & $\%$ & 0.00 & 0.00 & 0.00 & -0.02 & 0.00 & 0.00 \\
\hline & Wind & $\%$ & 0.00 & 0.00 & 0.00 & -0.29 & 0.00 & 0.00 \\
\hline & Coal & $\%$ & 0.00 & 0.00 & 0.00 & 1.64 & 0.00 & 0.00 \\
\hline & Hydroelectric & $\%$ & 0.00 & -0.30 & 0.00 & -1.63 & 0.00 & 0.00 \\
\hline & Natural Gas & $\%$ & 0.00 & 0.00 & 0.00 & 1.86 & 0.00 & 0.00 \\
\hline & Geothermal & $\%$ & 0.00 & -0.07 & 0.00 & 0.00 & 0.00 & 0.00 \\
\hline & Petroleum & $\%$ & 8.38 & -0.43 & 9.30 & 10.57 & 11.00 & 0.62 \\
\hline 4 & Peak Load & $\mathrm{kW}$ & 481.93 & -50.39 & 537.43 & 875.02 & $1,852.10$ & 78.00 \\
\hline 7 & $\begin{array}{l}\text { Annual Electricity } \\
\text { Production }\end{array}$ & $\mathrm{MWh}$ & -37.98 & 5.58 & 161.86 & 140.47 & 9.56 & -43.80 \\
\hline 12 & $\mathrm{CO} 2$ Emissions & Tons & -26.54 & 14.32 & 163.69 & 151.67 & 42.56 & -10.41 \\
\hline \multirow{3}{*}{13} & SOx Emissions & Tons & -0.01 & 0.01 & 0.09 & 0.09 & 0.05 & 0.01 \\
\hline & NOx Emissions & Tons & 0.00 & 0.01 & 0.05 & 0.05 & 0.03 & 0.00 \\
\hline & PM-10 Emissions & Tons & 0.00 & 0.00 & 0.02 & 0.02 & 0.00 & 0.00 \\
\hline \multirow[b]{2}{*}{21} & Feeder Real Load & $\mathrm{kW}$ & -4.34 & 0.64 & 18.48 & 16.04 & 1.09 & -5.00 \\
\hline & $\begin{array}{l}\text { Feeder Reactive } \\
\text { Load } \\
\end{array}$ & kVAR & -1.03 & 0.92 & 4.77 & 8.81 & 2.77 & -0.08 \\
\hline 29 & Distribution Losses & $\%$ & 0.00 & 0.00 & -0.01 & -0.01 & 0.00 & 0.00 \\
\hline 30 & \begin{tabular}{|l} 
Distribution Power \\
Factor
\end{tabular} & $\mathrm{pf}$ & 0.000 & 0.000 & 0.000 & 0.000 & 0.000 & 0.000 \\
\hline 39 & $\mathrm{CO} 2$ Emissions & Tons & -26.71 & 14.11 & 166.20 & 153.91 & 42.20 & -10.89 \\
\hline \multirow{3}{*}{40} & SOx Emissions & Tons & -0.01 & 0.01 & 0.09 & 0.09 & 0.05 & 0.01 \\
\hline & NOx Emis sions & Tons & 0.00 & 0.01 & 0.05 & 0.05 & 0.03 & 0.00 \\
\hline & PM-10 Emissions & Tons & 0.00 & 0.00 & 0.02 & 0.02 & 0.00 & 0.00 \\
\hline
\end{tabular}


Table 4.18: TOU/CPP with enabling technologies impact metrics for region 3

\begin{tabular}{|c|c|c|c|c|c|c|}
\hline Index & $\Delta$ Metric & Units & 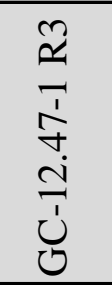 & 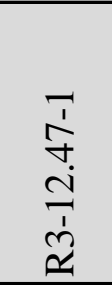 & 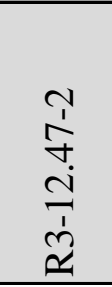 & 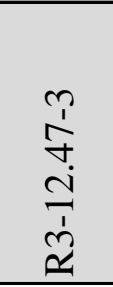 \\
\hline 1 & $\begin{array}{l}\text { Hourly Customer } \\
\text { Electricity Usage }\end{array}$ & $\mathrm{kWh}$ & -8.98 & 1.23 & -4.32 & 23.97 \\
\hline 2 & $\begin{array}{l}\text { Monthly Customer } \\
\text { Electricity Usage } \\
\end{array}$ & MWh & -6.56 & 0.90 & -3.16 & 17.50 \\
\hline \multirow{10}{*}{3} & Peak Generation & $\mathrm{kW}$ & 438.26 & -287.48 & -235.61 & -155.86 \\
\hline & Nuclear & $\%$ & 1.07 & 0.00 & -1.07 & -1.07 \\
\hline & Solar & $\%$ & 0.00 & 0.00 & 0.00 & 0.00 \\
\hline & Bio & $\%$ & 0.02 & 0.00 & -0.02 & -0.02 \\
\hline & Wind & $\%$ & 0.40 & 0.00 & -0.40 & -0.40 \\
\hline & Coal & $\%$ & 1.28 & 0.00 & -1.28 & -1.28 \\
\hline & Hydroelectric & $\%$ & 0.82 & -1.44 & -0.82 & -0.82 \\
\hline & Natural Gas & $\%$ & -3.79 & 0.00 & 3.79 & 3.79 \\
\hline & Geothermal & $\%$ & 0.15 & -1.40 & -0.15 & -0.15 \\
\hline & Petroleum & $\%$ & 6.79 & -0.25 & 0.40 & 0.92 \\
\hline 4 & Peak Load & $\mathrm{kW}$ & 438.26 & -287.48 & -235.61 & -155.86 \\
\hline 7 & $\begin{array}{l}\text { Annual Electricity } \\
\text { Production }\end{array}$ & $\mathrm{MWh}$ & -79.51 & 9.03 & -38.75 & 213.36 \\
\hline 12 & $\mathrm{CO} 2$ Emissions & Tons & -14.10 & 112.62 & -3.43 & 223.57 \\
\hline \multirow{3}{*}{13} & SOx Emis sions & Tons & 0.02 & 0.09 & 0.01 & 0.11 \\
\hline & NOx Emissions & Tons & 0.01 & 0.05 & 0.01 & 0.06 \\
\hline & PM-10 Emissions & Tons & 0.00 & 0.02 & 0.00 & 0.03 \\
\hline \multirow[b]{2}{*}{21} & Feeder Real Load & $\mathrm{kW}$ & -9.08 & 1.03 & -4.42 & 24.36 \\
\hline & \begin{tabular}{|l} 
Feeder Reactive \\
Load \\
\end{tabular} & kVAR & -2.38 & 1.44 & -1.09 & 10.54 \\
\hline 29 & Distribution Losses & $\%$ & 0.00 & -0.01 & 0.00 & -0.01 \\
\hline 30 & $\begin{array}{l}\text { Distribution Power } \\
\text { Factor }\end{array}$ & $\mathrm{pf}$ & 0.000 & 0.000 & 0.000 & 0.000 \\
\hline 39 & $\mathrm{CO} 2$ Emissions & Tons & -14.54 & 113.35 & -3.88 & 228.30 \\
\hline \multirow{3}{*}{40} & SOx Emis sions & Tons & 0.02 & 0.09 & 0.01 & 0.11 \\
\hline & NOx Emis sions & Tons & 0.01 & 0.05 & 0.01 & 0.07 \\
\hline & PM-10 Emissions & Tons & 0.00 & 0.02 & 0.00 & 0.03 \\
\hline
\end{tabular}


Table 4.19: TOU/CPP with enabling technologies impact metrics for region 4

\begin{tabular}{|c|c|c|c|c|c|c|}
\hline Index & $\Delta$ Metric & Units & 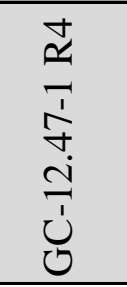 & 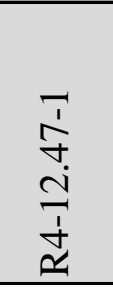 & 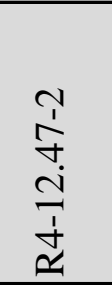 & 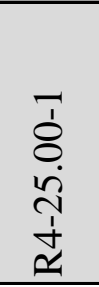 \\
\hline 1 & $\begin{array}{l}\text { Hourly Customer } \\
\text { Electricity Usage }\end{array}$ & $\mathrm{kWh}$ & -10.47 & 7.33 & 6.75 & 2.97 \\
\hline 2 & $\begin{array}{l}\text { Monthly Customer } \\
\text { Electricity Usage } \\
\end{array}$ & $\mathrm{MWh}$ & -7.65 & 5.35 & 4.93 & 2.17 \\
\hline \multirow{10}{*}{3} & Peak Generation & $\mathrm{kW}$ & $1,000.43$ & 914.68 & 430.98 & 176.85 \\
\hline & Nuclear & $\%$ & 0.00 & 1.67 & -1.67 & -1.13 \\
\hline & Solar & $\%$ & 0.00 & 0.00 & 0.00 & 0.00 \\
\hline & Bio & $\%$ & 0.00 & 0.03 & -0.03 & -0.03 \\
\hline & Wind & $\%$ & 0.00 & -0.01 & 0.01 & 0.05 \\
\hline & Coal & $\%$ & 0.00 & -1.08 & 1.08 & 0.86 \\
\hline & Hydroelectric & $\%$ & 0.00 & 0.89 & -0.89 & 0.23 \\
\hline & Natural Gas & $\%$ & 0.00 & -1.35 & 1.35 & -0.10 \\
\hline & Geothermal & $\%$ & 0.00 & 0.00 & 0.00 & 0.00 \\
\hline & Petroleum & $\%$ & 16.08 & 24.12 & 20.82 & 26.39 \\
\hline 4 & Peak Load & $\mathrm{kW}$ & $1,000.43$ & 914.68 & 430.98 & 176.85 \\
\hline 7 & $\begin{array}{l}\text { Annual Electricity } \\
\text { Production }\end{array}$ & MWh & -92.59 & 63.99 & 59.34 & 26.19 \\
\hline 12 & $\mathrm{CO} 2$ Emissions & Tons & -76.64 & 88.95 & 64.53 & 27.00 \\
\hline \multirow{3}{*}{13} & SOx Emis sions & Tons & -0.03 & 0.05 & 0.03 & 0.01 \\
\hline & NOx Emissions & Tons & -0.02 & 0.03 & 0.02 & 0.01 \\
\hline & PM-10 Emissions & Tons & -0.01 & 0.01 & 0.01 & 0.00 \\
\hline \multirow[b]{2}{*}{21} & Feeder Real Load & $\mathrm{kW}$ & -10.57 & 7.30 & 6.77 & 2.99 \\
\hline & \begin{tabular}{|l} 
Feeder Reactive \\
Load \\
\end{tabular} & kVAR & -2.75 & 3.53 & 3.20 & 1.49 \\
\hline 29 & Distribution Losses & $\%$ & 0.00 & -0.01 & -0.02 & -0.02 \\
\hline 30 & \begin{tabular}{|l} 
Distribution Power \\
Factor \\
\end{tabular} & $\mathrm{pf}$ & 0.000 & 0.001 & 0.000 & 0.000 \\
\hline 39 & CO2 Emissions & Tons & -77.14 & 90.24 & 65.42 & 27.44 \\
\hline \multirow{3}{*}{40} & SOx Emis sions & Tons & -0.03 & 0.05 & 0.03 & 0.01 \\
\hline & NOx Emissions & Tons & -0.02 & 0.03 & 0.02 & 0.01 \\
\hline & PM-10 Emissions & Tons & -0.01 & 0.01 & 0.01 & 0.00 \\
\hline
\end{tabular}


Table 4.20: TOU/CPP with enabling technologies impact metrics for region 5

\begin{tabular}{|c|c|c|c|c|c|c|c|c|c|c|}
\hline Index & $\Delta$ Metric & Units & 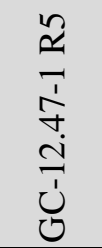 & 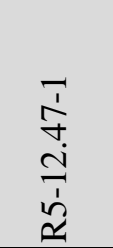 & 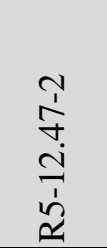 & 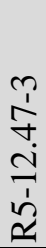 & 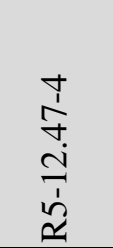 & 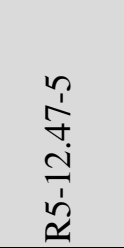 & 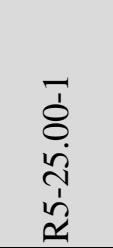 & $\begin{array}{l}7 \\
\delta \\
0 \\
\dot{0} \\
\hat{n} \\
1 \\
2\end{array}$ \\
\hline 1 & $\begin{array}{l}\text { Hourly Customer } \\
\text { Electricity Usage }\end{array}$ & $\mathrm{kWh}$ & -11.09 & 6.93 & -6.25 & - & -1.45 & 5.07 & 3.08 & 5.02 \\
\hline 2 & $\begin{array}{l}\text { Monthly Customer } \\
\text { Electricity Usage }\end{array}$ & MWh & -8.10 & 5.06 & -4.56 & - & -1.06 & 3.70 & 2.25 & 3.67 \\
\hline \multirow{10}{*}{3} & Peak Generation & $\mathrm{kW}$ & 983.14 & $1,758.29$ & 913.19 & - & $1,601.67$ & $2,170.30$ & $3,019.10$ & $3,233.50$ \\
\hline & Nuclear & $\%$ & 0.00 & 0.00 & 0.00 & - & 0.00 & 0.32 & 0.00 & 0.00 \\
\hline & Solar & $\%$ & 0.00 & 0.00 & 0.00 & - & 0.00 & 0.00 & 0.00 & 0.00 \\
\hline & Bio & $\%$ & 0.00 & 0.00 & 0.00 & - & 0.00 & 0.02 & 0.00 & 0.00 \\
\hline & Wind & $\%$ & 0.00 & 0.00 & 0.00 & - & 0.00 & -0.26 & 0.00 & 0.00 \\
\hline & Coal & $\%$ & 0.00 & 0.00 & 0.00 & - & 0.00 & -0.20 & 0.00 & 0.00 \\
\hline & Hydroelectric & $\%$ & 0.00 & 0.00 & 0.00 & - & 0.00 & -0.15 & 0.00 & 0.00 \\
\hline & Natural Gas & $\%$ & 0.00 & 0.00 & 0.00 & - & 0.00 & 0.39 & 0.00 & 0.00 \\
\hline & Geothermal & $\%$ & 0.00 & 0.00 & 0.00 & - & 0.00 & 0.00 & 0.00 & 0.00 \\
\hline & Petroleum & $\%$ & 16.83 & 18.60 & 18.29 & - & 21.27 & 24.26 & 24.58 & 26.02 \\
\hline 4 & Peak Load & $\mathrm{kW}$ & 983.14 & $1,758.29$ & 913.19 & - & $1,601.67$ & $2,170.30$ & $3,019.10$ & $3,233.50$ \\
\hline 7 & $\begin{array}{l}\text { Annual Electricity } \\
\text { Production }\end{array}$ & MWh & -98.17 & 59.13 & -60.14 & - & -16.48 & 41.91 & 25.97 & 43.19 \\
\hline 12 & $\mathrm{CO} 2$ Emis sions & Tons & -137.67 & -198.28 & -161.39 & - & -230.56 & -200.19 & -286.14 & -304.81 \\
\hline \multirow{3}{*}{13} & SOx Emis sions & Tons & -0.08 & -0.20 & -0.12 & - & -0.20 & -0.20 & -0.28 & -0.30 \\
\hline & NOx Emis sions & Tons & -0.05 & -0.11 & -0.07 & - & -0.11 & -0.12 & -0.17 & -0.18 \\
\hline & PM-10 Emis sions & Tons & -0.02 & -0.03 & -0.02 & - & -0.04 & -0.04 & -0.07 & -0.07 \\
\hline \multirow[b]{2}{*}{21} & Feeder Real Load & $\mathrm{kW}$ & -11.21 & 6.75 & -6.87 & - & -1.88 & 4.78 & 2.96 & 4.93 \\
\hline & $\begin{array}{l}\text { Feeder Reactive } \\
\text { Load }\end{array}$ & kVAR & -2.98 & 5.09 & -0.93 & - & 2.98 & 7.17 & 10.70 & 11.48 \\
\hline 29 & Distribution Losses & $\%$ & 0.00 & -0.01 & -0.02 & - & -0.01 & -0.01 & 0.00 & 0.00 \\
\hline 30 & $\begin{array}{l}\text { Distribution Power } \\
\text { Factor }\end{array}$ & $\mathrm{pf}$ & 0.000 & 0.000 & 0.000 & - & 0.000 & 0.000 & 0.000 & 0.000 \\
\hline 39 & $\mathrm{CO} 2$ Emis sions & Tons & -138.39 & -201.54 & -166.29 & - & -236.41 & -206.30 & -290.71 & -309.28 \\
\hline \multirow{3}{*}{40} & SOx Emis sions & Tons & -0.08 & -0.20 & -0.12 & - & -0.20 & -0.20 & -0.28 & -0.30 \\
\hline & NOx Emis sions & Tons & -0.05 & -0.11 & -0.07 & - & -0.11 & -0.12 & -0.17 & -0.18 \\
\hline & PM-10 Emis sions & Tons & -0.02 & -0.03 & -0.03 & - & -0.04 & -0.05 & -0.07 & -0.07 \\
\hline
\end{tabular}




\subsection{DLC Impact Metrics}

Table 4.21: DLC impact metrics for region 1

\begin{tabular}{|c|c|c|c|c|c|c|c|c|}
\hline Index & $\Delta$ Metric & Units & 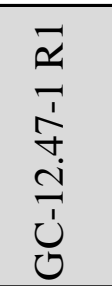 & $\begin{array}{l}\overrightarrow{1} \\
\vec{J} \\
\stackrel{d}{c} \\
\frac{1}{a}\end{array}$ & 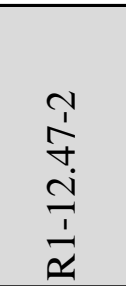 & 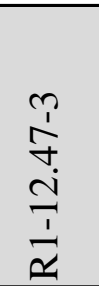 & 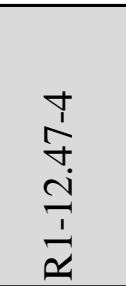 & $\begin{array}{l}\overline{1} \\
\dot{8} \\
\stackrel{1}{\alpha} \\
\stackrel{1}{\alpha}\end{array}$ \\
\hline 1 & $\begin{array}{l}\text { Hourly Customer } \\
\text { Electricity Usage }\end{array}$ & $\mathrm{kWh}$ & 0.43 & -1.87 & -0.75 & 0.02 & -0.89 & -0.02 \\
\hline 2 & $\begin{array}{l}\text { Monthly Customer } \\
\text { Electricity Usage }\end{array}$ & MWh & 0.32 & -1.36 & -0.54 & 0.01 & -0.65 & -0.01 \\
\hline \multirow{10}{*}{3} & Peak Generation & $\mathrm{kW}$ & 126.02 & $4,595.86$ & $1,554.98$ & -49.81 & $1,685.76$ & 14.17 \\
\hline & Nuclear & $\%$ & 0.00 & 0.00 & 0.00 & 0.00 & 0.59 & 0.00 \\
\hline & Solar & $\%$ & 0.00 & 0.00 & 0.00 & 0.00 & 0.04 & 0.00 \\
\hline & Bio & $\%$ & 0.00 & 0.00 & 0.00 & 0.00 & -0.05 & 0.00 \\
\hline & Wind & $\%$ & 0.00 & 0.00 & 0.00 & 0.00 & 0.52 & 0.00 \\
\hline & Coal & $\%$ & 0.00 & 0.00 & 0.00 & -0.76 & -1.50 & 0.00 \\
\hline & Hydroelectric & $\%$ & 0.00 & 0.00 & 0.00 & 0.00 & 10.56 & 0.00 \\
\hline & Natural Gas & $\%$ & 0.00 & 0.00 & 0.00 & 0.00 & -9.86 & 0.00 \\
\hline & Geothermal & $\%$ & 0.00 & 0.00 & 0.00 & -2.84 & -0.27 & 0.00 \\
\hline & Petroleum & $\%$ & 2.37 & 62.71 & 58.14 & -0.35 & 33.37 & 0.61 \\
\hline 4 & Peak Load & $\mathrm{kW}$ & 126.02 & $4,595.86$ & $1,554.98$ & -49.81 & $1,685.76$ & 14.17 \\
\hline 7 & $\begin{array}{l}\text { Annual Electricity } \\
\text { Production }\end{array}$ & MWh & 3.82 & -16.61 & -6.61 & 0.15 & -7.87 & -0.18 \\
\hline 12 & $\mathrm{CO} 2$ Emissions & Tons & 2.17 & 18.33 & 5.16 & -0.28 & 2.07 & -0.44 \\
\hline \multirow{3}{*}{13} & SOx Emissions & Tons & 0.00 & 0.02 & 0.01 & 0.00 & 0.01 & 0.00 \\
\hline & NOx Emissions & Tons & 0.00 & 0.01 & 0.00 & 0.00 & 0.00 & 0.00 \\
\hline & PM-10 Emissions & Tons & 0.00 & 0.00 & 0.00 & 0.00 & 0.00 & 0.00 \\
\hline \multirow[b]{2}{*}{21} & Feeder Real Load & $\mathrm{kW}$ & 0.44 & -1.90 & -0.75 & 0.02 & -0.90 & -0.02 \\
\hline & \begin{tabular}{|l} 
Feeder Reactive \\
Load
\end{tabular} & kVAR & 0.29 & 6.21 & 2.11 & 0.25 & 2.61 & 0.37 \\
\hline 29 & Distribution Losses & $\%$ & 0.00 & 0.00 & 0.00 & 0.00 & 0.00 & 0.00 \\
\hline 30 & \begin{tabular}{|l|} 
Distribution Power \\
Factor
\end{tabular} & pf & 0.000 & 0.000 & 0.000 & 0.000 & 0.000 & 0.000 \\
\hline 39 & $\mathrm{CO} 2$ Emissions & Tons & 2.18 & 18.82 & 5.33 & -0.28 & 2.10 & -0.45 \\
\hline \multirow{3}{*}{40} & SOx Emissions & Tons & 0.00 & 0.02 & 0.01 & 0.00 & 0.01 & 0.00 \\
\hline & NOx Emissions & Tons & 0.00 & 0.01 & 0.00 & 0.00 & 0.00 & 0.00 \\
\hline & PM-10 Emissions & Tons & 0.00 & 0.00 & 0.00 & 0.00 & 0.00 & 0.00 \\
\hline
\end{tabular}


Table 4.22: DLC impact metrics for region 2

\begin{tabular}{|c|c|c|c|c|c|c|c|c|}
\hline Index & $\Delta$ Metric & Units & 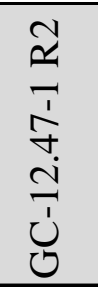 & 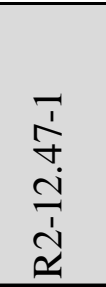 & 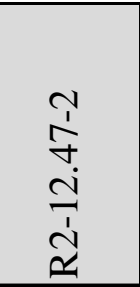 & $\begin{array}{l}m \\
\stackrel{1}{+} \\
\dot{d} \\
\stackrel{1}{1} \\
\stackrel{d}{d}\end{array}$ & 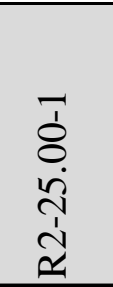 & 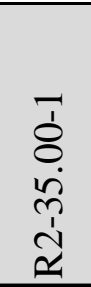 \\
\hline 1 & $\begin{array}{l}\text { Hourly Customer } \\
\text { Electricity Usage }\end{array}$ & $\mathrm{kWh}$ & 0.46 & 0.11 & -1.56 & -2.78 & -1.06 & 0.98 \\
\hline 2 & $\begin{array}{l}\text { Monthly Customer } \\
\text { Electricity Usage }\end{array}$ & MWh & 0.34 & 0.08 & -1.14 & -2.03 & -0.78 & 0.71 \\
\hline \multirow{10}{*}{3} & Peak Generation & $\mathrm{kW}$ & 84.06 & -92.09 & $1,513.51$ & $3,408.54$ & 117.80 & -42.60 \\
\hline & Nuclear & $\%$ & 0.00 & 0.00 & 0.00 & -1.62 & 0.00 & 0.00 \\
\hline & Solar & $\%$ & 0.00 & 0.00 & 0.00 & 0.00 & 0.00 & 0.00 \\
\hline & Bio & $\%$ & 0.00 & 0.00 & 0.00 & -0.02 & 0.00 & 0.00 \\
\hline & Wind & $\%$ & 0.00 & 0.00 & 0.00 & -0.29 & 0.00 & 0.00 \\
\hline & Coal & $\%$ & 0.00 & 0.00 & 0.00 & 1.64 & 0.00 & 0.00 \\
\hline & Hydroelectric & $\%$ & 0.00 & -0.96 & 0.00 & -1.63 & 0.00 & 0.00 \\
\hline & Natural Gas & $\%$ & 0.00 & 0.00 & 0.00 & 1.86 & 0.00 & 0.00 \\
\hline & Geothermal & $\%$ & 0.00 & -0.07 & 0.00 & 0.00 & 0.00 & 0.00 \\
\hline & Petroleum & $\%$ & 1.46 & -0.43 & 26.20 & 40.26 & 0.70 & -0.34 \\
\hline 4 & Peak Load & $\mathrm{kW}$ & 84.06 & -92.09 & $1,513.51$ & $3,408.54$ & 117.80 & -42.60 \\
\hline 7 & \begin{tabular}{|l} 
Annual Electricity \\
Production
\end{tabular} & MWh & 4.07 & 0.99 & -14.13 & -25.01 & -9.76 & 8.52 \\
\hline 12 & $\mathrm{CO} 2$ Emissions & Tons & 2.78 & 7.54 & -2.38 & -6.02 & 17.56 & 11.88 \\
\hline \multirow{3}{*}{13} & SOx Emissions & Tons & 0.00 & 0.01 & 0.00 & 0.00 & 0.02 & 0.01 \\
\hline & NOx Emissions & Tons & 0.00 & 0.00 & 0.00 & 0.00 & 0.01 & 0.00 \\
\hline & PM-10 Emissions & Tons & 0.00 & 0.00 & 0.00 & 0.00 & 0.00 & 0.00 \\
\hline \multirow{2}{*}{21} & Feeder Real Load & $\mathrm{kW}$ & 0.46 & 0.11 & -1.61 & -2.85 & -1.11 & 0.97 \\
\hline & Feeder Reactive Load & kVAR & 0.30 & 1.26 & 3.03 & 5.44 & 4.05 & 2.23 \\
\hline 29 & Distribution Losses & $\%$ & 0.00 & 0.00 & 0.00 & 0.00 & 0.00 & 0.00 \\
\hline 30 & $\begin{array}{l}\text { Distribution Power } \\
\text { Factor }\end{array}$ & $\mathrm{pf}$ & 0.000 & 0.000 & 0.000 & 0.000 & 0.000 & 0.000 \\
\hline 39 & $\mathrm{CO} 2$ Emis sions & Tons & 2.78 & 7.63 & -2.53 & -6.21 & 17.56 & 11.93 \\
\hline \multirow{3}{*}{40} & SOx Emissions & Tons & 0.00 & 0.01 & 0.00 & 0.00 & 0.02 & 0.01 \\
\hline & NOx Emissions & Tons & 0.00 & 0.00 & 0.00 & 0.00 & 0.01 & 0.00 \\
\hline & PM-10 Emissions & Tons & 0.00 & 0.00 & 0.00 & 0.00 & 0.00 & 0.00 \\
\hline
\end{tabular}


Table 4.23: DLC impact metrics for region 3

\begin{tabular}{|c|c|c|c|c|c|c|}
\hline Index & $\Delta$ Metric & Units & 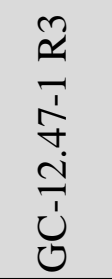 & 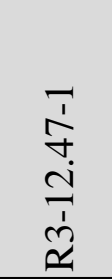 & 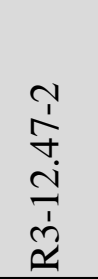 & 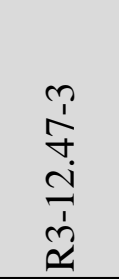 \\
\hline 1 & $\begin{array}{l}\text { Hourly Customer } \\
\text { Electricity Usage }\end{array}$ & $\mathrm{kWh}$ & -0.61 & -0.22 & 1.50 & -1.76 \\
\hline 2 & $\begin{array}{l}\text { Monthly Customer } \\
\text { Electricity Usage }\end{array}$ & MWh & -0.44 & -0.16 & 1.09 & -1.29 \\
\hline \multirow{10}{*}{3} & Peak Generation & $\mathrm{kW}$ & 133.40 & -422.98 & 39.52 & $2,286.35$ \\
\hline & Nuclear & $\%$ & 1.07 & 0.00 & 0.00 & 0.00 \\
\hline & Solar & $\%$ & 0.00 & 0.00 & 0.00 & 0.00 \\
\hline & Bio & $\%$ & 0.02 & 0.00 & 0.00 & 0.00 \\
\hline & Wind & $\%$ & 0.40 & 0.00 & 0.00 & 0.00 \\
\hline & Coal & $\%$ & 1.28 & 0.00 & 0.00 & 0.00 \\
\hline & Hydroelectric & $\%$ & 0.82 & -2.89 & 0.00 & 0.00 \\
\hline & Natural Gas & $\%$ & -3.79 & 0.00 & 0.00 & 0.00 \\
\hline & Geothermal & $\%$ & 0.15 & -1.40 & 0.00 & 0.00 \\
\hline & Petroleum & $\%$ & 2.16 & -0.25 & 0.89 & 27.16 \\
\hline 4 & Peak Load & $\mathrm{kW}$ & 133.40 & -422.98 & 39.52 & $2,286.35$ \\
\hline 7 & \begin{tabular}{|l|} 
Annual Electricity \\
Production
\end{tabular} & $\mathrm{MWh}$ & -5.36 & -2.11 & 13.33 & -15.95 \\
\hline 12 & $\mathrm{CO} 2$ Emissions & Tons & -5.45 & 3.65 & 7.66 & 2.37 \\
\hline \multirow{3}{*}{13} & SOx Emissions & Tons & 0.00 & 0.00 & 0.00 & 0.01 \\
\hline & NOx Emissions & Tons & 0.00 & 0.00 & 0.00 & 0.00 \\
\hline & PM-10 Emis sions & Tons & 0.00 & 0.00 & 0.00 & 0.00 \\
\hline \multirow[b]{2}{*}{21} & Feeder Real Load & $\mathrm{kW}$ & -0.61 & -0.24 & 1.52 & -1.82 \\
\hline & $\begin{array}{l}\text { Feeder Reactive } \\
\text { Load } \\
\end{array}$ & kVAR & 0.01 & 2.21 & 0.73 & 4.96 \\
\hline 29 & Distribution Losses & $\%$ & 0.00 & 0.00 & 0.00 & 0.00 \\
\hline 30 & \begin{tabular}{|l|} 
Distribution Power \\
Factor
\end{tabular} & $\mathrm{pf}$ & 0.000 & 0.000 & 0.000 & 0.000 \\
\hline 39 & $\mathrm{CO} 2$ Emissions & Tons & -5.48 & 3.61 & 7.80 & 2.47 \\
\hline \multirow{3}{*}{40} & SOx Emissions & Tons & 0.00 & 0.00 & 0.00 & 0.01 \\
\hline & NOx Emissions & Tons & 0.00 & 0.00 & 0.00 & 0.00 \\
\hline & PM-10 Emissions & Tons & 0.00 & 0.00 & 0.00 & 0.00 \\
\hline
\end{tabular}


Table 4.24: DLC impact metrics for region 4

\begin{tabular}{|c|c|c|c|c|c|c|}
\hline Index & $\Delta$ Metric & Units & 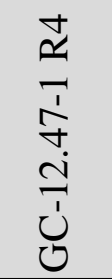 & 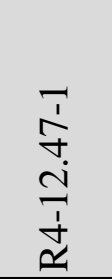 & 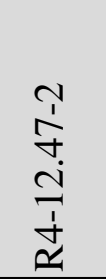 & 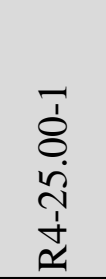 \\
\hline 1 & $\begin{array}{l}\text { Hourly Customer } \\
\text { Electricity Usage }\end{array}$ & $\mathrm{kWh}$ & 0.23 & -0.50 & -0.48 & -0.25 \\
\hline 2 & $\begin{array}{l}\text { Monthly Customer } \\
\text { Electricity Usage }\end{array}$ & MWh & 0.17 & -0.36 & -0.35 & -0.18 \\
\hline \multirow{10}{*}{3} & Peak Generation & $\mathrm{kW}$ & 143.41 & 482.89 & 485.21 & 272.63 \\
\hline & Nuclear & $\%$ & 1.67 & 0.00 & -1.67 & -1.67 \\
\hline & Solar & $\%$ & 0.00 & 0.00 & 0.00 & 0.00 \\
\hline & Bio & $\%$ & 0.03 & 0.00 & -0.03 & -0.03 \\
\hline & Wind & $\%$ & -0.01 & 0.00 & 0.01 & 0.01 \\
\hline & Coal & $\%$ & -1.08 & 0.00 & 1.08 & 1.08 \\
\hline & Hydroelectric & $\%$ & 0.89 & 0.00 & -0.89 & -0.89 \\
\hline & Natural Gas & $\%$ & -1.35 & 0.00 & 1.35 & 1.35 \\
\hline & Geothermal & $\%$ & 0.00 & 0.00 & 0.00 & 0.00 \\
\hline & Petroleum & $\%$ & 3.45 & 10.06 & 23.30 & 29.04 \\
\hline 4 & Peak Load & $\mathrm{kW}$ & 143.41 & 482.89 & 485.21 & 272.63 \\
\hline 7 & $\begin{array}{l}\text { Annual Electricity } \\
\text { Production }\end{array}$ & MWh & 2.01 & -4.59 & -4.27 & -2.21 \\
\hline 12 & $\mathrm{CO} 2$ Emis sions & Tons & 2.25 & 6.00 & -1.17 & -1.57 \\
\hline \multirow{3}{*}{13} & SOx Emissions & Tons & 0.00 & 0.01 & 0.00 & 0.00 \\
\hline & NOx Emissions & Tons & 0.00 & 0.00 & 0.00 & 0.00 \\
\hline & PM-10 Emissions & Tons & 0.00 & 0.00 & 0.00 & 0.00 \\
\hline \multirow[b]{2}{*}{21} & Feeder Real Load & $\mathrm{kW}$ & 0.23 & -0.52 & -0.49 & -0.25 \\
\hline & \begin{tabular}{|l} 
Feeder Reactive \\
Load \\
\end{tabular} & kVAR & 0.24 & 2.12 & 1.34 & 0.60 \\
\hline 29 & Distribution Losses & $\%$ & 0.00 & 0.00 & 0.00 & 0.00 \\
\hline 30 & \begin{tabular}{|l}
$\begin{array}{l}\text { Distribution Power } \\
\text { Factor }\end{array}$ \\
\end{tabular} & $\mathrm{pf}$ & 0.000 & 0.000 & 0.000 & 0.000 \\
\hline 39 & $\mathrm{CO} 2$ Emis sions & Tons & 2.25 & 6.12 & -1.19 & -1.60 \\
\hline \multirow{3}{*}{40} & SOx Emissions & Tons & 0.00 & 0.01 & 0.00 & 0.00 \\
\hline & NOx Emissions & Tons & 0.00 & 0.00 & 0.00 & 0.00 \\
\hline & PM-10 Emissions & Tons & 0.00 & 0.00 & 0.00 & 0.00 \\
\hline
\end{tabular}


Table 4.25: DLC impact metrics for region 5

\begin{tabular}{|c|c|c|c|c|c|c|c|c|c|c|}
\hline Index & $\Delta$ Metric & Units & 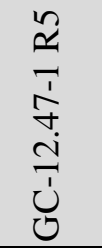 & 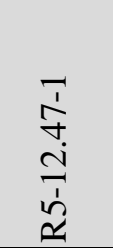 & 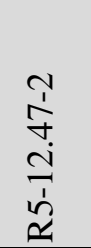 & 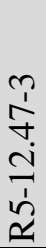 & 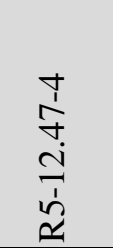 & 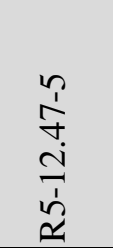 & 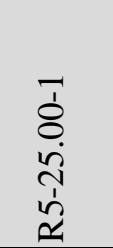 & 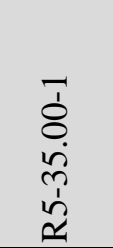 \\
\hline 1 & $\begin{array}{l}\text { Hourly Customer } \\
\text { Electricity Usage }\end{array}$ & kWh & 0.62 & -0.81 & 0.07 & - & -0.99 & -2.19 & -2.98 & -3.08 \\
\hline 2 & $\begin{array}{l}\text { Monthly Customer } \\
\text { Electricity Usage }\end{array}$ & MWh & 0.46 & -0.59 & 0.05 & - & -0.72 & -1.60 & -2.18 & -2.25 \\
\hline \multirow{10}{*}{3} & Peak Generation & $\mathrm{kW}$ & 275.50 & $1,207.79$ & 73.07 & - & $1,163.83$ & $2,538.50$ & $3,678.70$ & $3,435.60$ \\
\hline & Nuclear & $\%$ & 0.00 & 0.00 & 0.00 & - & 0.00 & 0.32 & 0.00 & 0.00 \\
\hline & Solar & $\%$ & 0.00 & 0.00 & 0.00 & - & 0.00 & 0.00 & 0.00 & 0.00 \\
\hline & Bio & $\%$ & 0.00 & 0.00 & 0.00 & - & 0.00 & 0.02 & 0.00 & 0.00 \\
\hline & Wind & $\%$ & 0.00 & 0.00 & 0.00 & - & 0.00 & -0.26 & 0.00 & 0.00 \\
\hline & Coal & $\%$ & 0.00 & 0.00 & 0.00 & - & 0.00 & -0.20 & 0.00 & 0.00 \\
\hline & Hydroelectric & $\%$ & 0.00 & 0.00 & 0.00 & - & 0.00 & -0.15 & 0.00 & 0.00 \\
\hline & Natural Gas & $\%$ & 0.00 & 0.00 & 0.00 & - & 0.00 & 0.39 & 0.00 & 0.00 \\
\hline & Geothermal & $\%$ & 0.00 & 0.00 & 0.00 & - & 0.00 & 0.00 & 0.00 & 0.00 \\
\hline & Petroleum & $\%$ & 4.72 & 12.78 & 1.46 & - & 15.45 & 28.35 & 29.95 & 27.64 \\
\hline 4 & Peak Load & $\mathrm{kW}$ & 275.50 & $1,207.79$ & 73.07 & - & $1,163.83$ & $2,538.50$ & $3,678.70$ & $3,435.60$ \\
\hline 7 & $\begin{array}{l}\text { Annual Electricity } \\
\text { Production }\end{array}$ & MWh & 5.52 & -7.30 & 0.53 & - & -9.01 & -20.13 & -26.88 & -27.52 \\
\hline 12 & $\mathrm{CO} 2$ Emissions & Tons & 5.19 & -14.14 & -2.10 & - & -14.95 & -27.47 & -39.13 & -40.07 \\
\hline \multirow{3}{*}{13} & SOx Emis sions & Tons & 0.00 & -0.01 & 0.00 & - & -0.01 & -0.02 & -0.02 & -0.02 \\
\hline & NOx Emis sions & Tons & 0.00 & -0.01 & 0.00 & - & -0.01 & -0.01 & -0.02 & -0.02 \\
\hline & PM-10 Emissions & Tons & 0.00 & 0.00 & 0.00 & - & 0.00 & -0.01 & -0.01 & -0.01 \\
\hline \multirow[b]{2}{*}{21} & Feeder Real Load & $\mathrm{kW}$ & 0.63 & -0.83 & 0.06 & - & -1.03 & -2.30 & -3.07 & -3.14 \\
\hline & $\begin{array}{l}\text { Feeder Reactive } \\
\text { Load }\end{array}$ & kVAR & 0.35 & 3.95 & 1.48 & - & 3.58 & 5.42 & 7.71 & 7.96 \\
\hline 29 & Distribution Losses & $\%$ & 0.00 & 0.00 & 0.00 & - & 0.00 & 0.00 & 0.00 & 0.00 \\
\hline 30 & $\begin{array}{l}\text { Distribution Power } \\
\text { Factor }\end{array}$ & $\mathrm{pf}$ & 0.000 & 0.000 & 0.000 & - & 0.000 & 0.000 & 0.000 & 0.000 \\
\hline 39 & $\mathrm{CO} 2$ Emissions & Tons & 5.22 & -14.37 & -2.19 & - & -15.32 & -28.32 & -39.82 & -40.65 \\
\hline \multirow{3}{*}{40} & SOx Emis sions & Tons & 0.00 & -0.01 & 0.00 & - & -0.01 & -0.02 & -0.02 & -0.03 \\
\hline & NOx Emis sions & Tons & 0.00 & -0.01 & 0.00 & - & -0.01 & -0.01 & -0.02 & -0.02 \\
\hline & PM-10 Emis sions & Tons & 0.00 & 0.00 & 0.00 & - & 0.00 & -0.01 & -0.01 & -0.01 \\
\hline
\end{tabular}




\subsection{Additional Impact Metrics}

Table 4.26: Additional TOU/CPP with technology impact metrics for region 1

\begin{tabular}{|c|c|c|c|c|c|c|c|c|}
\hline Index & $\Delta$ Metric & Units & 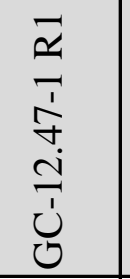 & 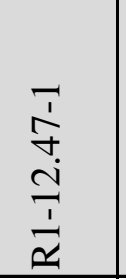 & 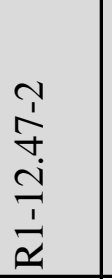 & 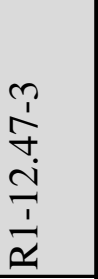 & 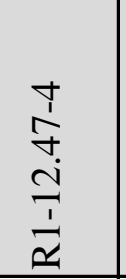 & 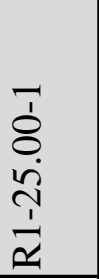 \\
\hline \multirow{5}{*}{$7 *$} & Instantaneous Peak Load & $\mathrm{kW}$ & $-1,587.2$ & -751.2 & -490.4 & -391.4 & -645.7 & -527.9 \\
\hline & 1 Hour Peak Load & $\mathrm{kW}$ & 20.8 & $-1,475.0$ & -411.9 & 4.1 & -617.6 & -217.2 \\
\hline & 6 Hour Peak Load & $\mathrm{kW}$ & -192.9 & -877.2 & -276.0 & -22.7 & -374.3 & -105.0 \\
\hline & Flattened Peak Load & $\mathrm{kW}$ & -534.8 & $-1,483.5$ & -548.6 & -201.6 & $-1,225.6$ & -278.2 \\
\hline & $\begin{array}{l}\text { Flattened Peak Load } \\
\text { including Rebound }\end{array}$ & $\mathrm{kW}$ & -479.9 & $-1,316.4$ & -488.9 & -190.9 & $-1,201.1$ & -254.9 \\
\hline \multirow{5}{*}{$7^{*}$} & Instaneous Peak Load & $\%$ & -32.1 & -13.4 & -21.6 & -33.6 & -17.1 & -26.1 \\
\hline & 1 Hour Peak Load & $\%$ & 0.4 & -22.3 & -17.0 & 0.4 & -15.2 & -9.9 \\
\hline & 6 Hour Peak Load & $\%$ & -3.9 & -13.5 & -11.9 & -2.3 & -10.5 & -5.0 \\
\hline & Flattened Peak Load & $\%$ & -10.1 & -20.2 & -20.5 & -16.0 & -24.3 & -12.0 \\
\hline & $\begin{array}{l}\text { Flattened Peak Load } \\
\text { including Rebound }\end{array}$ & $\%$ & -9.0 & -18.0 & -18.3 & -15.1 & -23.8 & -11.0 \\
\hline
\end{tabular}


Table 4.27: Additional TOU/CPP with technology impact metrics for region 2

\begin{tabular}{|c|c|c|c|c|c|c|c|c|}
\hline Index & $\Delta$ Metric & Units & 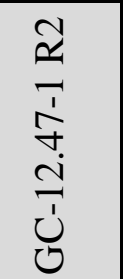 & 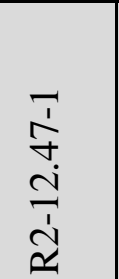 & 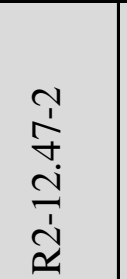 & 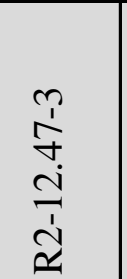 & 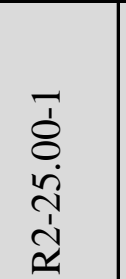 & 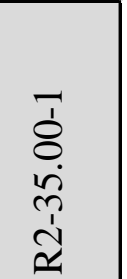 \\
\hline \multirow{5}{*}{$7 *$} & Instantaneous Peak Load & $\mathrm{kW}$ & $-1,627.2$ & $-1,536.9$ & $-1,296.7$ & $-3,000.6$ & $-5,641.9$ & $-2,094.5$ \\
\hline & 1 Hour Peak Load & $\mathrm{kW}$ & -566.8 & -119.4 & -983.8 & $-1,940.1$ & $-2,642.3$ & 87.2 \\
\hline & 6 Hour Peak Load & $\mathrm{kW}$ & -195.7 & -42.4 & -181.6 & -785.4 & -569.5 & 94.0 \\
\hline & Flattened Peak Load & $\mathrm{kW}$ & -676.8 & -731.4 & -914.7 & $-2,484.5$ & $-2,531.3$ & $-2,338.1$ \\
\hline & \begin{tabular}{|l|} 
Flattened Peak Load \\
including Rebound
\end{tabular} & $\mathrm{kW}$ & -660.0 & -731.4 & -887.2 & $-2,333.9$ & $-2,358.0$ & $-2,338.1$ \\
\hline \multirow{5}{*}{ 7* } & Instaneous Peak Load & $\%$ & -31.4 & -26.1 & -58.1 & -39.1 & -36.1 & -21.2 \\
\hline & 1 Hour Peak Load & $\%$ & -10.3 & -2.0 & -40.2 & -24.6 & -16.5 & 0.9 \\
\hline & 6 Hour Peak Load & $\%$ & -4.7 & -1.0 & -15.0 & -14.3 & -4.1 & 1.0 \\
\hline & Flattened Peak Load & $\%$ & -11.8 & -11.6 & -35.6 & -29.0 & -15.0 & -18.4 \\
\hline & $\begin{array}{l}\text { Flattened Peak Load } \\
\text { including Rebound }\end{array}$ & $\%$ & -11.5 & -11.6 & -34.6 & -27.3 & -14.0 & -18.4 \\
\hline
\end{tabular}


Table 4.28: Additional TOU/CPP with technology impact metrics for region 3

\begin{tabular}{|c|c|c|c|c|c|c|}
\hline Index & $\Delta$ Metric & Units & 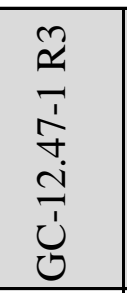 & 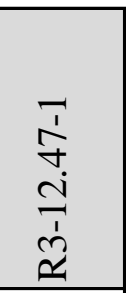 & 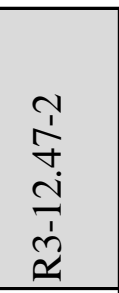 & 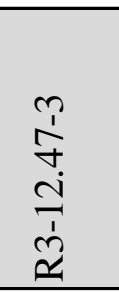 \\
\hline \multirow{5}{*}{$7^{*}$} & Instantaneous Peak Load & $\mathrm{kW}$ & $-2,369.0$ & $-2,788.8$ & $-1,595.0$ & $-2,042.8$ \\
\hline & 1 Hour Peak Load & $\mathrm{kW}$ & -52.4 & -193.8 & -436.9 & -742.8 \\
\hline & 6 Hour Peak Load & $\mathrm{kW}$ & -173.6 & -617.5 & 36.9 & -231.5 \\
\hline & Flattened Peak Load & $\mathrm{kW}$ & $-1,043.4$ & $-1,247.7$ & -621.3 & $-1,429.3$ \\
\hline & $\begin{array}{l}\text { Flattened Peak Load } \\
\text { including Rebound }\end{array}$ & $\mathrm{kW}$ & $-1,043.4$ & $-1,247.7$ & -621.2 & $-1,429.3$ \\
\hline \multirow{5}{*}{$7^{*}$} & Instaneous Peak Load & $\%$ & -39.0 & -33.2 & -38.5 & -26.4 \\
\hline & 1 Hour Peak Load & $\%$ & -0.9 & -2.3 & -9.9 & -9.6 \\
\hline & 6 Hour Peak Load & $\%$ & -3.9 & -9.4 & 1.2 & -4.1 \\
\hline & Flattened Peak Load & $\%$ & -15.8 & -13.4 & -14.1 & -17.0 \\
\hline & $\begin{array}{l}\text { Flattened Peak Load } \\
\text { including Rebound }\end{array}$ & $\%$ & -15.8 & -13.4 & -14.1 & -17.0 \\
\hline
\end{tabular}


Table 4.29: Additional TOU/CPP with technology impact metrics for region 4

\begin{tabular}{|c|c|c|c|c|c|c|}
\hline Index & $\Delta$ Metric & Units & 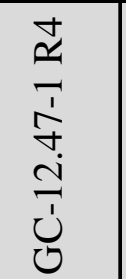 & 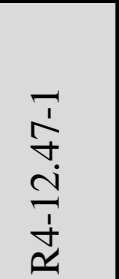 & 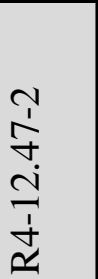 & $\begin{array}{l}\overline{1} \\
8 \\
\dot{d} \\
\tilde{y} \\
\dot{d} \\
\simeq\end{array}$ \\
\hline \multirow{5}{*}{$7 *$} & Instantaneous Peak Load & $\mathrm{kW}$ & $-2,143.6$ & $-1,940.4$ & -911.4 & -462.4 \\
\hline & 1 Hour Peak Load & $\mathrm{kW}$ & -401.0 & -663.1 & -494.8 & -109.4 \\
\hline & 6 Hour Peak Load & $\mathrm{kW}$ & -305.3 & -456.2 & -232.5 & -55.9 \\
\hline & Flattened Peak Load & $\mathrm{kW}$ & -747.1 & $-1,195.9$ & -644.0 & -345.5 \\
\hline & \begin{tabular}{|l|}
$\begin{array}{l}\text { Flattened Peak Load } \\
\text { including Rebound }\end{array}$ \\
\end{tabular} & $\mathrm{kW}$ & -715.8 & $-1,047.7$ & -576.4 & -308.2 \\
\hline \multirow{5}{*}{$7^{*}$} & Instaneous Peak Load & $\%$ & -38.0 & -44.6 & -46.6 & -55.3 \\
\hline & 1 Hour Peak Load & $\%$ & -6.7 & -15.7 & -24.4 & -14.2 \\
\hline & 6 Hour Peak Load & $\%$ & -6.0 & -12.7 & -15.5 & -10.9 \\
\hline & Flattened Peak Load & $\%$ & -12.0 & -24.9 & -29.2 & -36.6 \\
\hline & $\begin{array}{l}\text { Flattened Peak Load } \\
\text { including Rebound }\end{array}$ & $\%$ & -11.5 & -21.8 & -26.1 & -32.6 \\
\hline
\end{tabular}


Table 4.30: Additional TOU/CPP with technology impact metrics for region 5

\begin{tabular}{|c|c|c|c|c|c|c|c|c|c|c|}
\hline Index & $\Delta$ Metric & Units & 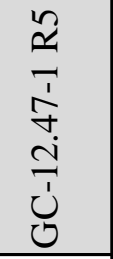 & 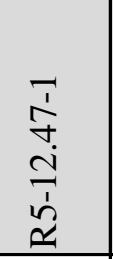 & 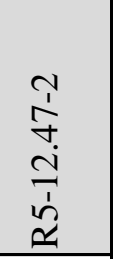 & 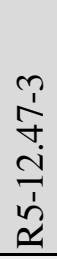 & 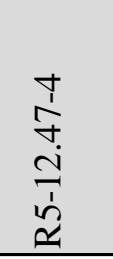 & 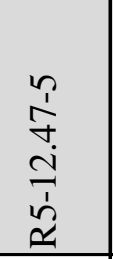 & 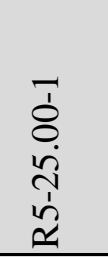 & 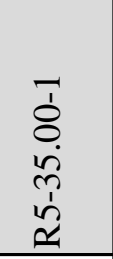 \\
\hline \multirow{5}{*}{$7 *$} & Instantaneous Peak Load & $\mathrm{kW}$ & $-1,856.2$ & $-3,048.2$ & $-1,878.2$ & - & $-2,848.5$ & $-3,462.8$ & $-4,917.1$ & $-4,679.4$ \\
\hline & 1 Hour Peak Load & $\mathrm{kW}$ & -290.4 & $-2,345.4$ & -978.7 & - & $-2,104.6$ & $-3,057.5$ & $-3,844.2$ & $-3,882.1$ \\
\hline & 6 Hour Peak Load & $\mathrm{kW}$ & -299.7 & -822.9 & -181.4 & - & -487.5 & -988.8 & $-1,483.6$ & $-1,440.3$ \\
\hline & Flattened Peak Load & $\mathrm{kW}$ & -586.2 & $-1,633.0$ & -775.3 & - & $-1,558.5$ & $-2,379.1$ & $-3,214.0$ & $-3,098.3$ \\
\hline & $\begin{array}{l}\text { Flattened Peak Load } \\
\text { including Rebound }\end{array}$ & $\mathrm{kW}$ & -531.0 & $-1,333.3$ & -663.6 & - & $-1,223.4$ & $-1,820.5$ & $-2,478.8$ & $-2,401.5$ \\
\hline \multirow{5}{*}{$7^{*}$} & Instaneous Peak Load & $\%$ & -34.2 & -37.9 & -41.1 & - & -42.9 & -43.3 & -47.3 & -44.6 \\
\hline & 1 Hour Peak Load & $\%$ & -5.4 & -25.7 & -21.0 & - & -30.0 & -36.4 & -33.7 & -33.4 \\
\hline & 6 Hour Peak Load & $\%$ & -5.6 & -9.6 & -4.0 & - & -7.4 & -12.3 & -13.6 & -13.2 \\
\hline & Flattened Peak Load & $\%$ & -10.0 & -17.3 & -15.5 & - & -20.7 & -26.3 & -26.2 & -24.9 \\
\hline & $\begin{array}{l}\text { Flattened Peak Load } \\
\text { including Rebound }\end{array}$ & $\%$ & -9.0 & -14.1 & -13.3 & - & -16.2 & -20.1 & -20.2 & -19.3 \\
\hline
\end{tabular}


Table 4.31: Additional DLC with technology impact metrics for region 1

\begin{tabular}{|c|c|c|c|c|c|c|c|c|}
\hline Index & $\Delta$ Metric & Units & 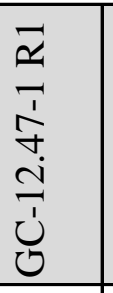 & 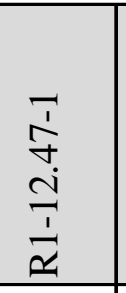 & 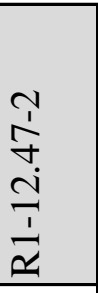 & 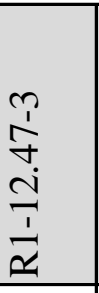 & 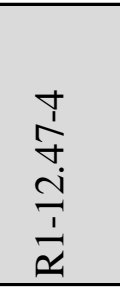 & 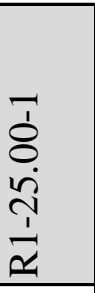 \\
\hline \multirow{5}{*}{$7 *$} & Instantaneous Peak Load & $\mathrm{kW}$ & -496.9 & $-1,990.7$ & -741.6 & -60.3 & -701.5 & -255.8 \\
\hline & 1 Hour Peak Load & $\mathrm{kW}$ & -288.8 & $-1,690.3$ & -504.3 & -71.8 & -625.2 & -152.6 \\
\hline & 6 Hour Peak Load & $\mathrm{kW}$ & -65.3 & $-1,166.9$ & -246.3 & 115.3 & -130.7 & -58.0 \\
\hline & Flattened Peak Load & $\mathrm{kW}$ & -208.3 & $-2,062.2$ & -715.5 & -150.4 & $-1,252.8$ & -142.9 \\
\hline & \begin{tabular}{|l|}
$\begin{array}{l}\text { Flattened Peak Load } \\
\text { including Rebound }\end{array}$ \\
\end{tabular} & $\mathrm{kW}$ & -208.3 & $-1,223.3$ & -434.4 & -147.4 & $-1,042.2$ & -142.8 \\
\hline \multirow{5}{*}{$7^{*}$} & Instaneous Peak Load & $\%$ & -10.1 & -31.6 & -32.9 & -5.8 & -18.4 & -11.8 \\
\hline & 1 Hour Peak Load & $\%$ & -5.5 & -24.8 & -19.8 & -6.2 & -15.1 & -6.6 \\
\hline & 6 Hour Peak Load & $\%$ & -1.4 & -19.0 & -10.9 & 11.6 & -3.9 & -3.0 \\
\hline & Flattened Peak Load & $\%$ & -3.9 & -28.1 & -26.8 & -11.9 & -24.8 & -6.2 \\
\hline & $\begin{array}{l}\text { Flattened Peak Load } \\
\text { including Rebound }\end{array}$ & $\%$ & -3.9 & -16.7 & -16.2 & -11.7 & -20.6 & -6.2 \\
\hline
\end{tabular}


Table 4.32: Additional DLC with technology impact metrics for region 2

\begin{tabular}{|c|c|c|c|c|c|c|c|c|}
\hline Index & $\Delta$ Metric & Units & 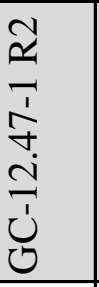 & 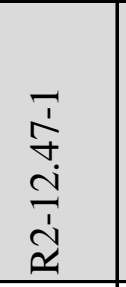 & 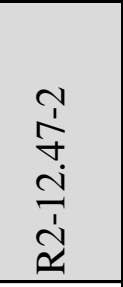 & 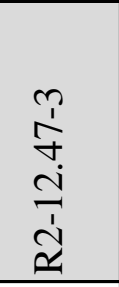 & 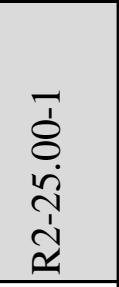 & $\begin{array}{l}\overline{1} \\
\delta \\
\ddot{n} \\
\tilde{1} \\
\tilde{d}\end{array}$ \\
\hline \multirow{5}{*}{$7^{*}$} & Instantaneous Peak Load & $\mathrm{kW}$ & -462.5 & $-1,103.6$ & $-1,212.2$ & $-2,656.7$ & $-2,677.7$ & -243.7 \\
\hline & 1 Hour Peak Load & $\mathrm{kW}$ & -456.7 & -180.1 & -660.1 & $-1,754.1$ & $-1,140.5$ & -510.1 \\
\hline & 6 Hour Peak Load & $\mathrm{kW}$ & -39.8 & -249.1 & 81.7 & -802.9 & -759.3 & -226.2 \\
\hline & Flattened Peak Load & $\mathrm{kW}$ & -474.6 & -758.9 & $-1,051.4$ & $-2,649.0$ & $-1,927.9$ & $-1,688.1$ \\
\hline & $\begin{array}{l}\text { Flattened Peak Load } \\
\text { including Rebound }\end{array}$ & $\mathrm{kW}$ & -474.6 & -758.9 & -956.5 & $-2,256.8$ & $-1,839.9$ & $-1,688.1$ \\
\hline \multirow{5}{*}{ 7* } & Instaneous Peak Load & $\%$ & -8.6 & -18.7 & -51.3 & -34.4 & -17.1 & -2.5 \\
\hline & 1 Hour Peak Load & $\%$ & -8.1 & -3.0 & -27.1 & -21.7 & -7.2 & -4.9 \\
\hline & 6 Hour Peak Load & $\%$ & -1.0 & -6.4 & 7.4 & -15.4 & -5.4 & -2.7 \\
\hline & Flattened Peak Load & $\%$ & -8.3 & -12.1 & -40.9 & -31.0 & -11.4 & -13.3 \\
\hline & $\begin{array}{l}\text { Flattened Peak Load } \\
\text { including Rebound }\end{array}$ & $\%$ & -8.3 & -12.1 & -37.3 & -26.4 & -10.9 & -13.3 \\
\hline
\end{tabular}


Table 4.33: Additional DLC with technology impact metrics for region 3

\begin{tabular}{|c|c|c|c|c|c|c|}
\hline Index & $\Delta$ Metric & Units & 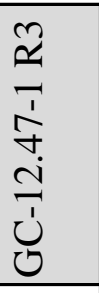 & 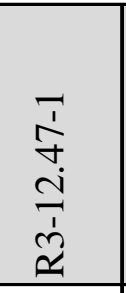 & 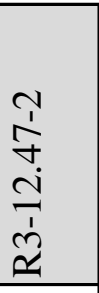 & 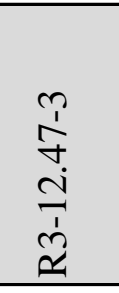 \\
\hline \multirow{5}{*}{$7 *$} & Instantaneous Peak Load & $\mathrm{kW}$ & -256.4 & $-1,502.5$ & -560.2 & $-2,095.9$ \\
\hline & 1 Hour Peak Load & $\mathrm{kW}$ & -276.3 & -346.3 & -240.1 & $-1,730.2$ \\
\hline & 6 Hour Peak Load & $\mathrm{kW}$ & -127.8 & 58.0 & 193.7 & -543.7 \\
\hline & Flattened Peak Load & $\mathrm{kW}$ & -803.2 & $-1,239.3$ & -444.5 & $-1,979.6$ \\
\hline & $\begin{array}{l}\text { Flattened Peak Load } \\
\text { including Rebound } \\
\end{array}$ & $\mathrm{kW}$ & -803.2 & $-1,239.3$ & -444.5 & $-1,592.0$ \\
\hline \multirow{5}{*}{$7^{*}$} & Instaneous Peak Load & $\%$ & -4.4 & -17.8 & -13.9 & -27.8 \\
\hline & 1 Hour Peak Load & $\%$ & -4.5 & -4.0 & -5.8 & -21.5 \\
\hline & 6 Hour Peak Load & $\%$ & -2.9 & 1.0 & 6.9 & -9.6 \\
\hline & Flattened Peak Load & $\%$ & -12.2 & -13.3 & -10.1 & -23.5 \\
\hline & $\begin{array}{l}\text { Flattened Peak Load } \\
\text { including Rebound }\end{array}$ & $\%$ & -12.2 & -13.3 & -10.1 & -18.9 \\
\hline
\end{tabular}


Table 4.34: Additional DLC with technology impact metrics for region 4

\begin{tabular}{|c|c|c|c|c|c|c|}
\hline Index & $\Delta$ Metric & Units & 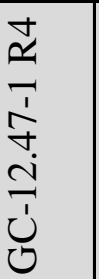 & 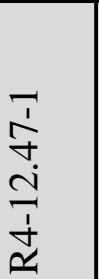 & 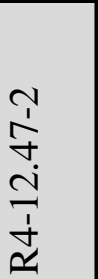 & $\begin{array}{l}\overline{1} \\
\delta \\
\dot{d} \\
\dot{1} \\
\dot{1}\end{array}$ \\
\hline \multirow{5}{*}{$7^{*}$} & Instantaneous Peak Load & $\mathrm{kW}$ & -435.3 & -989.7 & -644.8 & -213.0 \\
\hline & 1 Hour Peak Load & $\mathrm{kW}$ & -425.7 & -825.9 & -335.3 & -273.7 \\
\hline & 6 Hour Peak Load & $\mathrm{kW}$ & -280.0 & -45.5 & 26.5 & -8.7 \\
\hline & Flattened Peak Load & $\mathrm{kW}$ & -542.6 & -865.8 & -553.1 & -309.9 \\
\hline & $\begin{array}{l}\begin{array}{l}\text { Flattened Peak Load } \\
\text { including Rebound }\end{array} \\
\end{array}$ & $\mathrm{kW}$ & -542.6 & -792.0 & -507.1 & -279.1 \\
\hline \multirow{5}{*}{$7^{*}$} & Instaneous Peak Load & $\%$ & -7.5 & -22.5 & -32.7 & -26.0 \\
\hline & 1 Hour Peak Load & $\%$ & -6.9 & -17.2 & -16.6 & -29.0 \\
\hline & 6 Hour Peak Load & $\%$ & -5.4 & -1.3 & 1.9 & -1.6 \\
\hline & Flattened Peak Load & $\%$ & -8.7 & -18.0 & -25.1 & -32.8 \\
\hline & $\begin{array}{l}\text { Flattened Peak Load } \\
\text { including Rebound }\end{array}$ & $\%$ & -8.7 & -16.5 & -23.0 & -29.5 \\
\hline
\end{tabular}


Table 4.35: Additional DLC with technology impact metrics for region 5

\begin{tabular}{|c|c|c|c|c|c|c|c|c|c|c|}
\hline Index & $\Delta$ Metric & Units & 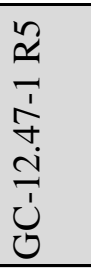 & 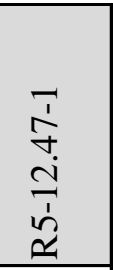 & 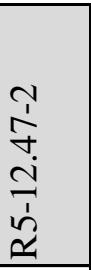 & 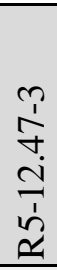 & 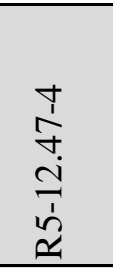 & 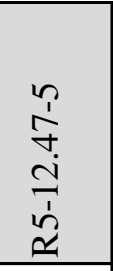 & 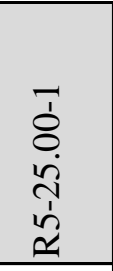 & 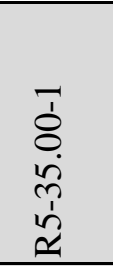 \\
\hline \multirow{5}{*}{$7 *$} & Instantaneous Peak Load & $\mathrm{kW}$ & -36.3 & $-1,701.9$ & -599.5 & - & $-1,522.9$ & $-2,404.4$ & $-3,253.8$ & $-2,514.2$ \\
\hline & 1 Hour Peak Load & $\mathrm{kW}$ & -94.7 & -880.0 & -283.7 & - & -448.3 & $-1,094.4$ & $-2,162.8$ & $-1,929.2$ \\
\hline & 6 Hour Peak Load & $\mathrm{kW}$ & -148.5 & -410.2 & 19.4 & - & -471.9 & -671.6 & -766.2 & $-1,147.4$ \\
\hline & Flattened Peak Load & $\mathrm{kW}$ & -202.5 & $-1,262.2$ & -384.9 & - & $-1,061.7$ & $-1,809.4$ & $-2,355.2$ & $-2,306.0$ \\
\hline & $\begin{array}{l}\text { Flattened Peak Load } \\
\text { including Rebound }\end{array}$ & $\mathrm{kW}$ & -202.5 & $-1,056.1$ & -371.0 & - & -819.7 & $-1,359.4$ & $-1,755.1$ & $-1,721.0$ \\
\hline \multirow{5}{*}{$7 *$} & Instaneous Peak Load & $\%$ & -0.7 & -20.0 & -13.6 & - & -22.5 & -28.8 & -29.5 & -23.3 \\
\hline & 1 Hour Peak Load & $\%$ & -1.6 & -9.6 & -5.8 & - & -6.2 & -13.0 & -18.2 & -16.2 \\
\hline & 6 Hour Peak Load & $\%$ & -2.8 & -4.9 & 0.4 & - & -6.9 & -8.6 & -7.2 & -10.7 \\
\hline & Flattened Peak Load & $\%$ & -3.5 & -13.4 & -7.7 & - & -14.1 & -20.0 & -19.2 & -18.6 \\
\hline & $\begin{array}{l}\text { Flattened Peak Load } \\
\text { including Rebound }\end{array}$ & $\%$ & -3.5 & -11.2 & -7.4 & - & -10.9 & -15.0 & -14.3 & -13.8 \\
\hline
\end{tabular}




\section{Conclusions and Observations}

The conclusions and observations for this report will be divided into two sections: overall and technology specific. The overall conclusions and observations will address the analysis in general, while the technology specific area will focus on the five individual technology cases explored within the DR area.

\subsection{Demand Response Observations and Conclusions}

This report has discussed the results from simulations of various demand response programs represented within the SGIG proposals on a nationally representative set of distribution feeders, focusing on residential customers. This section will provide overall observations and conclusions from this analysis. A brief summary of this section will also be presented in Sections 5.2 and 5.3 .

Demand response programs are designed to directly engage customers at the end-use level to meet demand reduction goals at the utility level. However, the goals of a demand response program can vary widely, from reducing exposure to wholesale or real-time energy prices to localized capacity management to emergency management. Strategies for meeting these goals vary just as widely; there is no "one size fits all" demand response strategy. Careful analysis of not only the initial effects, but also the longer term response of the system, is critical to understanding the actual benefits that can be realized from the program. From the evaluation of the SGIG project proposals, it was determined that the main focus of the deployed DR programs was peak demand reduction.

This study has looked at the effects of a large scale deployment of a few representative demand response programs: TOU, TOU with CPP, and DLC. These were the most commonly proposed methods within the SGIG proposals. In addition, the effects of adding technology designed to aid customer involvement and automate response were simulated. To simulate these deployments, this study used representative feeder and load information [5][29] and representative consumer interactions [8][13]-[15] to give a conservative estimate of the benefits associated with demand response programs. Information about the actual technologies being deployed from the SGIG proposals was limited, and made it difficult to ascertain the actual strategies used when this analysis was started. To that end, this analysis has tried to estimate the minimum and maximum response levels available from demand response resources with and without enabling technologies. The enabling technologies used are more advanced than will more than likely be used in the SGIG projects, but are an attempt to represent the upper bound of the amount of available response on a system.

It should be noted, that these results represent an approximation of the average response that could be seen by customers on representative feeders with average loading. Actual results will vary, dependent on load composition, weather conditions, and customer education and 
interaction, and as such, when deployed, should be analyzed on a case by case basis to determine the actual benefits.

The results have shown that when properly coordinated and deployed, demand response programs have the potential to significantly reduce the peak load. However, a common occurrence with TOU, TOU/CPP, and DLC programs is a "rebound" effect, or increase in load after the release of the DR signal. This can be exacerbated by synchronizing signals, such as automated controls. Additionally, static control signals (such as a CPP price) tend to use the resource unevenly across the time interval using more resource at the beginning with less and less response as time progresses, leading to a less than ideal reduction in peak load. And the more aggressively the resources is used, whether in how deep it is pushed or for how long, the greater the potential for a large rebound or payback when the signal is released. It is assumed that utilities investigated these interactions, and properly accounted for it within their operations, as is commonly done. However, as the DOE metrics were designed in [2], the peak load metrics could not fully capture the true benefits of these DR programs. To account for this, and to show the true benefits of DR, an alternate set of metrics were presented in Section 2.4. In addition, estimates were made from the available simulated data as to the potential of demand reduction across various time horizons, regardless of the complex controls needed to make this occur. These results and metrics are presented in Section 4.3.

From the simulation results, when the rebound was not properly accounted for, peak increases of more than $25 \%$ in CPP and 60\% in DLC were seen. Additionally, one feeder in region 5 was unable to support the rapid change in load created by the release of the control signals, resulting in voltage collapse on the system. However, when the rebound is properly accounted for in the control system and the reduction is proportioned evenly across the desired time period (six hours in this case as demonstrated in the alternate metrics), sustained peak reductions of $4 \%$ to $34 \%$ with CPP and $4 \%$ to $37 \%$ with DLC, and instantaneous reductions of over $55 \%$, can be seen. While the addition of automated controls and other enabling technologies increases the complexity of the system and the control schema required, on average, it increases the potential peak reduction by nearly $14 \%$ over cases without enabling technologies, as customers are more successfully engaged in the DR process.

The main advantage of TOU or TOU/CPP programs over that of DLC is the long term annual shift in energy consumption; TOU programs encourage behavioral changes year round while DLC is only employed 15 times per year. This leads to an average reduction in energy consumption approaching $1 \%$ and as much as a $2 \%$ reduction in $\mathrm{CO}_{2}$ emissions in TOU programs, which is not seen in DLC programs.

Properly studied and deployed demand response programs are effective at reducing peak demand. However, the response of loads to a common DR signal is not necessarily well understood, and many considerations must be made to make the system behave to meet the 
design goals. This study should not be considered an exhaustive analysis of demand response programs, but rather an exemplary approach to analyzing specific DR implementations and an approximation of the potential benefits of standard TOU, TOU/CPP, and DLC programs. The following sections will further summarize the observations made here.

\subsection{Demand Response Observations and Conclusions Summary}

The analysis presented in this report has shown that with a few exceptions, the benefits of the DR technologies deployed in the SGIG projects can be quantified and tracked using the SGIG metrics guidebook [2]. The information available from the SGIG proposals, however, made it difficult to ascertain the actual strategies deployed for the various programs, including possible "best practice" considerations. Additionally, the analysis did not take into account the secondary effects of pricing programs, such as customers upgrading their equipment to reduce their bill or the long term changes in customer participation and engagement. All conclusions are based on these assumptions. From the analysis conducted, and the metrics tracked, the following conclusions and observations can be made about DR technologies:

1) DR technologies are a customer centric approach to dealing with utility operational issues by directly engaging end-use customers.

2) DR programs have the potential to provide a significant peak load reduction; however deployments must take into account the effects on load diversity and the negative consequences which may occur (e.g. peak rebounds) must be actively managed.

3) The goals of the DR program strongly affect the type of program that should be employed, and careful consideration should be made to meet these goals. For example, if the goal is to reduce exposure to wholesale prices, which are not necessarily coincident with system peak, the implemented program will differ from other strategies.

\subsection{Conclusions and Observations for Specific Technologies}

The following subsections will give observations and concluding comments for the five technology cases within the DR area.

\subsubsection{Conclusions and Observations for TOU and TOU/CPP}

From the analysis of TOU and TOU/CPP, the following conclusions and observations can be made:

1) TOU and TOU/CPP can effectively reduce peak demand, but only during the time window specified and only for a limited amount of time. Depending upon the DR technology implemented the timing of the peak window and load composition, a "rebound" effect can be seen, shifting, and possibly increasing, the overall peak 
demand when viewed from the perspective of the individual feeder. However, when the requisite controls are properly accounted for, load can be flattened across a peak with a reduction between $4 \%$ and $34 \%$.

2) Employment of automated controls, In-Home Displays, and Home Energy Management systems increases the potential for peak reduction by TOU and TOU/CPP by increasing the participation of the customer through equipment interaction, but can also exacerbate the rebound effect. When properly implemented, the increase in peak demand reduction is on average $14 \%$ greater when using enabling technologies.

3) TOU and TOU/CPP can reduce energy consumption, but on the order of less than $1 \%$. This is understandable, as the systems are mainly designed to manage peak demand or shift energy usage.

4) TOU and TOU/CPP consistently reduce losses on the system; however, the loss reduction is typically less than $2 \%$ of total losses or approximately $0.05 \%$ of total energy consumption.

5) The effects on $\mathrm{CO}_{2}$ (and other pollutant) emissions are highly dependent on the generation mixture during peak and rebound periods, but typically reduce overall $\mathrm{CO}_{2}$ emissions by moving demand from more carbon intensive generation to less carbon intensive generation. Reduction of $\mathrm{CO}_{2}$ emissions can be as great as $5 \%$, but typically range from a $1 \%$ increase to a $2 \%$ decrease in emissions, depending upon generation mix.

6) There are a number of DR control strategies available for implementation, but there is no "one size fits all" strategy. Secondary effects should be expected with each, but the consequences can be reduced with proper study and diversification.

\subsubsection{Conclusions and Observations for DLC}

From the analysis of DLC, the following conclusions and observations can be made:

1) DLC can effectively reduce peak demand during the control period. Because of the direct control by the utility, the potential for reduction is greater than with TOU or CPP. However, because reduction is greater, the peak "rebound" can also be greater than that seen in the TOU or CPP cases. When the rebound is properly accounted for through a proper control strategy and the peak is flattened across the six hour period, peak reductions between $4 \%$ and $37 \%$ can be achieved.

2) DLC has little to no effect on annual energy consumption (less than $+/-0.1 \%$ ) and little effect on system losses (less than $-0.15 \%$ ). TOU programs have a continuous effect by 
shifting load all year long, while the DLC and CPP signals are only applied 15 days per year, minimizing the effects on energy consumption and losses.

3) DLC had minor effects on $\mathrm{CO}_{2}$ (and other pollutant) emissions. Changes were less than $+/-0.5 \%$. By moving demand from more carbon intensive generation to less carbon intensive generation, some reduction was seen, but this only occurs 15 days per year.

4) Similar to DR, there is no "one size fits all" strategy for DLC. Careful simulation and observation should be made about the system it is to be implemented on. Consequences such as rebound should be mitigated with a combination of plans or diversification of the control signal. 


\section{Appendix A: SGIG Program Impact Metrics}

An important component of the SGIG projects is the transfer of information from the individual projects to the broader industry audience. The aim of this transfer is to allow individuals, research organizations, and utilities to better understand the performance of the various technologies deployed on the various projects. Due to the large amount of potential data, it is not feasible for each grant recipient to provide all of the available raw data. To address the issue of data collection, the "Guidebook for ARRA Smart Grid Program Metrics and Benefits" [2] was developed as a starting point for the discussion of data collection and impact categories. Specifically, the document contained a table of impact metrics against which each project could be evaluated; it is these metrics that are used in the 4 technical reports in this series to evaluate the impact of the various technologies. Table A.1 is a complete list of all 74 metrics listed in the Guidebook and is included in this appendix as a reference. Not every metric is used for each technology, only those that are relevant to the specific technology are examined in Section 2.

Table A.1: SGIG program impact metrics from guidebook

\begin{tabular}{|c|c|c|c|c|}
\hline$\#$ & Metric & $\begin{array}{l}\text { Project } \\
\text { Value }\end{array}$ & $\begin{array}{l}\text { System } \\
\text { Value }\end{array}$ & Remarks \\
\hline \multicolumn{5}{|c|}{ A 2.1 IMPACT METRICS: AMI and Customer Systems } \\
\hline \multicolumn{5}{|c|}{ Metrics Related Primarily to Economic Benefits } \\
\hline 1 & $\begin{array}{l}\text { Hourly Customer } \\
\text { Electricity Usage }\end{array}$ & $\begin{array}{l}\mathrm{kWh} \\
\$ / \mathrm{kWh}\end{array}$ & $\begin{array}{c}\text { Not } \\
\text { Applicable }\end{array}$ & $\begin{array}{l}\text { Hourly electricity consumption information (kWh) } \\
\text { and applicable retail tariff rate. Nature of this data will } \\
\text { be negotiated with DOE }\end{array}$ \\
\hline 2 & $\begin{array}{l}\text { Monthly Customer } \\
\text { Electricity Usage }\end{array}$ & $\begin{array}{l}\mathrm{MWh} \\
\$ / \mathrm{kWh}\end{array}$ & $\begin{array}{c}\text { Not } \\
\text { Applicable }\end{array}$ & $\begin{array}{l}\text { Monthly electricity consumption information }(\mathrm{kWh}) \\
\text { and applicable retail tariff rate. The nature of this data } \\
\text { will be negotiated with DOE }\end{array}$ \\
\hline 3 & $\begin{array}{l}\text { Peak Generation and } \\
\text { Mix }\end{array}$ & $\begin{array}{l}\text { MW } \\
\text { Mix }\end{array}$ & $\begin{array}{l}\text { MW } \\
\text { Mix }\end{array}$ & Specify intermittent generation by type and amount \\
\hline 4 & Peak Load and Mix & $\begin{array}{l}\text { MW } \\
\text { Mix }\end{array}$ & $\begin{array}{l}\text { MW } \\
\text { Mix }\end{array}$ & Specify controllable load by type \\
\hline 5 & $\begin{array}{l}\text { Annual Generation } \\
\text { Cost }\end{array}$ & $\$$ & $\$$ & Total cost of generation to serve load \\
\hline 6 & $\begin{array}{l}\text { Hourly Generation } \\
\text { Cost }\end{array}$ & \$/MWh & $\$ / \mathrm{MWh}$ & Aggregate or market price of energy in each hour \\
\hline 7 & $\begin{array}{l}\text { Annual Electricity } \\
\text { Production }\end{array}$ & MWh & MWh & Total electricity produced by central generation \\
\hline 8 & $\begin{array}{l}\text { Ancillary Services } \\
\text { Cost }\end{array}$ & $\$$ & $\$$ & Total cost of Ancillary services \\
\hline 9 & $\begin{array}{l}\text { Meter Operations } \\
\text { Cost }\end{array}$ & $\$$ & $\begin{array}{c}\text { Not } \\
\text { Applicable }\end{array}$ & $\begin{array}{l}\text { Includes operations, maintenance, reading and data } \\
\text { management }\end{array}$ \\
\hline 10 & Truck Rolls Avoided & \# & $\begin{array}{c}\text { Not } \\
\text { Applicable }\end{array}$ & $\begin{array}{l}\text { Could include trips for meter reading, } \\
\text { connection/disconnection, inspection and maintenance }\end{array}$ \\
\hline \multicolumn{5}{|c|}{ Metrics Related Primarily to Environmental Benefits } \\
\hline
\end{tabular}




\begin{tabular}{|c|c|c|c|c|}
\hline 11 & $\begin{array}{l}\text { Meter Operations } \\
\text { Vehicle Miles }\end{array}$ & Miles & $\begin{array}{c}\text { Not } \\
\text { Applicable } \\
\end{array}$ & Total miles accumulated related to meter operations \\
\hline 12 & $\mathrm{CO} 2$ Emissions & Tons & Tons & Could be modeled or estimated \\
\hline 13 & $\begin{array}{l}\text { Pollutant Emissions } \\
\text { (SOx, NOx, PM-10) }\end{array}$ & Tons & Tons & Could be modeled or estimated \\
\hline \multicolumn{5}{|c|}{ Metrics Related Primarily to AMI System Performance } \\
\hline 14 & $\begin{array}{l}\text { Meter Data } \\
\text { Completeness }\end{array}$ & $\%$ & $\begin{array}{c}\text { Not } \\
\text { Applicable }\end{array}$ & $\begin{array}{l}\text { Portion of meters that are online and successfully } \\
\text { reporting in }\end{array}$ \\
\hline 15 & $\begin{array}{l}\text { Meters Reported } \\
\text { Daily by } 2 A M\end{array}$ & $\%$ & $\begin{array}{c}\text { Not } \\
\text { Applicable }\end{array}$ & $\begin{array}{l}\text { Portion of meter reads received by } 2 \mathrm{AM} \text { the following } \\
\text { day }\end{array}$ \\
\hline \multicolumn{5}{|c|}{ A 2.2 Impact Metrics: Electric Distribution Systems } \\
\hline \multicolumn{5}{|c|}{ Metrics Related to Economic Benefits } \\
\hline 16 & $\begin{array}{l}\text { Hourly Customer } \\
\text { Electricity Usage* }\end{array}$ & $\begin{array}{c}\mathrm{kWh} \\
\$ / \mathrm{kWh}\end{array}$ & $\begin{array}{c}\text { Not } \\
\text { Applicable }\end{array}$ & $\begin{array}{l}\text { Hourly electricity consumption information }(\mathrm{kWh}) \\
\text { and applicable retail tariff rate. }\end{array}$ \\
\hline 17 & $\begin{array}{l}\text { Annual Storage } \\
\text { Dispatch* }\end{array}$ & KWh & $\begin{array}{c}\text { Not } \\
\text { Applicable }\end{array}$ & $\begin{array}{l}\text { Total number of hours that storage is dispatched for } \\
\text { retail load shifting }\end{array}$ \\
\hline 18 & $\begin{array}{l}\text { Average Energy } \\
\text { Storage Efficiency* }\end{array}$ & $\%$ & $\begin{array}{c}\text { Not } \\
\text { Applicable }\end{array}$ & Efficiency of energy storage devices installed \\
\hline 19 & $\begin{array}{l}\text { Monthly Demand } \\
\text { Charges* }\end{array}$ & $\begin{array}{l}\$ / \mathrm{kW}- \\
\text { month }\end{array}$ & $\begin{array}{c}\text { Not } \\
\text { Applicable }\end{array}$ & Average commercial or industrial demand charges \\
\hline 20 & $\begin{array}{l}\text { Distribution Feeder } \\
\text { or Equipment } \\
\text { Overload Incidents }\end{array}$ & $\#$ & $\begin{array}{c}\text { Not } \\
\text { Applicable }\end{array}$ & $\begin{array}{l}\text { The total time during the reporting period that feeder } \\
\text { or equipment loads exceeded design ratings }\end{array}$ \\
\hline 21 & $\begin{array}{l}\text { Distribution Feeder } \\
\text { Load }\end{array}$ & $\begin{array}{l}\text { MW } \\
\text { MVAR }\end{array}$ & $\begin{array}{c}\text { Not } \\
\text { Applicable }\end{array}$ & $\begin{array}{l}\text { Real and reactive power readings for those feeders } \\
\text { involved in the project. Information should be based } \\
\text { on hourly loads }\end{array}$ \\
\hline 22 & $\begin{array}{l}\text { Deferred } \\
\text { Distribution } \\
\text { Capacity } \\
\text { Investments } \\
\end{array}$ & $\$$ & $\begin{array}{c}\text { Not } \\
\text { Applicable }\end{array}$ & $\begin{array}{l}\text { The value of the capital project(s) deferred, and the } \\
\text { time of the deferral }\end{array}$ \\
\hline 23 & $\begin{array}{l}\text { Equipment Failure } \\
\text { Incidents }\end{array}$ & $\#$ & $\begin{array}{c}\text { Not } \\
\text { Applicable }\end{array}$ & $\begin{array}{l}\text { Incidents of equipment failure within the project } \\
\text { scope, including reason for failure }\end{array}$ \\
\hline 24 & $\begin{array}{l}\text { Distribution } \\
\text { Equipment } \\
\text { Maintenance Cost }\end{array}$ & $\$$ & $\begin{array}{c}\text { Not } \\
\text { Applicable }\end{array}$ & $\begin{array}{l}\text { Activity based cost for distribution equipment } \\
\text { maintenance during the reporting period }\end{array}$ \\
\hline 25 & $\begin{array}{l}\text { Distribution } \\
\text { Operations Cost }\end{array}$ & $\$$ & $\begin{array}{c}\text { Not } \\
\text { Applicable }\end{array}$ & $\begin{array}{l}\text { Activity based cost for distribution operations during } \\
\text { the reporting period }\end{array}$ \\
\hline 26 & $\begin{array}{l}\text { Distribution Feeder } \\
\text { Switching } \\
\text { Operations }\end{array}$ & $\#$ & $\begin{array}{c}\text { Not } \\
\text { Applicable }\end{array}$ & $\begin{array}{l}\text { Activity based cost for feeders switching operations } \\
\text { during the reporting period }\end{array}$ \\
\hline 27 & $\begin{array}{l}\text { Distribution } \\
\text { Capacitor Switching } \\
\text { Cost }\end{array}$ & $\$$ & $\begin{array}{c}\text { Not } \\
\text { Applicable }\end{array}$ & $\begin{array}{l}\text { Activity based cost for capacitor switching operations } \\
\text { during the reporting period }\end{array}$ \\
\hline 28 & $\begin{array}{l}\text { Distribution } \\
\text { Restoration Cost }\end{array}$ & $\$$ & $\begin{array}{c}\text { Not } \\
\text { Applicable }\end{array}$ & $\begin{array}{l}\text { Total cost for distribution restoration during the } \\
\text { reporting period }\end{array}$ \\
\hline 29 & Distribution Losses & $\%$ & $\begin{array}{c}\text { Not } \\
\text { Applicable }\end{array}$ & $\begin{array}{l}\text { Losses for the portion of the distribution system } \\
\text { involved in the project. Modeled or calculated. }\end{array}$ \\
\hline 30 & $\begin{array}{l}\text { Distribution Power } \\
\text { Factor }\end{array}$ & $\mathrm{pf}$ & $\begin{array}{c}\text { Not } \\
\text { Applicable }\end{array}$ & $\begin{array}{l}\text { Power factor for the portion of the distribution system } \\
\text { involved in the project. Modeled or calculated. }\end{array}$ \\
\hline
\end{tabular}




\begin{tabular}{|c|c|c|c|c|}
\hline 31 & Truck Rolls Avoided & $\#$ & $\begin{array}{c}\text { Not } \\
\text { Applicable }\end{array}$ & $\begin{array}{l}\text { Estimate of the number of times a crew would have } \\
\text { been dispatched to perform a distribution operations } \\
\text { or maintenance function }\end{array}$ \\
\hline \multicolumn{5}{|c|}{ Metrics Related Primarily to Reliability Benefits } \\
\hline 32 & SAIF & Index & $\begin{array}{c}\text { Not } \\
\text { Applicable }\end{array}$ & \multirow{3}{*}{$\begin{array}{l}\text { As defined in IEEE Std 1366-2003, and do not } \\
\text { include major events days. Only events involving } \\
\text { infrastructure that is part of the project should be } \\
\text { included. }\end{array}$} \\
\hline 33 & SAIDI/CAIDI & Index & $\begin{array}{c}\text { Not } \\
\text { Applicable }\end{array}$ & \\
\hline 34 & MAIFI & Index & $\begin{array}{c}\text { Not } \\
\text { Applicable }\end{array}$ & \\
\hline 35 & $\begin{array}{l}\text { Outrage Response } \\
\text { Time }\end{array}$ & Minutes & $\begin{array}{c}\text { Not } \\
\text { Applicable }\end{array}$ & Time between outage occurrence and action initiated \\
\hline 36 & $\begin{array}{l}\text { Major Event } \\
\text { Information }\end{array}$ & $\begin{array}{c}\text { Event } \\
\text { Statistics }\end{array}$ & $\begin{array}{c}\text { Not } \\
\text { Applicable }\end{array}$ & $\begin{array}{l}\text { Information should including, but not limited to } \\
\text { project infrastructure involved (transmission lines, } \\
\text { substations and feeders), cause of the event, number } \\
\text { of customers affected, total time for restoration, and } \\
\text { restoration costs. }\end{array}$ \\
\hline 37 & $\begin{array}{l}\text { Number of High } \\
\text { Impedance Faults } \\
\text { Cleared }\end{array}$ & \# & $\begin{array}{c}\text { Not } \\
\text { Applicable }\end{array}$ & $\begin{array}{l}\text { Faults cleared that could be designed as high } \\
\text { impedance or slow clearing }\end{array}$ \\
\hline \multicolumn{5}{|c|}{ Metrics Related Primarily to Environmental Benefits } \\
\hline 38 & $\begin{array}{l}\text { Distribution } \\
\text { Operations Vehicle } \\
\text { Miles }\end{array}$ & Miles & $\begin{array}{c}\text { Not } \\
\text { Applicable }\end{array}$ & $\begin{array}{l}\text { Total miles for distribution operations and } \\
\text { maintenance during the reporting period }\end{array}$ \\
\hline 39 & $\mathrm{CO} 2$ Emissions & Tons & Tons & Could be modeled or estimated \\
\hline 40 & $\begin{array}{l}\text { Pollutant Emissions } \\
\text { (SOx, NOx, PM-10) }\end{array}$ & Tons & Tons & Could be modeled or estimated \\
\hline \multicolumn{5}{|c|}{ A 2.3 Impact Metrics: Electric Transmission Systems } \\
\hline \multicolumn{5}{|c|}{ Metrics Related Primarily to Economic Benefits } \\
\hline 41 & $\begin{array}{l}\text { Annual Storage } \\
\text { Dispatch* }\end{array}$ & MWh & MWh & $\begin{array}{l}\text { Total number of hours that storage is dispatched for } \\
\text { wholesale energy markets or Ancillary services }\end{array}$ \\
\hline 42 & $\begin{array}{l}\text { Capacity Market } \\
\text { Value* }\end{array}$ & \$/MW & \$/MW & Capacity value \\
\hline 43 & $\begin{array}{l}\text { Ancillary Services } \\
\text { Prices* }\end{array}$ & $\$ / \mathrm{MWh}$ & $\$ / M W h$ & $\begin{array}{l}\text { Ancillary service price during hours when Storage } \\
\text { was dispatched }\end{array}$ \\
\hline 44 & $\begin{array}{l}\text { Annual Generation } \\
\text { Cost }\end{array}$ & $\begin{array}{c}\text { Not } \\
\text { Applicable } \\
\end{array}$ & $\$$ & Total cost generation to serve load \\
\hline 45 & $\begin{array}{l}\text { Hourly Generation } \\
\text { Cost }\end{array}$ & $\begin{array}{c}\text { Not } \\
\text { Applicable } \\
\end{array}$ & $\$ / \mathrm{MWh}$ & Aggregate or market price of energy in each hour \\
\hline 46 & $\begin{array}{l}\text { Peak Generation and } \\
\text { Mix }\end{array}$ & $\begin{array}{c}\text { Not } \\
\text { Applicable }\end{array}$ & $\begin{array}{l}\text { MW } \\
\text { Mix }\end{array}$ & Specify intermittent generation by type and amount \\
\hline 47 & Peak Load and Mix & $\begin{array}{c}\text { Not } \\
\text { Applicable }\end{array}$ & $\begin{array}{l}\text { MW } \\
\text { Mix }\end{array}$ & Specify controllable load by type \\
\hline 48 & $\begin{array}{l}\text { Annual Generation } \\
\text { Dispatch }\end{array}$ & $\begin{array}{c}\text { Not } \\
\text { Applicable } \\
\end{array}$ & $\begin{array}{l}\text { MW } \\
\text { Mix }\end{array}$ & Total electricity produced by central generation \\
\hline 49 & $\begin{array}{l}\text { Ancillary Services } \\
\text { Cost }\end{array}$ & $\begin{array}{c}\text { Not } \\
\text { Applicable }\end{array}$ & $\$$ & Total cost of Ancillary services \\
\hline 50 & Congestion Cost & MW & $\begin{array}{c}\text { Not } \\
\text { Applicable }\end{array}$ & $\begin{array}{l}\text { Total transmission congestion cost during the } \\
\text { reporting period }\end{array}$ \\
\hline
\end{tabular}




\begin{tabular}{|c|c|c|c|c|}
\hline 51 & $\begin{array}{l}\text { Transmission Line or } \\
\text { Equipment Overload } \\
\text { Incidents }\end{array}$ & \# & $\begin{array}{c}\text { Not } \\
\text { Applicable }\end{array}$ & $\begin{array}{l}\text { The total time during the reporting period that line } \\
\text { loads exceeded design ratings }\end{array}$ \\
\hline 52 & $\begin{array}{l}\text { Transmission Line } \\
\text { Load }\end{array}$ & $\begin{array}{l}\text { MW } \\
\text { MVAR }\end{array}$ & $\begin{array}{c}\text { Not } \\
\text { Applicable }\end{array}$ & $\begin{array}{l}\text { Real and reactive power readings for those lines } \\
\text { involved in the project. Information should be based } \\
\text { on hourly loads }\end{array}$ \\
\hline 53 & $\begin{array}{l}\text { Deferred } \\
\text { Transmission } \\
\text { Capacity } \\
\text { Investments } \\
\end{array}$ & $\$$ & $\begin{array}{c}\text { Not } \\
\text { Applicable }\end{array}$ & $\begin{array}{l}\text { The value of the capital project(s) deferred, and the } \\
\text { time of the deferral }\end{array}$ \\
\hline 54 & $\begin{array}{l}\text { Equipment Failure } \\
\text { Incidents }\end{array}$ & \# & $\begin{array}{c}\text { Not } \\
\text { Applicable }\end{array}$ & $\begin{array}{l}\text { Incidents of equipment failure within the project } \\
\text { scope, including reason for failure }\end{array}$ \\
\hline 55 & $\begin{array}{l}\text { Transmission } \\
\text { Equipment } \\
\text { Maintenance Cost }\end{array}$ & $\$$ & $\begin{array}{c}\text { Not } \\
\text { Applicable }\end{array}$ & $\begin{array}{l}\text { Activity based cost for transmission equipment } \\
\text { maintenance during the reporting period }\end{array}$ \\
\hline 56 & $\begin{array}{l}\text { Transmission } \\
\text { Operations Cost }\end{array}$ & $\$$ & $\begin{array}{c}\text { Not } \\
\text { Applicable }\end{array}$ & $\begin{array}{l}\text { Activity based cost for transmission operations during } \\
\text { the reporting period }\end{array}$ \\
\hline 57 & $\begin{array}{l}\text { Transmission } \\
\text { Restoration Cost }\end{array}$ & $\$$ & $\begin{array}{c}\text { Not } \\
\text { Applicable }\end{array}$ & $\begin{array}{l}\text { Total cost for transmission restoration during the } \\
\text { reporting period }\end{array}$ \\
\hline 58 & Transmission Losses & $\%$ & $\begin{array}{c}\text { Not } \\
\text { Applicable }\end{array}$ & $\begin{array}{l}\text { Losses for the portion of the transmission system } \\
\text { involved in the project. Could be modeled or } \\
\text { calculated. }\end{array}$ \\
\hline 59 & $\begin{array}{l}\text { Transmission Power } \\
\text { Factor }\end{array}$ & $\mathrm{pf}$ & $\begin{array}{c}\text { Not } \\
\text { Applicable }\end{array}$ & $\begin{array}{l}\text { Power factor for the portion of the transmission } \\
\text { system involved in the project. Could be modeled or } \\
\text { calculated. }\end{array}$ \\
\hline \multicolumn{5}{|c|}{ Metrics Related Primarily to Transmission Reliability } \\
\hline 60 & $\begin{array}{l}\text { BPS Transmission } \\
\text { Related Events } \\
\text { Resulting in Loss of } \\
\text { Load (NERC ALR } \\
\text { 1-4) }\end{array}$ & \# & $\begin{array}{c}\text { Not } \\
\text { Applicable }\end{array}$ & $\begin{array}{l}\text { BPS Transmission Related Events Resulting in Loss } \\
\text { of Load (NERC ALR 1-4) }\end{array}$ \\
\hline 61 & $\begin{array}{l}\text { Energy Emergency } \\
\text { Alert } 3 \text { (NERC ALR } \\
6-2 \text { ) }\end{array}$ & \# & $\begin{array}{c}\text { Not } \\
\text { Applicable }\end{array}$ & Energy Emergency Alert 3 (NERC ALR-6-2) \\
\hline \multicolumn{5}{|c|}{ Metrics Related Primarily to Environmental Benefits } \\
\hline 62 & $\begin{array}{l}\text { Transmission } \\
\text { Operations Vehicle } \\
\text { Miles }\end{array}$ & Miles & $\begin{array}{c}\text { Not } \\
\text { Applicable }\end{array}$ & $\begin{array}{l}\text { Total mileage for transmission operations and } \\
\text { maintenance during the reporting period }\end{array}$ \\
\hline 63 & $\mathrm{Co}_{2}$ Emissions & tons & tons & Could be modeled or estimated \\
\hline 64 & $\begin{array}{l}\text { Pollutant Emissions } \\
\text { (SOx, NOx, PM-10) }\end{array}$ & tons & tons & Could be modeled or estimated \\
\hline \multicolumn{5}{|c|}{ Metrics Related Primarily to Energy Security Benefits } \\
\hline 65 & $\begin{array}{l}\text { Number, Type, and } \\
\text { Size }\end{array}$ & $\begin{array}{c}\text { Events } \\
\text { Cause } \\
\text { Load Lost }\end{array}$ & $\begin{array}{c}\text { Not } \\
\text { Applicable }\end{array}$ & $\begin{array}{l}\text { Causes could include line trips, generator trips, or } \\
\text { other large disturbances }\end{array}$ \\
\hline 66 & Duration & $\begin{array}{c}\text { Minutes/ } \\
\text { Hours }\end{array}$ & $\begin{array}{c}\text { Not } \\
\text { Applicable }\end{array}$ & \\
\hline 67 & PMU Dynamic Data & PMU Data & $\begin{array}{c}\text { Not } \\
\text { Applicable }\end{array}$ & From related PMU's \\
\hline
\end{tabular}




\begin{tabular}{|c|c|c|c|c|}
\hline 68 & Detection & Application & $\begin{array}{c}\text { Not } \\
\text { Applicable }\end{array}$ & Application that detected the event \\
\hline 69 & Events Prevented & \# & $\begin{array}{c}\text { Not } \\
\text { Applicable }\end{array}$ & Include reason for prevention \\
\hline \multicolumn{5}{|c|}{ Metrics related primarily to PMU/PDC System Performance } \\
\hline 70 & $\begin{array}{l}\text { PMU Data } \\
\text { Completeness }\end{array}$ & $\%$ & $\begin{array}{c}\text { Not } \\
\text { Applicable }\end{array}$ & $\begin{array}{l}\text { Portion of PMU that are operational and successfully } \\
\text { provided data }\end{array}$ \\
\hline 71 & $\begin{array}{l}\text { Network } \\
\text { Completeness }\end{array}$ & $\%$ & $\begin{array}{c}\text { Not } \\
\text { Applicable }\end{array}$ & Portion of PMUs networked into regional PDCs \\
\hline 72 & $\begin{array}{l}\text { PMU/PDC } \\
\text { Performance }\end{array}$ & $\begin{array}{l}\text { Reliability } \\
\text { Quality }\end{array}$ & $\begin{array}{c}\text { Not } \\
\text { Applicable }\end{array}$ & \\
\hline 73 & $\begin{array}{l}\text { Communications } \\
\text { Performance }\end{array}$ & Availability & $\begin{array}{c}\text { Not } \\
\text { Applicable }\end{array}$ & \\
\hline 74 & $\begin{array}{l}\text { Application } \\
\text { Performance }\end{array}$ & Description & $\begin{array}{c}\text { Not } \\
\text { Applicable }\end{array}$ & $\begin{array}{l}\text { Usefulness of applications, including reliability } \\
\text { improvements, markets and congestion management, } \\
\text { operational efficiency }\end{array}$ \\
\hline
\end{tabular}

The metrics shown in Table A.1 were developed for field demonstrations and were not originally intended for simulations. To address this issue, definitions of the metrics in Table A.1 as implemented in the analysis will be given. Because the simulations in this report only examine impacts at the distribution level, transmission level impact metrics will not be examined. Of the distribution metrics, many will not be used because are associated with a monetary cost that would require information from a specific utility. For example, meter operation costs.

The metrics will be presented in two separate places in this report. Appendix E will contain the metric values for each technology on each feeder. These values are individual to a single technology. Section 4.1, 4.2, and 4.3 will show the difference in metric values between the base case and the specific technology, for each feeder.

1) Hourly customer electricity usage: Instead of reporting a time series of values for an entire year this metric will report the average hourly end-use consumption.

2) Monthly customer electricity usage: Instead of reporting a time series of values for an entire year this metric will report the average monthly end-use consumption.

3) Peak generation and mix: This metric will report the peak generation as well as the percentages for generation composition. This is the generation that is required to supply the demand as measured at the substation. The generation composition will include the breakdown of central generation as well as distributed resources on the distribution system. 
4) Peak load and mix: This is the maximum annual end-use demand as consumed by the end-use customers. This is the load that the utilities meter and charge for. The percent of load that is controllable will also be included.

5) Annual generation cost: Because this is dependent on the business structure of specific utilities, this metric will not be used in evaluating the simulation results.

6) Hourly generation cost: Because this is dependent on the business structure of specific utilities, this metric will not be used in evaluating the simulation results.

7) Annual electricity production: This metric reports the total energy that is required to supply the demand as measured at the substation

8) Ancillary services cost: Because this is dependent on the business structure of specific utilities, this metric will not be used in evaluating the simulation results.

9) Meter operations cost: Because this is dependent on the business structure of specific utilities, this metric will not be used in evaluating the simulation results.

10) Truck rolls avoided: Because this is dependent on the operational procedures of specific utilities, this metric will not be used in evaluating the simulation results.

11) Meter operations vehicle miles: Because this is dependent on the operational procedures of specific utilities, this metric will not be used in evaluating the simulation results.

12) $\mathrm{CO} 2$ emissions: This metric measures the $\mathrm{CO}_{2}$ emissions required to supply the electricity to the end-use load.

13) Pollutant emissions: This metric measures SOx, NOx, and PM-10 emissions required to supply the electricity to the end-use load.

14) Meter data completeness: Because this is dependent on the operational procedures of specific utilities, this metric will not be used in evaluating the simulation results.

15) Meter reported daily by 2 a.m.: Because this is dependent on the operational procedures of specific utilities, this metric will not be used in evaluating the simulation results.

16) Hourly customer electricity usage: For the purposes of this work, this metric is identical to metric 1 , and will not be used.

17) Annual storage dispatch: This metric examines the total number of hours that energy storage is dispatched.

18) Average energy storage efficiency: This is the average round trip efficiency for all energy storage units on a feeder. 
19) Monthly demand charge: Because this is dependent on the business structure of specific utilities, this metric will not be used in evaluating the simulation results.

20) Distribution feeder or equipment overloads incidents: Because the taxonomy of prototypical feeders is used for analysis there are not overloads included. This is because the average distribution feeder does not normally have overload conditions. As a result, this metric will not be used.

21) Distribution feeder load: This metric gives the annual average hourly load as measured at the substation. Both real and reactive powers are examined.

22) Deferred distribution capacity investment: Because this is dependent on the business structure of specific utilities, this metric will not be used in evaluating the simulation results.

23) Equipment failure incidents: Because the conducted analysis uses representative technologies there is no information associated with equipment failure. The only failures are faults included for the analysis of FDIR. As a result this metric will not be used.

24) Distribution equipment maintenance cost: Because this is dependent on the business structure of specific utilities, this metric will not be used in evaluating the simulation results.

25) Distribution operations cost: Because this is dependent on the business structure of specific utilities, this metric will not be used in evaluating the simulation results.

26) Distribution feeder switching operations: Because this is dependent on the operational procedures and business structure of specific utilities, this metric will not be used in evaluating the simulation results.

27) Distribution capacitor switching costs: Because this is dependent on the operational procedures and business structure of specific utilities, this metric will not be used in evaluating the simulation results.

28) Distribution restoration cost: Because this is dependent on the business structure of specific utilities, this metric will not be used in evaluating the simulation results.

29) Distribution losses: This metric measures the distribution losses; both series and shunt losses are included. Series losses due to overhead lines, underground lines, transformers, and triplex lines are included. Shunt losses due to underground lines and transformers are included. For the purposes of this metric all losses are combined into a single value but some plots will be provided that break the losses into the various components. 
30) Distribution power factor: The distribution power factor is the power factor as calculated at the substation.

31) Truck tolls avoided: Because this is dependent on the operational procedures of specific utilities, this metric will not be used in evaluating the simulation results.

32) SAIFI: As defined in IEEE standard 1366 SAIFI is the system average interruption frequency index. SAIFI indicated how often the average customer experiences a sustained interruption and is calculated by dividing the sum of the total number of customers interrupted by the total number of customers served.

33) SAIDI/CAIDI: As defined in IEEE standard 1366 SAIDI is the system average interruption duration index. SAIDI indicates the total duration of interruption for the average customers and is calculated by dividing the sum of the customer interruption durations by the total number of customers served. As defined in IEEE standard 1366 CAIDI is the customer average interruption duration index. CAIDI represents the average time required to restore service and is calculated by dividing the sum of the customer interruption durations by the total number of customers interrupted.

34) MAIFI: As defined in IEEE standard 1366 MAIFI is the momentary average interruption frequency index. MAIFI is the average frequency of momentary interruptions and is calculated by dividing the sum of the total number of customer momentary interruptions by the total number of customers served.

35) Outage response time: When a fault occurs on the system there are several important times. How long to identify the existence of a fault, how long to locate the fault, and how long to repair the fault. The outage response time is the time between the occurrence of the fault and the time to identify the existence of the fault.

36) Major event information: Major events generally impact a large geographic area which includes multiple distribution substations and the interconnecting transmission or subtransmission system. Since this report is looking primarily at individual feeders this metric will not be used.

37) Number of high impedance faults cleared: This metric is based on the occurrence of high impedance faults in a specific system. The occurrence of faults is only handled in the fault detection identification and restoration technology; high impedance faults are not specifically examined.

38) Distribution operations vehicle miles: Because this is dependent on the operational procedures of specific utilities, this metric will not be used in evaluating the simulation results. 
39) $\mathrm{CO}_{2}$ emissions: This metric measures the $\mathrm{CO}_{2}$ emissions required to supply the demand as measured at the substations.

40) Pollutant emissions: This metric measures the SOx, NOx, and PM-10 emissions required to supply the demand as measured at the substations. 


\section{Appendix B: Taxonomy of Prototypical Distribution Feeders}

As part of the DOE-OE Modern Grid Initiative (MGI) efforts in 2008, a Taxonomy of Prototypical Distribution Feeders was developed [4]. The feeders within this taxonomy were designed to provide researchers with an openly available set of distribution feeder models which are representative of those seen in the continental United States. To construct these representative feeder models, actual feeder models were obtained from utilities across the country and their fundamental characteristics were examined. A detailed statistical analysis was conducted to determine the optimal subset of feeders that could effectively represent the entire data set. The development of the complete Taxonomy of feeder was an extensive process and is fully documented in the report titled "Modern Grid Initiative Distribution Taxonomy Final Report" [4].

Because climate and energy consumption are closely coupled, the prototypical feeders were divided into five climate regions, Figure B.1, based on the U.S DOE handbook (1980) providing design guidance for energy-efficient small office buildings [17].

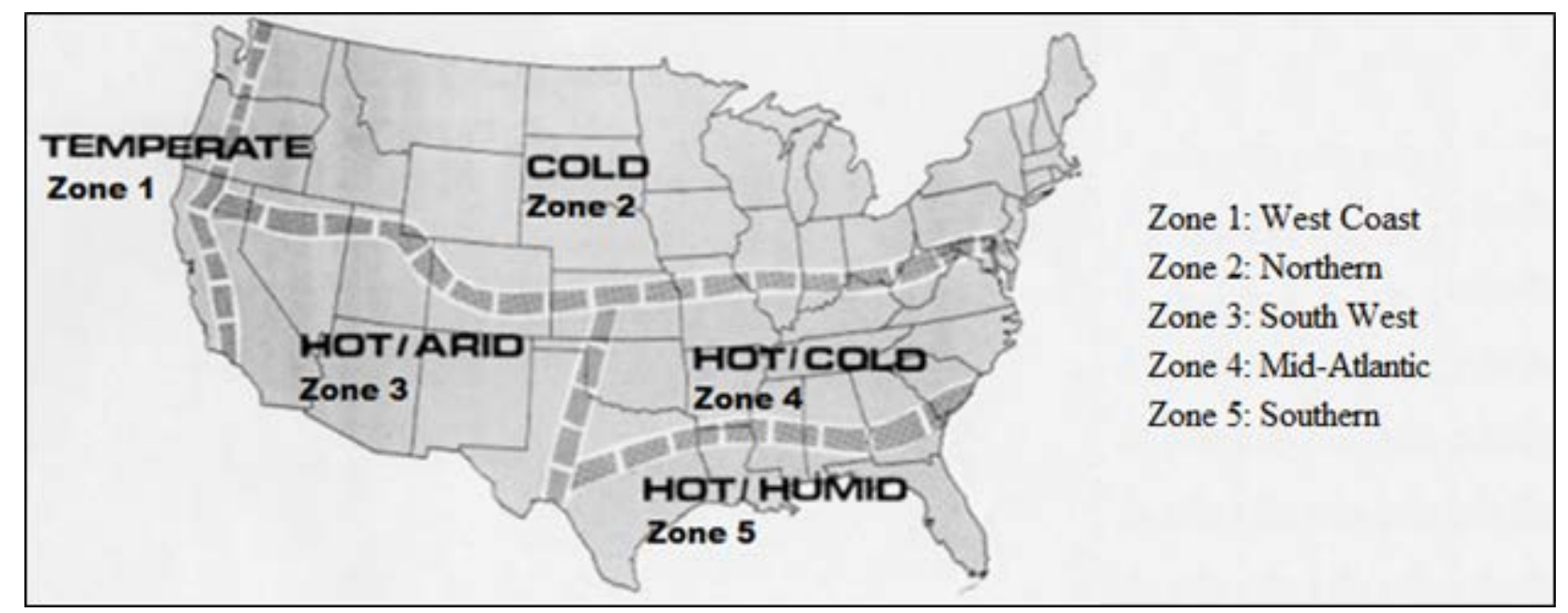

Figure B.1: Climate Zones Used for Development of Prototypical Feeders

Within each of the climate zones, there are a set of feeders that are approximations of the types of feeders that are seen within that zone. Table B.1 gives a summary of the 24 prototypical feeders, including feeder name, base voltage, peak load, and a qualitative description. The peak loading used for the SGIG project analysis is slightly different than the original values from the 2008 report. The difference in peak load is due to improved modeling methods used to represent end-use load. These methods will be discussed in Sections B.2.1 and B.2.2. 
Table B.1: Summary of prototypical feeders

\begin{tabular}{|l|r|r|l|}
\hline Feeder & \multicolumn{1}{|c|}{$\begin{array}{c}\text { Base } \\
\mathrm{kV}\end{array}$} & Peak kVA & \multicolumn{1}{|}{ Description } \\
\hline R1-12.47-1 & 12.5 & 4,300 & Moderate suburban and rural \\
\hline R1-12.47-2 & 12.47 & 2,400 & Moderate suburban and light rural \\
\hline R1-12.47-3 & 12.47 & 1,800 & Small urban center \\
\hline R1-12.47-4 & 12.47 & 4,900 & Heavy suburban \\
\hline R1-25.00-1 & 24.9 & 2,300 & Light rural \\
\hline R2-12.47-1 & 12.47 & 6,700 & Light urban \\
\hline R2-12.47-2 & 12.47 & 6,700 & Moderate suburban \\
\hline R2-12.47-3 & 12.47 & 4,800 & Light suburban \\
\hline R2-25.00-1 & 24.9 & 21,300 & Moderate urban \\
\hline R2-35.00-1 & 34.5 & 6,900 & Light rural \\
\hline R3-12.47-1 & 12.47 & 11,600 & Heavy urban \\
\hline R3-12.47-2 & 12.47 & 4,000 & Moderate urban \\
\hline R3-12.47-3 & 12.47 & 9,400 & Heavy suburban \\
\hline R4-12.47-1 & 13.8 & 6,700 & Heavy urban with rural spur \\
\hline R4-12.47-2 & 12.5 & 2,100 & Light suburban and moderate urban \\
\hline R4-25.00-1 & 24.9 & 1,000 & Light rural \\
\hline R5-12.47-1 & 13.8 & 10,800 & Heavy suburban and moderate urban \\
\hline R5-12.47-2 & 12.47 & 4,200 & Moderate suburban and heavy urban \\
\hline R5-12.47-3 & 13.8 & 4,800 & Moderate rural \\
\hline R5-12.47-4 & 12.47 & 6,200 & Moderate suburban and urban \\
\hline R5-12.47-5 & 12.47 & 8,500 & Moderate suburban and light urban \\
\hline R5-25.00-1 & 22.9 & 9,300 & Heavy suburban and moderate urban \\
\hline R5-35.00-1 & 34.5 & 12,100 & Moderate suburban and light urban \\
\hline GC-12.47-1 & 12.47 & 5,400 & Single large commercial or industrial \\
\hline
\end{tabular}

The original prototypical feeders were modeled in detail from the substation to the end-use point of interconnection, but did not include detailed load models. To use these feeders for an accurate analytic assessment of the SGIG projects, it was necessary to model the end-use load in the appropriate level of detail as was done for the 2010 report on Conservation Voltage Reduction [19].

\section{B.1 End-use Load Models}

The taxonomy of prototypical feeders accurately represents the electrical infrastructure of the distribution feeders, but not the end-use loads. Since it is the end-use loads that consume the majority of the energy on a distribution feeder, it is critical to accurately represent their operation. 
For the taxonomy of feeders to be of use the end-use loads are classified into various categories. In 2010 an analysis of conservation voltage reduction was conducted in GridLAB-D that classified loads as shown in Table B.2 [19]. Because the analysis of the SGIG projects includes technologies other than conservation voltage reduction, a more complete handling of end-use load classifications is necessary and will be discussed in detail in section B.2. This is especially true of technologies such as demand response where the physical characteristics of the buildings are fundamental.

Table B.2: End-use load classifications

\begin{tabular}{|l|l|}
\hline \multicolumn{1}{|c|}{ Load Class } & \multicolumn{1}{c|}{ Description } \\
\hline Residential 1 & Pre-1980<2000 sqft. \\
\hline Residential 2 & Post-1980 <2000 sqft. \\
\hline Residential 3 & Pre-1980 $>2000$ sqft. \\
\hline Residential 4 & Post-1980 $>2000$ sqft. \\
\hline Residential 5 & Mobile Homes \\
\hline Residential 6 & Apartment Complex \\
\hline Commercial 1 & $>35$ kVA \\
\hline Commercial 2 & $<35$ kVA \\
\hline Industrial & All Industrial \\
\hline
\end{tabular}

Regardless of how end-use loads are classified, the component end-use loads are modeled as a combination of ZIP models and multi-state physical models. The ZIP load model and the multistate model are described in the following sections.

\section{B.1.1 ZIP Loads}

ZIP models are two state models, energized and de-energized. When energized there is only a single operational state and the energy consumption can be determined using (B1) for real power, (B2) for reactive power, and (B3) as a constraint [18].

$$
\begin{aligned}
& P_{i}=\left[\frac{\left|V_{a}^{2}\right|}{\left|V_{n}^{2}\right|} \cdot\left|S_{n}\right| \cdot Z_{\%} \cdot \cos \left(Z_{\theta}\right)+\frac{\left|V_{a}\right|}{\left|V_{n}\right|} \cdot\left|S_{n}\right| \cdot I_{\%} \cdot \cos \left(I_{\theta}\right)+\left|S_{n}\right| \cdot P_{\%} \cdot \cos \left(P_{\theta}\right)\right] \\
& Q_{i}=\left[\frac{\left|V_{a}^{2}\right|}{\left|V_{n}^{2}\right|} \cdot\left|S_{n}\right| \cdot Z_{\%} \cdot \sin \left(Z_{\theta}\right)+\frac{\left|V_{a}\right|}{\left|V_{n}\right|} \cdot\left|S_{n}\right| \cdot I_{\%} \cdot \sin \left(I_{\theta}\right)+\left|S_{n}\right| \cdot P_{\%} \cdot \sin \left(P_{\theta}\right)\right] \\
& 100=Z_{\%}+I_{\%}+P_{\%}
\end{aligned}
$$




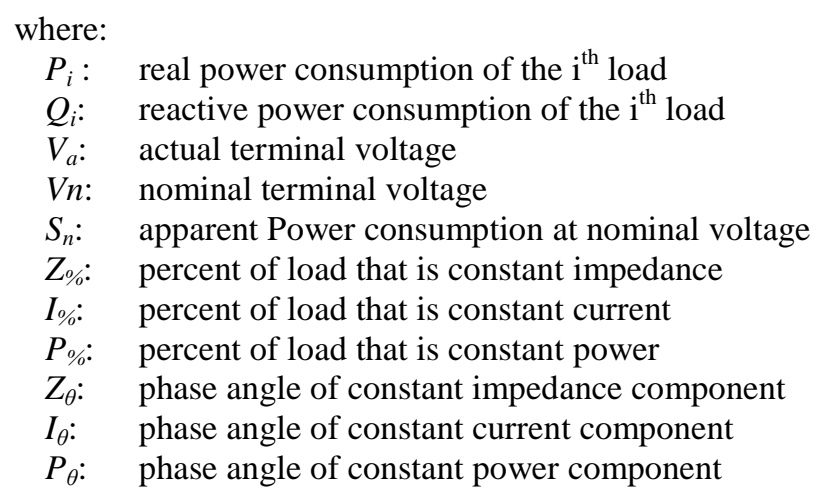

In a time-variant load representation, the coefficients of the ZIP model, $V_{\mathrm{n}}, S_{\mathrm{n}}, Z \%, I \%, P \%$, $Z_{\theta}, I_{\theta}$, and $P_{\theta}$, remain constant, but the power consumption, $P_{i}$ and $Q_{i}$, of the $i^{\text {th }}$ load varies with the actual terminal voltage, $V_{a}$. The ZIP model is similar to the polynomial representation used in many commercial software packages. In the polynomial representation of the ZIP load, the constant coefficient is equivalent to $P \%$, the linear coefficient is equivalent to $I \%$, and the quadratic coefficient is equivalent to $Z \%$. The ZIP model only varies the power consumption as a function of actual terminal voltage, $V_{a}$.

In (B1) and (B2), there are six constants that define the voltage dependent behavior of the ZIP load: $Z_{\%}, I_{\%}, P_{\%}, Z_{\theta}, I_{\theta}$, and $P_{\theta}$. Because the actual value of the distribution feeder voltage continually changes, it is critical to understand how the energy consumption of end-use loads will vary. Specifically, what are the six constants that accurately reflect various end-use loads? For loads such as a heating element, it is clear that the load is $100 \% \mathrm{Z}$, but for more complicated loads such as a Liquid Crystal Display (LCD) or Compact Florescent Light (CFL), the proper ratios are not as apparent.

As part of the 2010 report on conservation voltage reduction a number of laboratory tests were conducted to determine the six constants for various end-use loads; these values have been incorporated into the end-use load models for this study. Figure B.2 is an example of the laboratory testing that was conducted on a $13 \mathrm{~W}$ compact florescent light bulb. 

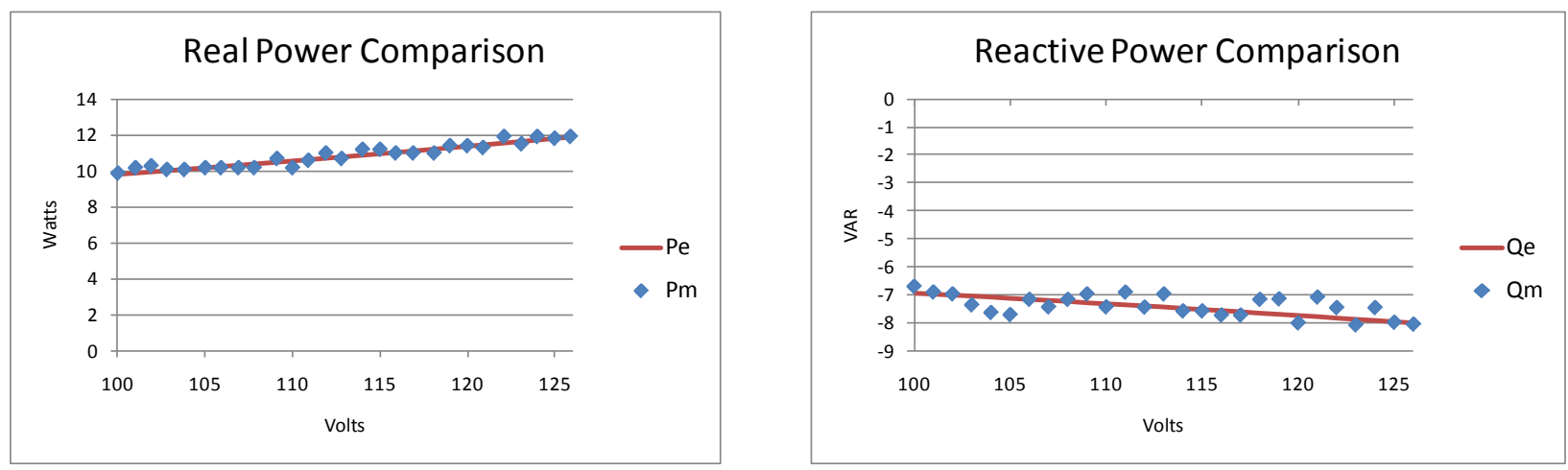

Figure B.2: Voltage dependent energy consumption of 13W CFL

\begin{tabular}{|l|c|c|c|c|c|c|}
\cline { 2 - 7 } \multicolumn{1}{c|}{} & \multicolumn{6}{c|}{ ZIP Values } \\
\cline { 2 - 7 } \multicolumn{1}{c|}{ Z-\% } & I-\% & P-\% & Z-pf & I- pf & P-pf \\
\hline
\end{tabular}

In traditional distribution analysis ZIP models are generally not developed for every individual load, instead models are developed for load classes such as residential, commercial, and industrial. Every load within a given load class then uses the same ZIP values with the exception of the apparent power consumption at nominal voltage, $S_{n}$. The value of $S_{n}$ for each load may change at 1-hour intervals to generate a daily load profile at the feeder level. The use of similar ZIP values for each load class, which only change at 1-hour intervals, is not able to represent coincidental load peaks that occur at the distribution level.

\section{B.1.2 Single-State Detailed Physical Models}

When the energy consumption of an end-use load is a function of variables other than terminal voltage, the use of a ZIP model is not adequate. This is true of any load with an external control system or an internal control loop. To illustrate this issue, the air conditioning system of a single family residence will be examined while in the cooling mode. As with the ZIP model, an air conditioning system is a two state model (ON or OFF), but only has a single operational state.

Because a cooling system operates to maintain internal air temperature within a band, parameters such as near term history of operation, time of year, outside air temperature, building construction, and terminal voltage will impact the instantaneous power consumption, as well as the energy consumption. To examine these issues, a physical model of the cooling system and the structure of the building, is constructed using an equivalent thermal parameter (ETP) model [18]. Because the ETP model has been shown to be an accurate representation of residential and small commercial building instantaneous power draw, as well as energy consumption, it will be used for the formulation of the physical model. 
Figure B.3 is a diagram showing the heat flow for the ETP model of a single family residence, i.e., a house. While the heating/cooling system can be one of any numerous types, for the purposes of this paper, it is assumed that the system is a heat pump in the cooling mode. In addition to the heat removal of the heat pump while cooling and the heat gain through the building exterior, there are two additional significant flows of heat within a house: incident solar radiation and internal gains from waste heat generated by end-use loads. These sources and sinks of heat constitute the total heat energy exchange in the house. This flow of heat is then divided between the air in the house and the mass of the house, i.e., walls and furniture. A portion of the incident solar energy shining through a window will heat the interior air of the house, while the remaining incident energy will be absorbed by the walls, floors, and furniture. The same division occurs with the waste heat from end-use loads. The internal air temperature of the house is thermally coupled to the internal mass temperature, and the internal air temperature is then thermally coupled to the outside air temperature through the thermal envelope of the house.

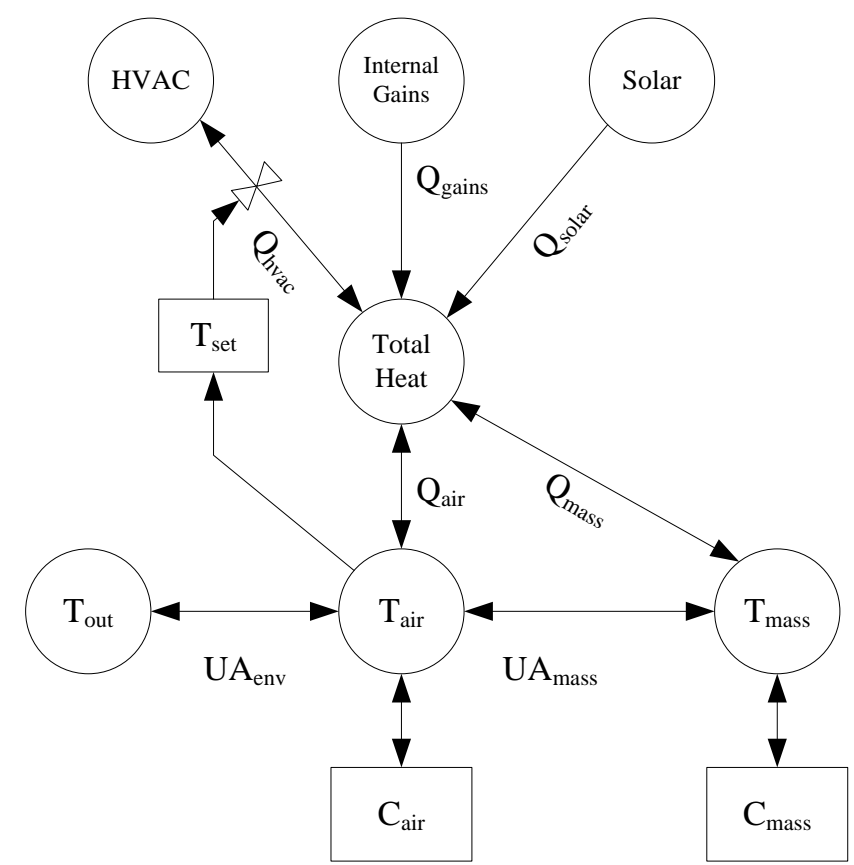

Figure B.3: The ETP mode of a residential heating/cooling system

where,

$\begin{array}{ll}C_{\text {air }}: & \text { air heat capacity }\left(\mathrm{Btu} /{ }^{\circ} \mathrm{F}\right) \\ C_{\text {mass }}: & \text { mass heat capacity }\left(\mathrm{Btu} /{ }^{\circ} \mathrm{F}\right) \\ U A_{\text {env }}: & \text { external gain } / \text { heat loss coefficient }\left(\mathrm{Btu} /{ }^{\circ} \mathrm{F}-\mathrm{h}\right) \\ U A_{\text {mass }}: & \text { internal gain } / \text { heat loss coefficient }\left(\mathrm{Btu} /{ }^{\circ} \mathrm{F}-\mathrm{h}\right) \\ T_{\text {out }}: & \text { air temperature outside the house }\left({ }^{\circ} \mathrm{F}\right)\end{array}$




$\begin{array}{ll}T_{\text {air }}: & \text { air temperature inside the house }\left({ }^{\circ} \mathrm{F}\right) \\ T_{\text {mass }}: & \text { mass temperature inside the house }\left({ }^{\circ} \mathrm{F}\right) \\ T_{\text {set }}: & \text { temperature set points of HVAC system }\left({ }^{\circ} \mathrm{F}\right) \\ Q_{\text {air }}: & \text { heat rate to house air }(\mathrm{Btu} / \mathrm{h}) \\ Q_{\text {gains }}: & \text { heat rate from appliance waste heat }(\mathrm{Btu} / \mathrm{h}), \\ Q_{\text {hvac }}: & \text { heat rate from HVAC system }(\mathrm{Btu} / \mathrm{h}), \\ Q_{\text {mass }}: & \text { heat rate to house mass }(\mathrm{Btu} / \mathrm{h}), \text { and } \\ Q_{\text {solar }}: & \text { heat rate from solar gains }(\mathrm{Btu} / \mathrm{h}) .\end{array}$

Equation (B4) is the second order differential equation that describes the heat flows shown in Figure B1 [18]. Its solution determines the time-varying temperature of the house, both air and mass, given the thermal inputs. With the inside air temperature, $T_{\text {air }}$, known, the thermal behavior of the heat pump system in response to the defined thermostatic set point, $T_{\text {set }}$, can be determined.

$a \frac{d^{2} T_{a i r}}{d t^{2}}+b \frac{d T_{a i r}}{d t}+c T_{a i r}=d$

Where,

$$
\begin{aligned}
& a=\frac{C_{\text {mass }} \cdot C_{\text {air }}}{U A_{\text {mass }}} \\
& b=\frac{C_{\text {mass }} \cdot\left(U A_{\text {env }}+U A_{\text {mass }}\right)}{U A_{\text {mass }}}+C_{\text {air }}
\end{aligned}
$$

$c=U A_{\text {env }}$

$d=Q_{\text {mass }}+Q_{\text {air }}+\left(U A_{\text {env }} \cdot T_{\text {out }}\right)$

With the temperature of the house known from (B4) and the occupant-controlled set point fixed, the operation of the cooling system can be determined. Based on these values, the cooling system will operate long enough to remove the heat necessary to maintain the inside air temperature, $T_{a i r}$, within the desired range. The electrical input energy to the motor, $S_{\text {comp-motor, }}$ necessary to provide the thermal heat energy is a function of two elements: the heat flow through the cooling unit, $Q_{h v a c}$, and the electrical losses of the compressor motor, $S_{\text {losses }}$, as shown in (B5) [18]. 
$S_{\text {comp-motor }}=\left[Q_{\text {hvac }}\left(T_{\text {out }}, V_{T}, C O P\right)+S_{\text {losses }}\left(V_{T}\right)\right]$

The coefficient of performance (COP) is a scalar value that relates the cooling rate of the heat pump unit to the mechanical power delivered by the compressor as a function of temperature and operation time. A higher value of COP indicates less electrical power is necessary to remove a given amount of heat from the air. $V_{T}$ is the terminal voltage of the system compressor motor. Additionally, it should be noted that $Q_{\text {hvac }}$ is expressed in terms of British thermal units (Btu) consistent with the conventions of the heating/cooling industry in the United States and the derivation of the ETP model of [18], while $S_{\text {losses }}$ is expressed in SI units. As a result, the two terms of (B5) must be converted using the conversion of $1.0 \mathrm{Btu} / \mathrm{h}=0.2931 \mathrm{~W}$.

Because both of the elements of (B5) are voltage dependent, changes in line voltage will cause a change in power consumption. The cooling system's heat removal rate, $Q_{h v a c}$, can be solved using heat transfer equations based on the available mechanical torque of the compressor [18]. The motor losses, $S_{\text {losses }}$, can be determined using the traditional split-phase motor model of [20] and [21]. When (B5) is implemented in a time series simulation, the result is a model that determines the energy consumption, both real and reactive, of the cooling system as a function of the outside air temperature, the inside air temperature, equipment parameters, terminal voltage, and occupant-controlled set point.

Unlike ZIP models that apply the same values to each load in a given load class, physical models are specific to each individual load. The values of physical models vary on a 1 second or 1 minute basis to capture the true time-variant nature of the end-use load.

The previous example of a physical model has examined a heat pump in the cooling mode, which is one of multiple operational states. Because of the design of heat pumps, their energy consumption varies according to their current operational state. To properly capture the energy consumption it is necessary to construct a multi-state load model.

\section{B.1.3 Multi-State Detailed Physical Models}

A multi-state time-variant load model uses more than one state to describe the energy consumption of an end-use load. Each state is governed either by a ZIP model and/or a physical model, with transitions between states determined by either internal state transition rules or external signals. For example, a typical heat pump has four normal operating states: State 1 (off), State 2 (cooling), State 3 (heating-normal), and State 4 (heating-emergency). State 2 operates as described in the previous section, and State 3 follows a similar description but with different values that represent the change in the heating cycle, i.e., heat is added instead of removed. State 4 operates as State 3, except that the COP is 1.0 and the load is a ZIP model. There are other abnormal states such as "stalled compressor motor" or "low refrigerant charge", but they will not 
be examined in this paper. Additionally, there are numerous heat pump types and many differing thermostatic controllers that are commercially available, but this paper will discuss a "typical" design. Because a heat pump has two heat-flow configurations, the value of $T_{\text {set }}$ must be split into a heating set point, $T_{\text {low }}$, and a cooling set point, $T_{\text {high }}$. These set points determine the mode of operation of the heat pump system at any given time: off, cooling, heating-normal, or heatingemergency, as shown in Figure B.4.

For a simple single state simulation, the heat pump system would be operating to either heat or cool the house, as discussed in the previous section. For a time-series simulation, the multi-state model captures the transitions between states. While a heat pump system may not transition through all operational states in a single day, it is likely that it will transition through more than one state in any given day. For example, on a mild autumn night, the heat pump may operate to heat the house, then as the sun heats the house during the day, it may be necessary to switch to cooling.

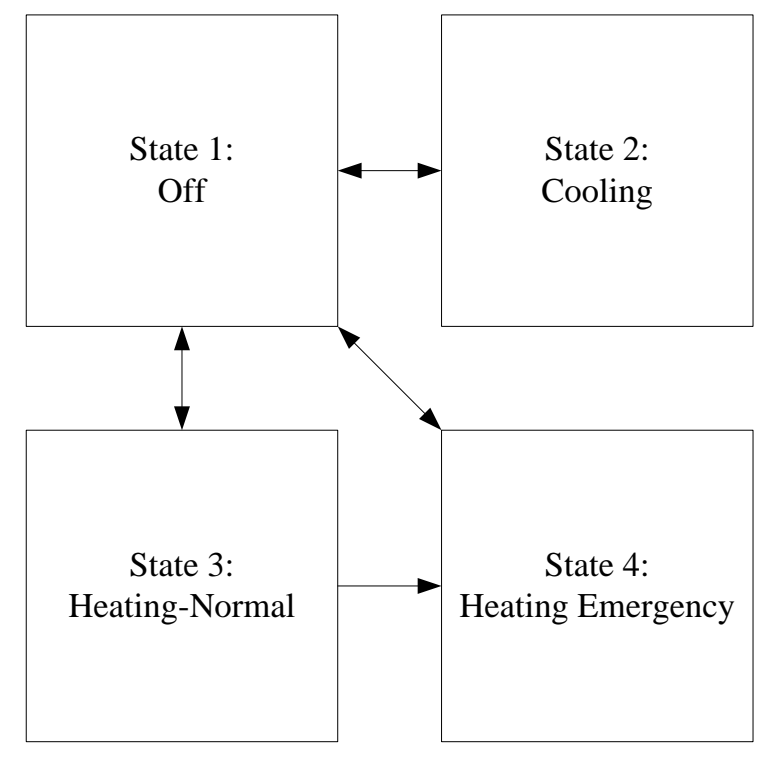

Figure B.4: Multi-state load model

To be in States 2, 3, or 4, the heat pump unit must be turned "on" with defined set points, both occupant-controlled and internal. The occupant-controlled set points are $T_{\text {high }}$ and $T_{\text {low. }}$. If the internal air temperature $T_{\text {air }}$ rises above $T_{\text {high }}$ plus a dead band, $D B_{\text {high }}$, then the heat pump will start cooling. If $T_{\text {air }}$ decreases below $T_{\text {low }}$ minus a dead band, $D B_{\text {low }}$ then the heat pump will start heating normally. If $T_{\text {out }}$ decreases to a temperature, $T_{\text {aux }}$, where the heat pump efficiency becomes too low to effectively heat the home, the system will start heating in the emergency state using resistive heating elements. In addition to the internal control parameters of $T_{a u x}$, the $D B_{\text {low }}$ and $D B_{\text {high }}$ are internal parameters that are not occupant-controlled, but are included to prevent the heat pump from cycling excessively. Table B.3 gives the logic for the allowable state transitions shown in Figure B.4. 
Table B.3: Heat pump state transition logic

\begin{tabular}{|c|c|c|}
\hline From State & To State & Transition Rule \\
\hline 1 & 2 & $T_{\text {air }}>\left(T_{\text {high }}+D B_{\text {high }}\right)$ \\
\hline 1 & 3 & $T_{\text {air }}<\left(T_{\text {low }}-D B_{\text {low }}\right)$ \\
\hline 1 & 4 & $T_{\text {air }}<\left(T_{\text {low }}-D B_{\text {low }}\right) \& T_{\text {out }}<$ \\
\hline 2 & 1 & $T_{\text {aux }}<\left(T_{\text {high }}-D B_{\text {high }}\right)$ \\
\hline 3 & 1 & $T_{\text {air }}>\left(T_{\text {low }}+D B_{\text {low }}\right)$ \\
\hline 3 & 4 & $T_{\text {out }}<T_{\text {aux }}$ \\
\hline 4 & 1 & $T_{\text {air }}>\left(T_{\text {low }}+D B_{\text {low }}\right)$ \\
\hline
\end{tabular}

Each of the four discrete states of operation has a different set of characteristics that determine the instantaneous power consumption. In State 1, there is no power draw because the system is off. In State 2 and State 3, there is an electric fan motor plus a compressor motor. Similar to State 3, State 4 provides heating with an associated electric fan for ventilation but with the difference that heating is provided by resistive heating elements and not a heat pump. The instantaneous power draw of the four states shown in Fig. 2 is given by (B6)-(B9).

State 1: Off

$$
S_{H V A C}=0
$$

State 2: Cooling

$$
S_{\text {HVAC }}=S_{\text {fan-motor }}+S_{\text {comp-motor }}
$$

State 3: Heating-Normal

$$
S_{\text {HVAC }}=S_{\text {fan-motor }}+S_{\text {comp-motor }}
$$

State 4: Heating-Emergency 


$$
S_{\text {HVAC }}=S_{\text {fan-motor }}+\frac{V_{T}^{2}}{R_{\text {elements }}}
$$

where,

$S_{\text {fan-motor }}$ : apparent power of ventilation fan motor (VA)

$S_{\text {comp-motor: }} \quad$ apparent power of compressor motor (VA)

$V_{T}: \quad$ terminal voltage of the heat pump unit $(\mathrm{V})$

$R_{\text {elements }}: \quad$ resistance of the heating coil elements $(\Omega)$

While the power consumption for State 2 and State 3, given by (B7) and (B8) respectively appear to be the same, there are different internal models for $Q_{h v a c}$, particularly with respect to the COPs. With the instantaneous power draw determined by (B6)-(B9), the time necessary to heat or cool the house to within the occupant-controlled set points is determined by the solution to (B4). The result is that variations in temperature, voltage, and efficiency are translated into a variable duty cycle of the heat pump. This information can then be used to determine the instantaneous power demand and the energy consumption of the heat pump over time.

\section{B.2 Model Extraction and Population}

Section B.1 discussed the physical infrastructure of the distribution feeders and gave an overview of the level of detail that is modeled at the end-use. This section describes how the detailed end-use models are populated onto the prototypical distribution feeders.

The taxonomy of prototypical feeders was originally populated with a series of spot loads representing a standard peak load study. Each spot load was classified as residential, commercial, agricultural, or industrial. In this analysis, due to the broad nature of industrial and agricultural loads and the difficulty in accurately representing these loads, each of these loads was re-classified as commercial, leaving only residential and commercial loads. Each load was replaced with building models appropriate to the region of the United States where the prototypical feeder was located. The representative commercial and residential models will be described here.

\section{B.2.1 Residential Loads}

At each triplex node, the residential spot load was replaced with a number of residential house models, which under peak conditions approximately matched the original spot load. The number of house models replacing the original peak load depended upon a scaling factor unique to each taxonomy feeder model and was used to calibrate the populated feeder model to the peak load study. For example, if the original spot load was $10 \mathrm{kVA}$ and the feeder scaling factor was determined to be $5 \mathrm{kVA} /$ house, the spot load would be replaced with two house models. In all cases, the number of homes was rounded to the nearest integer, while the residual from the 
rounding was used as a weighting factor. For example, if the same $10 \mathrm{kVA}$ load was used with a scaling factor of $5.5 \mathrm{kVA} /$ home, the number of homes would be 1.82 . The number was rounded to two homes and the difference of 0.18 was used as a weighting factor on the square footage of the homes populated at that location, creating two house models with a slightly lower than the average square footage. The scaling factor was used to calibrate the new feeder model to the peak load study. Multiple annual simulations were run on each feeder until the peak load for the annual simulation approximately equaled that of the peak load study.

The parameters of each home were determined by the climate region the feeder was located in. Data from the Energy Information Administration's (EIA) 2005 Residential Energy Consumption Survey [6] was used to create a population of homes for each feeder which contained the average characteristics from that region. The EIA divides the country into ten regions, while the U.S. DOE Handbook providing design guidance for energy-efficient small office buildings [22], which was used to create the taxonomy feeders, only uses five.

Table B.4 shows the weighting factors used to map the characteristics between the two sets of regional data.

Table B.4: Table of weighting factors for mapping regional parameters

\begin{tabular}{|ll|c|l|}
\hline \multirow{2}{*}{ Taxonomy Feeder Climate Regions } & \multicolumn{2}{|c|}{ Building Survey Climate Region Weighting } \\
\hline 1 & West Coast & 1 & Pacific \\
\hline \multirow{4}{*}{2} & \multirow{4}{*}{ Northern } & 0.5 & Mountain \\
\cline { 3 - 4 } & & 1 & W N Central \\
\cline { 3 - 4 } & & 1 & E N Central \\
\cline { 3 - 4 } & & 1 & Mid Atlantic \\
\cline { 3 - 4 } 3 & \multirow{3}{*}{ Southwest } & 1 & New England \\
\hline \multirow{3}{*}{4} & \multirow{3}{*}{ Mid-Atlantic } & 0.5 & Mountain \\
\cline { 3 - 4 } & & 0.33 & W S Central \\
\hline \multirow{3}{*}{5} & \multirow{3}{*}{ Southern } & 0.33 & W S Central \\
\cline { 3 - 4 } & & 0.5 & E S Central \\
\cline { 3 - 4 } & & 0.5 & S Atlantic \\
\hline & & 0.33 & W S Central \\
\cline { 3 - 4 } & & 0.5 & E S Central \\
\hline
\end{tabular}

From the EIA data and the weighting factors, a set of key, average building parameters were created as a basis for the population of each feeder. The residential building models were broken into three types: single family homes, apartments, and mobile homes. The age of the home was used to create a set of thermal integrity levels for each housing age and type, from poorly insulated to well insulated, and key parameters were assigned by region and age of home.

Table B.5 shows the average thermal integrity properties by age of the single family homes, apartments, and mobile homes. Each of these parameters was then randomized, where 
appropriate, around the average value with either a normal or uniform distribution to create a diversified population which approximately represents the average household characteristics in that region. More details on the randomizations used can be found in the feeder generator script found on the open source repository [3]. Table B.6, Table B.7, and Table B.8 provide a breakdown of the percentage of single family homes, apartments, and mobile homes, and their corresponding ages, used in creating the randomized population of buildings per region. In addition, other average parameter values were extracted from the EIA documentation, including square footage, cooling and heating set points, heating type, air conditioning penetration, electric water heater penetration, and pool pump penetration. These are listed in Table B.9 through Table B.11.

Table B.5: Residential thermal integrity values by age of home

\begin{tabular}{|c|c|c|c|c|c|c|c|c|c|c|c|}
\hline & $\begin{array}{c}\mathrm{R} \\
\text { Roof }\end{array}$ & $\begin{array}{c}\mathrm{R} \\
\text { Wall }\end{array}$ & $\begin{array}{c}\mathrm{R} \\
\text { Floor }\end{array}$ & $\begin{array}{c}\text { Glass } \\
\text { Layers }\end{array}$ & $\begin{array}{c}\text { Glass } \\
\text { Type }\end{array}$ & $\begin{array}{c}\text { Glazing } \\
\text { Treatment }\end{array}$ & $\begin{array}{c}\text { Window } \\
\text { Frame }\end{array}$ & $\begin{array}{c}\mathrm{R} \\
\text { Door }\end{array}$ & $\begin{array}{c}\text { Air } \\
\text { Infiltration }\end{array}$ & $\begin{array}{c}\text { COP } \\
\text { High }\end{array}$ & $\begin{array}{c}\text { COP } \\
\text { Low }\end{array}$ \\
\hline Single Family & & & & & & & & & & \\
\hline Pre-1940 & 16 & 10 & 10 & 1 & Glass & Clear & Alum. & 3 & 0.75 & 2.8 & 2.4 \\
\hline $1940-1949$ & 19 & 11 & 12 & 2 & Glass & Clear & Alum. & 3 & 0.75 & 3.0 & 2.5 \\
\hline $1950-1959$ & 19 & 14 & 16 & 2 & Glass & Clear & Alum. & 3 & 0.50 & 3.2 & 2.6 \\
\hline $1960-1969$ & 30 & 17 & 19 & 2 & Glass & Clear & TB & 3 & 0.50 & 3.4 & 2.8 \\
\hline $1970-1979$ & 34 & 19 & 20 & 2 & Glass & Clear & TB & 3 & 0.50 & 3.6 & 3.0 \\
\hline $1980-1989$ & 36 & 22 & 22 & 2 & Low-e & Clear & TB & 5 & 0.25 & 3.8 & 3.0 \\
\hline $1990-2005$ & 48 & 28 & 30 & 3 & Low-e & Abs. & Ins. & 11 & 0.25 & 4.0 & 3.0 \\
\hline Apartment & & & & & & & & & & & \\
\hline Pre-1960 & 13 & 12 & 9 & 1 & Glass & Clear & Alum. & 2 & 0.75 & 2.8 & 1.9 \\
\hline $1960-1989$ & 20 & 12 & 13 & 2 & Glass & Abs. & TB & 3 & 0.25 & 3.0 & 2.0 \\
\hline $1990-2005$ & 29 & 14 & 13 & 2 & Low-e & Refl. & Ins. & 6 & 0.13 & 3.2 & 2.1 \\
\hline Mobile Home & & & & & & & & & & \\
\hline $1960-1989$ & 13 & 9 & 12 & 1 & Glass & Clear & Alum. & 2 & 0.75 & 2.8 & 1.9 \\
\hline $1990-2005$ & 24 & 12 & 18 & 2 & Low-e & Clear & TB & 3 & 0.75 & 3.5 & 2.2 \\
\hline
\end{tabular}

Note 1: R is in units of ${ }^{\circ} \mathrm{F} . s f . h / B T U$, air infiltration is in units of air changes / hour, COP is in units of BTU/kWh

Note 2: Low-e refers to low emissivity glass, Abs. refers to absorptive glass, Refl. refers to reflective glass, Alum. refers to an aluminum frame, TB refers to thermal break insulation, Ins. refers to insulated

Table B.6: Percentage of single family homes in total population by age and region

\begin{tabular}{|l|c|c|c|c|c|c|c|}
\hline & Pre-1940 & $1940-1949$ & $1950-1959$ & $1960-1969$ & $1970-1979$ & $1980-1989$ & $1990-2005$ \\
\hline Region 1 & 8.05 & 7.24 & 10.90 & 8.67 & 13.84 & 12.64 & 12.97 \\
\hline Region 2 & 15.74 & 7.02 & 12.90 & 9.71 & 9.41 & 7.44 & 15.32 \\
\hline Region 3 & 4.48 & 2.52 & 8.83 & 8.43 & 11.85 & 13.15 & 24.11 \\
\hline Region 4 & 5.26 & 3.37 & 8.06 & 8.27 & 10.81 & 12.49 & 25.39 \\
\hline Region 5 & 5.26 & 3.37 & 8.06 & 8.27 & 10.81 & 12.49 & 25.39 \\
\hline
\end{tabular}


Table B.7: Percentage of apartments in total population by age and region

\begin{tabular}{|c|c|c|c|}
\hline & Pre-1960 & $1960-1989$ & $1990-2005$ \\
\hline Region 1 & 3.56 & 12.23 & 2.56 \\
\hline Region 2 & 4.81 & 8.87 & 3.03 \\
\hline Region 3 & 1.98 & 11.59 & 4.78 \\
\hline Region 4 & 2.17 & 10.91 & 5.02 \\
\hline Region 5 & 2.17 & 10.91 & 5.02 \\
\hline
\end{tabular}

Table B.8: Percentage of mobile homes in total population by age and region

\begin{tabular}{|c|c|c|}
\hline & $1960-1989$ & $1990-2005$ \\
\hline Region 1 & 5.54 & 1.81 \\
\hline Region 2 & 8.87 & 3.03 \\
\hline Region 3 & 5.24 & 3.02 \\
\hline Region 4 & 4.91 & 3.33 \\
\hline Region 5 & 4.91 & 3.33 \\
\hline
\end{tabular}

Table B.9: Percentage of key building parameters by region

\begin{tabular}{|c|c|c|c|c|c|c|c|}
\hline & \multicolumn{3}{|c|}{ Heating Fuel Type } & \multirow{2}{*}{$\begin{array}{c}\text { With Air } \\
\text { Conditioner }\end{array}$} & \multirow{2}{*}{$\begin{array}{l}\text { With Electric } \\
\text { Water Heater }\end{array}$} & \multirow{2}{*}{$\begin{array}{c}\text { With Pool } \\
\text { Pump* }\end{array}$} & \multirow{2}{*}{$\begin{array}{c}\text { One-Story } \\
\text { Home* }\end{array}$} \\
\hline & Non-Electric & Heat Pump & Resistance & & & & \\
\hline Region 1 & 70.51 & 3.21 & 26.28 & 43.48 & 25.45 & 9.04 & 68.87 \\
\hline Region 2 & 89.27 & 1.77 & 8.96 & 75.28 & 25.15 & 5.91 & 52.10 \\
\hline Region 3 & 67.23 & 5.59 & 27.18 & 52.59 & 34.80 & 8.18 & 77.45 \\
\hline Region 4 & 44.25 & 19.83 & 35.92 & 96.73 & 64.28 & 6.57 & 70.43 \\
\hline Region 5 & 44.25 & 19.83 & 35.92 & 96.73 & 64.28 & 6.57 & 70.43 \\
\hline
\end{tabular}

*Note: Percentage with pool pumps and one-story homes was only applied to single family homes. 
Table B.10: Percentage of nighttime heating and cooling set points by housing type

\begin{tabular}{|c|c|c|c|}
\hline & Single Family & Apartment & Mobile Home \\
\hline Set point $\left({ }^{\circ} \mathrm{F}\right)$ & \multicolumn{3}{|c|}{ Cooling } \\
\hline $65-69$ & 9.8 & 15.5 & 13.8 \\
\hline $70-70$ & 14.0 & 20.7 & 17.2 \\
\hline $71-73$ & 16.6 & 10.3 & 17.2 \\
\hline $74-76$ & 30.6 & 31.0 & 27.6 \\
\hline $77-79$ & 20.6 & 15.5 & 13.8 \\
\hline $80-85$ & 8.4 & 6.9 & 10.3 \\
\hline \multicolumn{3}{|c|}{ Heating } \\
\hline $59-63$ & 14.1 & 8.5 & 12.9 \\
\hline $64-66$ & 20.4 & 13.2 & 17.7 \\
\hline $67-69$ & 23.1 & 14.7 & 16.1 \\
\hline $70-70$ & 16.3 & 27.9 & 27.4 \\
\hline $71-73$ & 12.0 & 10.9 & 8.1 \\
\hline $74-79$ & 14.1 & 24.8 & 17.7 \\
\hline
\end{tabular}

Table B.11: Average square footage by building type and region

\begin{tabular}{|c|c|c|c|}
\hline & Single Family & Apartment & Mobile Home \\
\hline Region 1 & 2209 & 820 & 1054 \\
\hline Region 2 & 2951 & 798 & 1035 \\
\hline Region 3 & 2370 & 764 & 1093 \\
\hline Region 4 & 2655 & 901 & 1069 \\
\hline Region 5 & 2655 & 901 & 1069 \\
\hline
\end{tabular}

Of note is the cooling and heating set points found in Table B.10. Heating and cooling set points bins were chosen randomly and independently, except to require that the heating set point be below the cooling set point. Within each bin a uniform distribution was used to determine the actual nighttime set point for each home. Additionally, data from the surveys showed average daytime versus nighttime offsets. Offsets were uniformly distributed between zero and twice the average offset, and the time at which the offsets occurred was randomized across the population. Figure B.5 provides a few examples of the diversity of cooling set points established through this methodology, while Figure B.6 shows the average cooling set point on a summer day of all the residential homes within the $\mathrm{R} 1-12.47-2$ feeder. 


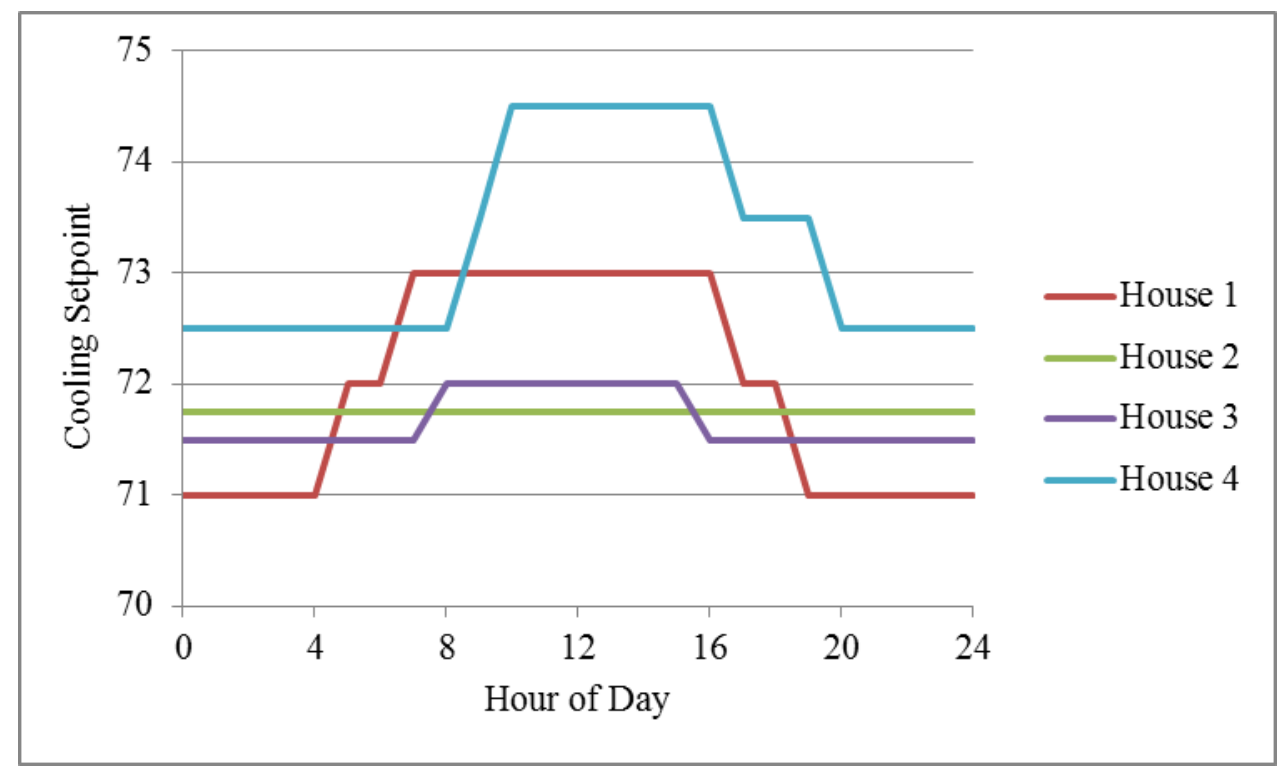

Figure B.5: Exemplary cooling set points diversified with time and daytime and nighttime offsets

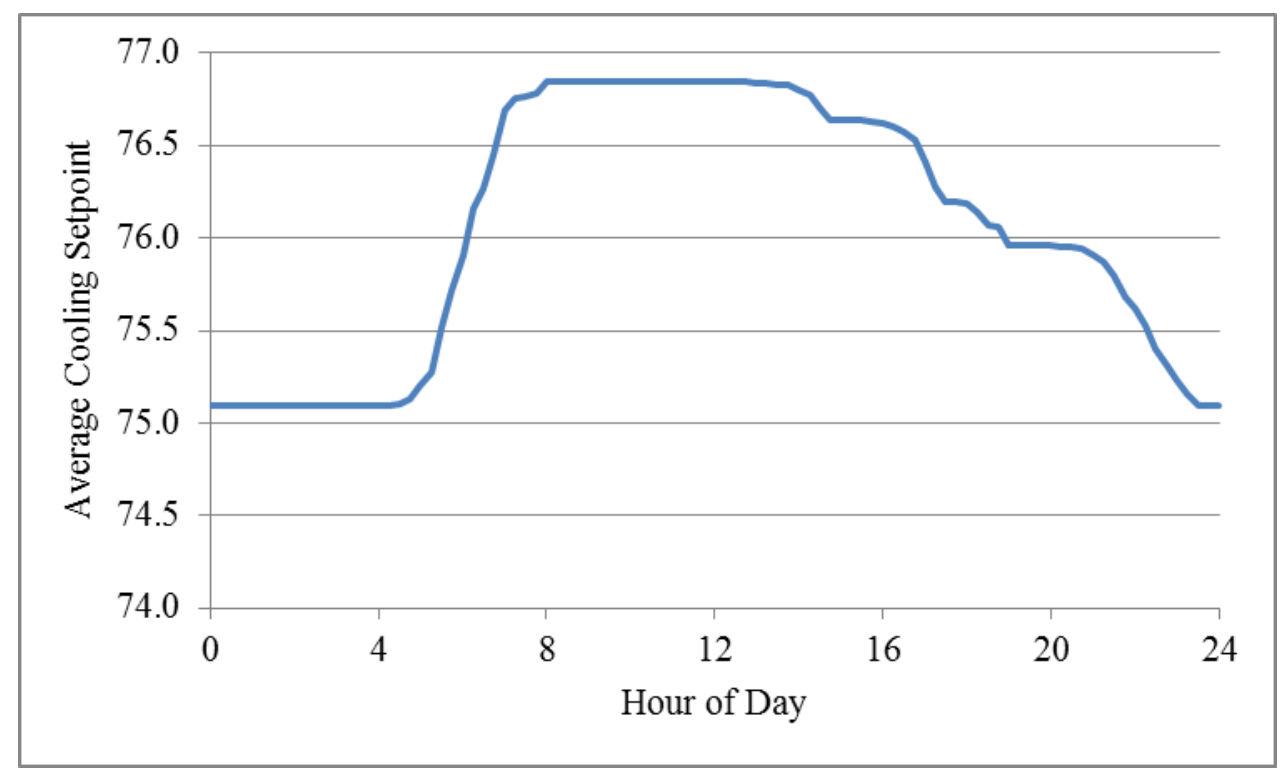

Figure B.6: Average cooling set points of entire population of R1-1247-2

It is important to note that the populated building models were not designed to represent any particular feeder circuit or city in the United States, but rather as a blended average of large climate regions within the United States. While this will not perfectly capture the behavior of any particular city or utility, it is designed as a representative analysis. Additional methods exist where a utility can provide very specific load data which is much more representative of the local population, and design an analysis which is much more suited to that particular application. 
The parameter values, in conjunction with estimated demand, were used to describe the state models of the hot water heater, HVAC system, and pool pump. However, additional loads were represented as scheduled ZIP loads. "Appliances" such as refrigerators and lights were divided into two categories: responsive and unresponsive loads. Responsive loads indicate that the customer is able to modify the behavior of the appliance due to a price signal, while unresponsive loads indicate that the customer is typically not willing or able to modify the behavior without investment in additional technologies (e.g. demand response enabled appliances). Responsive loads included lights, plug loads, clothes washers, clothes dryers, dishwashers, cooking ranges, and microwaves, while unresponsive loads included refrigerator and freezer loads. These were divided in anticipation of demand response studies and the shift of customer behavior that is associated with Time-of-Use or Critical Peak pricing. ELCAP load data [23] was used to create a base hourly load profile for responsive and unresponsive loads, with adjustments made for 20 years of increased efficiency and increased or decreased demand, and included seasonal and weekday versus weekend effects, as shown in Figure B.7 and Figure B.8. Additionally, loads were scaled as a function of square footage using a regression, again using ELCAP data. The proper scalar from the regression is shown in (B10):

$$
k=324.9 * \text { floor }_{\text {area }}{ }^{442} * 1000 / 8760
$$

The scalar was then randomized $+/-20 \%$ over a uniform distribution. While this provided no single home with a load shape representative of a time series of an actual home, the aggregate load shape was representative of an entire population of homes, and internal loading of each home provided internal heat gains appropriate to that size of home. 


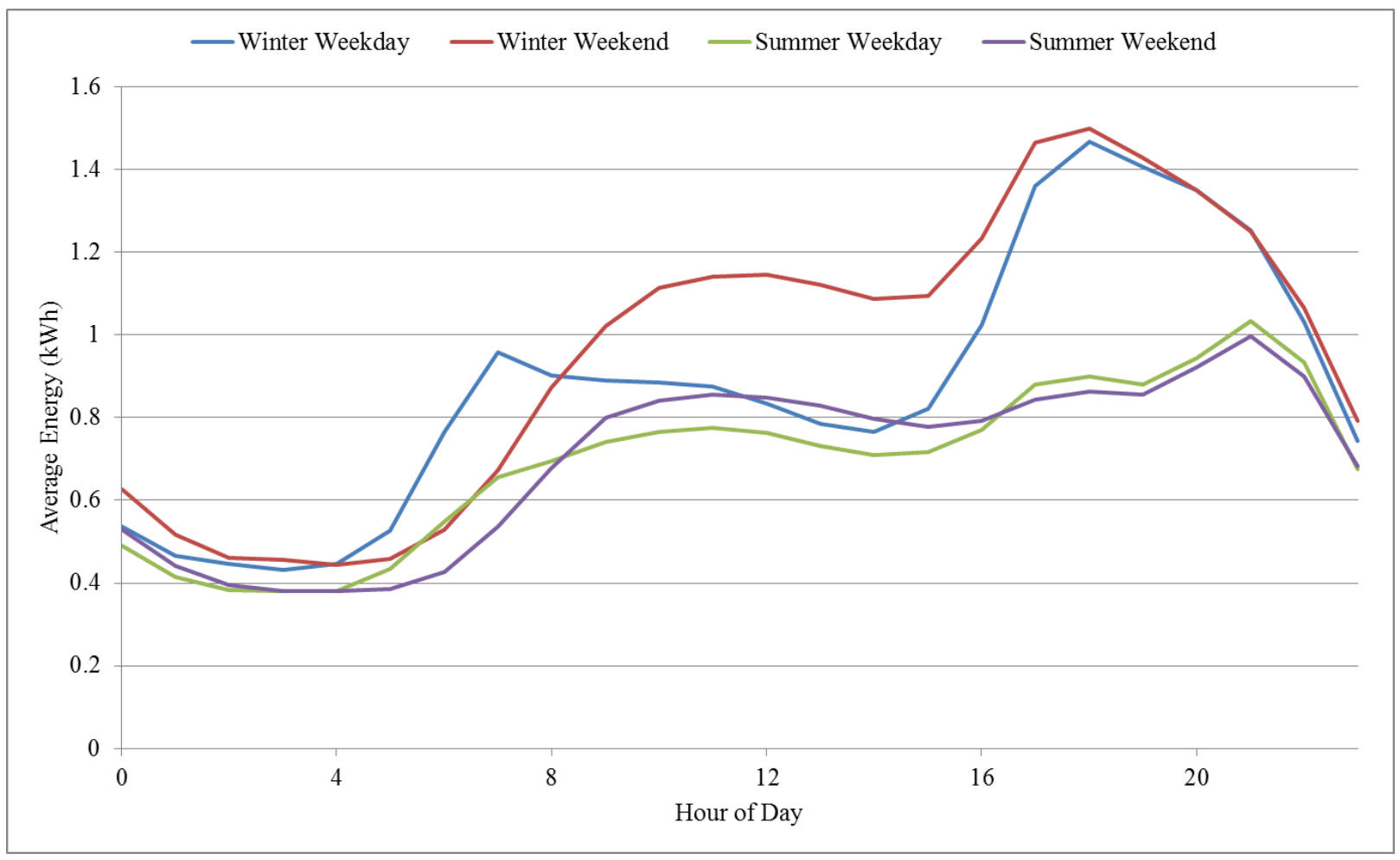

Figure B.7: Average energy consumption of responsive loads

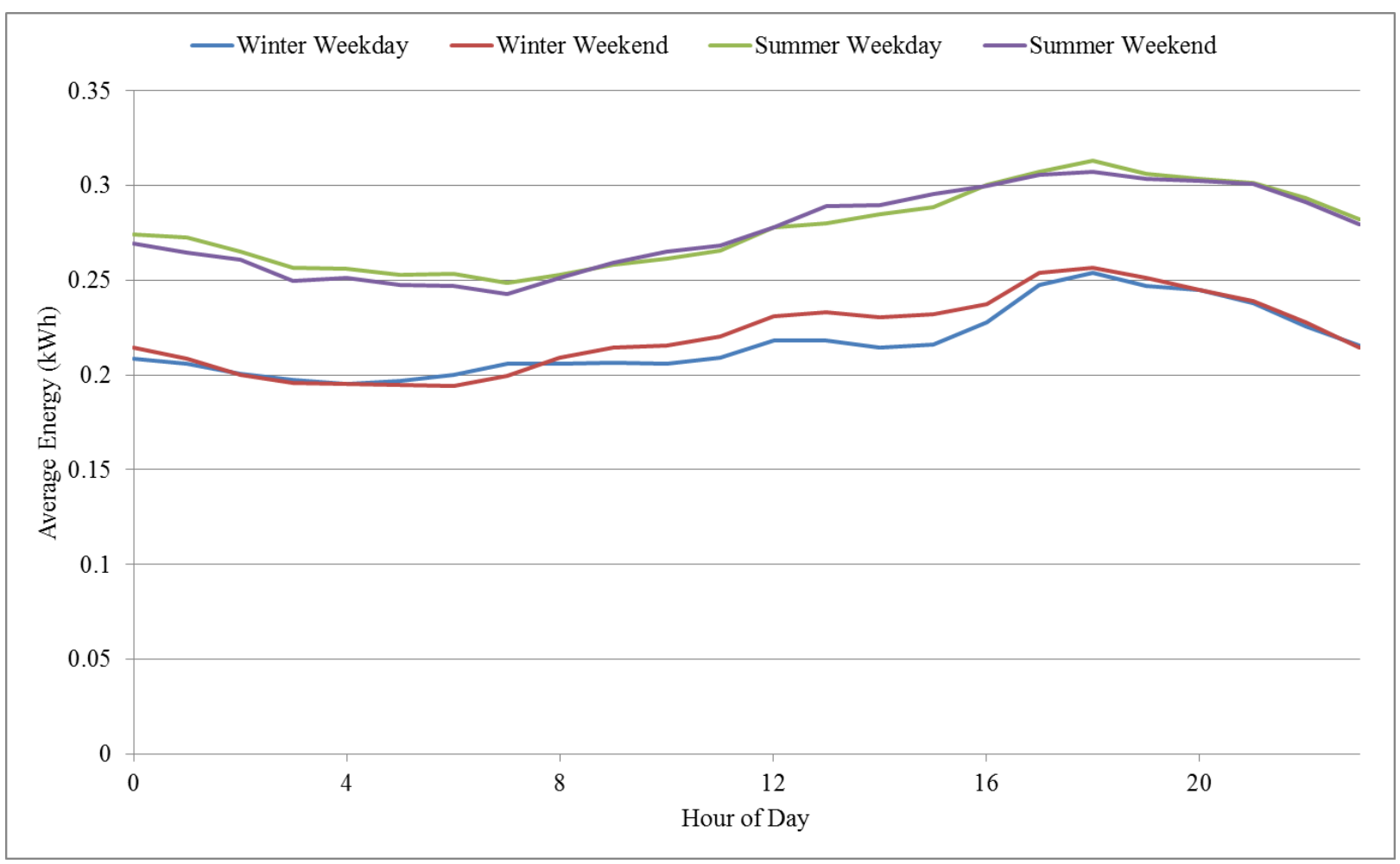

Figure B.8: Average energy consumption of unresponsive loads 


\section{B.2.2 Commercial Loads}

At this time, a fully implemented, multi-zone commercial building model is not available within GridLAB-D. However, to represent the "zones" of a commercial building, multiple house models were created to represent the commercial load. These loads were created using very generic commercial building characteristics and load patterns. The commercial loads (and the re-classified industrial and agricultural loads) were divided into three types: office buildings, large retail "box" buildings, and small retail strip malls. The key characteristics of these models were developed through federally-supported building codes and end-use metering studies, and are not based on regional differences as the residential models were [24][25]. Population of the prototypical feeders and the three types of buildings was performed by size of the original load and the number of phases the load was attached to. Similar to the residential loading, a scalar was used to calibrate the loading on each feeder model, modifying the number of loads and size of each load.

Office buildings were represented by a three-story, fifteen-zone model as shown in Figure B.9. These replaced loads within the taxonomy feeder that were three-phase and "larger", as defined by the scaling factor. The average square footage was $40,000 \mathrm{sf}$, with a uniform deviation of $50 \%$, while maintaining the geometrical relationship of each zone. Each of the zones has identical parameter values, except square footage, aspect ratio, external wall area, external floor area, and external ceiling area. Assumptions are made in this model to better represent the zonal attributes of a commercial building. It is assumed that the adjacent zone has approximately the same air and mass temperature as the current zone, so that there is no heat transfer across the boundaries. This means that the internal wall, ceiling, or floor areas do not lose or gain heat from adjacent zones, and can therefore be ignored when defining the thermal envelope of the building. For example, Zone 5 on the second floor in Figure B.9 will have an external wall area of $0 \mathrm{sf}$., an external floor area of $0 \mathrm{sf}$., and an external ceiling area of $0 \mathrm{sf}$. This zone would only have heat added (or removed) through end-use loads and the HVAC system. Zone 2 on the third floor will have an external wall area equal to one-half its total wall area, and external floor area also equal to $0 \mathrm{sf}$., and an external ceiling area equal to its floor area, allowing additional heat flows across the external boundaries. By defining each zone within the constraints of the geometrical model, then defining where heat transfer across boundaries is allowed and not allowed, a zonal model can be roughly represented. Notice that Figure B.9 contains a variable ' $x$ '. This variable would be adjusted by the randomly chosen square footage so that $3 * 1.5^{*} x^{2}$ equaled the total square footage, while all other parameters except for the widths of Zones 1-4 adjusted within the geometrical constraints. The other building type zones were defined in a similar manner. Table B.12 shows the key parameters used to define the office building zones. Additionally, since the office building is considered a larger, single owner, customer billing was performed as an aggregate of all the "zones". 


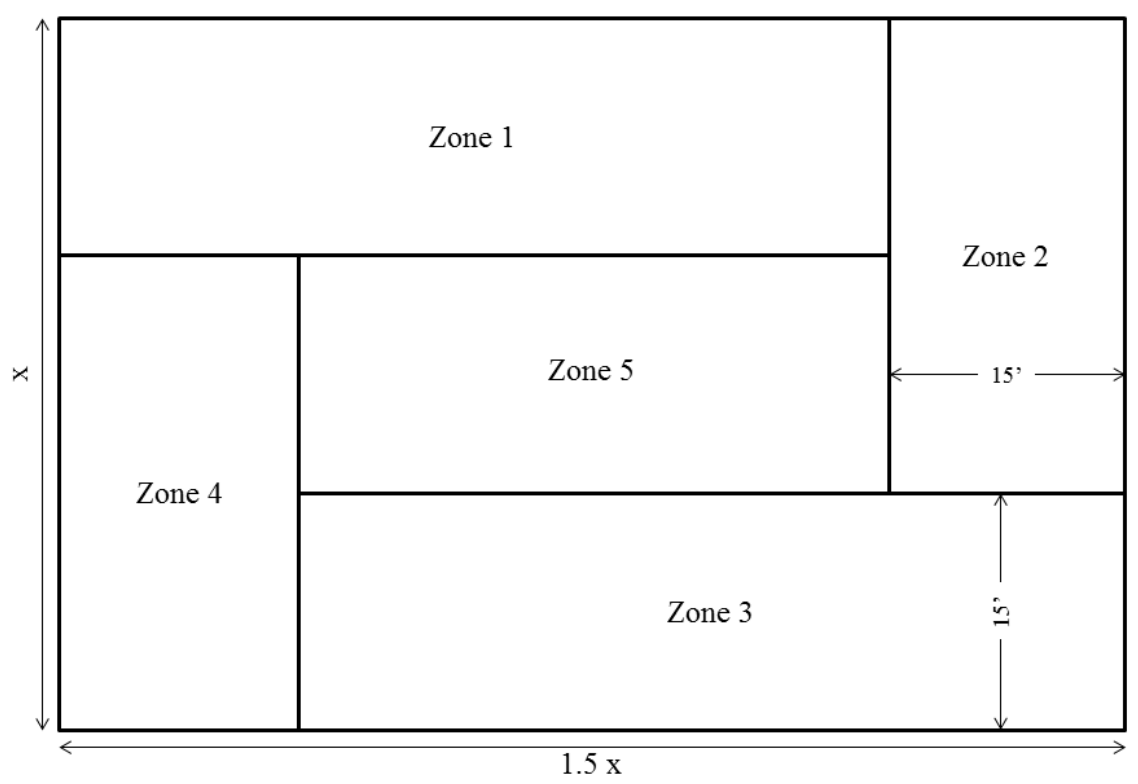

Figure B.9: Office zonal floor plan representing 1 of 3 identical floors

Table B.12: Key parameters for commercial buildings

\begin{tabular}{|c|c|c|c|}
\hline & Office & Big Box & Strip Mall \\
\hline Square Footage & $40,000+/-50 \%$ & $20,000+/-50 \%$ & $2400+/ 30 \%$ \\
\hline Ceiling Height & 13 & 14 & 12 \\
\hline Air Infiltration & 0.69 & 1.5 & 1.76 \\
\hline R Roof & 19 & 19 & 19 \\
\hline R Wall & 18.3 & 18.3 & 18.3 \\
\hline R Floor & 46 & 46 & 40 \\
\hline R Door & 3 & 3 & 2 \\
\hline Glazing Layers & 2 & 2 & Glass \\
\hline Glass Type & Glass & Glass & Low S \\
\hline Glazing Treatment* & Low S & Low S & 1 \\
\hline Window Frame & None & None & $0.03 / 0.05$ \\
\hline No. of Doors* & 0 & $0 / 1 / 24$ & 3.6 \\
\hline Window to Wall Ratio & $0 / 0.33$ & $0 / 0.76$ & $3+/-20 \%$ \\
\hline Internal Gains (W/sf) & 3.24 & 3.6 & \\
\hline Cooling COP & $3+/-20 \%$ & $3+/-20 \%$ & \\
\hline
\end{tabular}

*Note: Low $\mathrm{S}$ refers to low solar glazing.

*Note: Number of doors refers to the number of doors externally exposed, and is translated into a wall area used by the doors -24 doors refers to the surface area used by 24 doors. Office accounts for door area in the window area. 
Big box retail buildings were represented as a one-story, six-zone model as shown in Figure B.10, and were used to replace "larger" two-phase loads and "smaller" three-phase loads, as defined by the scaling factor. The overall square footage was defined as 20,000 sf., with a uniform deviation of 50\%. Table B.12 shows the key parameters used to define the retail big box building zones. Again, this building was considered a single occupant and customer billing was performed on the aggregate of all the "zones".

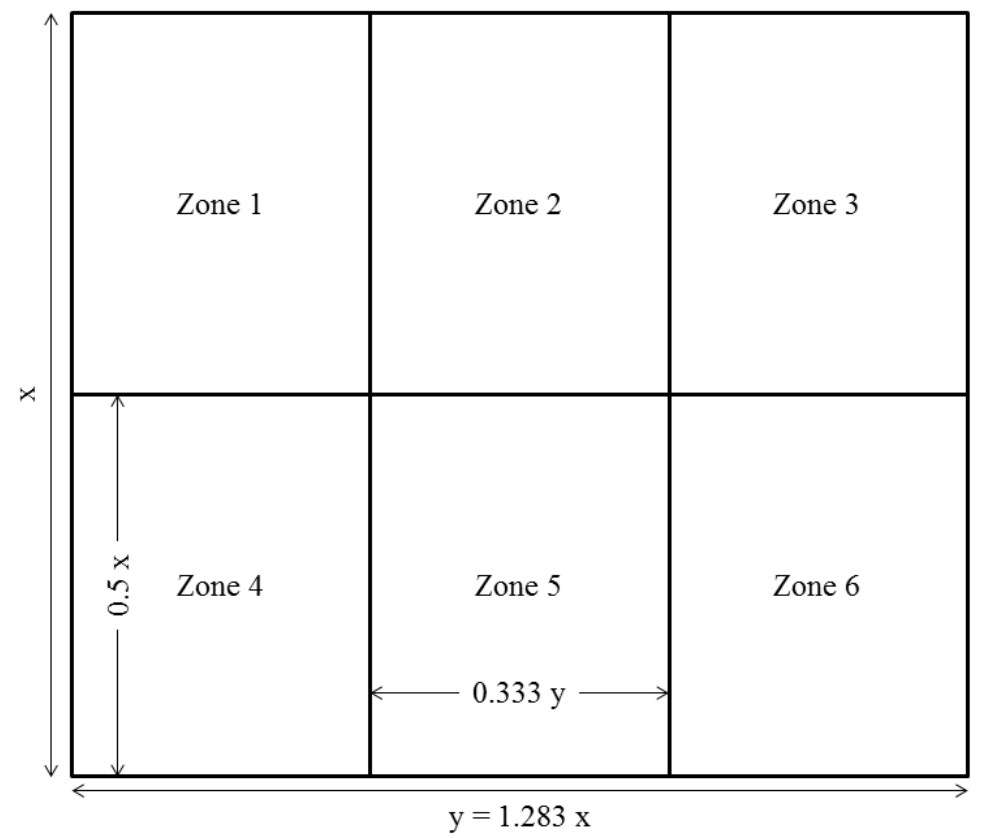

Figure B.10: Retail "big box" zonal floor plan

A retail strip mall model was used to represent all other loads, including all one-phase loads and "smaller" two- or three-phase loads. These were represented by one-story, single-zone models connected in series as shown in Figure B.11. Individual zones were defined as 1200 or 2400 sf., with a uniform deviation of $30 \%$. Table B.12 shows the key parameters used to define the retail strip mall building zones. In this case, ownership was considered on a per-zone basis, so customer billing was also performed on a per-zone basis. 


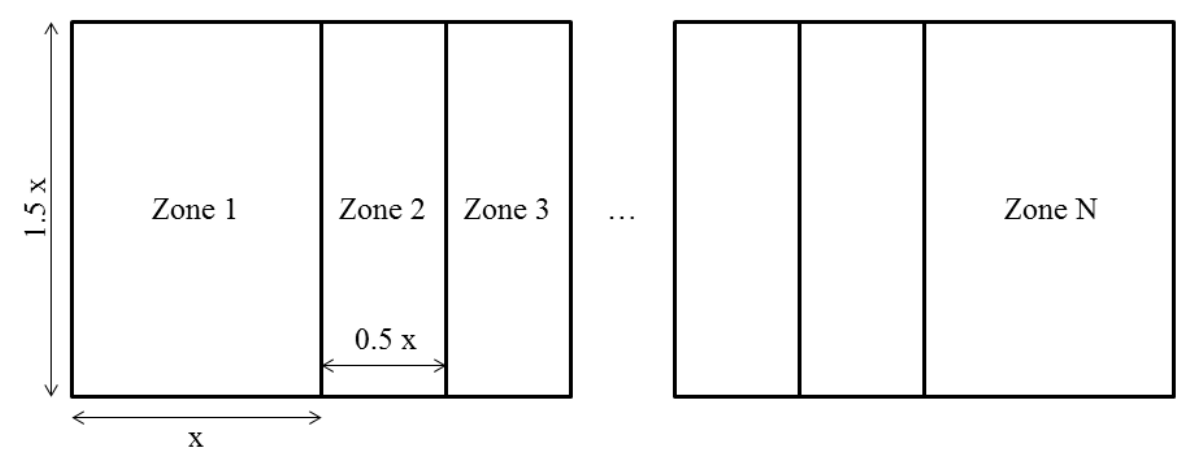

Figure B.11: Retail strip mall zonal floor plan with $\mathrm{N}$ zones depending upon scaling factor

Additionally, it was assumed that all commercial buildings had both heating and cooling systems and heating was always represented by a gas heating unit rather than a heat pump or resistive heat unit. Again, internal loads are very important drivers for both heating and cooling of the space, displacing heating load while adding cooling load. Commercial building load is highly occupant driven, and is typically very recurring. Data from end-use metering projects was used to create average end-use load shapes for weekdays and weekends [25]. Again, certain loads were slightly scaled up or down to reflect changes in efficiencies or standard usage. Weekdays are assumed to be Mon-Fri for office buildings, Mon.-Sun. for big box buildings, and Mon.-Sat. for strip malls. Average load shapes are shown in Figure B.12 through Figure B.15. Notice that the $\mathrm{y}$-axis is in units of W/sf. The load shape applied to each zone is scaled as a function of square footage then randomized on a zonal basis by $+/-20 \%$ over a uniform distribution. In addition to the magnitude randomization, the load shape was also randomly "skewed" in time. Each of the zones within the building were considered to be on the same schedule, however, across the population of buildings, not all started and ended at the same time. The load shapes were temporally shifted from those shown in Figure B.12 through Figure B.15 in 30-minute blocks using a normal distribution of average of 0 minutes and standard deviation of 30 minutes. This produced a more diversified load across the entire population. 


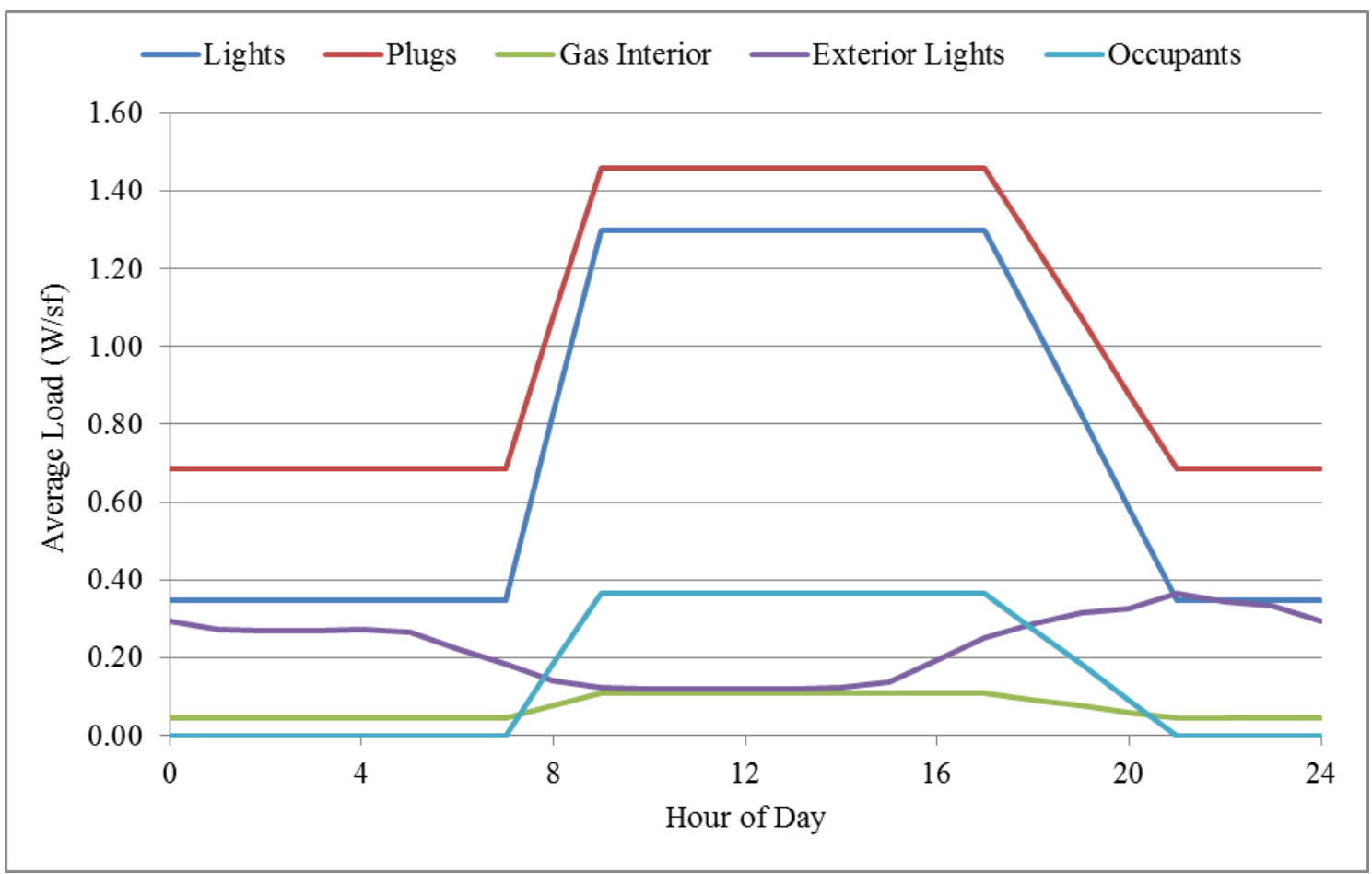

Figure B.12: Average office end-use load shape (weekday)

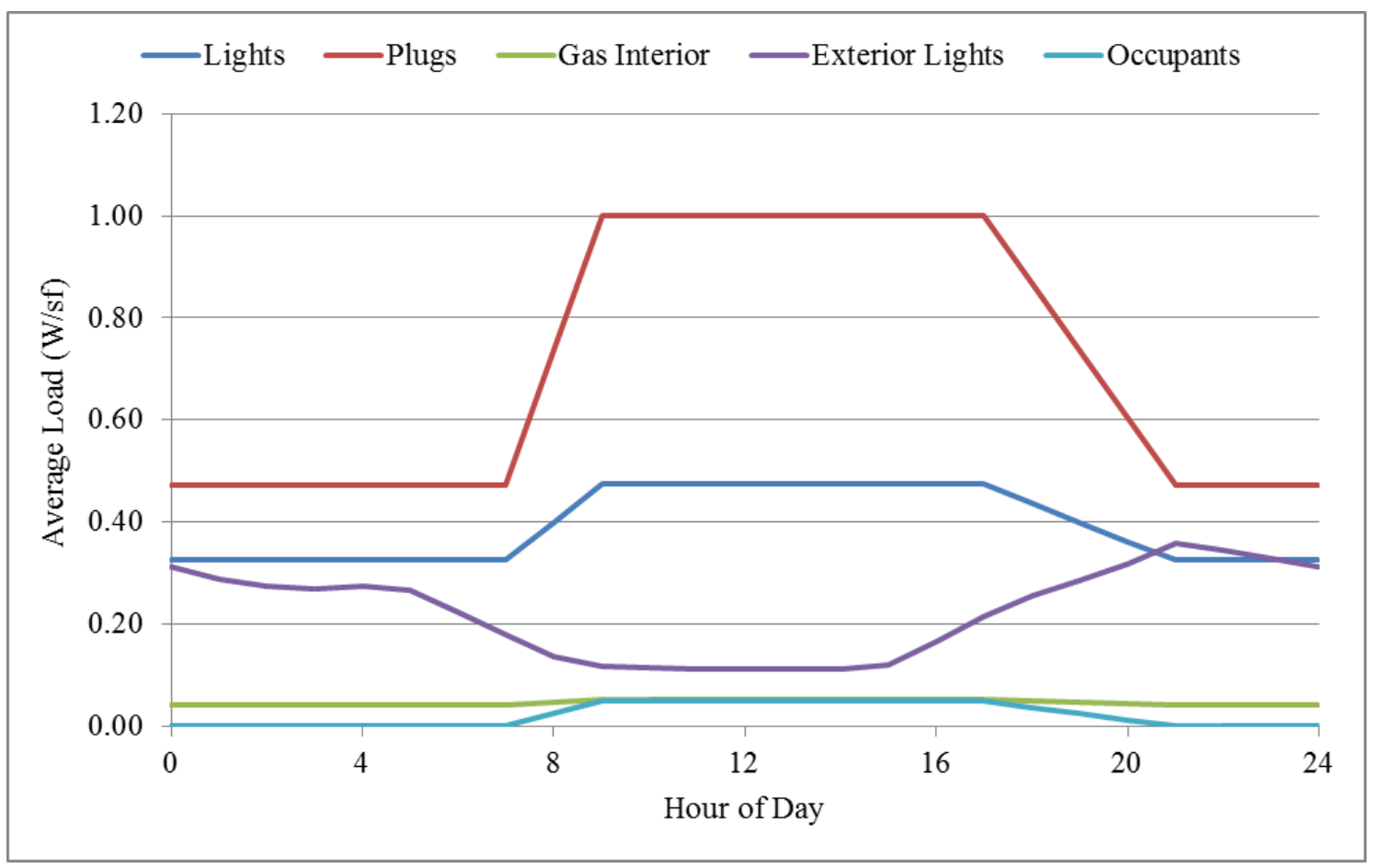

Figure B.13: Average office end-use load shape (weekend) 


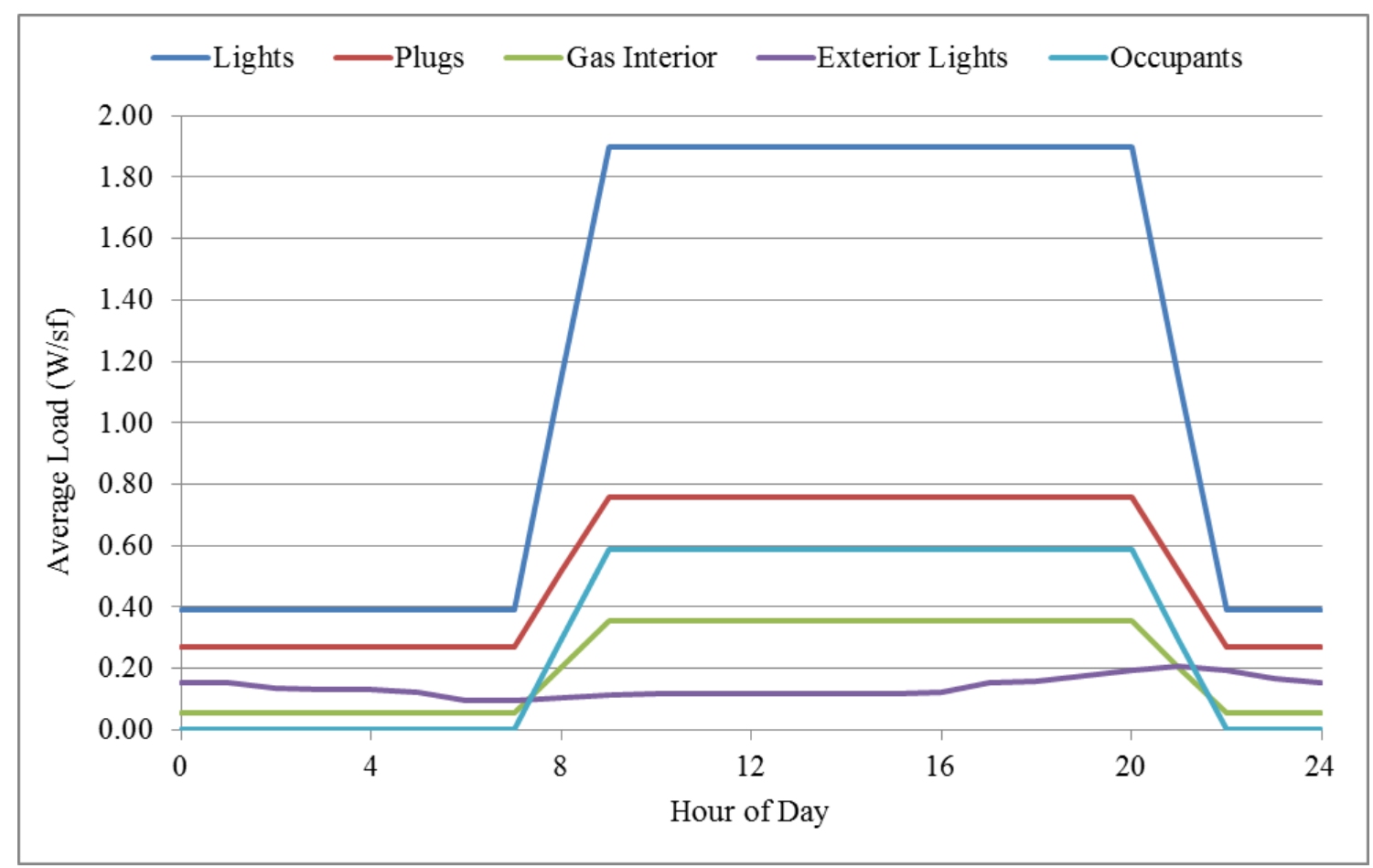

Figure B.14: Average big box and strip mall end-use load shape (weekday)

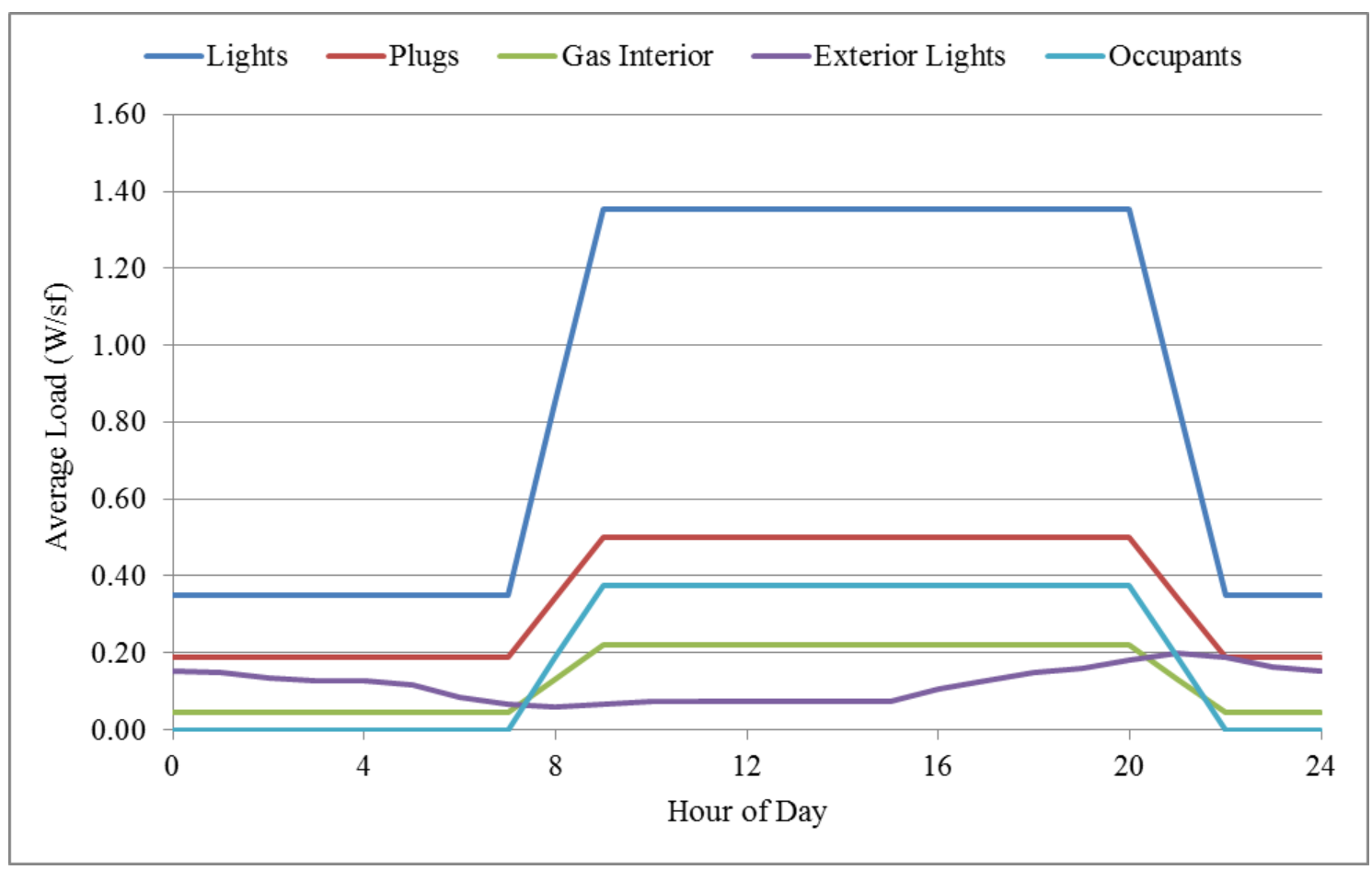

Figure B.15: Average big box and strip mall end-use load shape (weekend) 
Finally, there were a number of loads on the prototypical feeders that were far smaller than could be described by a building model at peak load, often less than $1 \mathrm{kVA}$. While there are a number of options for representation of these loads, such as traffic lights or a small espresso stand, it was determined that without data to indicate what these loads represented they would be best represented by street lighting loads. These small loads were converted to a scheduled one-, two-, or three-phase load, depending on the original load and the full rated load was applied during dark hours and zero load was applied during daylight hours. While it is understood that this is not an accurate representation of true street light loading and operation, the loads were small enough and infrequent enough that a simple scheduled load had little to no effect on the overall operation of the feeder circuits.

\section{B.3 Taxonomy Feeder Emission Profiles}

Increasing operational efficiency of the electrical power system can lead to a reduction in pollutant emissions. Peak load reduction or peak shifting has been shown to reduce emissions, mainly due to reducing the need to use "peaker" units. These are typically older, less efficient generators, designed for quick start-up and shutdown, and are often single cycle natural gas turbine generators or petroleum fired plants. Reduction in overall energy consumption or shifting of production to more efficient energy sources can also reduce emissions by reducing the amount of fuel burned for electricity production. Solutions for the amount of emissions created are traditionally performed at the transmission level, using optimal power flow and economic dispatch, and are typically not well-suited for distribution level simulation. The following section is a brief description of how GridLAB-D estimates emissions impacts at the distribution level.

To capture the emissions level benefits to the system, generation mixes were assumed in each region and the nine most heavily consumed fuels for electrical generation in the U.S. were used. In each region, the fuels are dispatched in order from first to last by capacity factor, as shown in Table B.13. Exceptions are made for a number of the renewable resources, such as wind, solar, and biomass, as they are assumed to be dispatched when available. The level of penetration by each fuel type was determined for each region by month as shown in Tables B.13-B.18. These values were determined from the EIA's Annual Electric Generator Report [6], utilizing state-bystate breakdowns of annual energy production. 
Table B.13: Dispatch order of fuel by region

\begin{tabular}{|c|c|c|c|c|c|}
\hline Region & 1 & 2 & 3 & 4 & 5 \\
\hline \multirow{4}{*}{$\begin{array}{l}\text { Order of } \\
\text { dispatch }\end{array}$} & Nuclear & Nuclear & Nuclear & Nuclear & Nuclear \\
\cline { 2 - 6 } & Solar & Solar & Solar & Solar & Solar \\
\cline { 2 - 6 } & Biomass & Biomass & Biomass & Biomass & Biomass \\
\cline { 2 - 6 } & Wind & Wind & Wind & Wind & Wind \\
\cline { 2 - 6 } & Natural Gas & Natural Gas & Natural Gas & Natural Gas & Coal \\
\cline { 2 - 6 } & Coal & Hydroelectric & Hydroelectric & Hydroelectric & Hydroelectric \\
\cline { 2 - 6 } & Geothermal & Geothermal & Geothermal & Geothermal & Geothermal \\
\cline { 2 - 6 } & Petroleum & Petroleum & Petroleum & Petroleum & Petroleum \\
\hline
\end{tabular}

Table B.14: Percent of energy consumed, broken down by fuel type and month in region 1

\begin{tabular}{|l|r|r|r|r|r|r|r|r|r|r|r|r|}
\hline Region 1 & Jan & Feb & \multicolumn{1}{|c|}{ Mar } & April & May & June & July & Aug & Sept & Oct & Nov & Dec \\
\hline Nuclear & 9.86 & 8.68 & 11.47 & 13.08 & 10.63 & 9.73 & 10.68 & 8.93 & 10.09 & 8.5 & 9.83 & 10.41 \\
\hline Solar & 0.01 & 0.08 & 0.18 & 0.23 & 0.25 & 0.24 & 0.25 & 0.24 & 0.21 & 0.15 & 0.09 & 0.04 \\
\hline Biomass & 0.58 & 0.78 & 0.77 & 0.72 & 0.73 & 0.73 & 0.67 & 0.65 & 0.72 & 0.82 & 0.81 & 0.73 \\
\hline Wind & 2.37 & 1.86 & 4.39 & 4.57 & 4.63 & 5.44 & 4.07 & 4.66 & 3.55 & 3.64 & 3.17 & 1.44 \\
\hline Hydroelectric & 43.43 & 37.29 & 38.84 & 49.88 & 56.78 & 58.39 & 36.88 & 29.63 & 26.32 & 31.09 & 36.02 & 36.29 \\
\hline Natural Gas & 34.61 & 41.6 & 34.96 & 25.6 & 22.89 & 21.1 & 41.38 & 48.31 & 51.24 & 45.88 & 42.02 & 42.13 \\
\hline Coal & 5.44 & 5.77 & 5.42 & 2.14 & 0.45 & 0.86 & 2.88 & 4.09 & 4.38 & 5.97 & 4 & 5.14 \\
\hline Geothermal & 3.29 & 3.49 & 3.51 & 3.35 & 3.29 & 3.1 & 2.84 & 3.09 & 3.11 & 3.54 & 3.63 & 3.35 \\
\hline Petroleum & 0.43 & 0.45 & 0.45 & 0.43 & 0.35 & 0.41 & 0.36 & 0.38 & 0.39 & 0.4 & 0.44 & 0.47 \\
\hline
\end{tabular}


Table B.15: Percent of energy consumed, broken down by fuel type and month in region 2

\begin{tabular}{|l|r|r|r|r|r|r|r|r|r|r|r|r|}
\hline Region 2 & Jan & \multicolumn{1}{l|}{ Feb } & \multicolumn{1}{c|}{ Mar } & April & May & June & July & Aug & Sept & Oct & Nov & Dec \\
\hline Nuclear & 26.47 & 26.9 & 27.74 & 25.27 & 28.52 & 27.95 & 26.33 & 24.75 & 27.04 & 25.09 & 25.63 & 25.42 \\
\hline Solar & 0 & 0 & 0.01 & 0.01 & 0.01 & 0.01 & 0.01 & 0.01 & 0.01 & 0.01 & 0 & 0 \\
\hline Biomass & 0.64 & 0.72 & 0.82 & 0.9 & 0.92 & 0.84 & 0.82 & 0.76 & 0.83 & 0.85 & 0.89 & 0.75 \\
\hline Wind & 2.23 & 2.71 & 2.9 & 3.34 & 2.79 & 1.7 & 1.41 & 1.6 & 1.73 & 2.82 & 3.22 & 2.99 \\
\hline Coal & 49.62 & 49.36 & 46.7 & 46.31 & 44.39 & 45.54 & 47.18 & 46.33 & 46.05 & 49.04 & 49.05 & 50.69 \\
\hline Natural Gas & 12.31 & 13.49 & 14.19 & 14.67 & 13.43 & 14.47 & 16.33 & 19.87 & 17.97 & 15.73 & 14.51 & 13.22 \\
\hline Hydroelectric & 6.11 & 5.99 & 6.92 & 9.11 & 9.51 & 9.05 & 7.42 & 6.08 & 5.98 & 6.13 & 6.34 & 6.43 \\
\hline Geothermal & 0.07 & 0.07 & 0.08 & 0.08 & 0.08 & 0.07 & 0.07 & 0.07 & 0.08 & 0.07 & 0.08 & 0.08 \\
\hline Petroleum & 2.55 & 0.74 & 0.64 & 0.32 & 0.34 & 0.37 & 0.43 & 0.6 & 0.33 & 0.27 & 0.28 & 0.43 \\
\hline
\end{tabular}

Table B.16: Percent of energy consumed, broken down by fuel type and month in region 3

\begin{tabular}{|l|c|r|r|r|r|r|r|r|r|r|r|r|}
\hline Region 3 & Jan & Feb & Mar & April & May & June & July & Aug & Sept & Oct & Nov & Dec \\
\hline Nuclear & 9.82 & 8.88 & 10.24 & 11.6 & 10.83 & 9.72 & 8.65 & 8.5 & 7.13 & 8.62 & 9.63 & 9.38 \\
\hline Solar & 0.01 & 0.05 & 0.13 & 0.16 & 0.17 & 0.13 & 0.13 & 0.14 & 0.13 & 0.1 & 0.06 & 0.03 \\
\hline Biomass & 0.22 & 0.28 & 0.29 & 0.29 & 0.25 & 0.25 & 0.23 & 0.21 & 0.25 & 0.27 & 0.29 & 0.26 \\
\hline Wind & 2.13 & 3.08 & 3.26 & 3.77 & 2.8 & 2.45 & 2.05 & 2.2 & 2.34 & 3.55 & 3.02 & 2.77 \\
\hline Coal & 50.18 & 43.95 & 41.77 & 42.34 & 43.59 & 41.52 & 40.24 & 41.42 & 43.7 & 47.9 & 49.94 & 46.58 \\
\hline Natural Gas & 32.79 & 37.12 & 37.34 & 33.17 & 33.92 & 37.88 & 41.67 & 41.48 & 40.32 & 33.07 & 31.29 & 34.43 \\
\hline Hydroelectric & 2.89 & 4.75 & 4.95 & 6.72 & 6.68 & 6.4 & 5.58 & 4.59 & 4.47 & 4.74 & 3.76 & 4.6 \\
\hline Geothermal & 1.63 & 1.62 & 1.7 & 1.67 & 1.53 & 1.4 & 1.25 & 1.26 & 1.42 & 1.52 & 1.79 & 1.7 \\
\hline Petroleum & 0.32 & 0.26 & 0.32 & 0.28 & 0.24 & 0.25 & 0.2 & 0.2 & 0.22 & 0.24 & 0.22 & 0.24 \\
\hline
\end{tabular}

Table B.17: Percent of energy consumed, broken down by fuel type and month in region 4

\begin{tabular}{|l|r|r|r|r|r|r|l|l|l|r|r|r|}
\hline Region 4 & Jan & Feb & Mar & April & May & June & July & Aug & Sept & Oct & Nov & Dec \\
\hline Nuclear & 23.16 & 23.97 & 23.95 & 24.4 & 24.92 & 22.45 & 23.15 & 21.91 & 23.58 & 24.33 & 23.99 & 22.77 \\
\hline Solar & 0 & 0 & 0 & 0 & 0 & 0 & 0 & 0 & 0 & 0 & 0 & 0 \\
\hline Biomass & 0.21 & 0.19 & 0.21 & 0.25 & 0.21 & 0.18 & 0.18 & 0.18 & 0.21 & 0.22 & 0.22 & 0.18 \\
\hline Wind & 0.69 & 0.88 & 1.03 & 1.16 & 0.78 & 0.64 & 0.53 & 0.6 & 0.59 & 1.13 & 1.18 & 1.04 \\
\hline Coal & 61.55 & 60.14 & 57.45 & 58.24 & 57.41 & 56.92 & 56.89 & 57.14 & 56.06 & 58.36 & 58.48 & 59.96 \\
\hline Natural Gas & 9.98 & 11.44 & 12.86 & 11.25 & 11.38 & 16.04 & 16.75 & 17.49 & 16.14 & 10.51 & 9.83 & 10.19 \\
\hline Hydroelectric & 3.37 & 2.67 & 3.71 & 4.21 & 4.73 & 3.32 & 2.05 & 2.2 & 3.09 & 5.09 & 5.96 & 5.51 \\
\hline Geothermal & 0 & 0 & 0 & 0 & 0 & 0 & 0 & 0 & 0 & 0 & 0 & 0 \\
\hline Petroleum & 1.04 & 0.71 & 0.8 & 0.49 & 0.56 & 0.45 & 0.45 & 0.48 & 0.36 & 0.36 & 0.34 & 0.36 \\
\hline
\end{tabular}


Table B.18: Percent of energy consumed, broken down by fuel type and month in region 5

\begin{tabular}{|l|l|l|l|r|r|r|r|r|r|r|r|r|}
\hline Region 5 & Jan & Feb & Mar & April & May & June & July & Aug & Sept & Oct & Nov & Dec \\
\hline Nuclear & 18.26 & 18.55 & 18.53 & 17.36 & 14.67 & 13.53 & 13.74 & 13.85 & 13.65 & 12.7 & 14.94 & 16.41 \\
\hline Solar & 0 & 0 & 0 & 0 & 0 & 0 & 0 & 0 & 0 & 0 & 0 & 0 \\
\hline Biomass & 0.46 & 0.45 & 0.48 & 0.46 & 0.3 & 0.31 & 0.31 & 0.33 & 0.34 & 0.39 & 0.46 & 0.46 \\
\hline Wind & 2.14 & 2.6 & 2.7 & 2.95 & 1.91 & 1.74 & 1.44 & 1.48 & 1.43 & 2.52 & 2.63 & 2.26 \\
\hline Natural Gas & 38.8 & 41.01 & 45.26 & 44.78 & 47.26 & 51.29 & 51.75 & 51.68 & 51.03 & 47.55 & 43.83 & 41.73 \\
\hline Coal & 37.3 & 34.53 & 29.66 & 30.82 & 32.04 & 30.37 & 30.38 & 30.17 & 30.72 & 33.46 & 35.06 & 35.97 \\
\hline Hydroelectric & 1.42 & 0.86 & 1.57 & 1.51 & 1.61 & 0.78 & 0.58 & 0.63 & 0.99 & 1.75 & 2.12 & 2.35 \\
\hline Geothermal & 0 & 0 & 0 & 0 & 0 & 0 & 0 & 0 & 0 & 0 & 0 & 0 \\
\hline Petroleum & 1.62 & 2 & 1.79 & 2.12 & 2.2 & 1.96 & 1.8 & 1.86 & 1.84 & 1.62 & 0.95 & 0.82 \\
\hline
\end{tabular}

At each 15-minute measurement interval, the energy consumed over the previous interval is used to determine the amount of energy delivered by each fuel source. The peak load of the base case for each month is used to scale the percentages. Figure B.16 shows an example of how this is performed in GridLAB-D using June in Region 3. It can be seen that the peak load for that month would utilize all the generation fuels at the levels shown in Table B.16. At the shown 15minute period, the base case load is approximately $95 \%$ of the peak for June for this particular feeder. During the same 15-minute period, the representative technology case is only $87 \%$ of the base case peak feeder loading. This results in a reduction of generation by approximately $3 \%$ for hydroelectric and $5 \%$ for natural gas. This calculation is performed at every 15 -minute interval to determine the energy consumed by each fuel type over the course of the entire annual simulation of 1-minute intervals. 


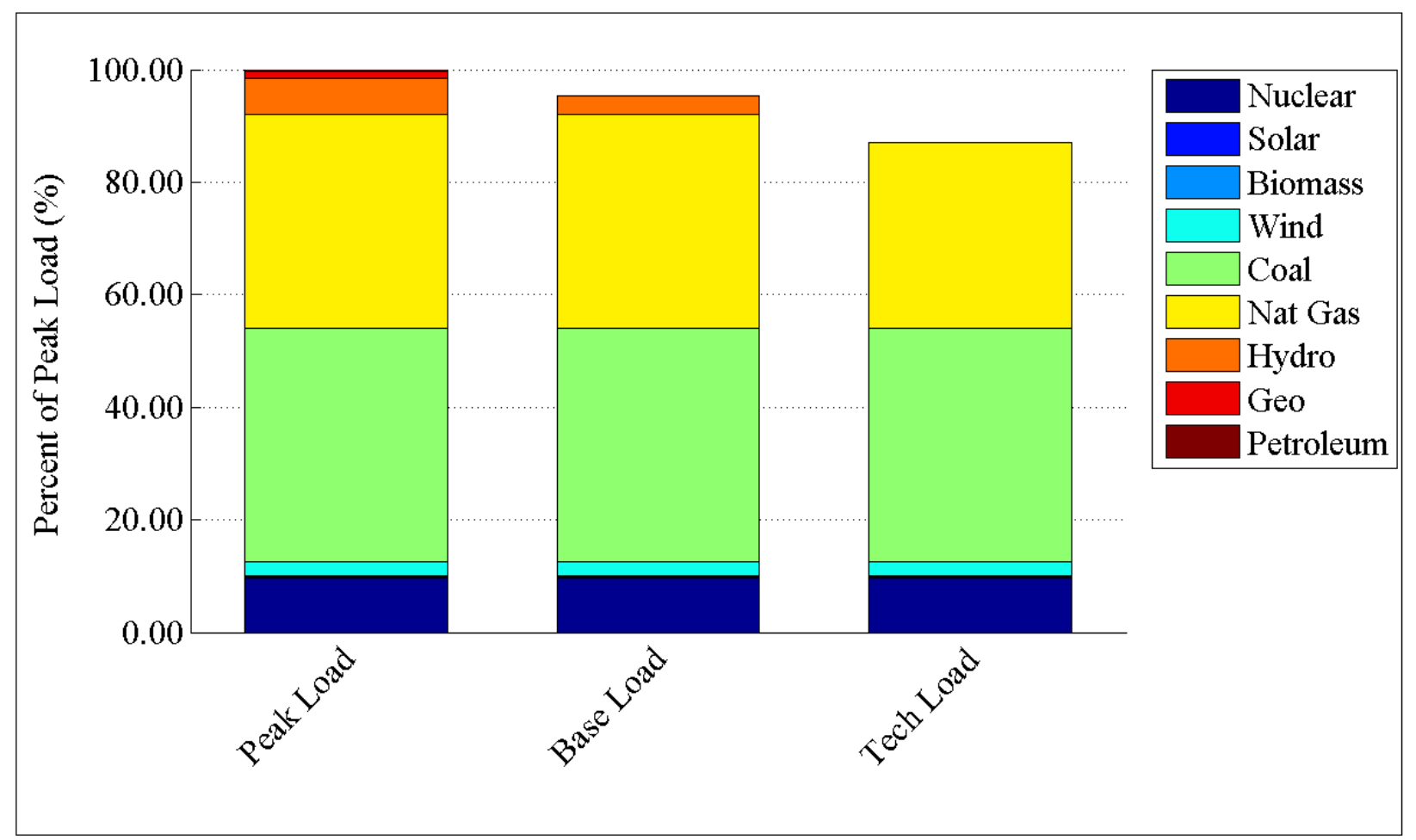

Figure B.16: Exemplary 15-minute interval comparing fuel dispatch for the peak load versus the base case load versus a technology modified load.

Assumed average thermal efficiencies are then used to convert the energy delivered to the amount of fuel used, where applicable. The values used are shown in Table B.19. Finally, assumed average values for conversion efficiencies are used to convert from fuel used to emissions levels for carbon dioxide, sulfur dioxide, and nitrous oxides. The conversion values assumed are shown in Table B.20. These values are not indicative of any single plant, but rather broad averages across the U.S. While this is a very simplified means of dispatching and assigning generation, ignoring complex issues such as inefficiencies due to warm-up cycles, maintenance periods, and economic or optimal dispatching, it should provide a general indication of how changes in operation of a distribution circuit can reduce pollutant emissions. 
Table B.19: Average thermal efficiencies by fuel type.

\begin{tabular}{|l|r|}
\hline & MBTUs / MWh \\
\hline Nuclear & 10.46 \\
\hline Solar & N/A \\
\hline Biomass & 12.93 \\
\hline Wind & N/A \\
\hline Natural Gas & 8.16 \\
\hline Coal & 10.41 \\
\hline Hydroelectric & N/A \\
\hline Geothermal & 21.02 \\
\hline Petroleum & 11 \\
\hline
\end{tabular}

Table B.20: Pollutant production per BTU of fuel (lbs./MBTU)

\begin{tabular}{|c|c|c|c|c|}
\hline & $\mathrm{CO}_{2}$ & $\mathrm{SO}_{2}$ & $\mathrm{NOx}$ & PM-10 \\
\hline Nuclear & 0 & 0 & 0 & 0.017157 \\
\hline Solar & 0 & 0 & 0 & 0.03 \\
\hline Biomass & 195 & 0 & 0.08 & 0.0232 \\
\hline Wind & 0 & 0 & 0 & 0 \\
\hline Natural Gas & 117.08 & 0.001 & 0.0075 & 0 \\
\hline Coal & 205.57 & 0.1 & 0.06 & 0 \\
\hline Hydroelectric & 0 & 0 & 0 & 0 \\
\hline Geothermal & 120 & 0.2 & 0 & 0 \\
\hline Petroleum & 225.13 & 0.1 & 0.04 & 0 \\
\hline
\end{tabular}

\section{B.4 Taxonomy Feeder Descriptions}

The previous sections have described the details of how each of the prototypical feeders is populated with end-use loads. This section is a reproduction of the individual prototypical feeder descriptions from [3] which describes the characteristics of the primary distribution system.

\section{B.4.1 Feeder 1: GC-12.47-1}

This feeder is representative of a single large commercial or industrial load, such as a very large shopping mall or a small lumber mill. These feeders may supply the load through a single large transformer or a group of smaller units. While there may be a couple of smaller loads the 
behavior of the feeder is primarily determined by the single large customer. This is a $12.47 \mathrm{kV}$ feeder with a peak load of approximately 5,400 kVA.

\section{B.4.2 Feeder 2: R1-12.47-1}

This feeder is a representation of a moderately populated suburban and rural area. This is composed mainly of single family residences with small amounts of light commercial. Approximately $60 \%$ of the circuit-feet are overhead and $40 \%$ are underground. It would be expected that this feeder is connected to adjacent feeders through normally open switches. For this reason it would be common to limit the feeder loading to $60 \%$ to ensure the ability to transfer load from other feeders, and vice versa. The majority of the load is located relatively near the substation. This is a $12.5 \mathrm{kV}$ feeder with a peak load of approximately $4,300 \mathrm{kVA}$.

\section{B.4.3 Feeder 3: R1-12.47-2}

This feeder is a representation of a moderately populated suburban and lightly populated rural area. This is composed mainly of single family residences with small amounts of light commercial. Approximately $70 \%$ of the circuit-feet are overhead and $30 \%$ underground. It would not be expected that this feeder is connected to adjacent feeders through normally open switches. Even though there are not adjacent feeders for transferring the load, the total feeder loading is low because of the sparse rural loading. In this model an urban substation is feeding a rural load through a long primary circuit. The majority of the load is located relatively distant with respect to the substation. This is a $12.47 \mathrm{kV}$ feeder with a peak load of approximately 2,400 kVA.

\section{B.4.4 Feeder 4: R1-12.47-3}

This feeder is a representation of a moderately populated urban area. This is composed mainly of mid-sized commercial loads with some residences, mostly multi-family. Approximately $85 \%$ of the circuit-feet are overhead and $15 \%$ underground. It would be expected that this feeder is connected to adjacent feeders through normally open switches. For this reason it would be common to limit the feeder loading to $60 \%$ to ensure the ability to transfer load from other feeders, and vice versa. Since this is a small urban core the loading of the feeder is well below $60 \%$. The majority of the load is located relatively near the substation. This is a $12.47 \mathrm{kV}$ feeder with a peak load of approximately 1,800 kVA.

\section{B.4.5 Feeder 5: R1-12.47-4}

This feeder is a representation of a heavily populated suburban area. This is composed mainly of single family homes and heavy commercial loads. None of the circuit-feet are overhead and $100 \%$ are underground. It would be expected that this feeder is connected to adjacent feeders through normally open switches. The majority of the load is located relatively near the substation. This is a $12.47 \mathrm{kV}$ feeder with a peak load of approximately 4,900 kVA. 


\section{B.4.6 Feeder 6: R1-25.00-1}

This feeder is a representation of a lightly populated rural area. This is composed of a mixture of residential, light commercial, industrial, and agricultural loads. Approximately $60 \%$ of the circuit-feet are overhead and $40 \%$ underground. It would be expected that this feeder is not connected to adjacent feeders through normally open switches. Due to rural location and low population density the feeder is not heavily loaded. The low population density and wide are covered are why this feeder is operated at $24.9 \mathrm{kV}$. The majority of the load is located relatively distant with respect to the substation. This is a $24.9 \mathrm{kV}$ feeder with a peak load of approximately $2,300 \mathrm{kVA}$.

\section{B.4.7 Feeder 7: R2-12.47-1}

This feeder is a representation of a lightly populated urban area. This is composed of single family homes, moderate commercial loads, light industrial loads, and some agricultural loads. This feeder supplies a college and an airport. Approximately $25 \%$ of the circuit-feet are overhead and $75 \%$ underground. It would be expected that this feeder is connected to adjacent feeders through normally open switches. For this reason it would be common to limit the feeder loading to $60 \%$ to ensure the ability to transfer load from other feeders, and vice versa. The majority of the load is located relatively near the substation. This is a $12.47 \mathrm{kV}$ feeder with a peak load of approximately 6,700 kVA.

\section{B.4.8 Feeder 8: R2-12.47-2}

This feeder is a representation of a moderately populated suburban area. This is composed mainly of single family homes with some light commercial loads. Approximately $80 \%$ of the circuit-feet are overhead and $20 \%$ underground. It would be expected that this feeder is connected to adjacent feeders through normally open switches. For this reason it would be common to limit the feeder loading to $60 \%$ to ensure the ability to transfer load from other feeders, and vice versa. The majority of the load is located relatively near the substation. This is a $12.47 \mathrm{kV}$ feeder with a peak load of approximately $6,700 \mathrm{kVA}$.

\section{B.4.9 Feeder 9: R2-12.47-3}

This feeder is a representation of a lightly populated suburban area. This is composed of single family homes, light commercial loads, light industrial loads, and some agricultural loads. Approximately $20 \%$ of the circuit-feet are overhead and $80 \%$ underground. It would be expected that this feeder is connected to adjacent feeders through normally open switches. For this reason it would be common to limit the feeder loading to $60 \%$ to ensure the ability to transfer load from other feeders, and vice versa. The majority of the load is located relatively near the substation. This is a $12.47 \mathrm{kV}$ feeder with a peak load of approximately $4,800 \mathrm{kVA}$. 


\section{B.4.10 Feeder 10: R2-25.00-1}

This feeder is a representation of a moderately populated suburban area. This is composed mainly of single family homes with some light and moderate commercial loads. Approximately $60 \%$ of the circuit-feet are overhead and $40 \%$ underground. It would be expected that this feeder is connected to adjacent feeders through normally open switches. For this reason it would be common to limit the feeder loading to $60 \%$ to ensure the ability to transfer load from other feeders, and vice versa. This is a heavily loaded feeder, well over $60 \%$, with the majority of the load is located relatively near the substation. This is a $24.9 \mathrm{kV}$ feeder with a peak load of approximately $21,300 \mathrm{kVA}$.

\section{B.4.11 Feeder 11: R2-35.00-1}

This feeder is a representation of a lightly populated rural area. This is composed mainly of single family homes with some light and moderate commercial loads. Approximately $90 \%$ of the circuit-feet are overhead and 10\% underground. It would be expected that this feeder is connected to adjacent feeders through normally open switches. But due to the long distances significant portions of the load cannot be shifted to adjacent feeders. In this model a single substation is serving a large geographic area, this is the reason for the higher voltage level; voltage regulators are used on this system. The majority of the load is located relatively distant with respect to the substation. This is a $34.5 \mathrm{kV}$ feeder with a peak load of approximately 6,900 kVA.

\section{B.4.12 Feeder 12: R3-12.47-1}

This feeder is a representation of a heavily populated urban area. This is composed of single family homes, heavy commercial loads, and a small amount of light industrial loads. Approximately $25 \%$ of the circuit-feet are overhead and $75 \%$ underground. It would be expected that this feeder is connected to adjacent feeders through normally open switches. Due to the heavy commercial loads it would be expected that this feeder would be loaded to a high percentage of its rating. The majority of the load is located relatively near the substation. This is a $12.47 \mathrm{kV}$ feeder with a peak load of approximately $11,600 \mathrm{kVA}$.

\section{B.4.13 Feeder 13: R3-12.47-2}

This feeder is a representation of a moderately populated urban area. This is composed of single family homes, light commercial loads, and a small amount of light industrial loads. Approximately $33 \%$ of the circuit-feet are overhead and $67 \%$ underground. It would be expected that this feeder is connected to adjacent feeders through normally open switches. For this reason it would be common to limit the feeder loading to $60 \%$ to ensure the ability to transfer load from other feeders, and vice versa. The majority of the load is located relatively near the substation. This is a $12.47 \mathrm{kV}$ feeder with a peak load of approximately $4,000 \mathrm{kVA}$. 


\section{B.4.14 Feeder 14: R3-12.47-3}

This feeder is a representation of a heavily populated suburban area. This is composed mainly of single family homes with some light agricultural loads. Approximately $75 \%$ of the circuit-feet are overhead and $25 \%$ underground. It would be expected that this feeder has limited connections to adjacent feeders through normally open switches. For this reason it would be common to limit the feeder loading to $75 \%$ to ensure the ability to transfer some loads from other feeders, and vice versa. Due to the low density of suburban loads the majority of the load is located relatively distant with respect to the substation. This is a $12.45 \mathrm{kV}$ feeder with a peak load of approximately $9,400 \mathrm{kVA}$.

\section{B.4.15 Feeder 15: R4-12.47-1}

This feeder is a representation of a heavily populated urban area with the primary feeder extending into a lightly populated rural area. In the urban areas the load is composed of moderate commercial loads with single and multi-family residences. On the rural spur the load is primarily single family residences. Approximately $92 \%$ of the circuit-feet are overhead and $8 \%$ underground. This feeder has connections to adjacent feeders in the urban area, but limited connections in the rural areas. For this reason it would be common to limit the feeder loading to $50 \%$ to ensure the ability to transfer most of the loads from other feeders, and vice versa. Most of the urban load is located near the substation while the rural load is located at a substantial distance. This is a $13.8 \mathrm{kV}$ feeder with a peak load of approximately $6,700 \mathrm{kVA}$.

\section{B.4.16 Feeder 16: R4-12.47-2}

This feeder is a representation of a lightly populated suburban area with a moderately populated urban area. The lightly populated suburban area is composed mostly of single family residences. The commercial complex is a single facility. Approximately $92 \%$ of the circuit-feet are overhead and $8 \%$ underground. This feeder has connections to adjacent feeders in the commercial complex, but limited connections in the rural areas. For this reason it would be common to limit the feeder loading to $50 \%$ to ensure the ability to transfer most of the loads from other feeders, and vice versa. Most of the suburban load is located near the substation while the commercial load is located at a substantial distance. This is a $12.5 \mathrm{kV}$ feeder with a peak load of approximately $2,100 \mathrm{kVA}$.

\section{B.4.17 Feeder 17: R4-25.00-1}

This feeder is a representation of a lightly populated rural area. The load is composed of single family residences with some light commercial. Approximately $88 \%$ of the circuit-feet are overhead and $12 \%$ underground. This feeder has connections to adjacent feeders. This combined with the low load density ensures the ability to transfer most of the loads from other feeders, and vice versa. Most of the load is located at a substantial distance from the substation, 
as is common for higher voltages in rural areas. This is a $24.9 \mathrm{kV}$ feeder with a peak load of approximately $1,000 \mathrm{kVA}$.

\section{B.4.18 Feeder 18: R5-12.47-1}

This feeder is a representation of a heavily populated suburban area and a moderate urban center. This is composed mainly of single family homes and moderate commercial loads. Approximately $95 \%$ of the circuit-feet are overhead and 5\% underground. It would be expected that this feeder has connections to adjacent feeders through normally open switches. For this reason it would be common to limit the feeder loading to $50 \%$ to ensure the ability to transfer most loads from other feeders, and vice versa. The suburban load is near the substation while the commercial load is at the end of the feeder. This is a $13.8 \mathrm{kV}$ feeder with a peak load of approximately $10,800 \mathrm{kVA}$.

\section{B.4.19 Feeder 19: R5-12.47-2}

This feeder is a representation of a moderate suburban area with a heavy urban area. This is composed mainly of heavy commercial and single family residences. Approximately $38 \%$ of the circuit-feet are overhead and $62 \%$ underground. It would be expected that this feeder has connections to adjacent feeders through normally open switches. For this reason it would be common to limit the feeder loading to $50 \%$ to ensure the ability to transfer most loads from other feeders, and vice versa. The heavy commercial load is near the substation while the single family residences are at the end of the feeder. This is a $12.47 \mathrm{kV}$ feeder with a peak load of approximately 4,200 kVA.

\section{B.4.20 Feeder 20: R5-12.47-3}

This feeder is a representation of a moderately populated rural area. This is composed mainly of single family residences with some light commercial. Approximately $92 \%$ of the circuit-feet are overhead and $8 \%$ underground. It would be expected that this feeder has limited connections to adjacent feeders through normally open switches. Due to the low load density of the large rural area the feeder is less than $50 \%$ loaded. The majority of the load is located relatively distant with respect to the substation. Voltage regulators are used on this feeder. This is a 13.8 $\mathrm{kV}$ feeder with a peak load of approximately 4,800 kVA.

\section{B.4.21 Feeder 21: R5-12.47-4}

This feeder is a representation of a moderately populated suburban and urban area. This is composed mainly of single family residences with some moderate commercial loads. Approximately $37 \%$ of the circuit-feet are overhead and $63 \%$ underground. It would be expected that this feeder has connections to adjacent feeders through normally open switches. For this reason it would be common to limit the feeder loading to $50 \%$ to ensure the ability to transfer most of the loads from other feeders, and vice versa. Most of the commercial load is near the 
substation and the residential load is spread out along the length of the entire feeder. This is a $12.47 \mathrm{kV}$ feeder with a peak load of approximately $6,200 \mathrm{kVA}$.

\section{B.4.22 Feeder 22: R5-12.47-5}

This feeder is a representation of a moderately populated suburban area with a lightly populated urban area. This is composed mainly of single family residences with some light commercial loads. Approximately $48 \%$ of the circuit-feet are overhead and $52 \%$ underground. It would be expected that this feeder has connections to adjacent feeders through normally open switches. For this reason it would be common to limit the feeder loading to $50 \%$ to ensure the ability to transfer most of the loads from other feeders, and vice versa. The residential load is spread out across the entire length of the feeder. The primary feeder extends a significant distance before there is any significant load, an express configuration. This is a configuration that can be seen in a well-established area when a new feeder must be routed through an existing area in order to reach areas of new load growth. This is a $12.47 \mathrm{kV}$ feeder with a peak load of approximately $8,500 \mathrm{kVA}$.

\section{B.4.23 Feeder 23: R5-25.00-1}

This feeder is a representation of a heavily populated suburban area with a moderately populated urban area. This is composed mainly of single family residences with some moderate commercial loads. Approximately $35 \%$ of the circuit-feet are overhead and $65 \%$ underground. It would be expected that this feeder has connections to adjacent feeders through normally open switches. For this reason it would be common to limit the feeder loading to $66 \%$ to ensure the ability to transfer most of the loads from other feeders, and vice versa. The residential load is spread out across the entire length of the feeder with the moderate commercial center near the substation. This is a $22.9 \mathrm{kV}$ feeder with a peak load of approximately $9,300 \mathrm{kVA}$.

\section{B.4.24 Feeder 24: R5-35.00-1}

This feeder is a representation of a moderately populated suburban area with a lightly populated urban area. This is composed mainly of single family residences with some moderate commercial loads. Approximately $10 \%$ of the circuit-feet are overhead and $90 \%$ underground. It would be expected that this feeder has connections to adjacent feeders through normally open switches. For this reason it would be common to limit the feeder loading to $50 \%$ to ensure the ability to transfer most of the loads from other feeders, and vice versa. The residential load is spread out across the entire length of the feeder with the moderate commercial center near the substation. This feeder is representative of a substation that is built in a "green field" where significant load growth is expected. The first feeders must go a significant distance before they reach the load, over time the load moves towards the substation and past it. This is a $34.5 \mathrm{kV}$ feeder with a peak load of approximately $12,100 \mathrm{kVA}$. 


\section{Appendix C: Simulation Technology and Methodology}

Simulations of the different project technologies and programs were accomplished using the GridLAB-D software. GridLAB-D provides an agent-based multi-disciplinary environment for the examination and evaluation of emerging technologies. By providing a multi-disciplinary simulation environment, it is possible to bring together diverse teams of experts from multiple fields of study to holistically examine complex systems.

GridLAB-D has been developed through funding from the Department of Energy, Office of Electricity. Through $\$ 5.5$ million of direct funding and supporting projects from DOE-OE, GridLAB-D has developed significant capabilities for analyzing smart grid deployments. The capabilities center on the functionality needed to simulate a distribution feeder power flow and attached loads. The development has included: unbalanced three-phase power flow solvers; detailed end-use models, particularly of a residential home's thermal integrity, HVAC cycles and water heater cycles; and a transactive market that supports double auction bidding. Different combinations of these capabilities enabled simulations of the various technologies and programs evaluated in this report.

GridLAB-D conducts time series simulations with variable time steps. The solution at each time step is a quasi-steady state solution for each of the modules. Convergence is achieved within each module and convergence across modules is coordinated via the GridLAB core as illustrated in Figure C.1.

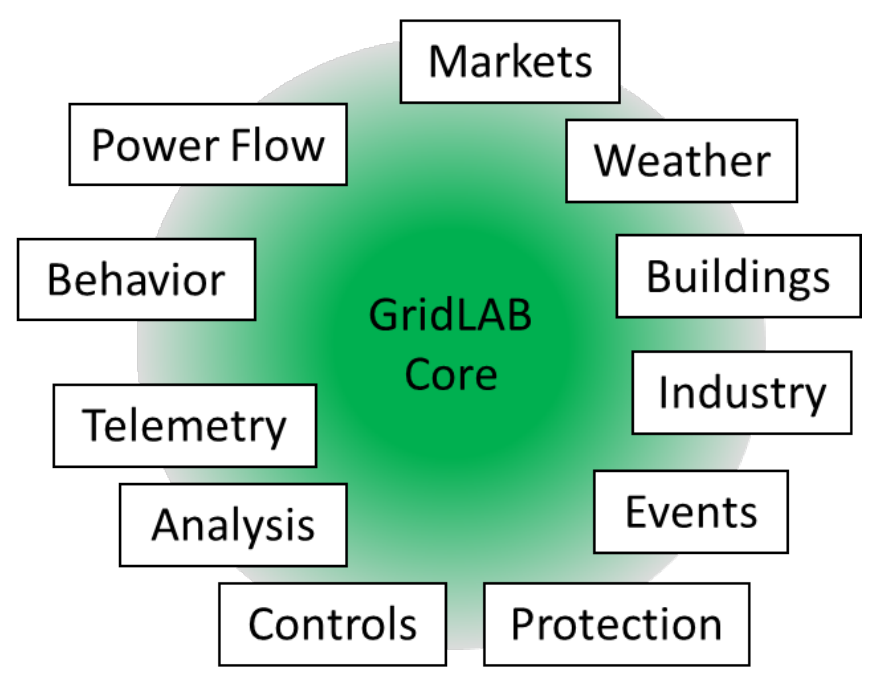

Figure C.1: GridLAB-D architecture

Time steps are also coordinated by the GridLAB-D core. This is necessary because the various modules in the simulation will generally have different time step requirements. At the end of a 
time step, every object in the model returns a 'sync' time that indicates how long the object will remain constant without outside influence. The GridLAB core then examines every object and determines what the smallest sync time is; this then becomes length of the next step. This process is performed at every time step so that the system has a variable step size. For a given state variable an example of the variable step sizes are shown in Figure C.2.

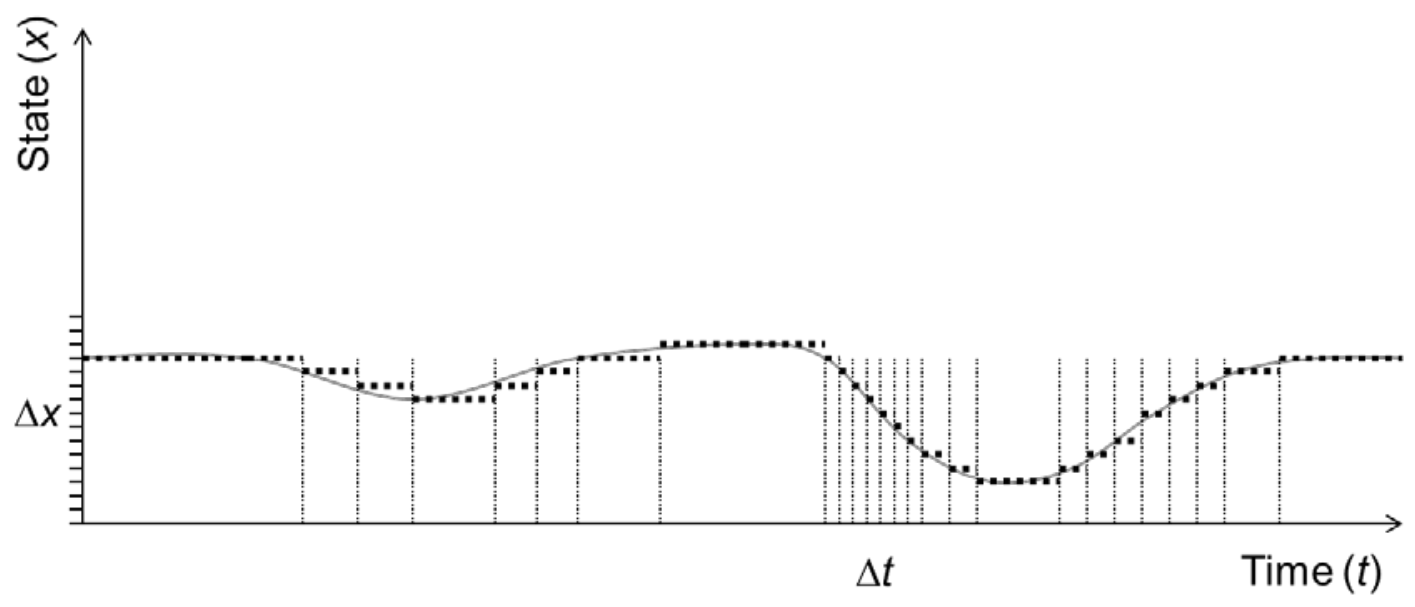

Figure C.2: Variable step sizes in GridLAB-D simulation

When analyzing operations at the distribution level, the major dynamics of interest are midterm and occur on the order of minutes to hours. For the purposes of this analysis, a minimum time step of one minute was enforced. For operations that occur at intervals of less than one minute, such as a 45-second delay on a voltage regulator, the operation is aggregated up to the one minute time step; multiple operations cannot occur during the enforced minimum of one minute. Because of the large number of objects and the forced minimum, the simulation proceeded at one-minute time steps for the majority of the simulations. As a result, there are approximately 500,000 time steps in an annual simulation of a single prototypical feeder.

Since the simulations for the SGIG analysis are being conducted over a one year period the minimum step size has been set to one minute. Even with a minimum one minute step size there is the possibility of 525,600 time steps in a single simulation. If a one second minimum step size were used there would be no significant increase in accuracy because most of the dynamic behavior has a time constant greater than one minute. Additionally, the number of time steps would increase by a factor of sixty resulting in significantly more computing time. 


\section{Appendix D: Plots for Individual Feeder Results}

This appendix contains the individual plots for each of the prototypical feeds for each technology, where necessary. Depending on the technology, different values will be plotted, consistent with those shown in Section 3.

\section{D.1 TOU and CPP Plots}

Consistent with the plots shown in Section 3.1.1, peak monthly demand, monthly energy consumption, monthly losses, and monthly $\mathrm{CO}_{2}$ emissions are plotted. Each graphic contains the base case, TOU/CPP with technology, TOU/CPP without enabling technology, TOU with technology, and TOU without enabling technology.

D.1.1 Detailed TOU and CPP Plots for GC-12.47-1_R1

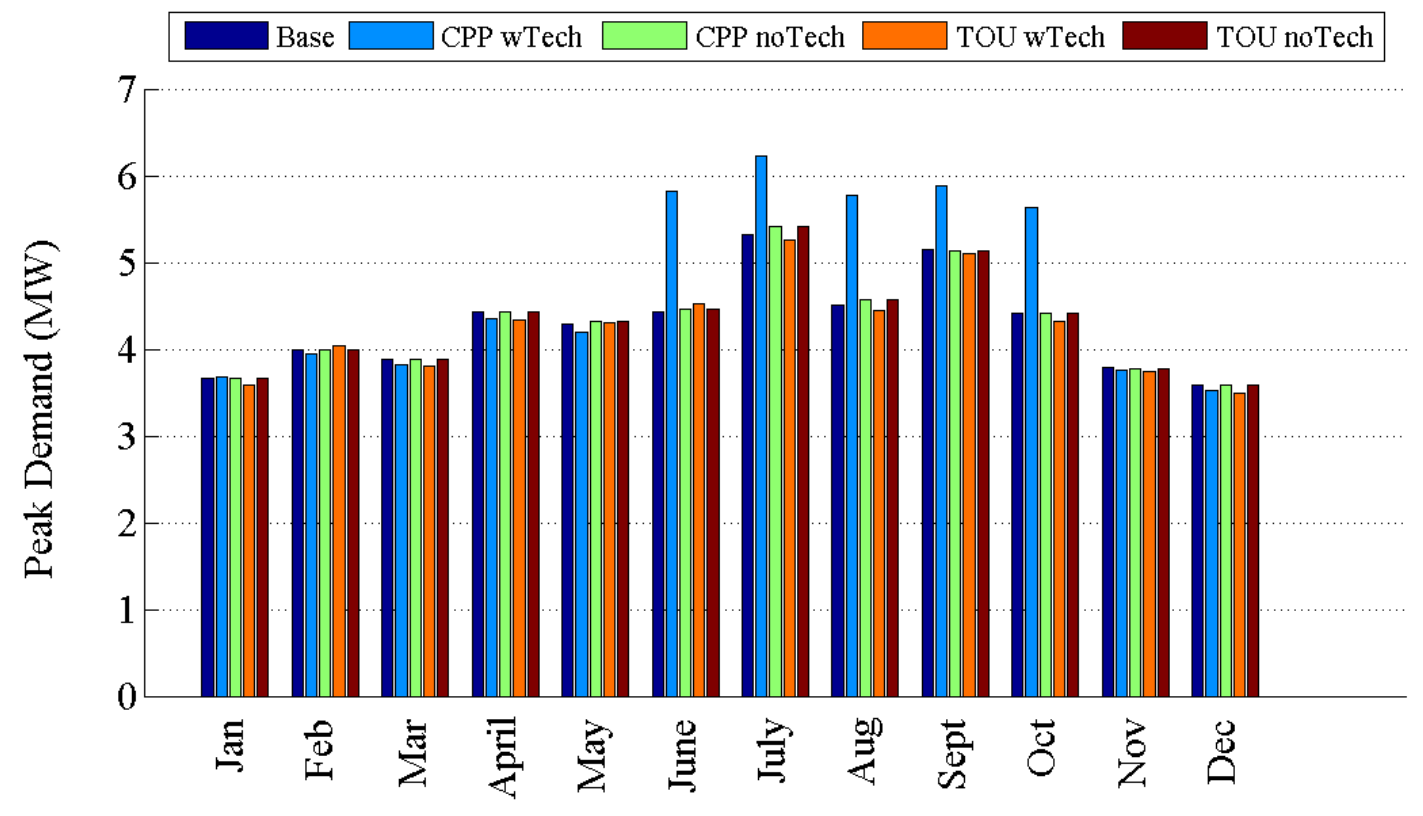

Figure D.1: Comparison of peak demand by month for GC-12.47-1_R1 


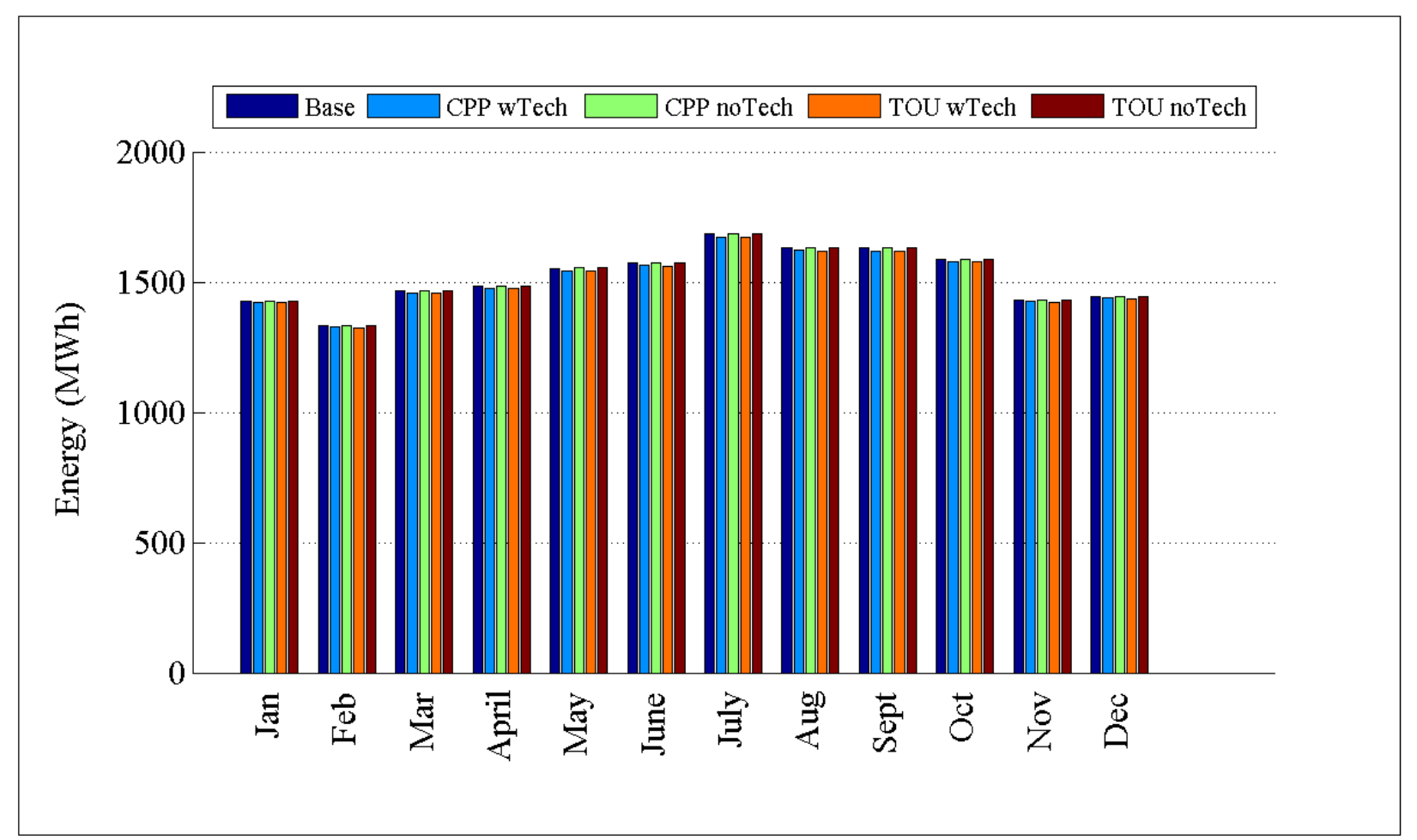

Figure D.2: Comparison of energy consumption by month for GC-12.47-1_R1

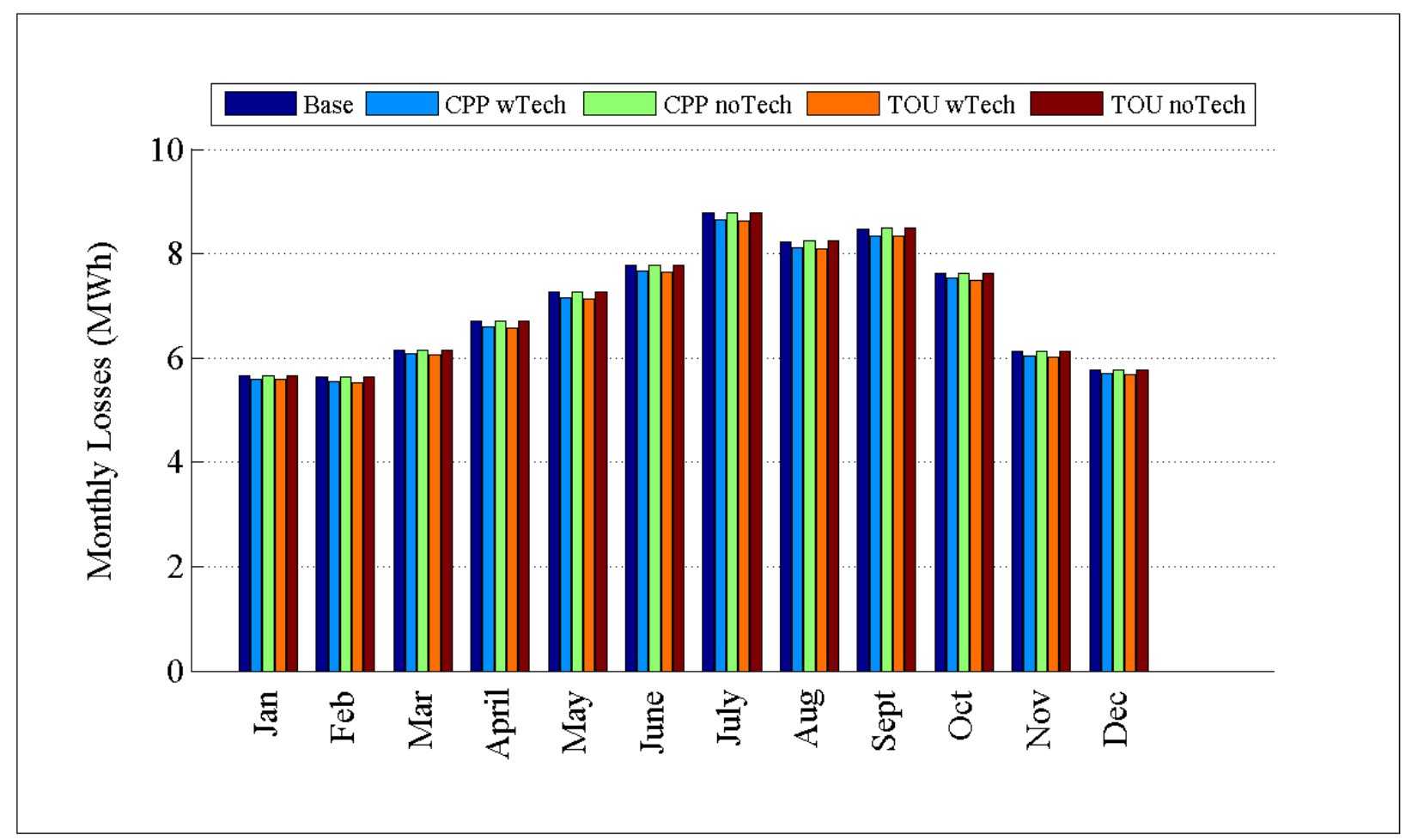

Figure D.3: Comparison of losses by month for GC-12.47-1_R1 


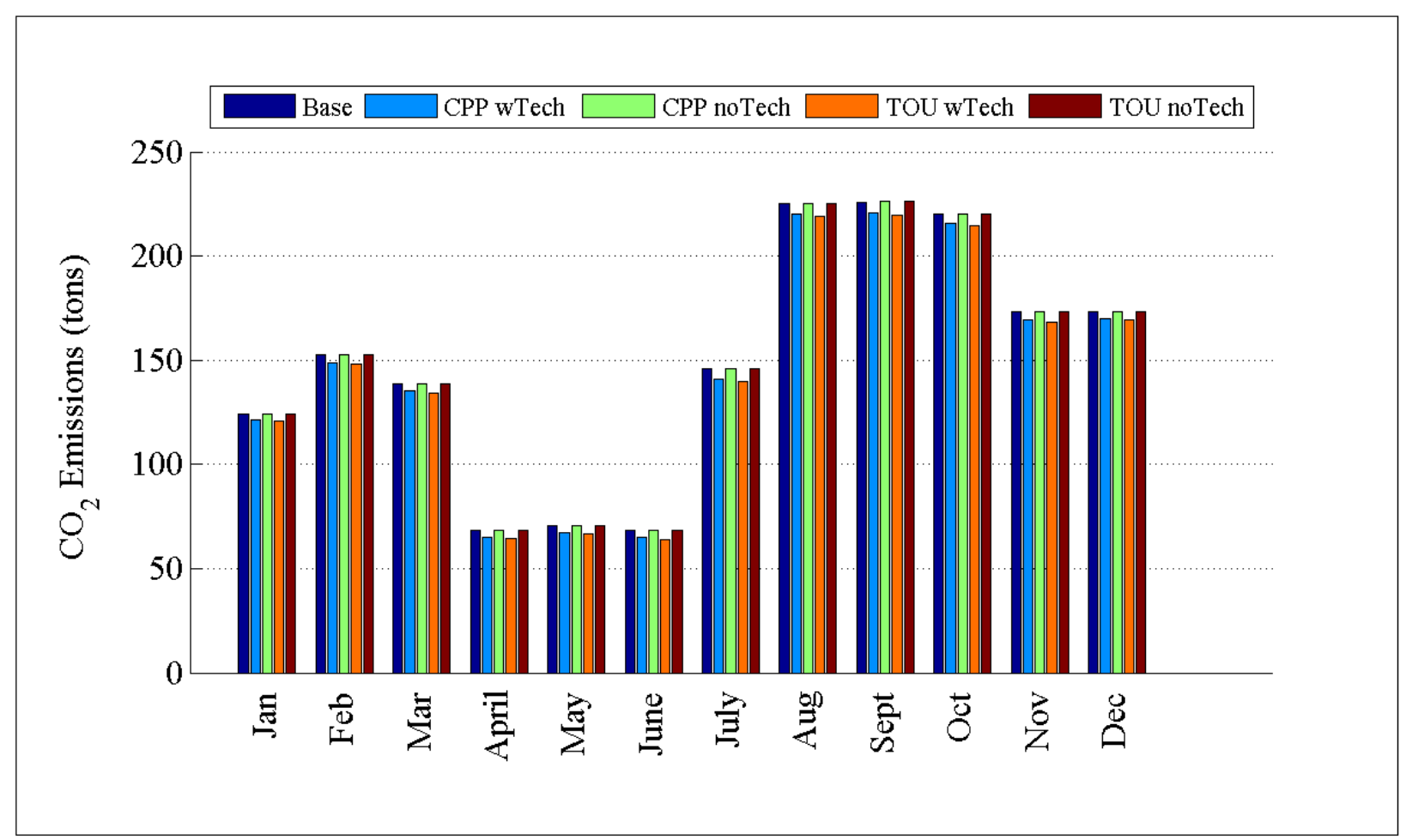

Figure D.4: Comparison of $\mathrm{CO}_{2}$ emissions by month for GC-12.47-1_R1

D.1.2 Detailed TOU and CPP Plots for R1-12.47-1 


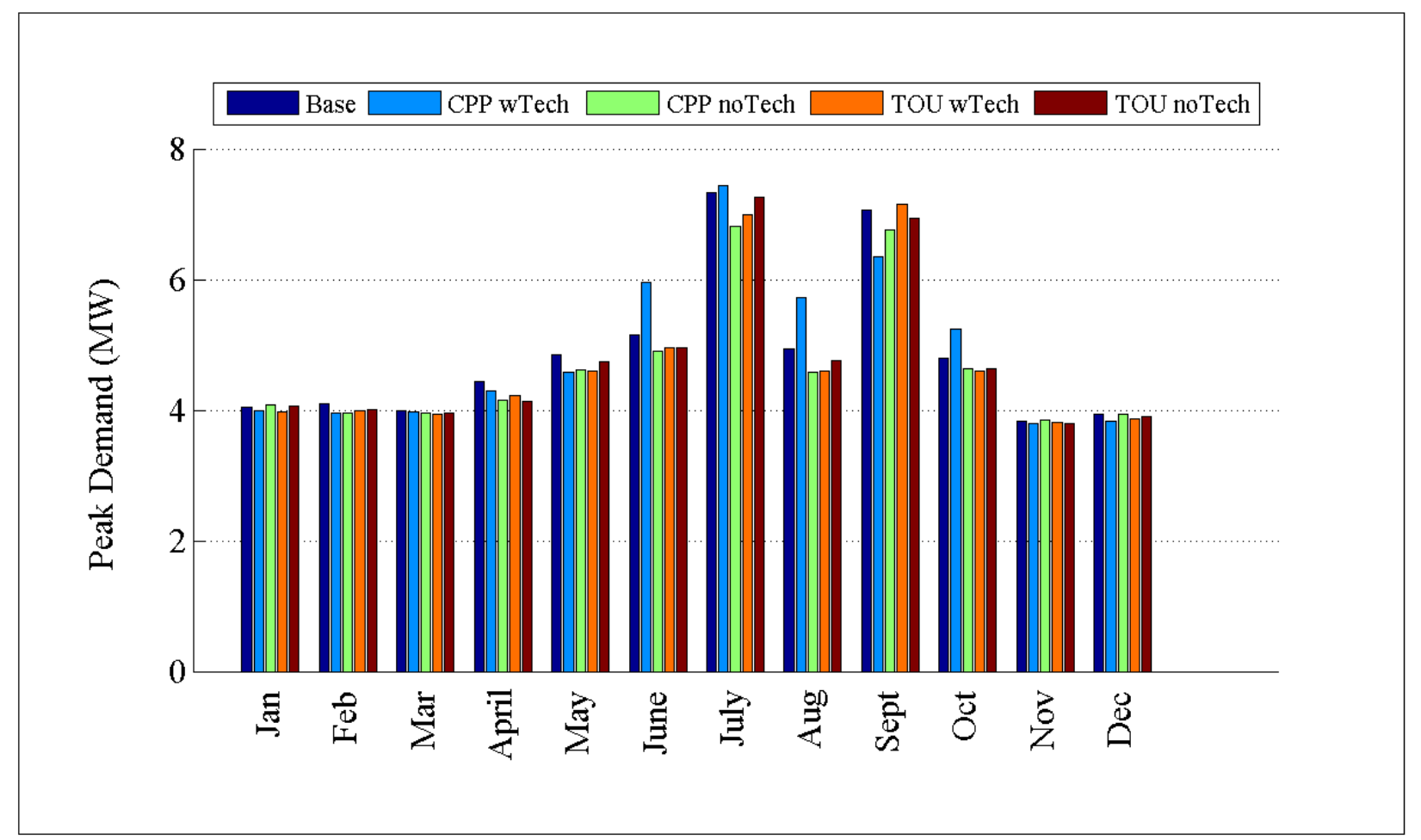

Figure D.5: Comparison of peak demand by month for R1-12.47-1

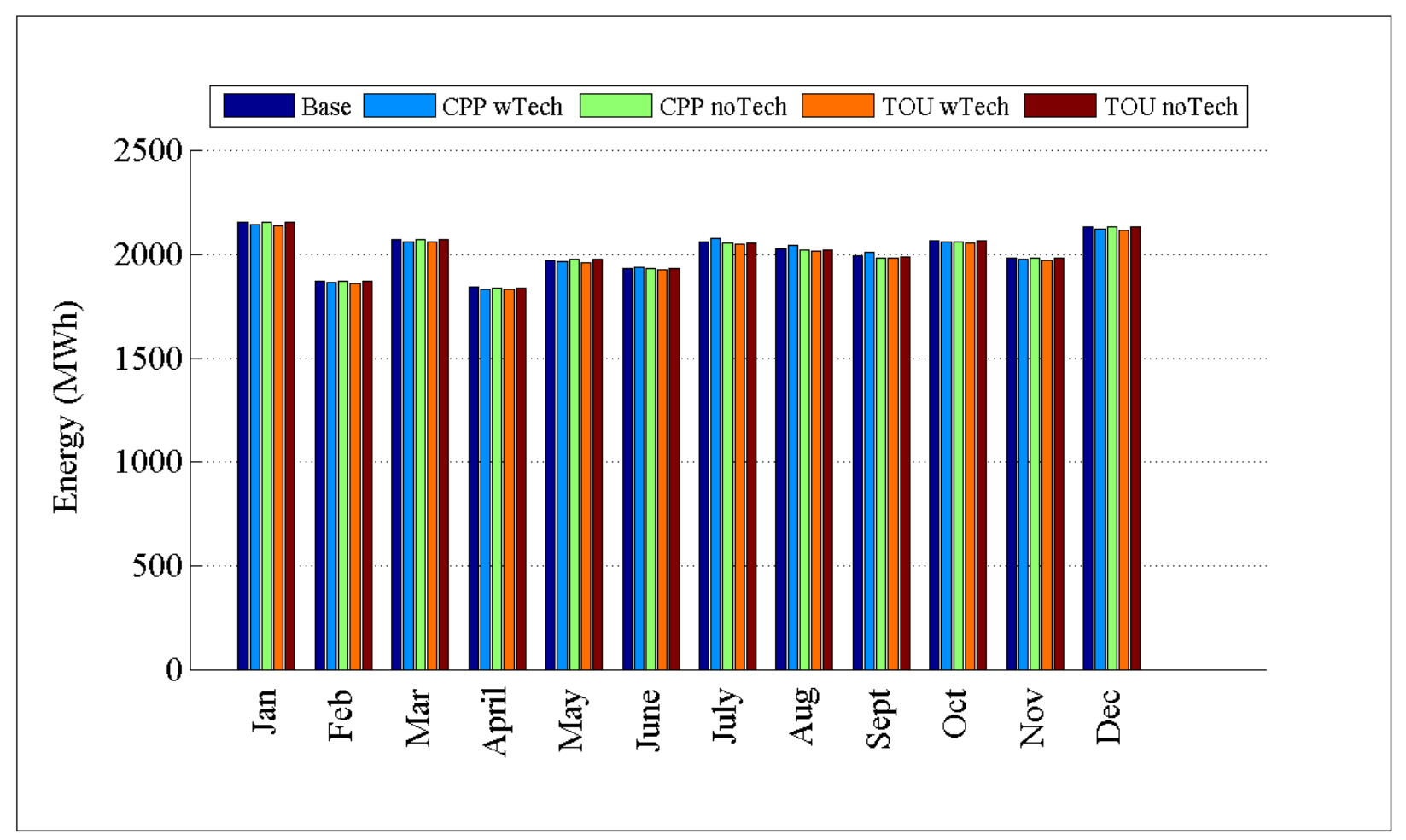

Figure D.6: Comparison of energy consumption by month for R1-12.47-1 


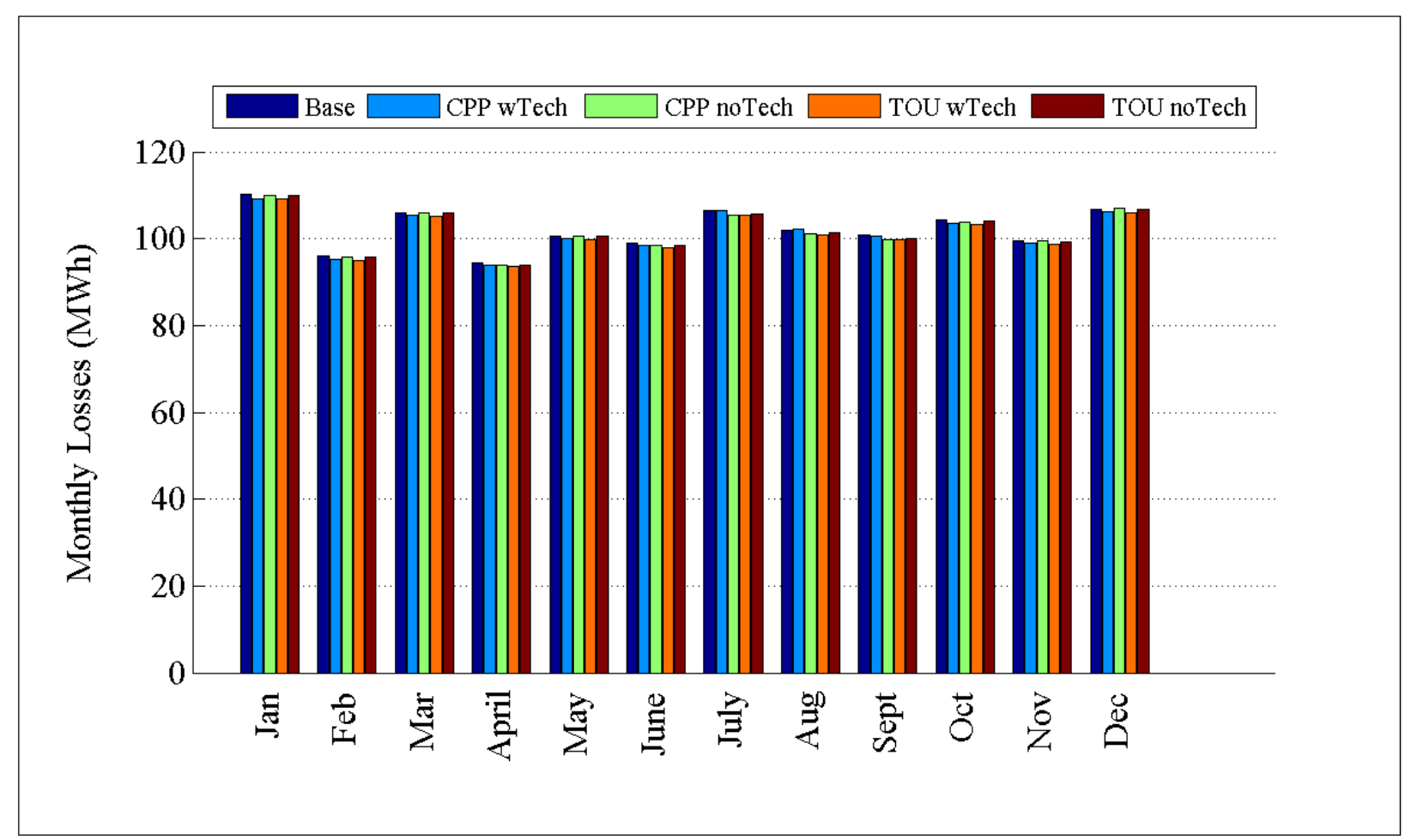

Figure D.7: Comparison of losses by month for R1-12.47-1

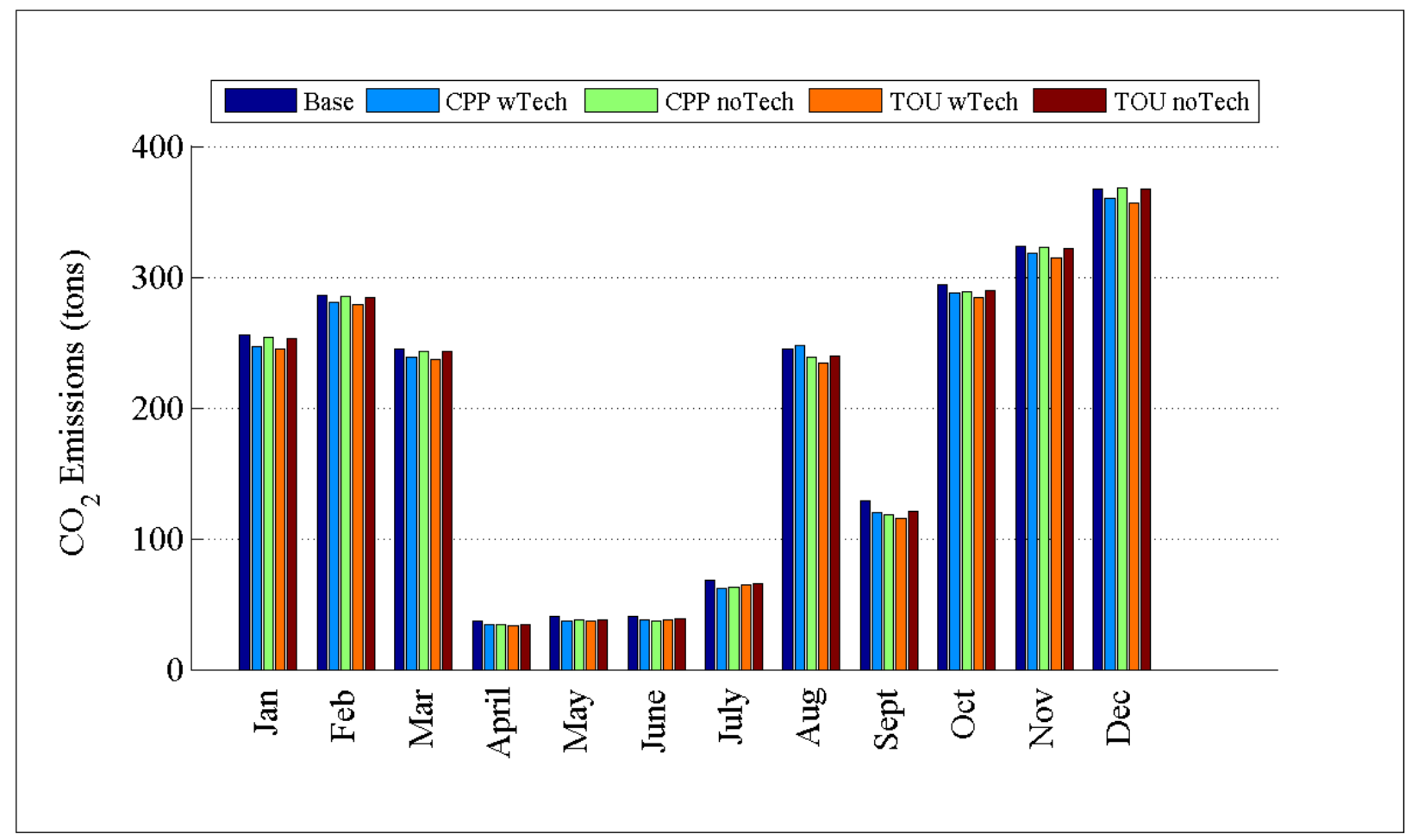

Figure D.8: Comparison of $\mathrm{CO}_{2}$ emissions by month for R1-12.47-1 
D.1.3 Detailed TOU and CPP Plots for R1-12.47-2

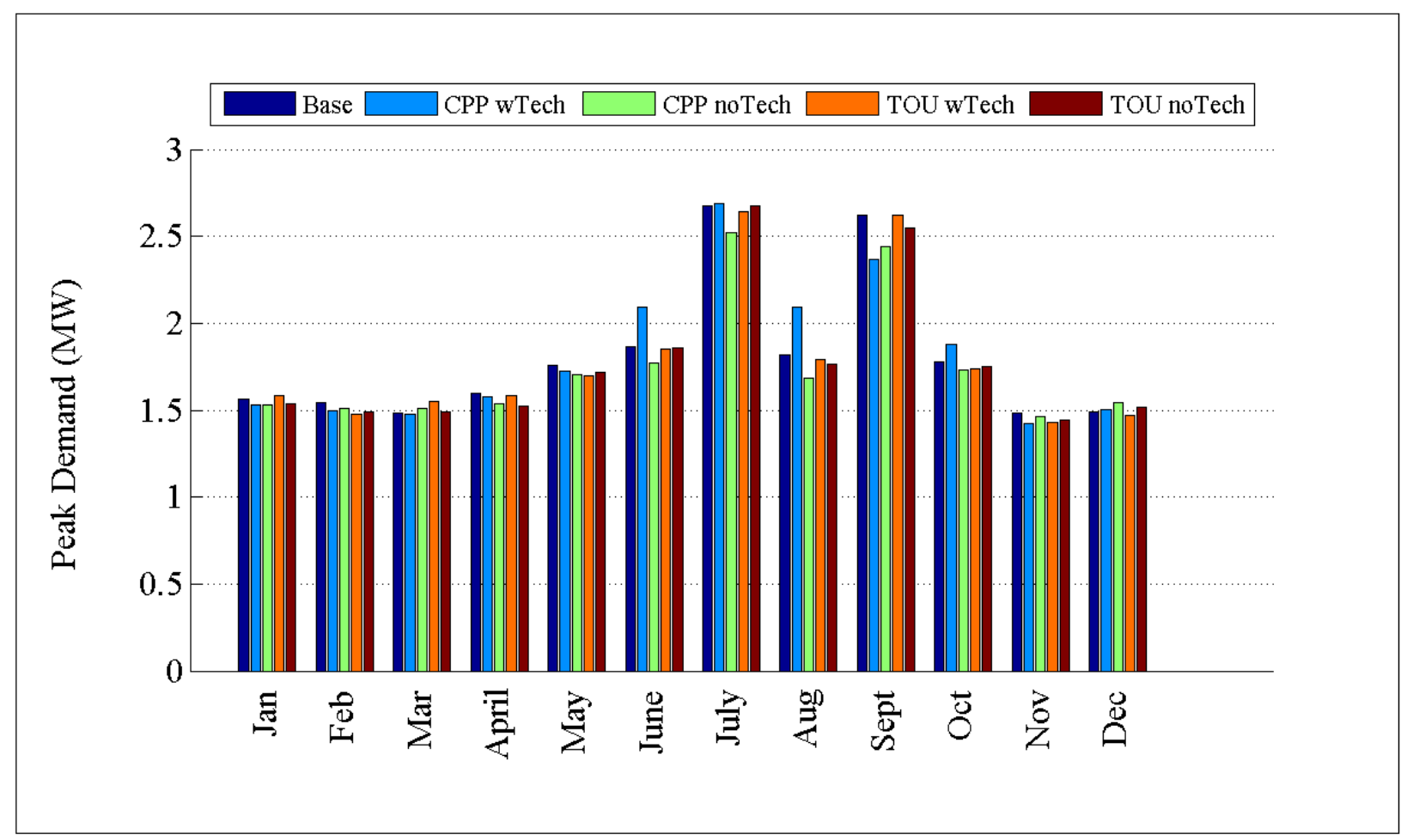

Figure D.9: Comparison of peak demand by month for R1-12.47-2 


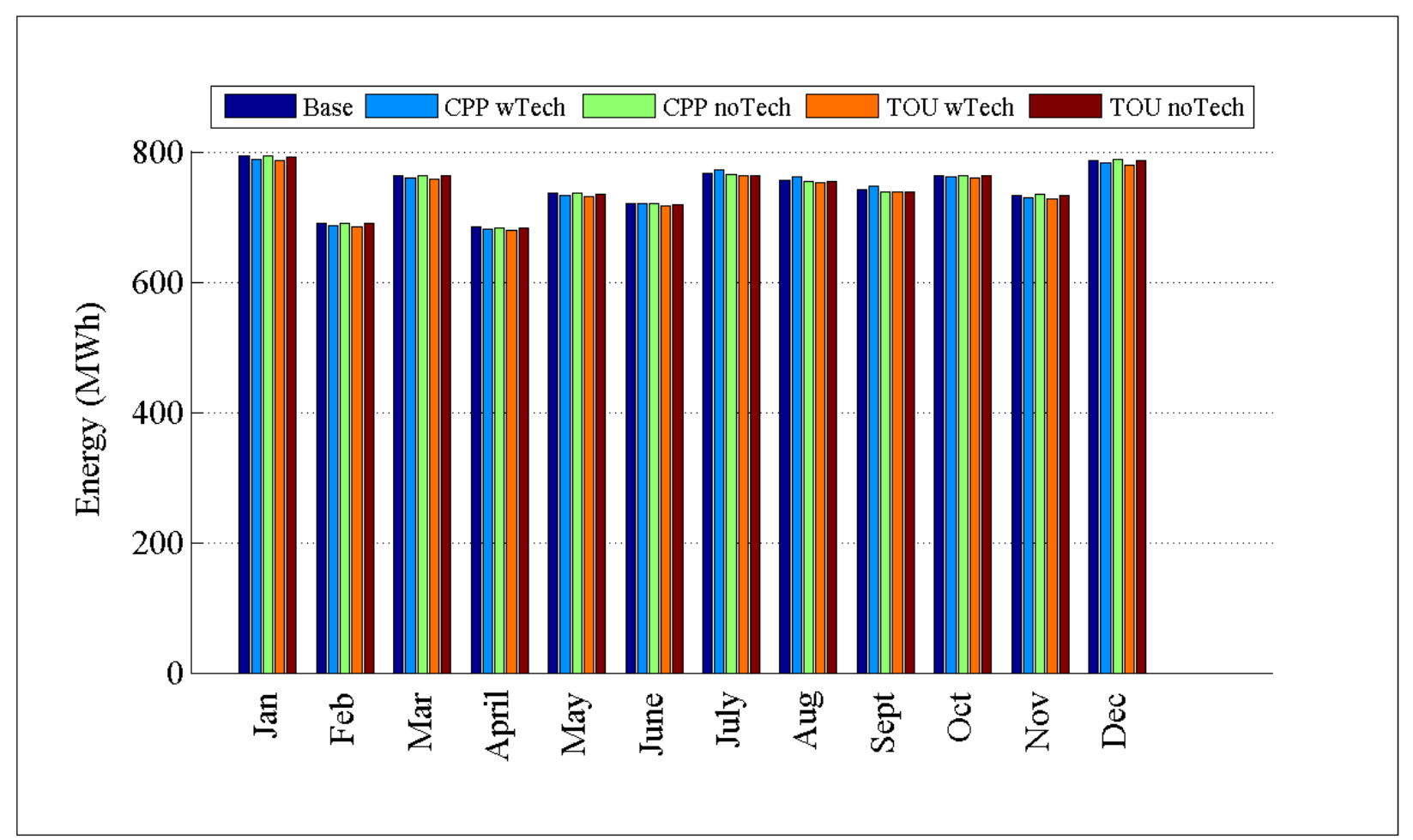

Figure D.10: Comparison of energy consumption by month for R1-12.47-2

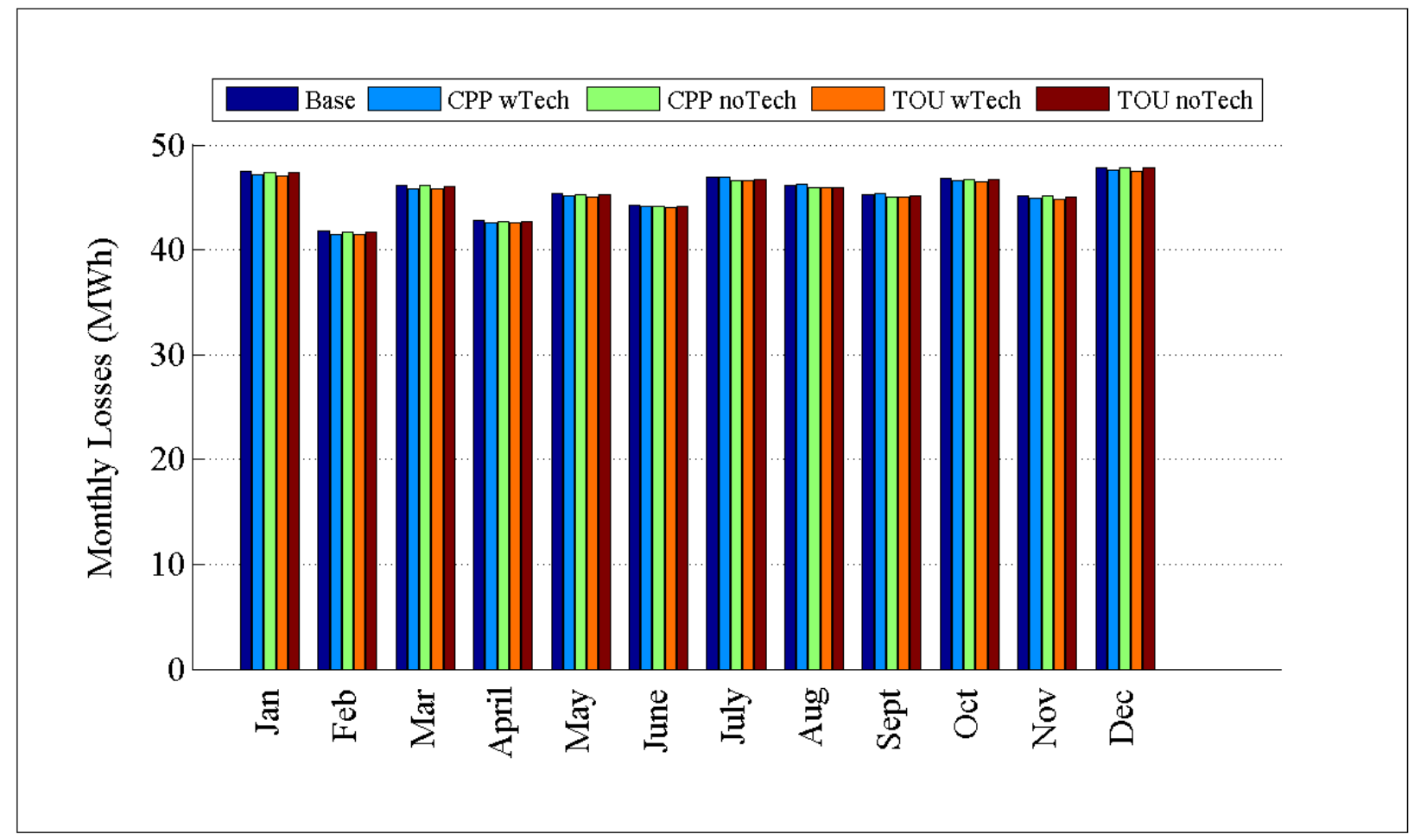

Figure D.11: Comparison of losses by month for R1-12.47-2 


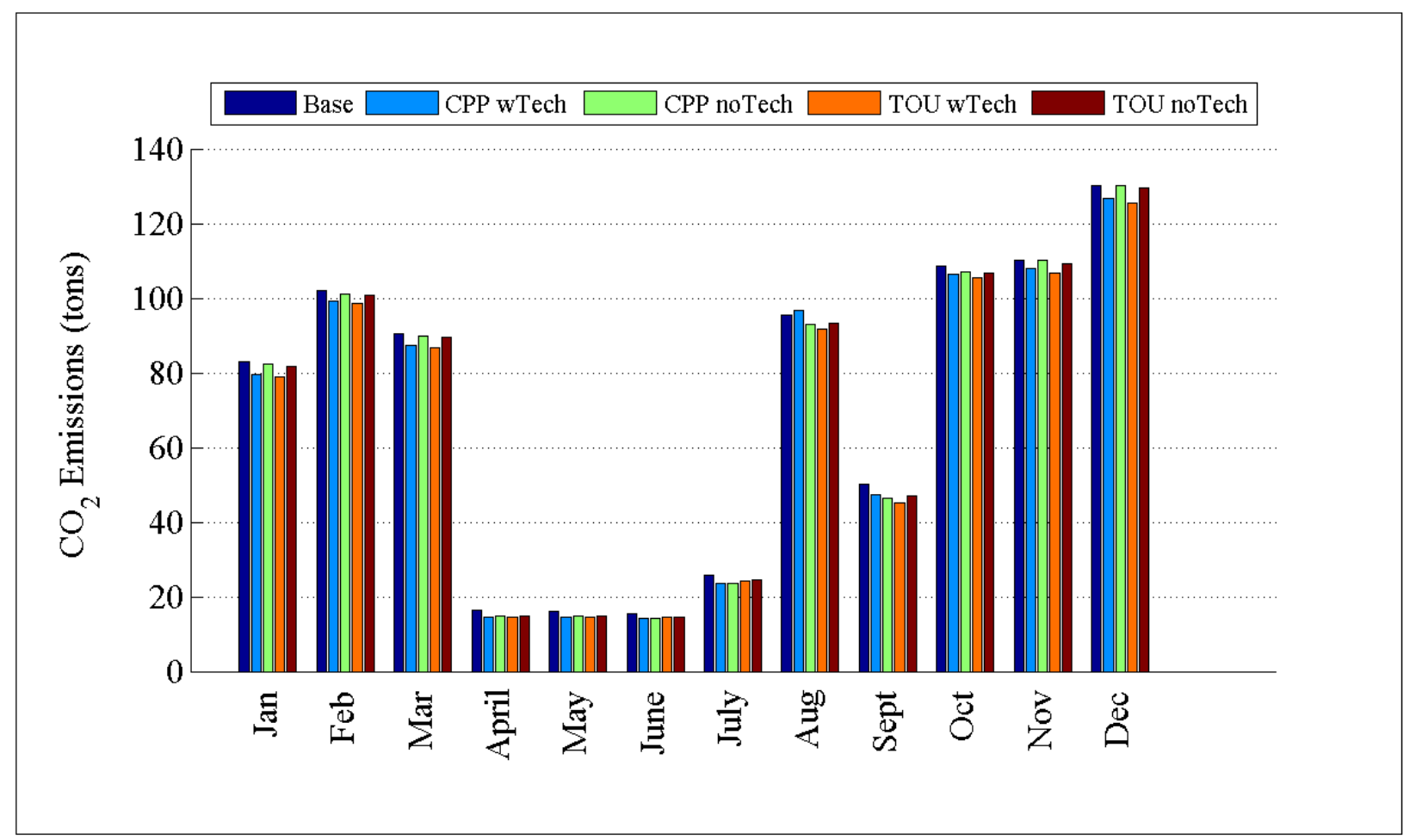

Figure D.12: Comparison of $\mathrm{CO}_{2}$ emissions by month for R1-12.47-2

D.1.4 Detailed TOU and CPP Plots for R1-12.47-3 


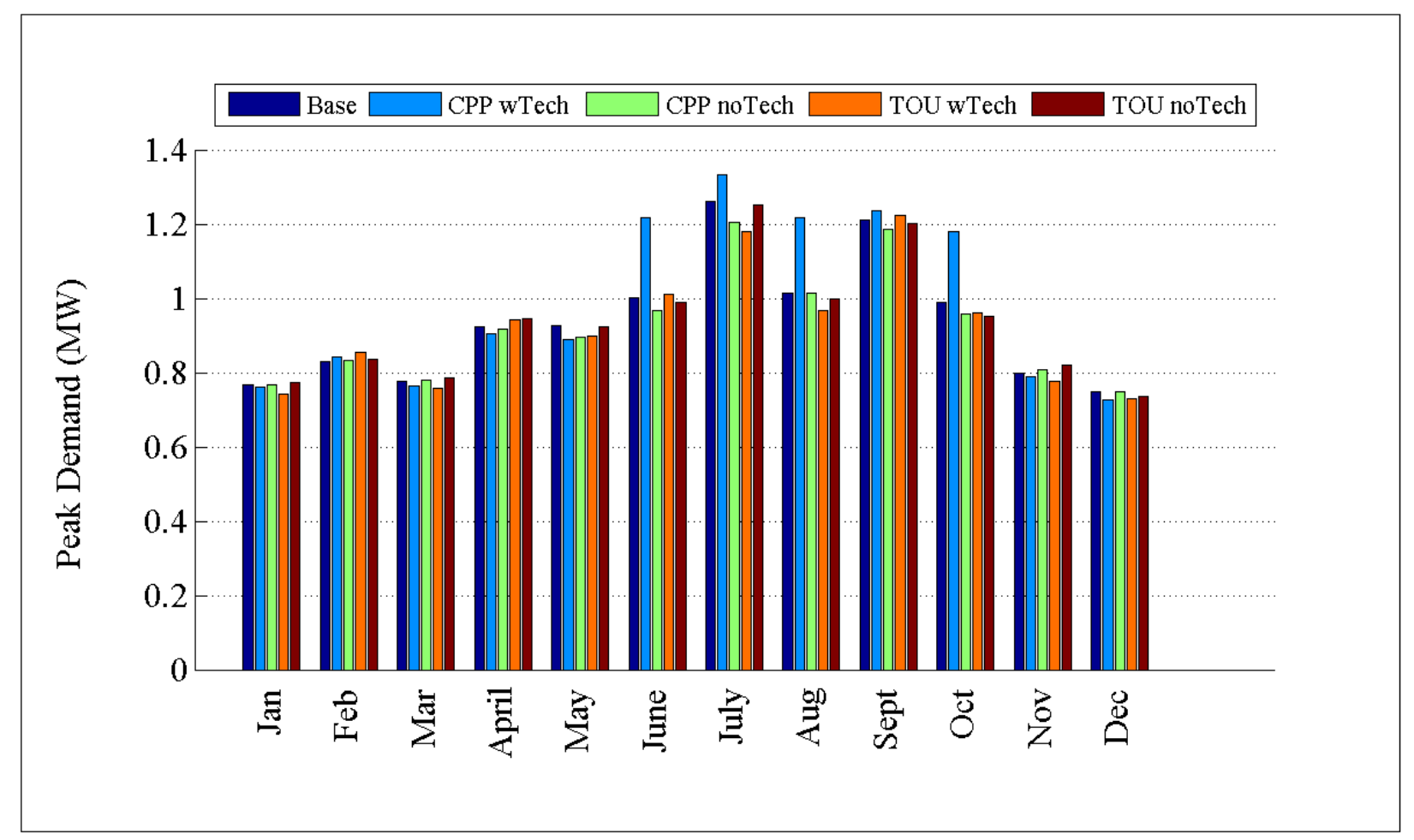

Figure D.13: Comparison of peak demand by month for R1-12.47-3

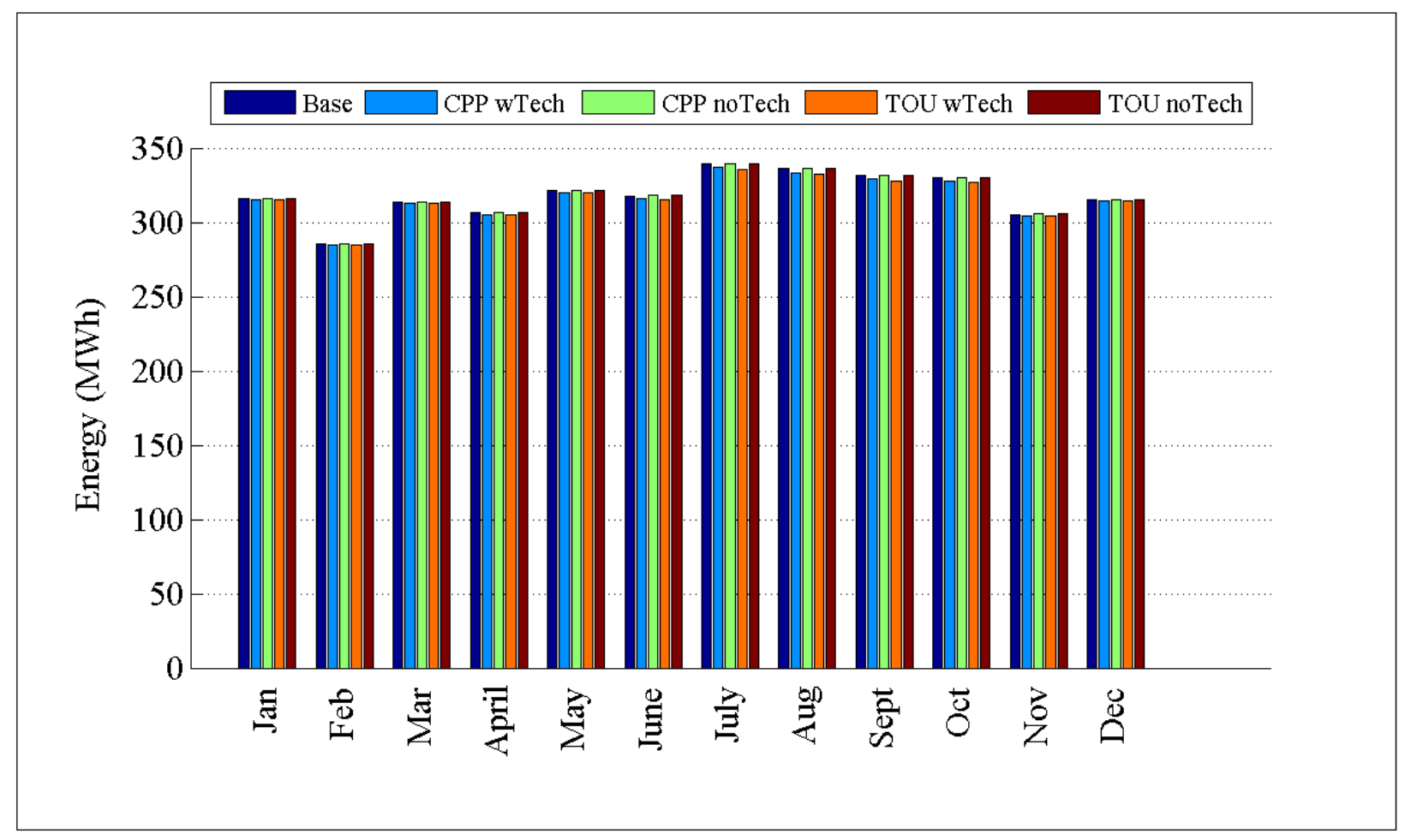

Figure D.14: Comparison of energy consumption by month for R1-12.47-3 


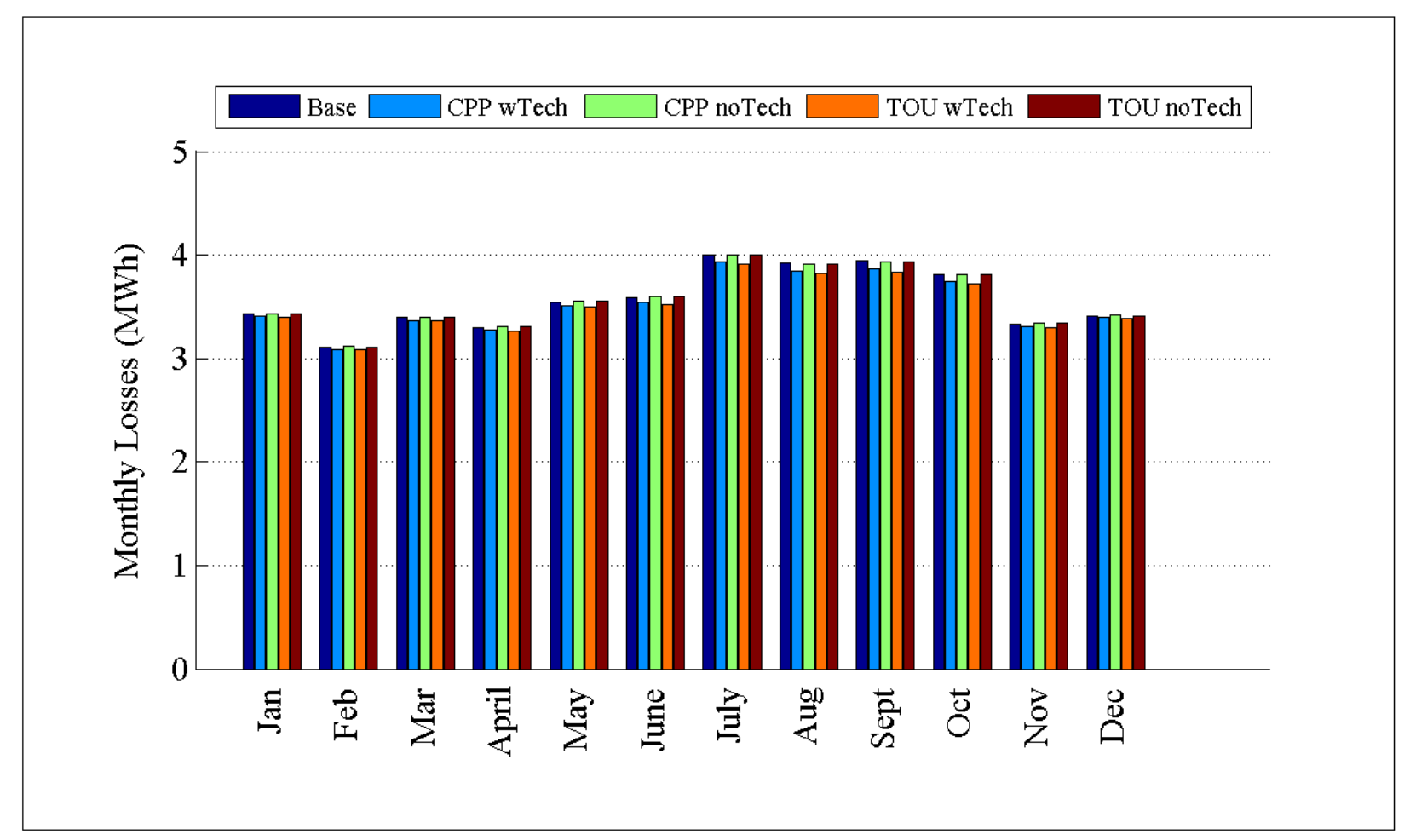

Figure D.15: Comparison of losses by month for R1-12.47-3

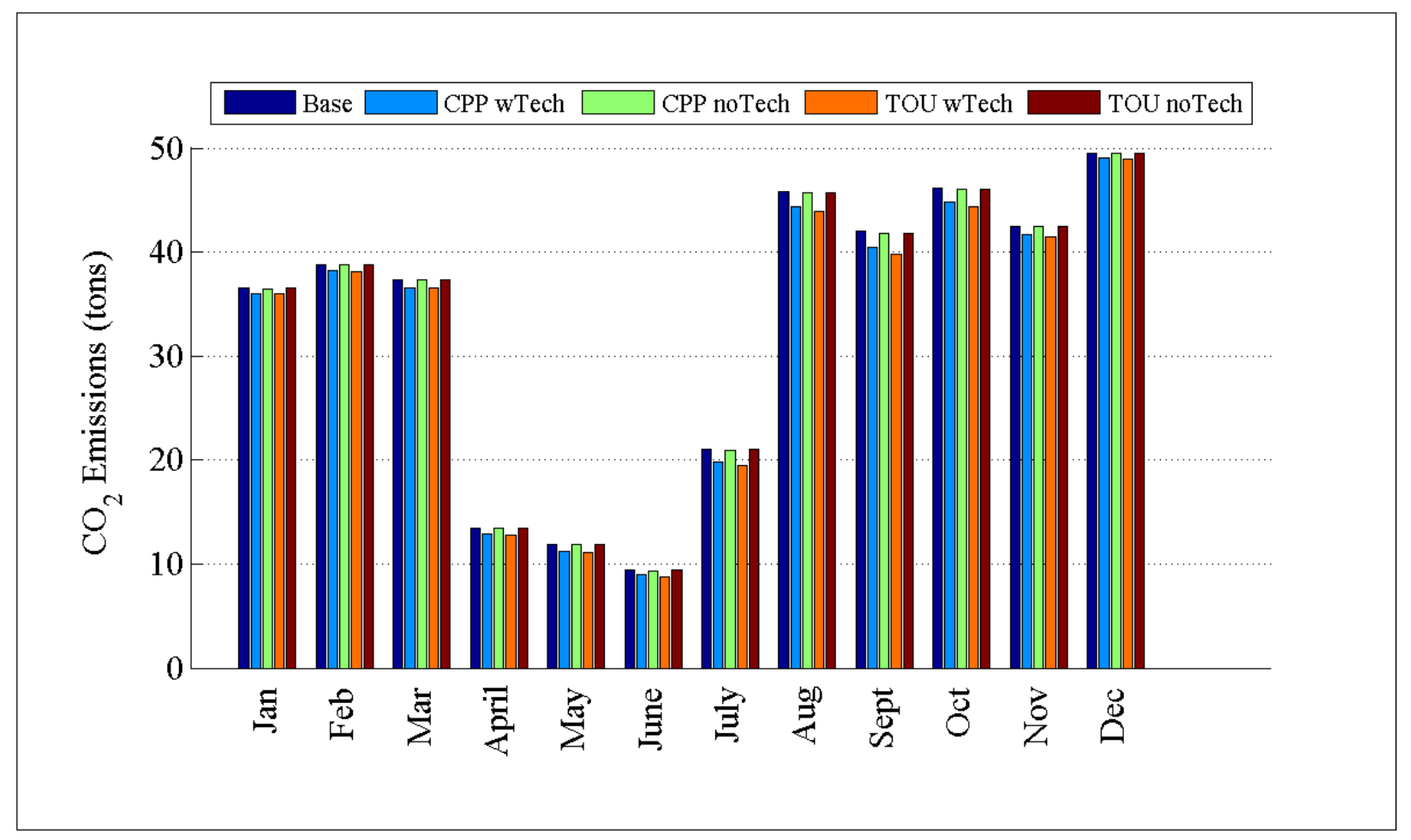

Figure D.16: Comparison of $\mathrm{CO}_{2}$ emissions by month for R1-12.47-3 
D.1.5 Detailed TOU and CPP Plots for R1-12.47-4

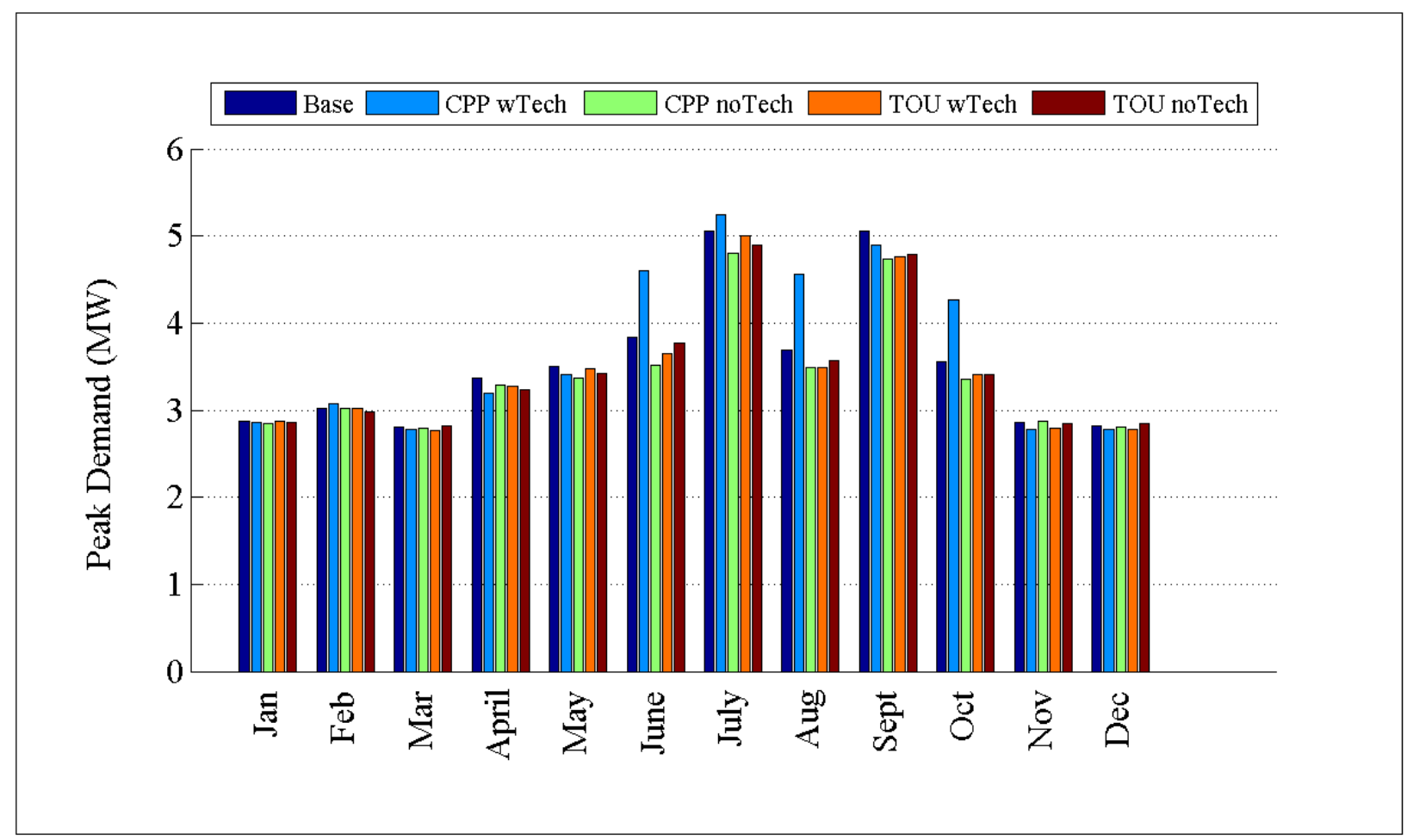

Figure D.17: Comparison of peak demand by month for R1-12.47-4 


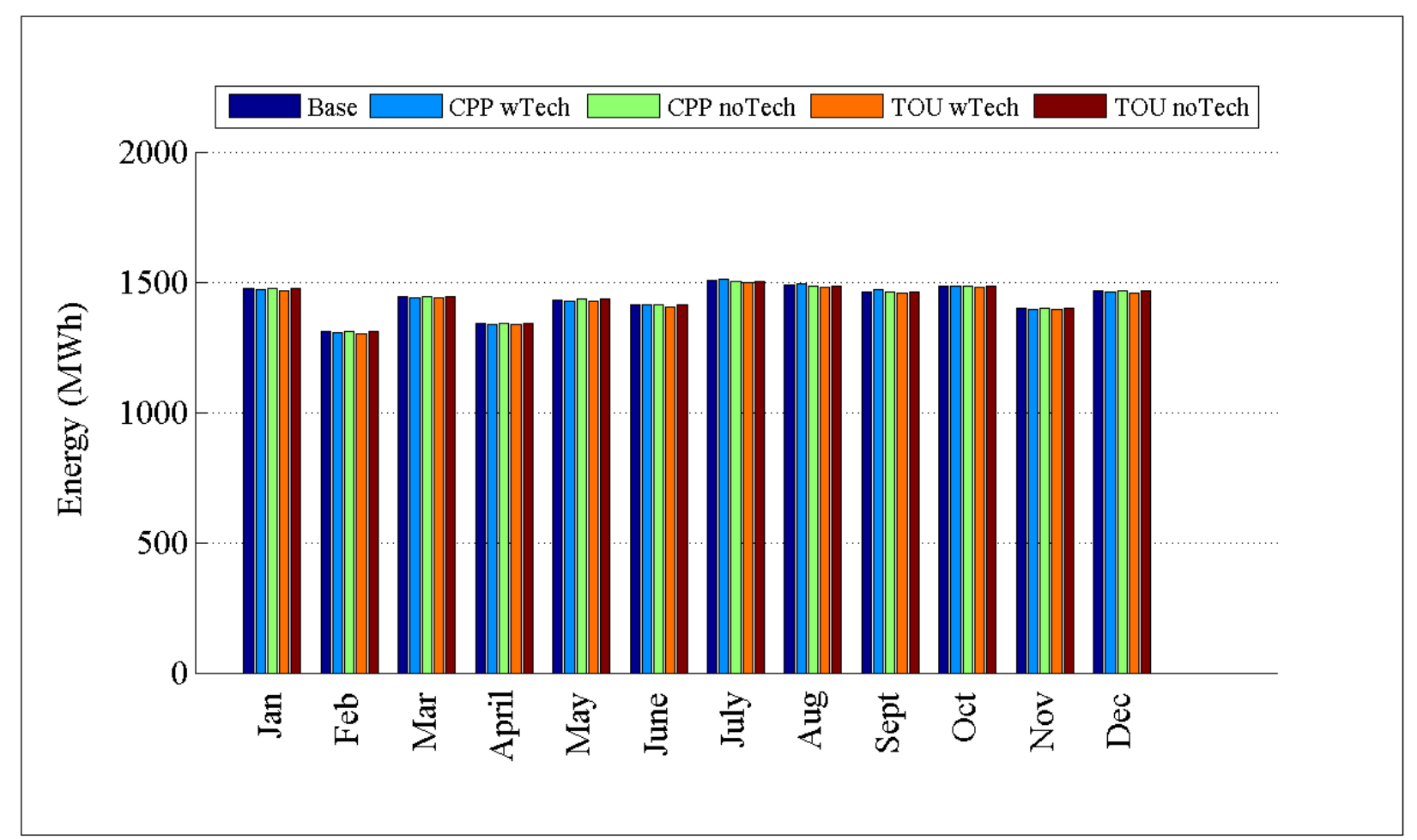

Figure D.18: Comparison of energy consumption by month for R1-12.47-4

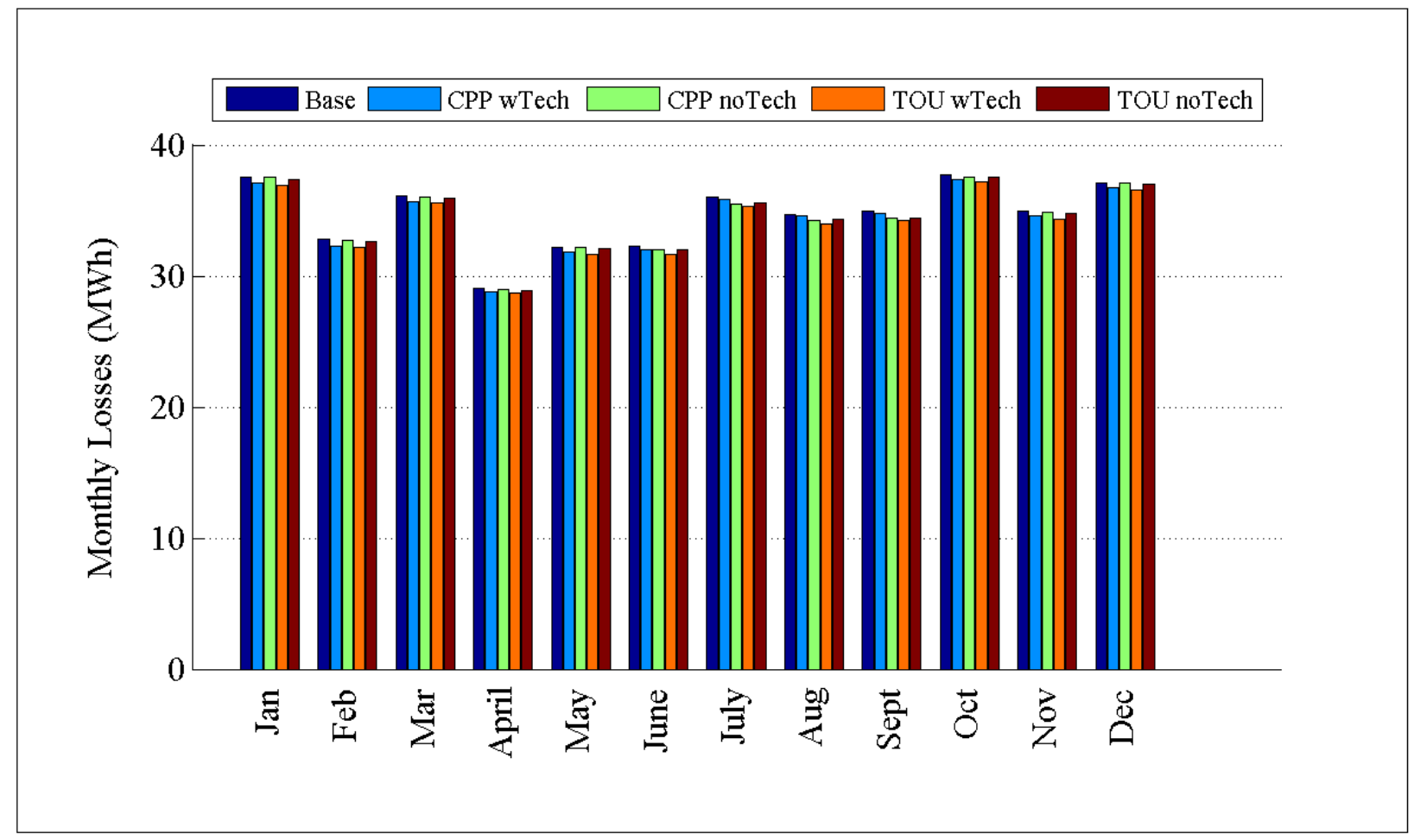

Figure D.19: Comparison of losses by month for R1-12.47-4 


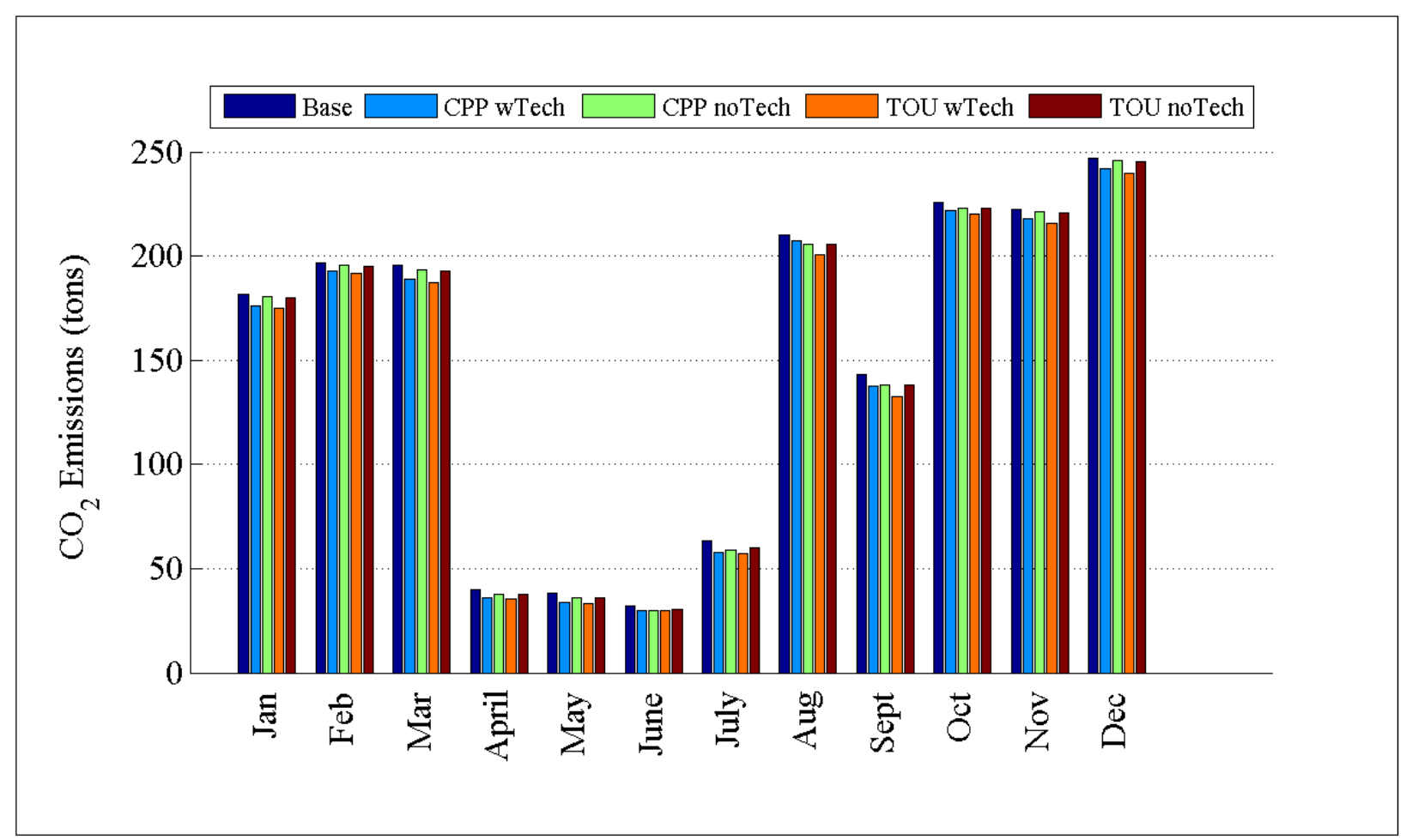

Figure D.20: Comparison of $\mathrm{CO}_{2}$ emissions by month for R1-12.47-4

D.1.6 Detailed TOU and CPP Plots for R1-25.00-1 


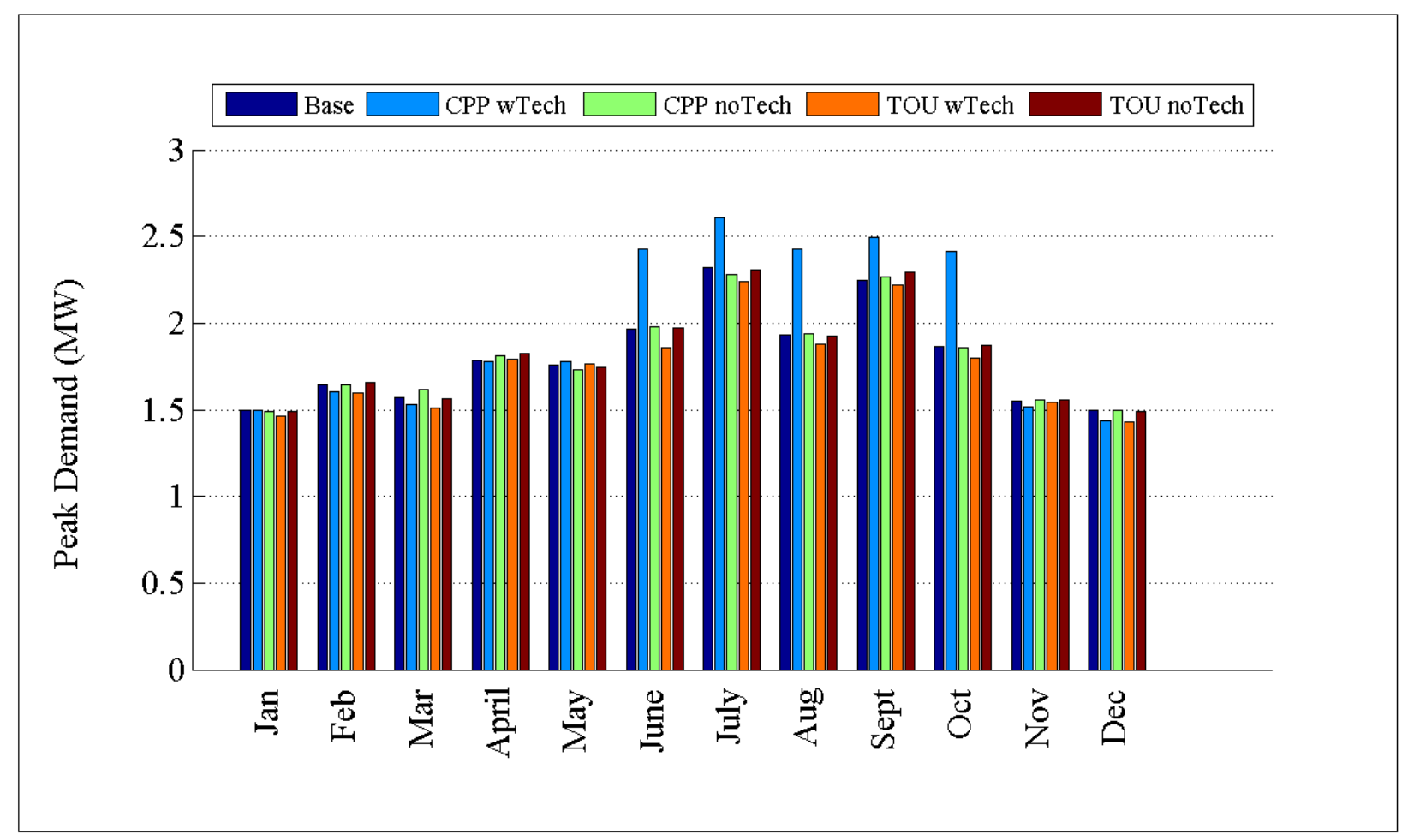

Figure D. 21: Comparison of peak demand by month for R1-25.00-1

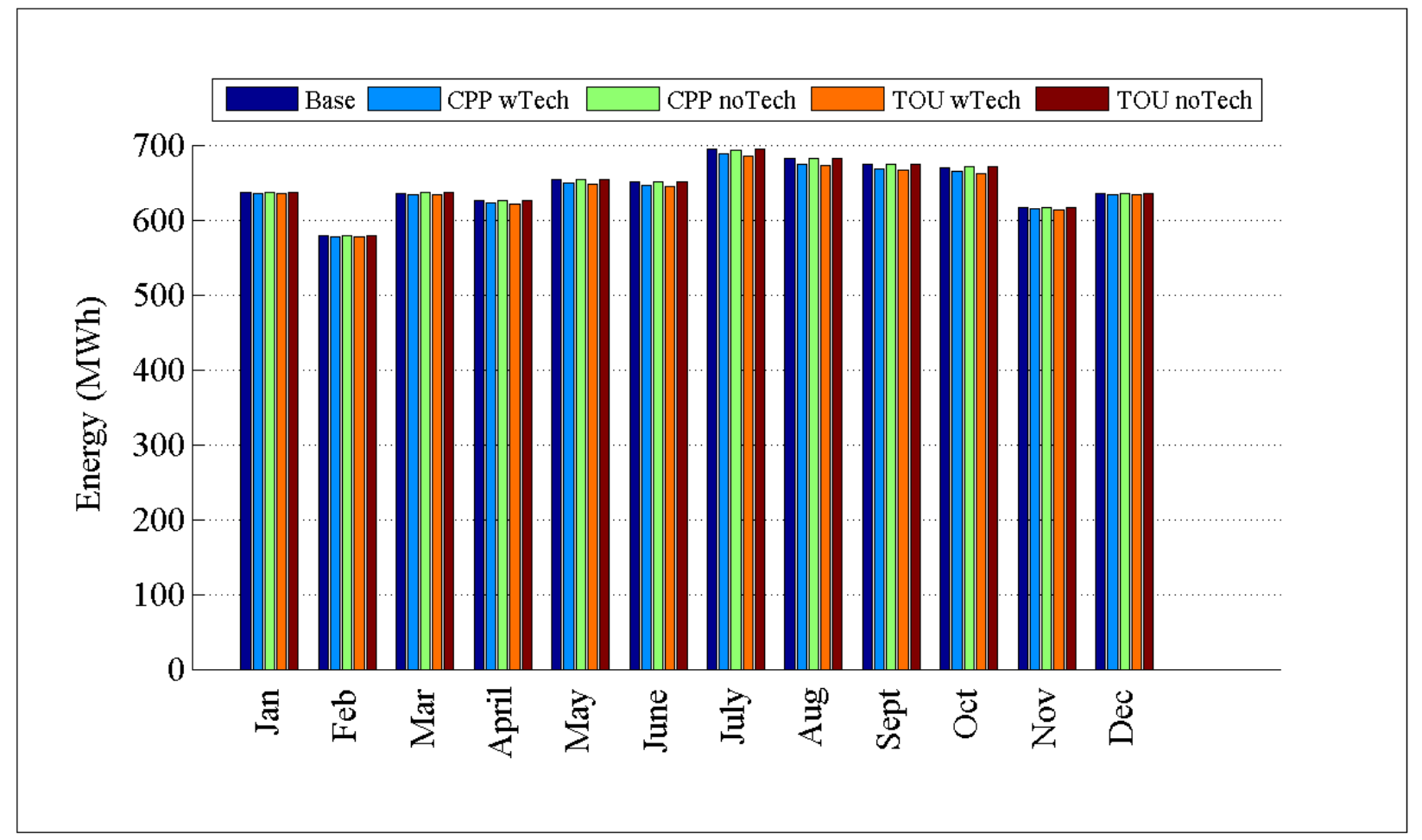

Figure D. 22: Comparison of energy consumption by month for R1-25.00-1 


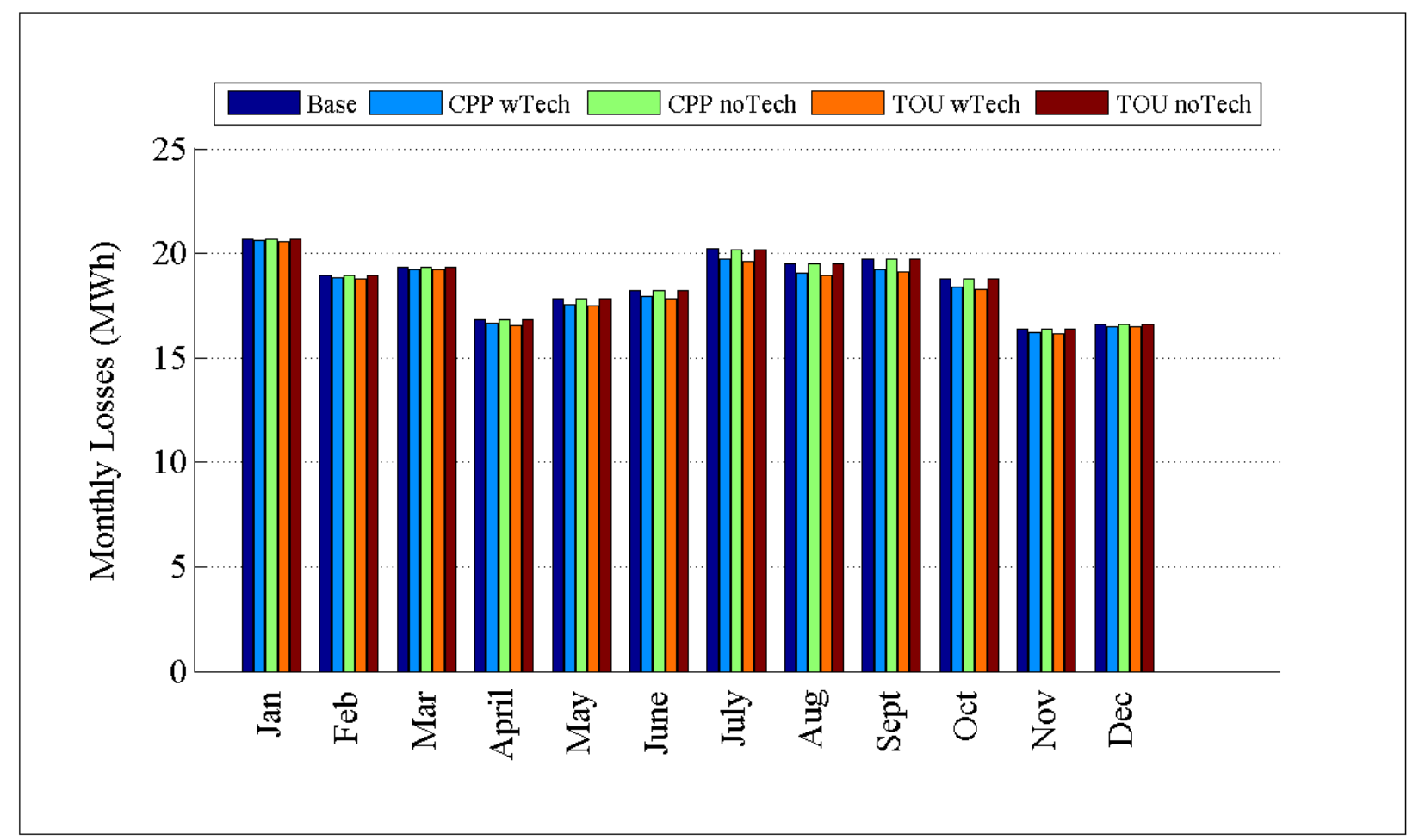

Figure D. 23: Comparison of losses by month for R1-25.00-1

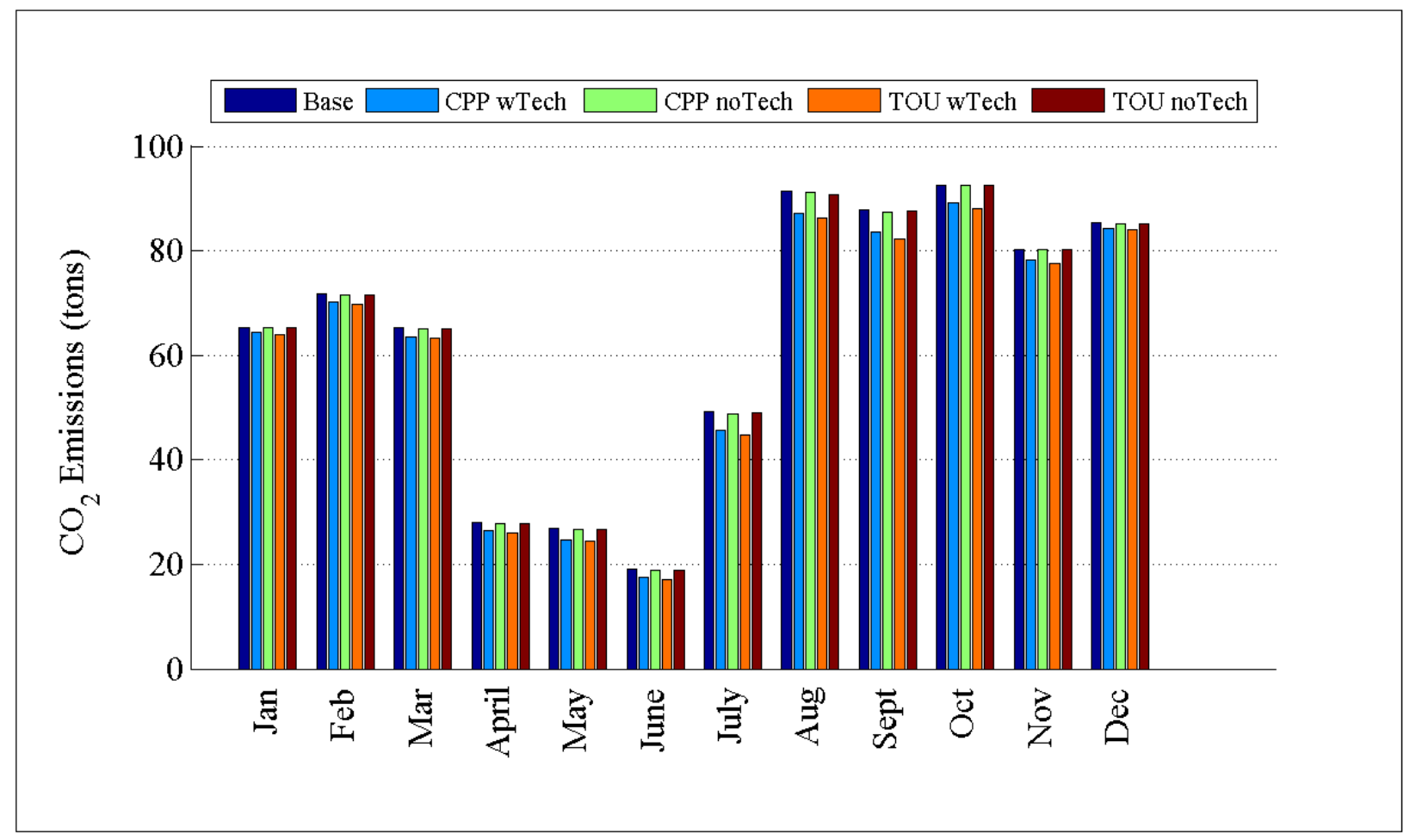

Figure D. 24: Comparison of $\mathrm{CO}_{2}$ emissions by month for R1-25.00-1 
D.1.7 Detailed TOU and CPP Plots for GC-12.47-1_R2

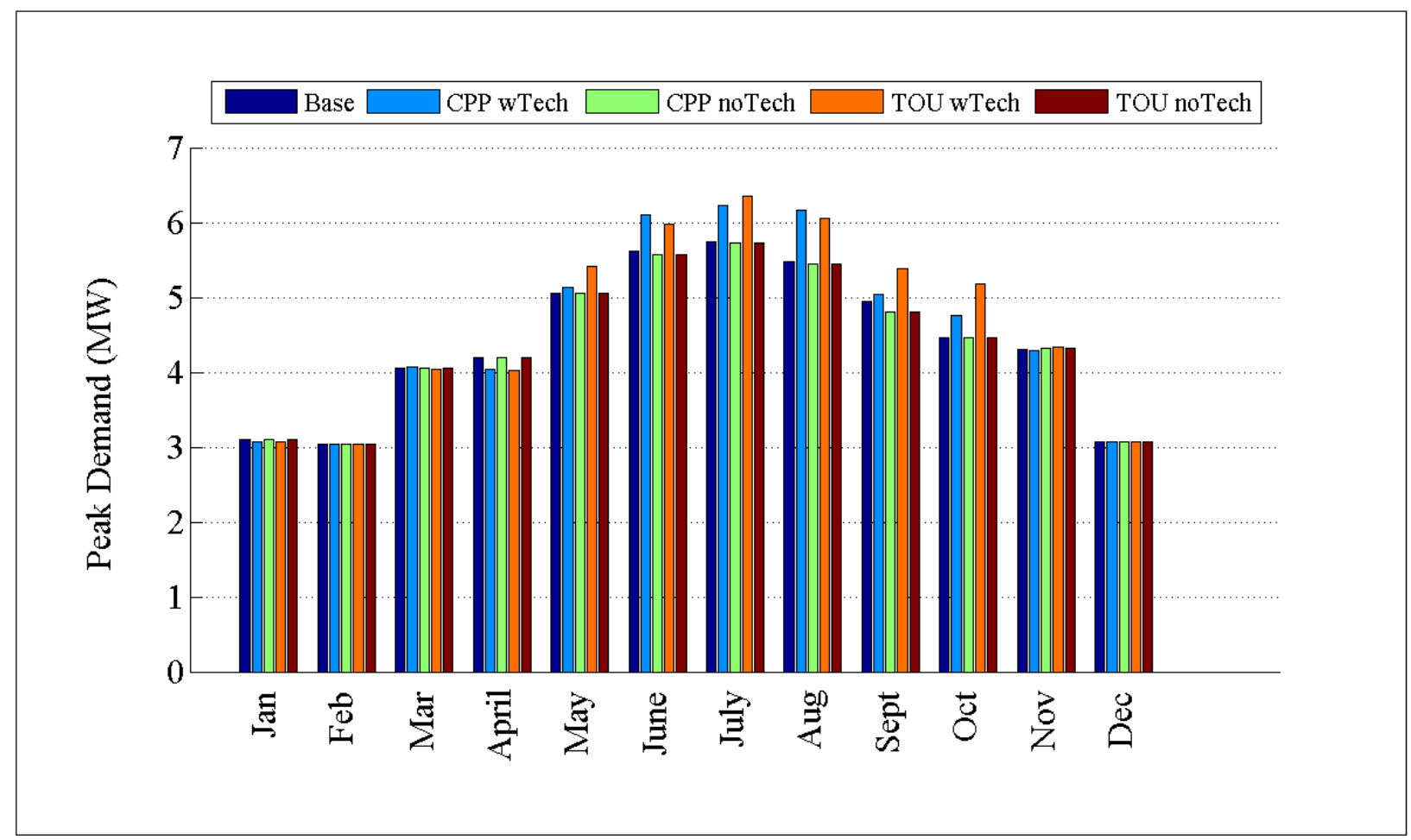

Figure D.25: Comparison of peak demand by month for GC-12.47-1_R2 


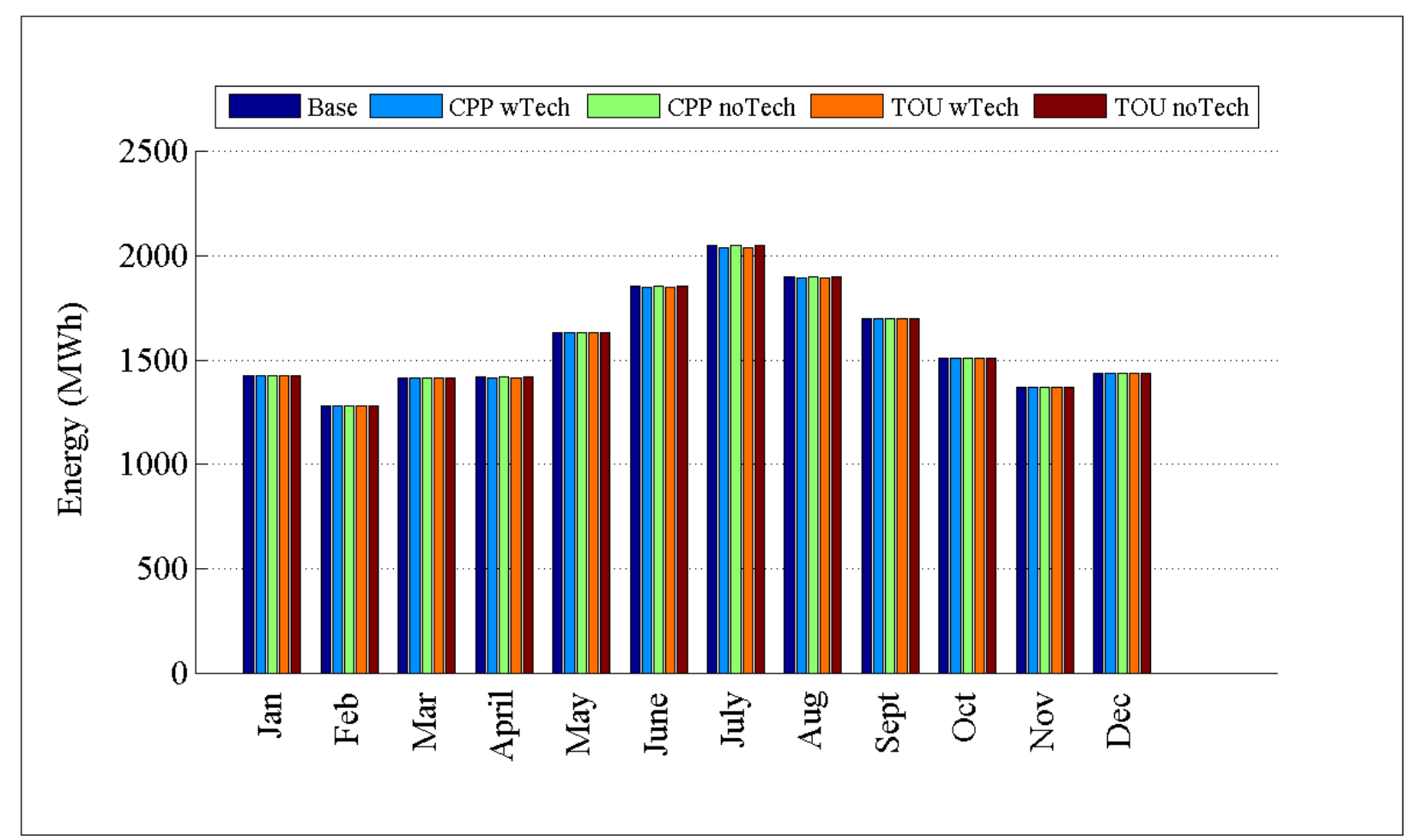

Figure D.26: Comparison of energy consumption by month for GC-12.47-1_R2

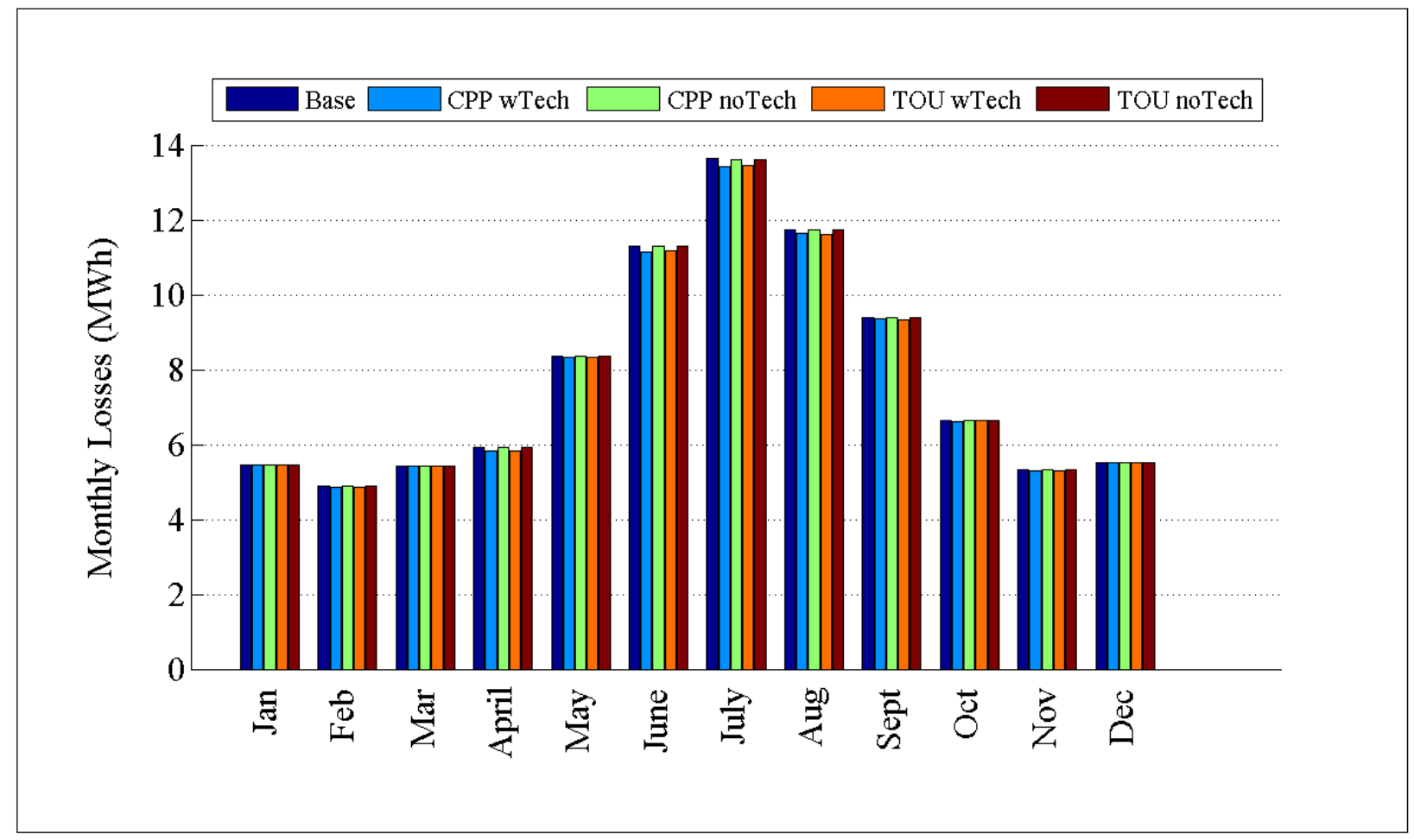

Figure D.27: Comparison of losses by month for GC-12.47-1_R2 


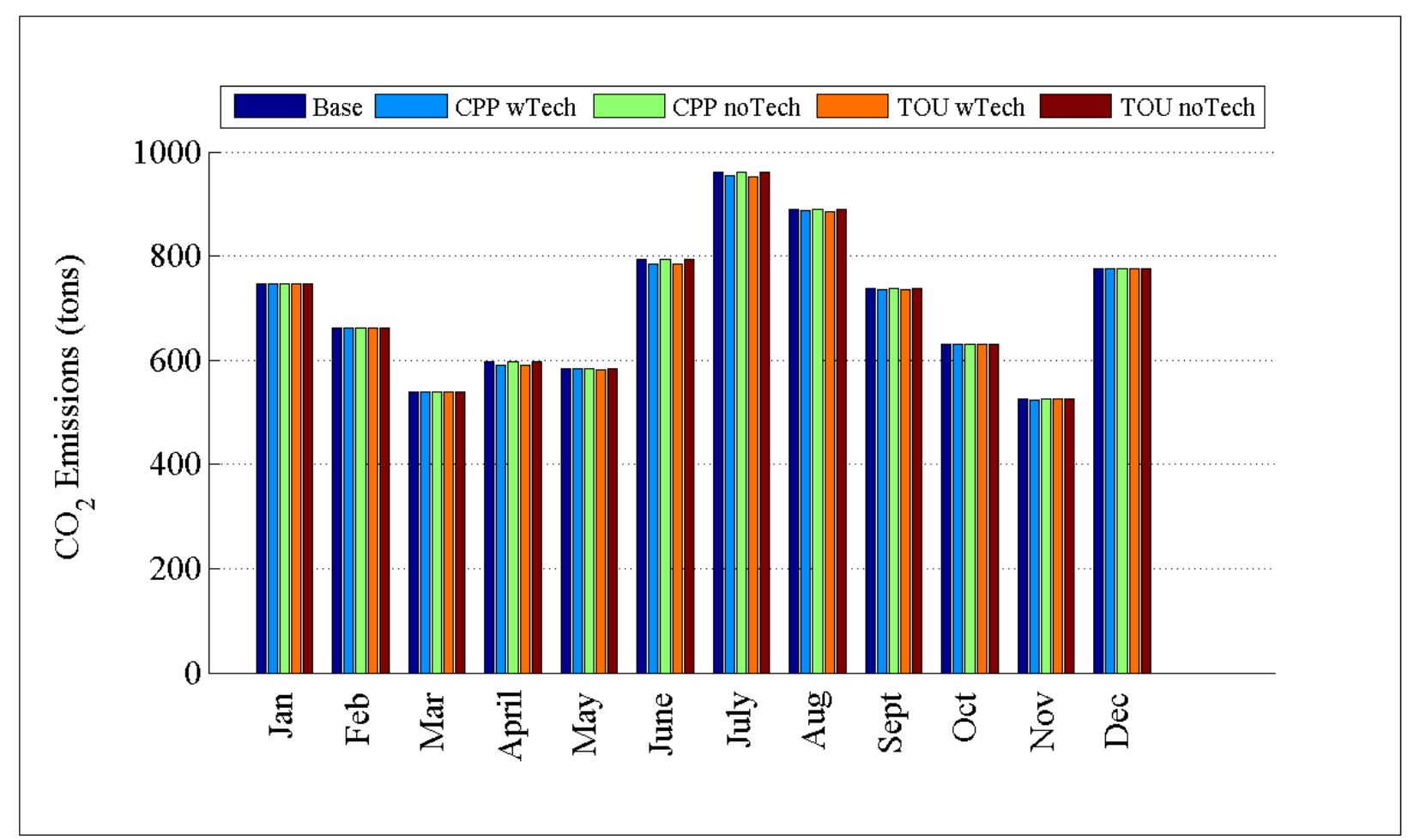

Figure D.28: Comparison of $\mathrm{CO}_{2}$ emissions by month for GC-12.47-1_R2

D.1.8 Detailed TOU and CPP Plots for R2-12.47-1 


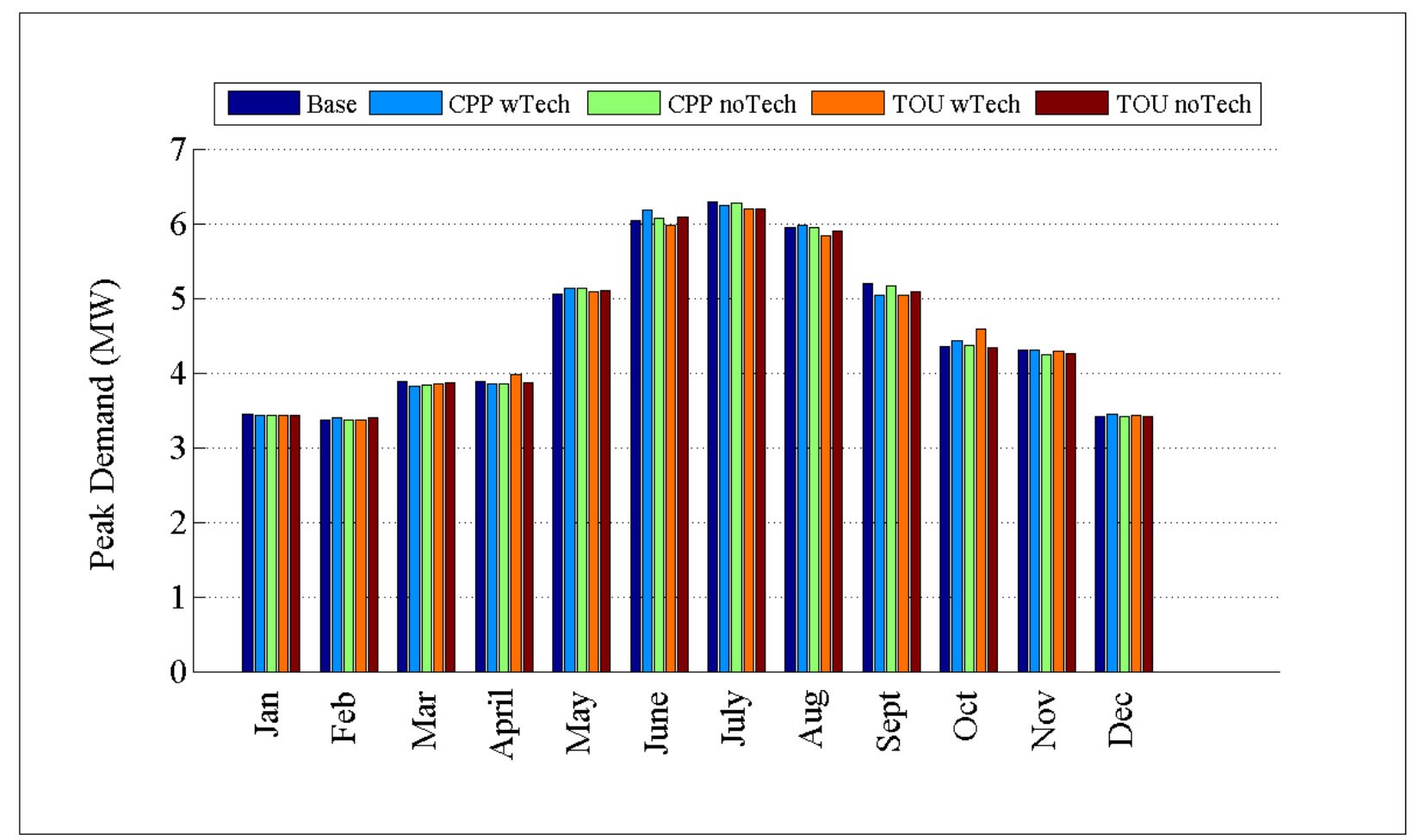

Figure D.29: Comparison of peak demand by month for R2-12.47-1

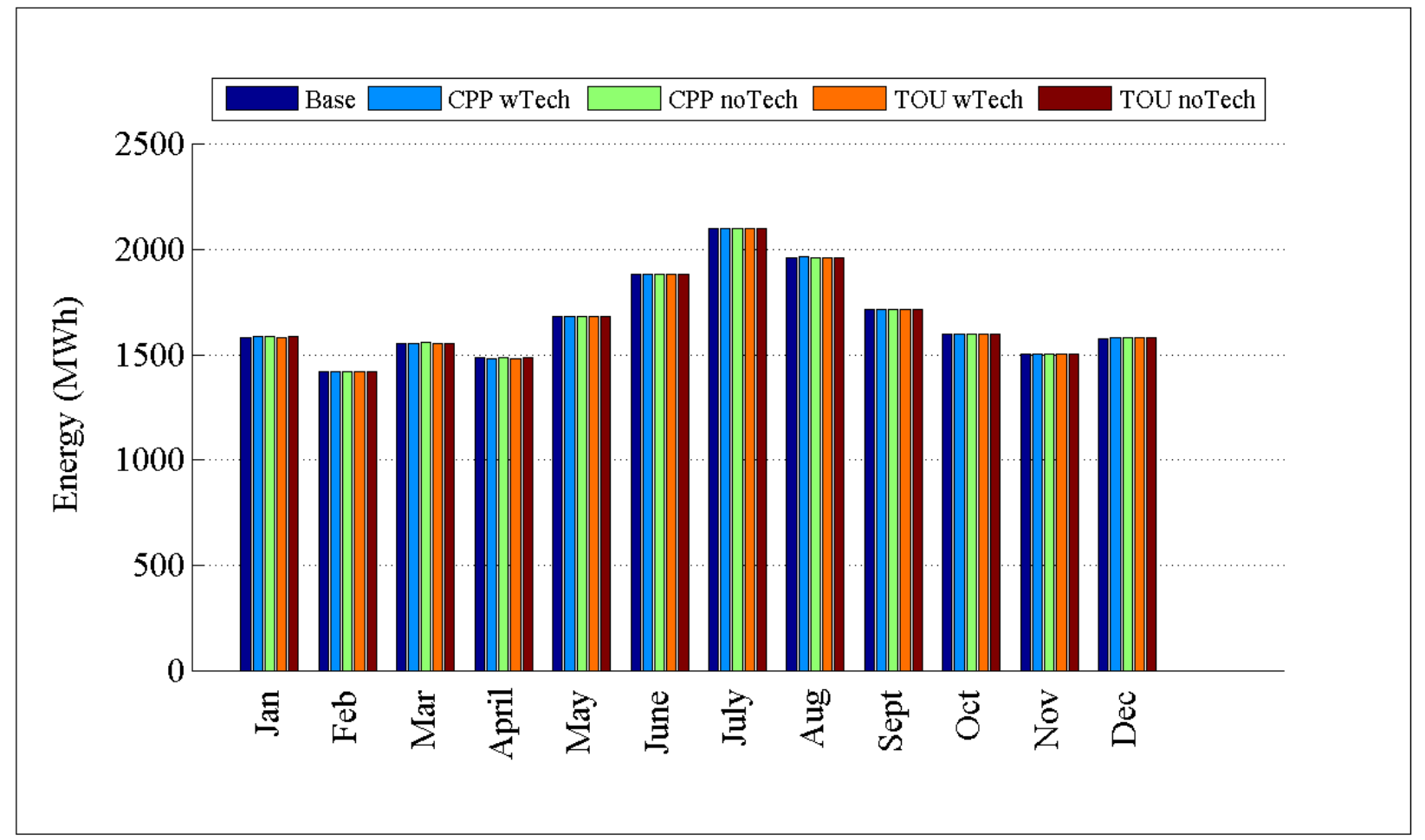

Figure D.30: Comparison of energy consumption by month for R2-12.47-1 


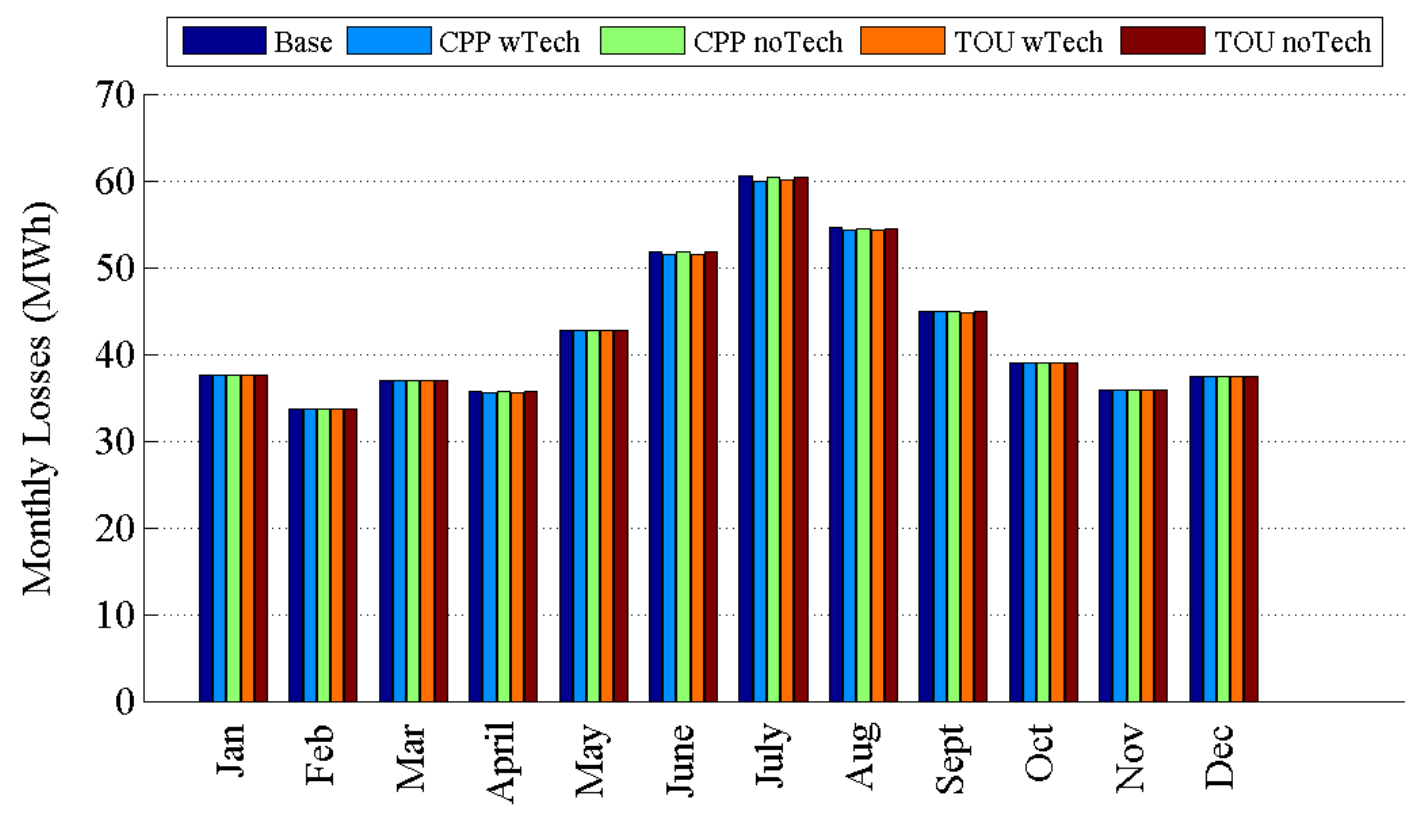

Figure D.31: Comparison of losses by month for R2-12.47-1

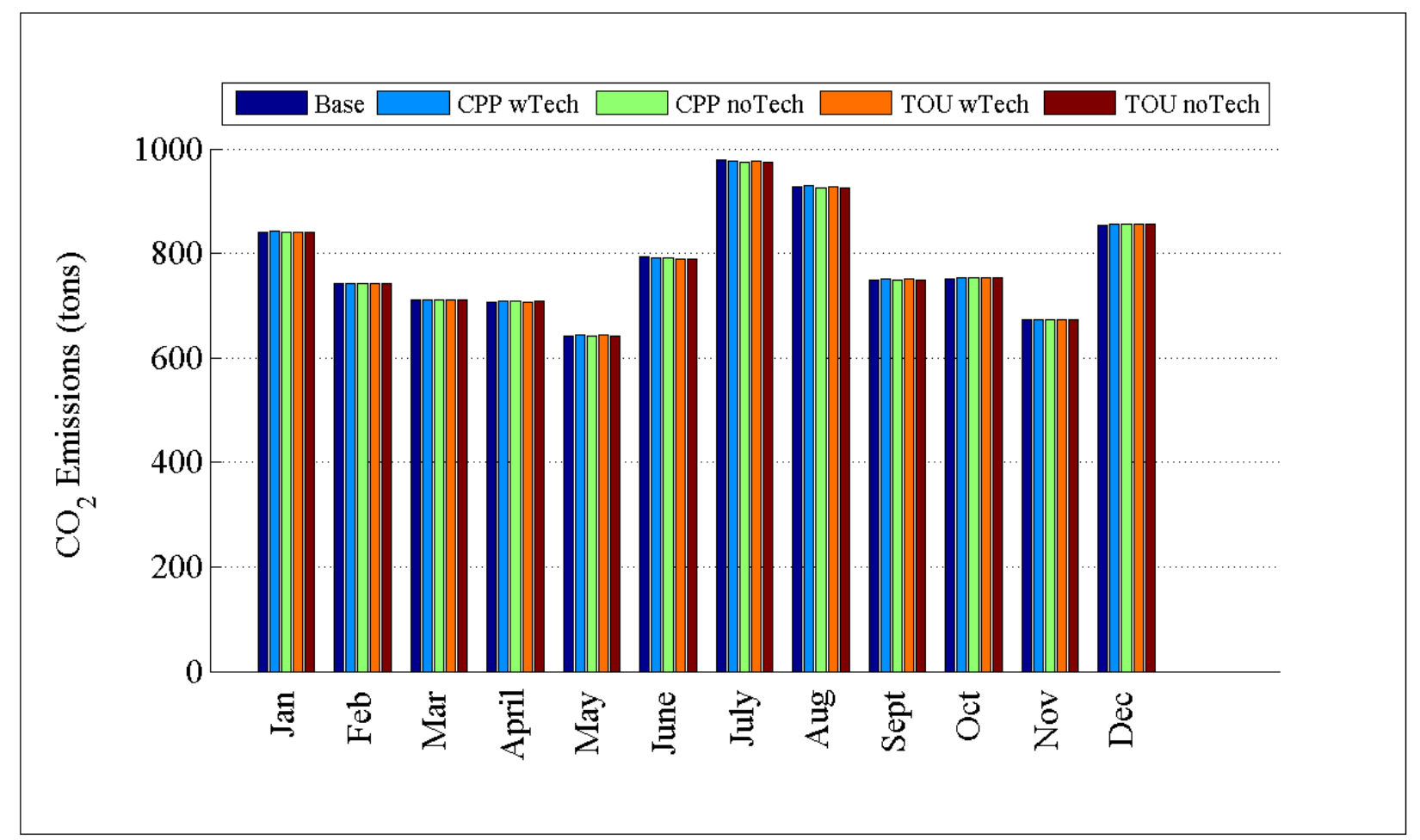

Figure D.32: Comparison of $\mathrm{CO}_{2}$ emissions by month for R2-12.47-1 
D.1.9 Detailed TOU and CPP Plots for R2-12.47-2

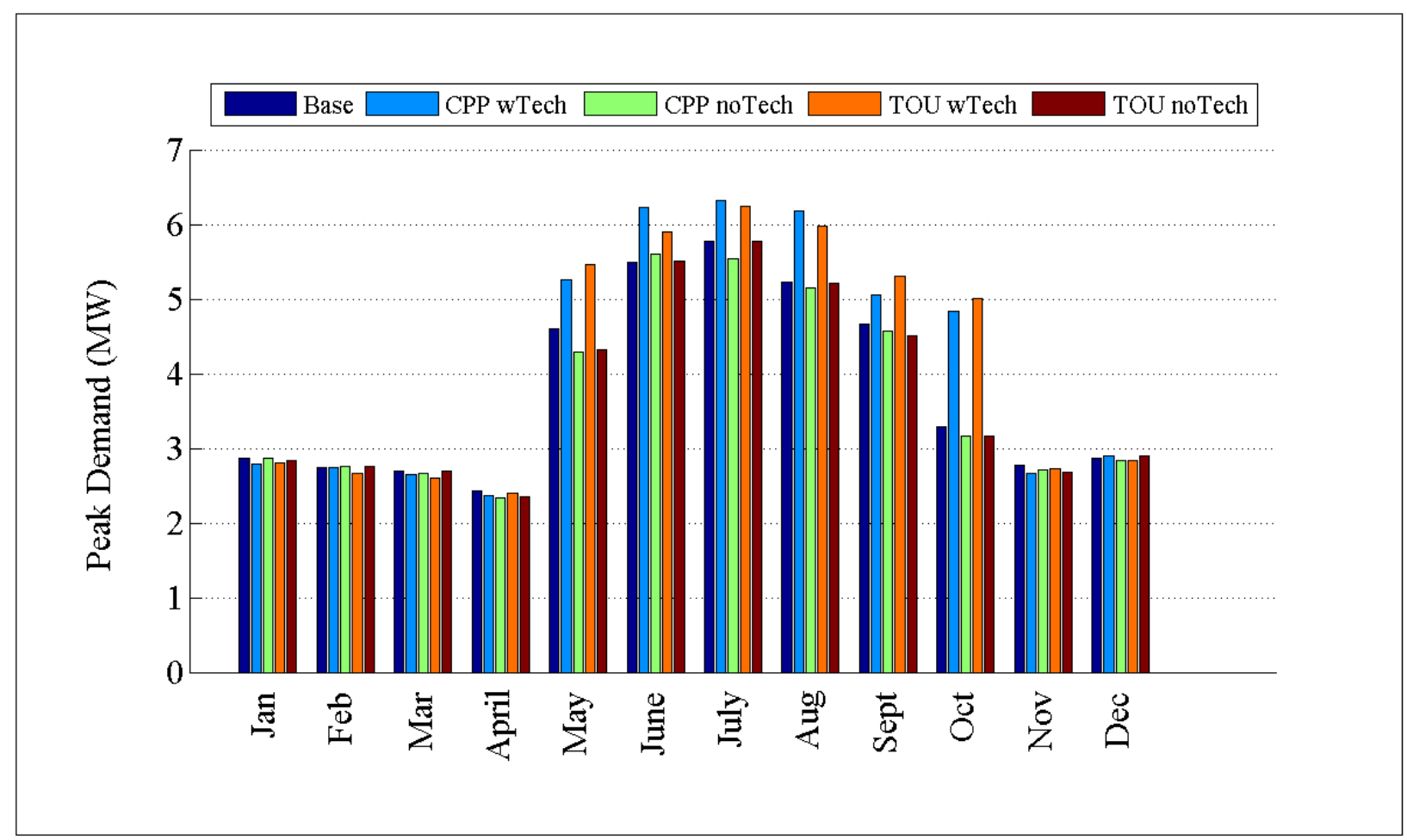

Figure D.33: Comparison of peak demand by month for R2-12.47-2 


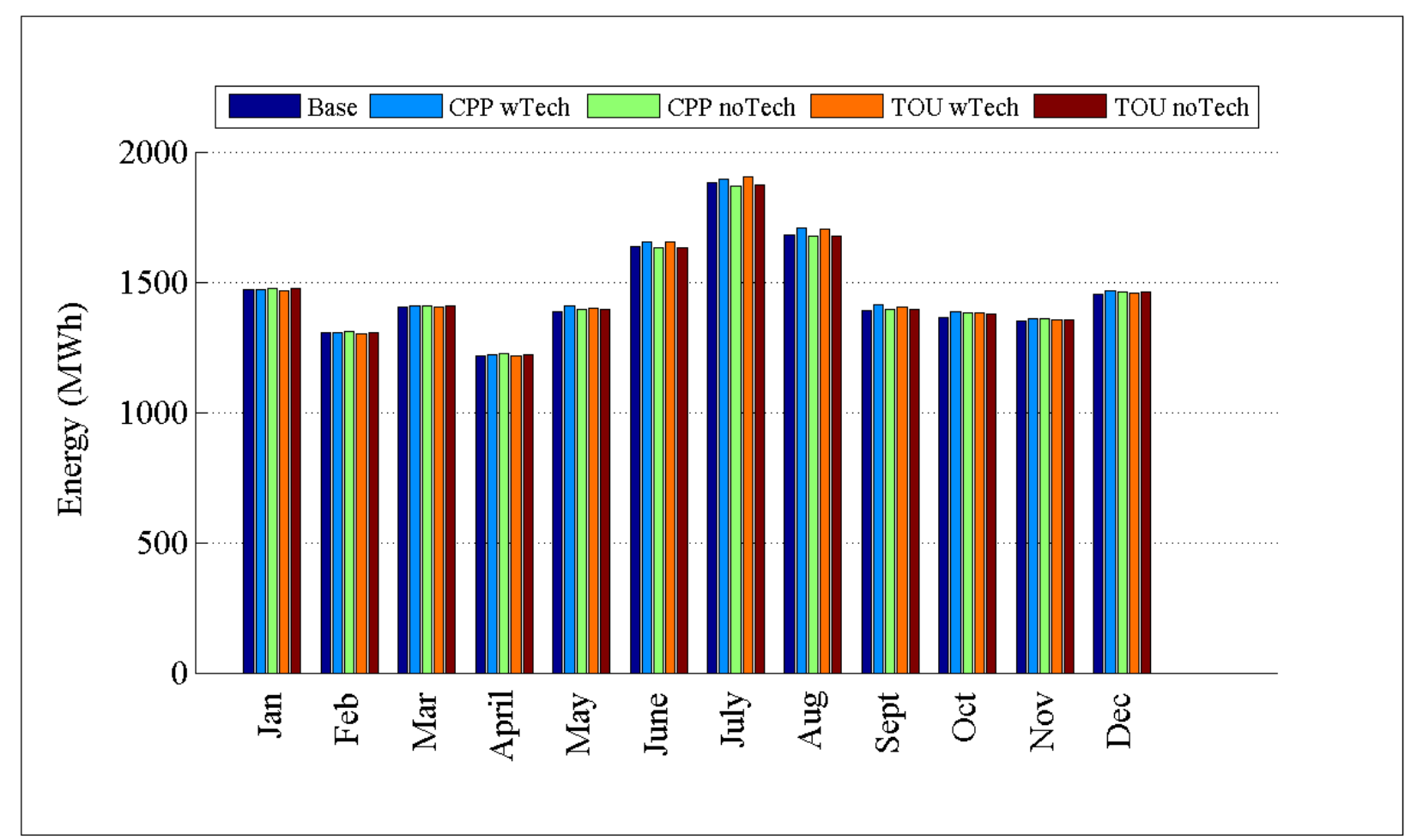

Figure D.34: Comparison of energy consumption by month for R2-12.47-2

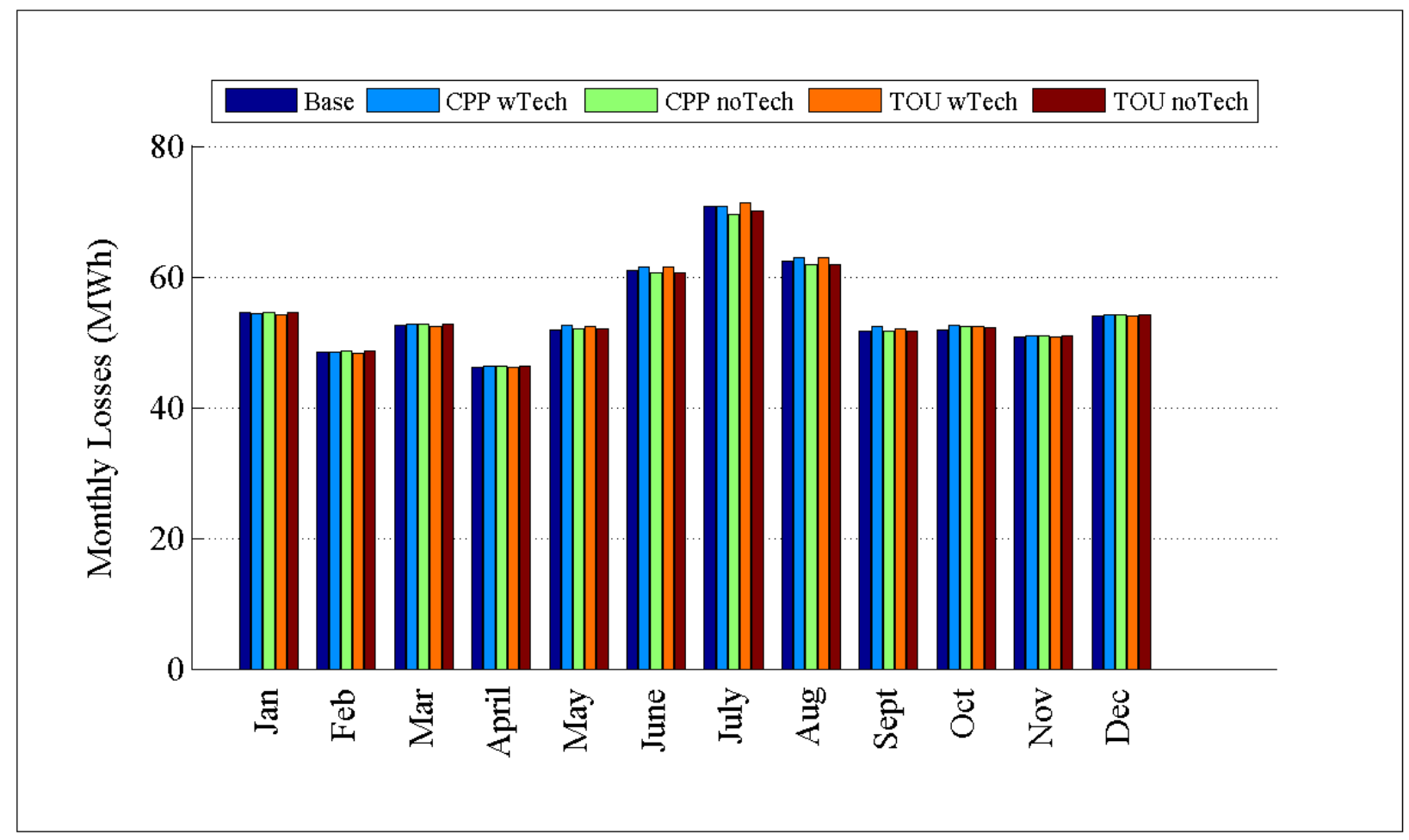

Figure D.35: Comparison of losses by month for R2-12.47-2 


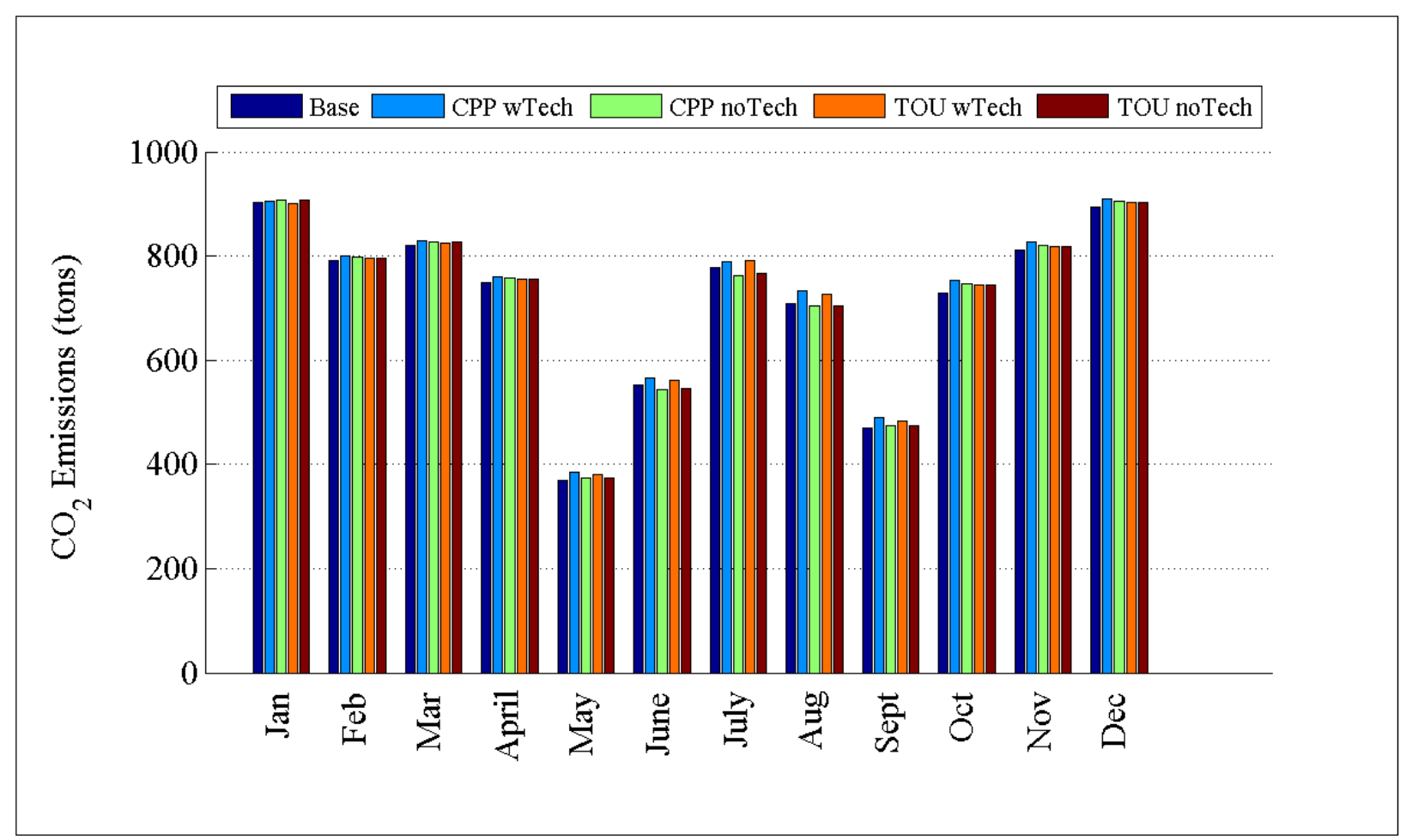

Figure D.36: Comparison of $\mathrm{CO}_{2}$ emissions by month for R2-12.47-2

D.1.10 Detailed TOU and CPP Plots for R2-12.47-3 


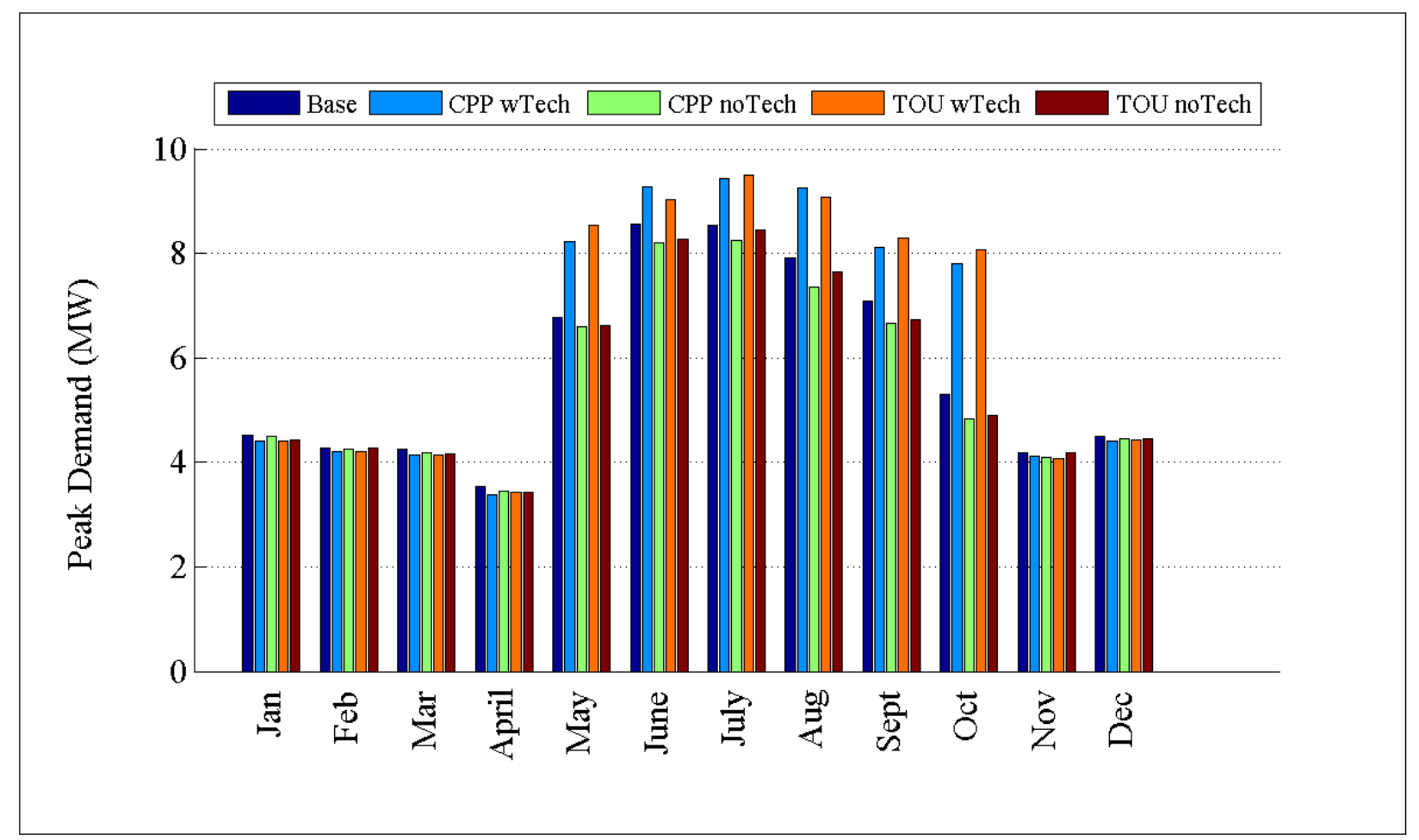

Figure D.37: Comparison of peak demand by month for R2-12.47-3

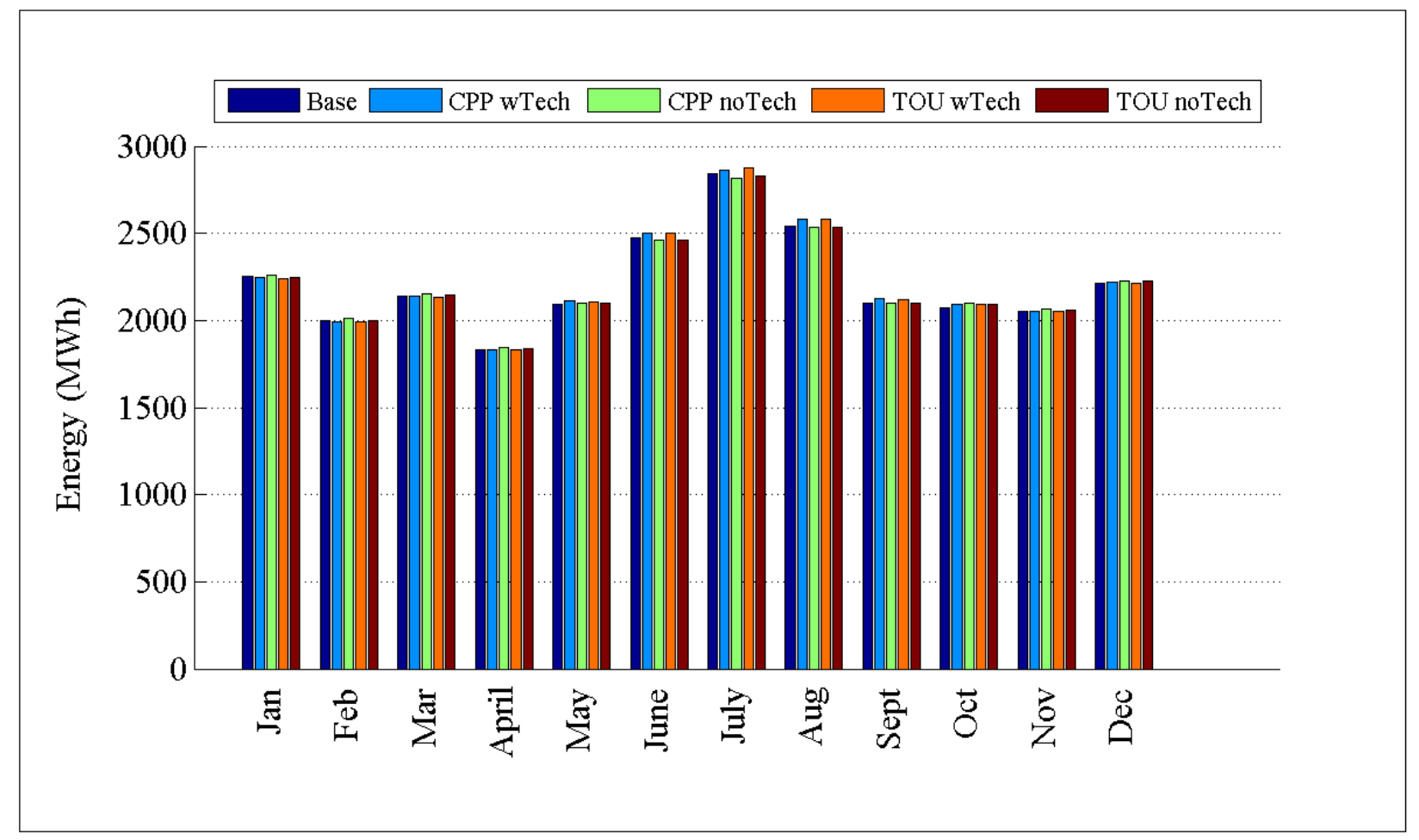

Figure D.38: Comparison of energy consumption by month for R2-12.47-3 


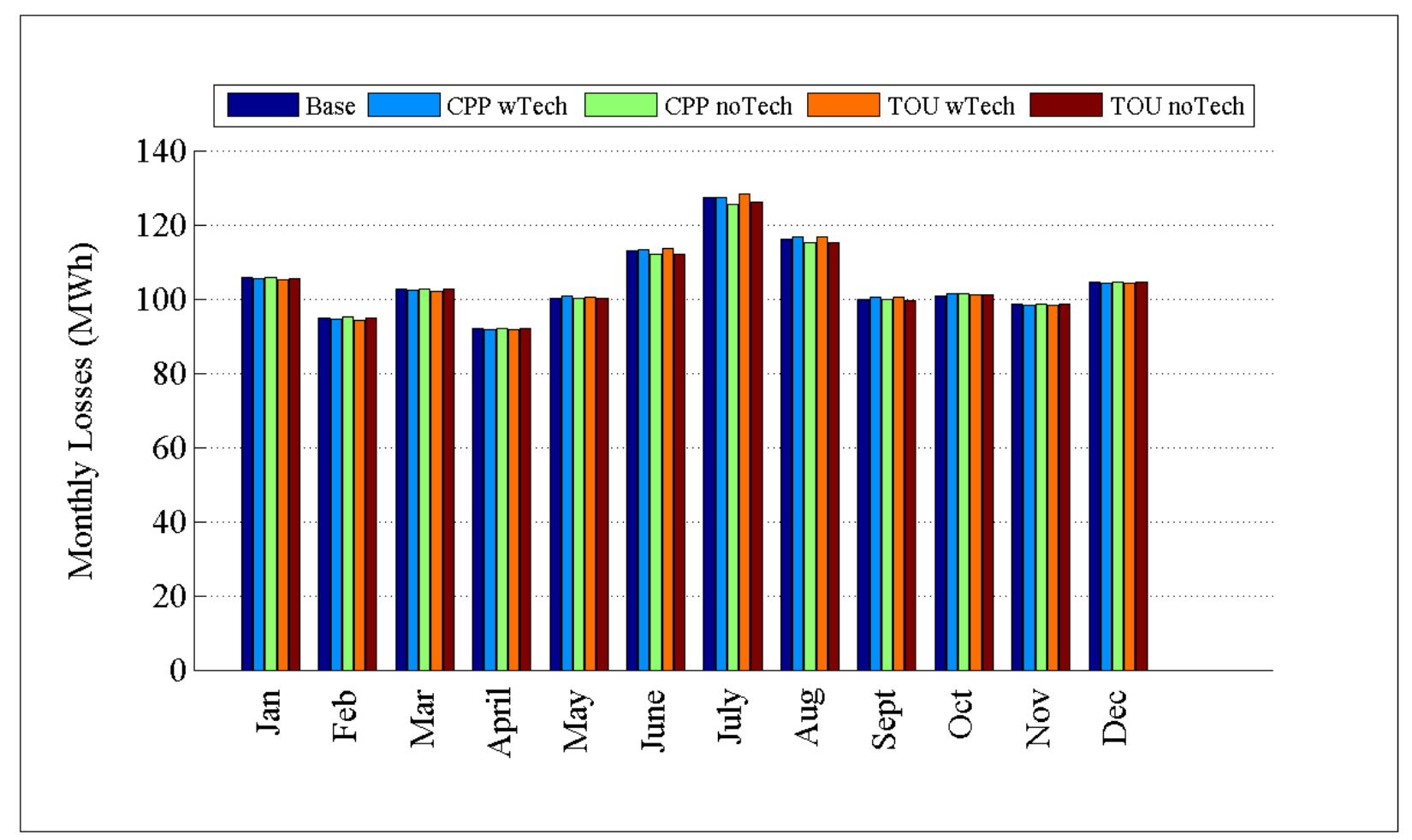

Figure D.39: Comparison of losses by month for R2-12.47-3

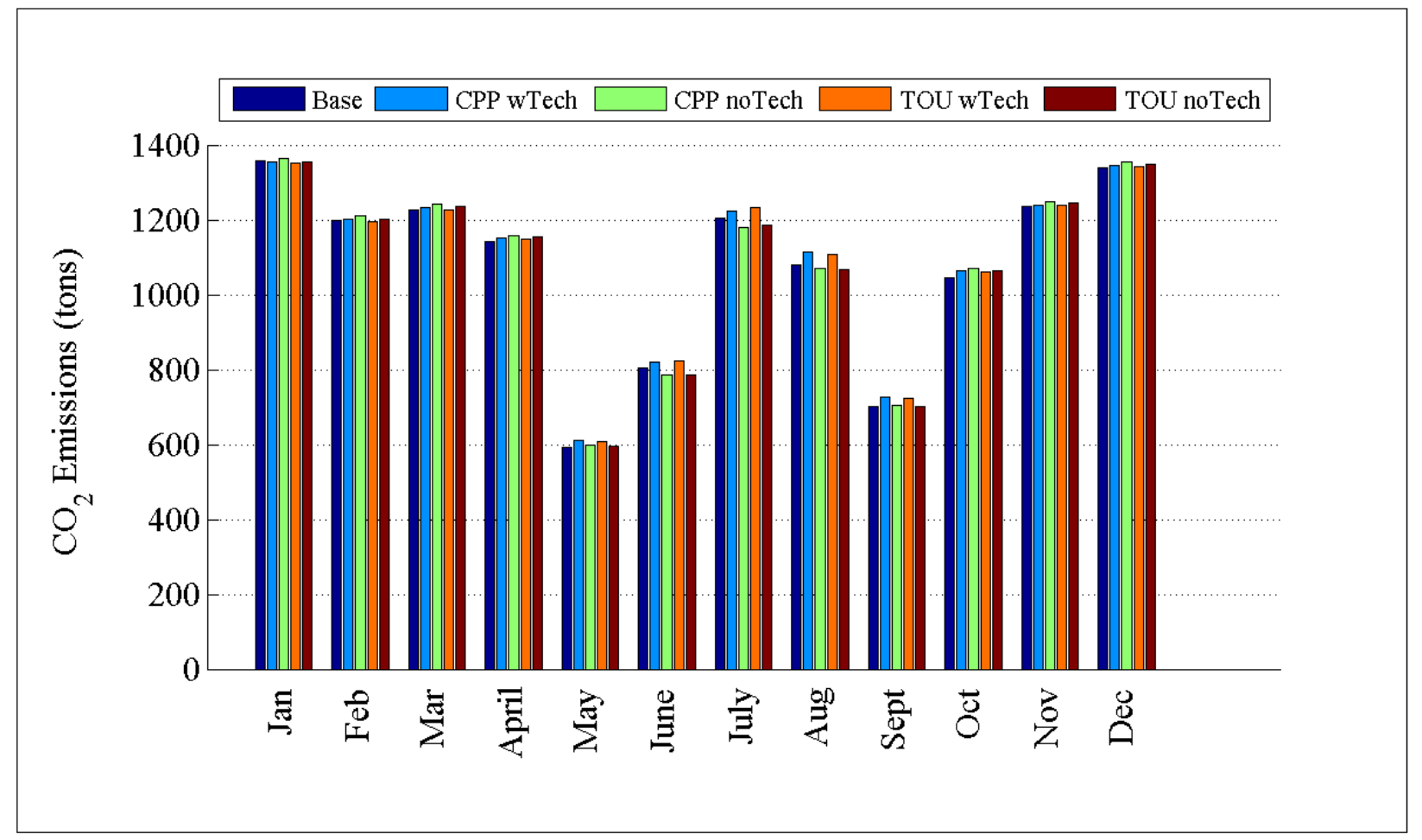

Figure D.40: Comparison of $\mathrm{CO}_{2}$ emissions by month for R2-12.47-3 


\section{D.1.11 Detailed TOU and CPP Plots for R2-25.00-1}

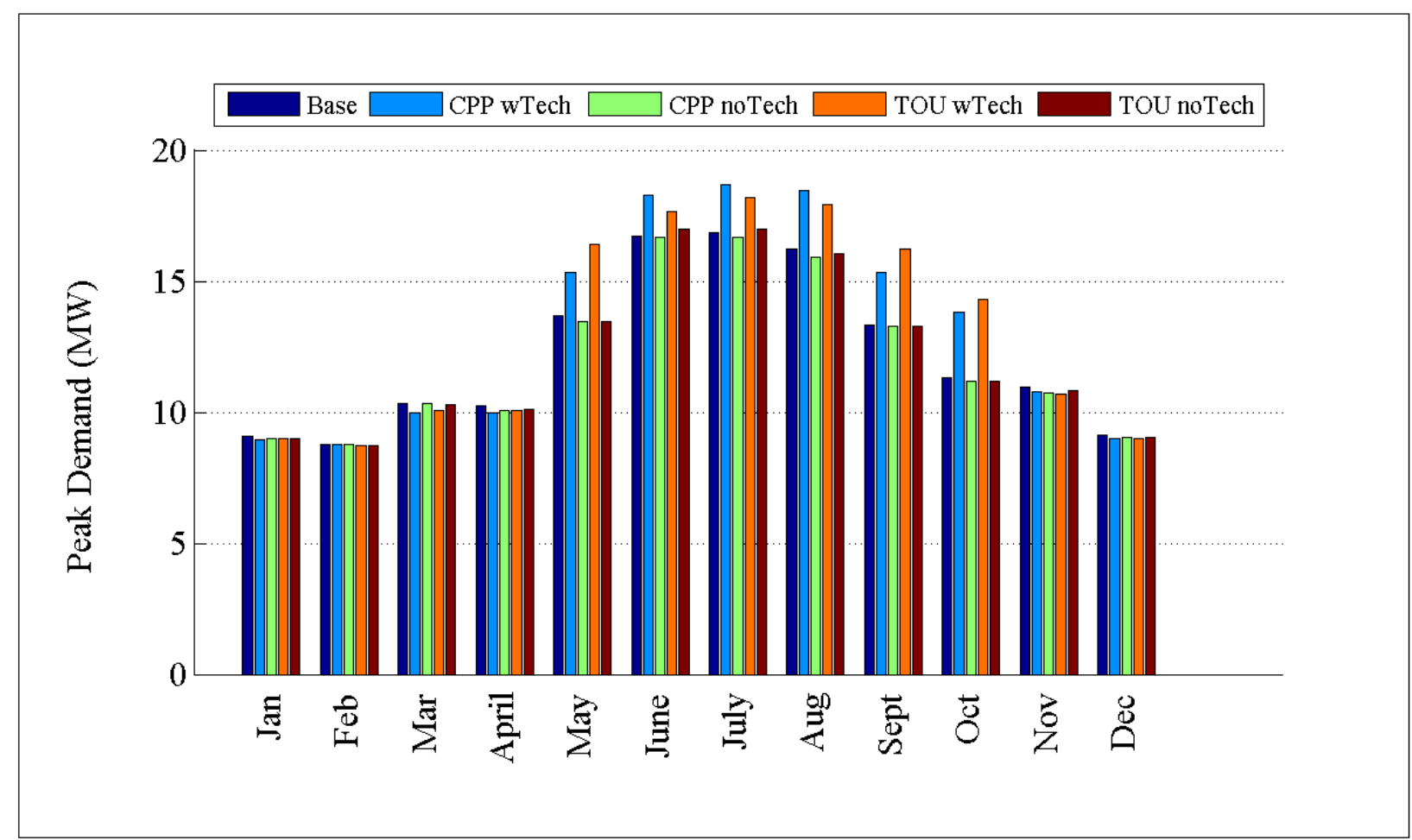

Figure D.41: Comparison of peak demand by month for R2-25.00-1 


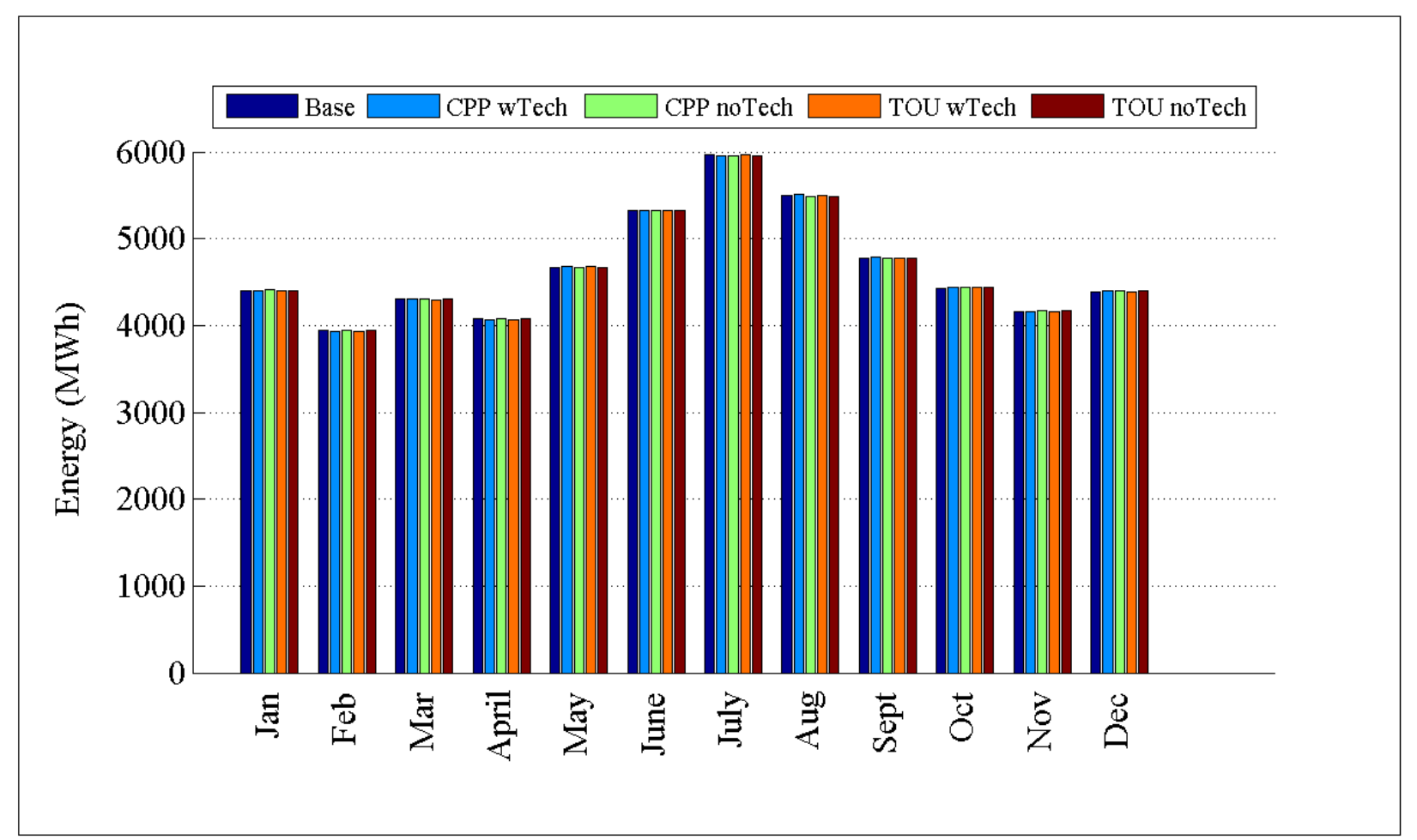

Figure D.42: Comparison of energy consumption by month for R2-25.00-1

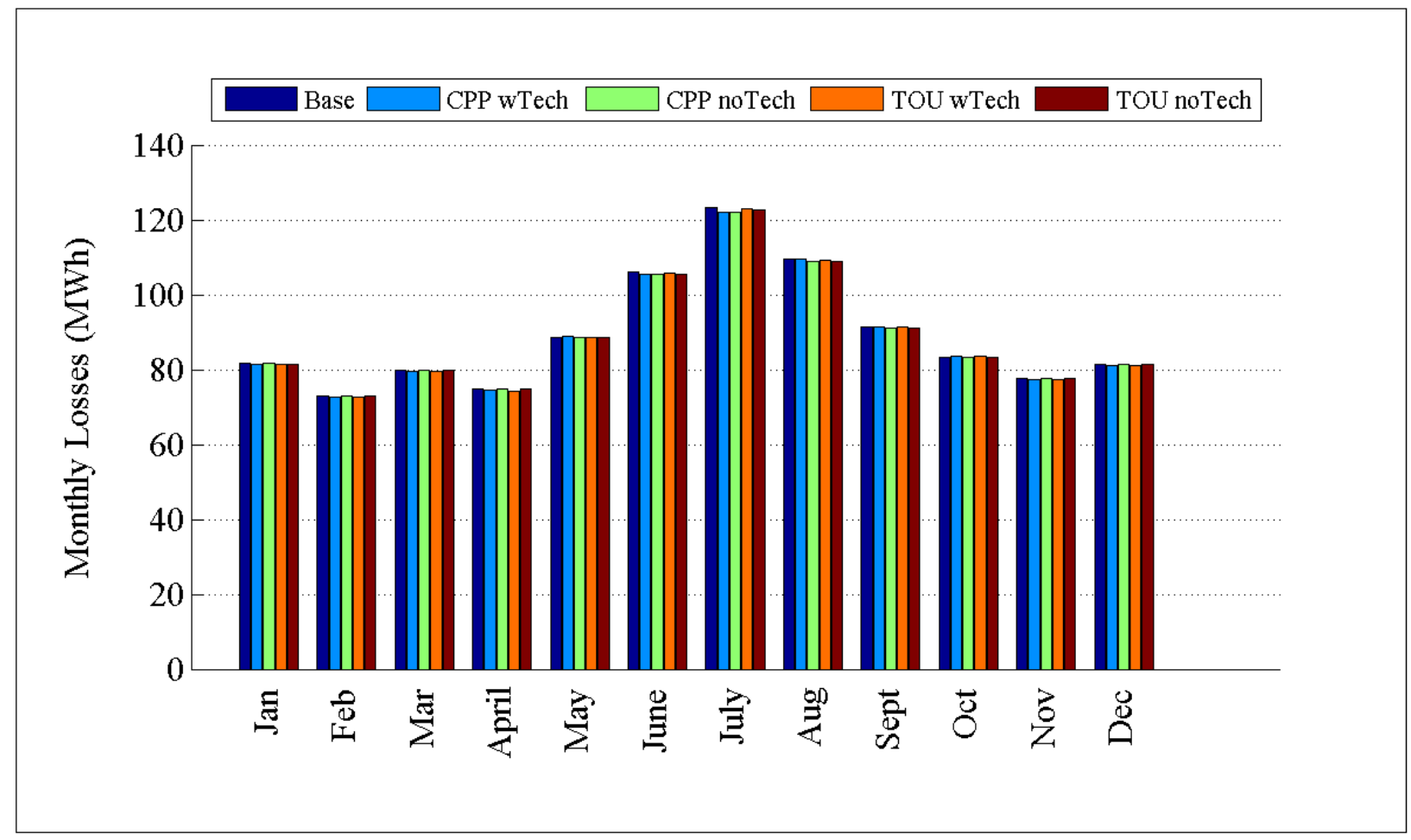

Figure D.43: Comparison of losses by month for R2-25.00-1 


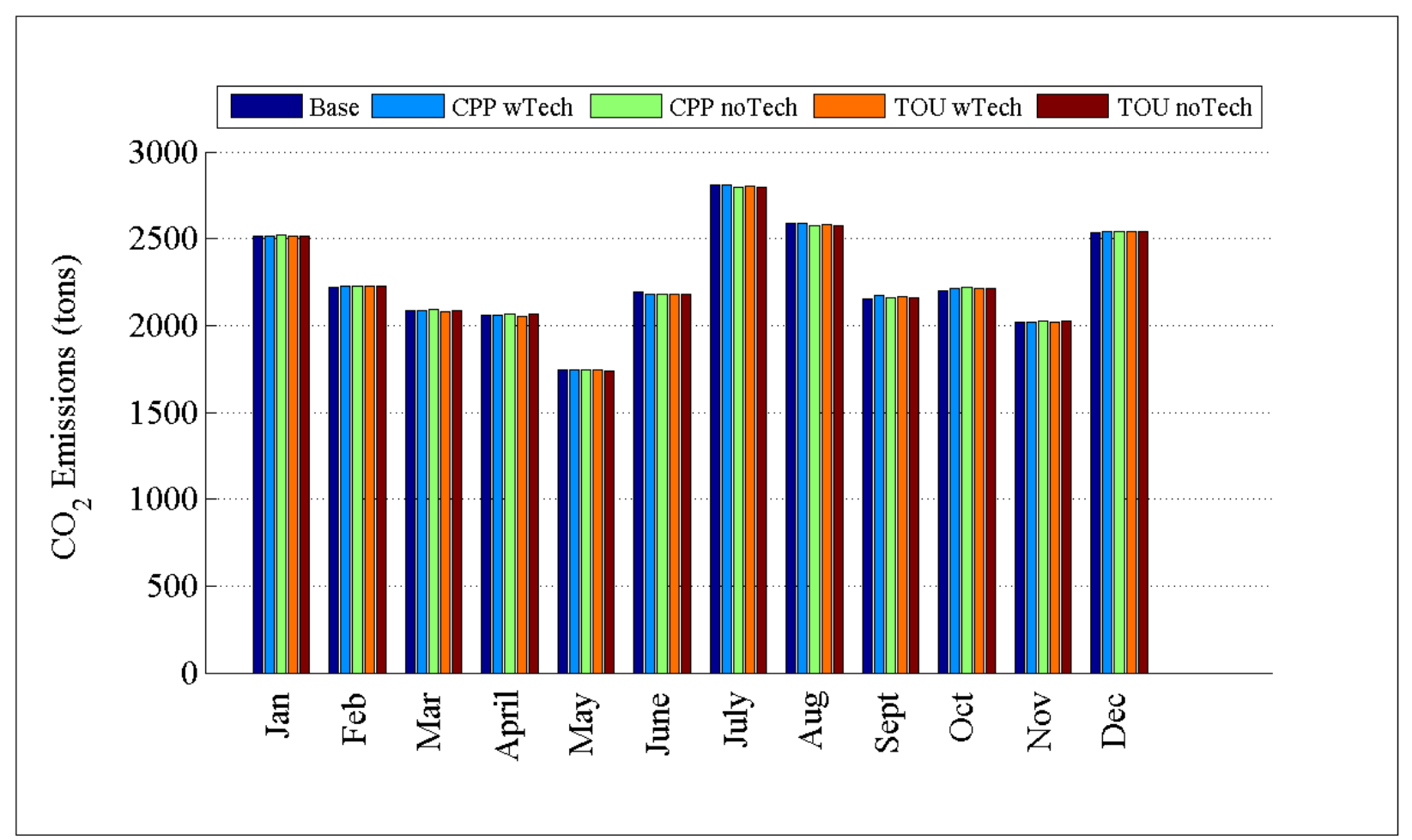

Figure D.44: Comparison of $\mathrm{CO}_{2}$ emissions by month for R2-25.00-1

D.1.12 Detailed TOU and CPP Plots for R2-35.00-1 


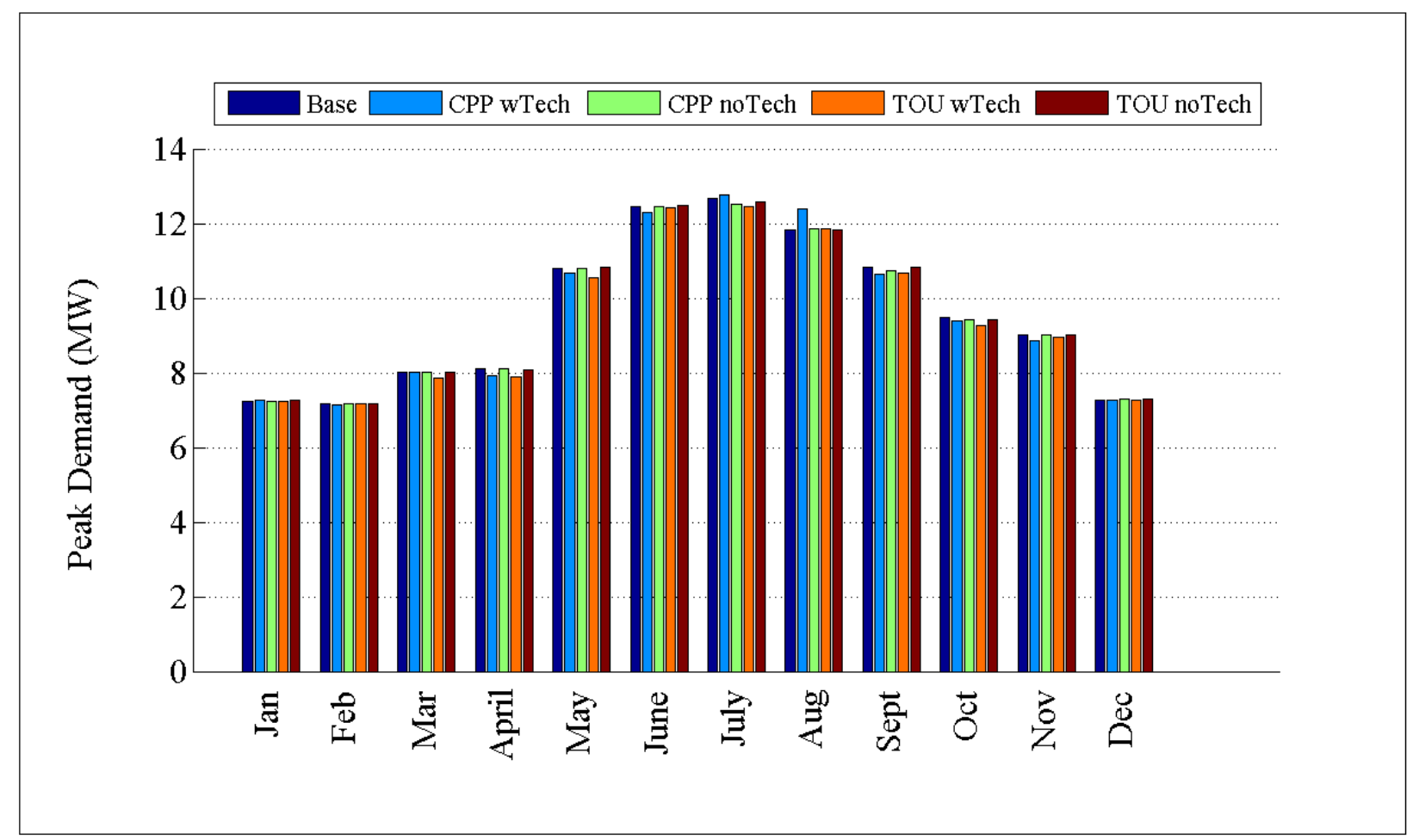

Figure D.45: Comparison of peak demand by month for R2-35.00-1

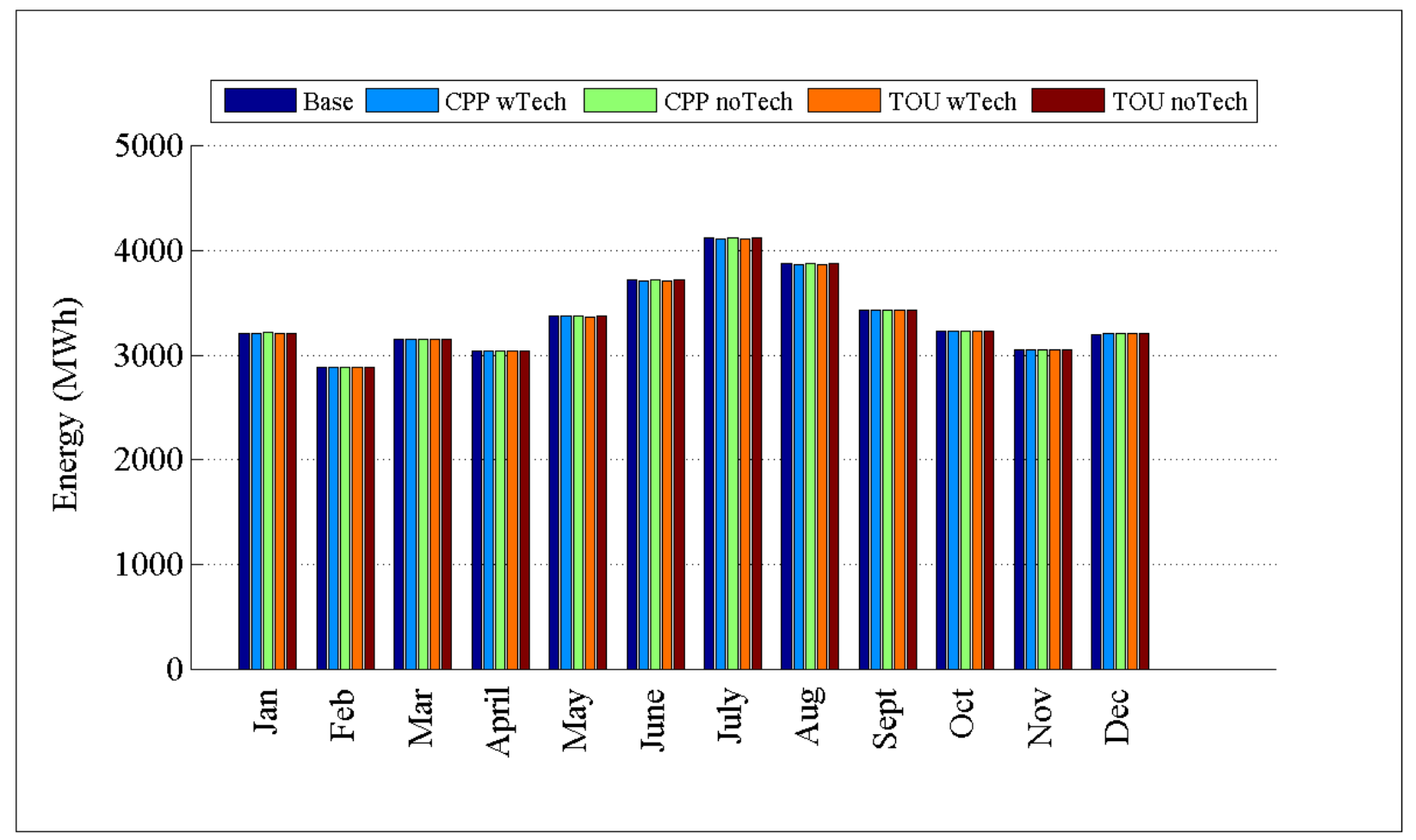

Figure D.46: Comparison of energy consumption by month for R2-35.00-1 


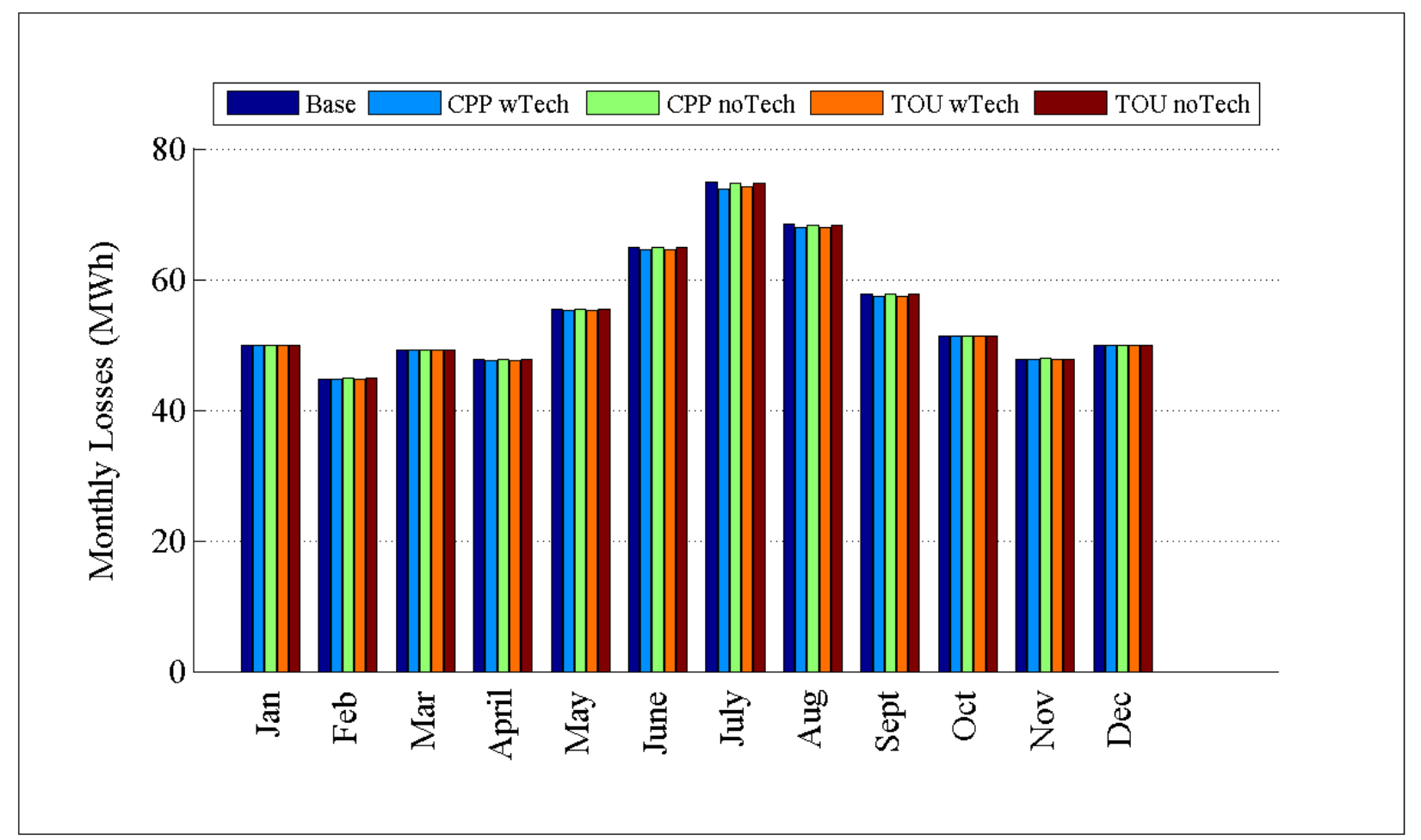

Figure D.47: Comparison of losses by month for R2-35.00-1

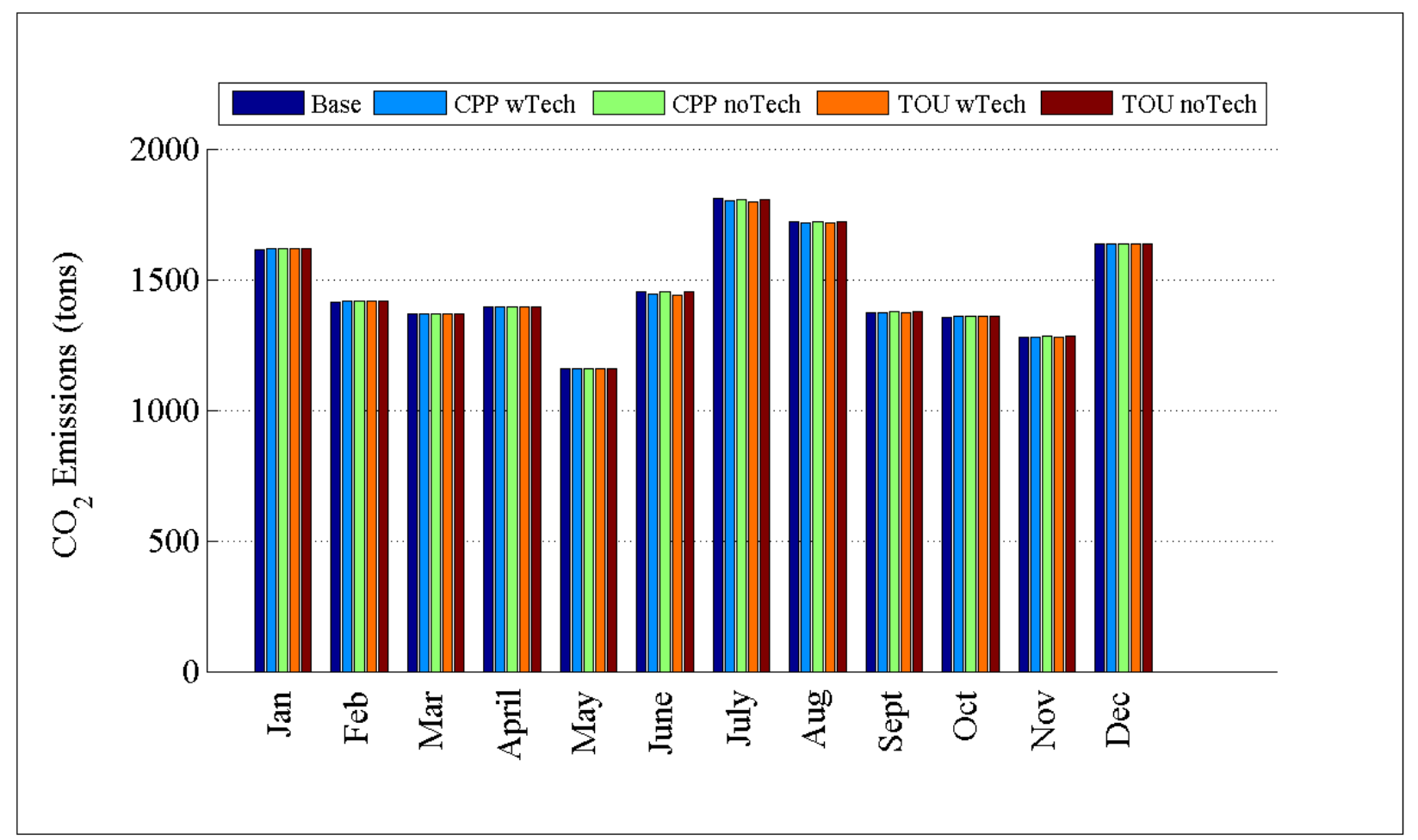

Figure D.48: Comparison of $\mathrm{CO}_{2}$ emissions by month for R2-35.00-1 
D.1.13 Detailed TOU and CPP Plots for GC-12.47-1_R3

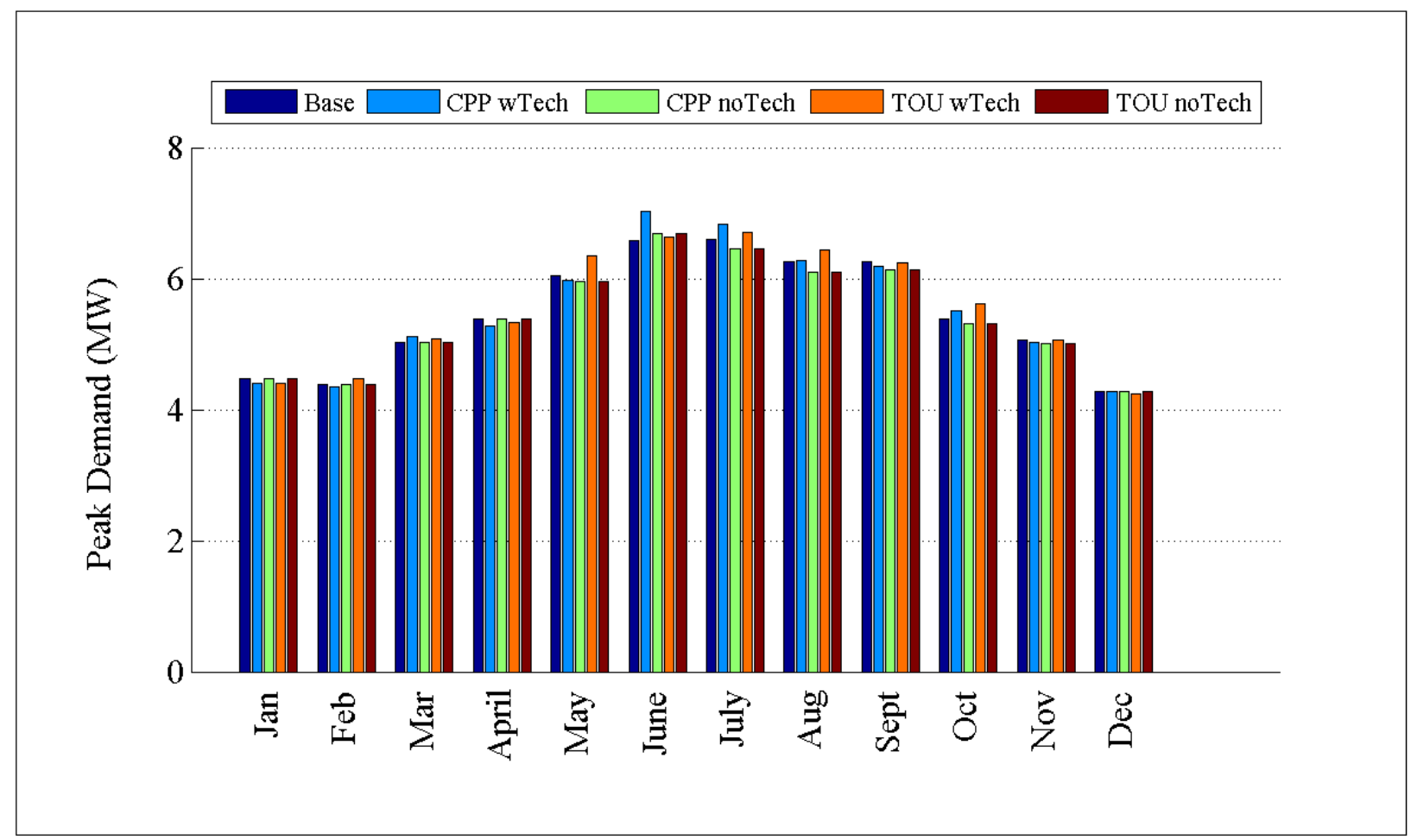

Figure D.49: Comparison of peak demand by month for GC-12.47-1_R3 


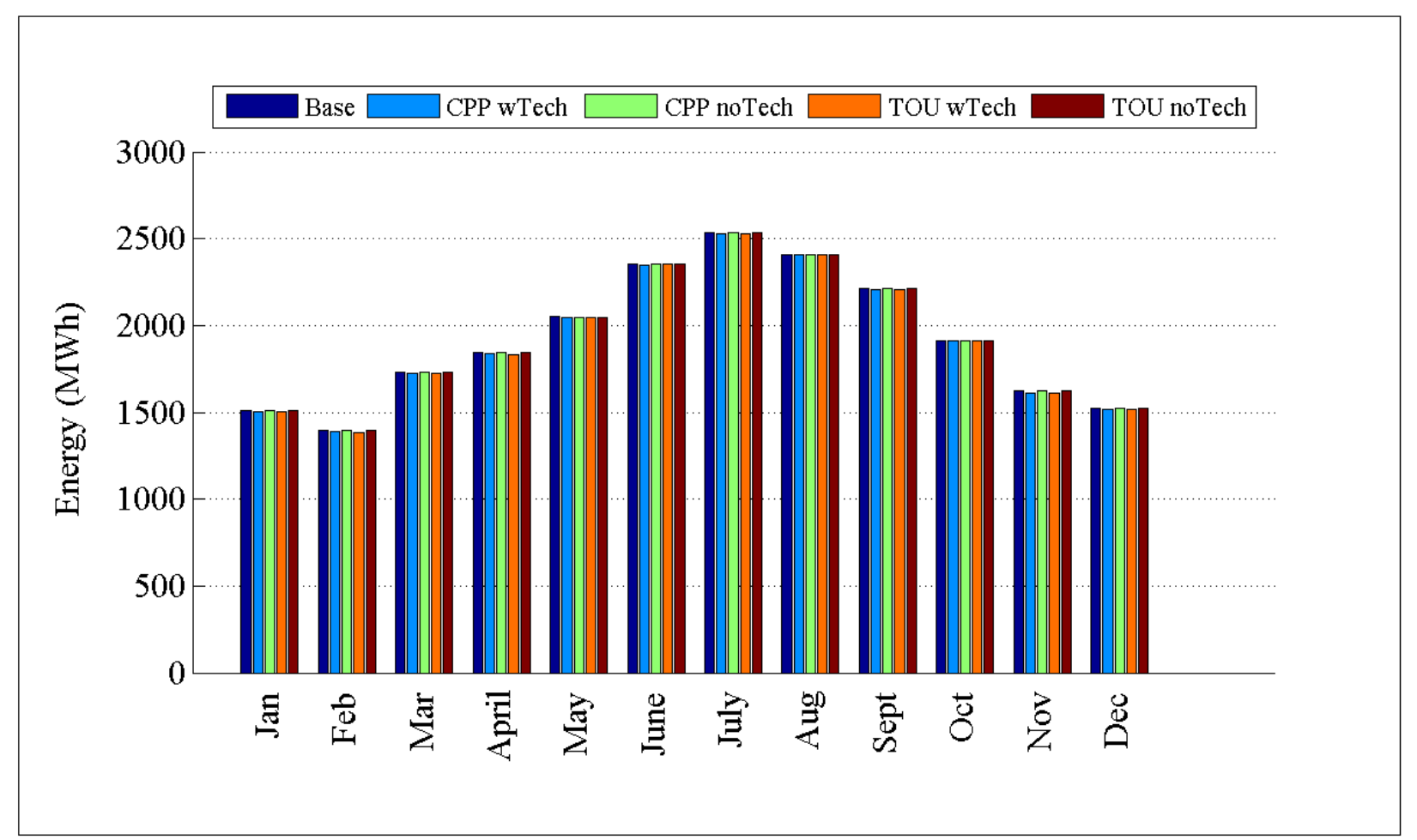

Figure D.50: Comparison of energy consumption by month for GC-12.47-1_R3

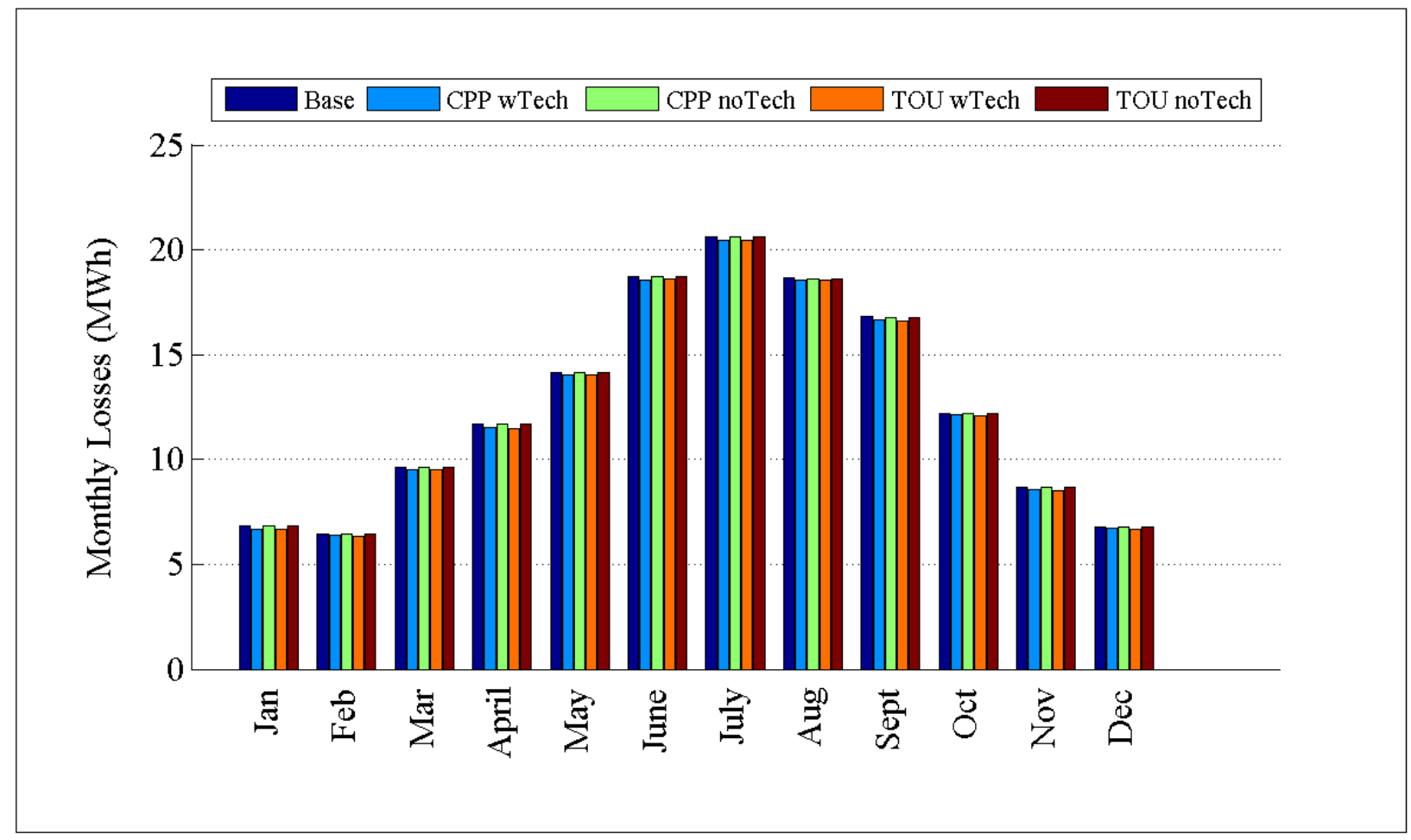

Figure D.51: Comparison of losses by month for GC-12.47-1_R3 


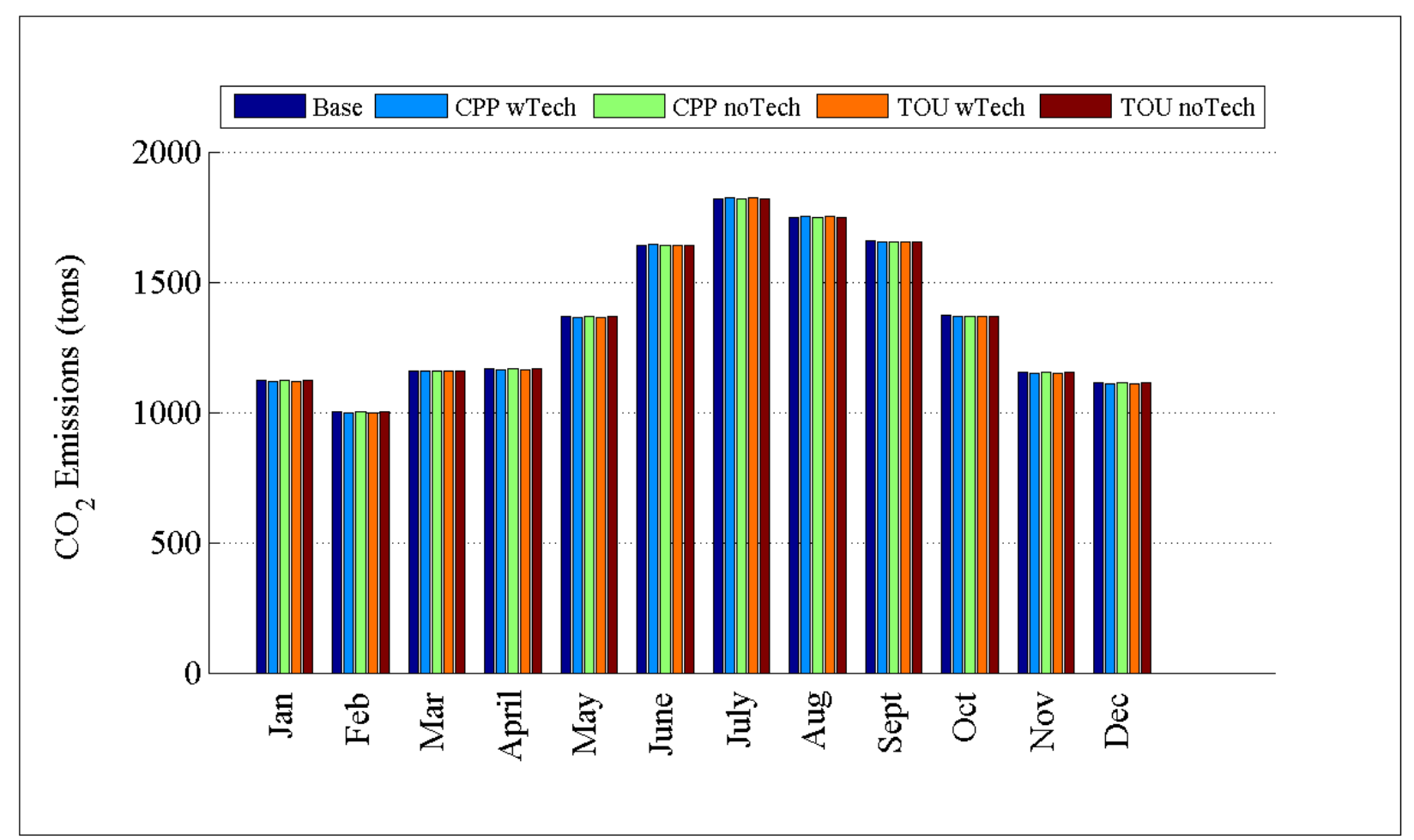

Figure D.52: Comparison of $\mathrm{CO}_{2}$ emissions by month for GC-12.47-1_R3

D.1.14 Detailed TOU and CPP Plots for R3-12.47-1 


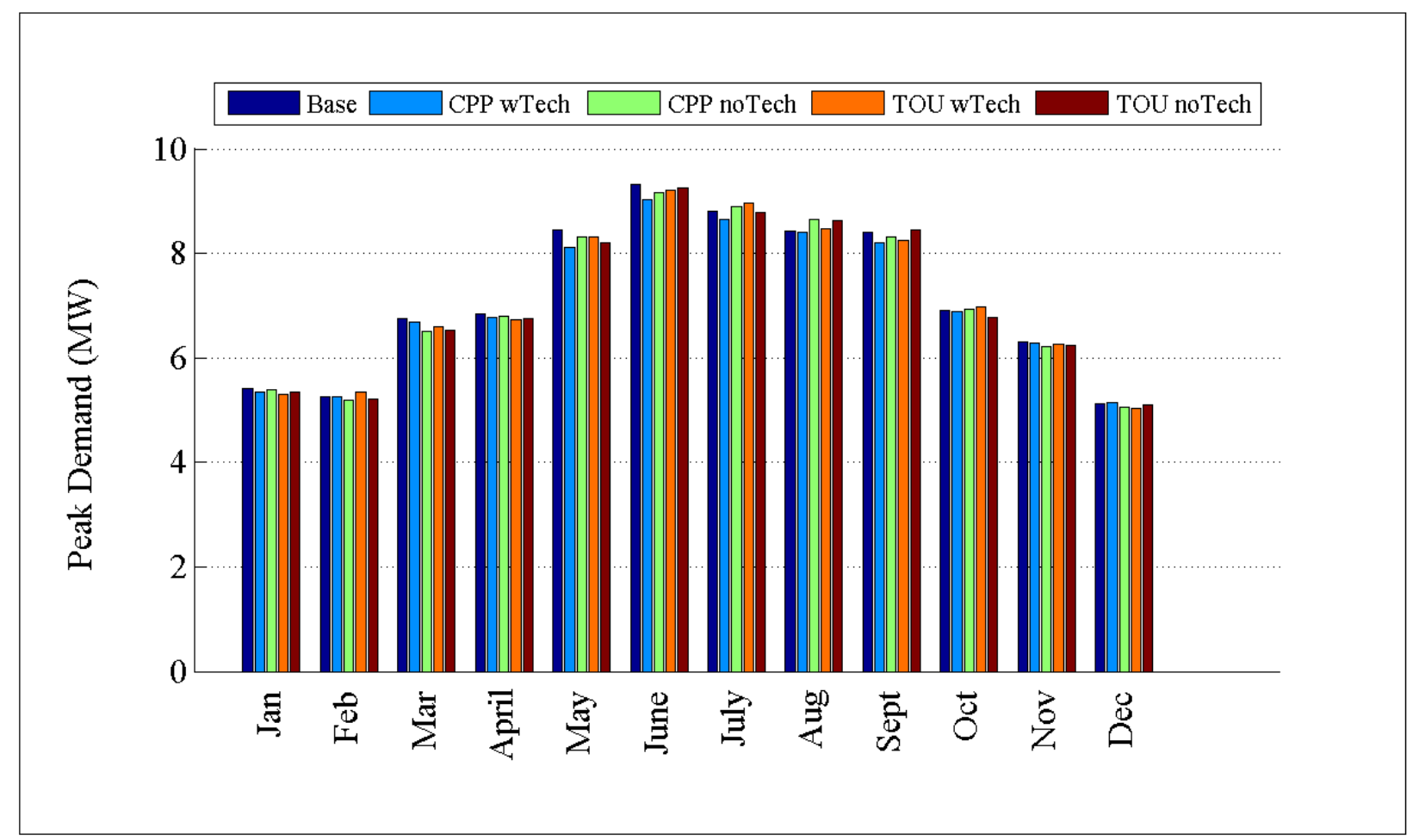

Figure D.53: Comparison of peak demand by month for R3-12.47-1

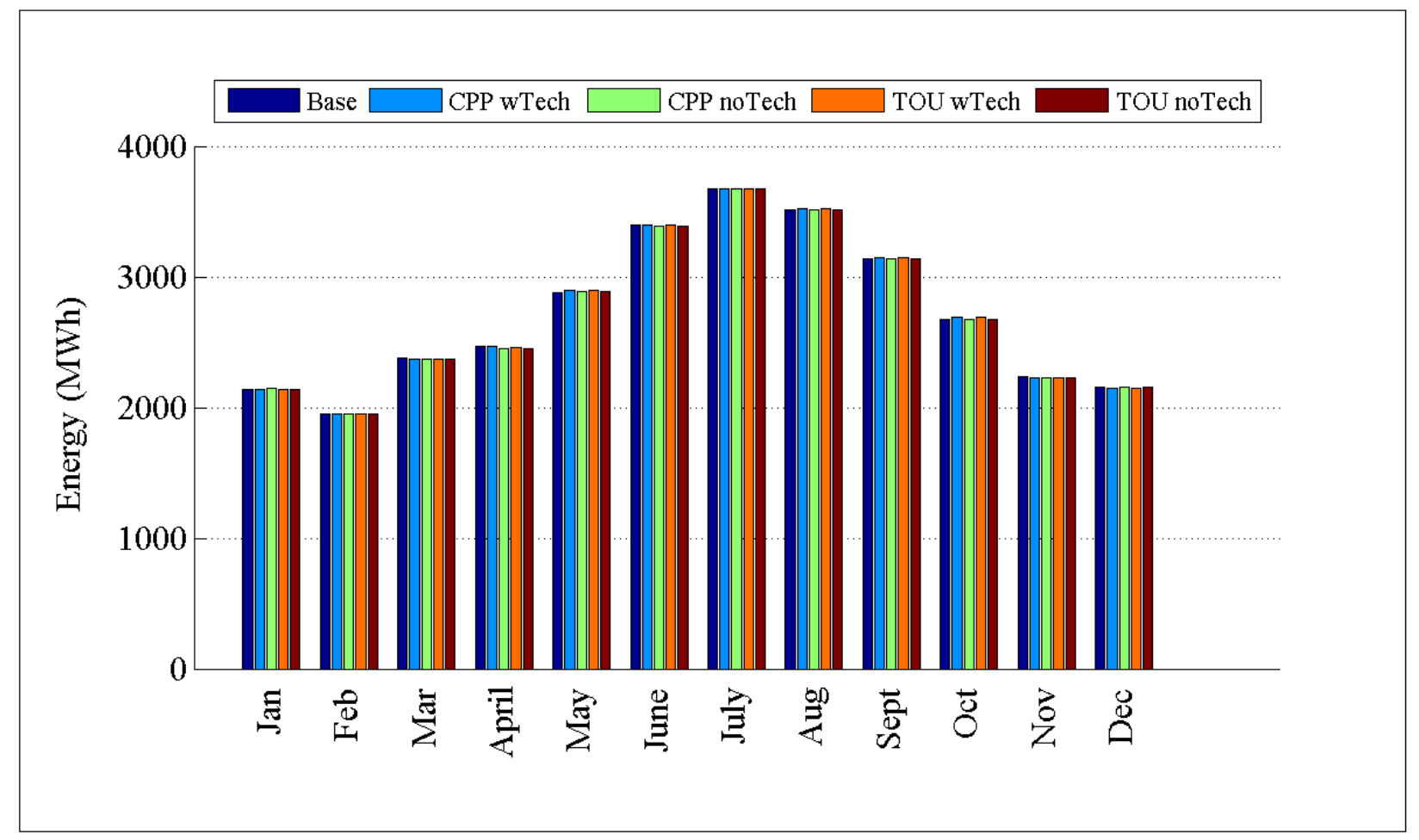

Figure D.54: Comparison of energy consumption by month for R3-12.47-1 


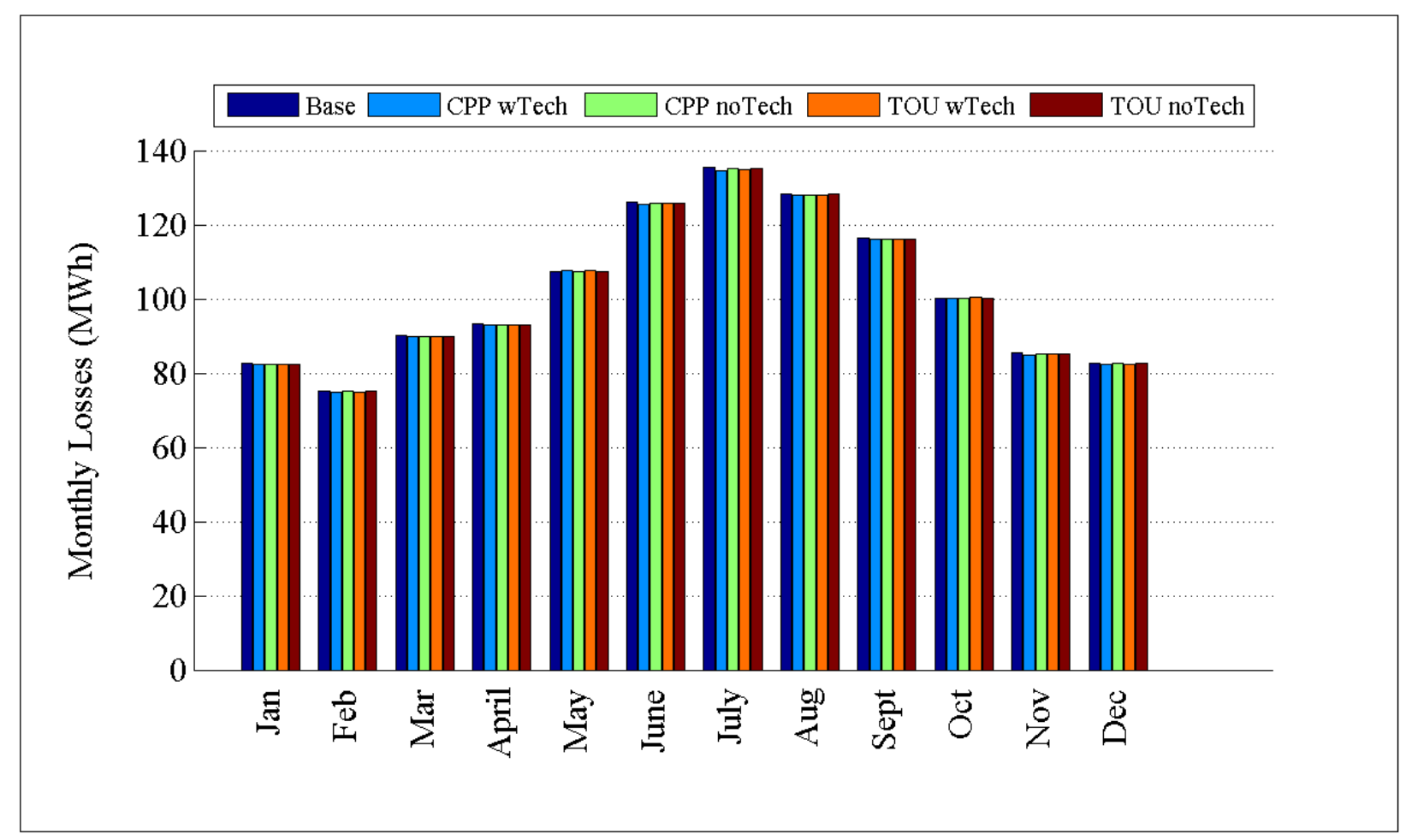

Figure D.55: Comparison of losses by month for R3-12.47-1

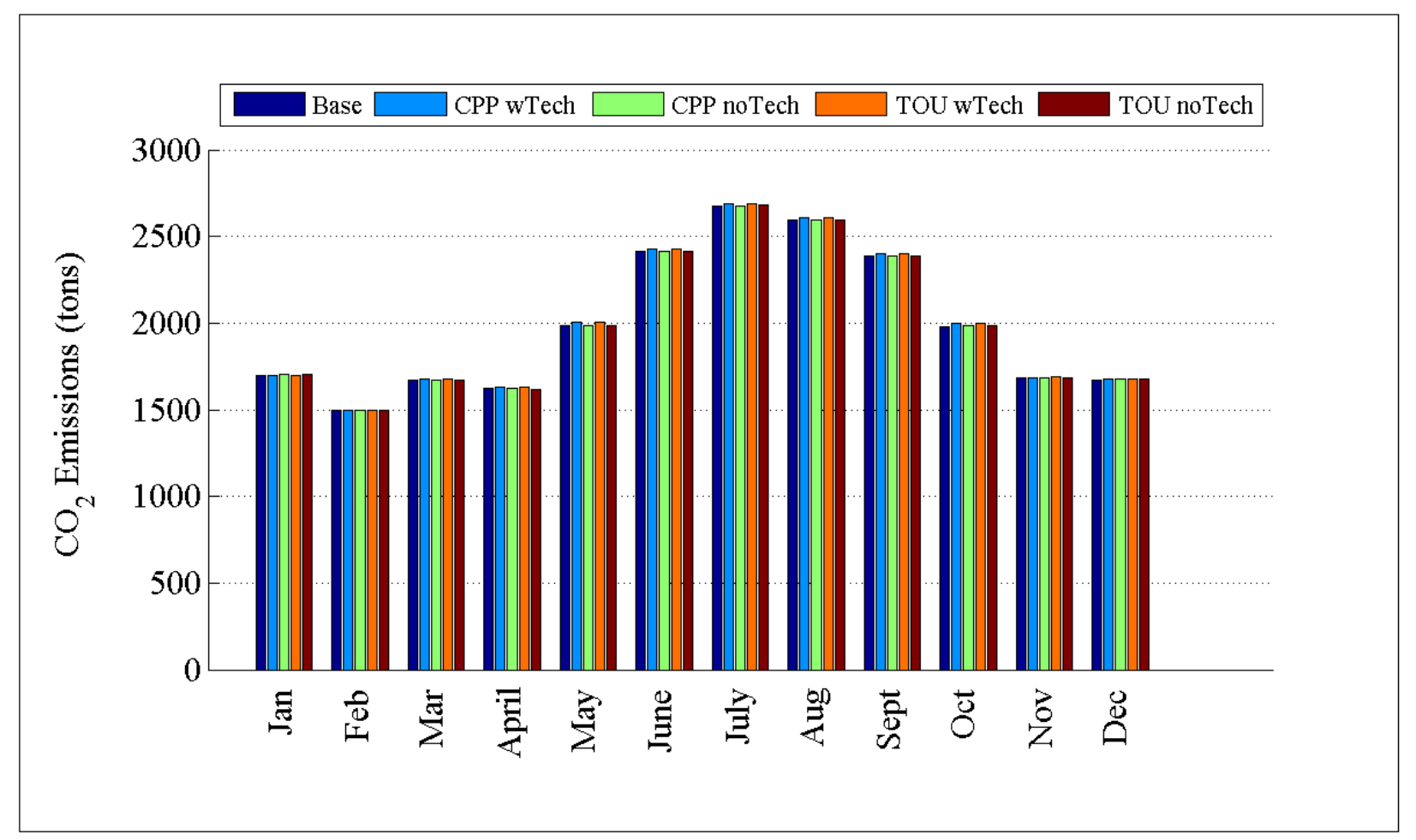

Figure D.56: Comparison of $\mathrm{CO}_{2}$ emissions by month for R3-12.47-1 
D.1.15 Detailed TOU and CPP Plots for R3-12.47-2

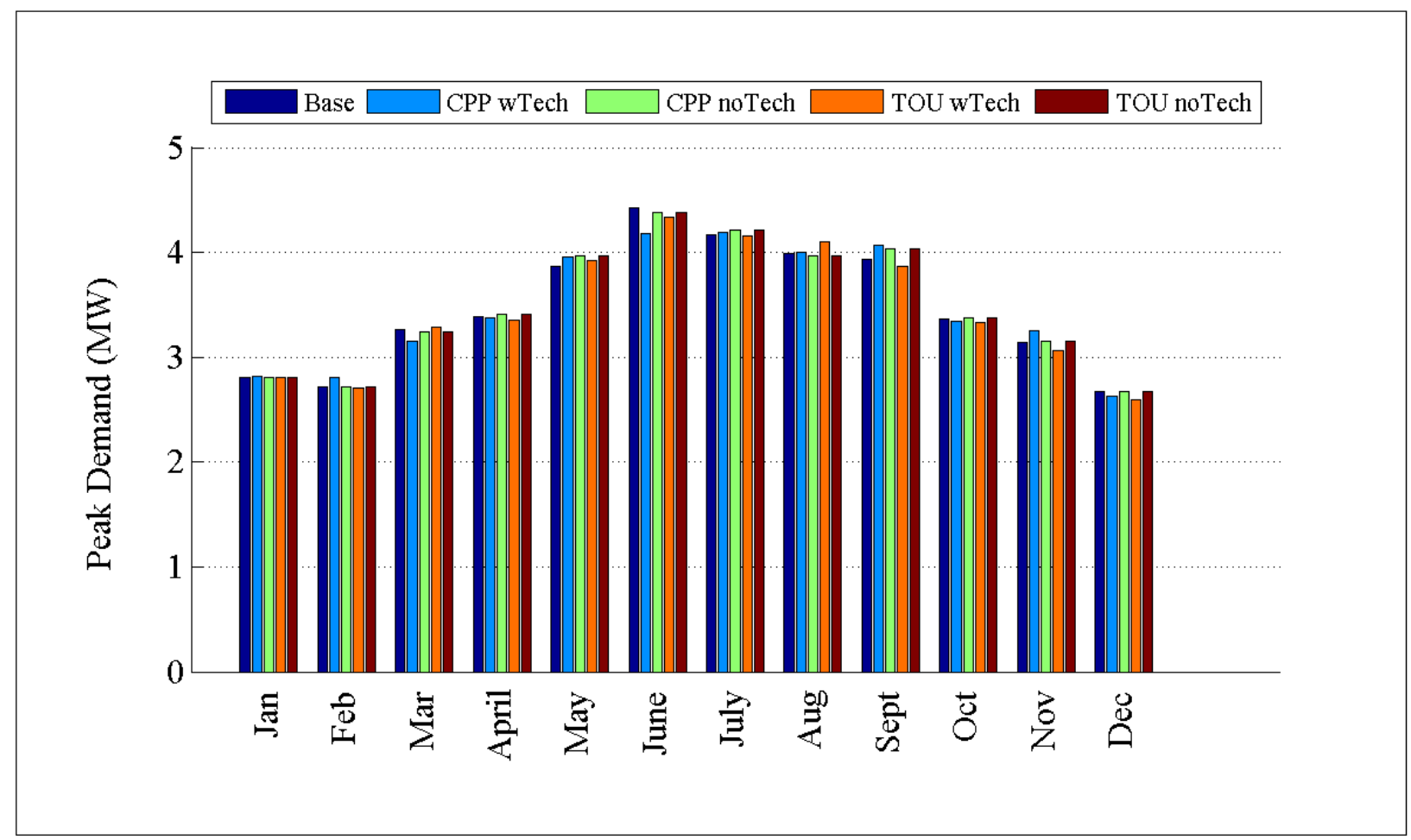

Figure D.57: Comparison of peak demand by month for R3-12.47-2 


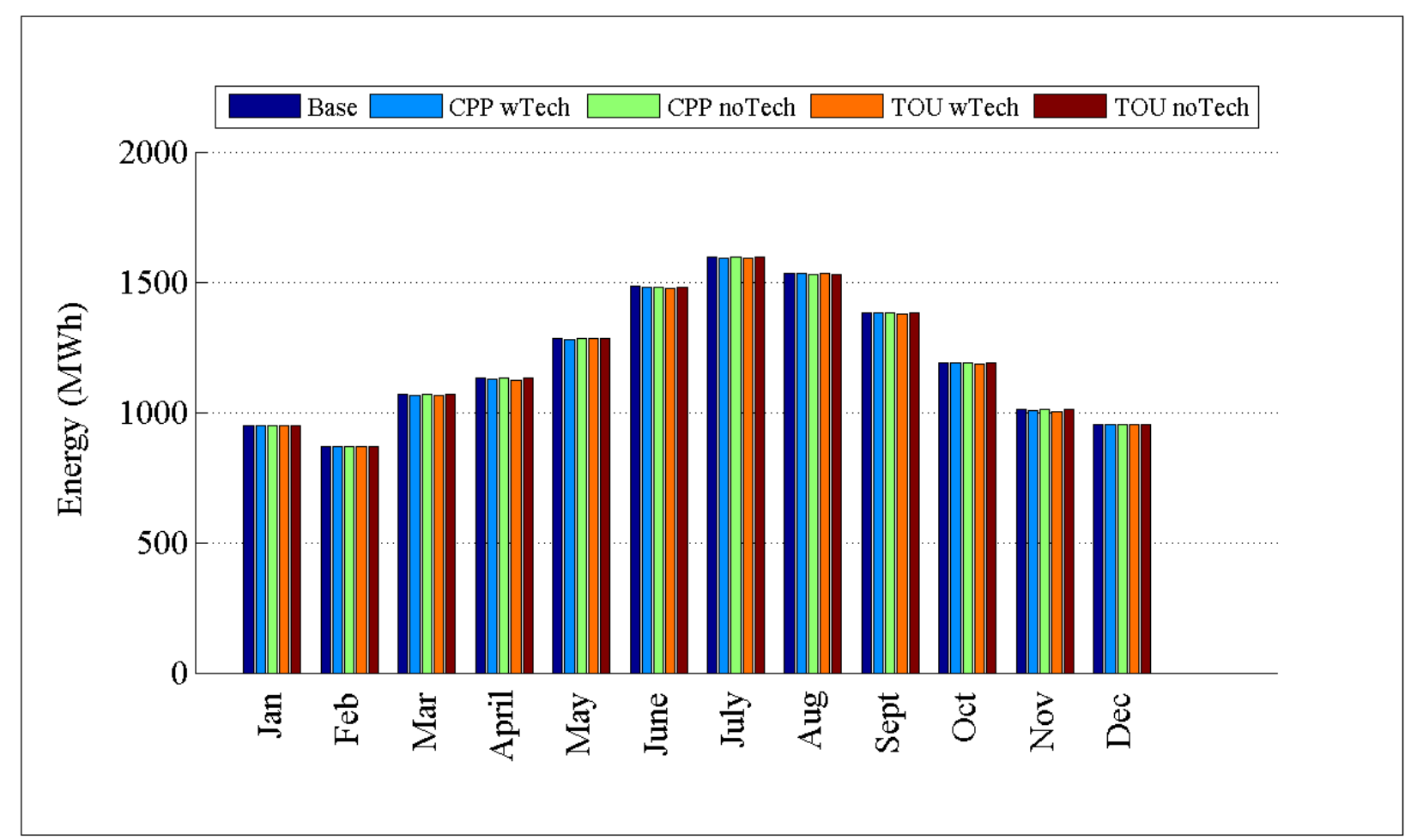

Figure D.58: Comparison of energy consumption by month for R3-12.47-2

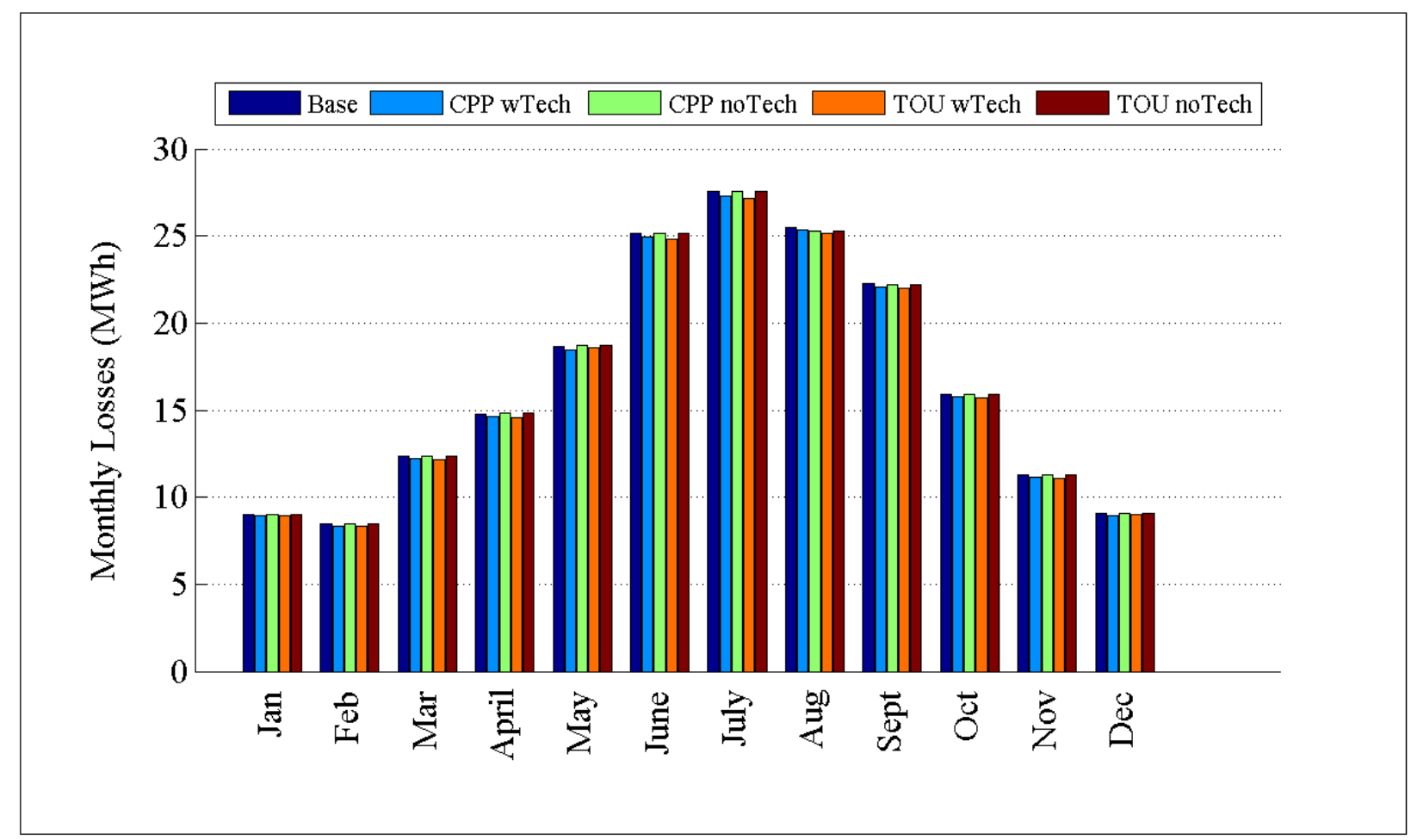

Figure D.59: Comparison of losses by month for R3-12.47-2 


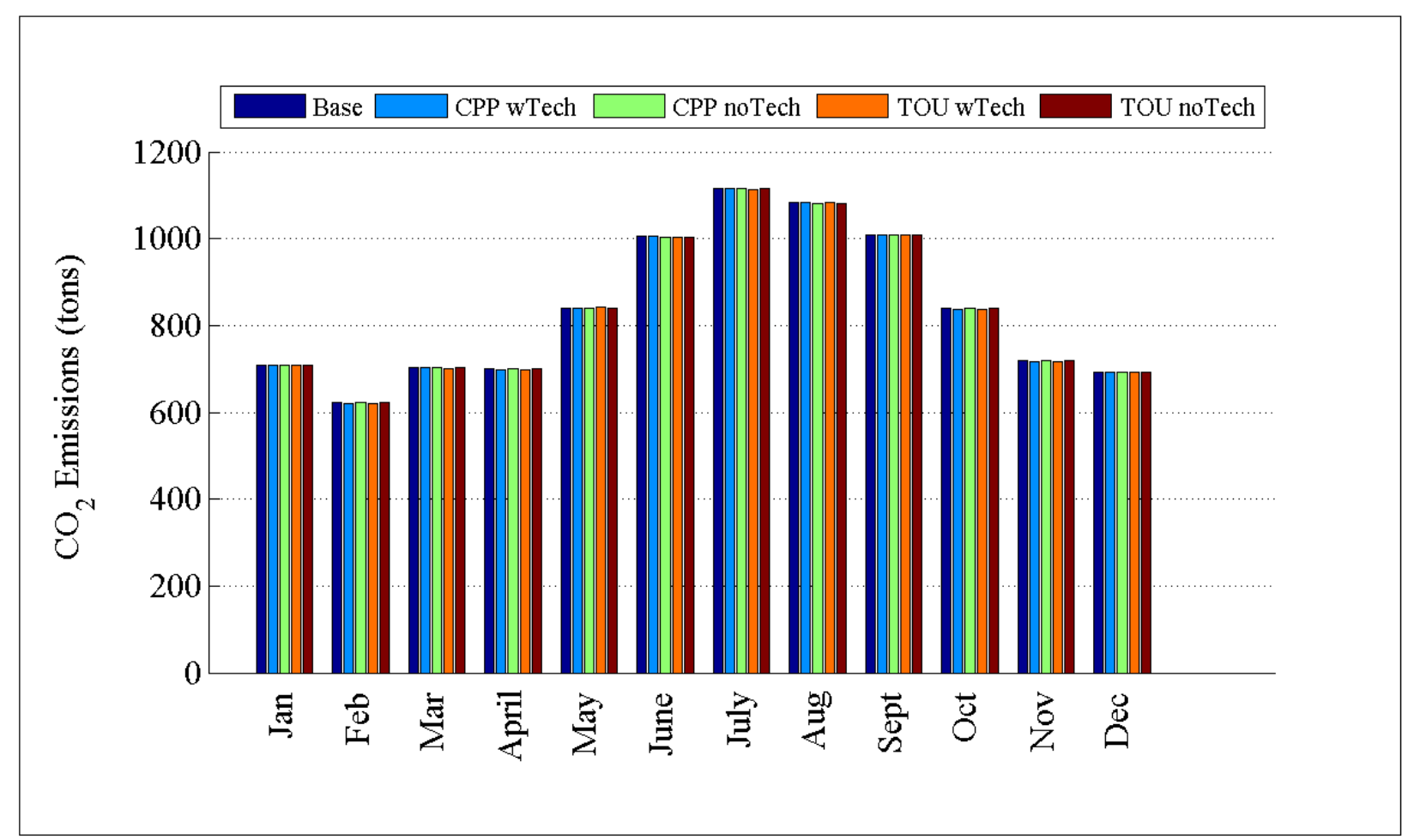

Figure D.60: Comparison of $\mathrm{CO}_{2}$ emissions by month for R3-12.47-2

D.1.16 Detailed TOU and CPP Plots for R3-12.47-3 


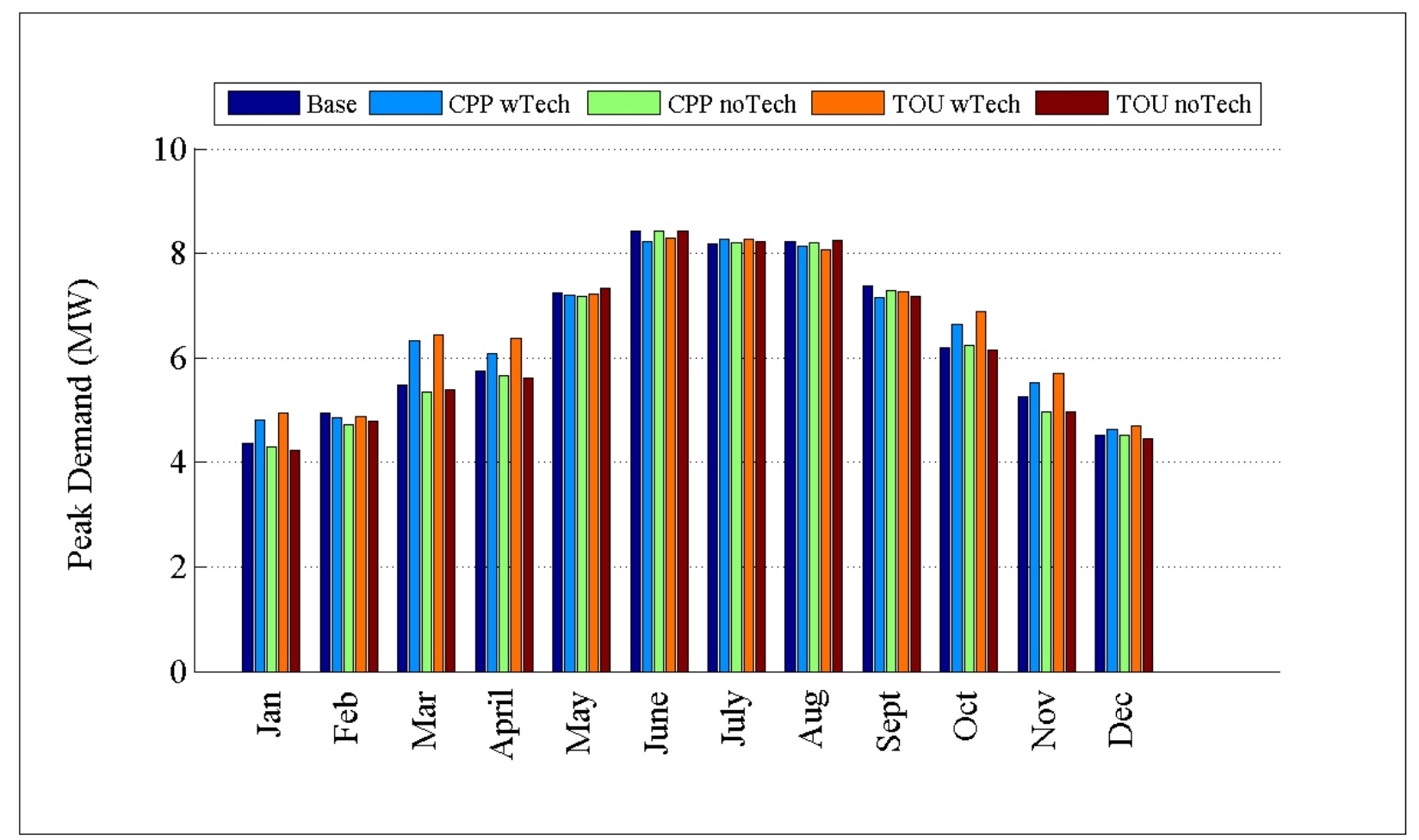

Figure D.61: Comparison of peak demand by month for R3-12.47-3

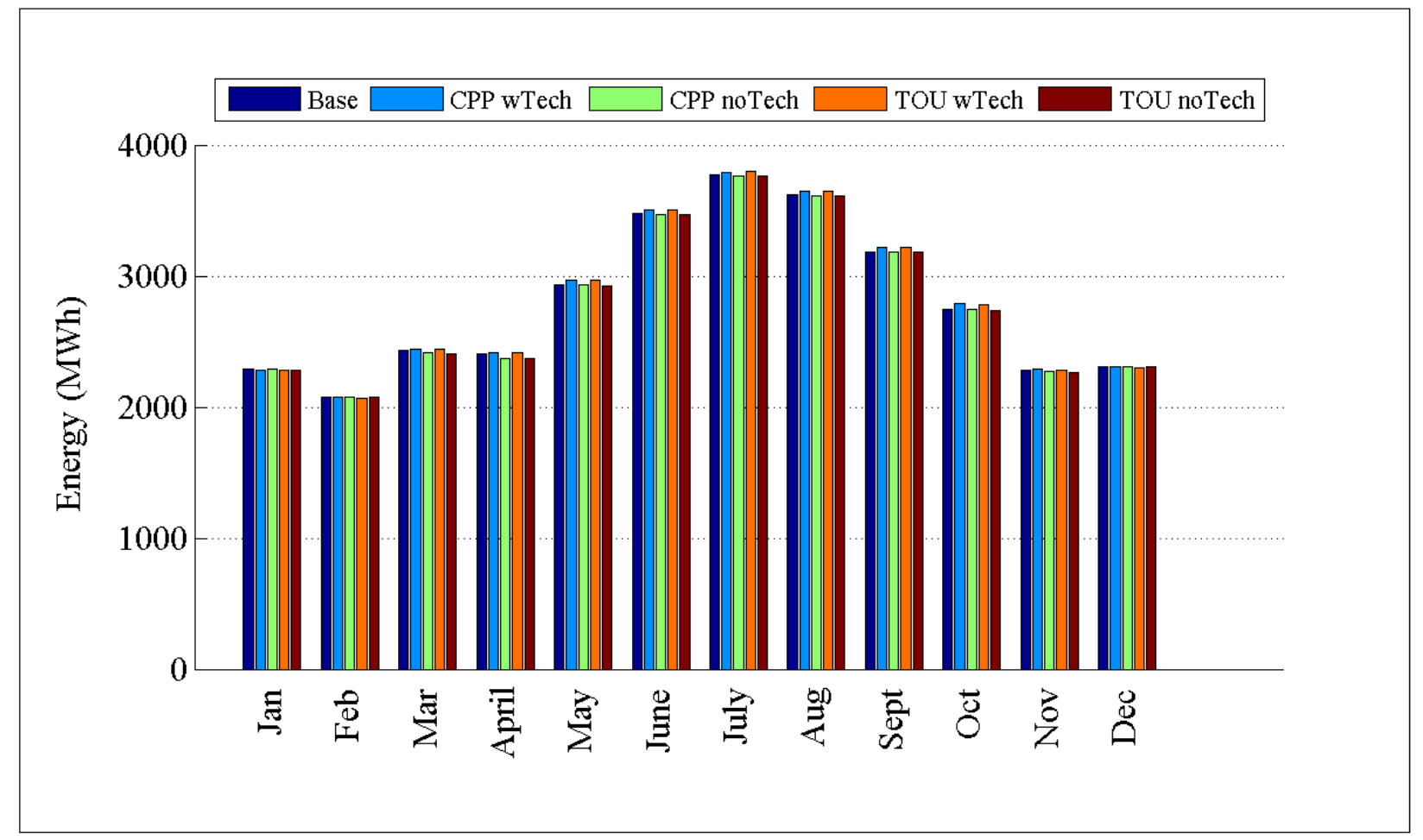

Figure D.62: Comparison of energy consumption by month for R3-12.47-3 


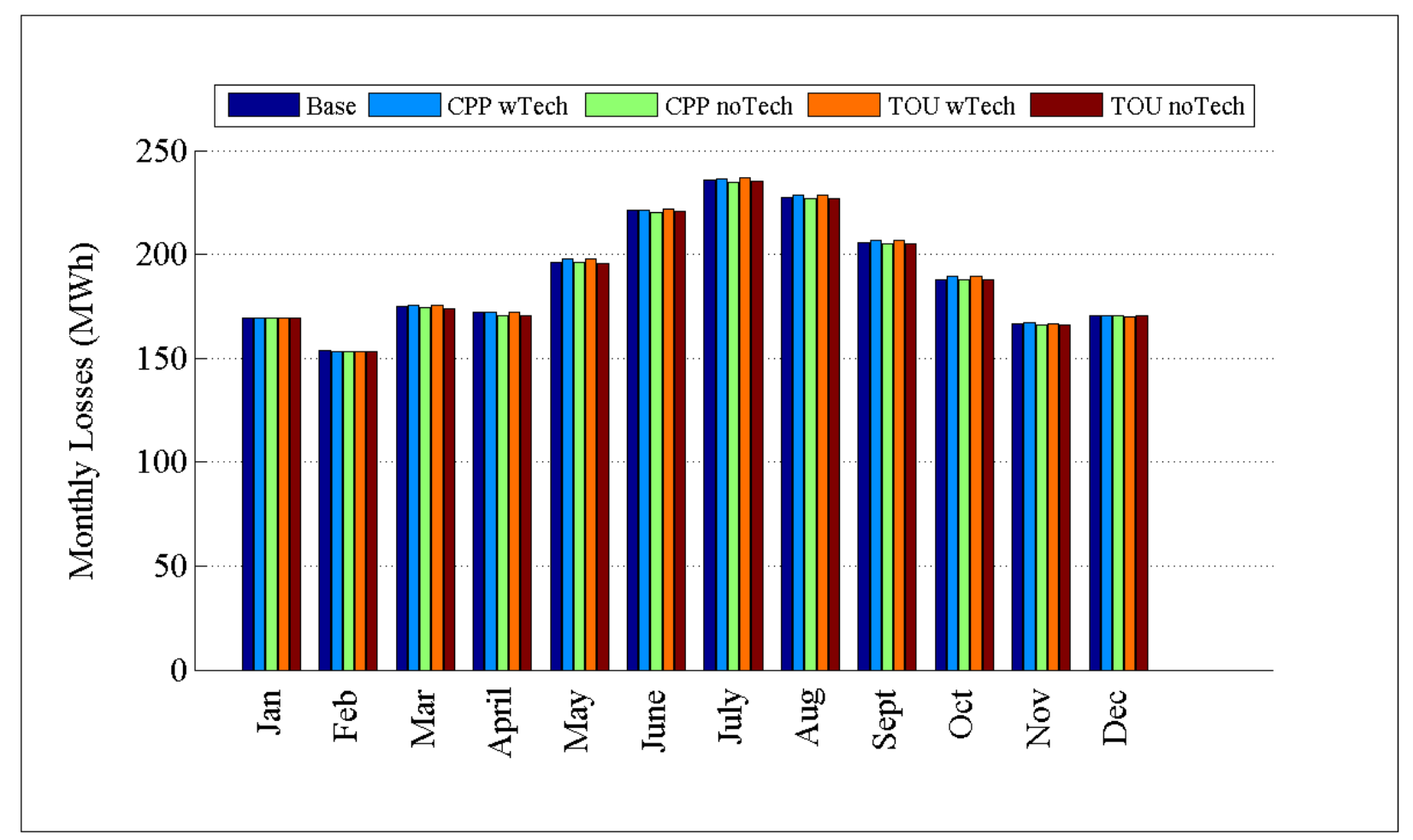

Figure D.63: Comparison of losses by month for R3-12.47-3

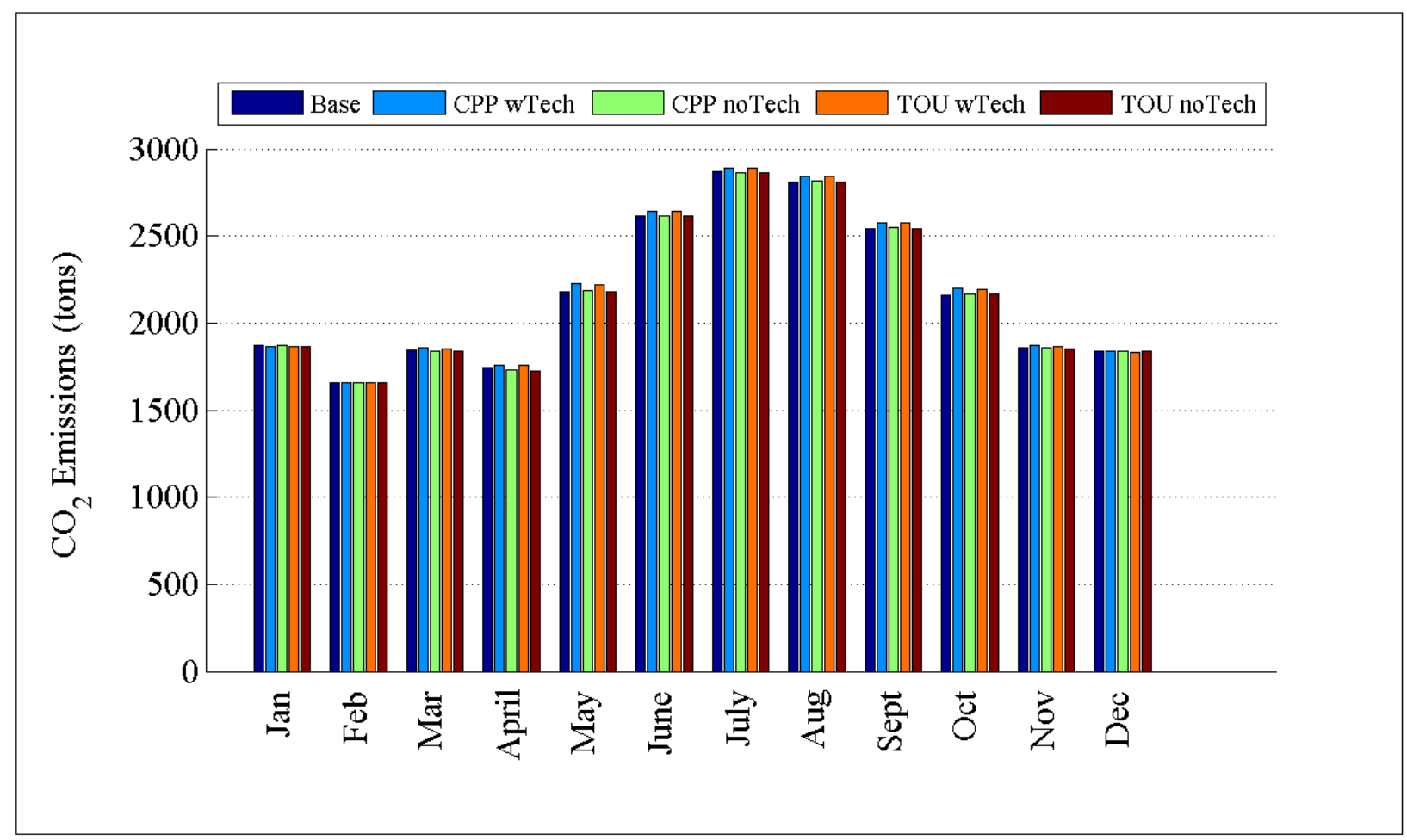

Figure D.64: Comparison of $\mathrm{CO}_{2}$ emissions by month for R3-12.47-3 
D.1.17 Detailed TOU and CPP Plots for GC-12.47-1_R4

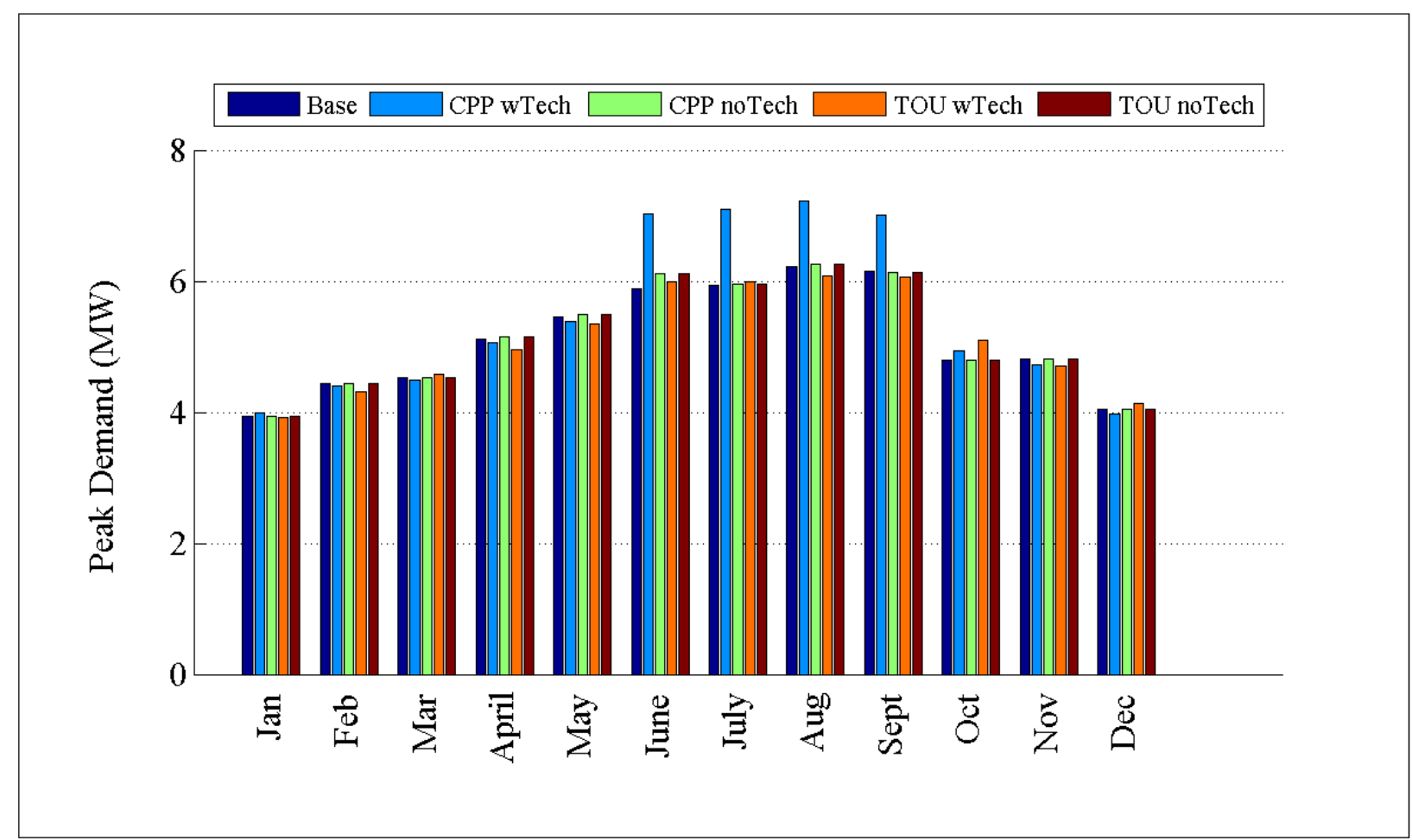

Figure D.65: Comparison of peak demand by month for GC-12.47-1_R4 


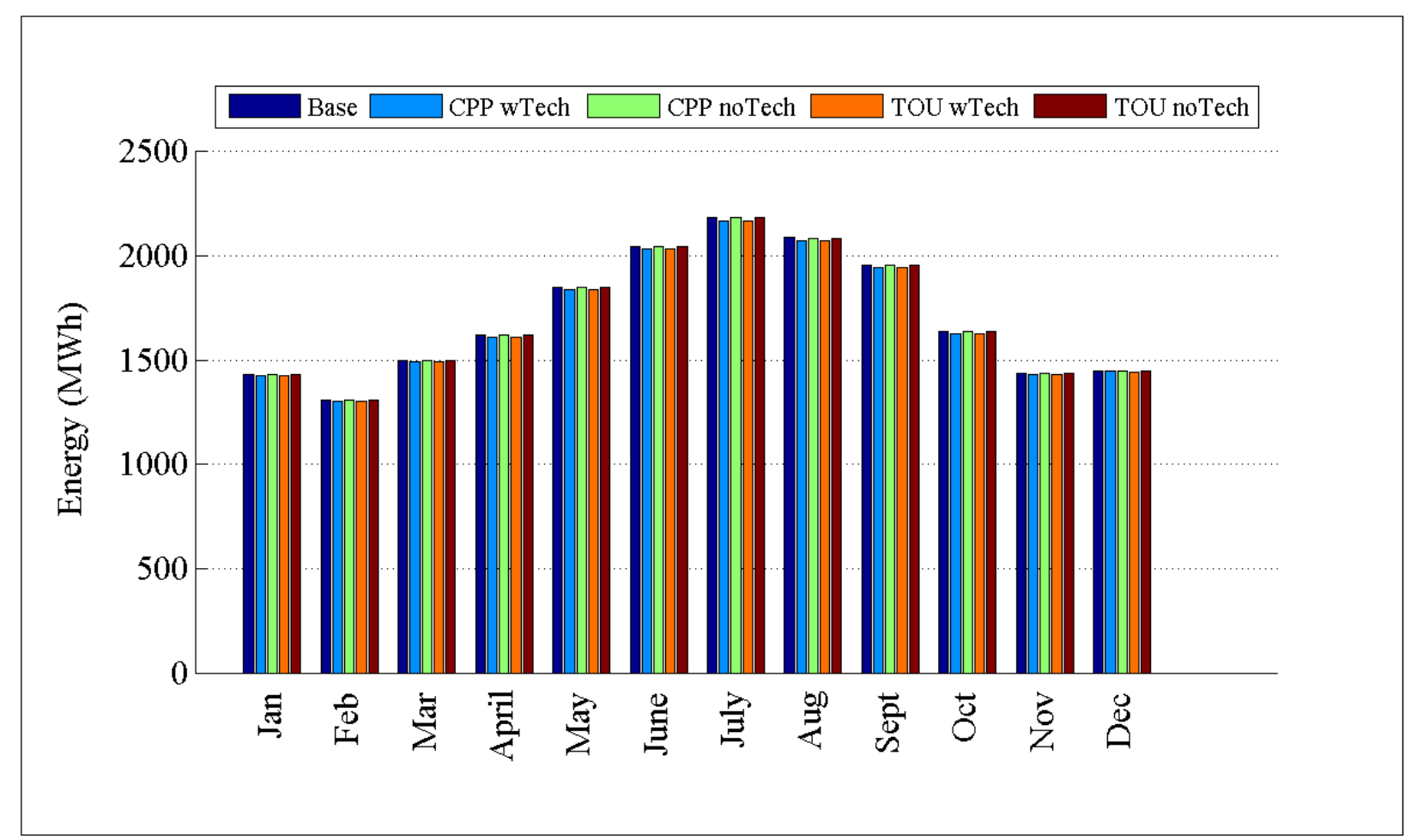

Figure D.66: Comparison of energy consumption by month for GC-12.47-1_R4

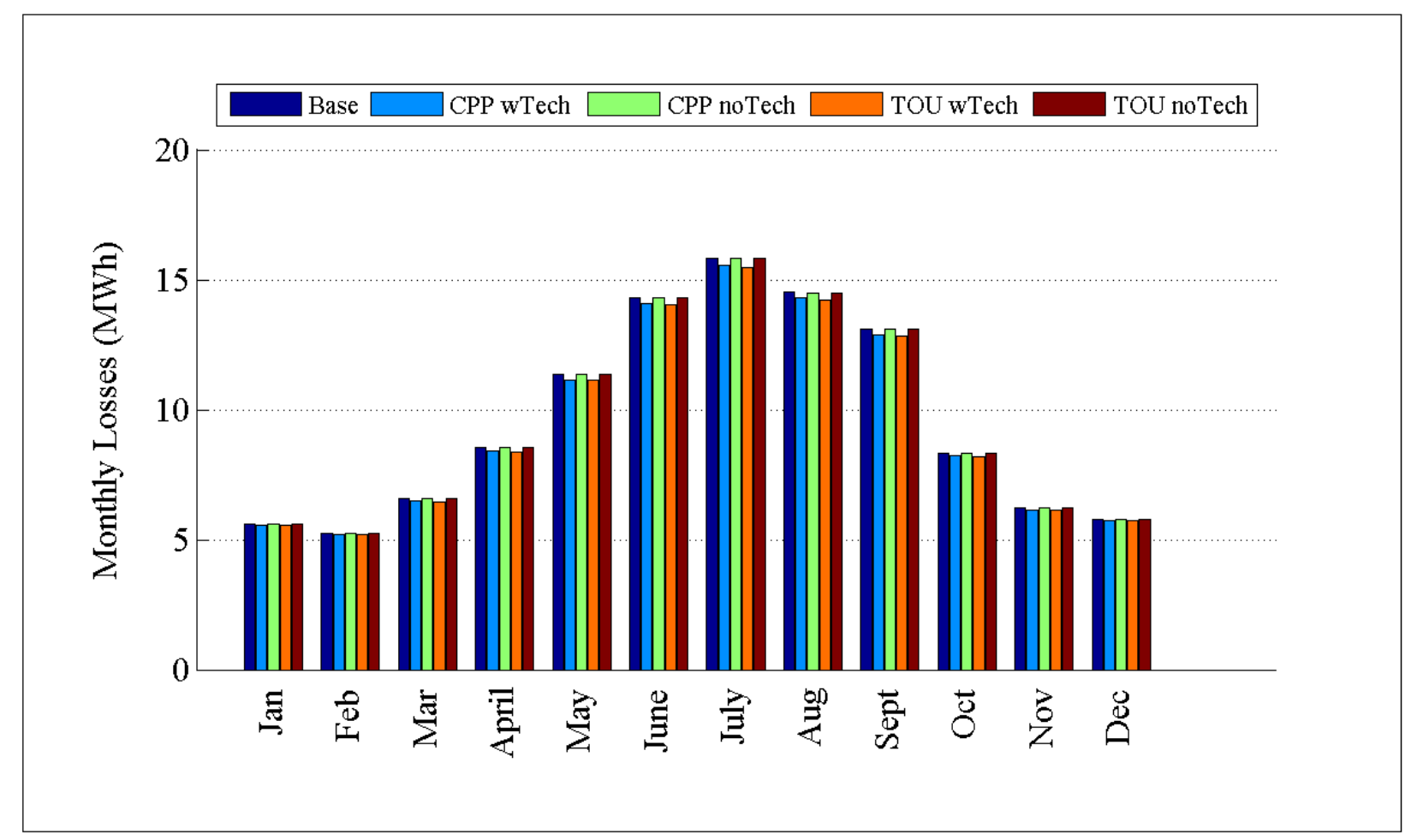

Figure D.67: Comparison of losses by month for GC-12.47-1_R4 


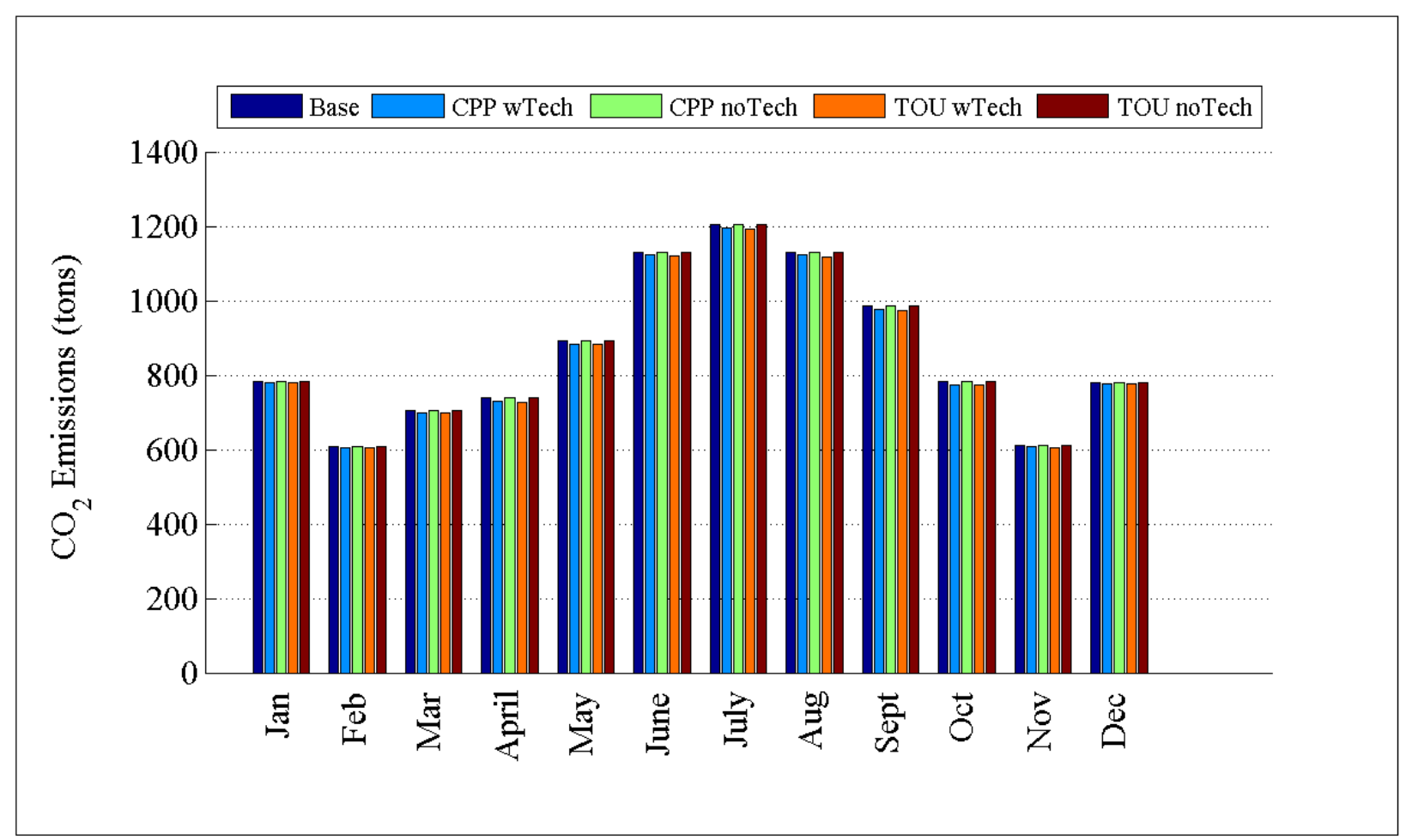

Figure D.68: Comparison of $\mathrm{CO}_{2}$ emissions by month for GC-12.47-1_R4

D.1.18 Detailed TOU and CPP Plots for R4-12.47-1 


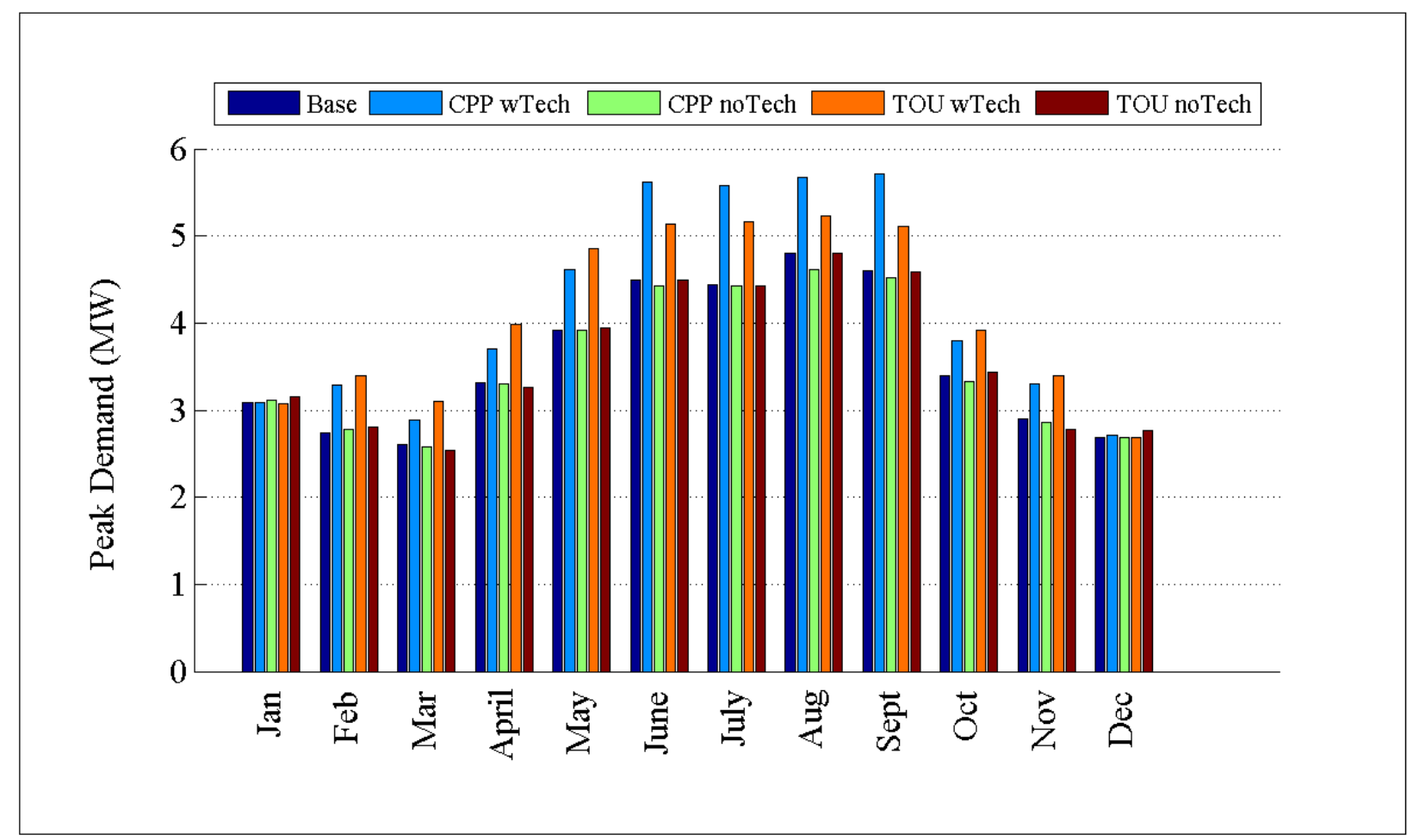

Figure D.69: Comparison of peak demand by month for R4-12.47-1

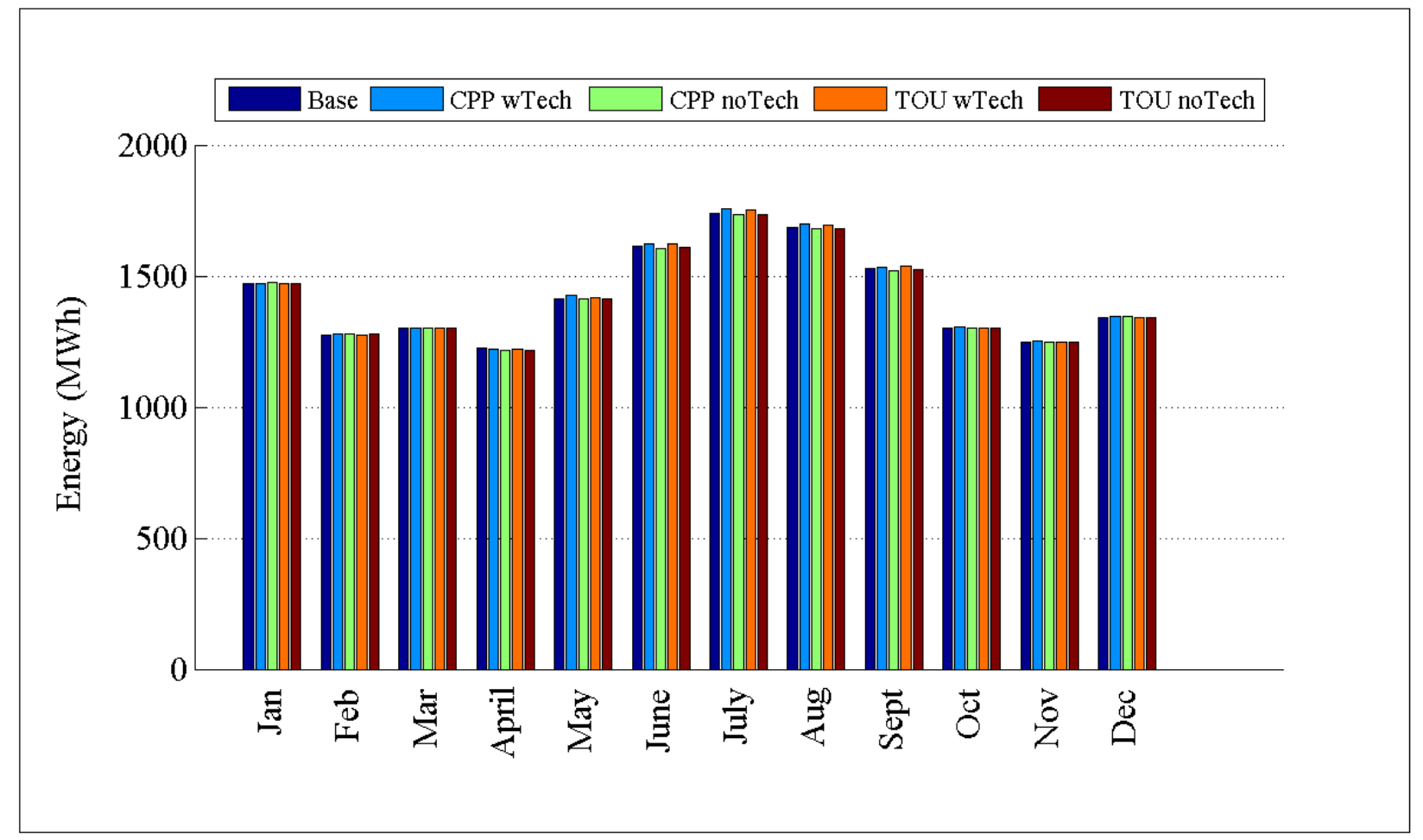

Figure D.70: Comparison of energy consumption by month for R4-12.47-1 


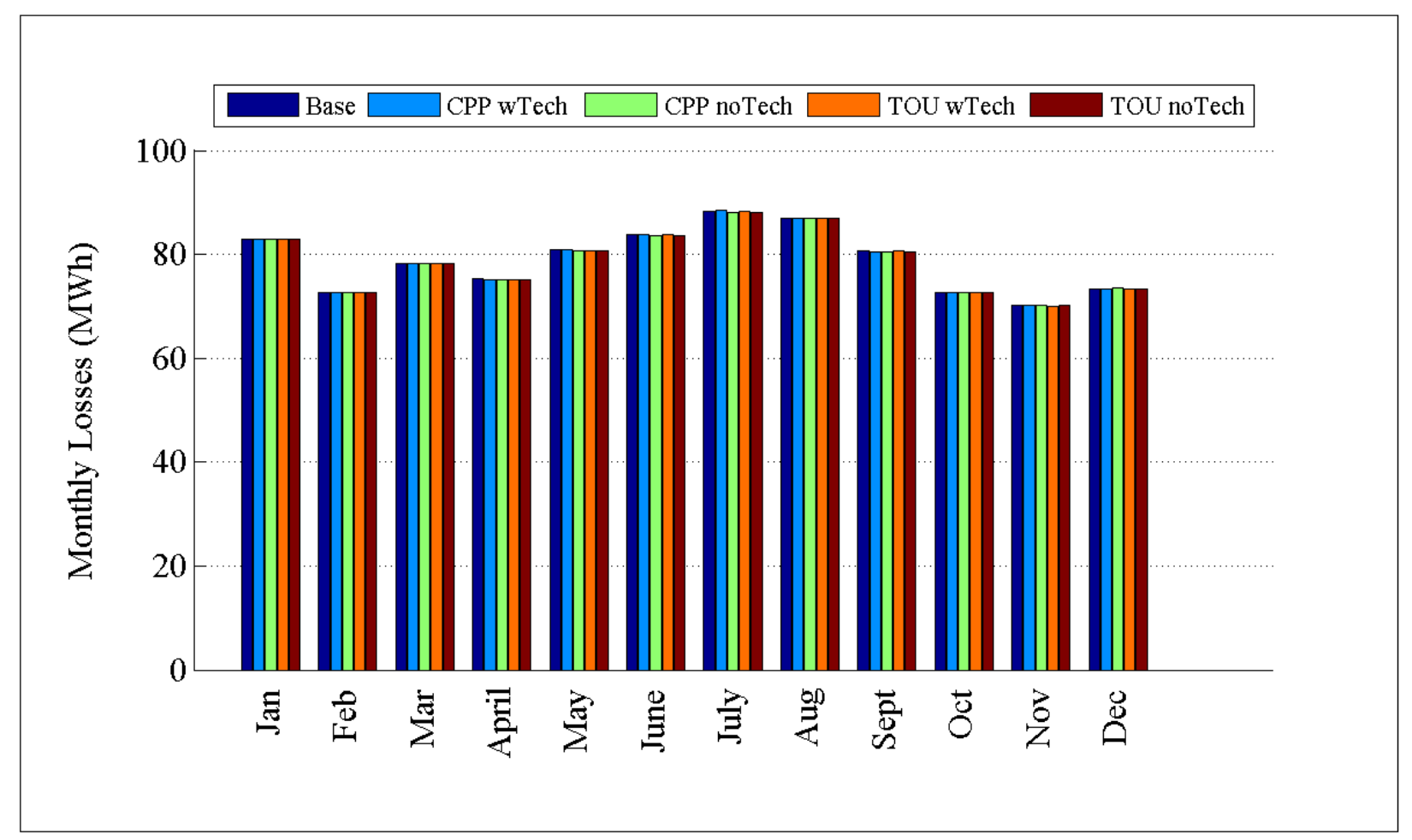

Figure D.71: Comparison of losses by month for R4-12.47-1

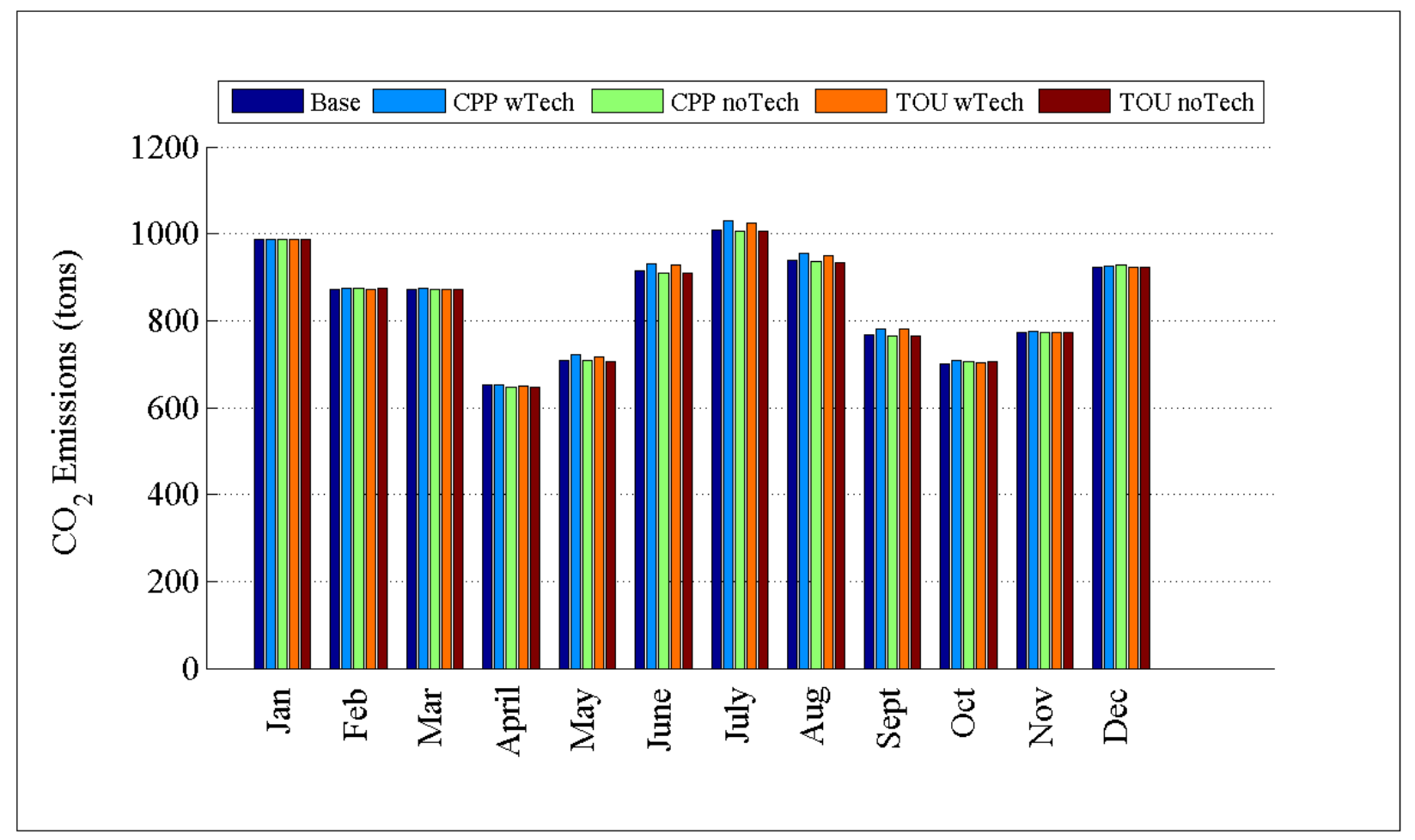

Figure D.72: Comparison of $\mathrm{CO}_{2}$ emissions by month for R4-12.47-1 


\section{D.1.19 Detailed TOU and CPP Plots for R4-12.47-2}

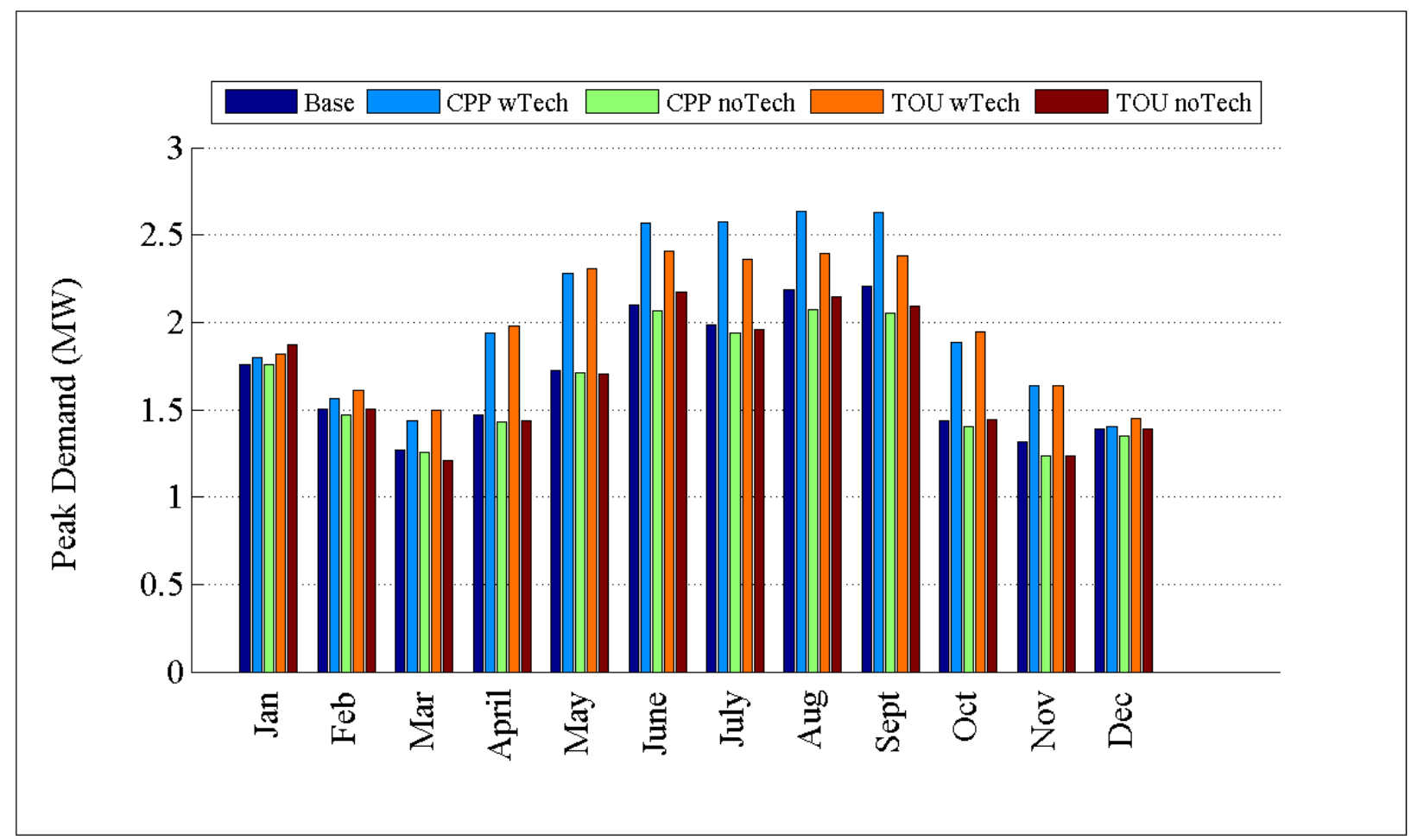

Figure D.73: Comparison of peak demand by month for R4-12.47-2 


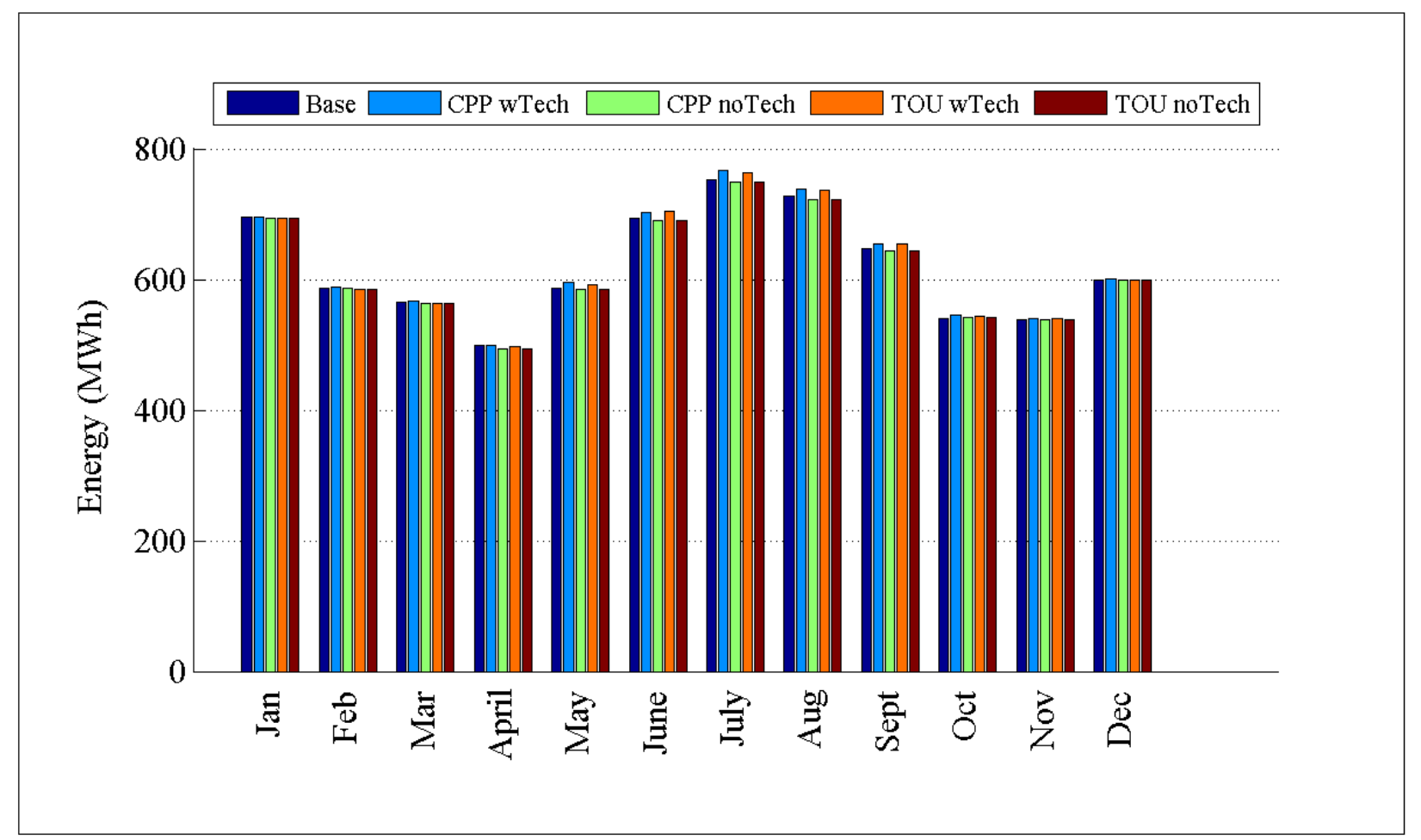

Figure D.74: Comparison of energy consumption by month for R4-12.47-2

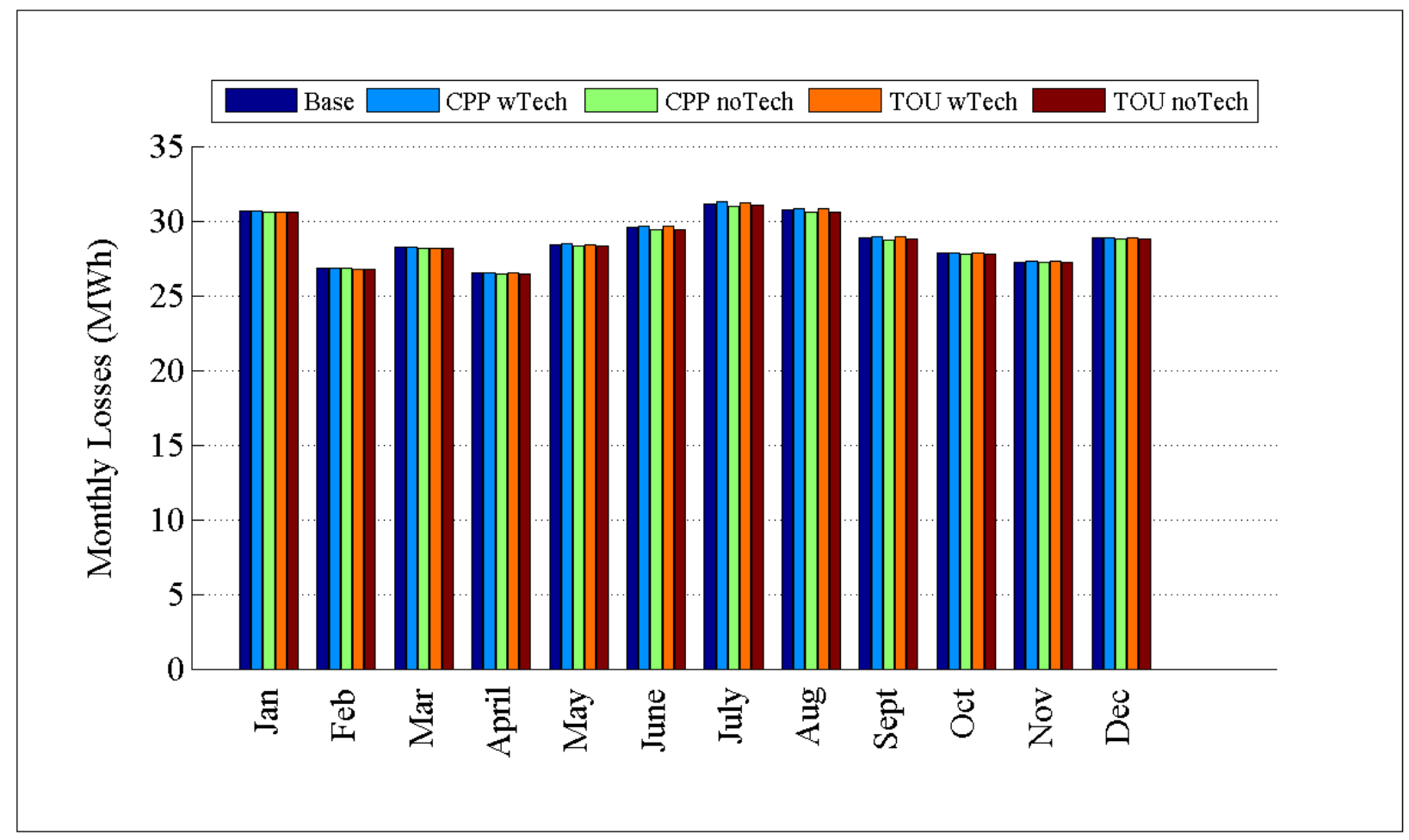

Figure D.75: Comparison of losses by month for R4-12.47-2 


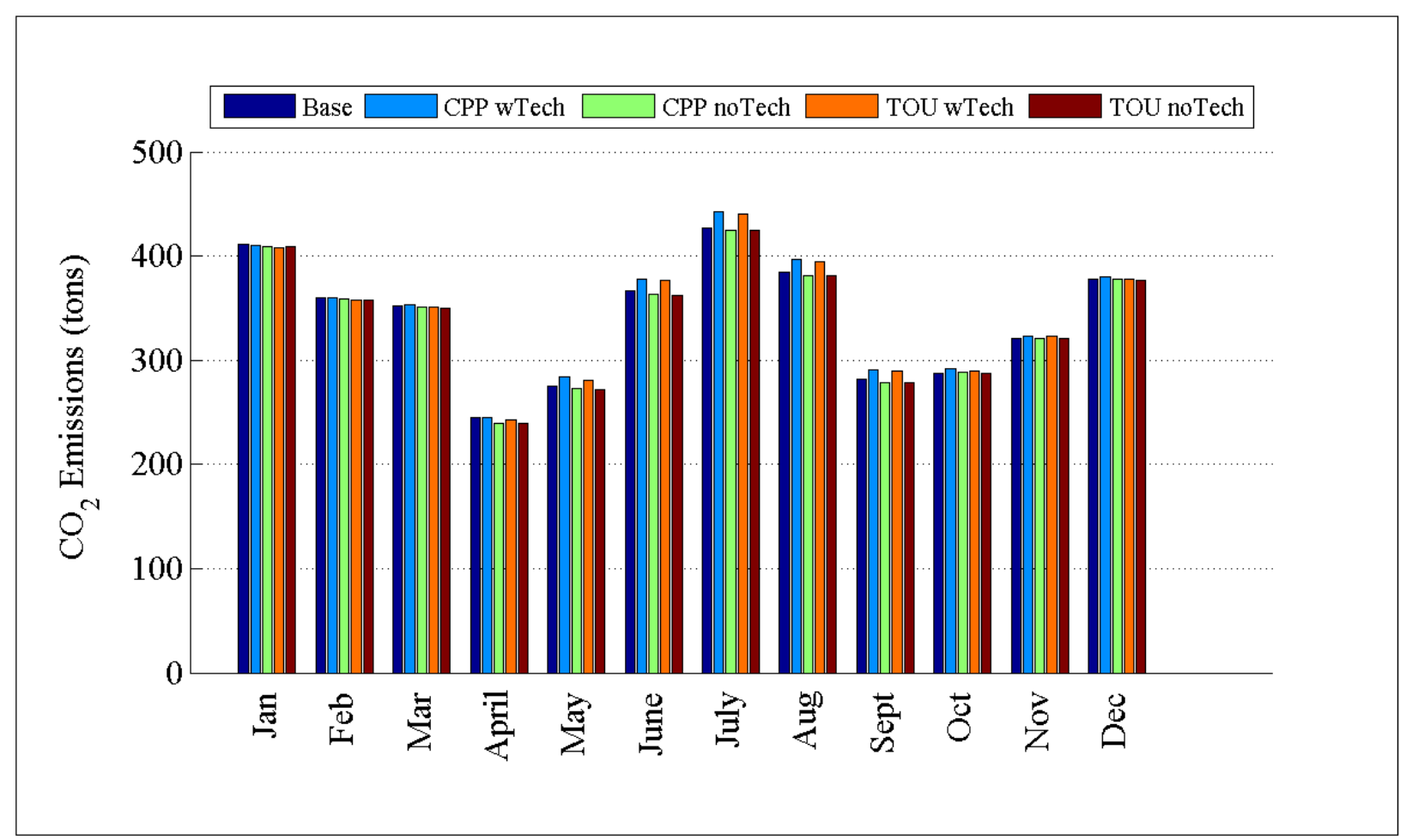

Figure D.76: Comparison of $\mathrm{CO}_{2}$ emissions by month for R4-12.47-2

D.1.20 Detailed TOU and CPP Plots for R4-25.00-1 


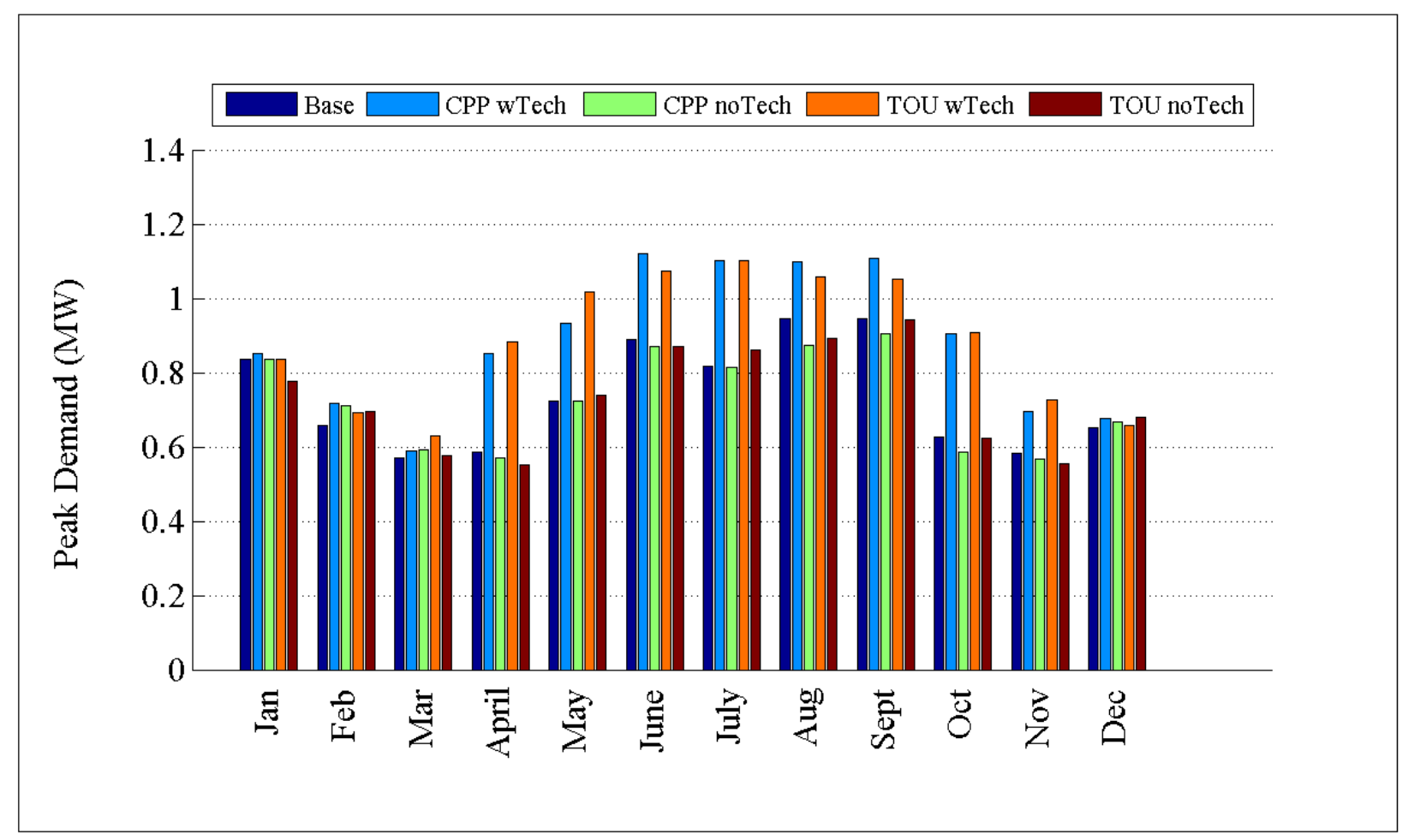

Figure D.77: Comparison of peak demand by month for R4-25.00-1

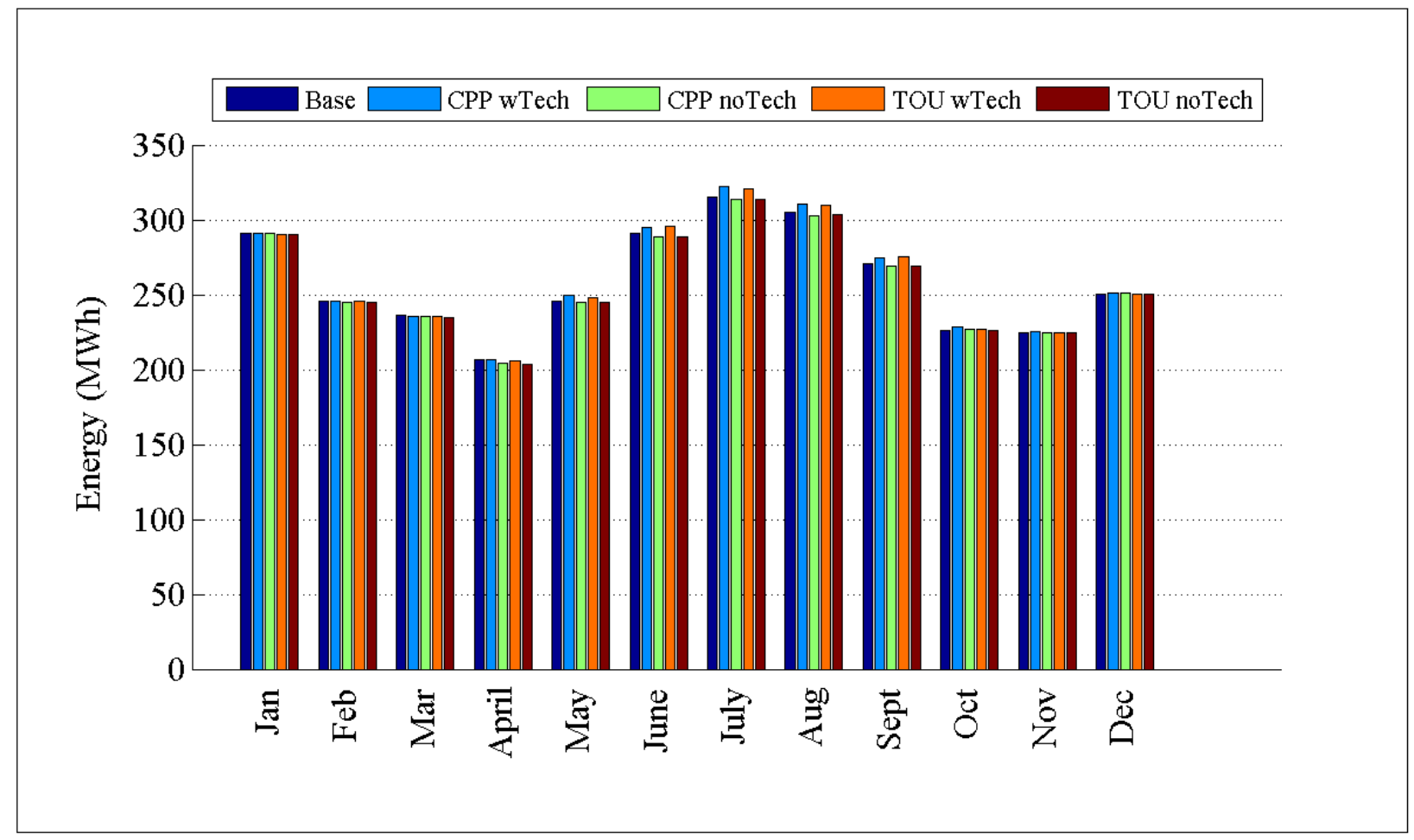

Figure D.78: Comparison of energy consumption by month for R4-25.00-1 


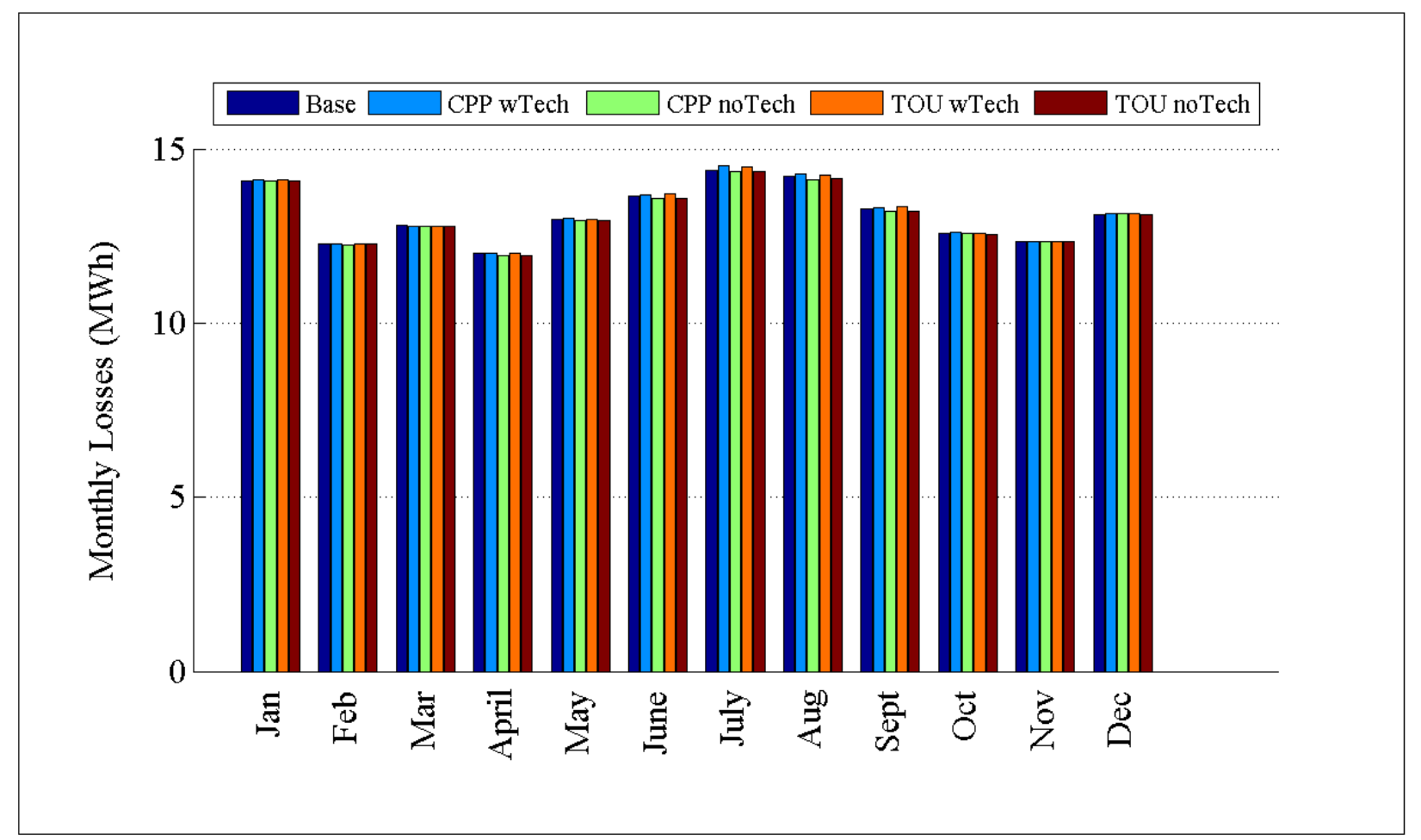

Figure D.79: Comparison of losses by month for R4-25.00-1

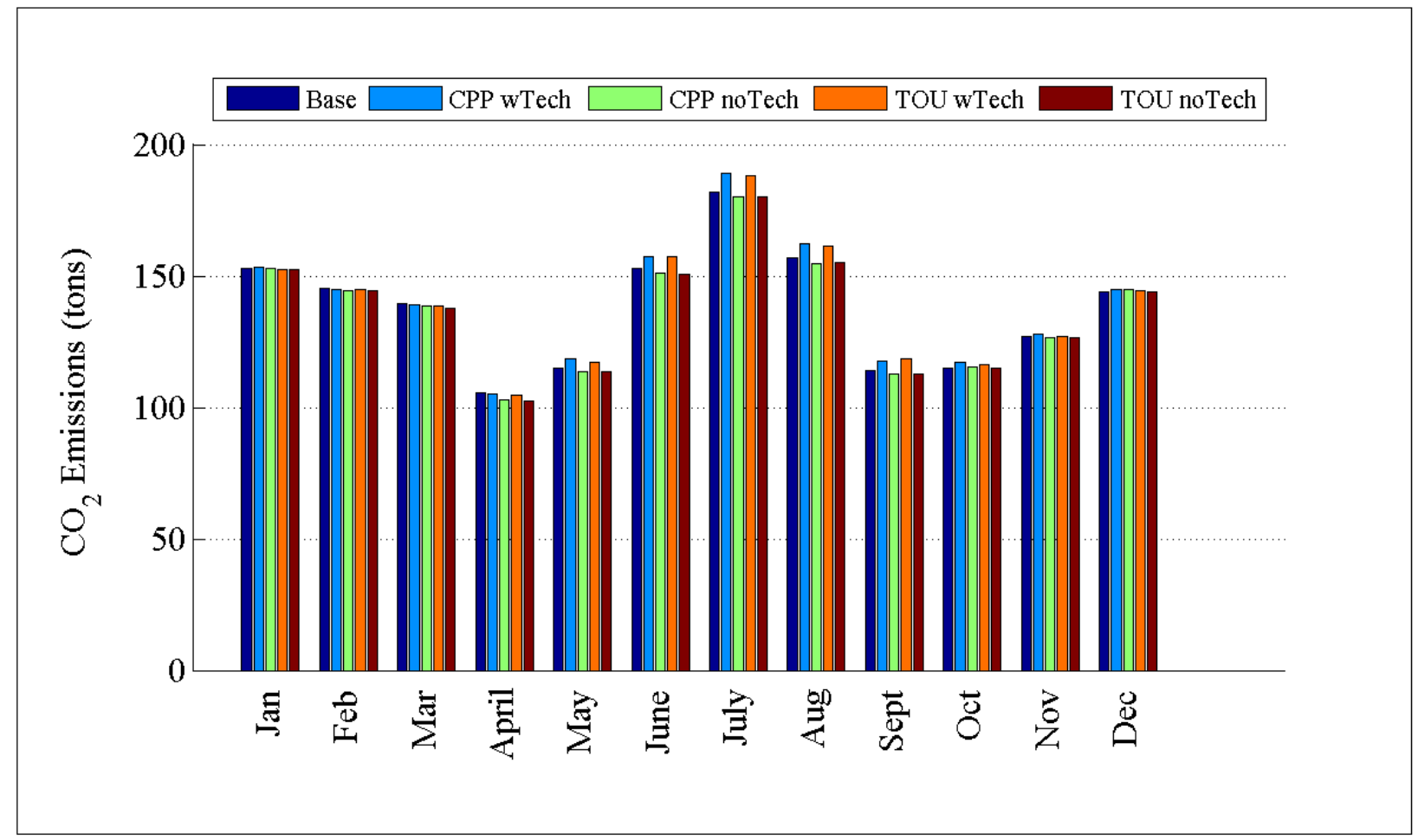

Figure D.80: Comparison of $\mathrm{CO}_{2}$ emissions by month for R4-25.00-1 
D.1.21 Detailed TOU and CPP Plots for GC-12.47-1_R5

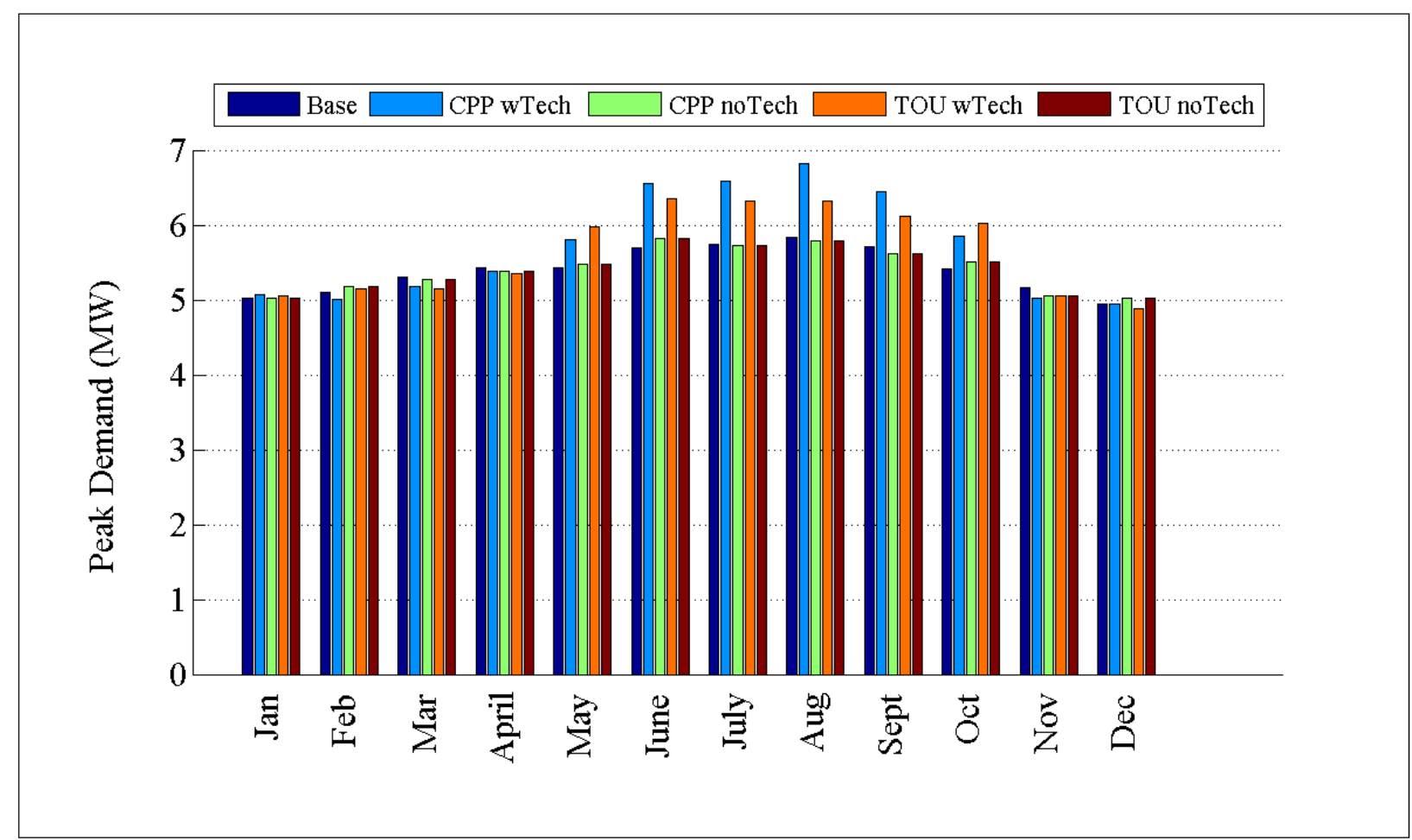

Figure D.81: Comparison of peak demand by month for GC-12.47-1_R5 


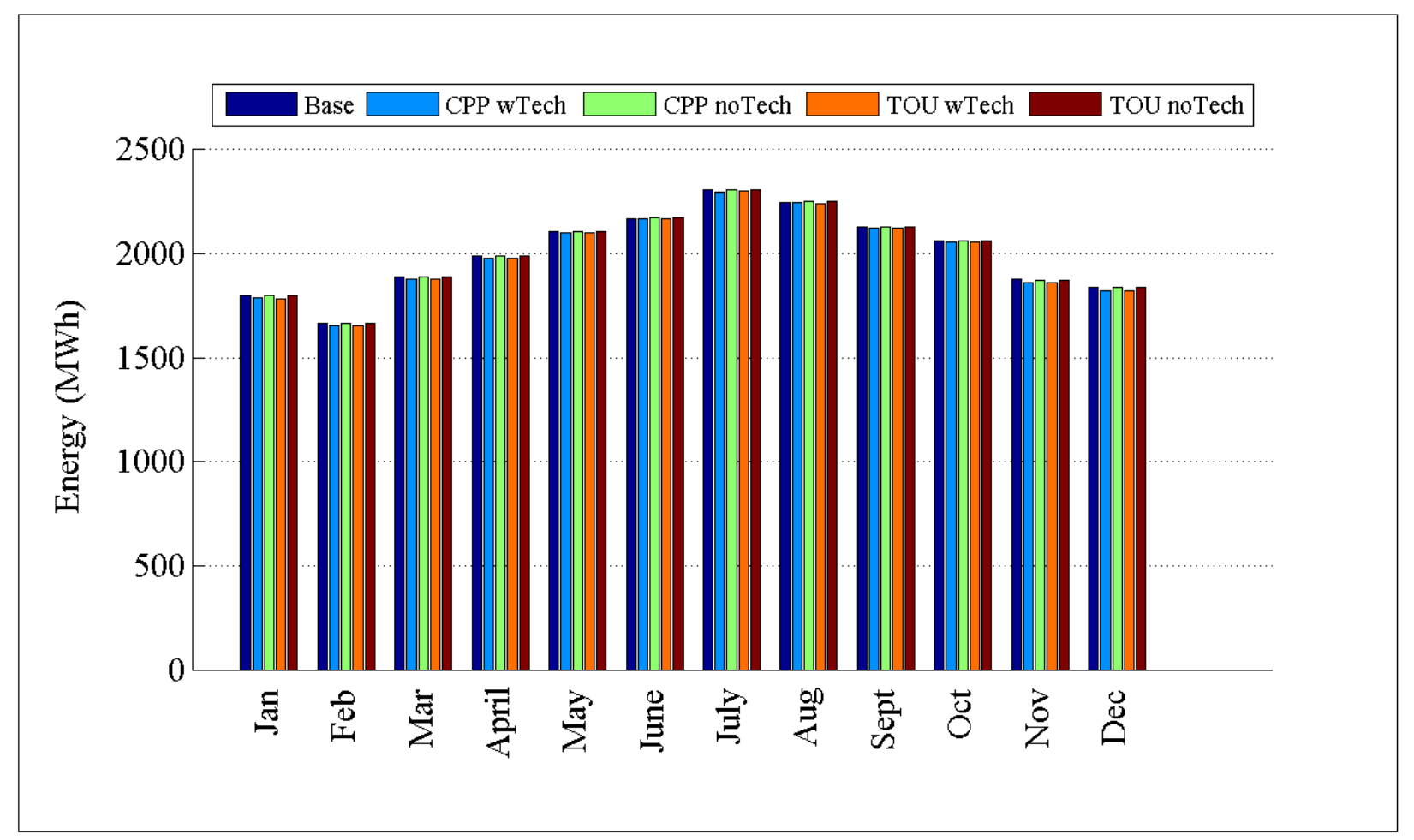

Figure D.82: Comparison of energy consumption by month for GC-12.47-1_R5

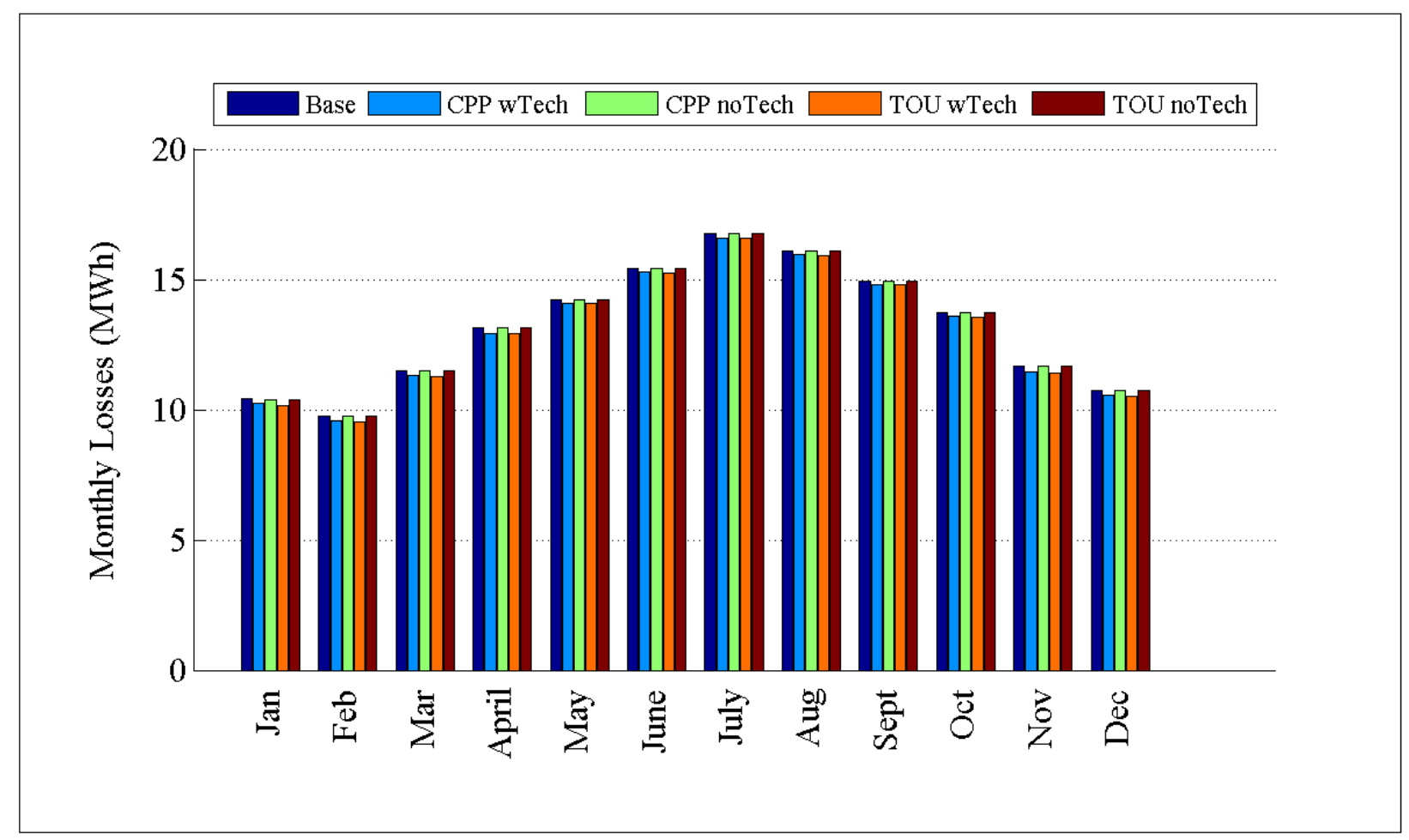

Figure D.83: Comparison of losses by month for GC-12.47-1_R5 


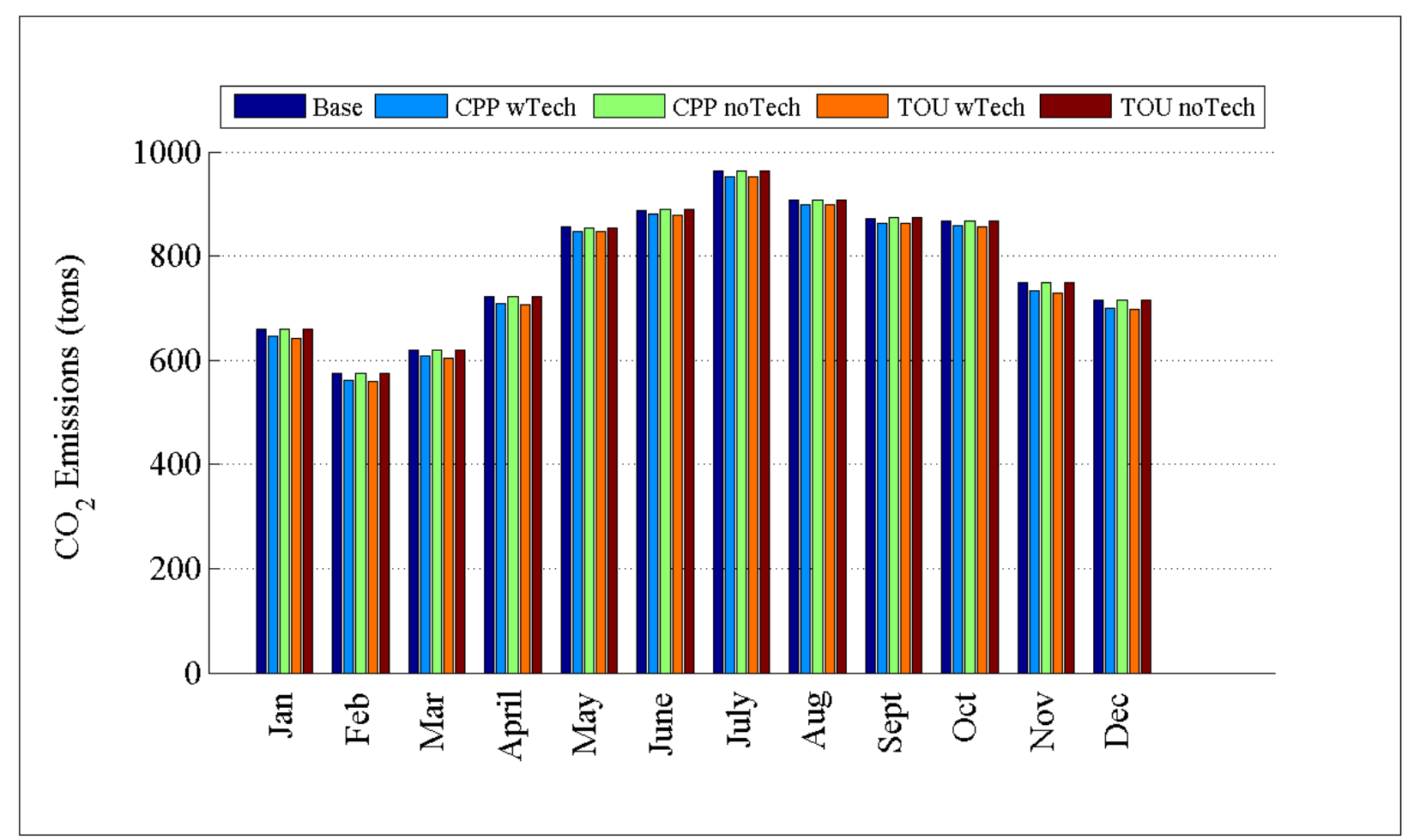

Figure D.84: Comparison of $\mathrm{CO}_{2}$ emissions by month for GC-12.47-1_R5

D.1.22 Detailed TOU and CPP Plots for R5-12.47-1 


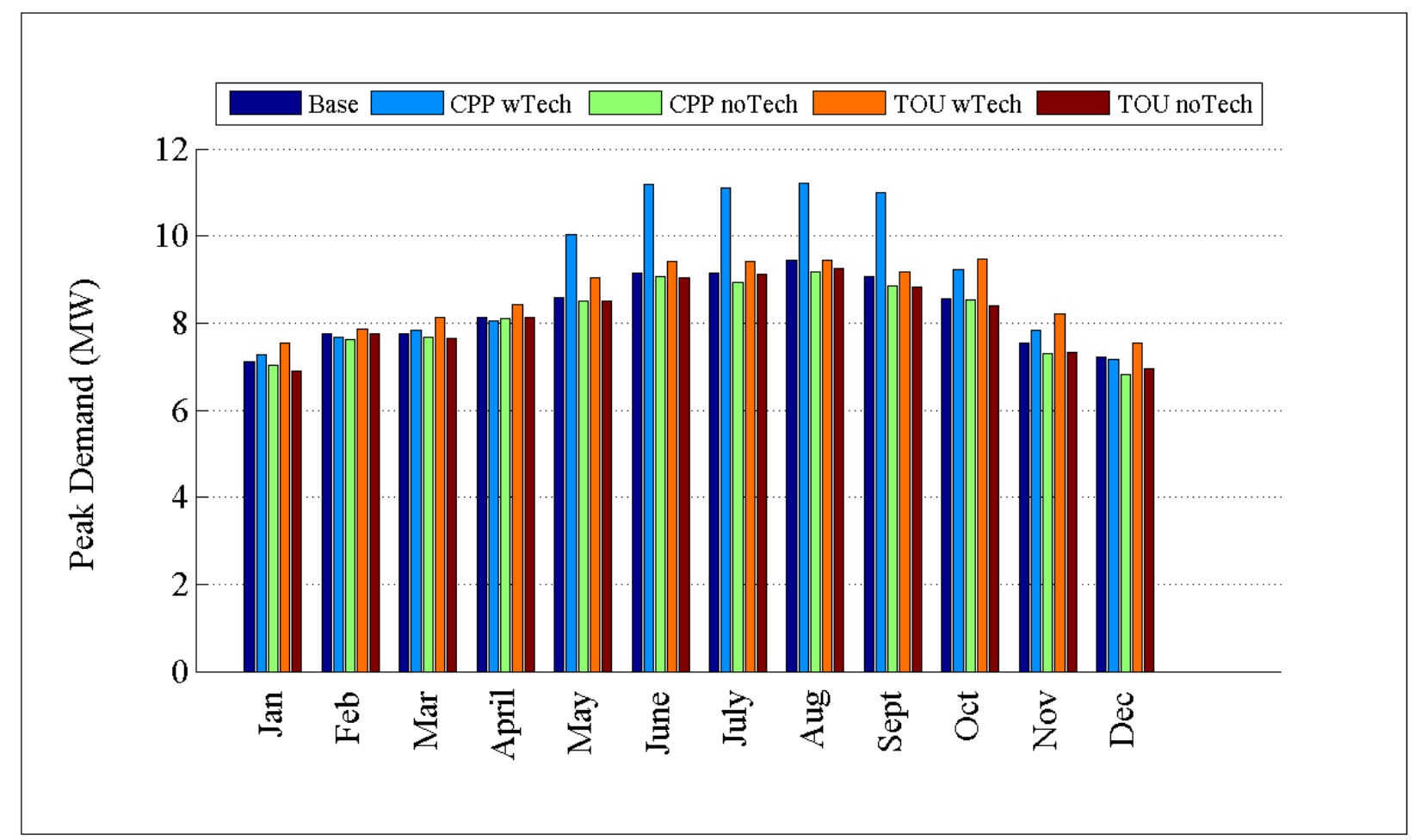

Figure D.85: Comparison of peak demand by month for R5-12.47-1

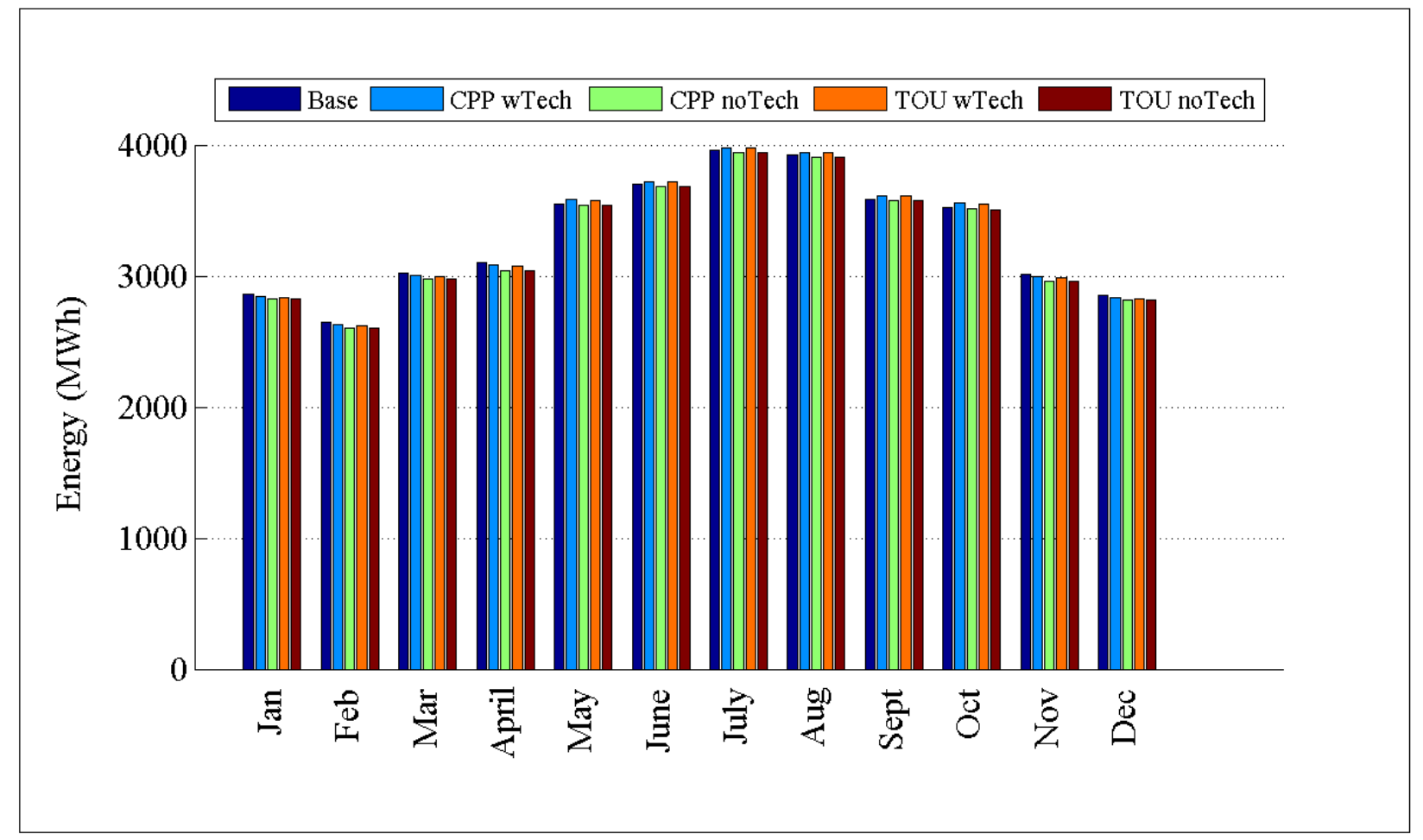

Figure D.86: Comparison of energy consumption by month for R5-12.47-1 


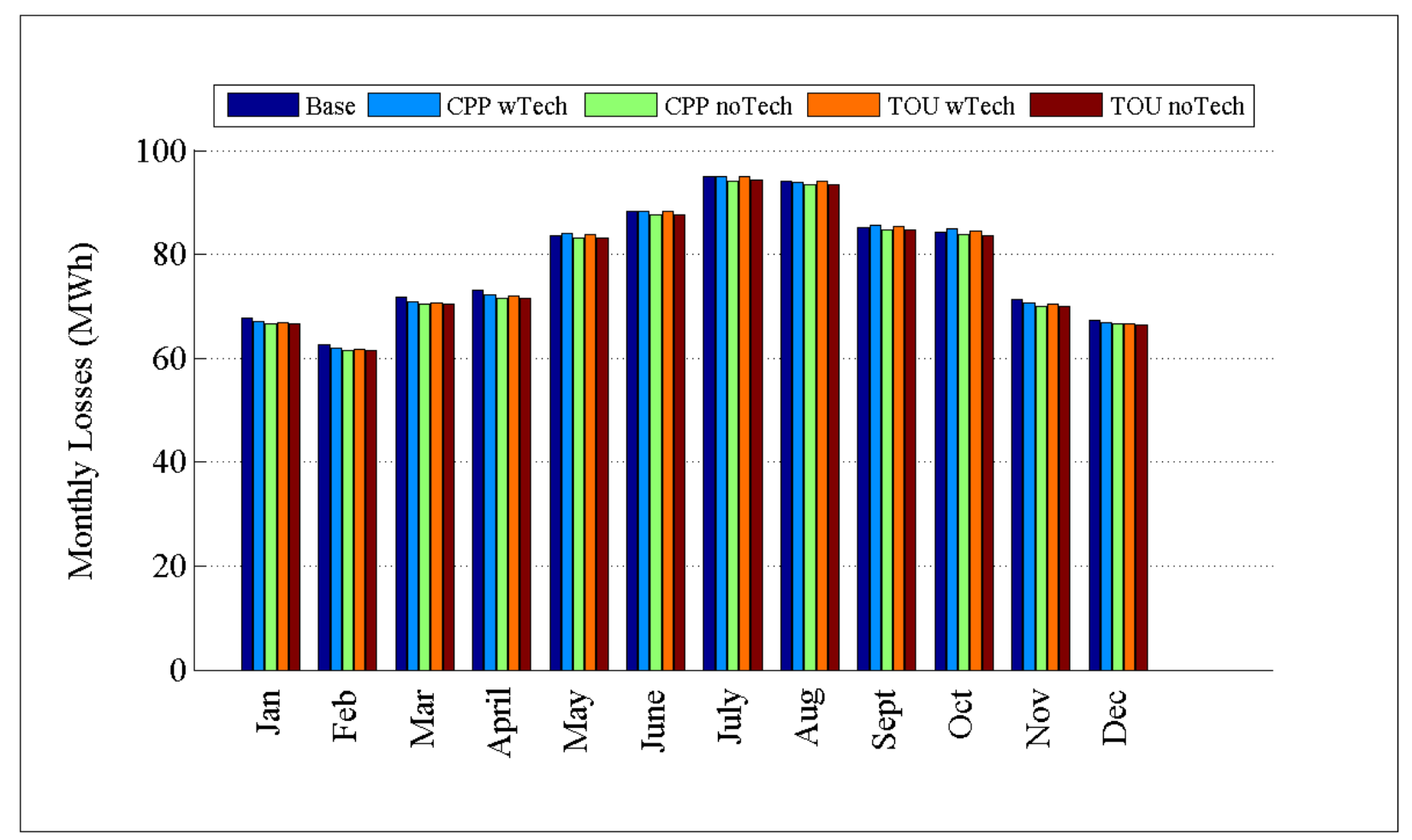

Figure D.87: Comparison of losses by month for R5-12.47-1

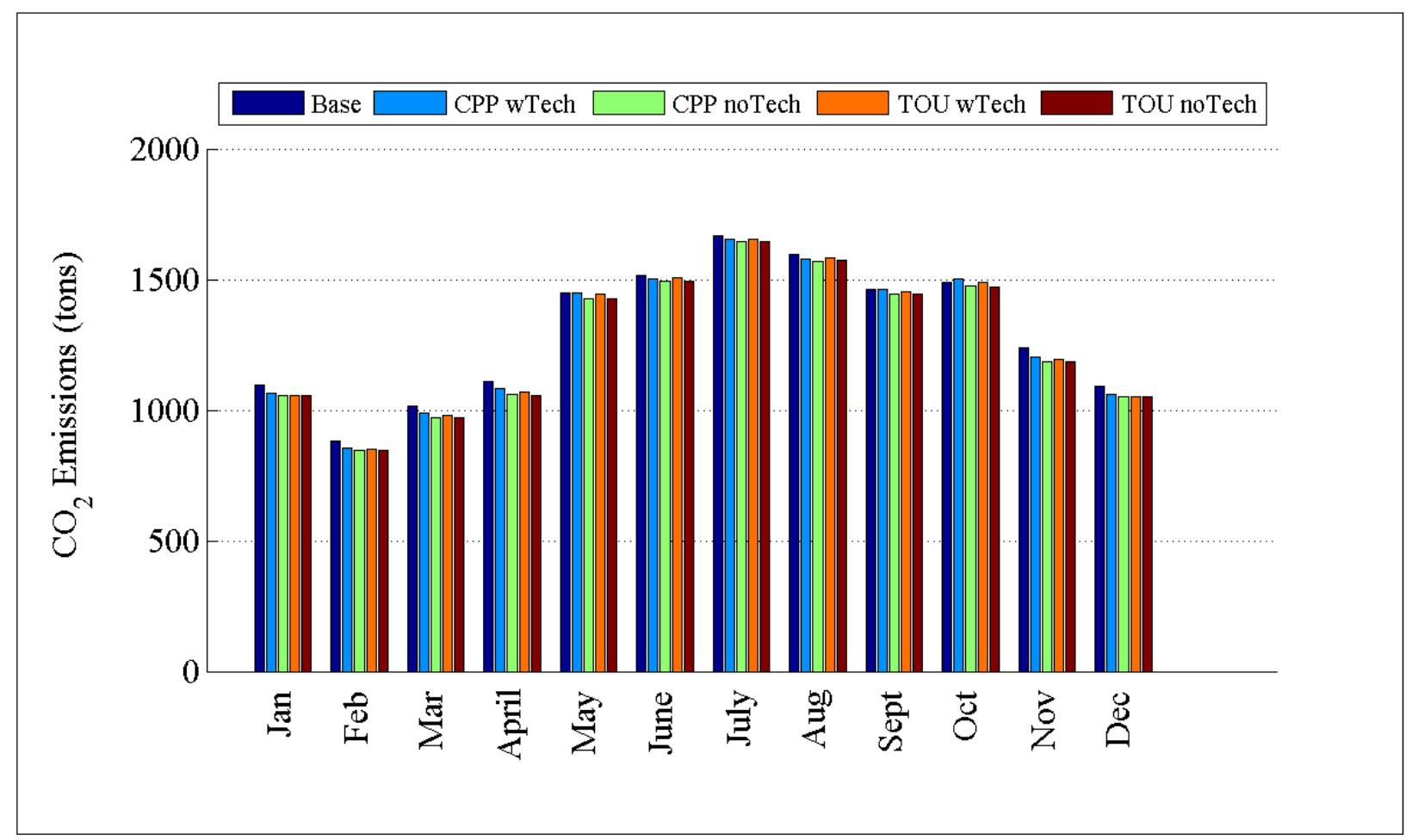

Figure D.88: Comparison of $\mathrm{CO}_{2}$ emissions by month for R5-12.47-1 
D.1.23 Detailed TOU and CPP Plots for R5-12.47-2

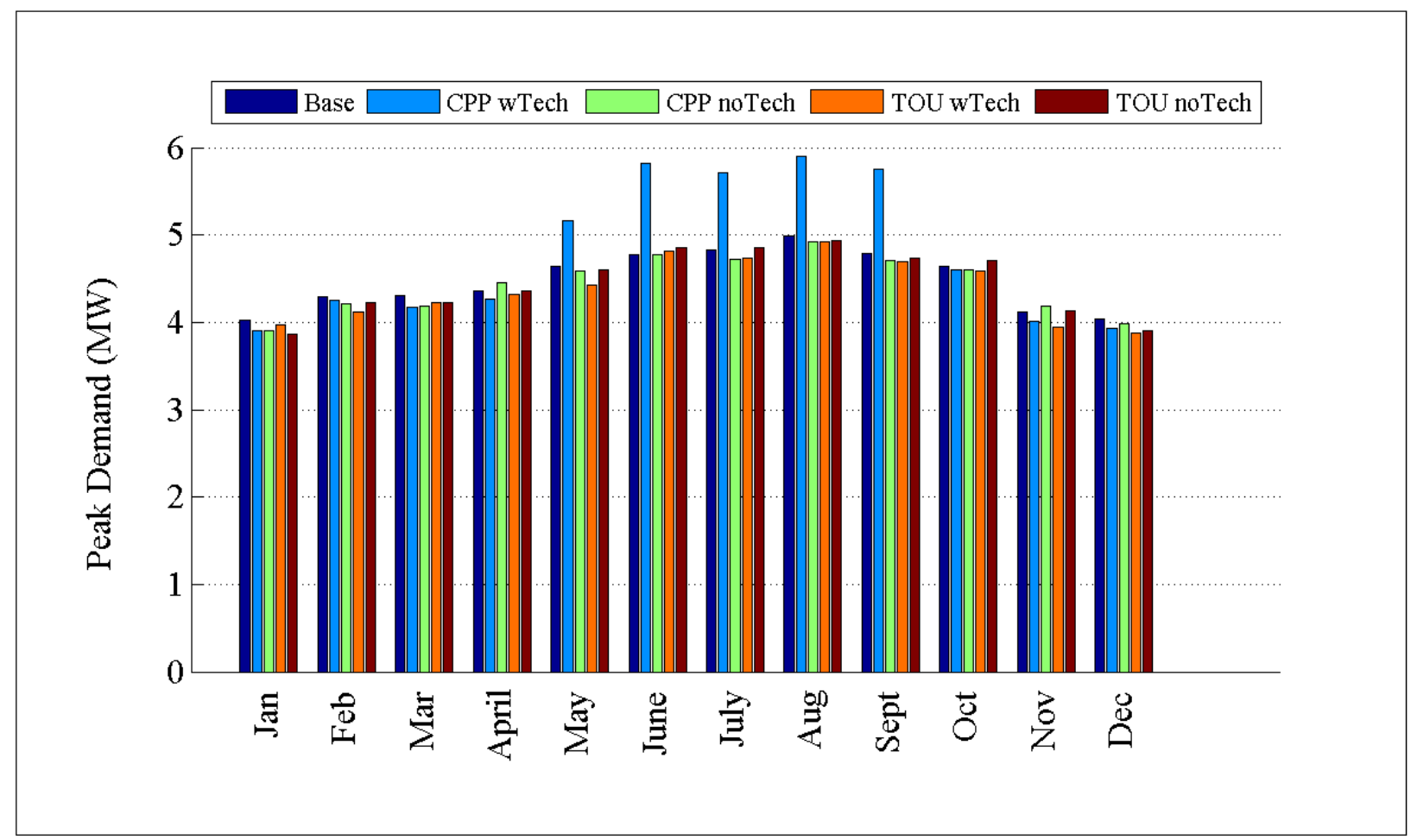

Figure D.89: Comparison of peak demand by month for R5-12.47-2 


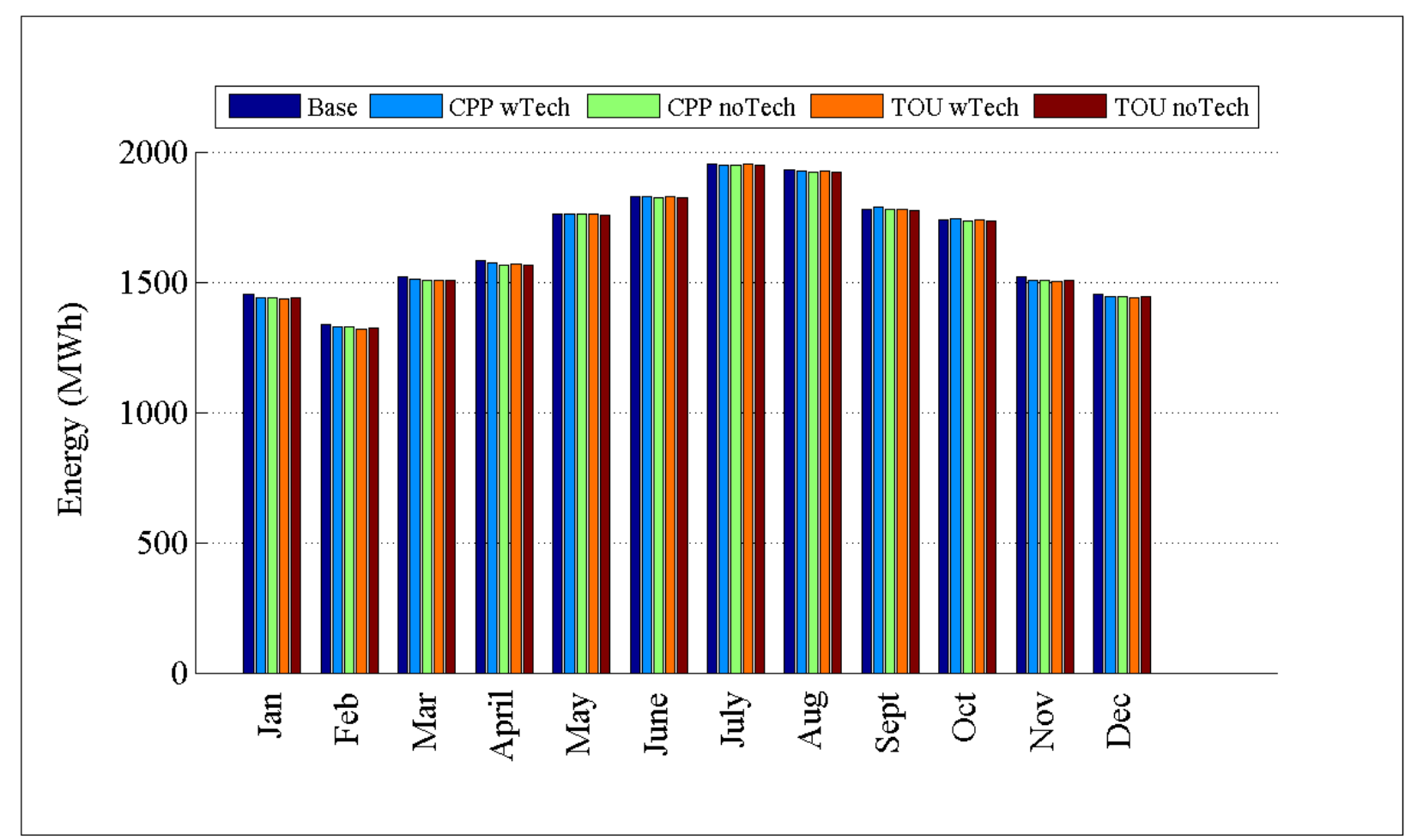

Figure D.90: Comparison of energy consumption by month for R5-12.47-2

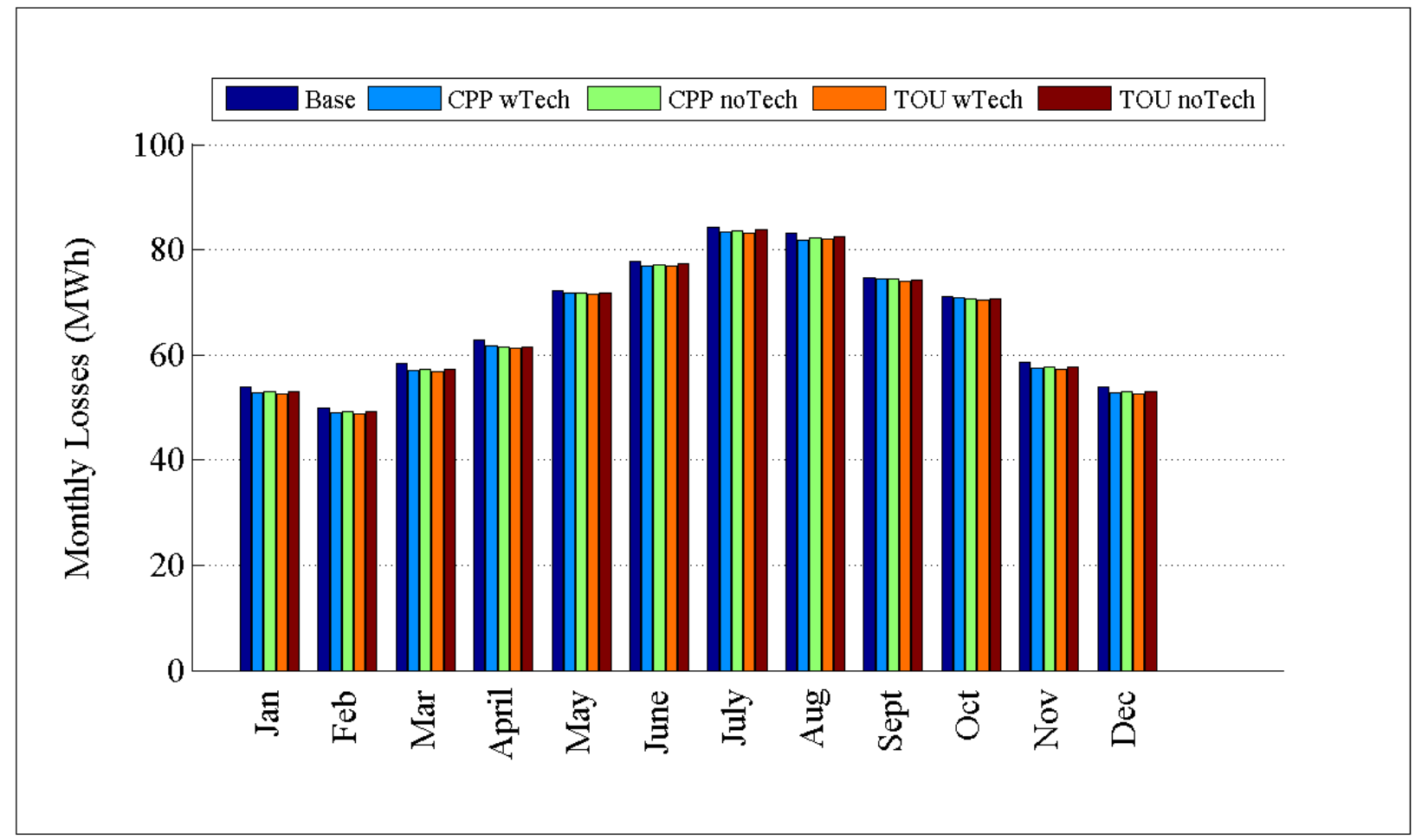

Figure D.91: Comparison of losses by month for R5-12.47-2 


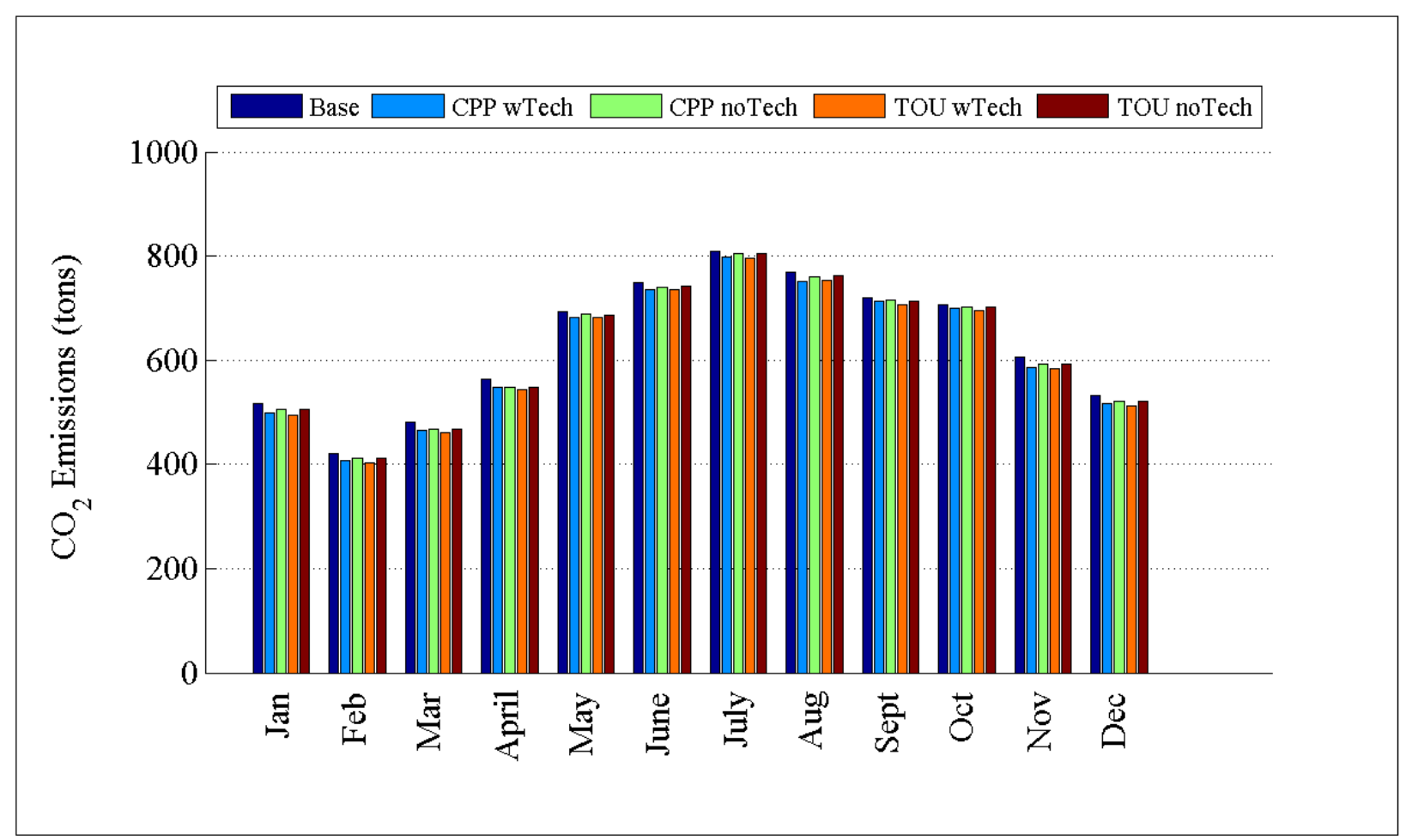

Figure D.92: Comparison of $\mathrm{CO}_{2}$ emissions by month for R5-12.47-2

D.1.24 Detailed TOU and CPP Plots for R5-12.47-3 


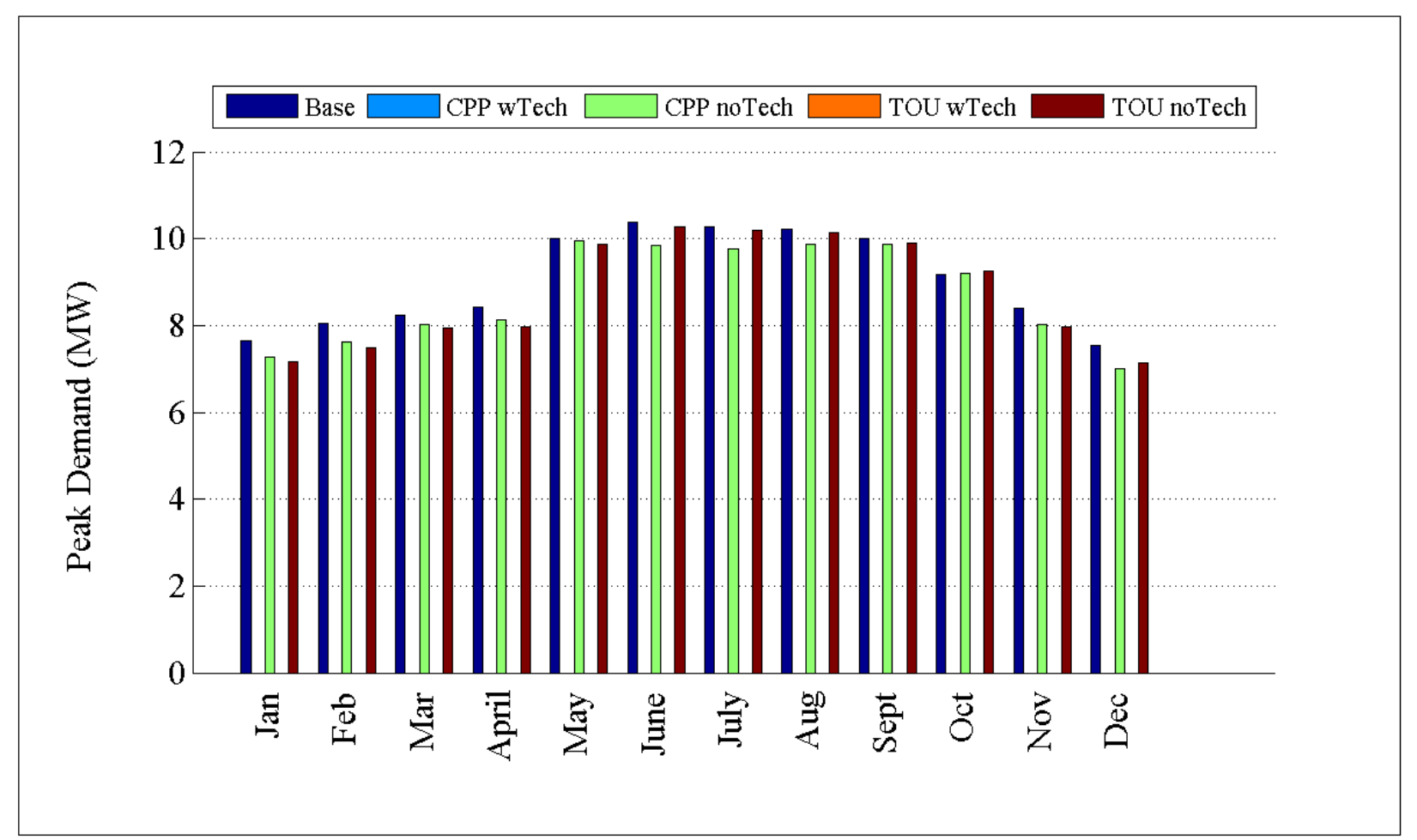

Figure D.93: Comparison of peak demand by month for R5-12.47-3

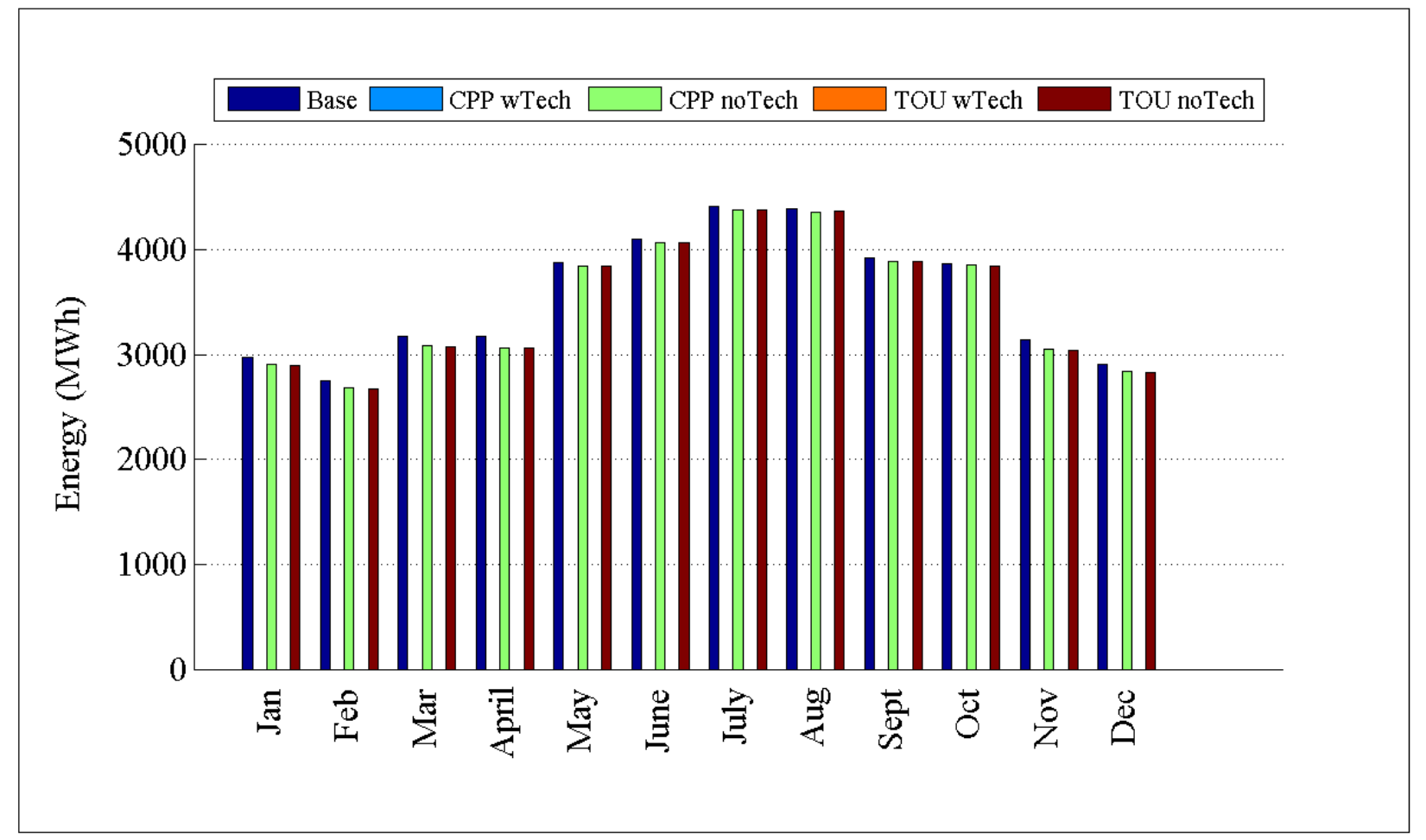

Figure D.94: Comparison of energy consumption by month for R5-12.47-3 


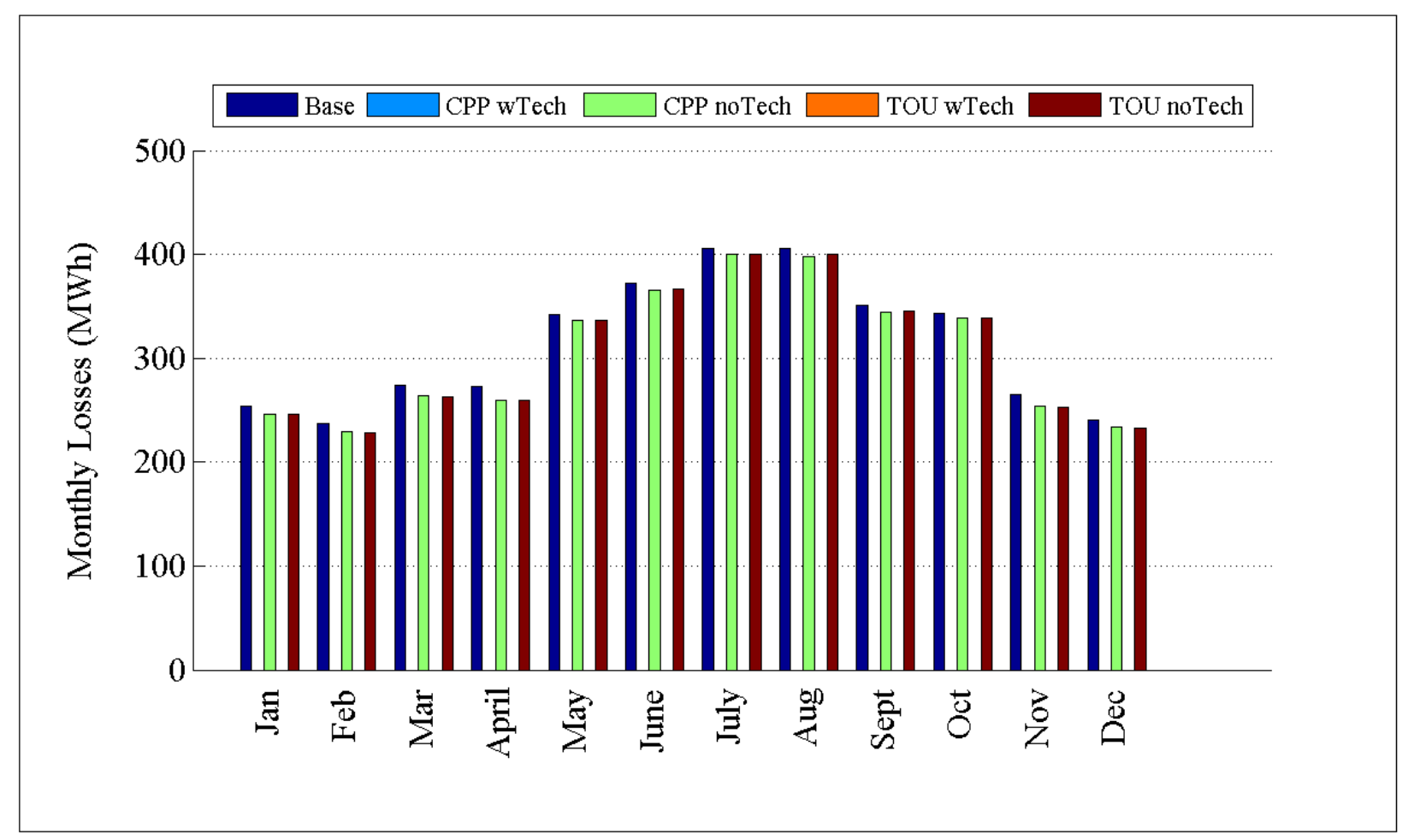

Figure D.95: Comparison of losses by month for R5-12.47-3

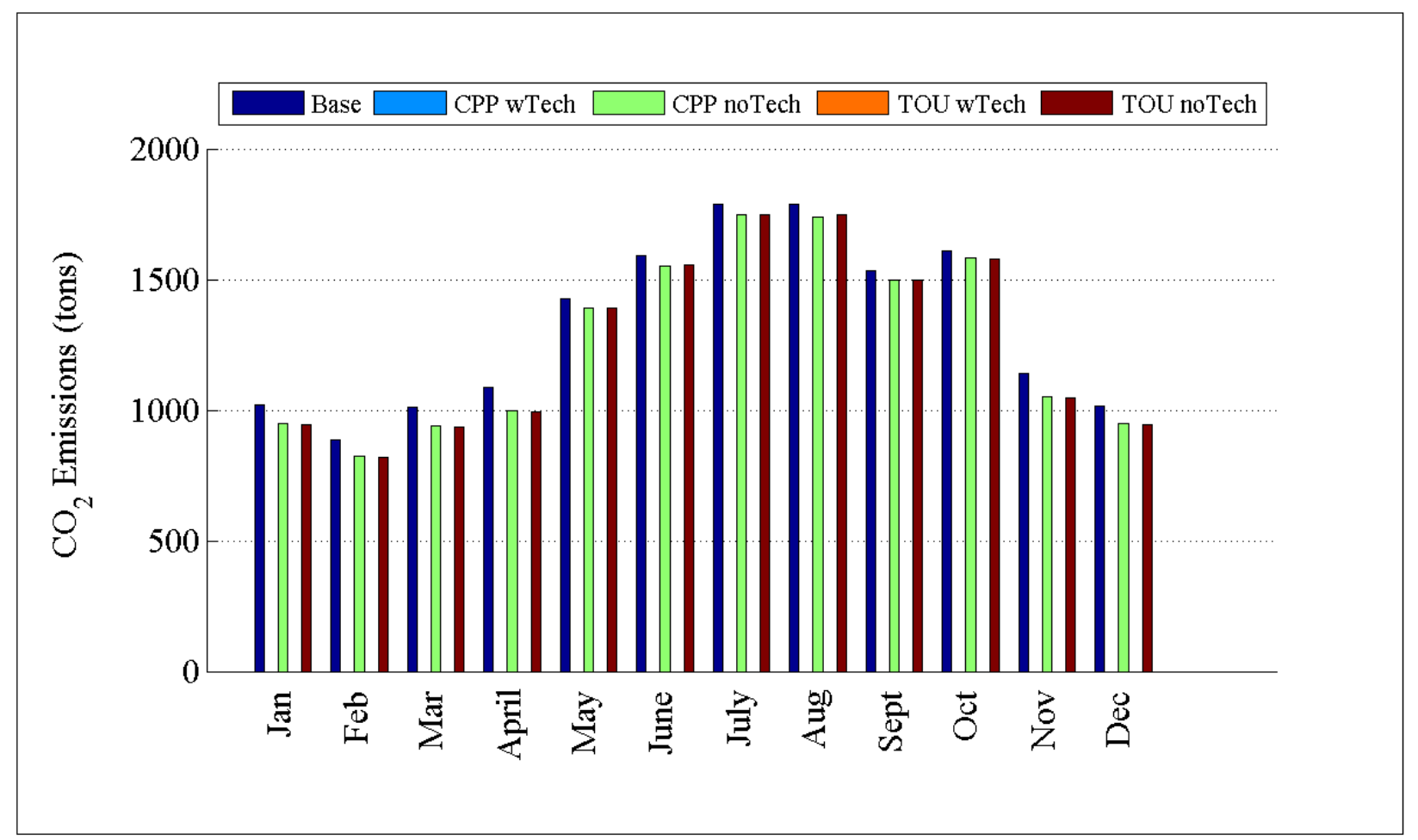

Figure D.96: Comparison of $\mathrm{CO}_{2}$ emissions by month for R5-12.47-3 


\section{D.1.25 Detailed TOU and CPP Plots for R5-12.47-4}

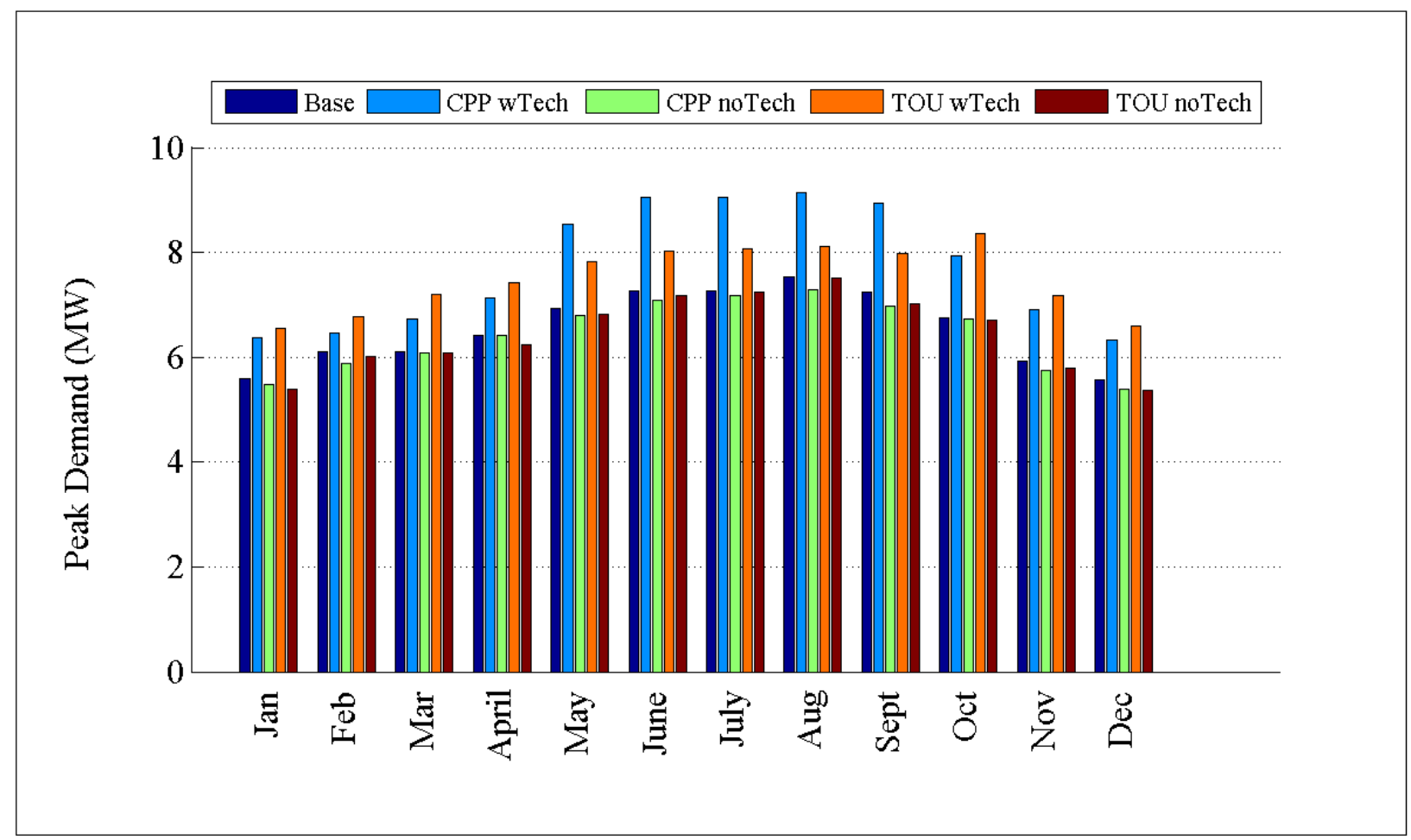

Figure D.97: Comparison of peak demand by month for R5-12.47-4 


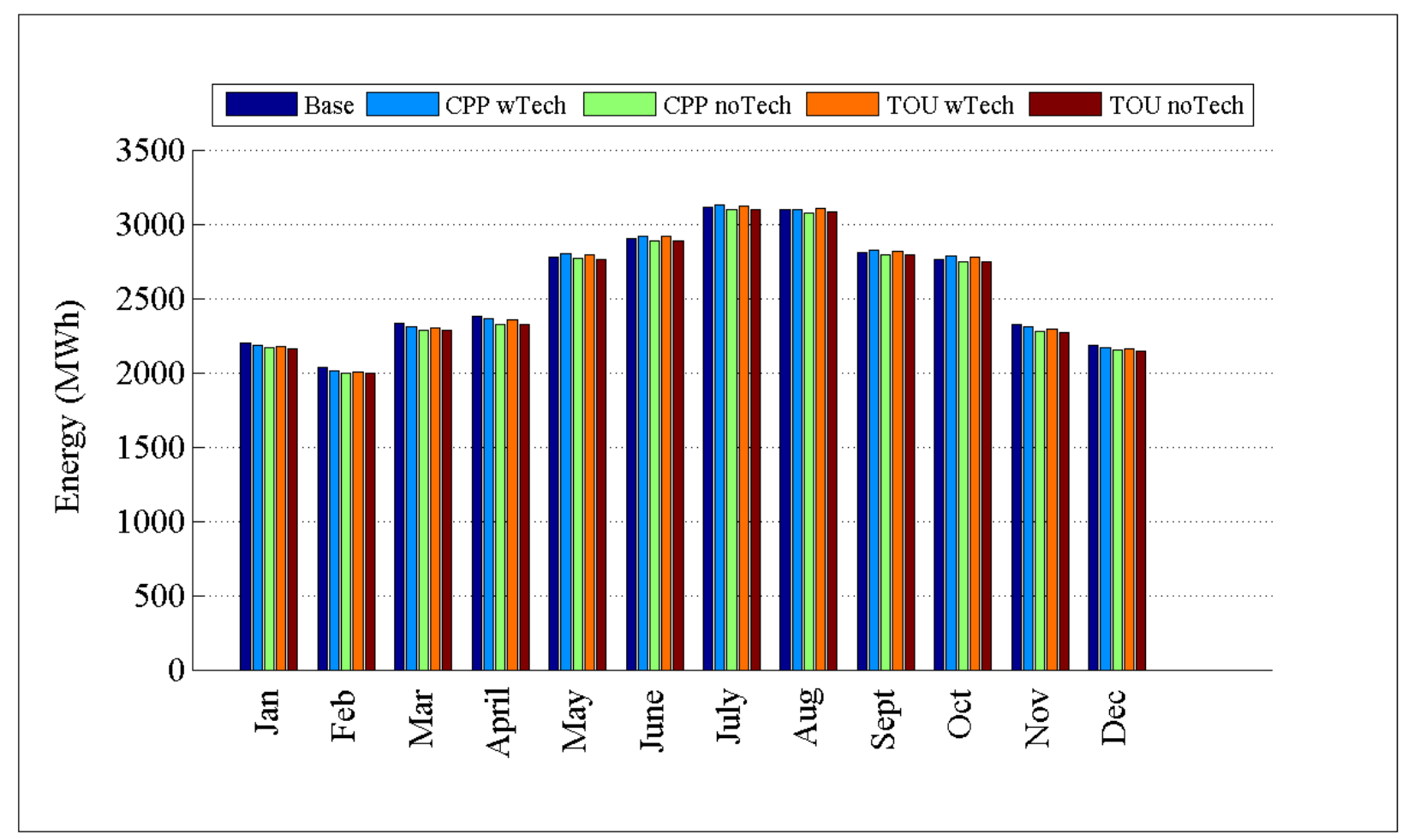

Figure D.98: Comparison of energy consumption by month for R5-12.47-4

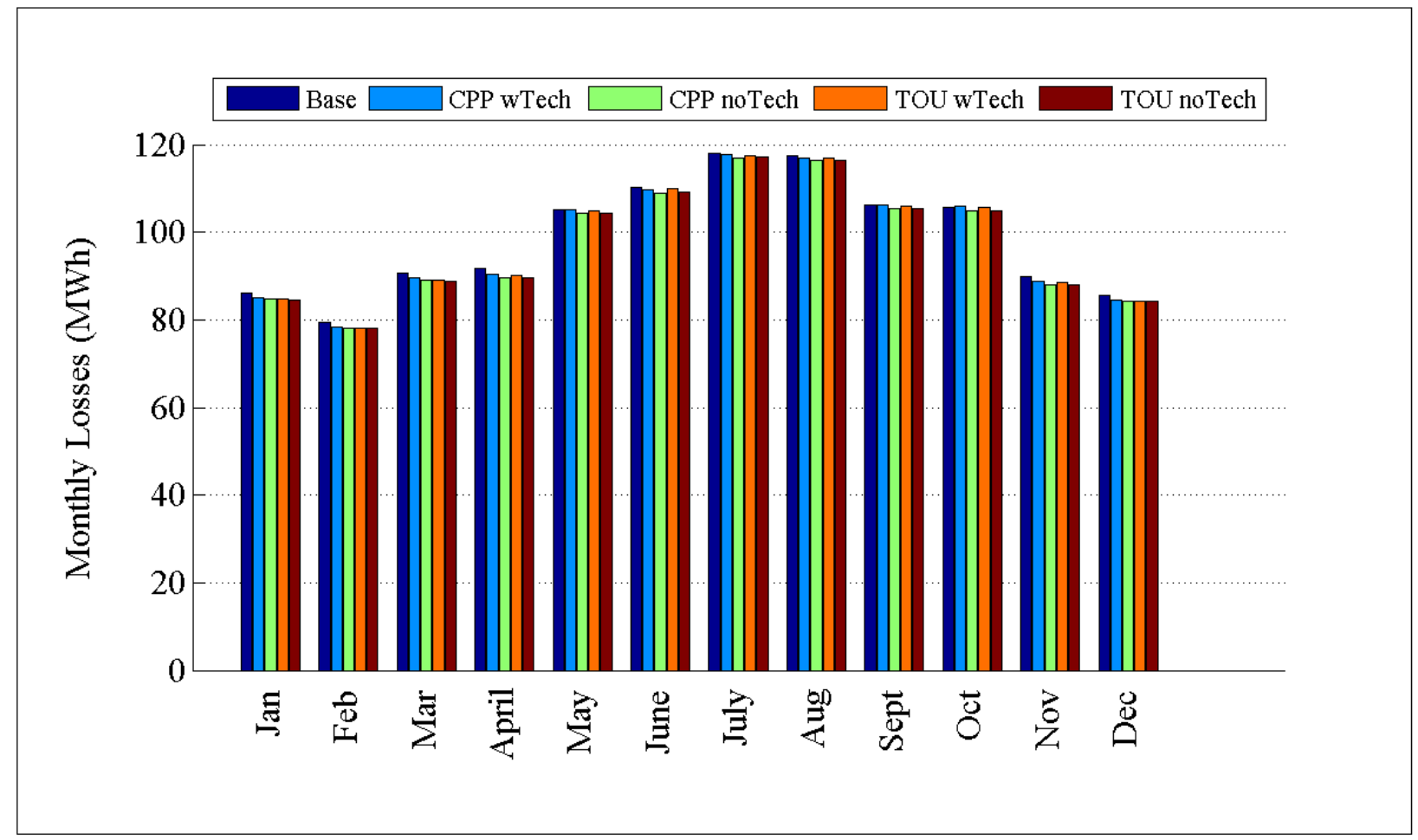

Figure D.99: Comparison of losses by month for R5-12.47-4 


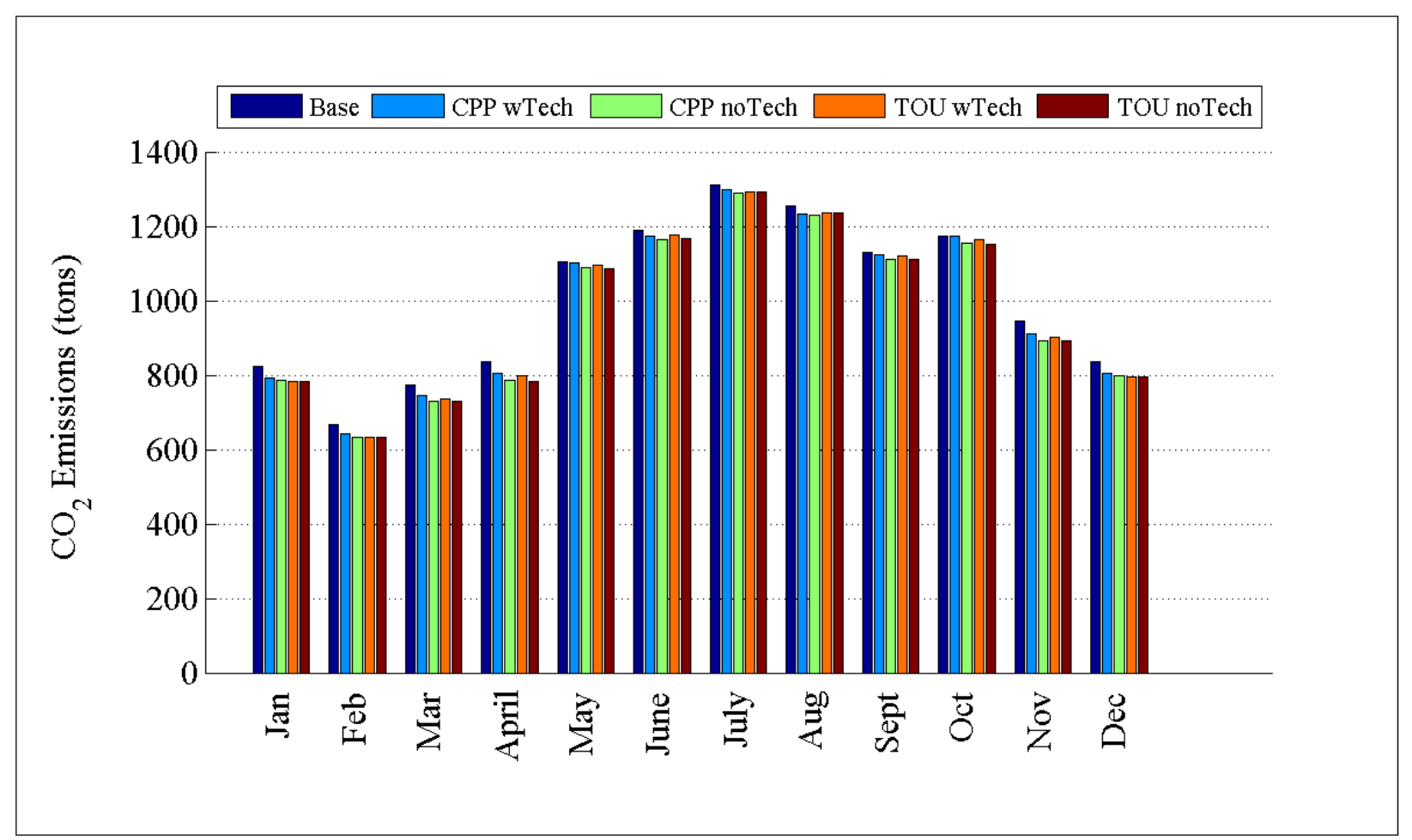

Figure D.100: Comparison of $\mathrm{CO}_{2}$ emissions by month for R5-12.47-4 
D.1.26 Detailed TOU and CPP Plots for R5-12.47-5

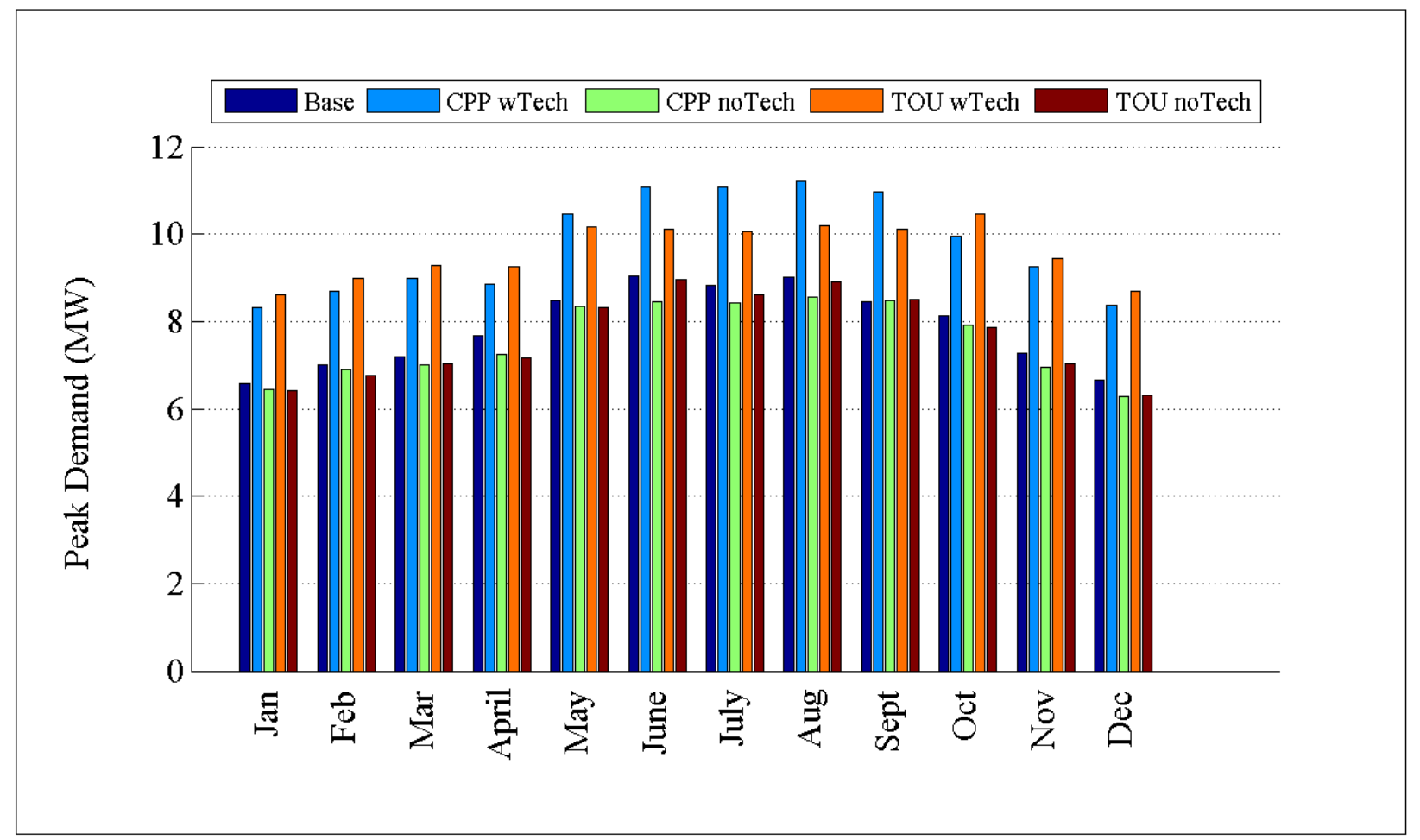

Figure D.101: Comparison of peak demand by month for R5-12.47-5

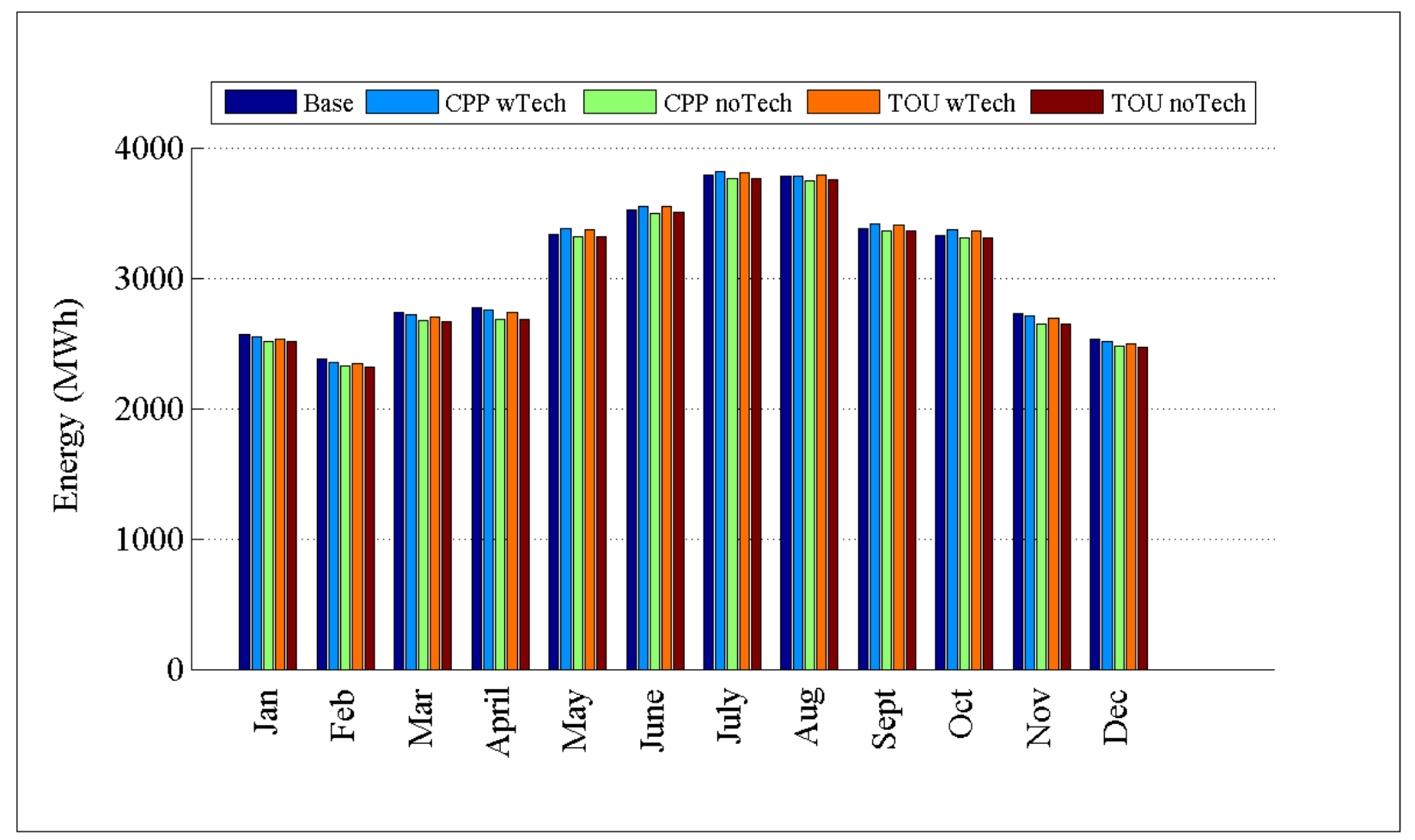

Figure D.102: Comparison of energy consumption by month for R5-12.47-5 


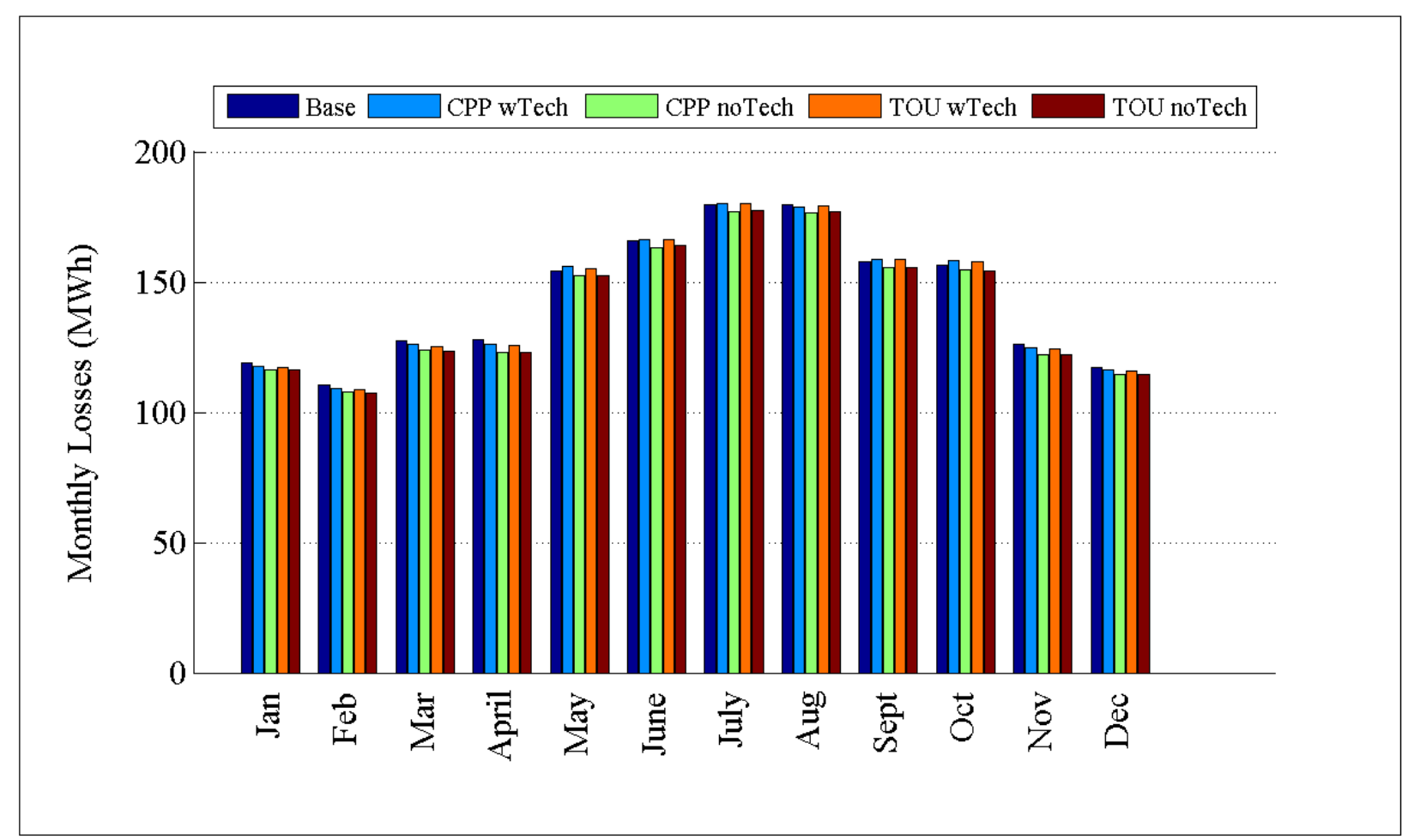

Figure D.103: Comparison of losses by month for R5-12.47-5

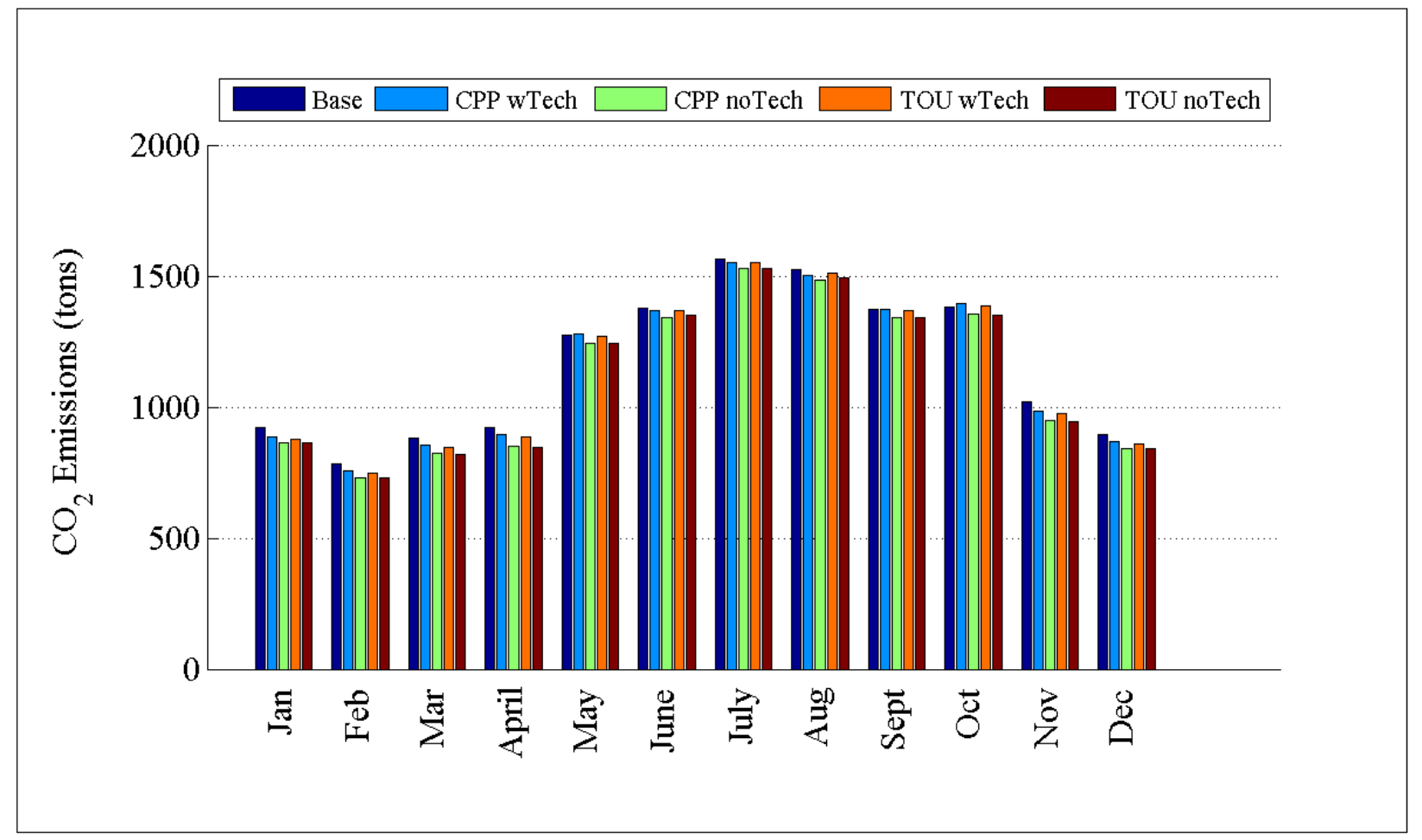

Figure D.104: Comparison of $\mathrm{CO}_{2}$ emissions by month for R5-12.47-5 
D.1.27 Detailed TOU and CPP Plots for R5-25.00-1

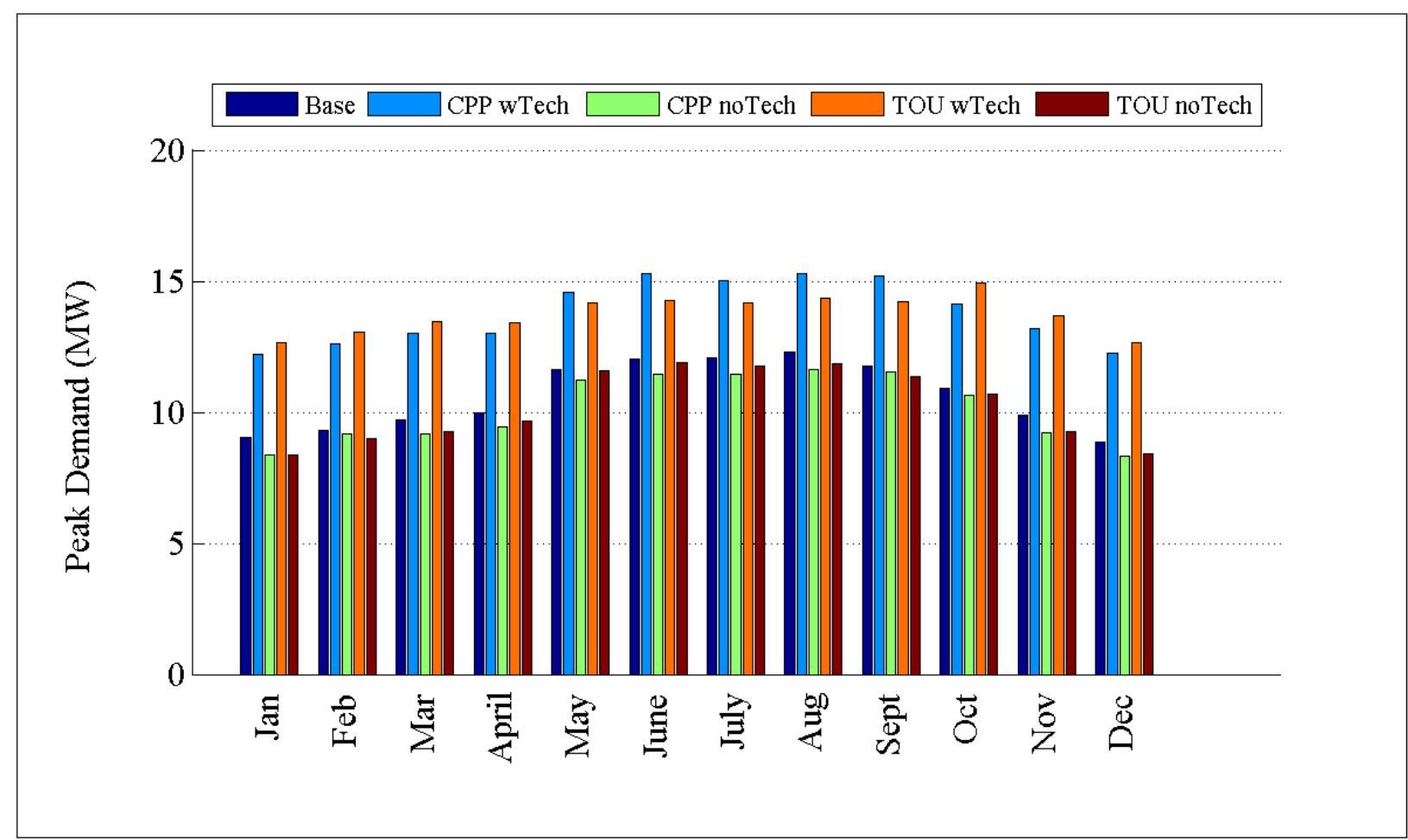

Figure D.105: Comparison of peak demand by month for R5-25.00-1

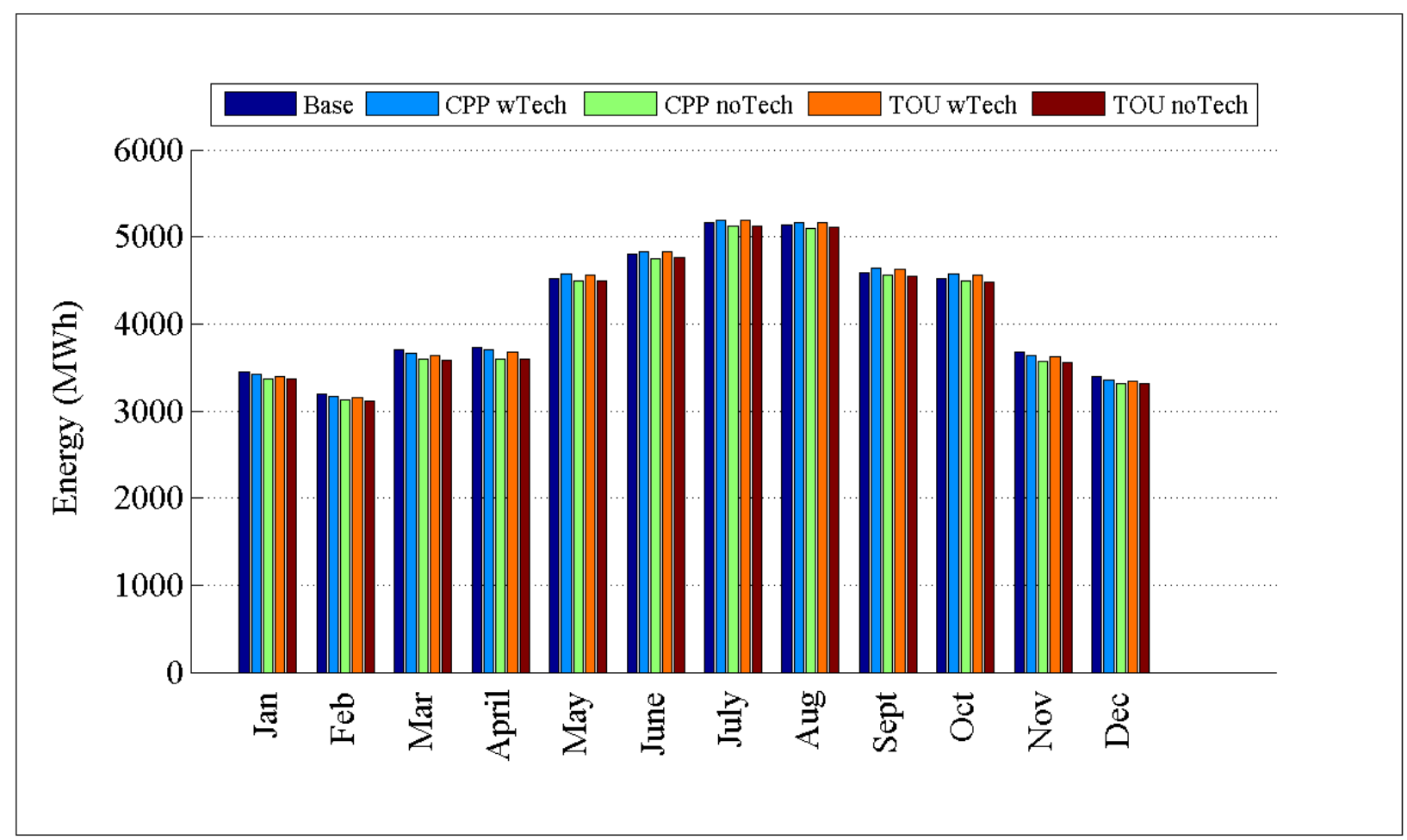


Figure D.106: Comparison of energy consumption by month for R5-25.00-1

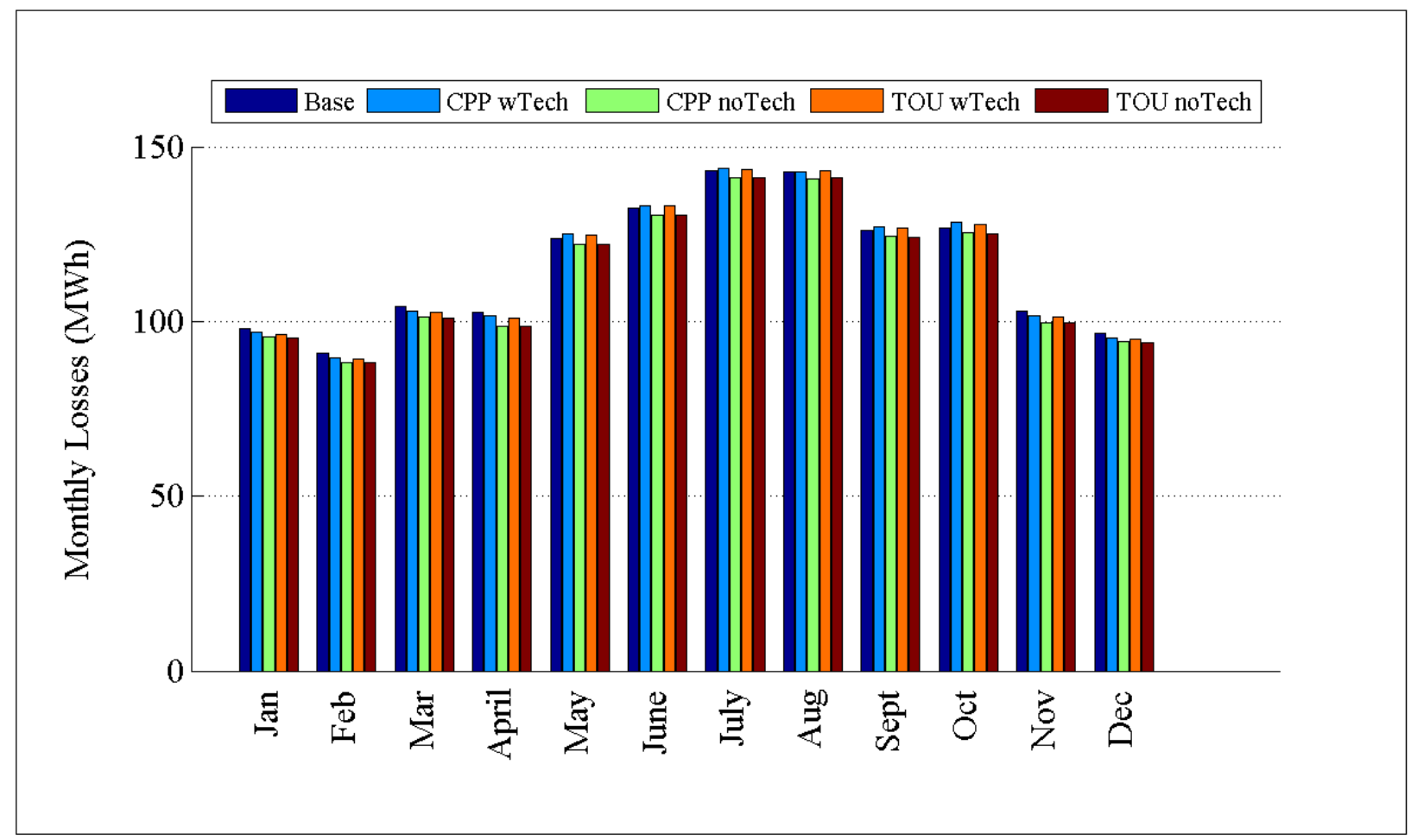

Figure D.107: Comparison of losses by month for R5-25.00-1

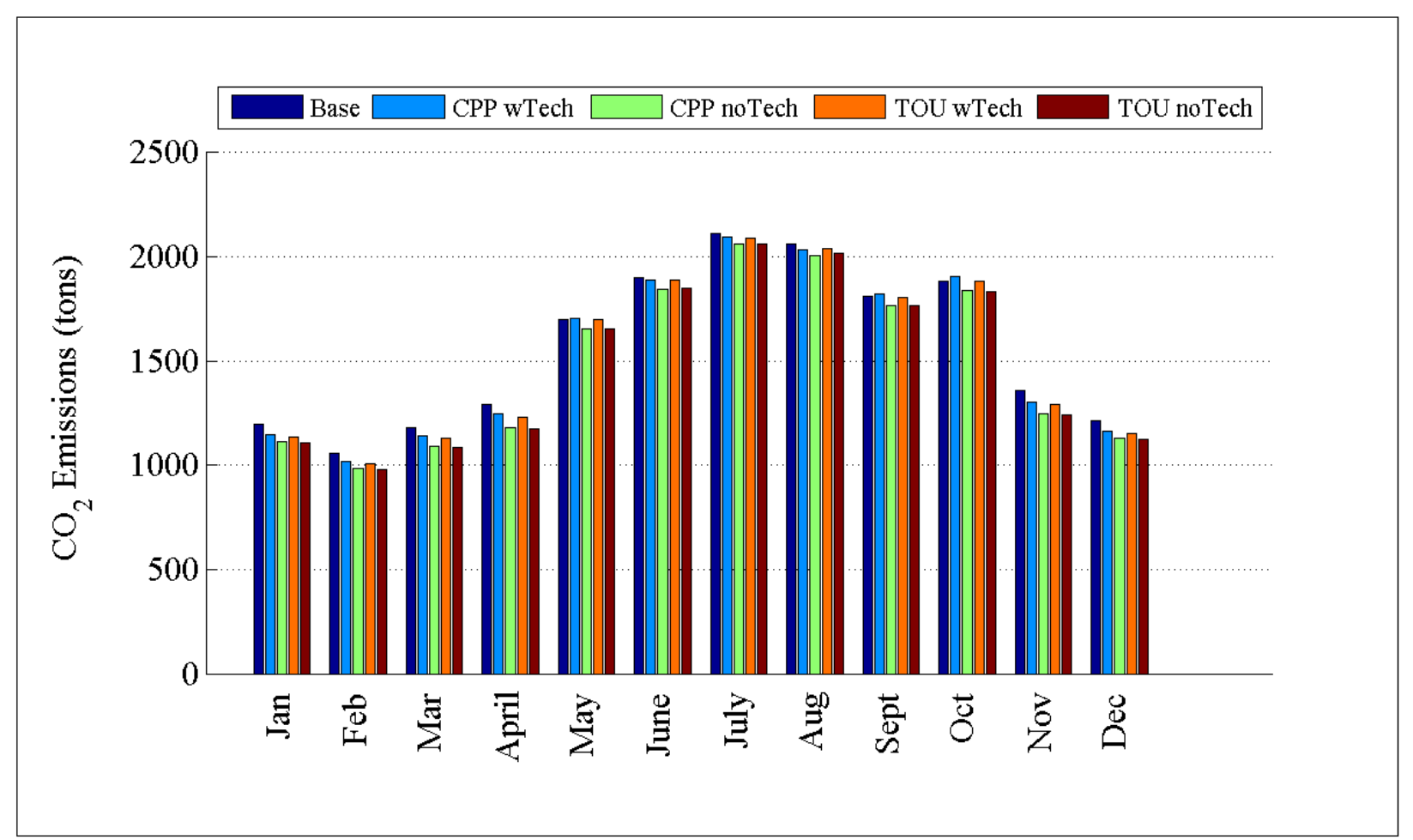

Figure D.108: Comparison of $\mathrm{CO}_{2}$ emissions by month for R5-25.00-1 


\section{D.1.28 Detailed TOU and CPP Plots for R5-35.00-1}

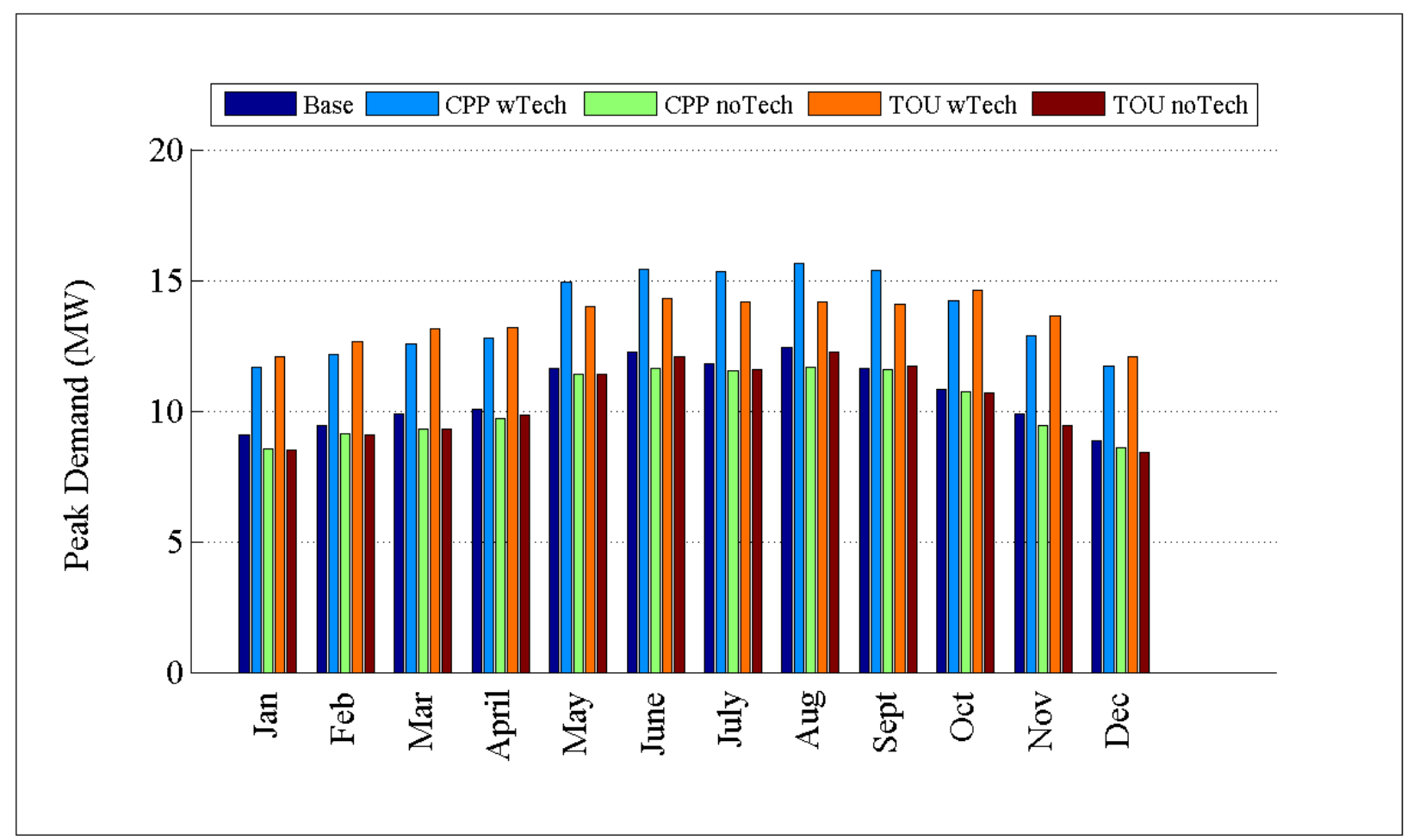

Figure D.109: Comparison of peak demand by month for R5-35.00-1 


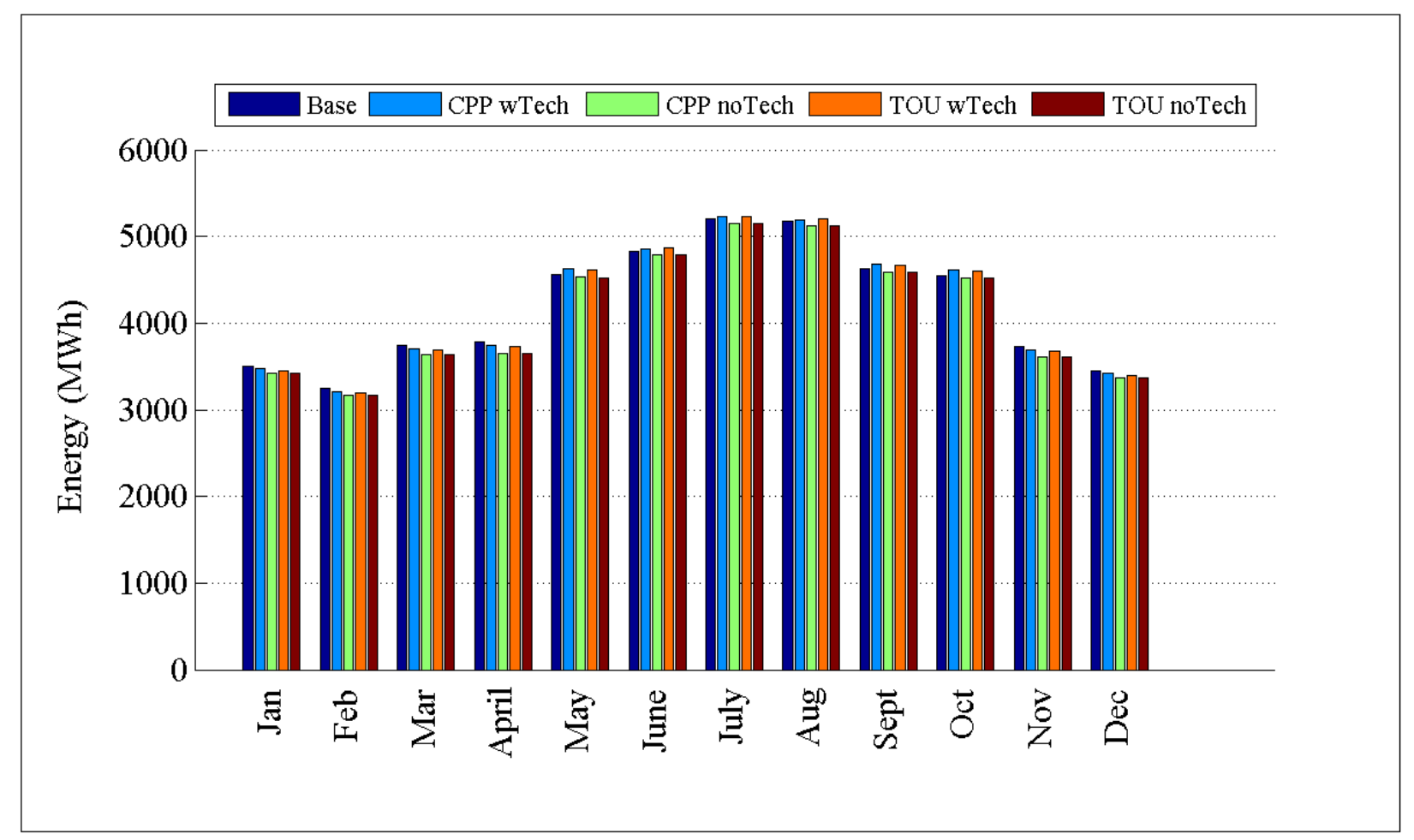

Figure D.110: Comparison of energy consumption by month for R5-35.00-1

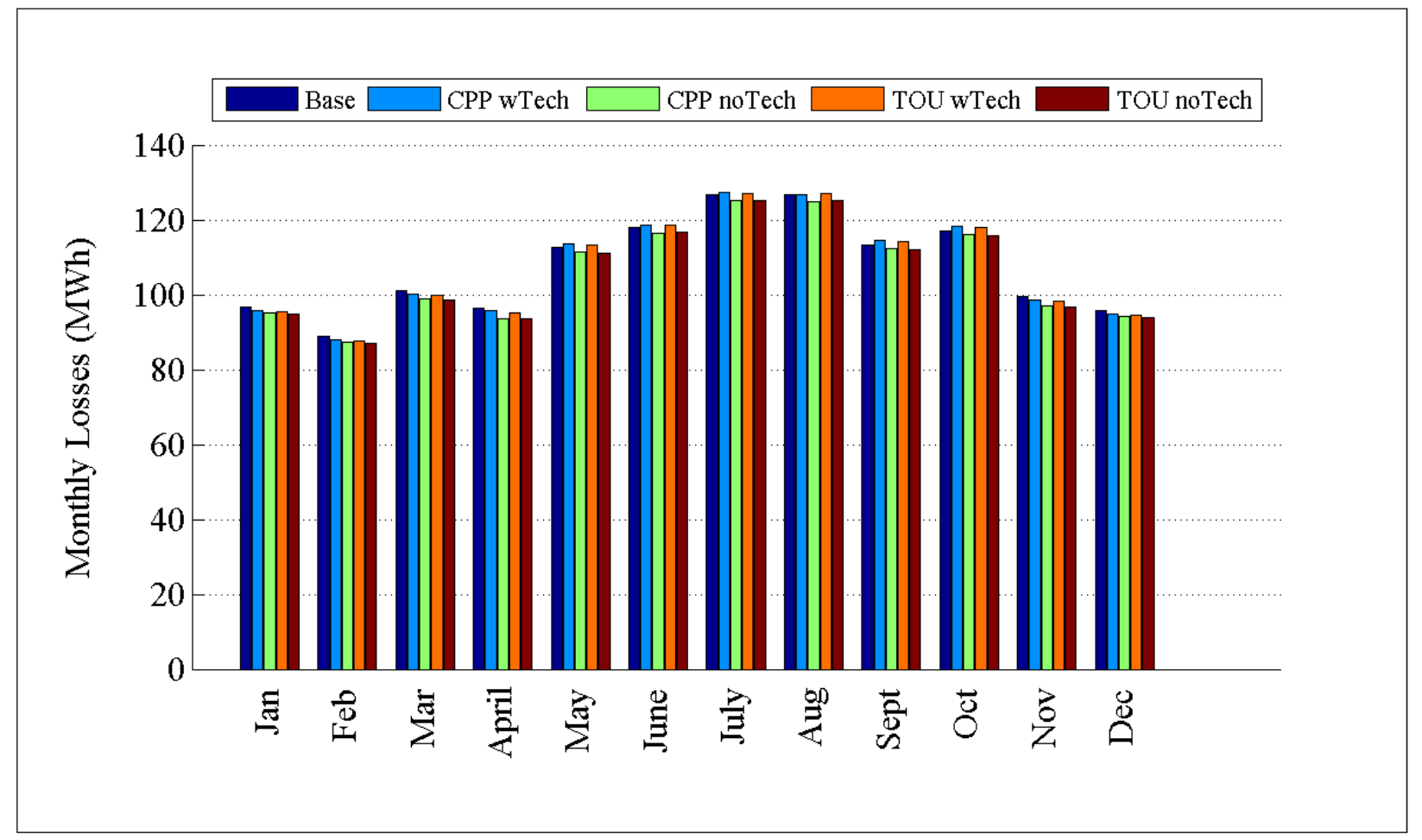

Figure D.111: Comparison of losses by month for R5-35.00-1 


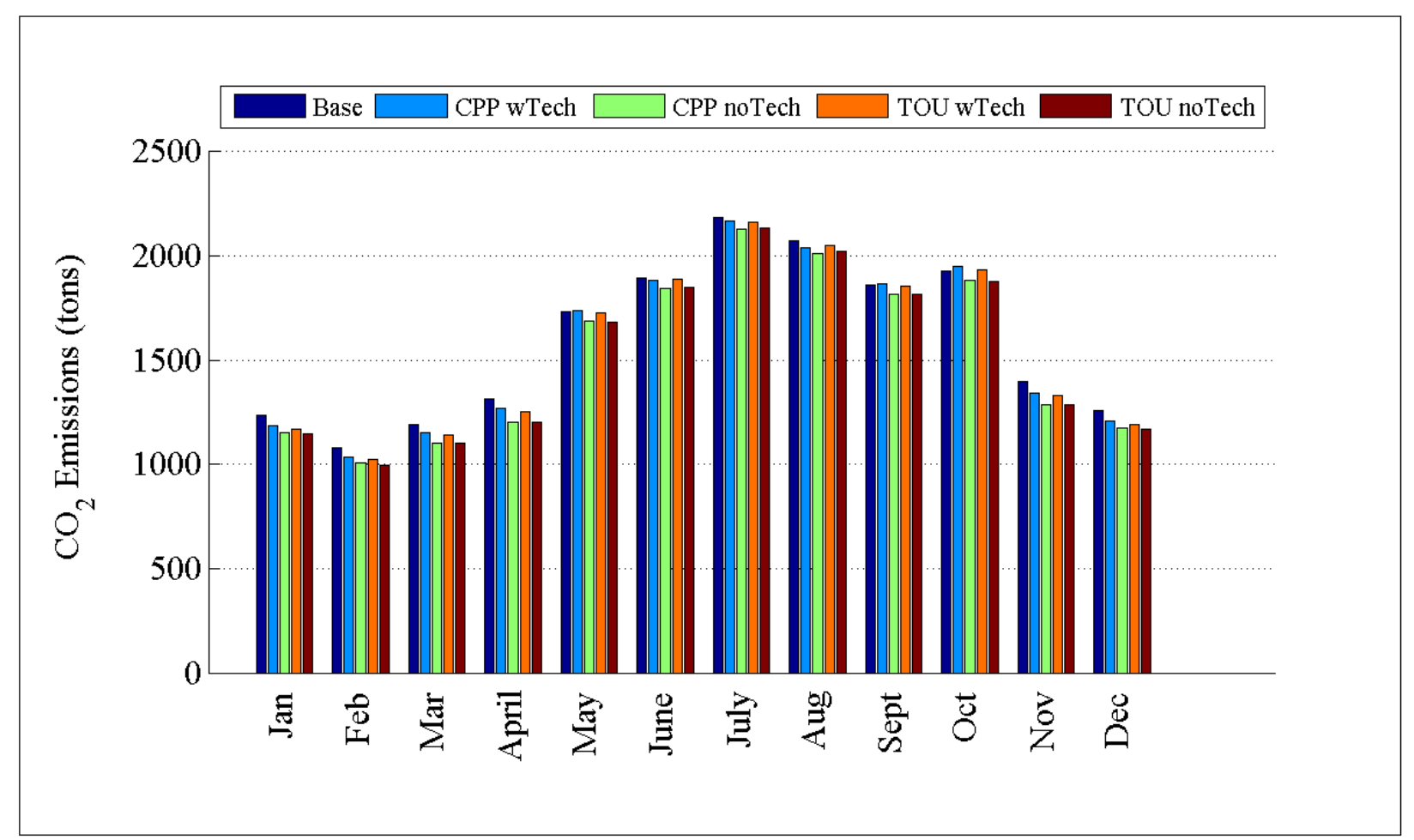

Figure D.112: Comparison of $\mathrm{CO}_{2}$ emissions by month for R5-35.00-1

\section{D.2 DLC Plots}

Consistent with the plots shown in Section 3.2.1, peak monthly demand, monthly energy consumption, monthly losses, and monthly $\mathrm{CO} 2$ emissions are plotted. Each graphic contains the base case and the DLC case. 
D.2.1 Detailed DLC Plots for GC-12.47-1_R1

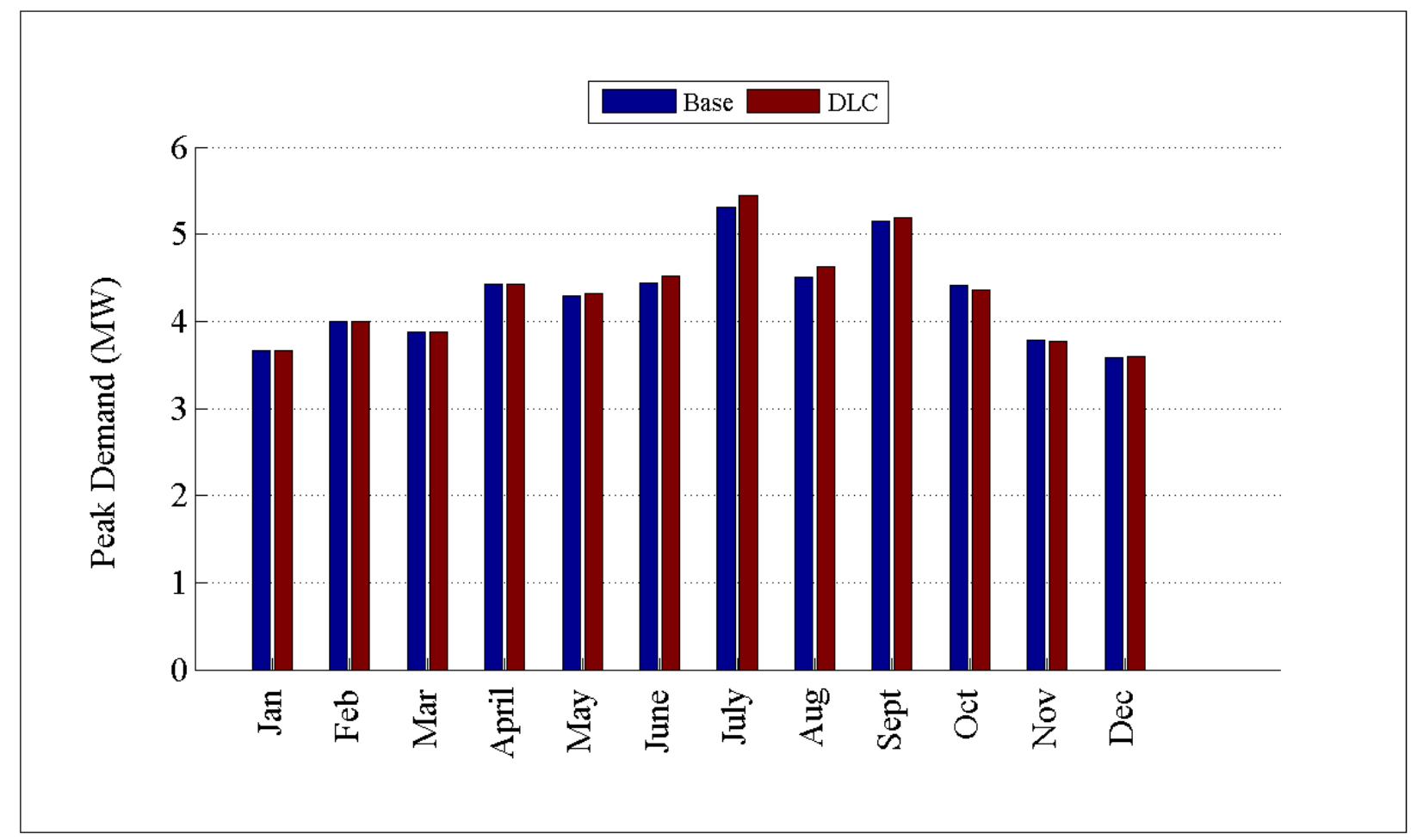

Figure D.113: Comparison of peak demand by month for GC-12.47-1_R1

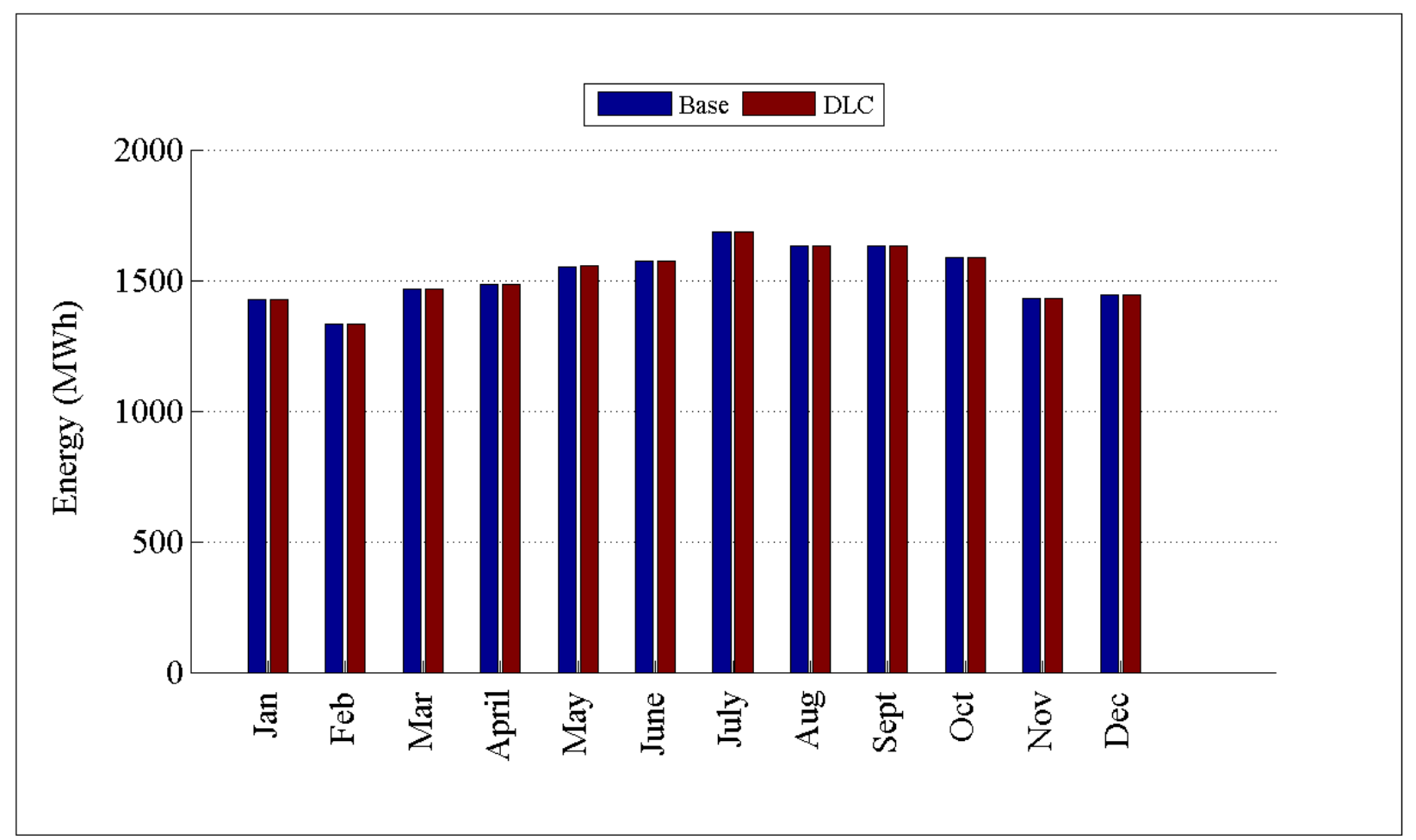

Figure D.114: Comparison of energy consumption by month for GC-12.47-1_R1 


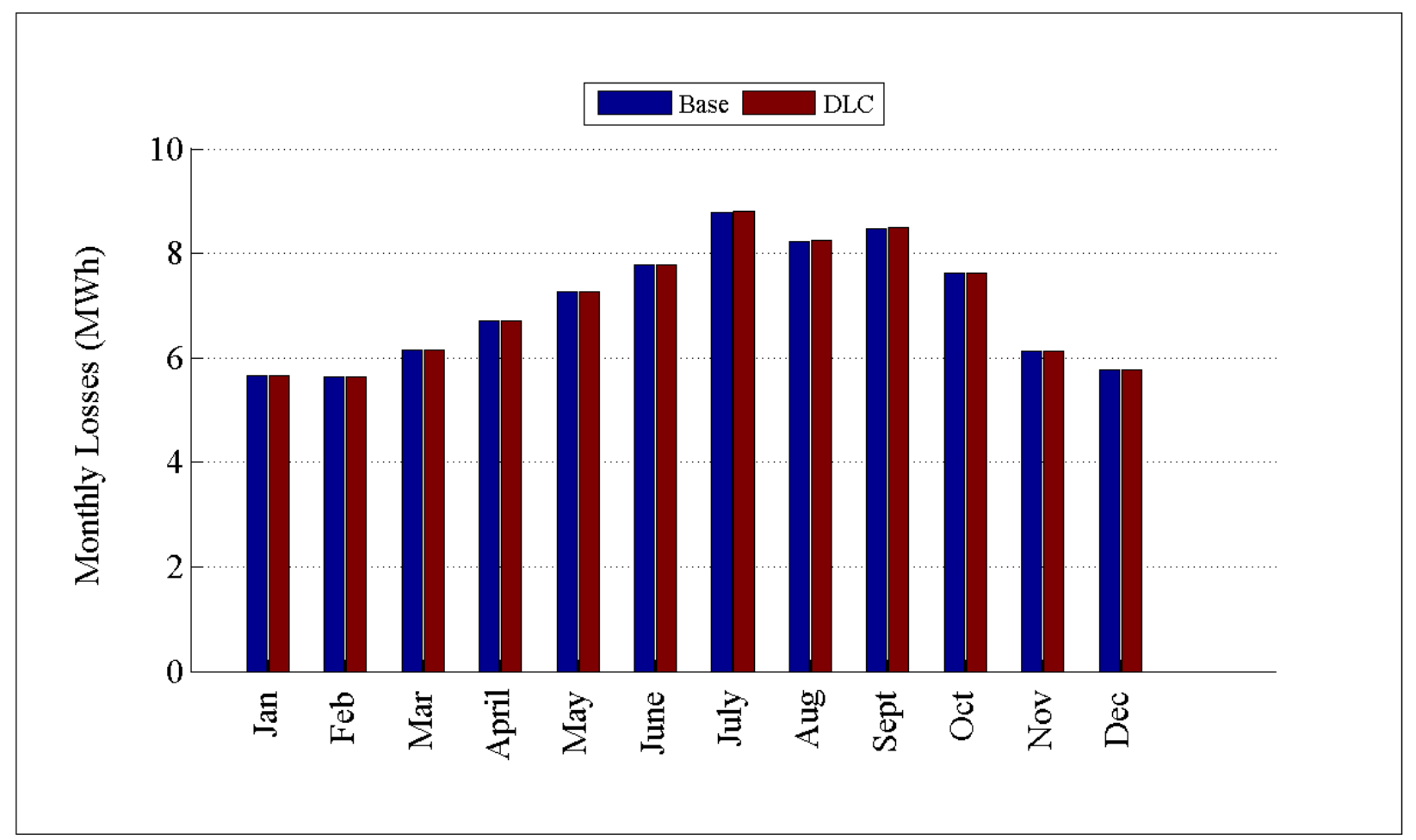

Figure D.115: Comparison of losses by month for GC-12.47-1_R1

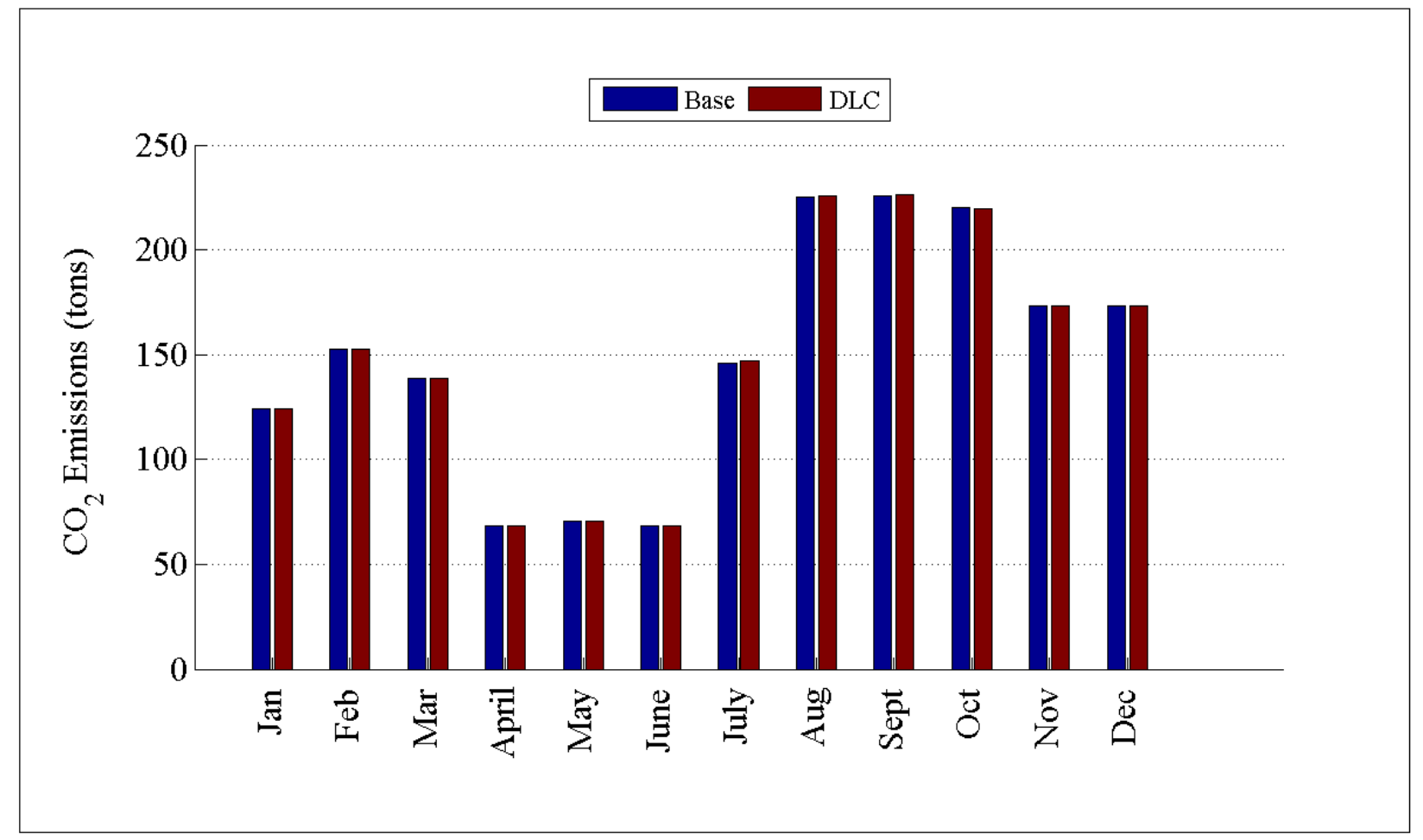

Figure D.116: Comparison of $\mathrm{CO}_{2}$ emissions by month for GC-12.47-1_R1 
D.2.2 Detailed DLC Plots for R1-12.47-1

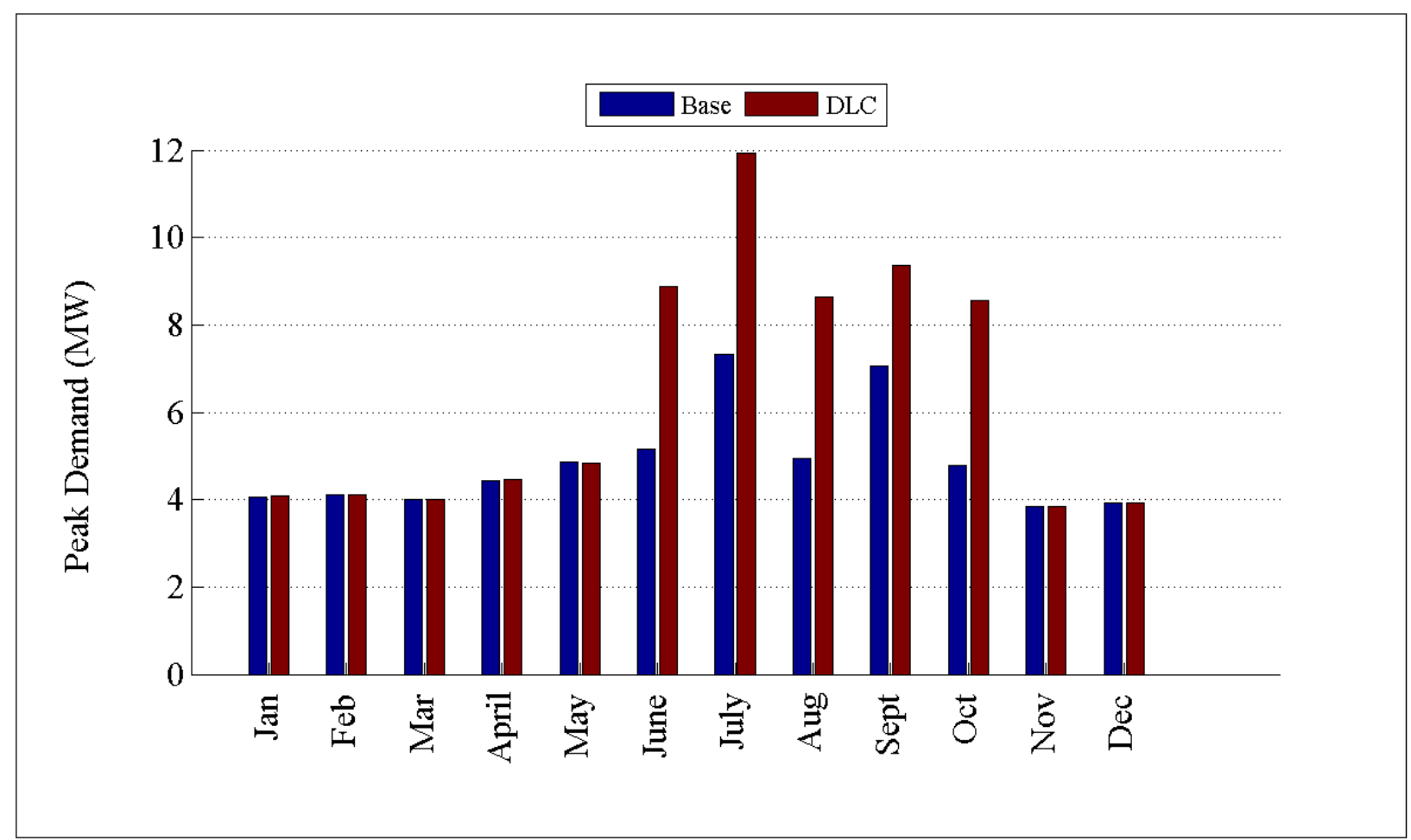

Figure D.117: Comparison of peak demand by month for R1-12.47-1

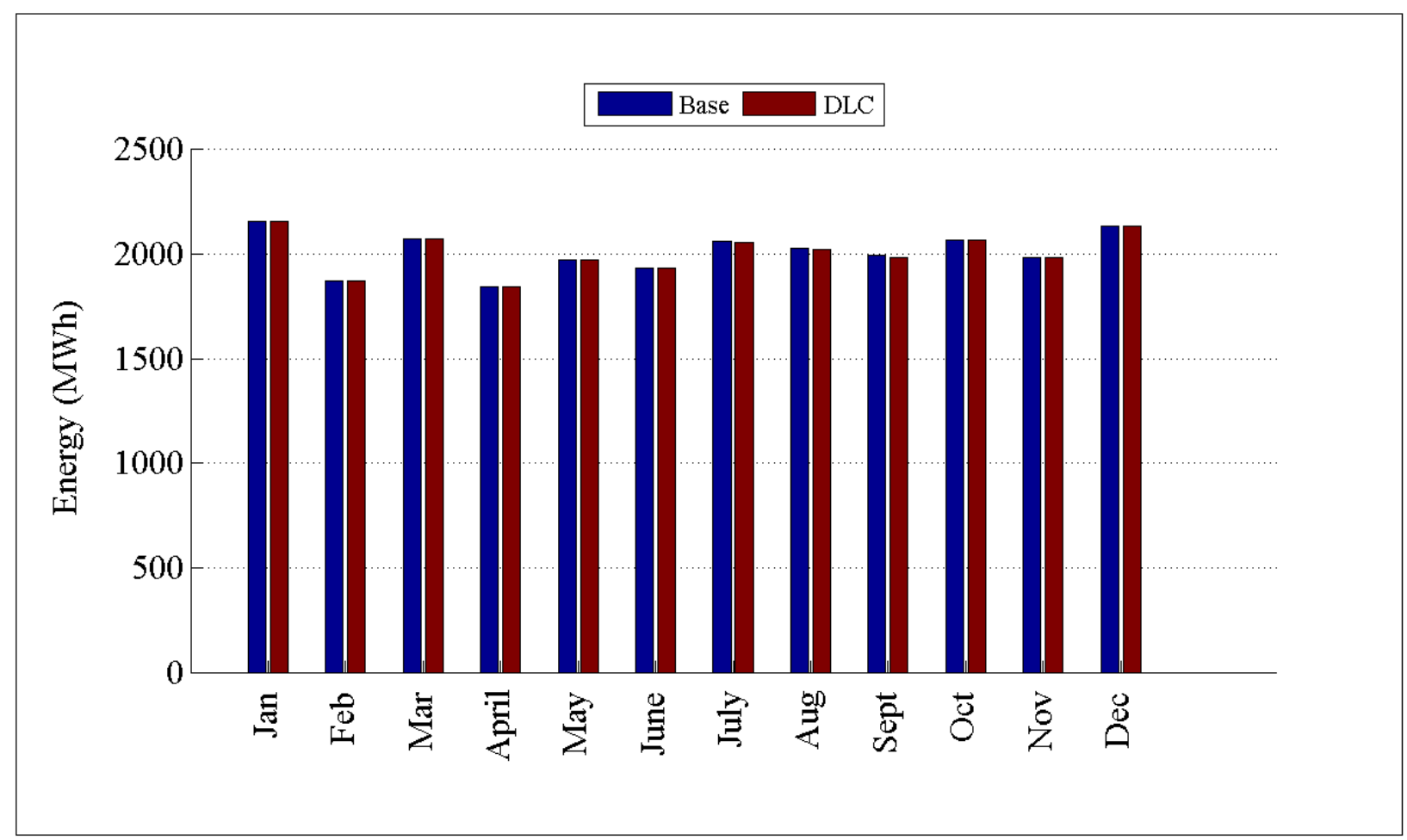


Figure D.118: Comparison of energy consumption by month for R1-12.47-1

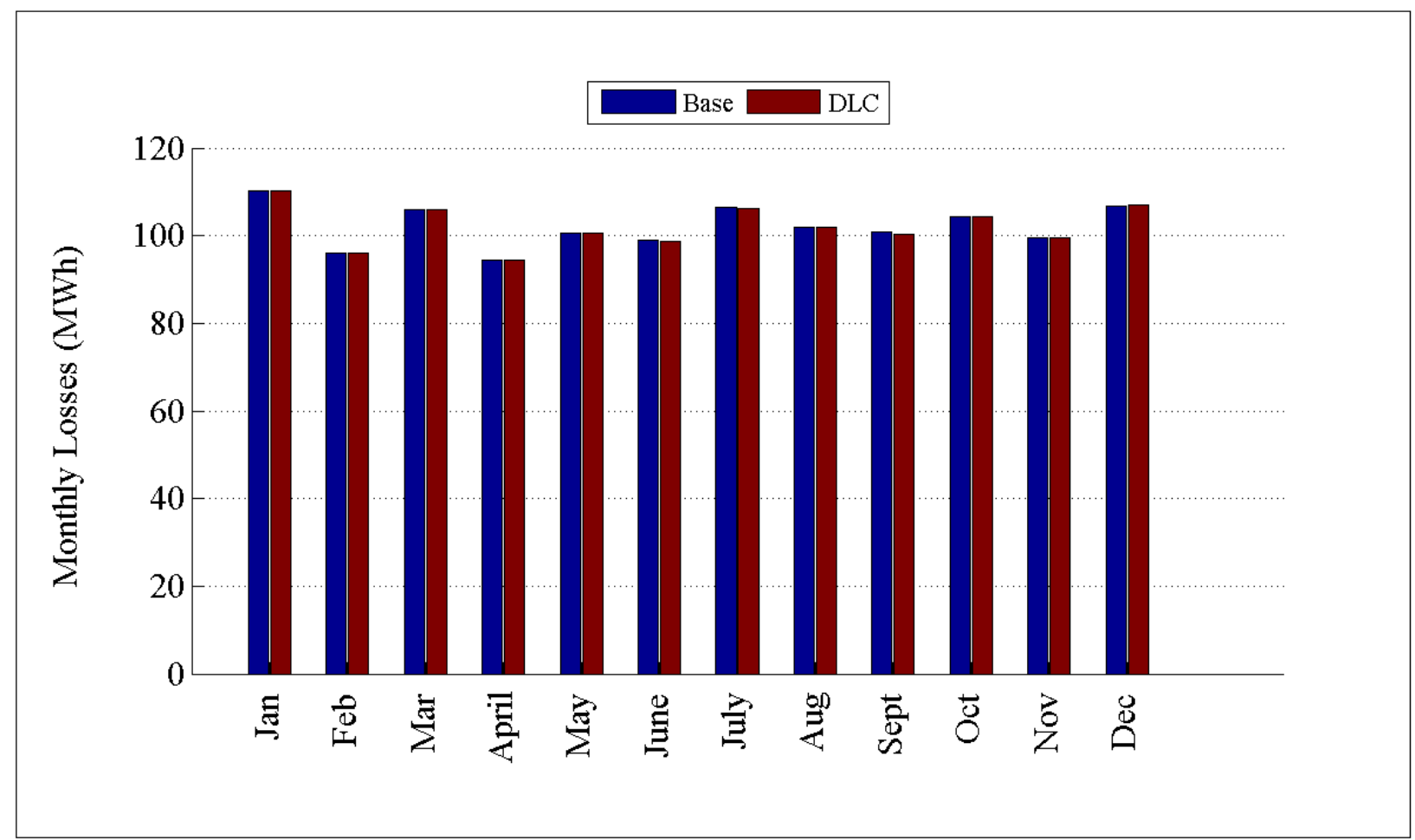

Figure D.119: Comparison of losses by month for R1-12.47-1

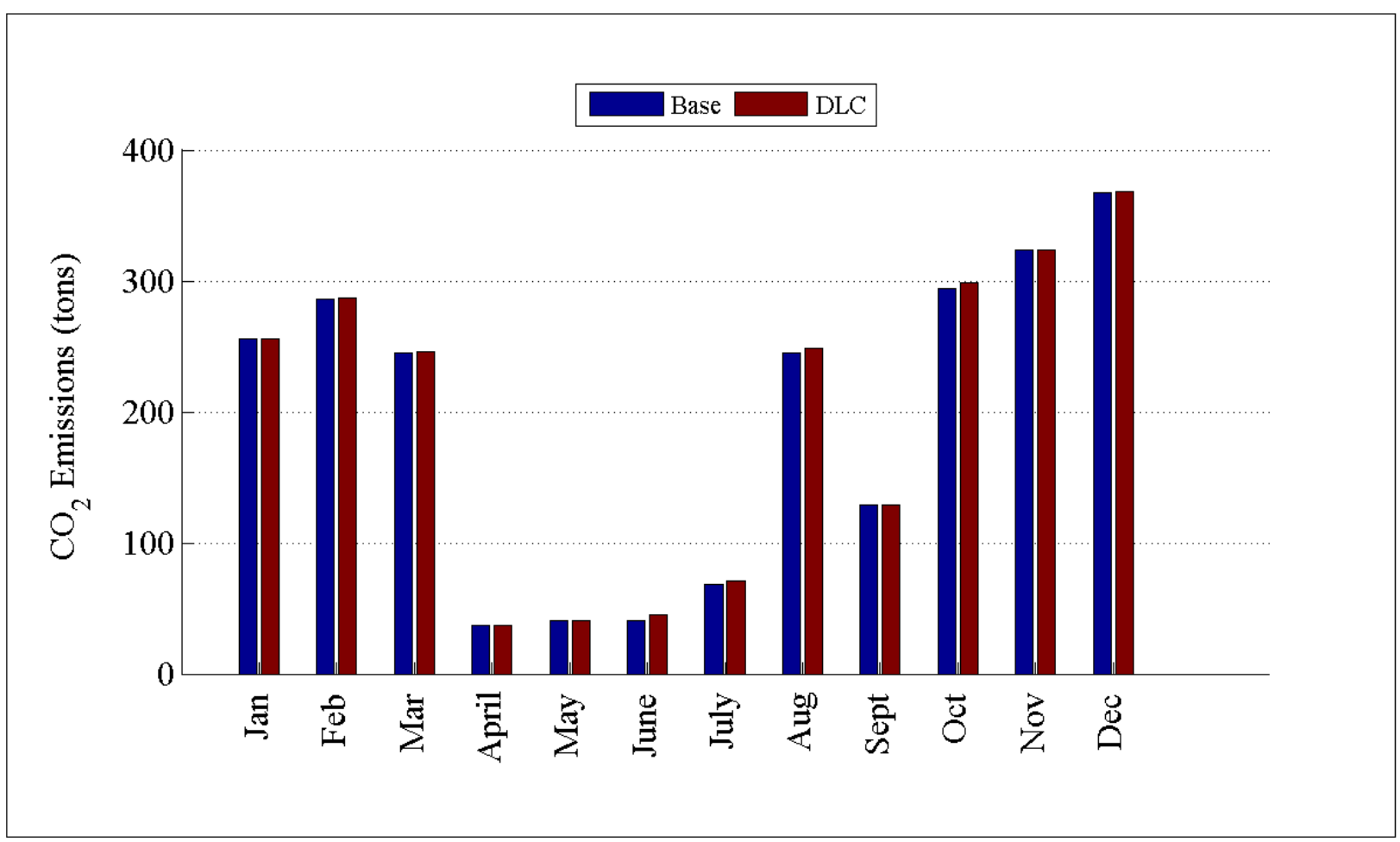

Figure D.120: Comparison of $\mathrm{CO}_{2}$ emissions by month for R1-12.47-1 
D.2.3 Detailed DLC Plots for R1-12.47-2

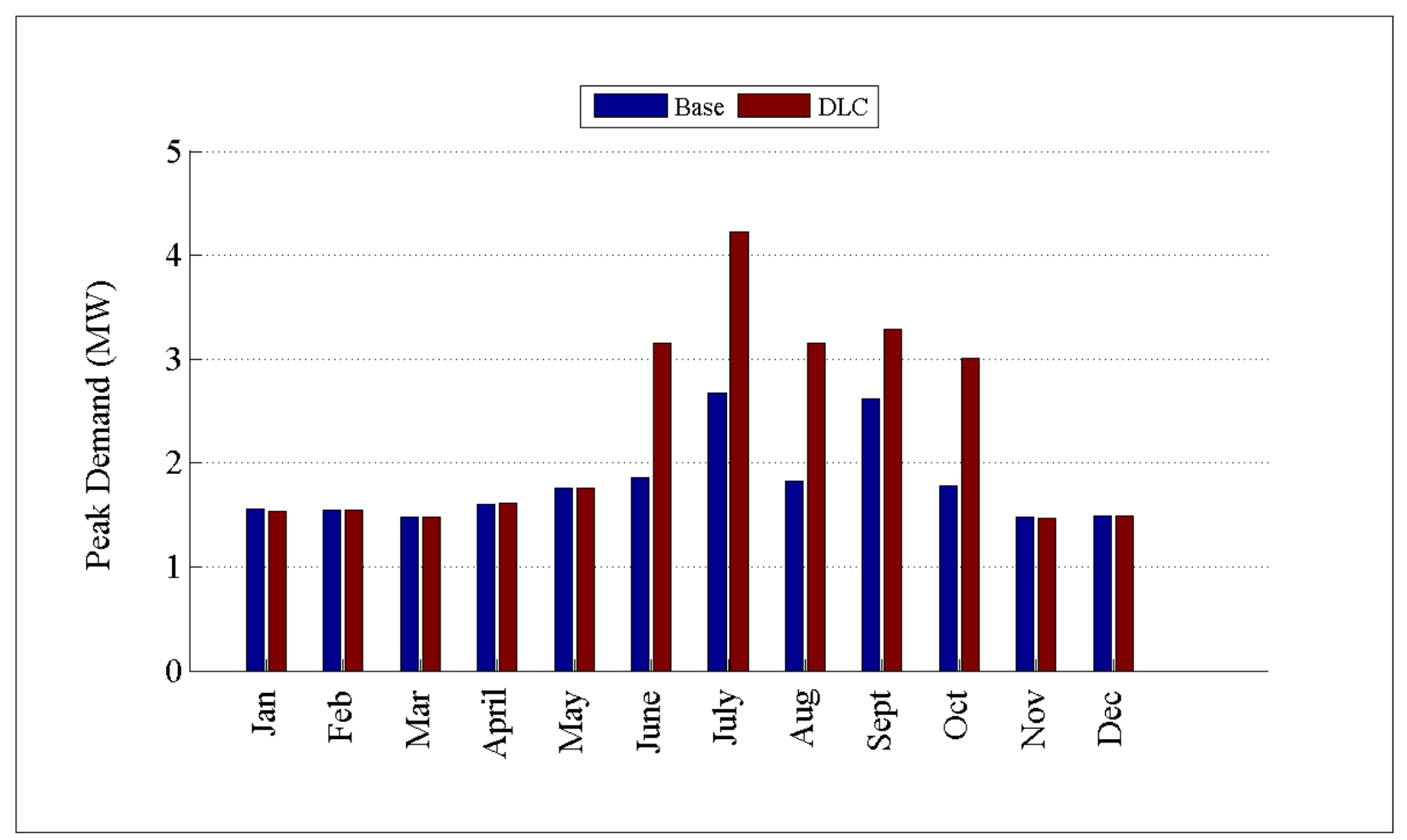

Figure D.121: Comparison of peak demand by month for R1-12.47-2 


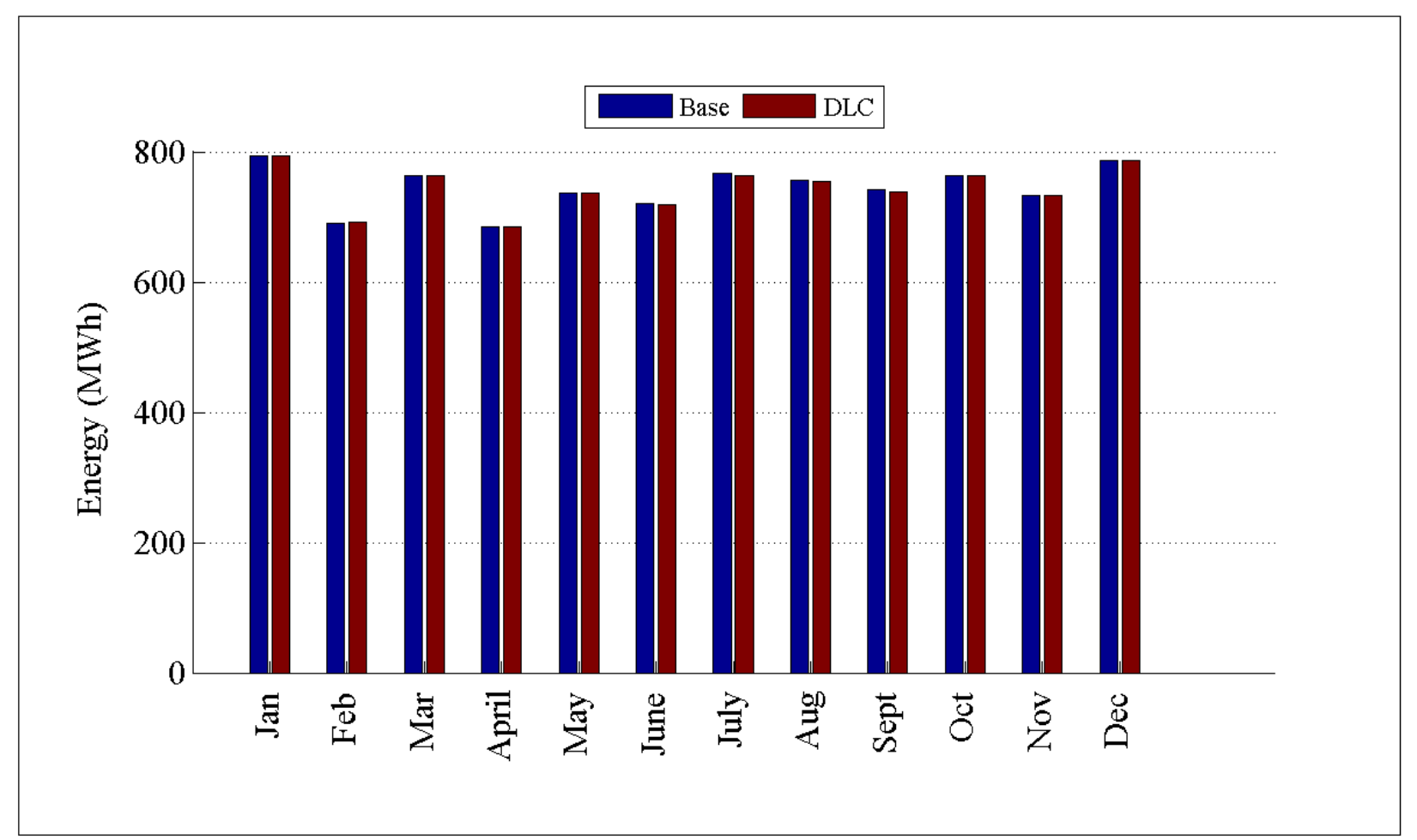

Figure D.122: Comparison of energy consumption by month for R1-12.47-2

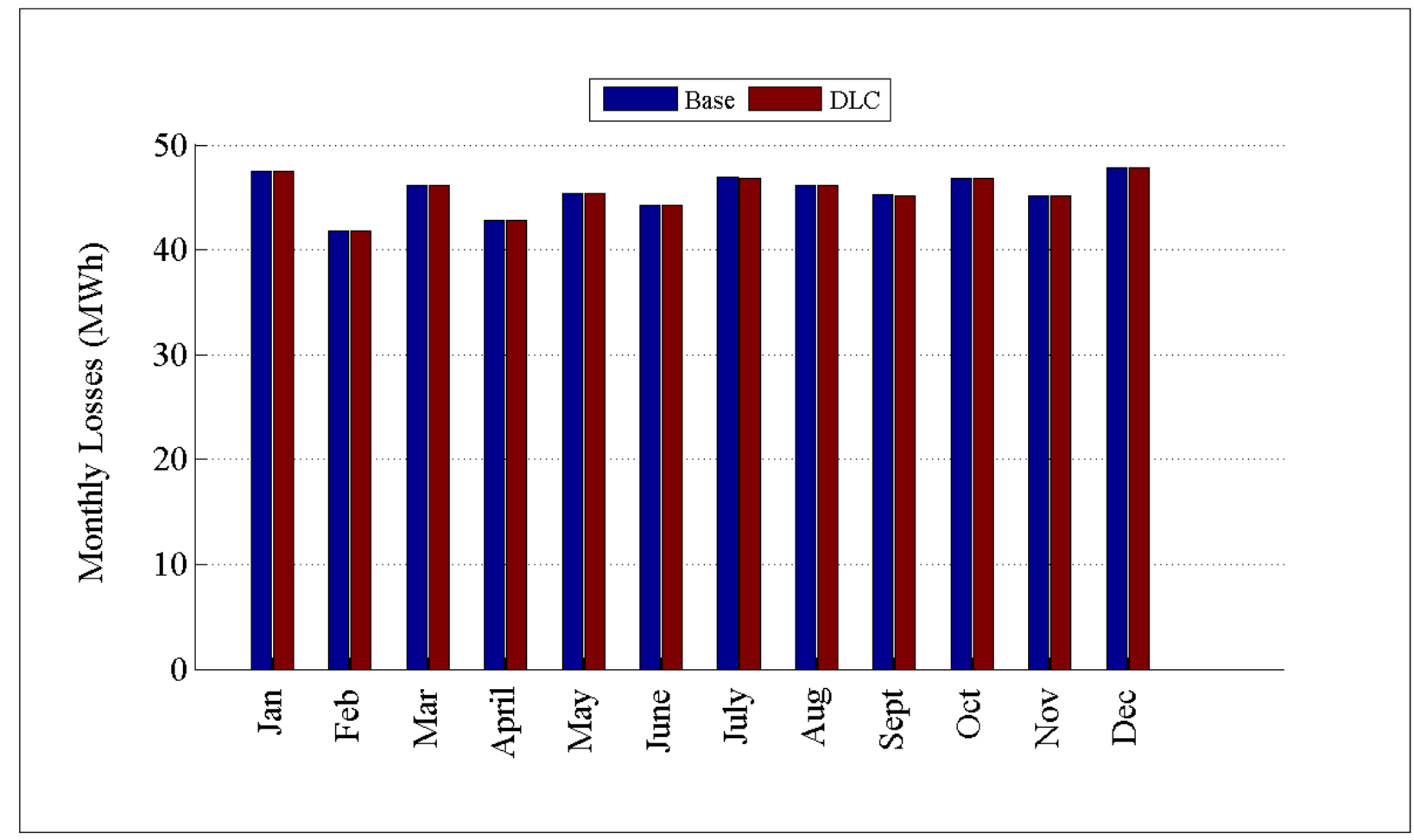

Figure D.123: Comparison of losses by month for R1-12.47-2 


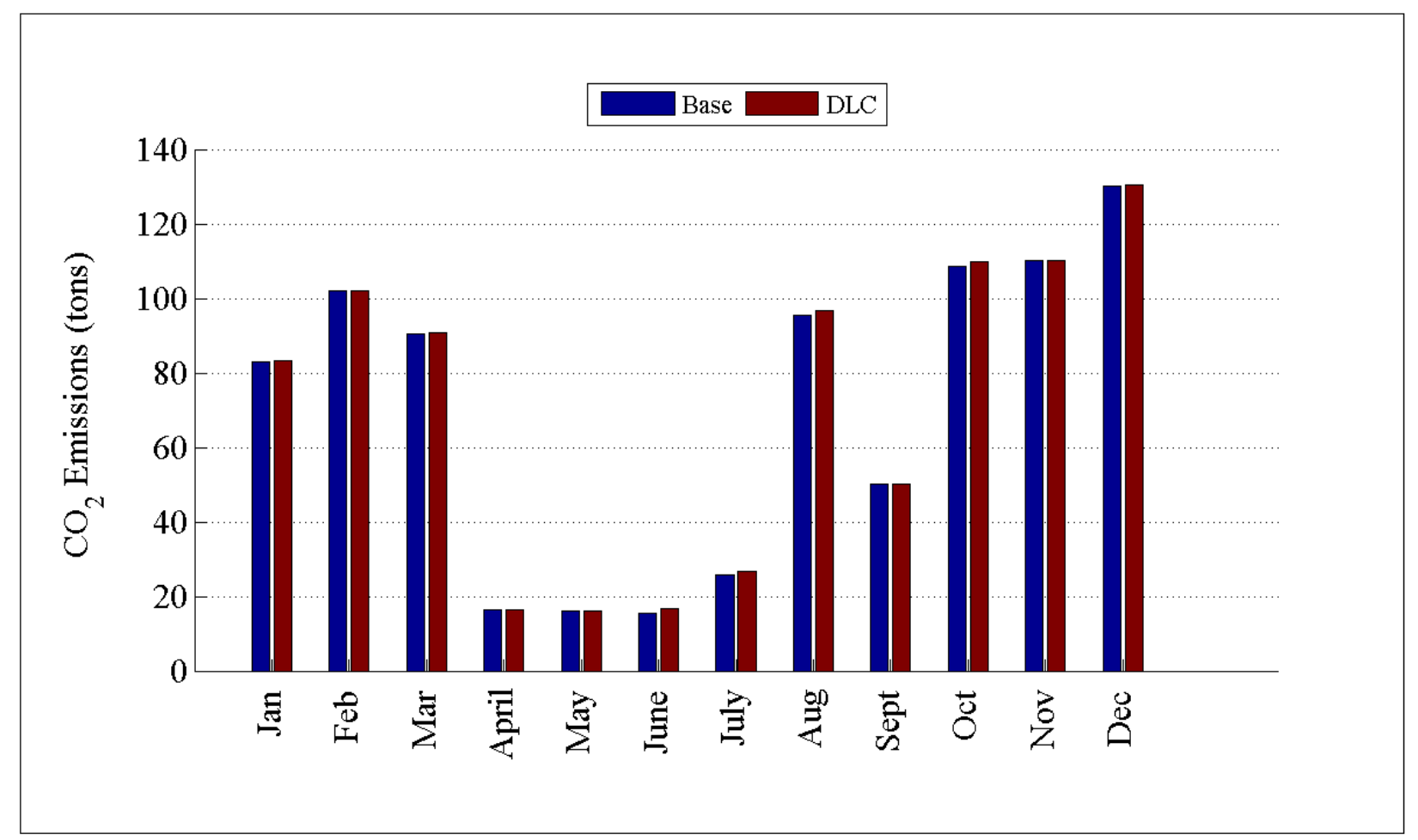

Figure D.124: Comparison of $\mathrm{CO}_{2}$ emissions by month for R1-12.47-2

D.2.4 Detailed DLC Plots for R1-12.47-3 


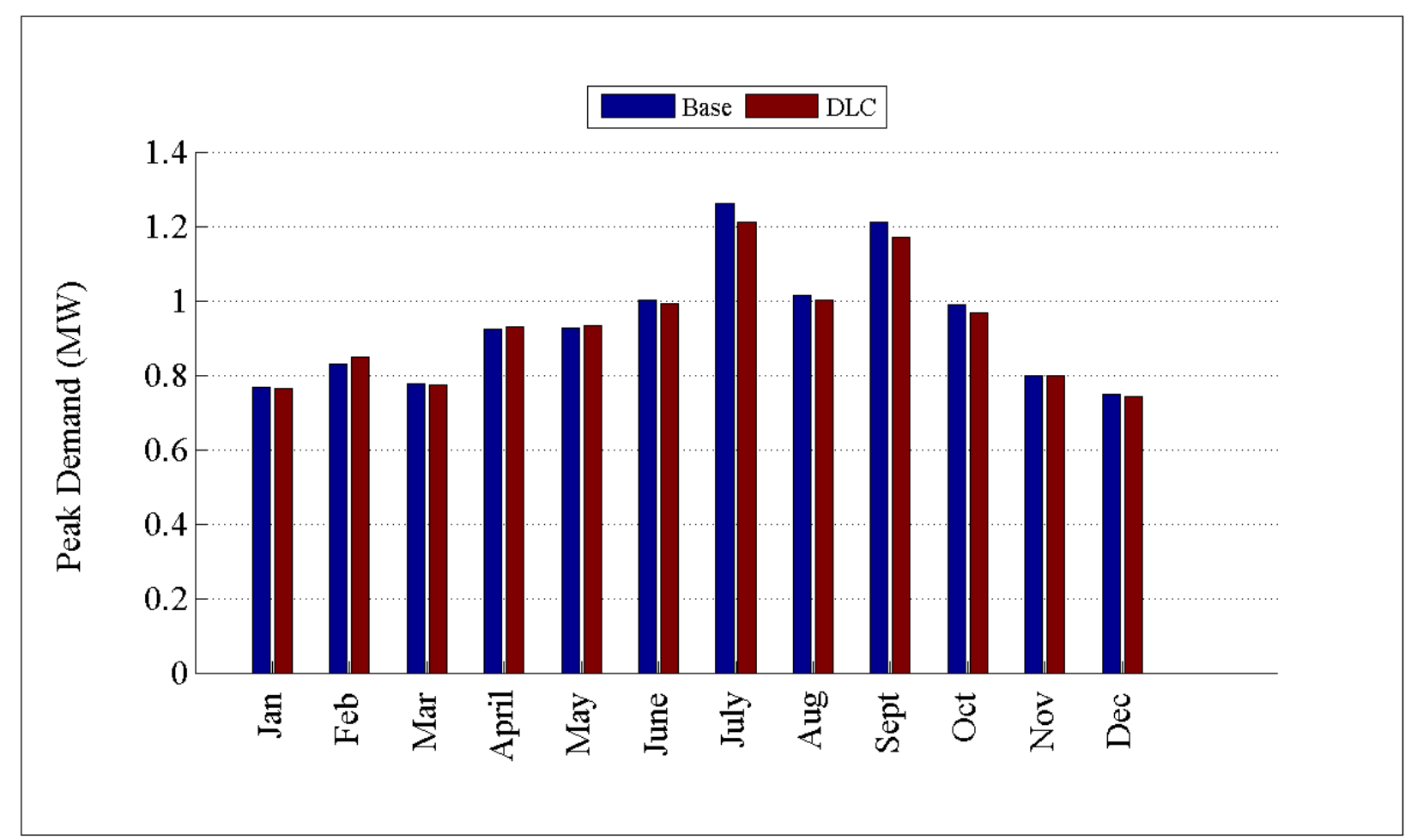

Figure D.125: Comparison of peak demand by month for R1-12.47-3

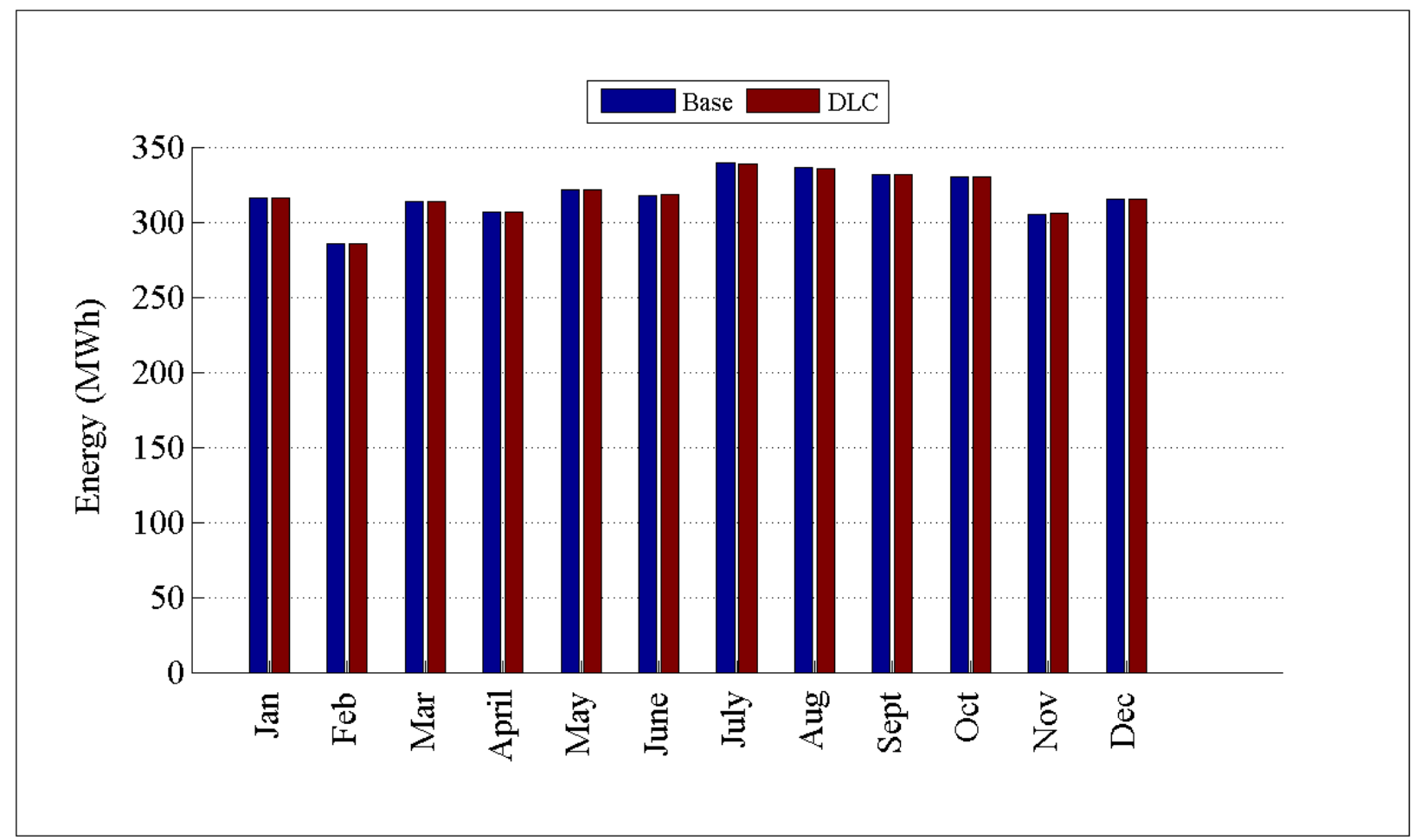

Figure D.126: Comparison of energy consumption by month for R1-12.47-3 


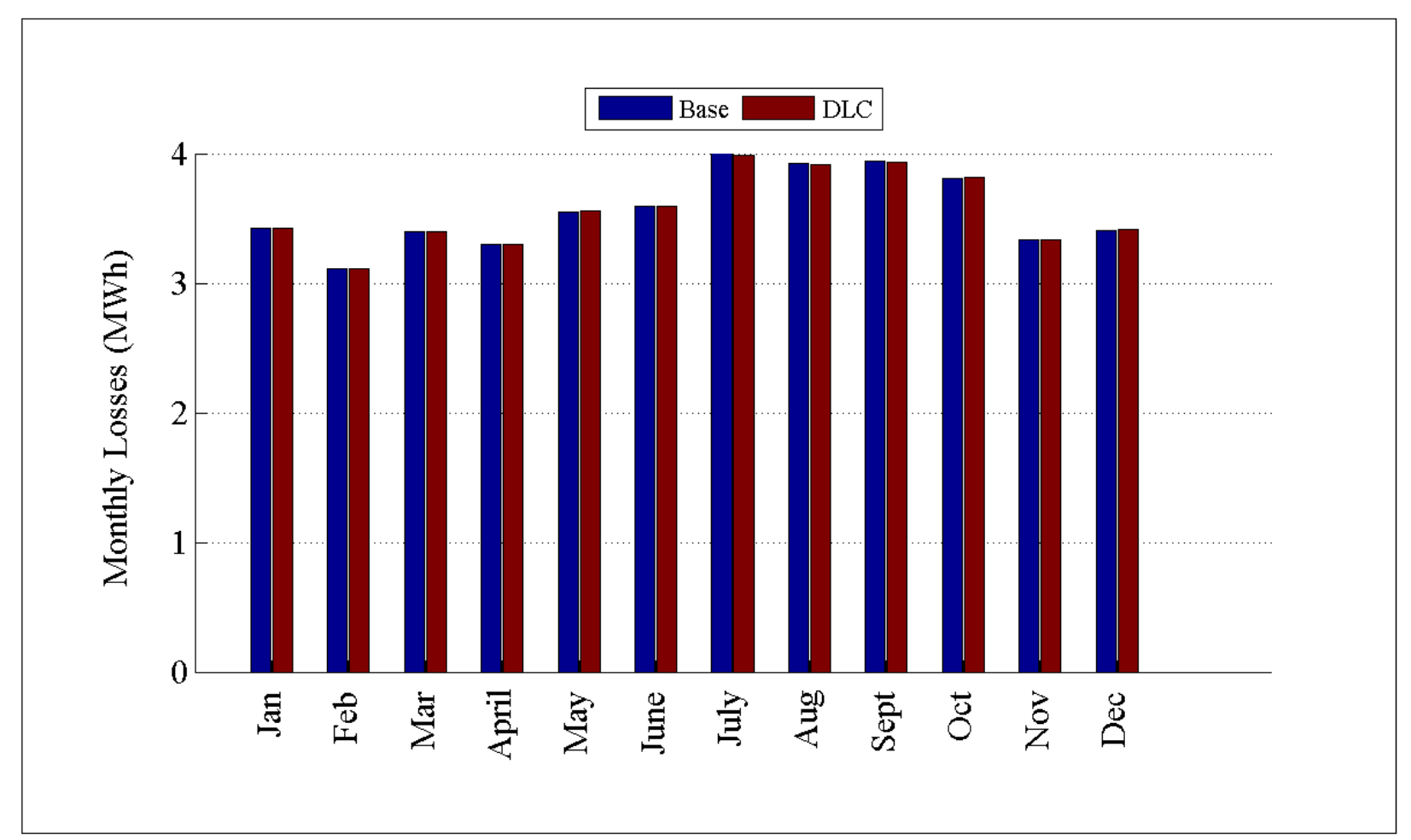

Figure D.127: Comparison of losses by month for R1-12.47-3

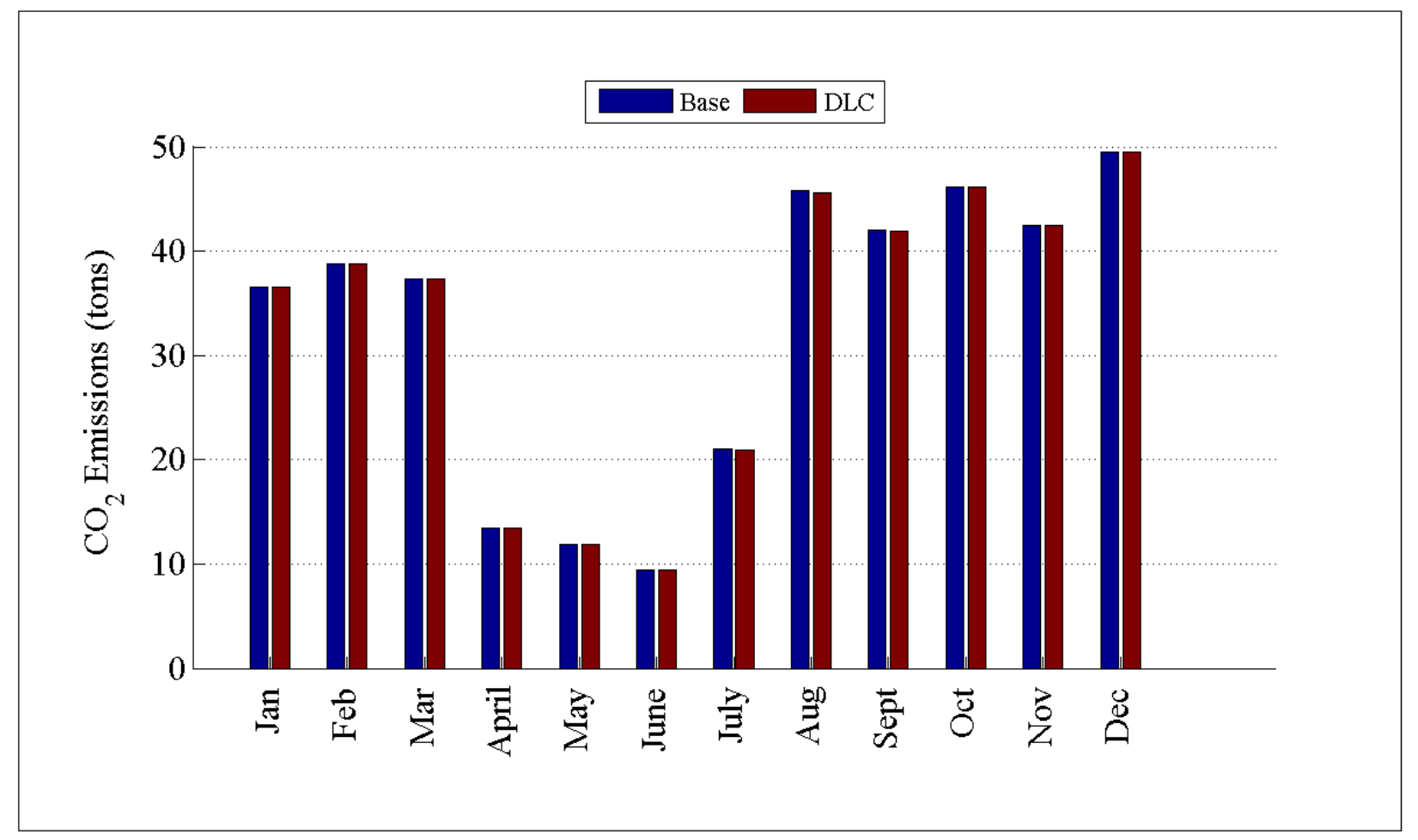

Figure D.128: Comparison of $\mathrm{CO}_{2}$ emissions by month for R1-12.47-3 
D.2.5 Detailed DLC Plots for R1-12.47-4

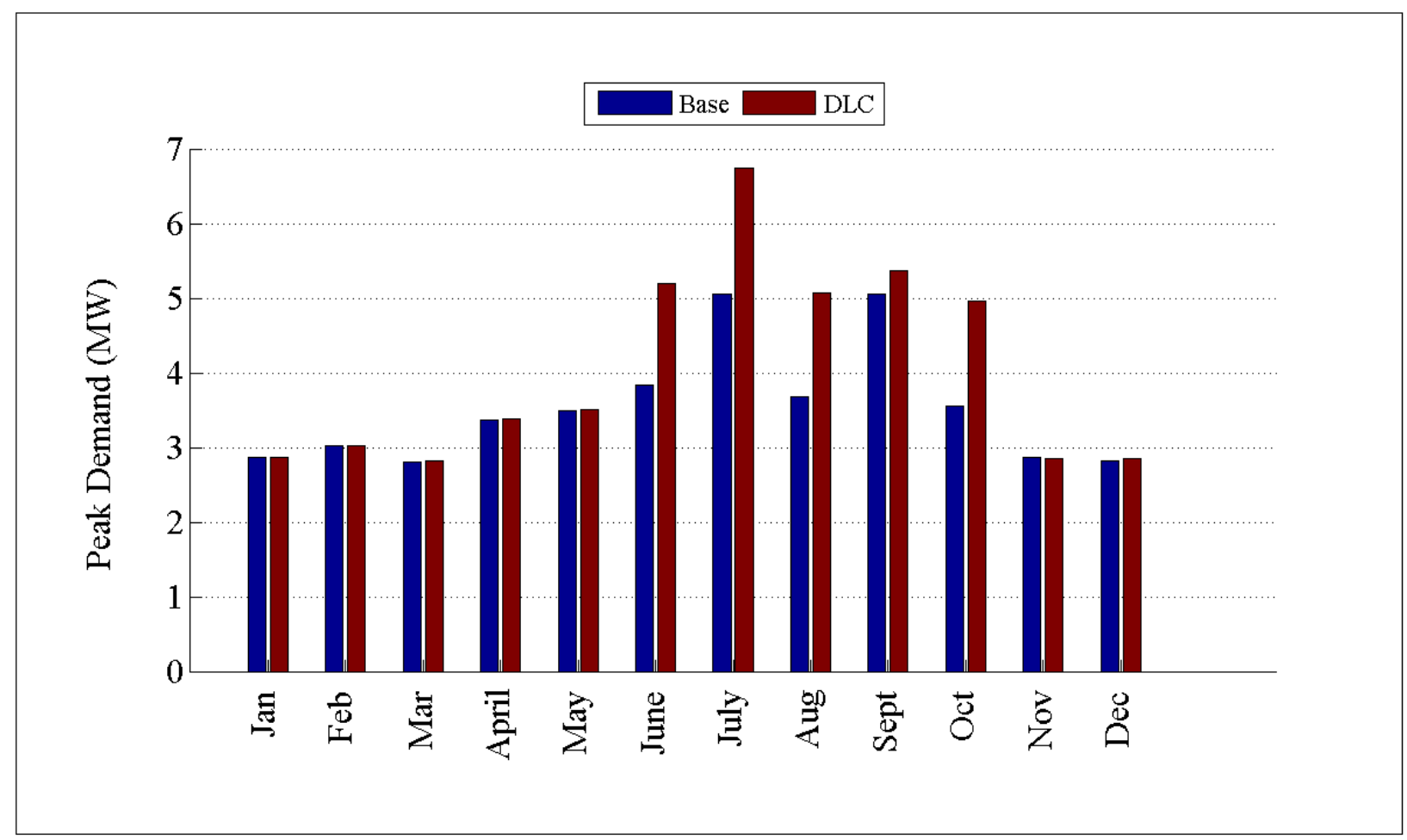

Figure D.129: Comparison of peak demand by month for R1-12.47-4 


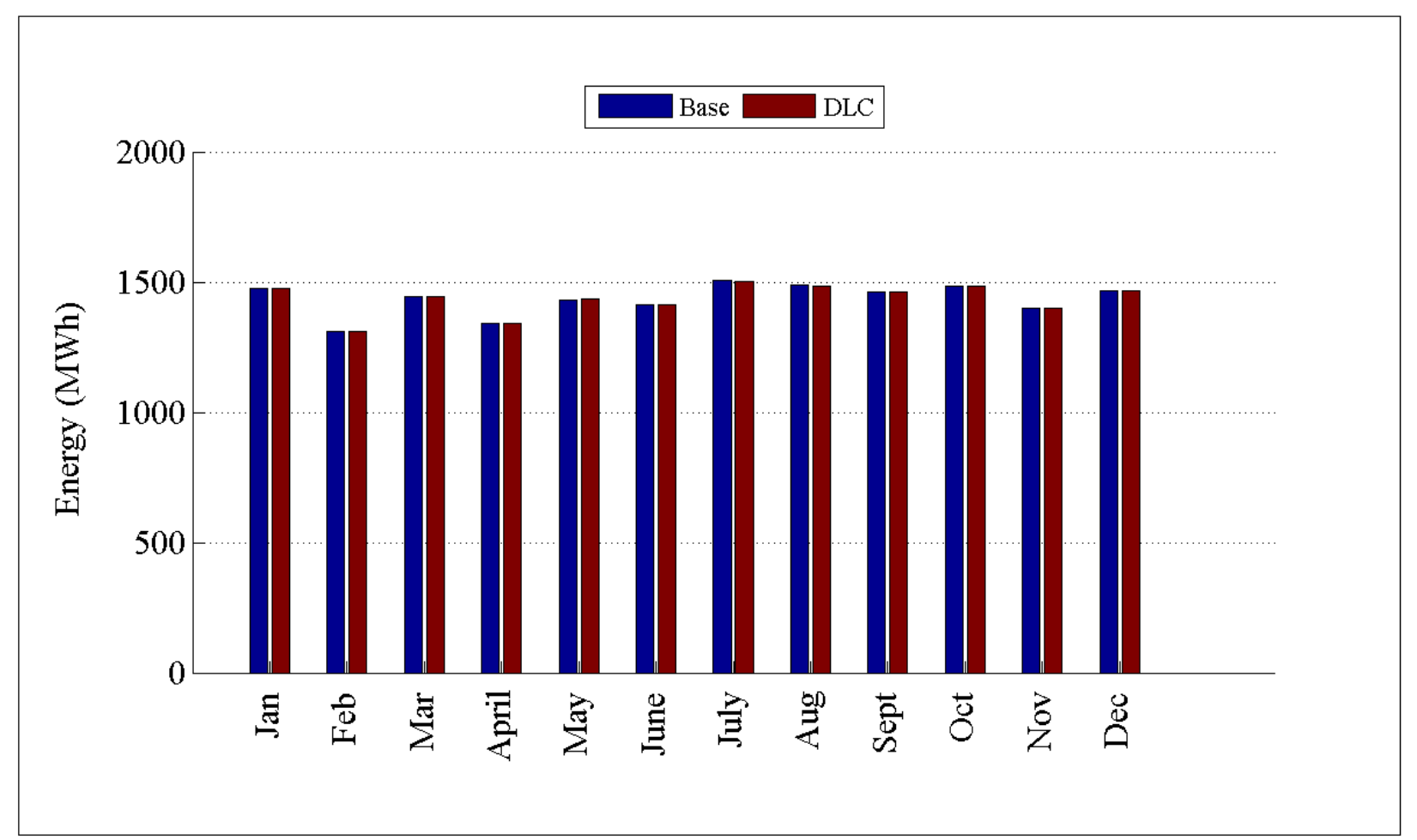

Figure D.130: Comparison of energy consumption by month for R1-12.47-4

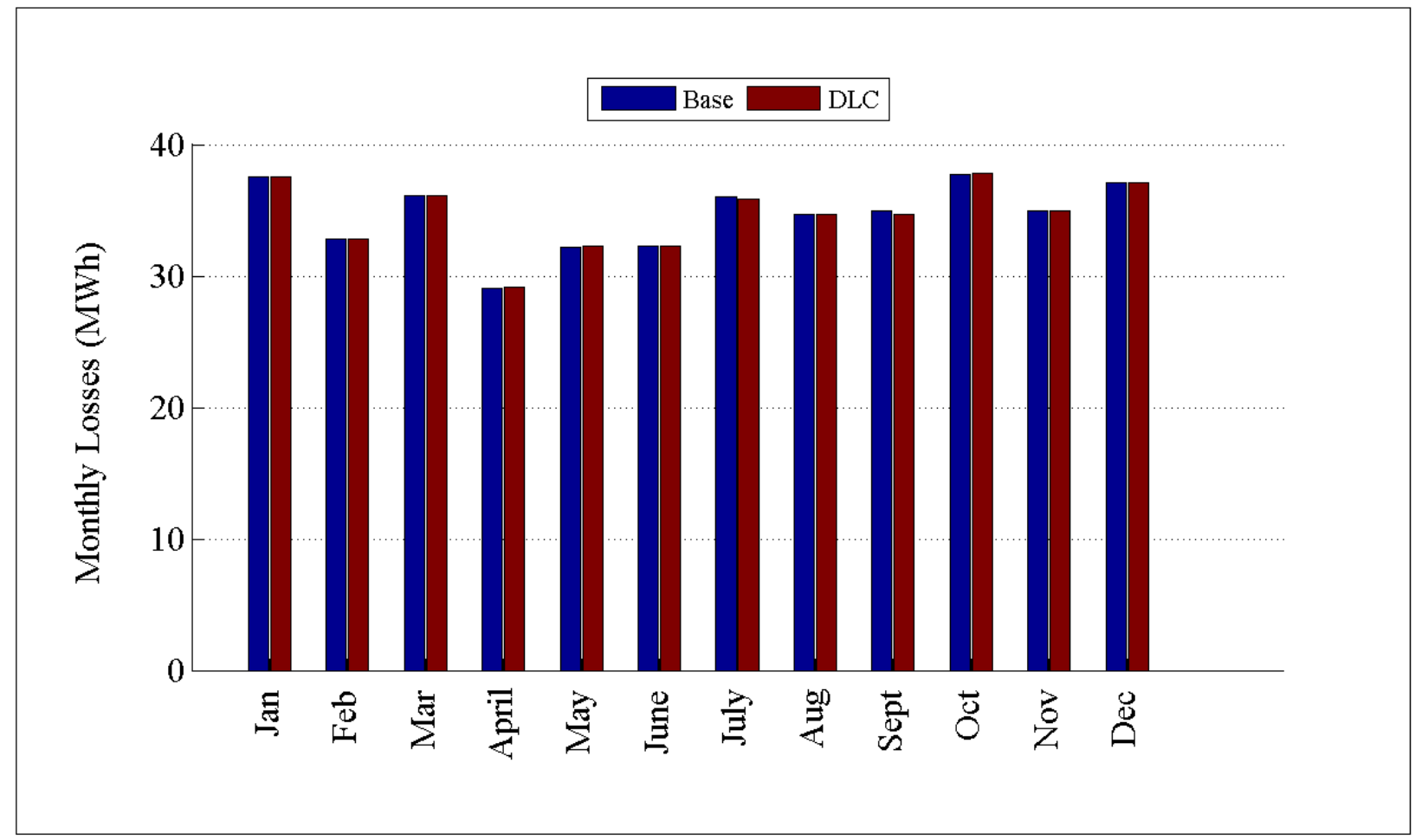

Figure D.131: Comparison of losses by month for R1-12.47-4 


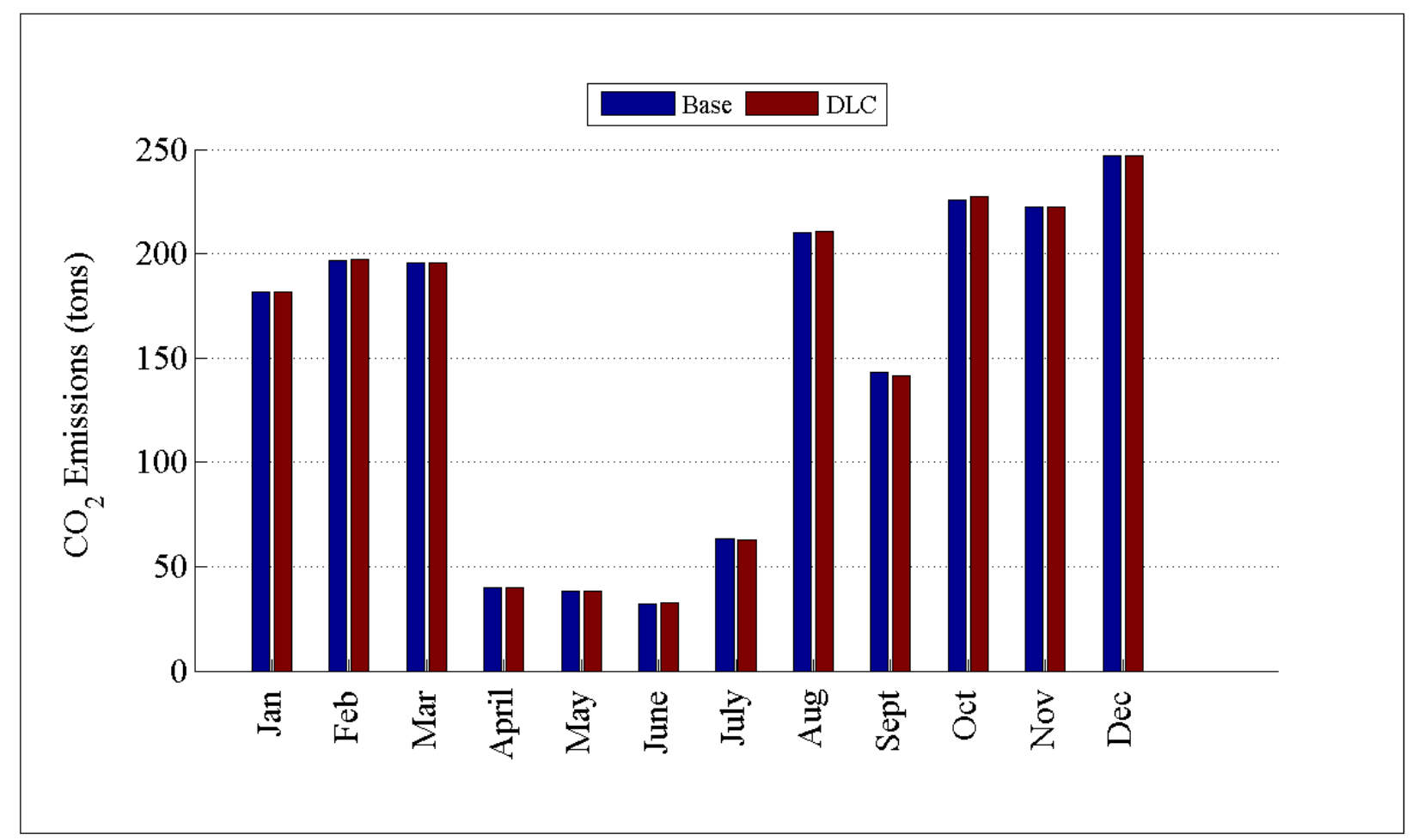

Figure D.132: Comparison of $\mathrm{CO}_{2}$ emissions by month for R1-12.47-4

D.2.6 Detailed DLC Plots for R1-25.00-1 


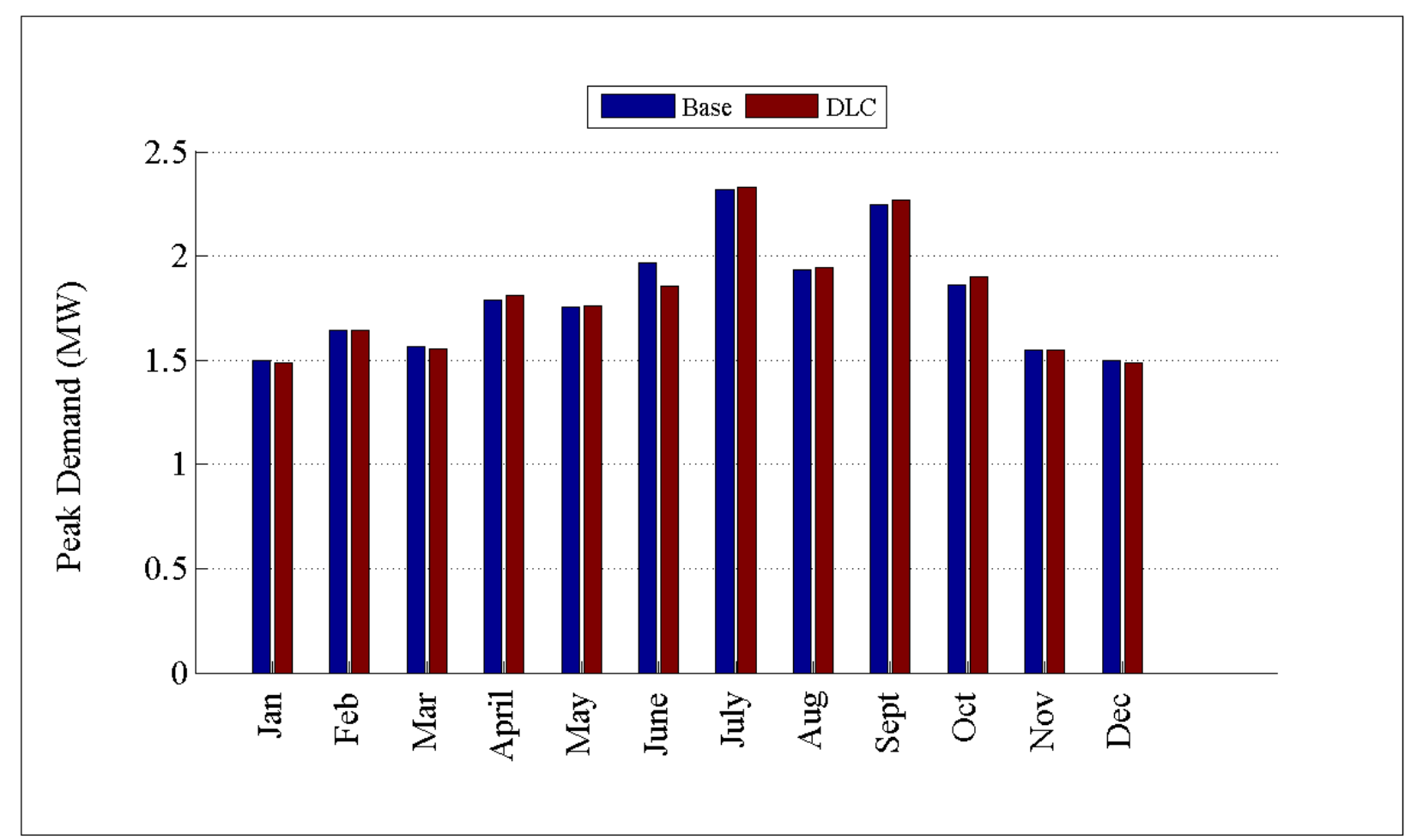

Figure D.133: Comparison of peak demand by month for R1-25.00-1

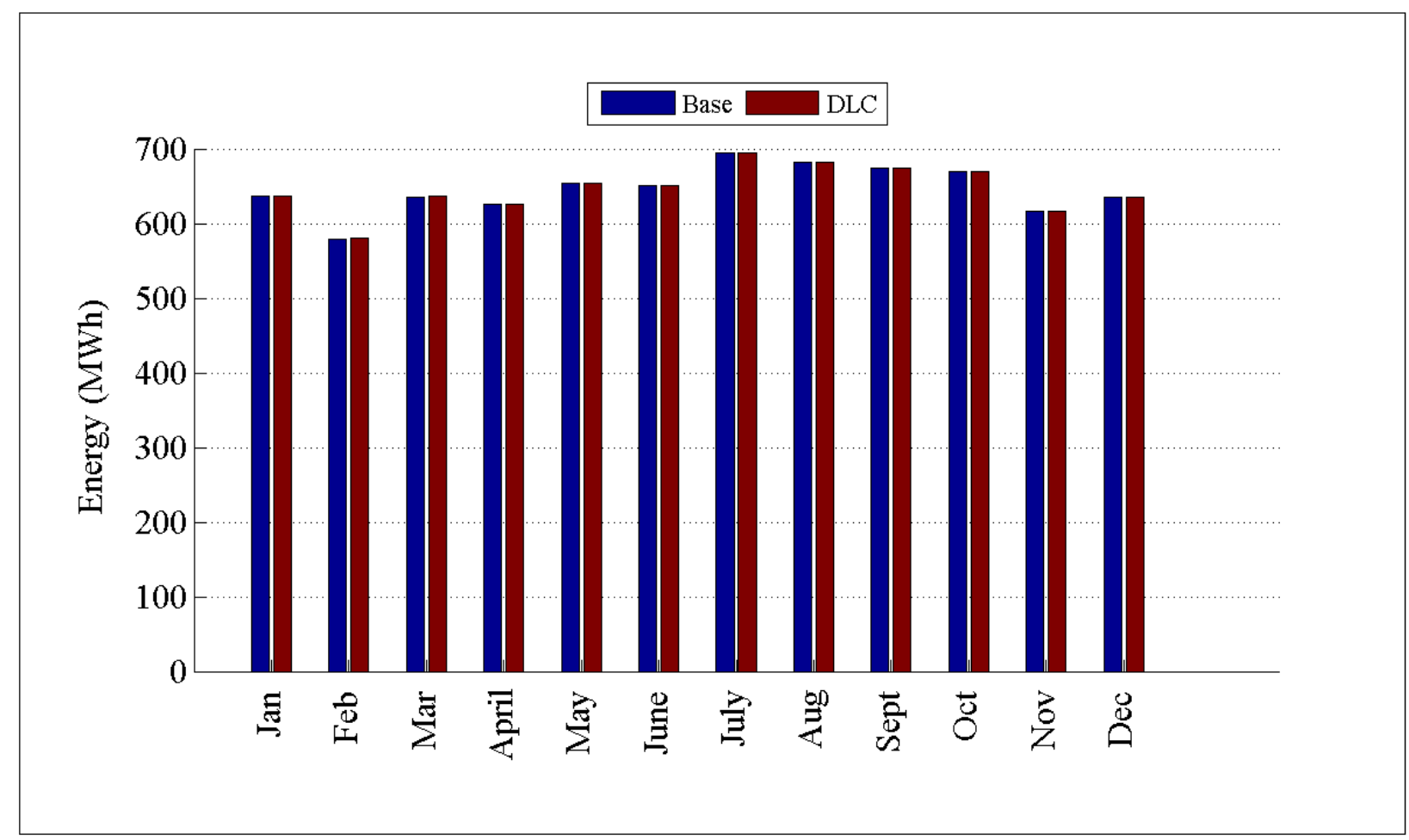

Figure D.134: Comparison of energy consumption by month for R1-25.00-1 


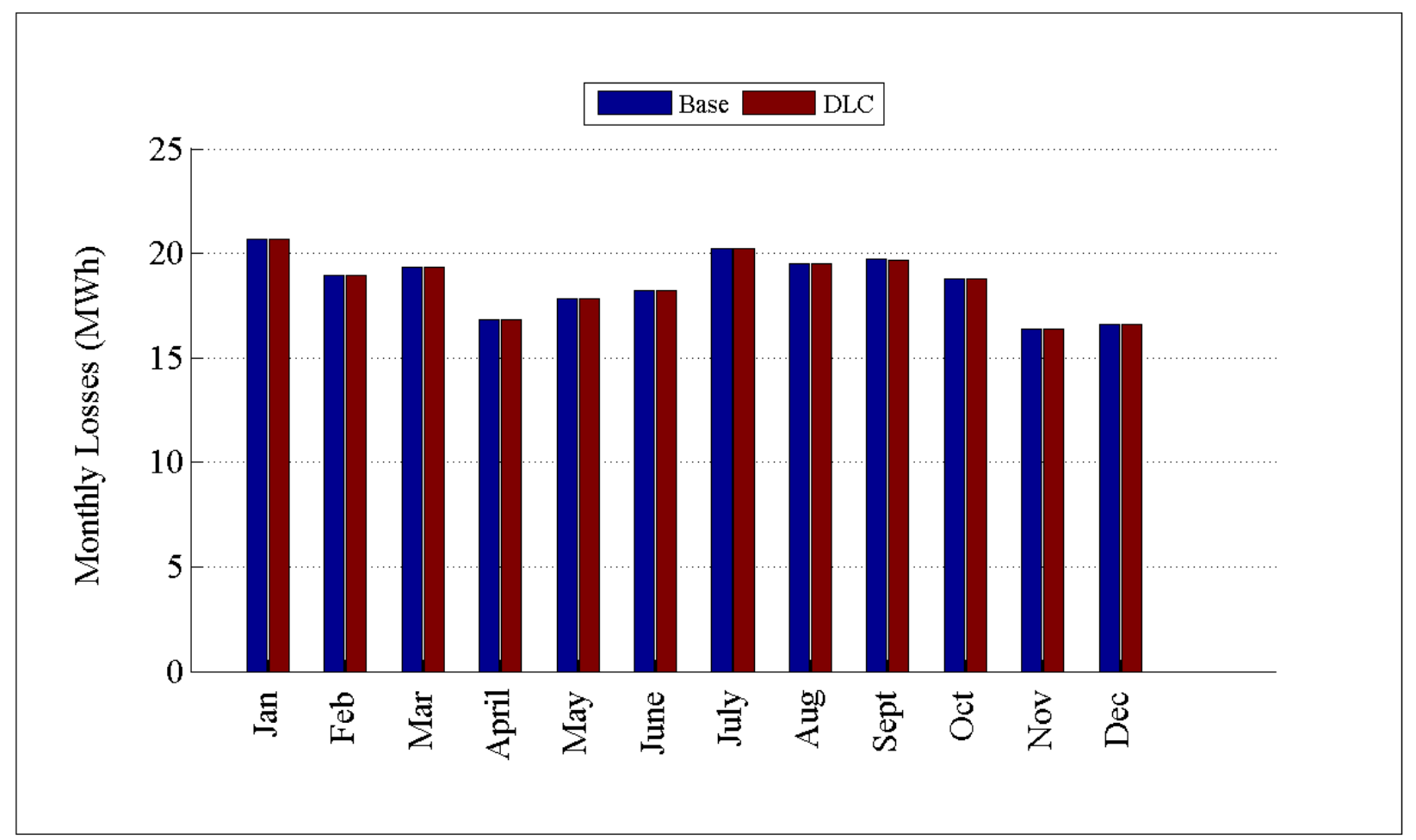

Figure D.135: Comparison of losses by month for R1-25.00-1

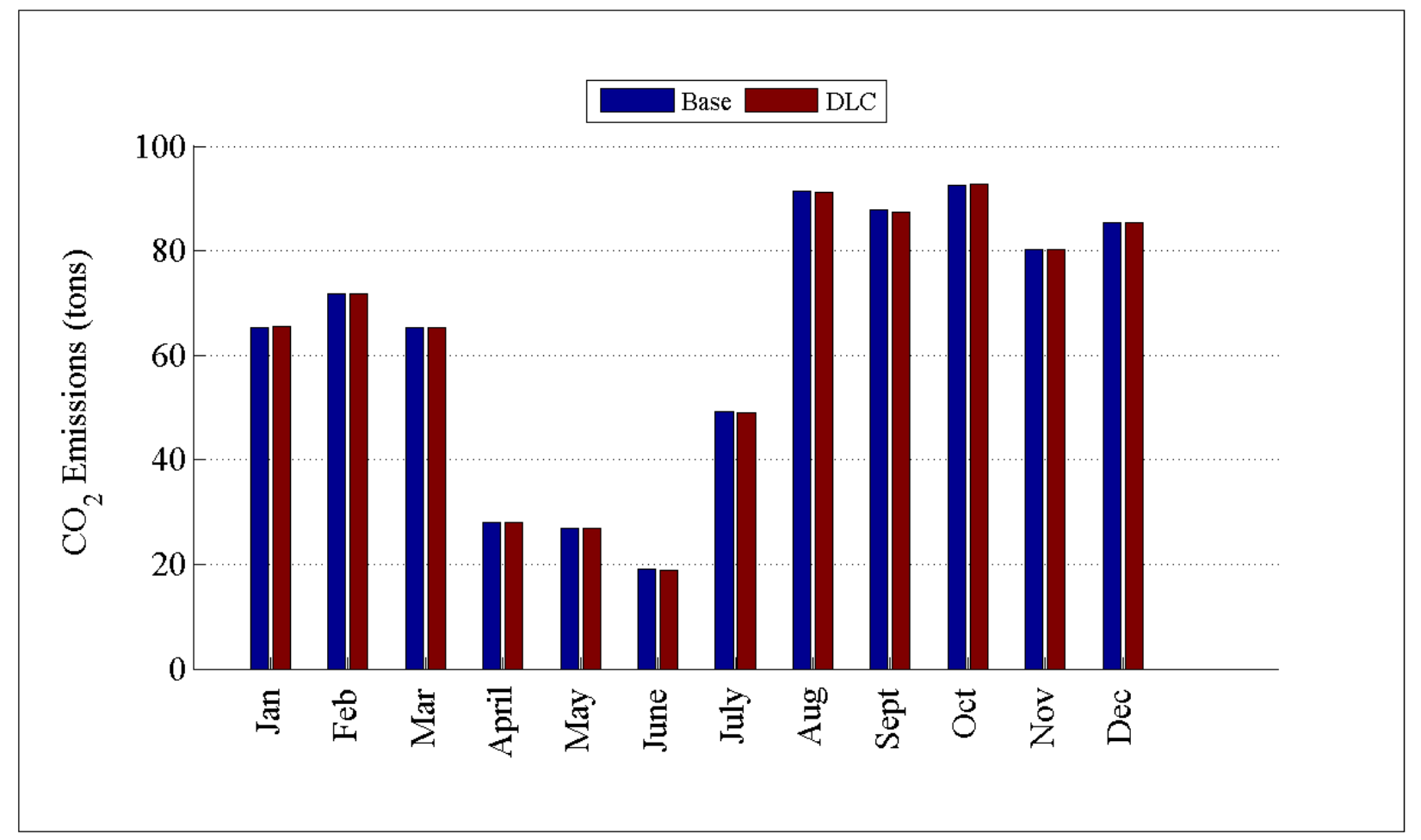

Figure D.136: Comparison of $\mathrm{CO}_{2}$ emissions by month for R1-25.00-1 
D.2.7 Detailed DLC Plots for GC-12.47-1_R2

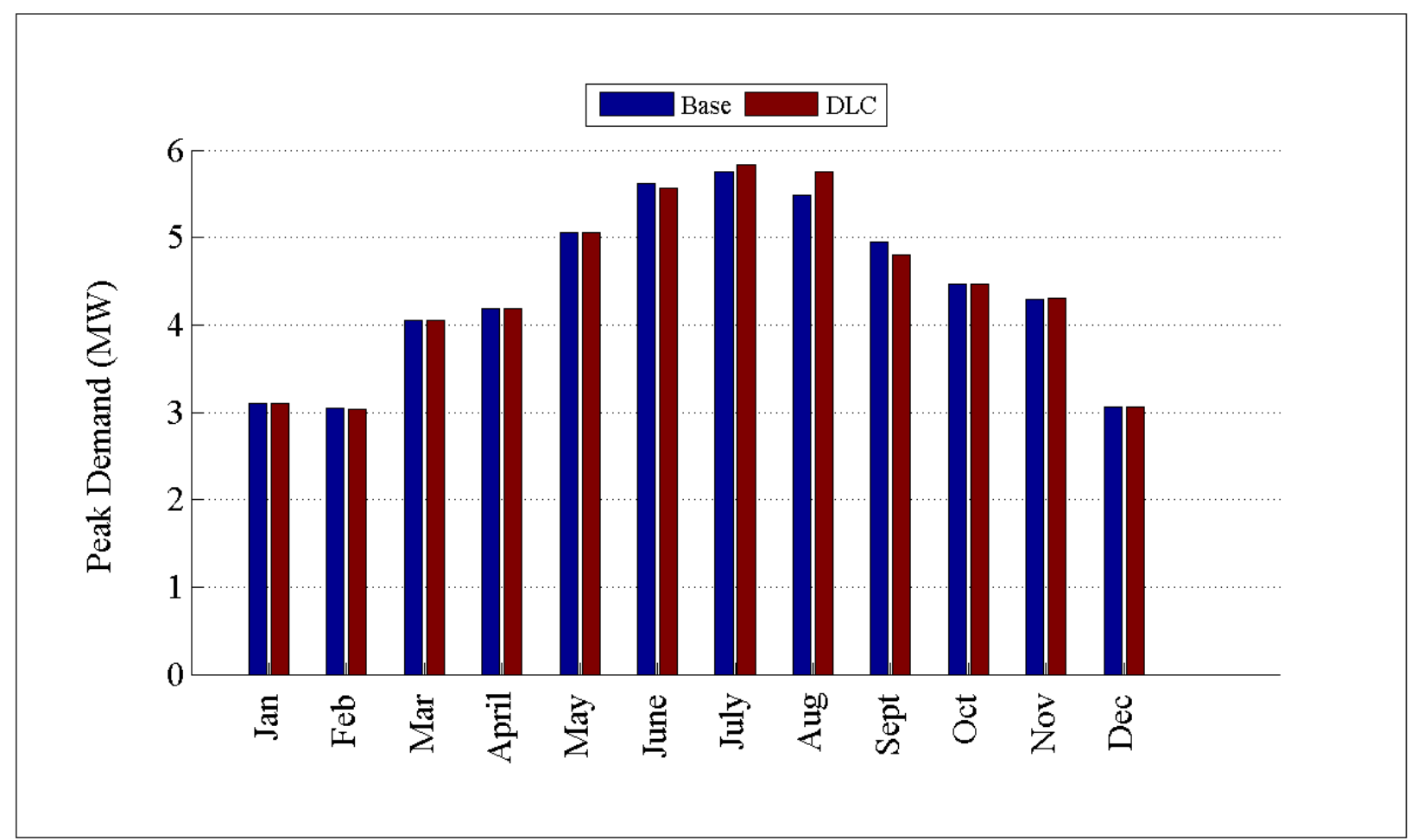

Figure D. 137: Comparison of peak demand by month for GC-12.47-1_R2

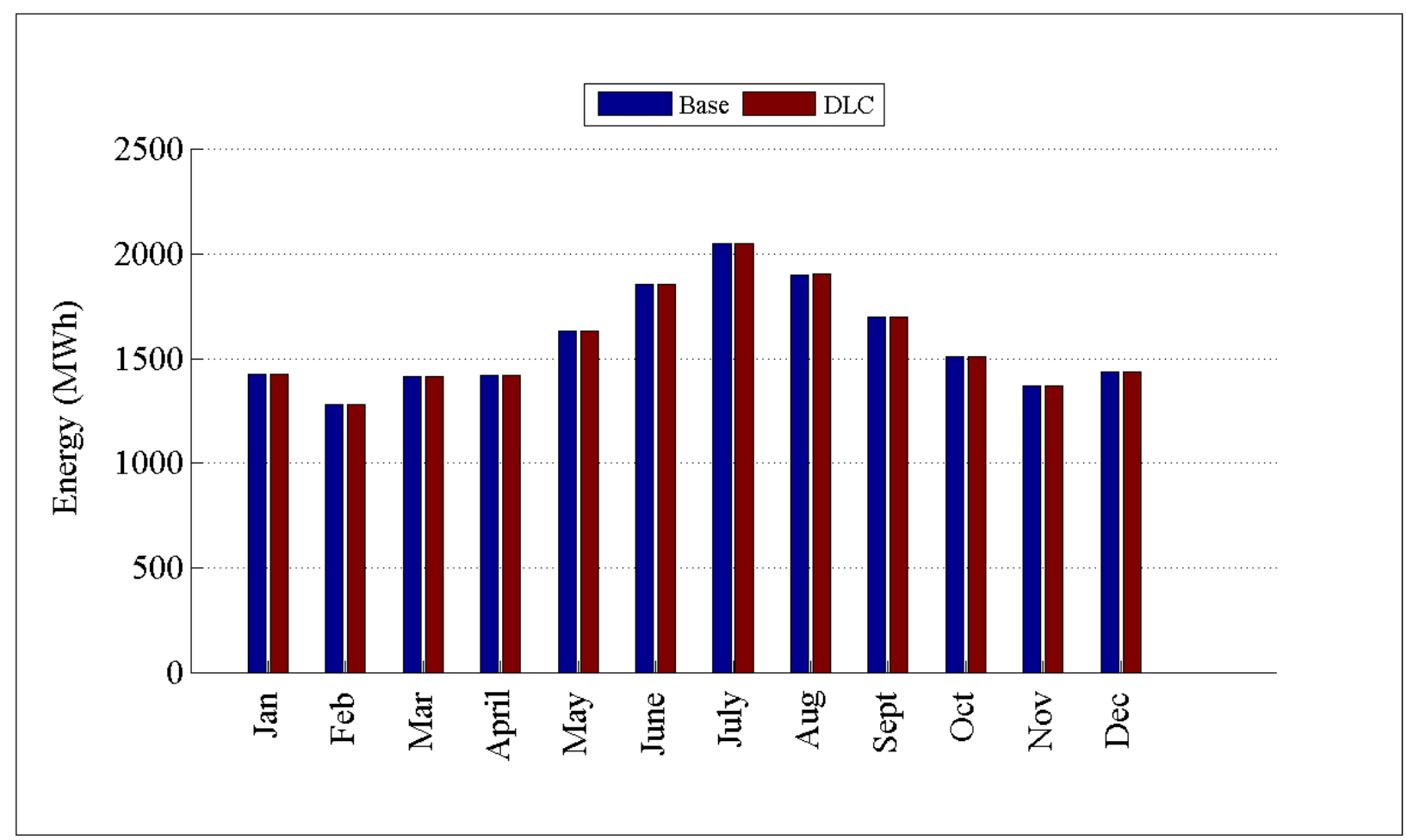


Figure D. 138: Comparison of energy consumption by month for GC-12.47-1_R2

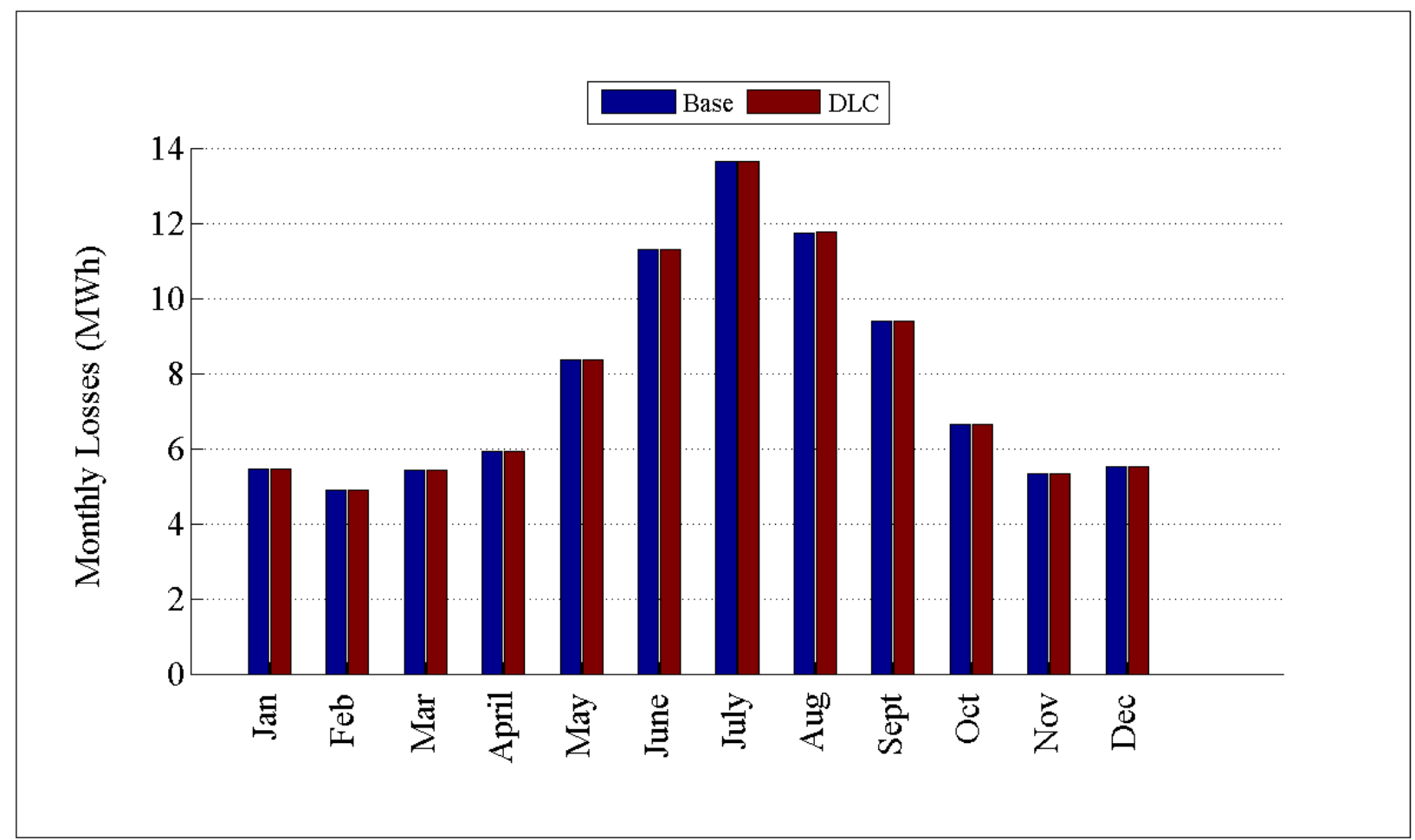

Figure D. 139: Comparison of losses by month for GC-12.47-1_R2

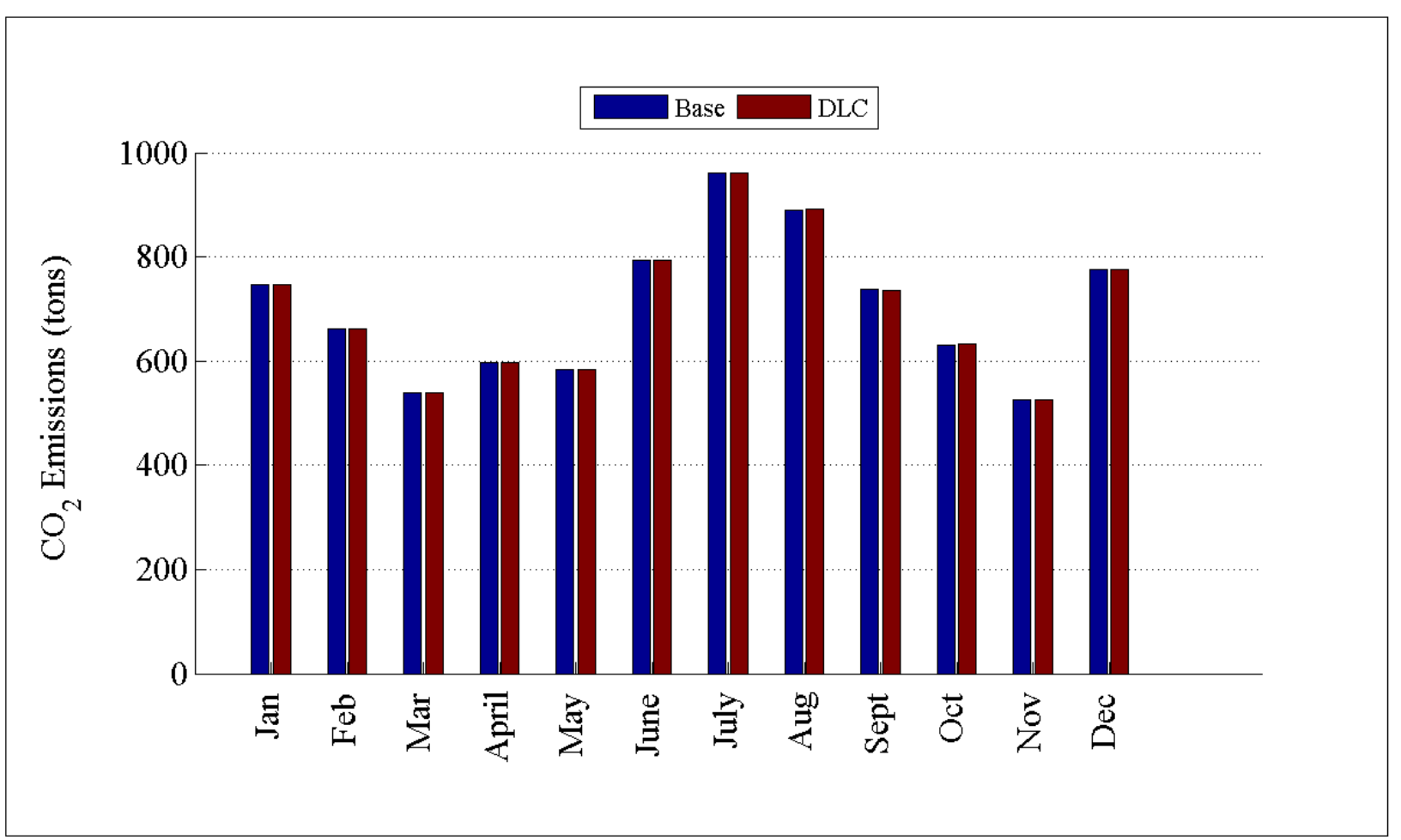

Figure D. 140: Comparison of $\mathrm{CO}_{2}$ emissions by month for GC-12.47-1_R2 
D.2.8 Detailed DLC Plots for R2-12.47-1

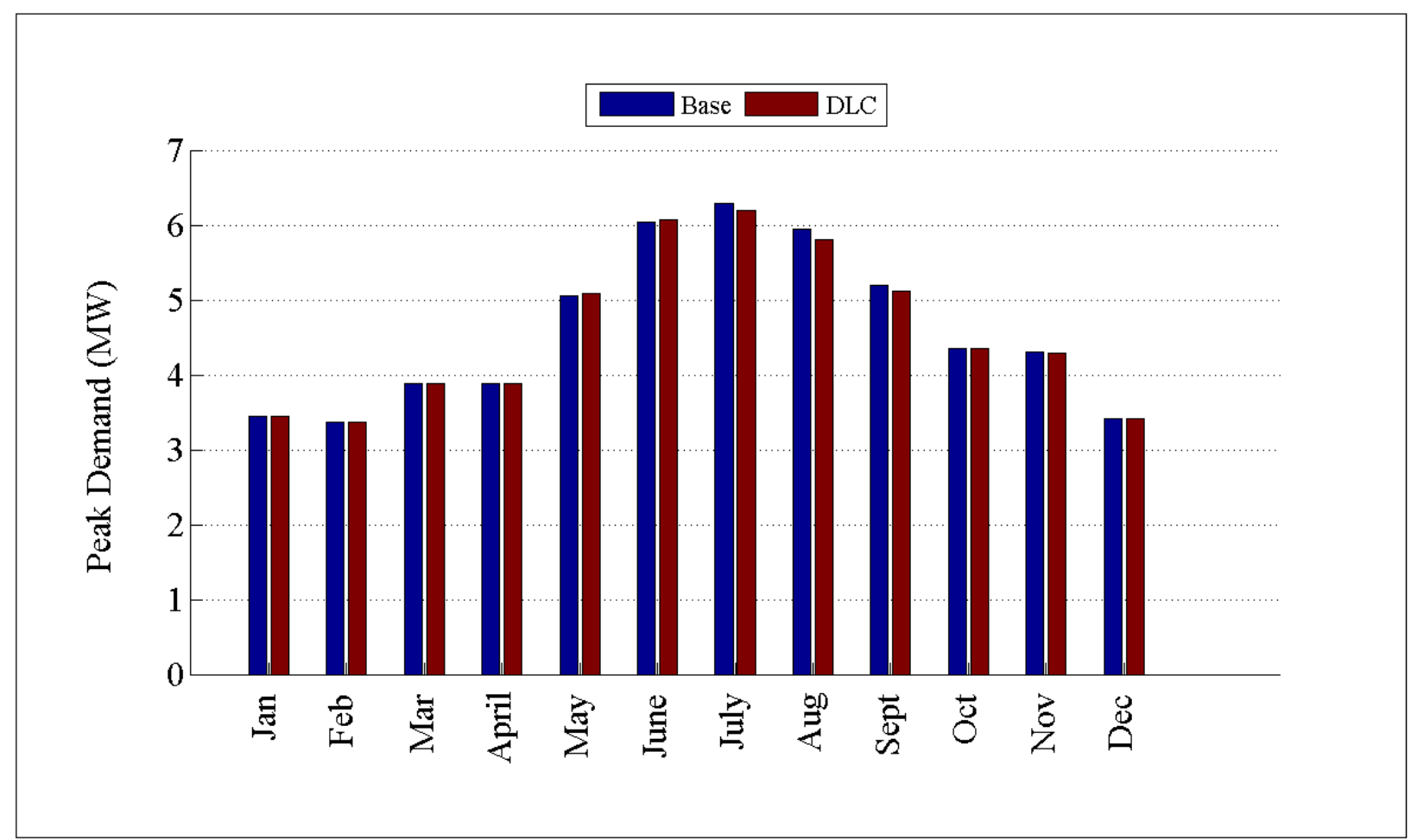

Figure D.141: Comparison of peak demand by month for R2-12.47-1 


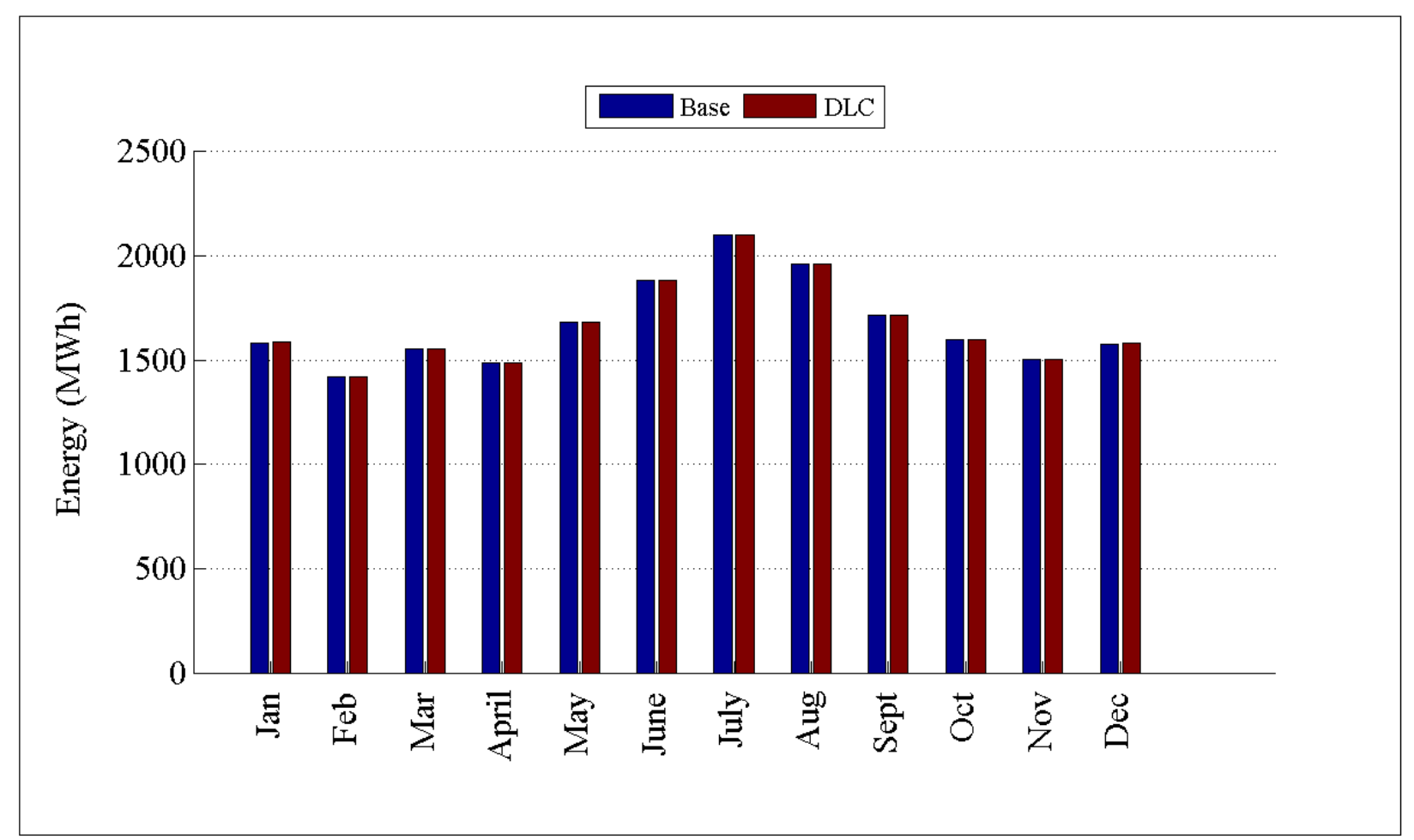

Figure D.142: Comparison of energy consumption by month for R2-12.47-1

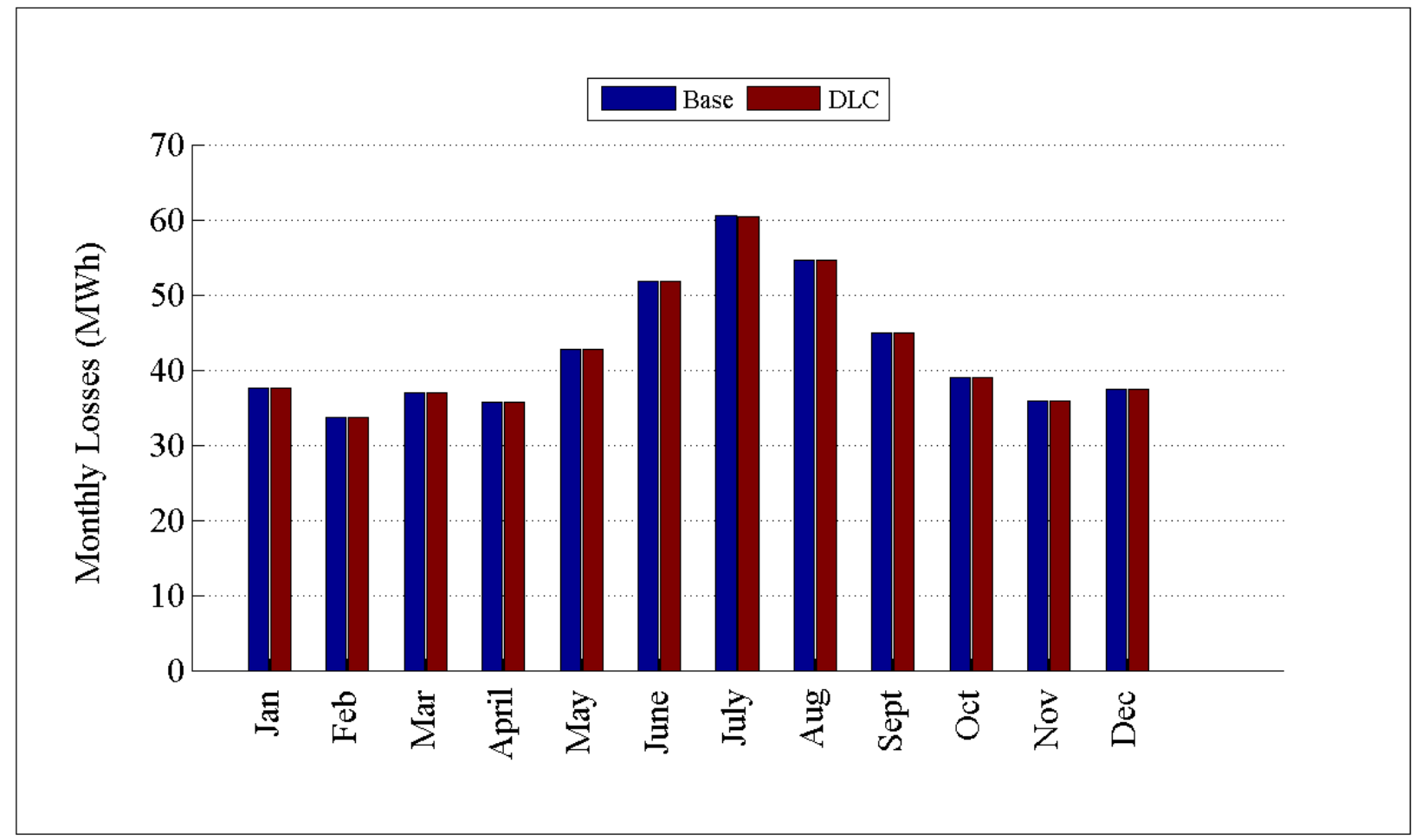

Figure D.143: Comparison of losses by month for R2-12.47-1 


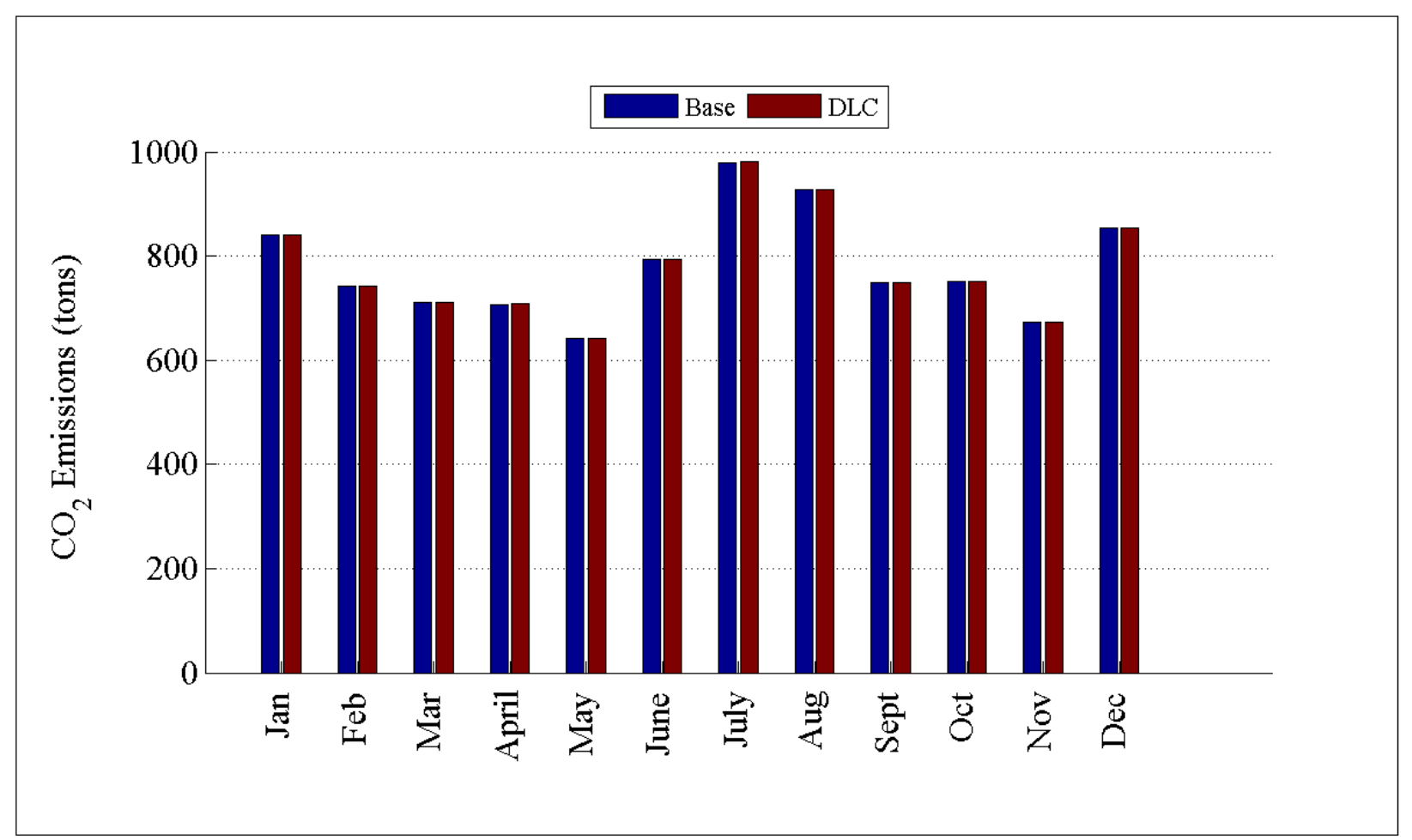

Figure D.144: Comparison of $\mathrm{CO}_{2}$ emissions by month for R2-12.47-1

D.2.9 Detailed DLC Plots for R2-12.47-2 


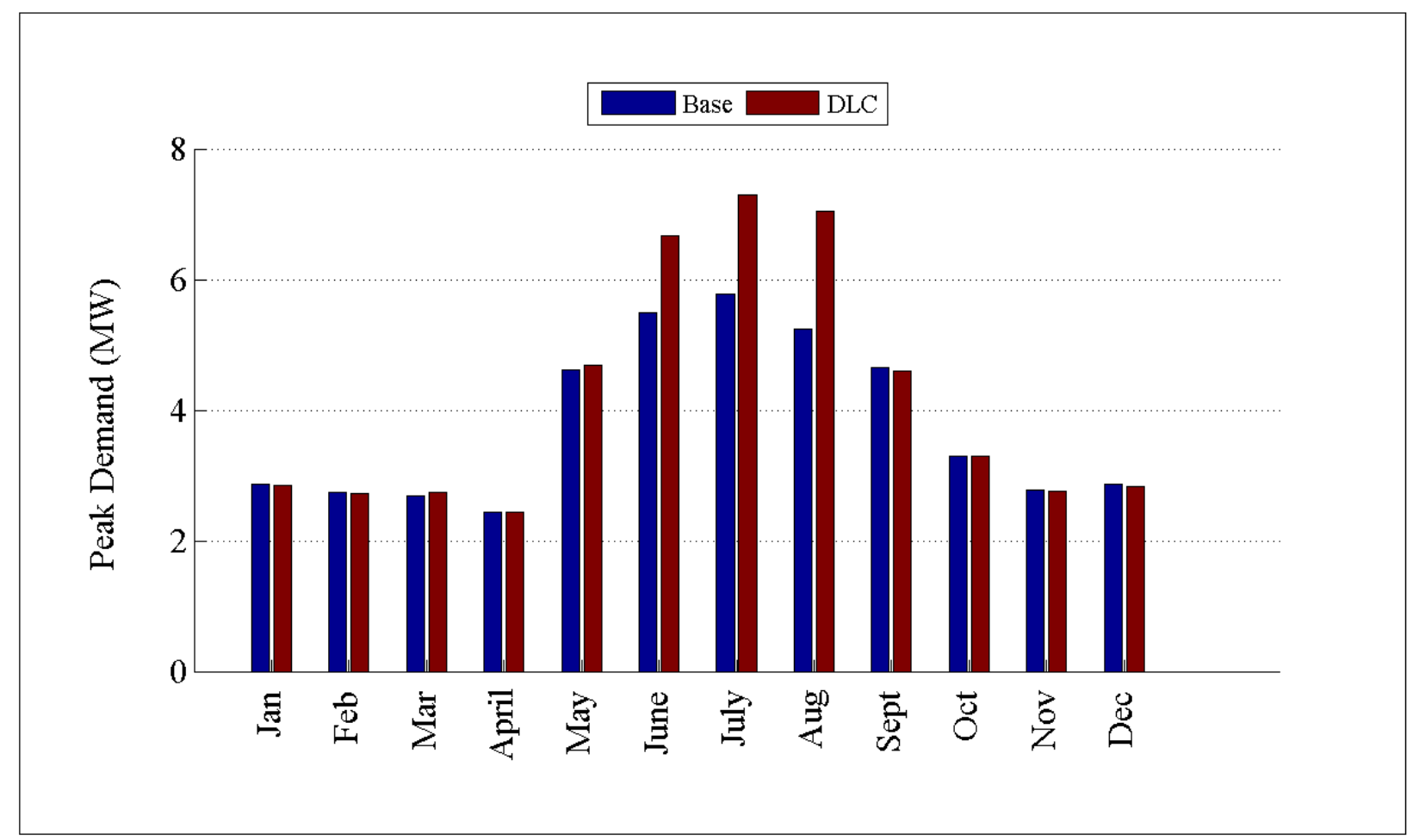

Figure D.145: Comparison of peak demand by month for R2-12.47-2

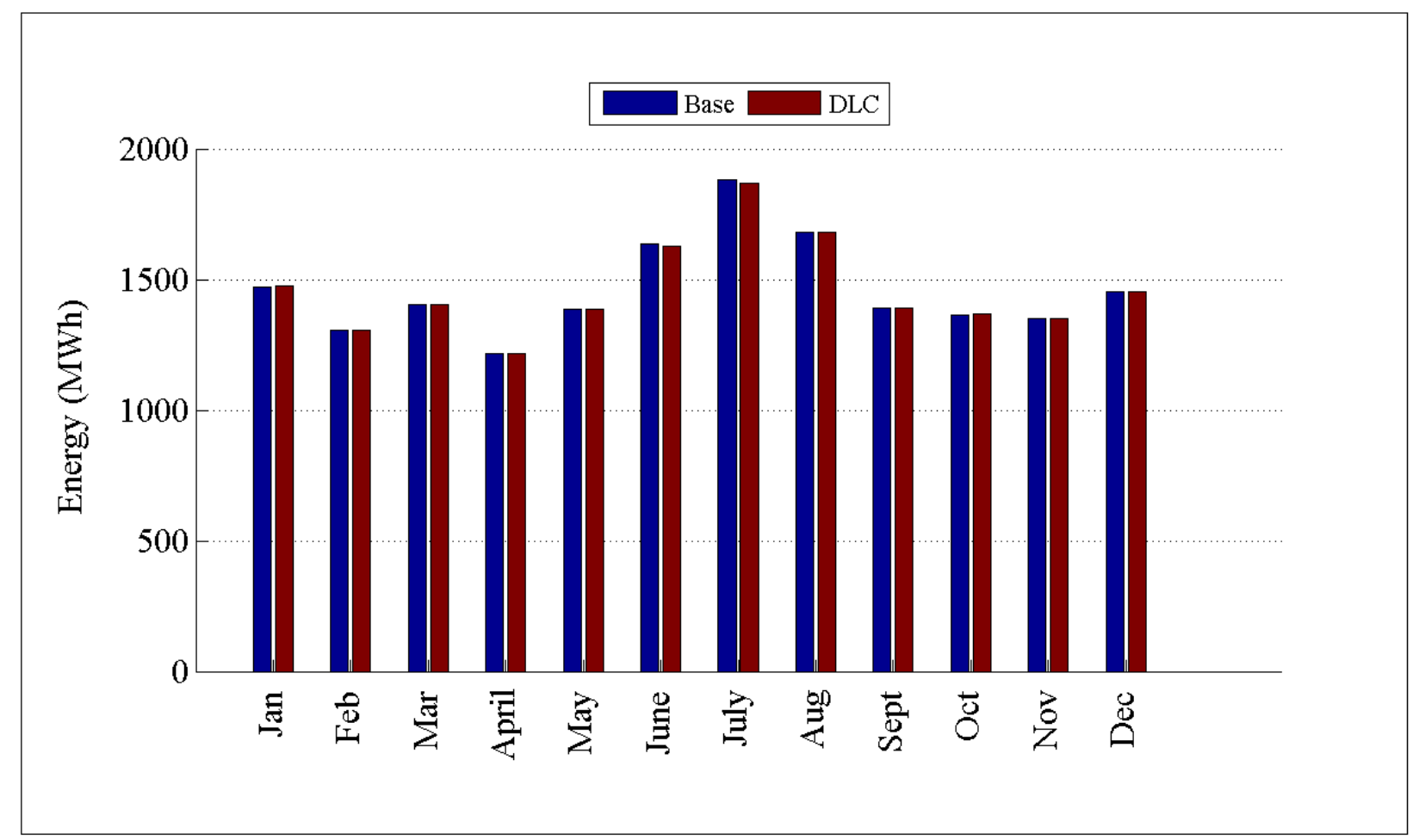

Figure D.146: Comparison of energy consumption by month for R2-12.47-2 


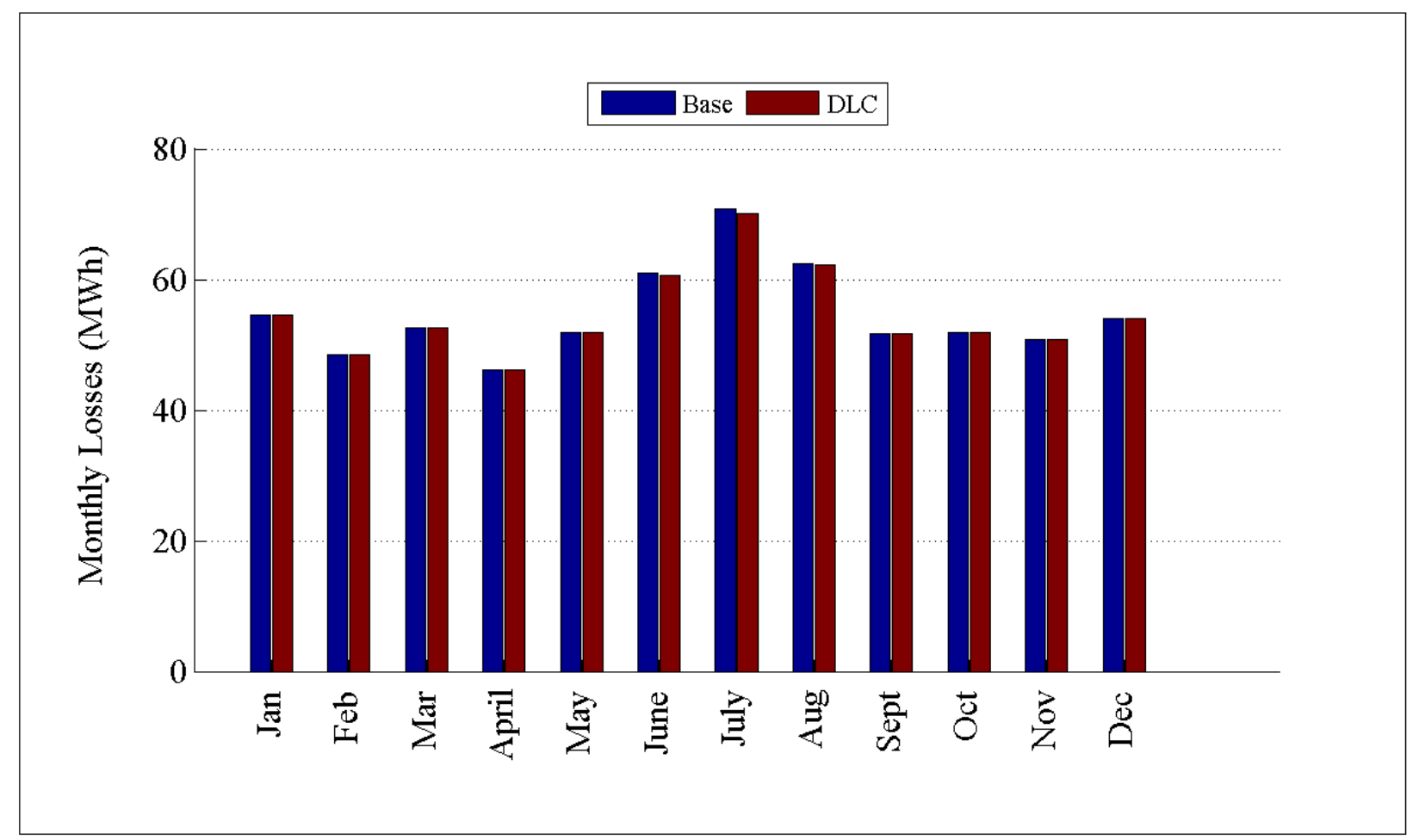

Figure D.147: Comparison of losses by month for R2-12.47-2

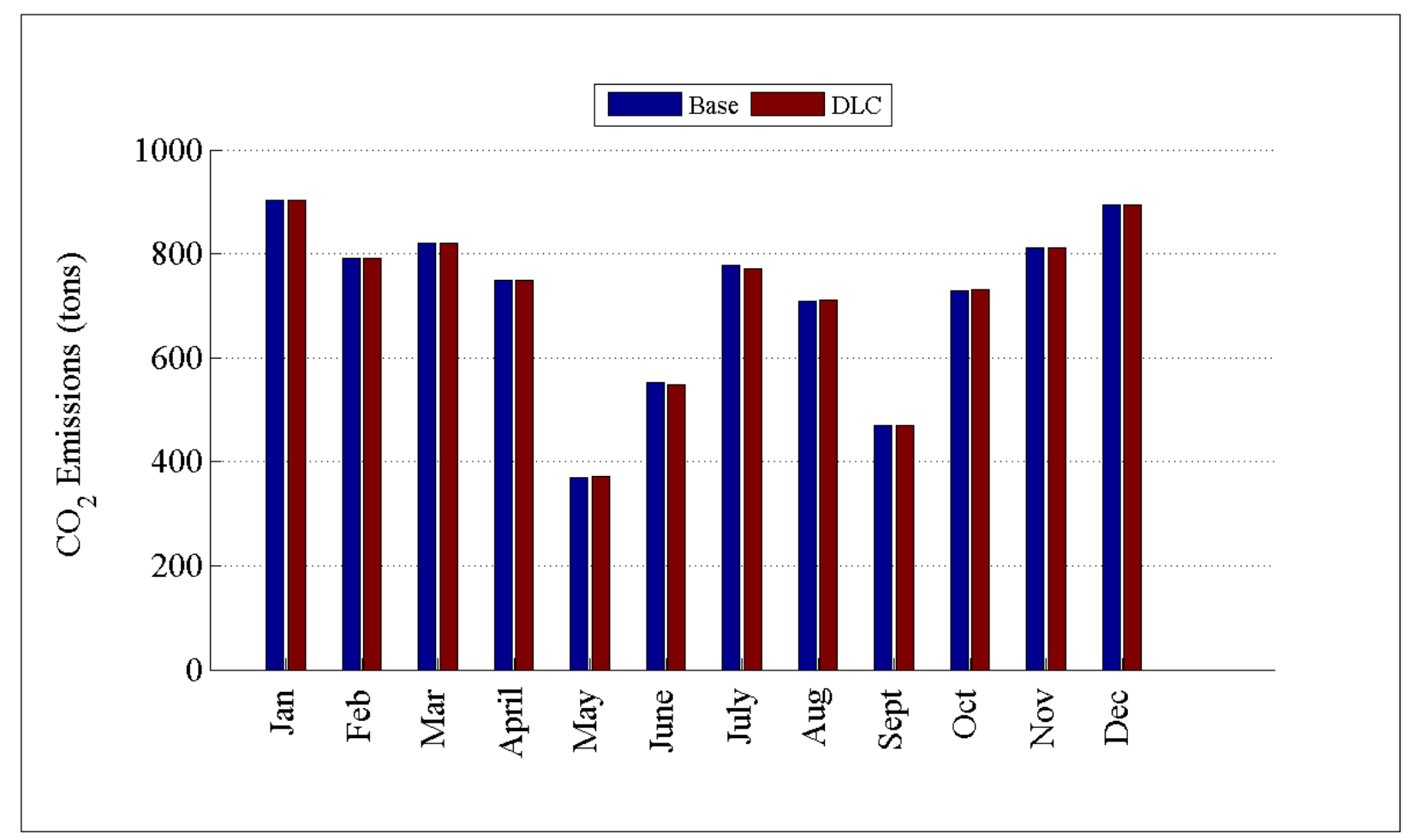

Figure D.148: Comparison of $\mathrm{CO}_{2}$ emissions by month for R2-12.47-2 
D.2.10 Detailed DLC Plots for R2-12.47-3

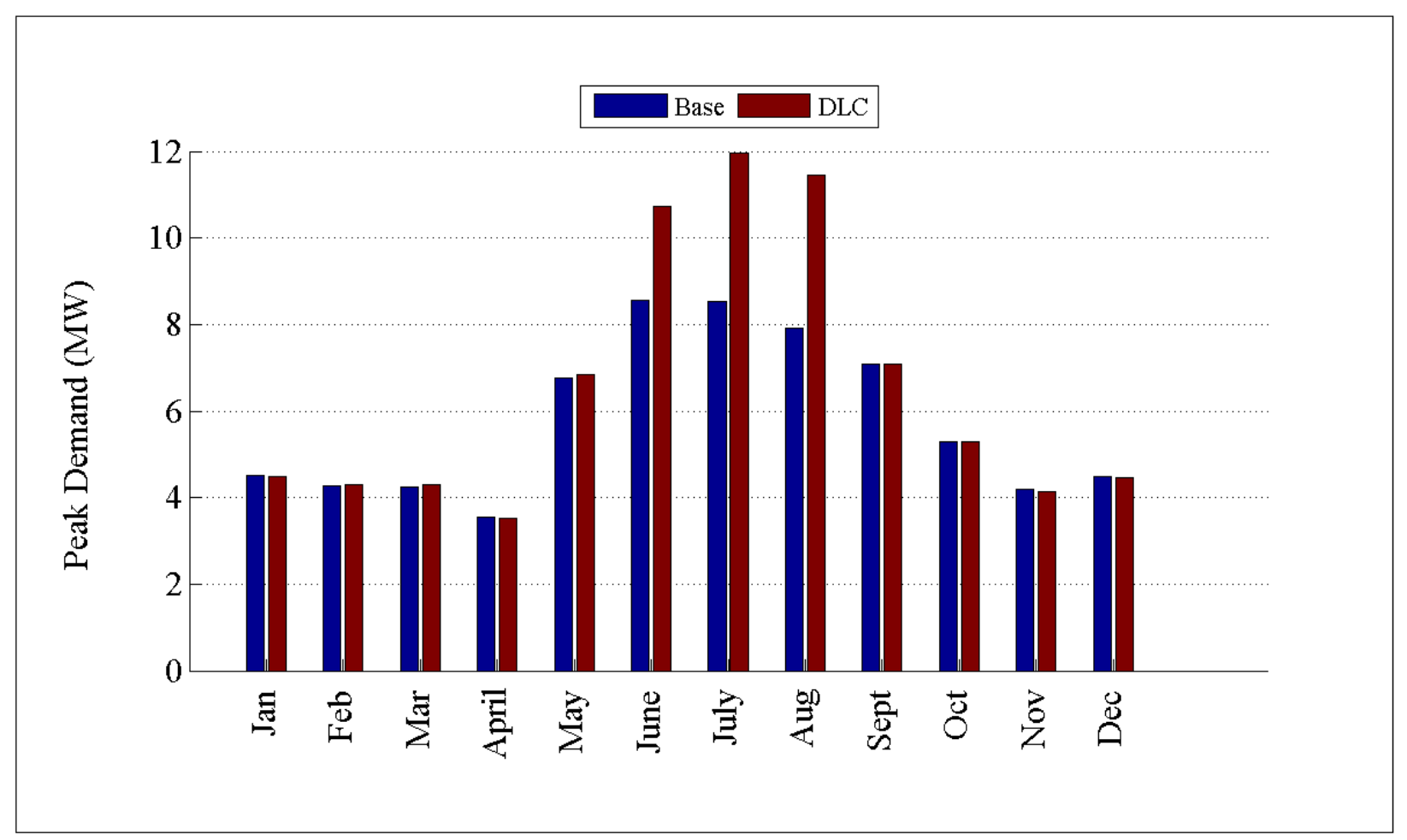

Figure D.149: Comparison of peak demand by month for R2-12.47-3 


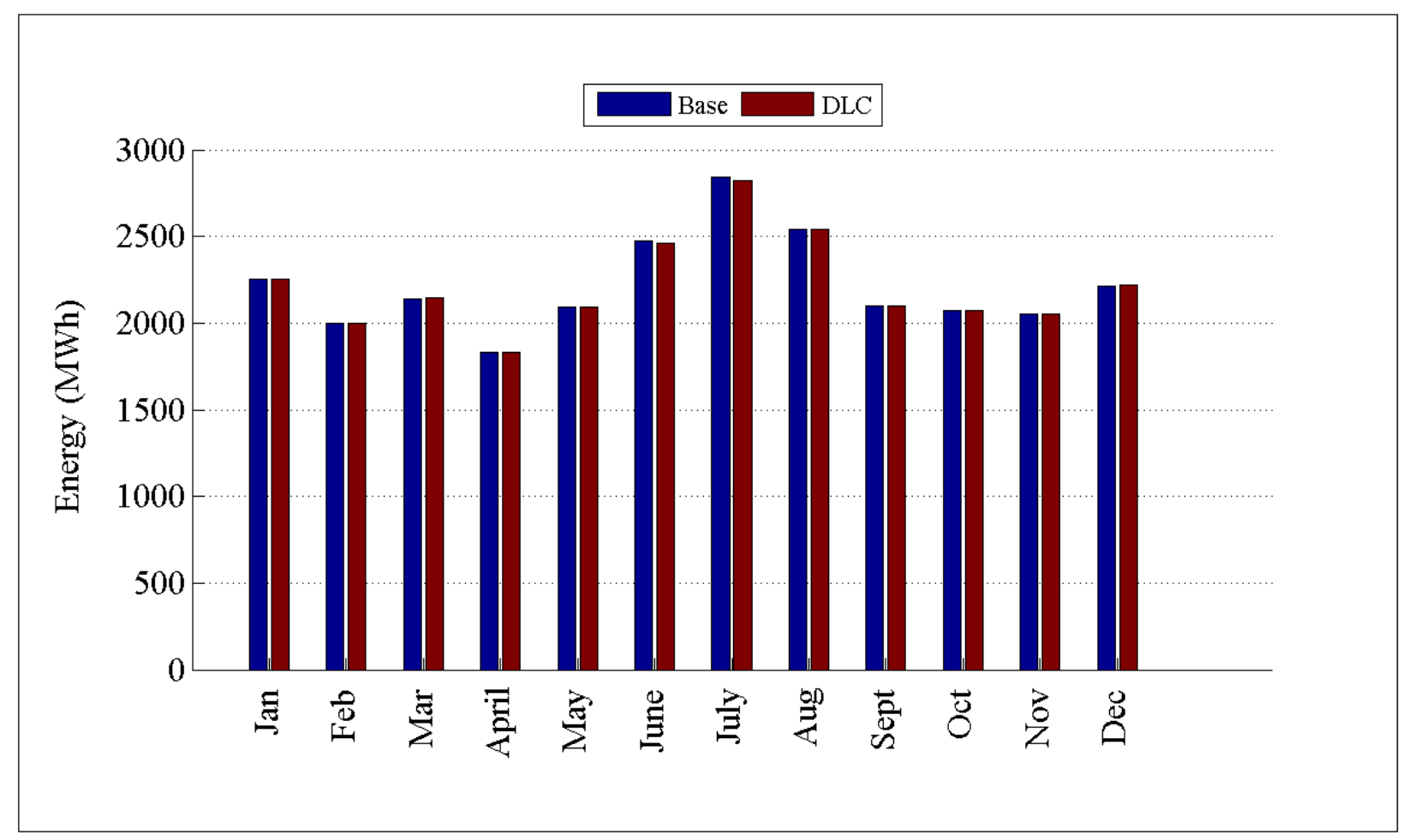

Figure D.150: Comparison of energy consumption by month for R2-12.47-3

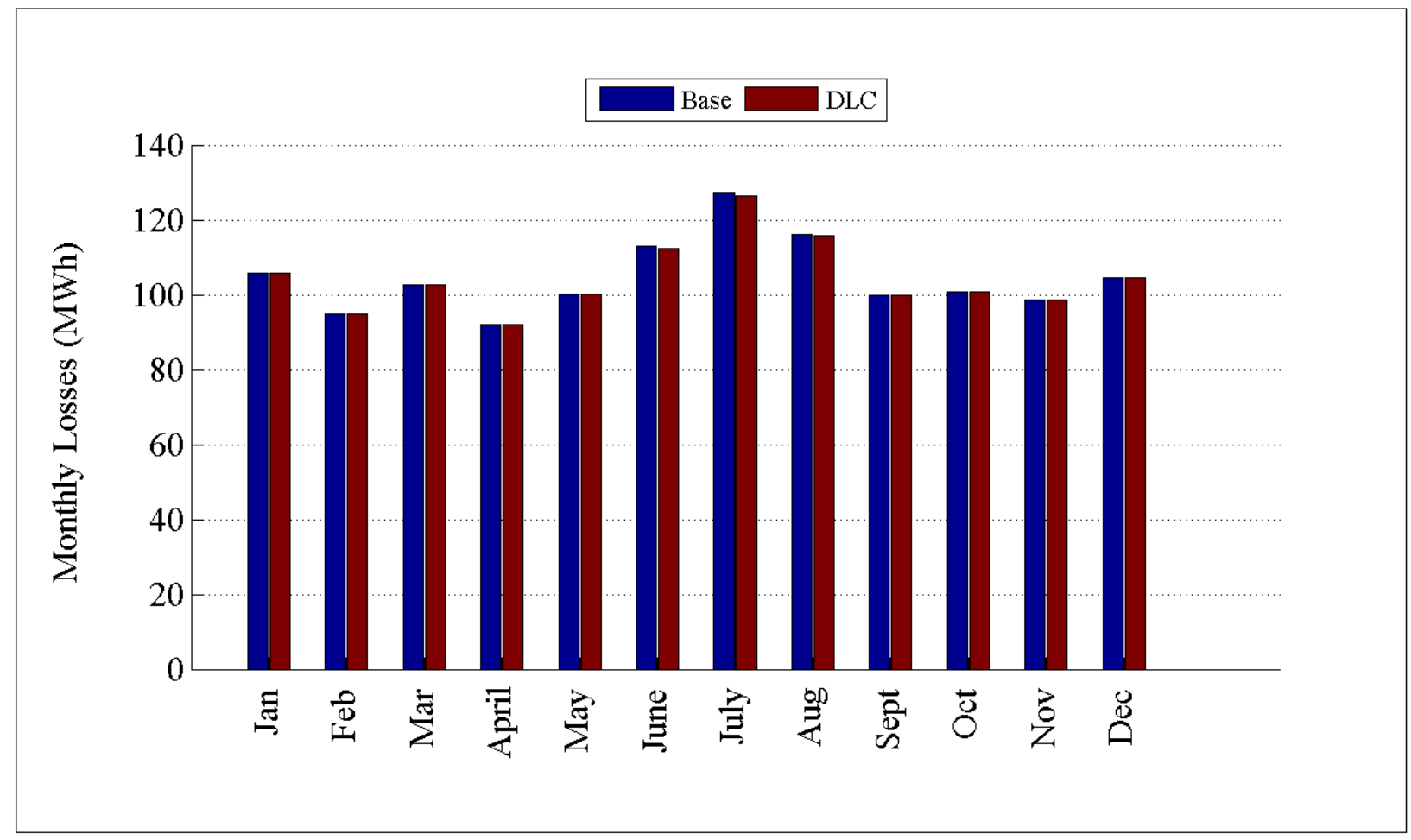

Figure D.151: Comparison of losses by month for R2-12.47-3 


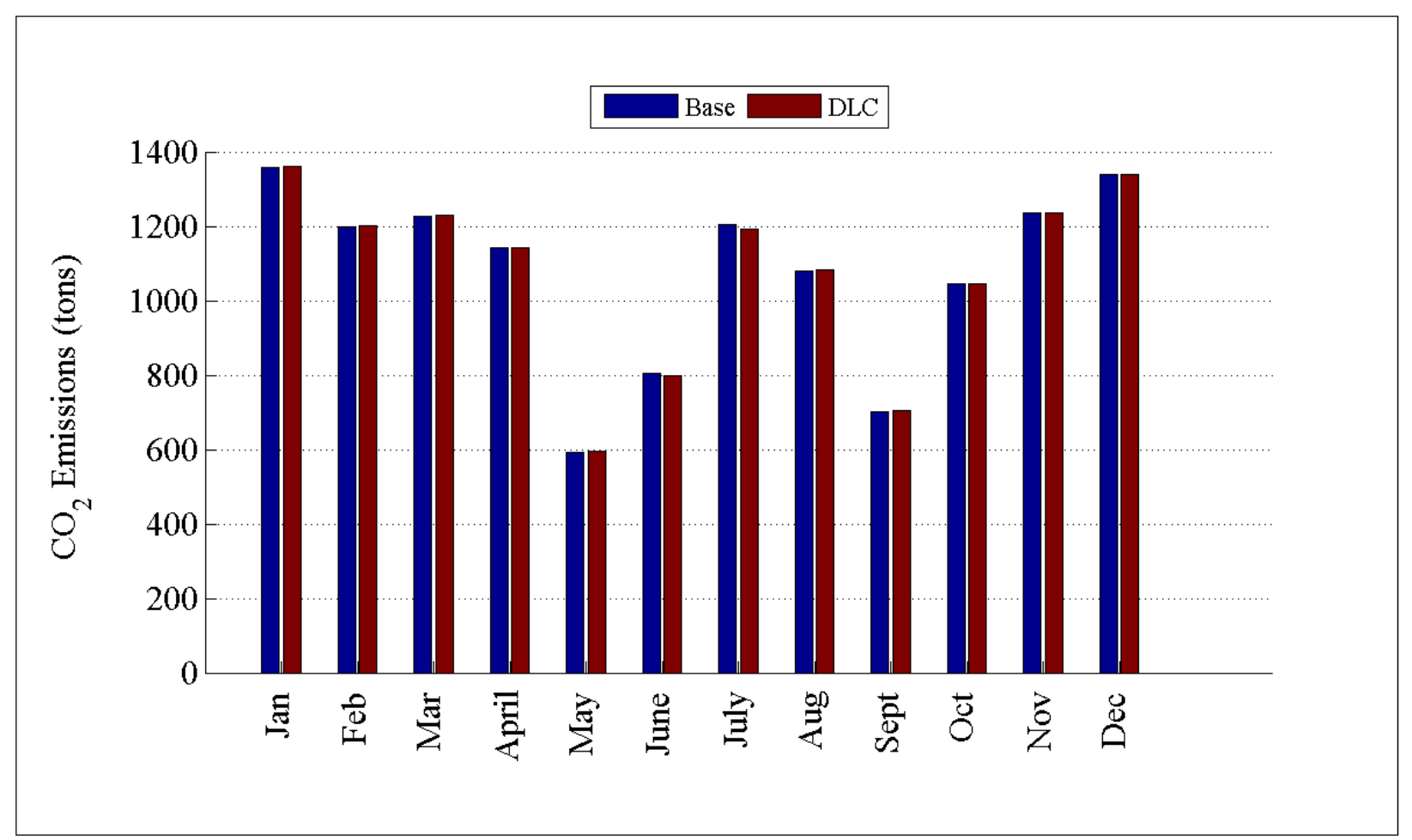

Figure D.152: Comparison of $\mathrm{CO}_{2}$ emissions by month for R2-12.47-3

D.2.11 Detailed DLC Plots for R2-25.00-1 


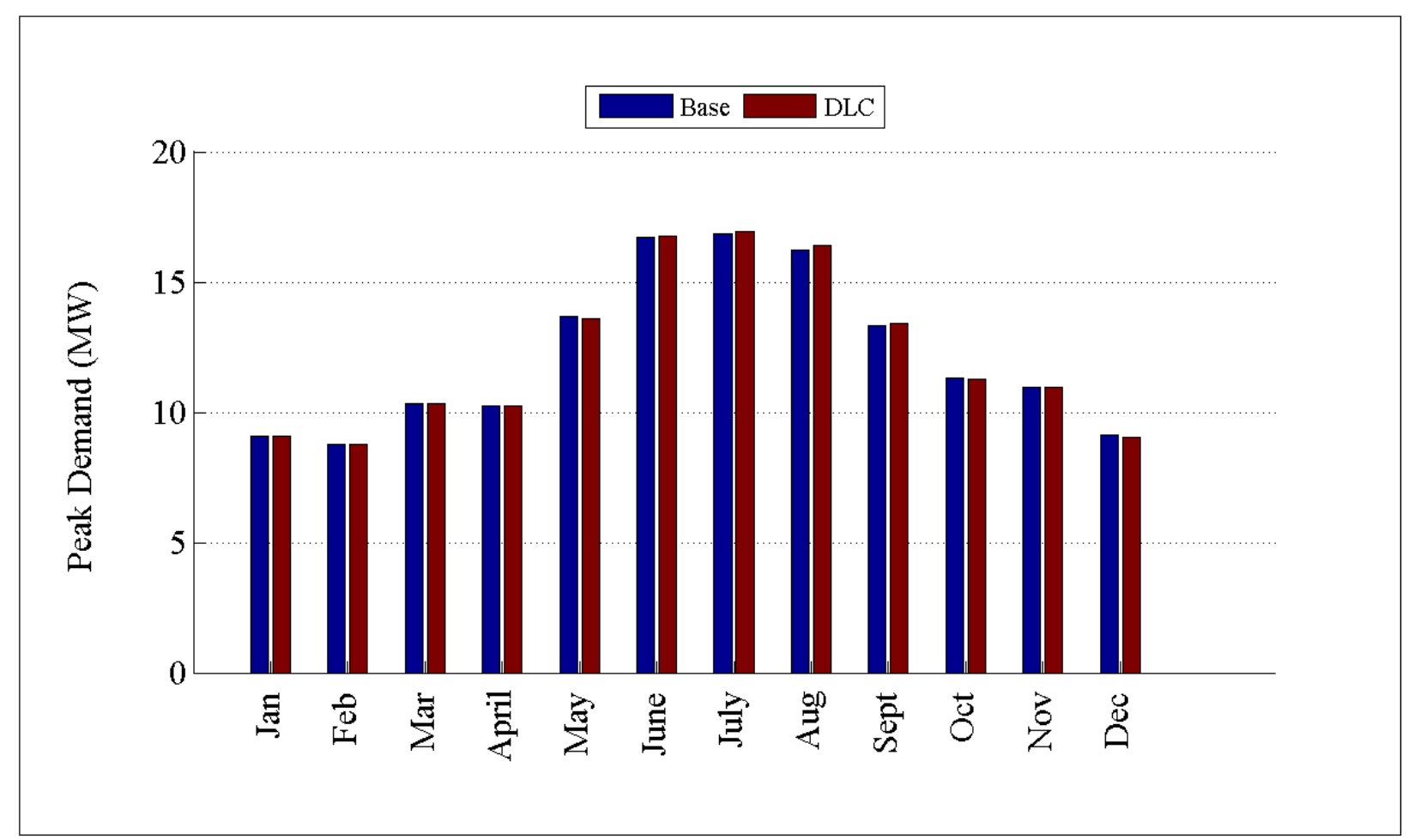

Figure D.153: Comparison of peak demand by month for R2-25.00-1

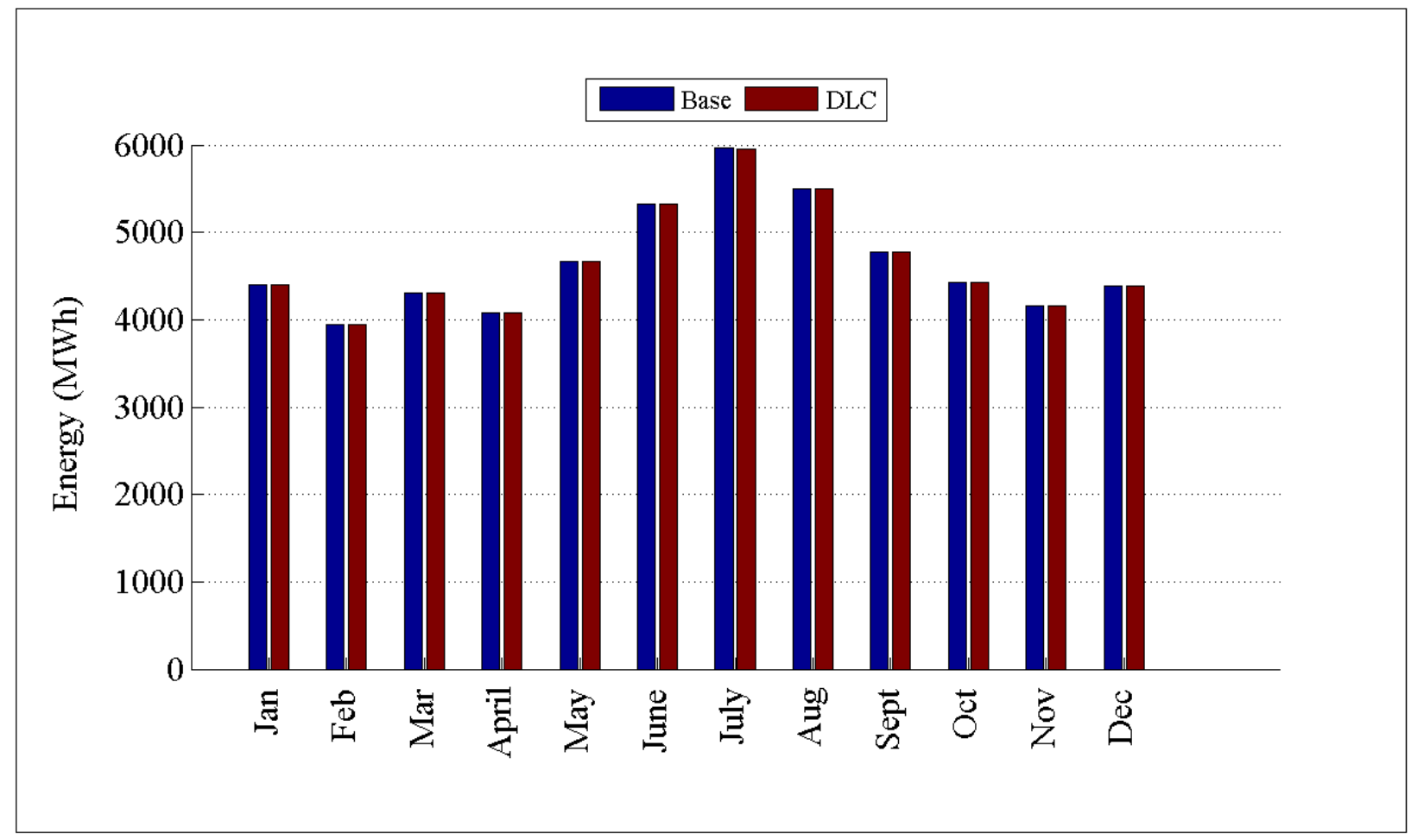

Figure D.154: Comparison of energy consumption by month for R2-25.00-1 


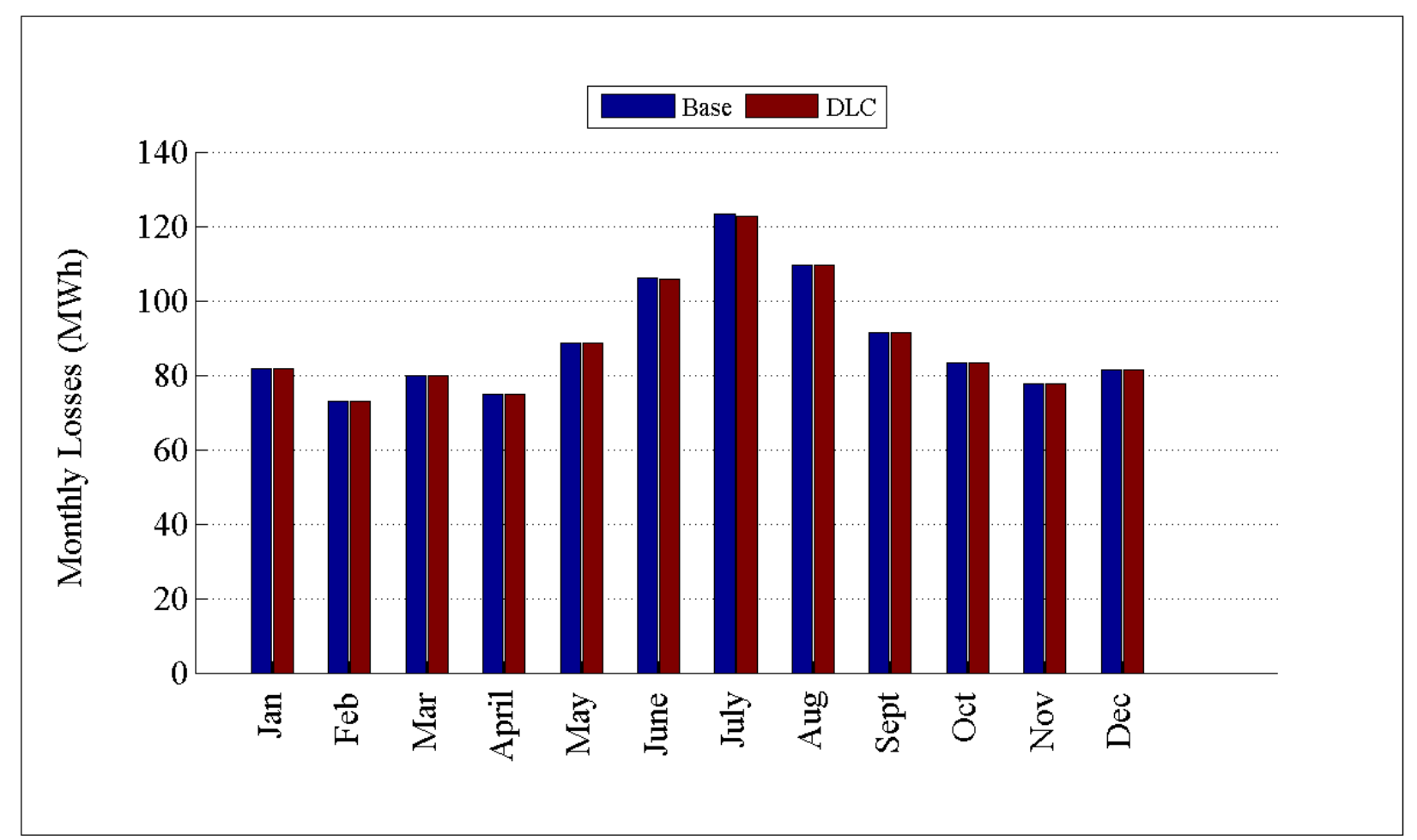

Figure D.155: Comparison of losses by month for R2-25.00-1

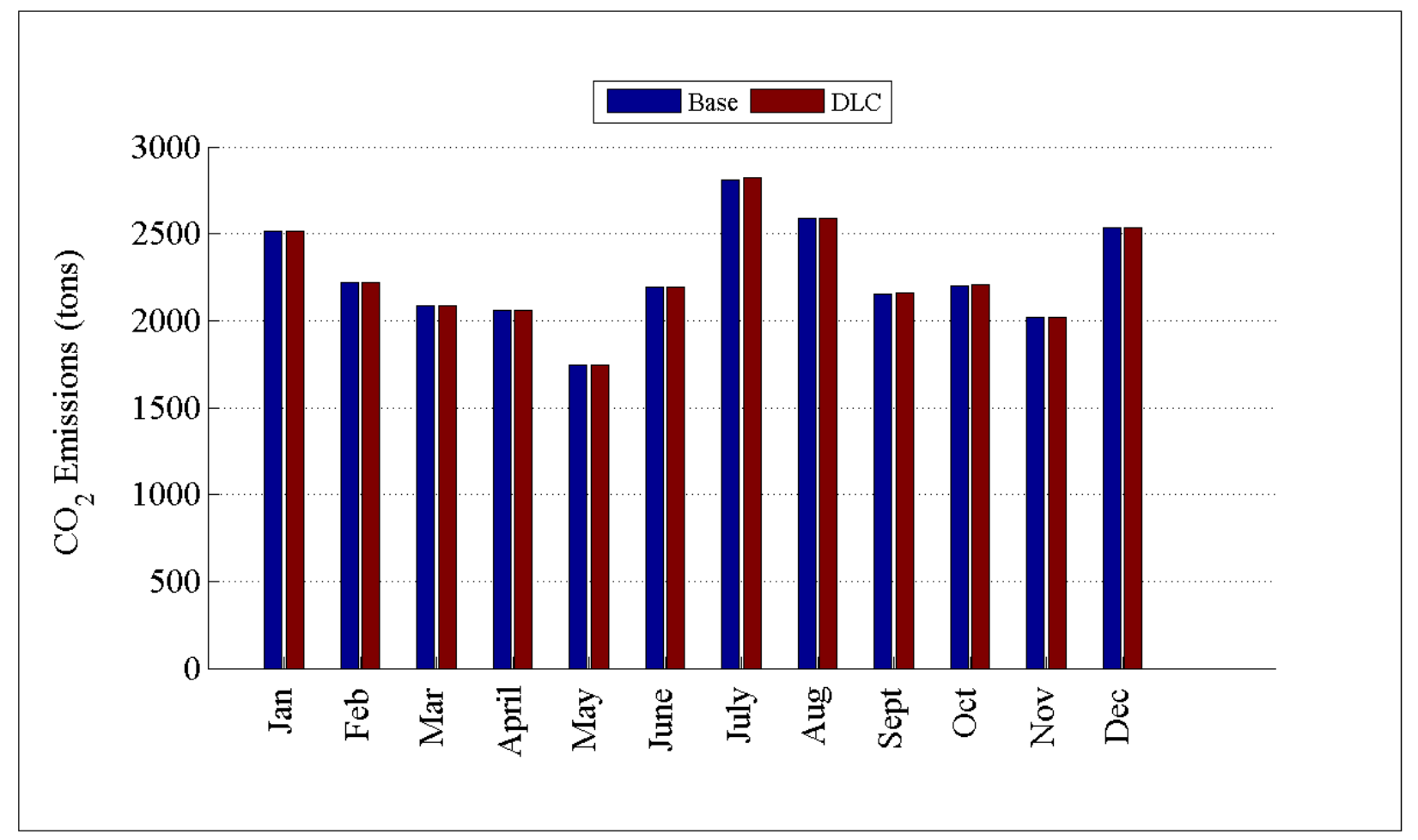

Figure D.156: Comparison of $\mathrm{CO}_{2}$ emissions by month for R2-25.00-1 
D.2.12 Detailed DLC Plots for R2-35.00-1

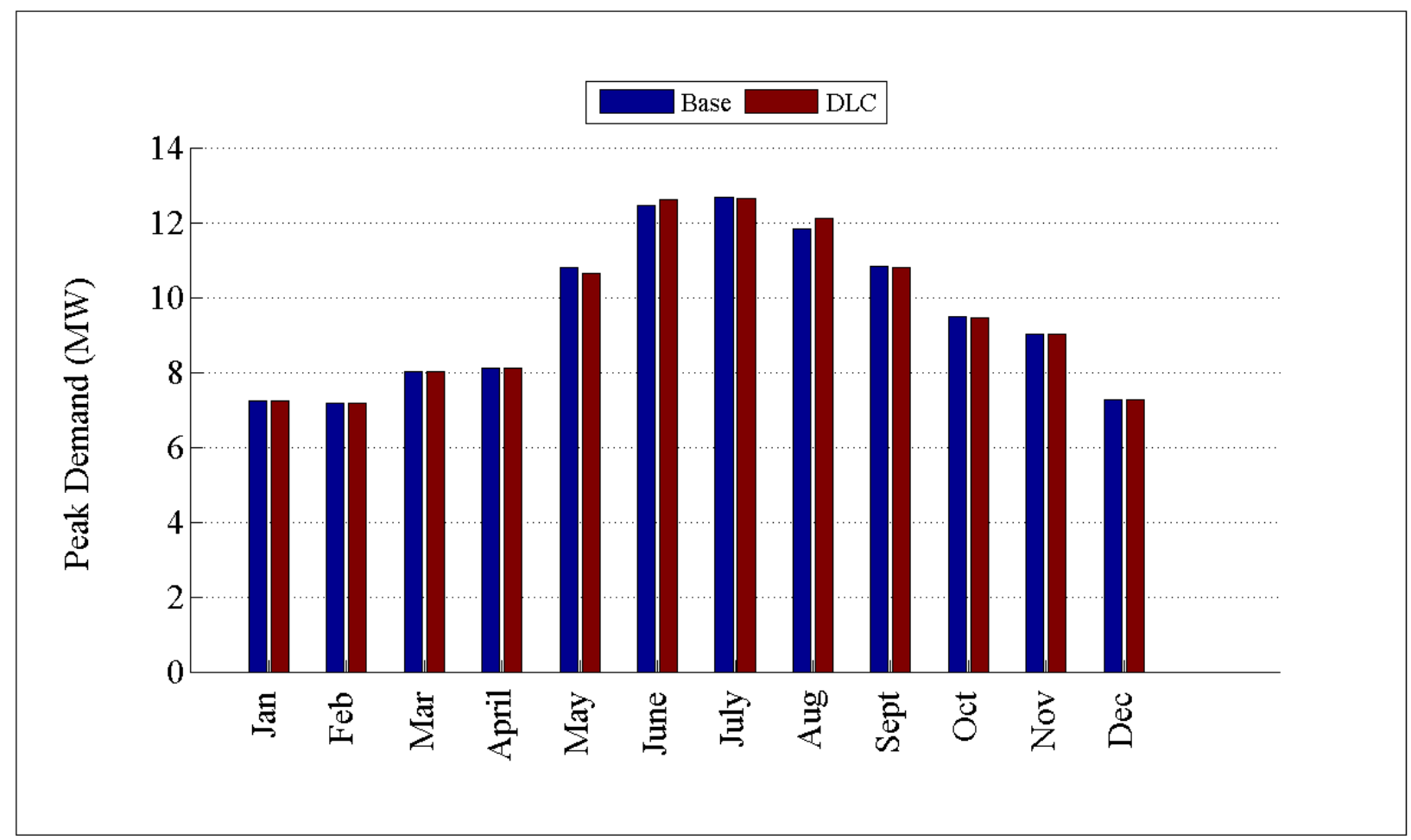

Figure D.157: Comparison of peak demand by month for R2-35.00-1 


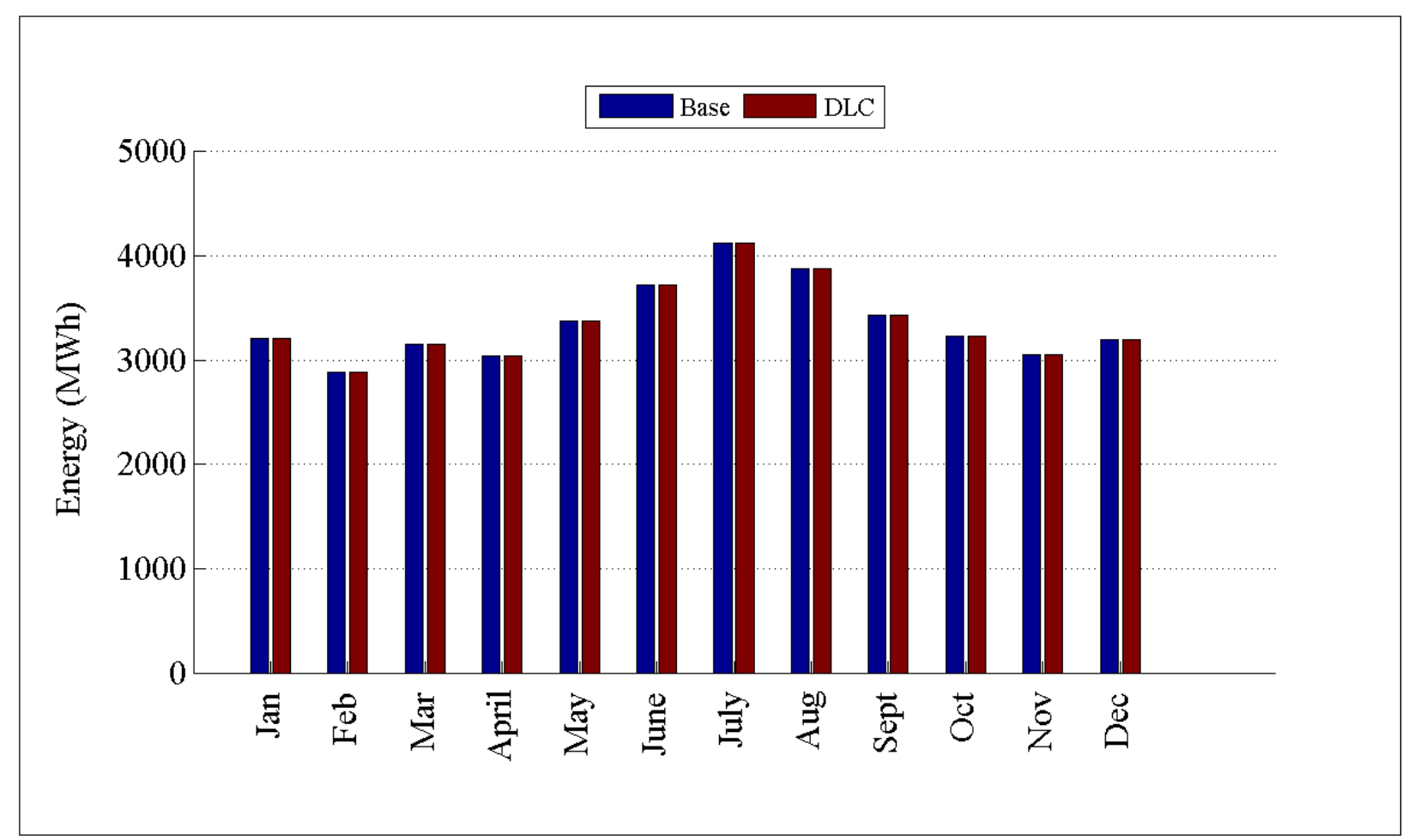

Figure D.158: Comparison of energy consumption by month for R2-35.00-1

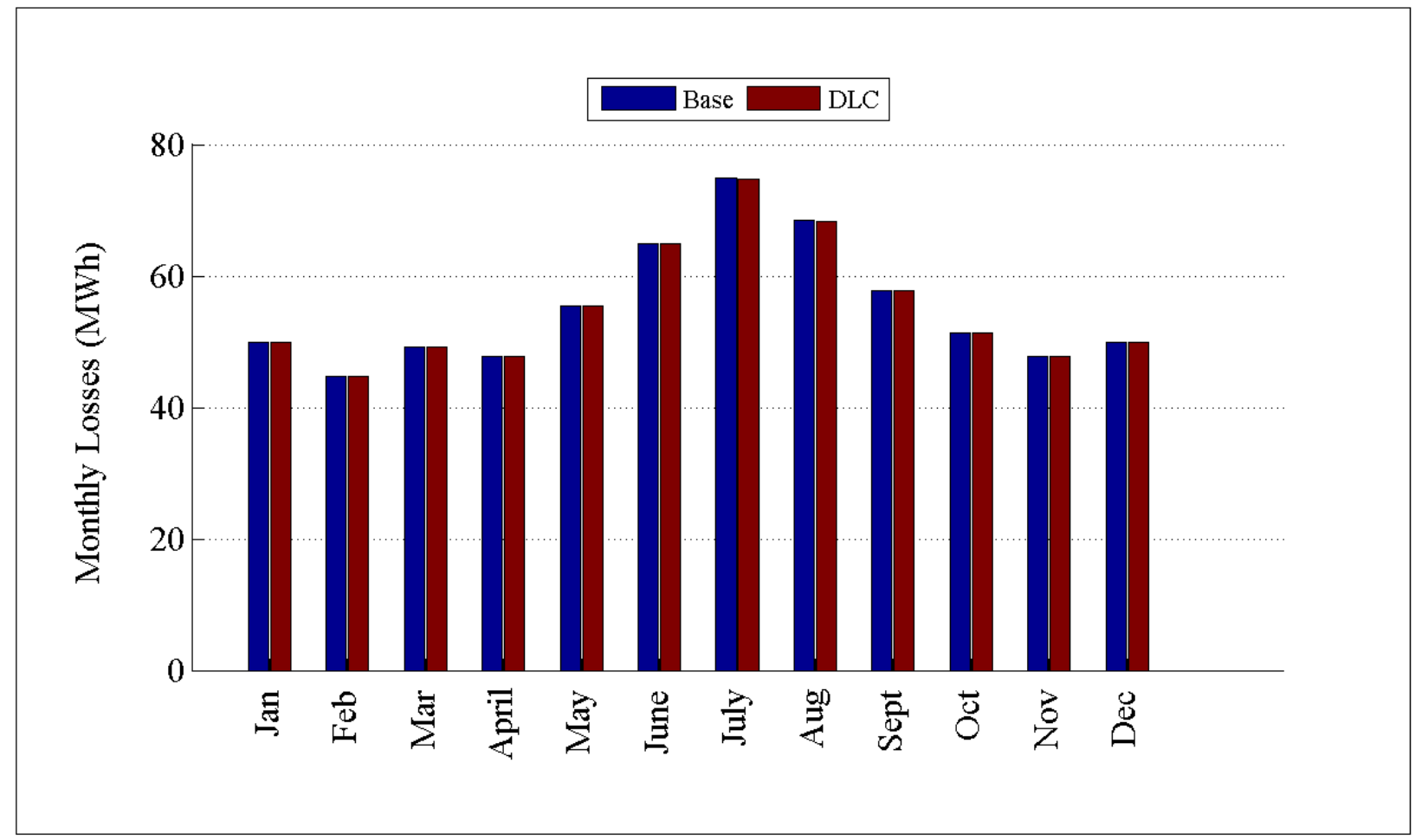

Figure D.159: Comparison of losses by month for R2-35.00-1 


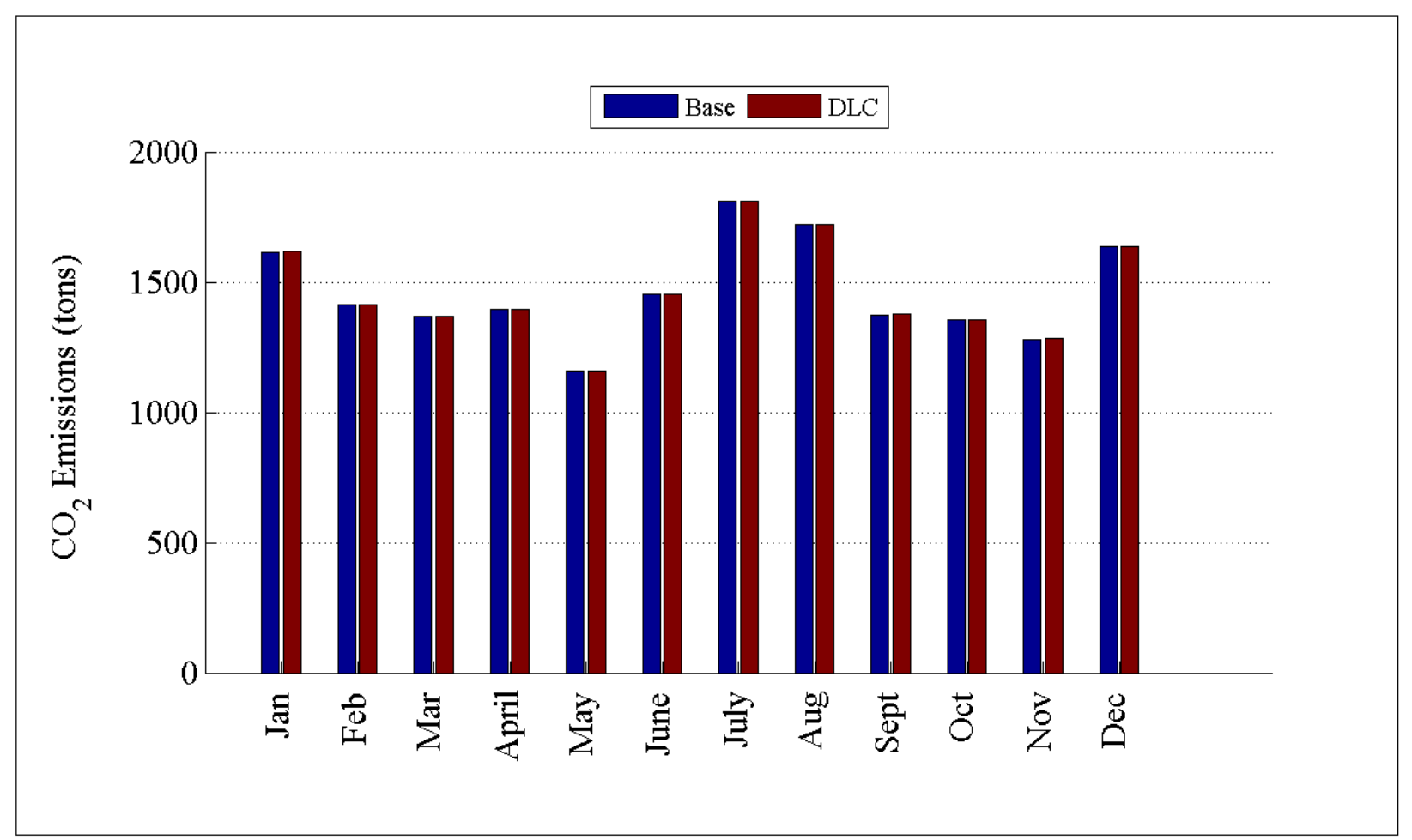

Figure D.160: Comparison of $\mathrm{CO}_{2}$ emissions by month for R2-35.00-1

D.2.13 Detailed DLC Plots for GC-12.47-1_R3 


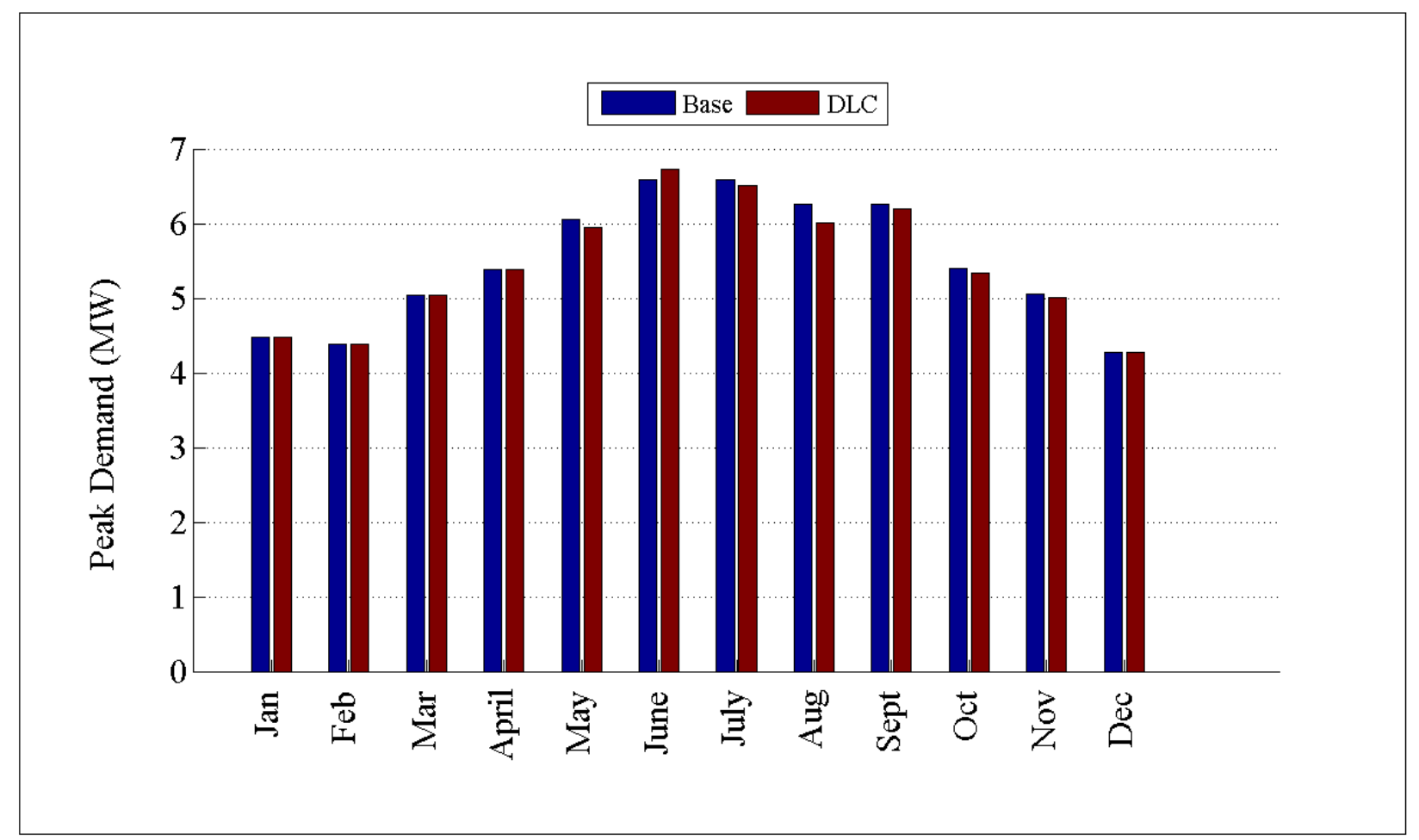

Figure D.161: Comparison of peak demand by month for GC-12.47-1_R3

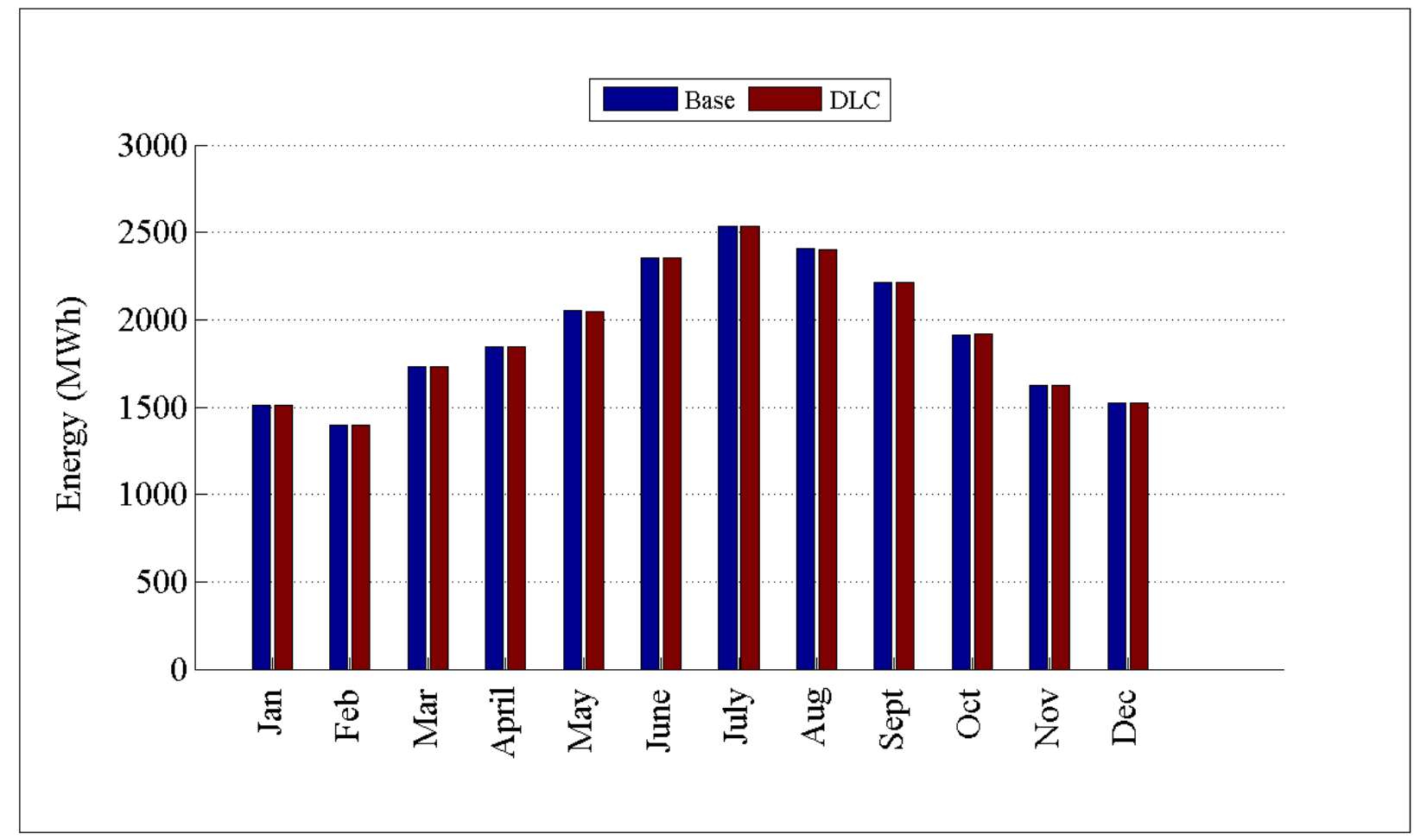

Figure D.162: Comparison of energy consumption by month for GC-12.47-1_R3 


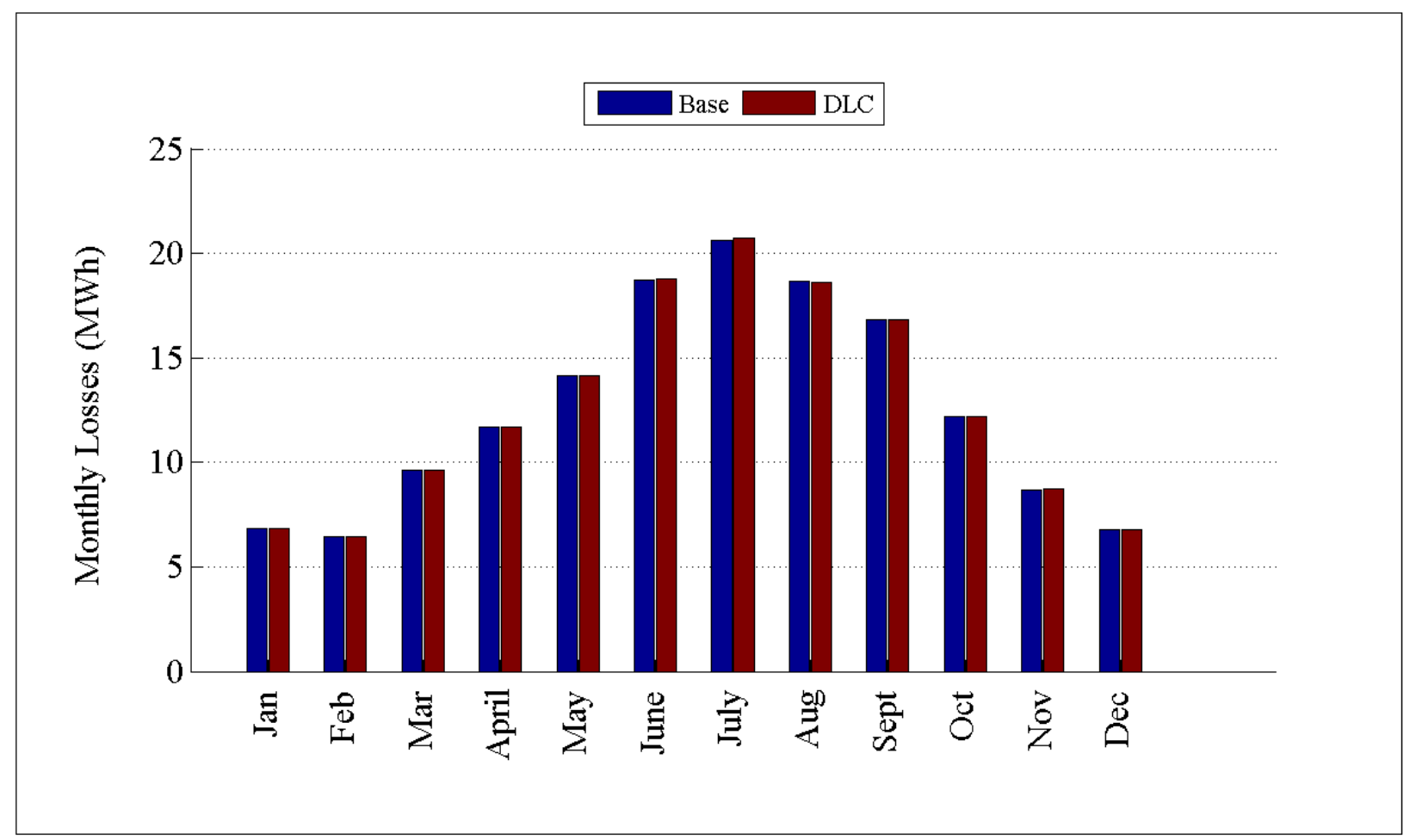

Figure D.163: Comparison of losses by month for GC-12.47-1_R3

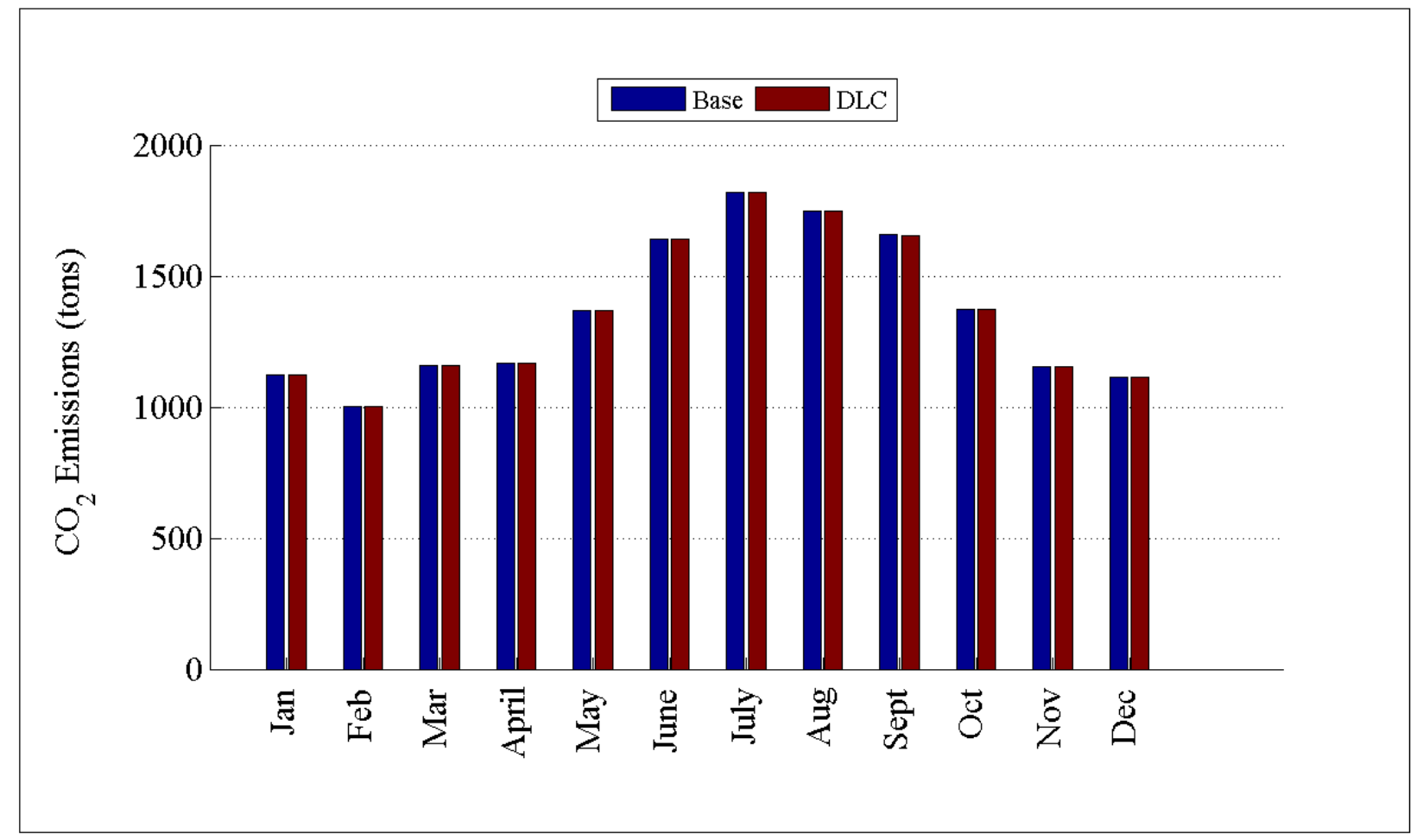

Figure D.164: Comparison of $\mathrm{CO}_{2}$ emissions by month for GC-12.47-1_R3 
D.2.14 Detailed DLC Plots for R3-12.47-1

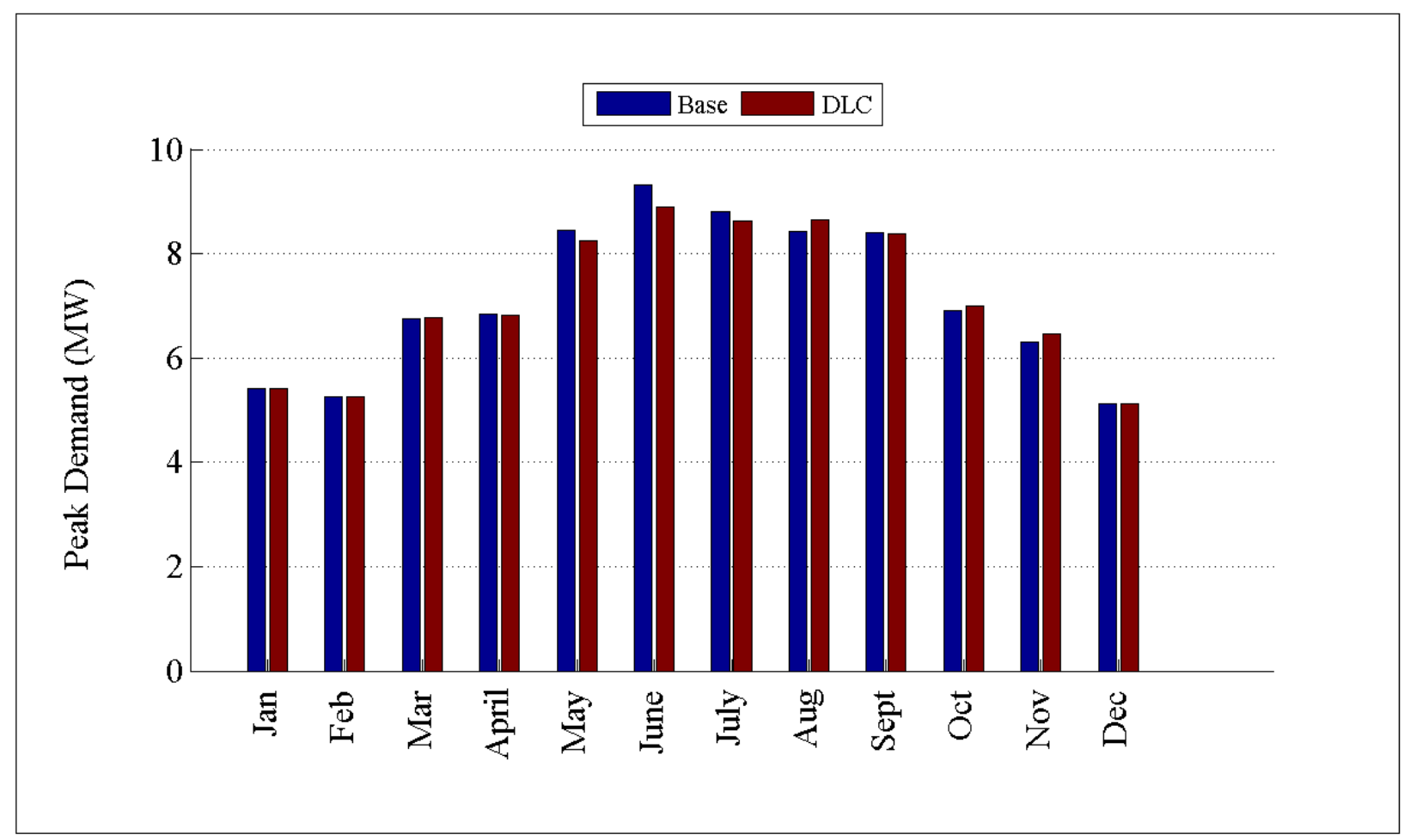

Figure D.165: Comparison of peak demand by month for R3-12.47-1 


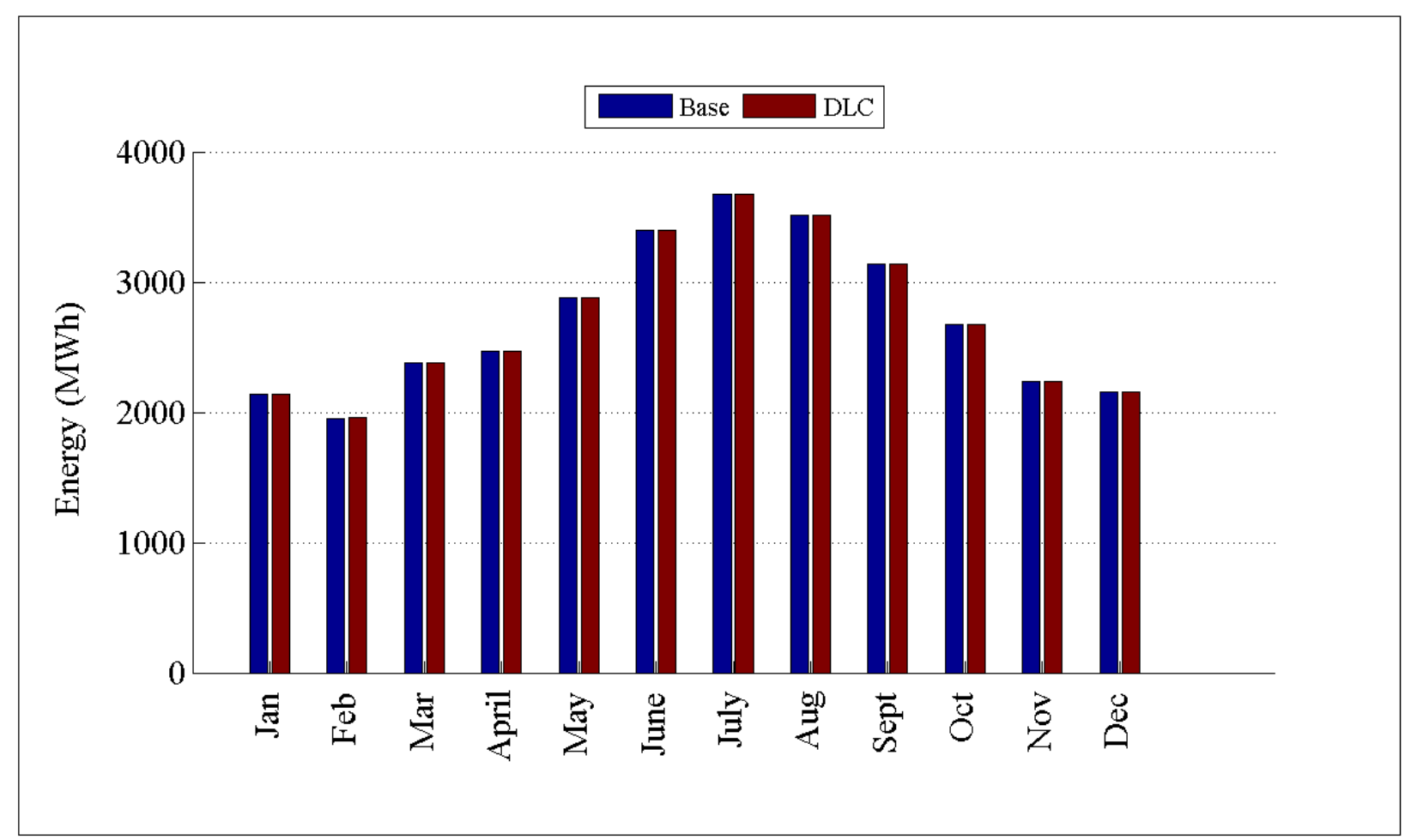

Figure D.166: Comparison of energy consumption by month for R3-12.47-1

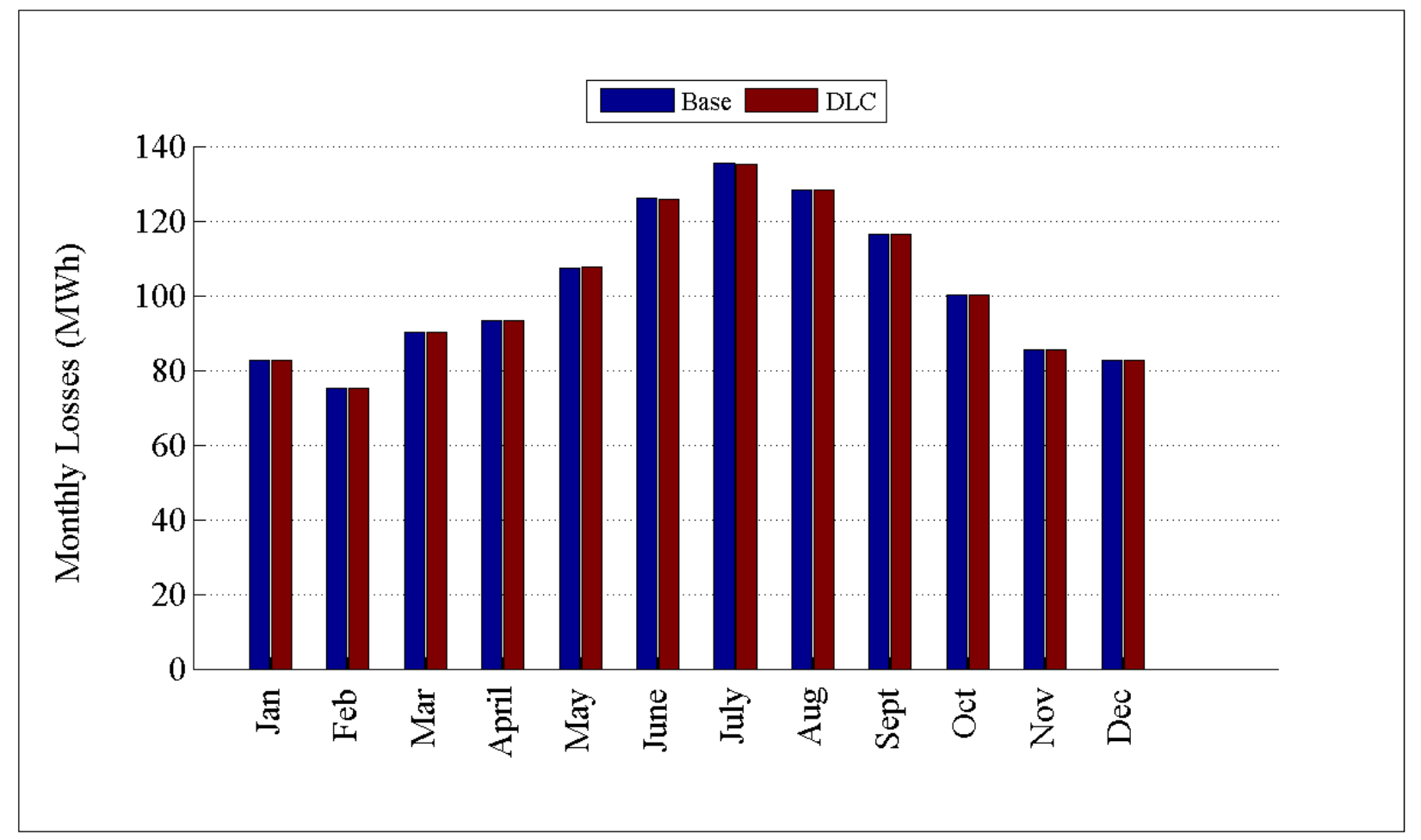

Figure D.167: Comparison of losses by month for R3-12.47-1 


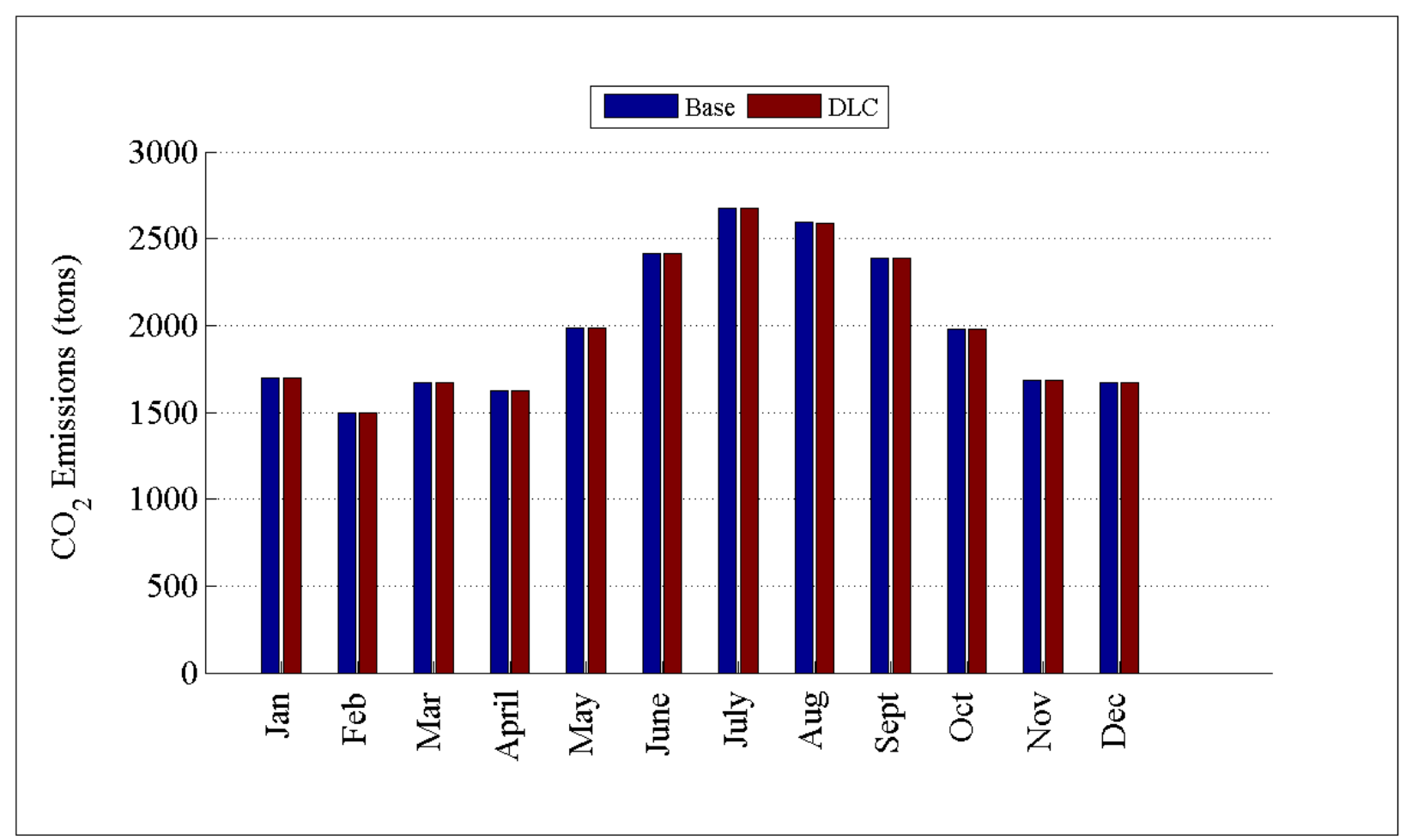

Figure D.168: Comparison of $\mathrm{CO}_{2}$ emissions by month for R3-12.47-1

D.2.15 Detailed DLC Plots for R3-12.47-2 


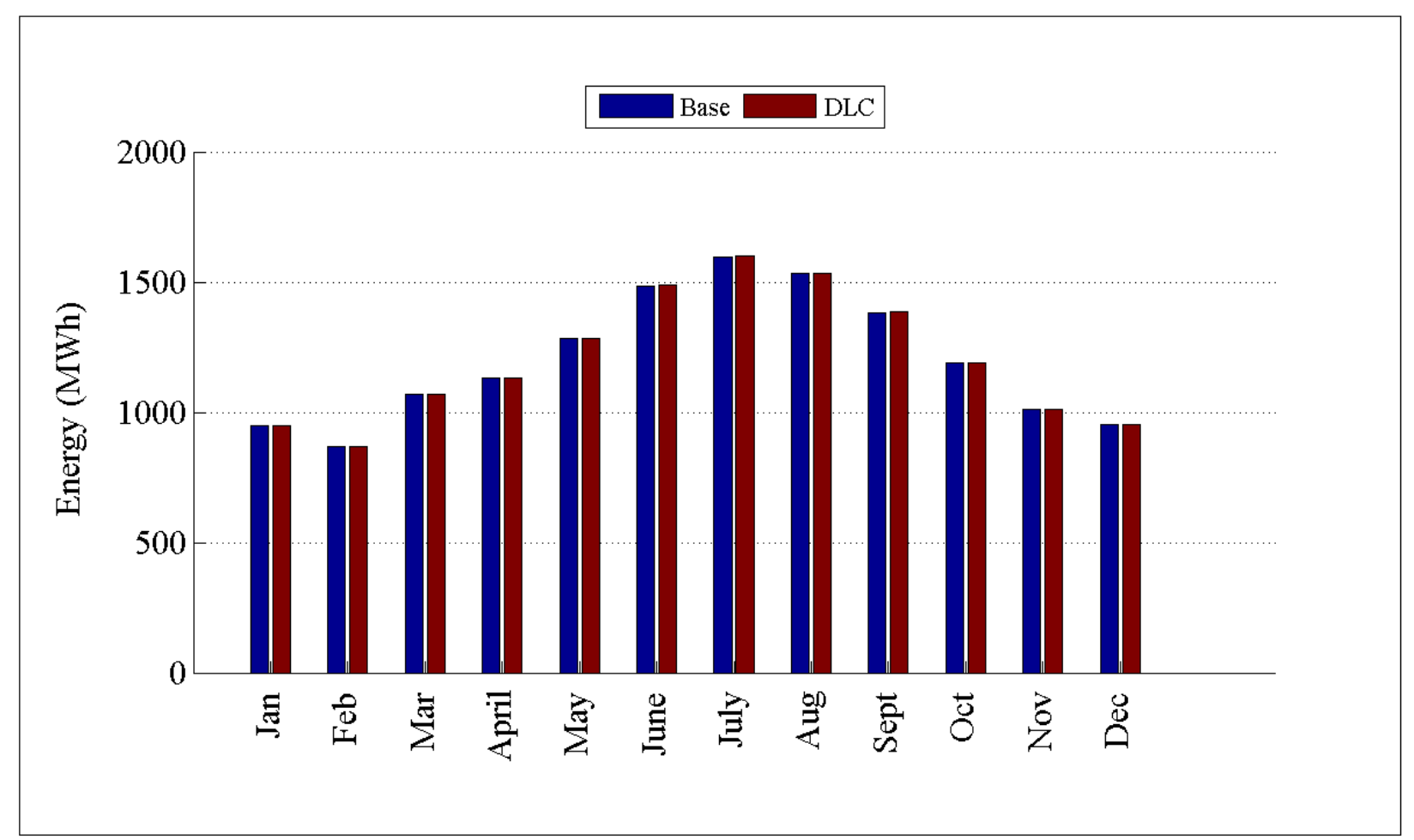

Figure D.169: Comparison of peak demand by month for R3-12.47-2

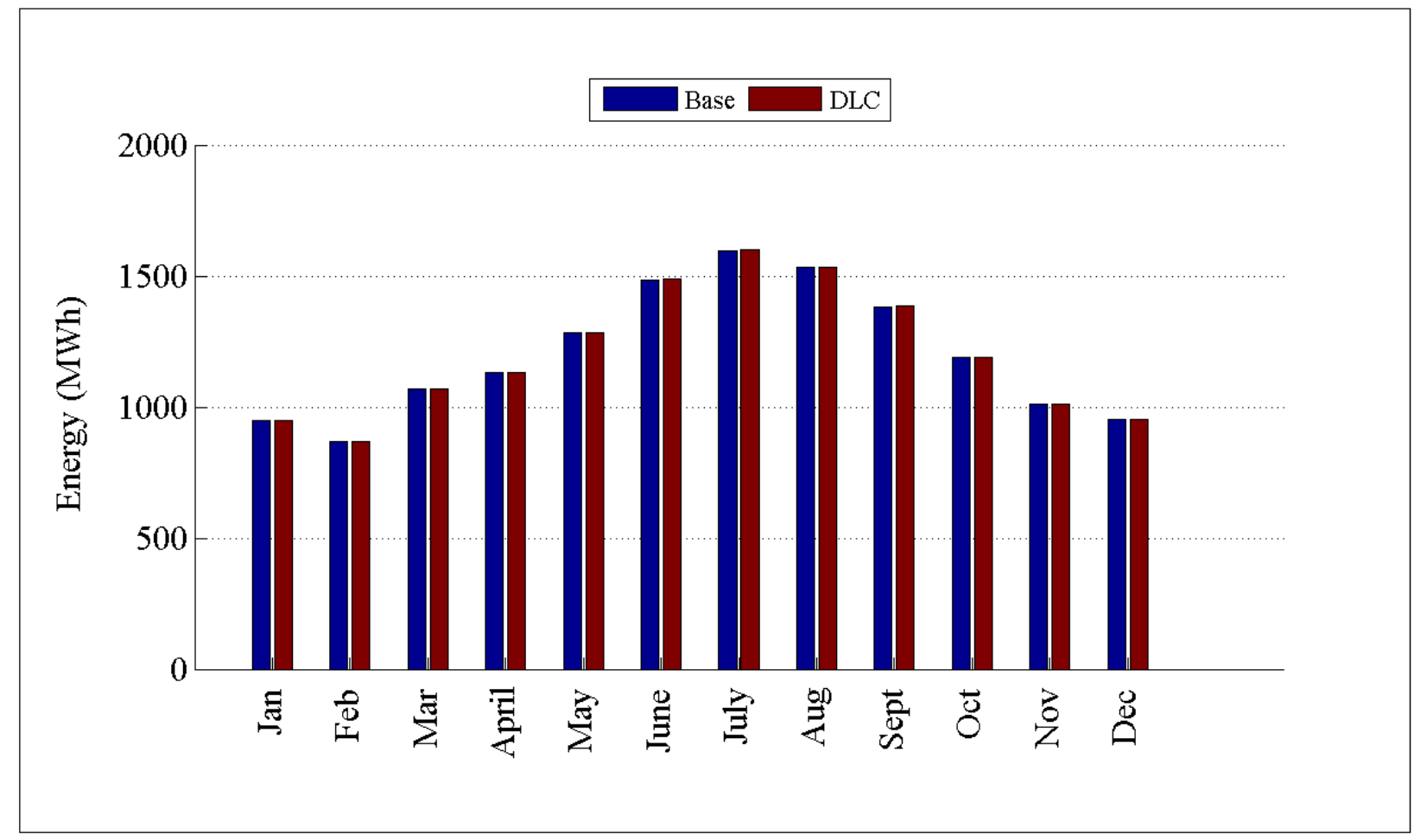

Figure D.170: Comparison of energy consumption by month for R3-12.47-2 


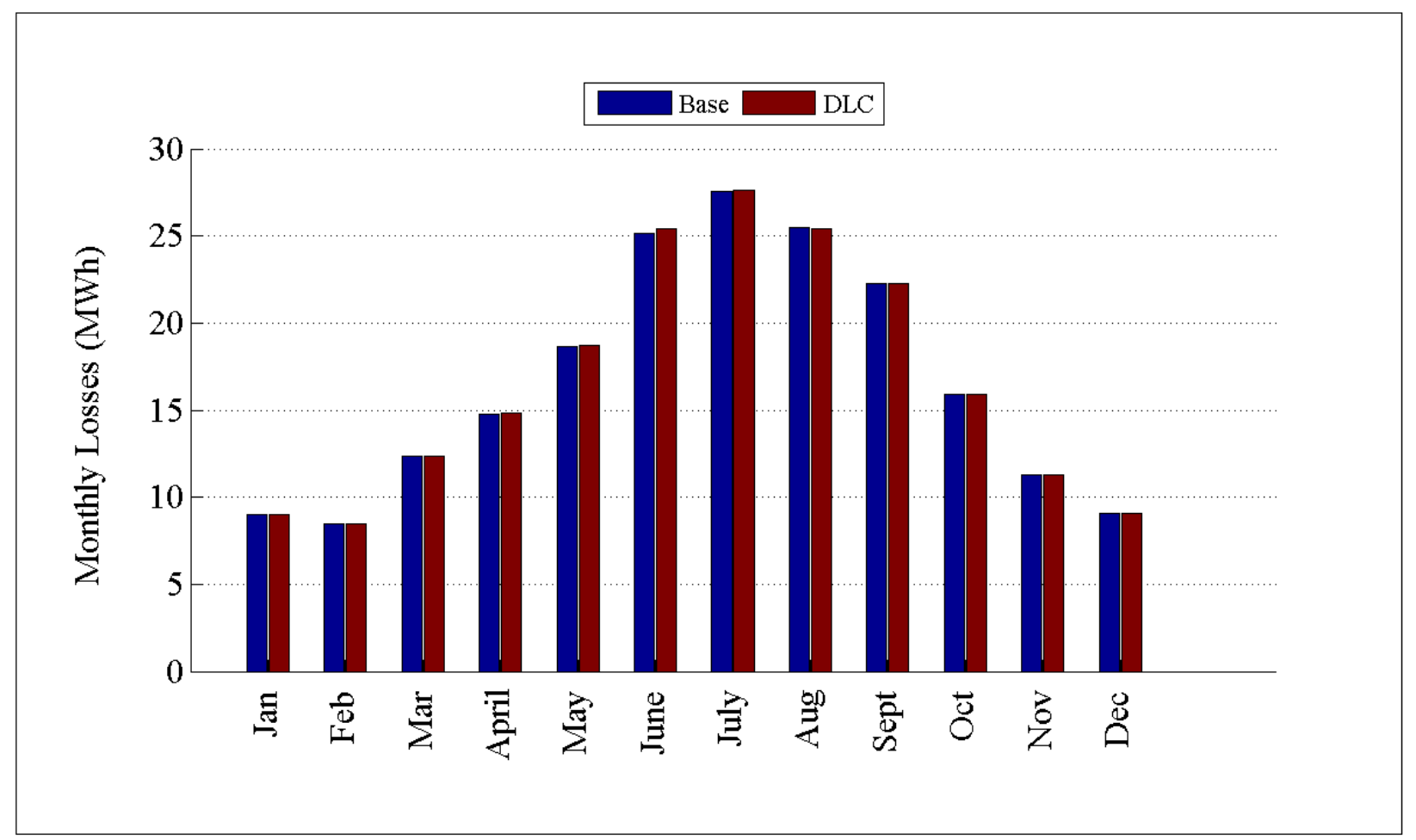

Figure D.171: Comparison of losses by month for R3-12.47-2

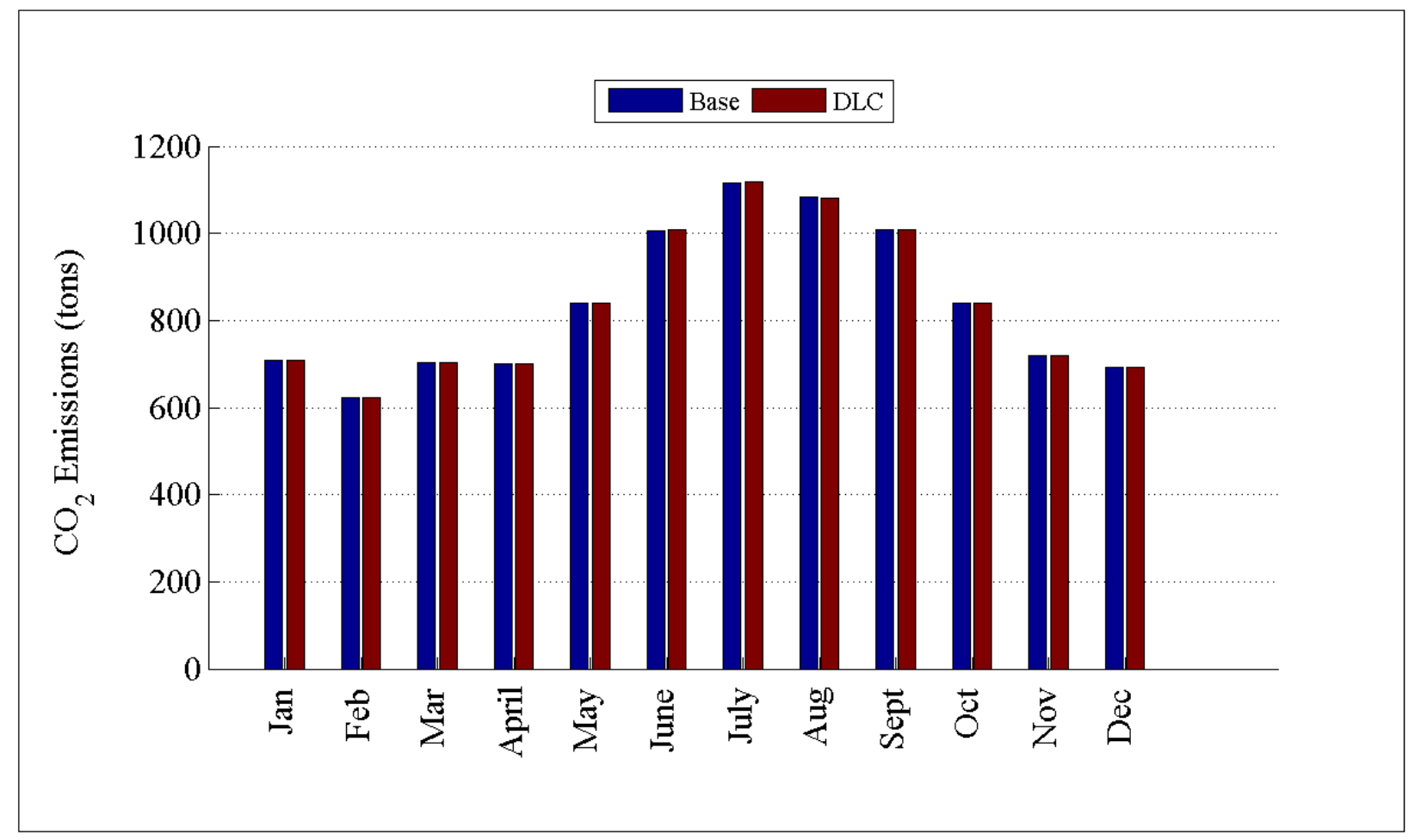

Figure D.172: Comparison of $\mathrm{CO}_{2}$ emissions by month for R3-12.47-2 
D.2.16 Detailed DLC Plots for R3-12.47-3

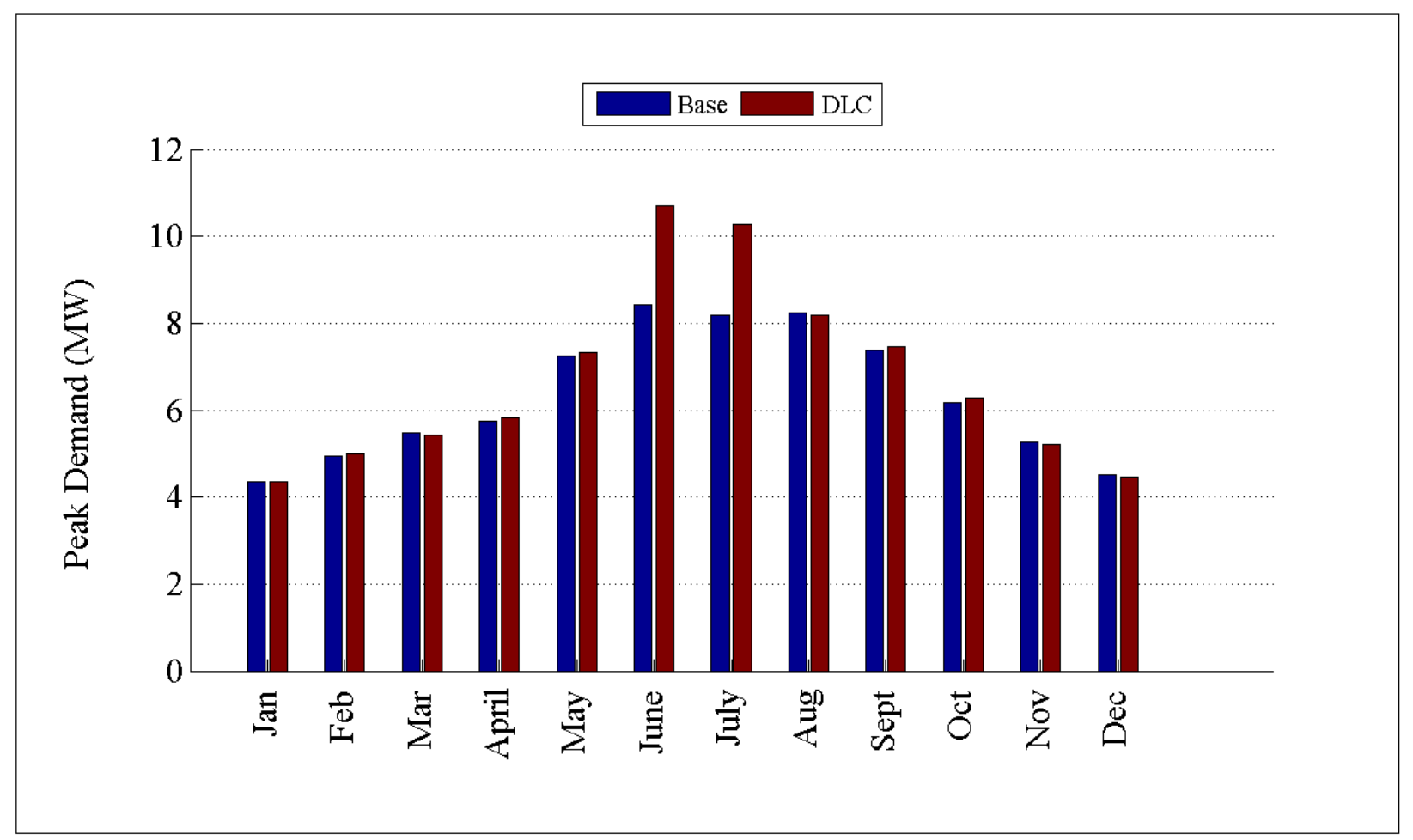

Figure D.173: Comparison of peak demand by month for R3-12.47-3 


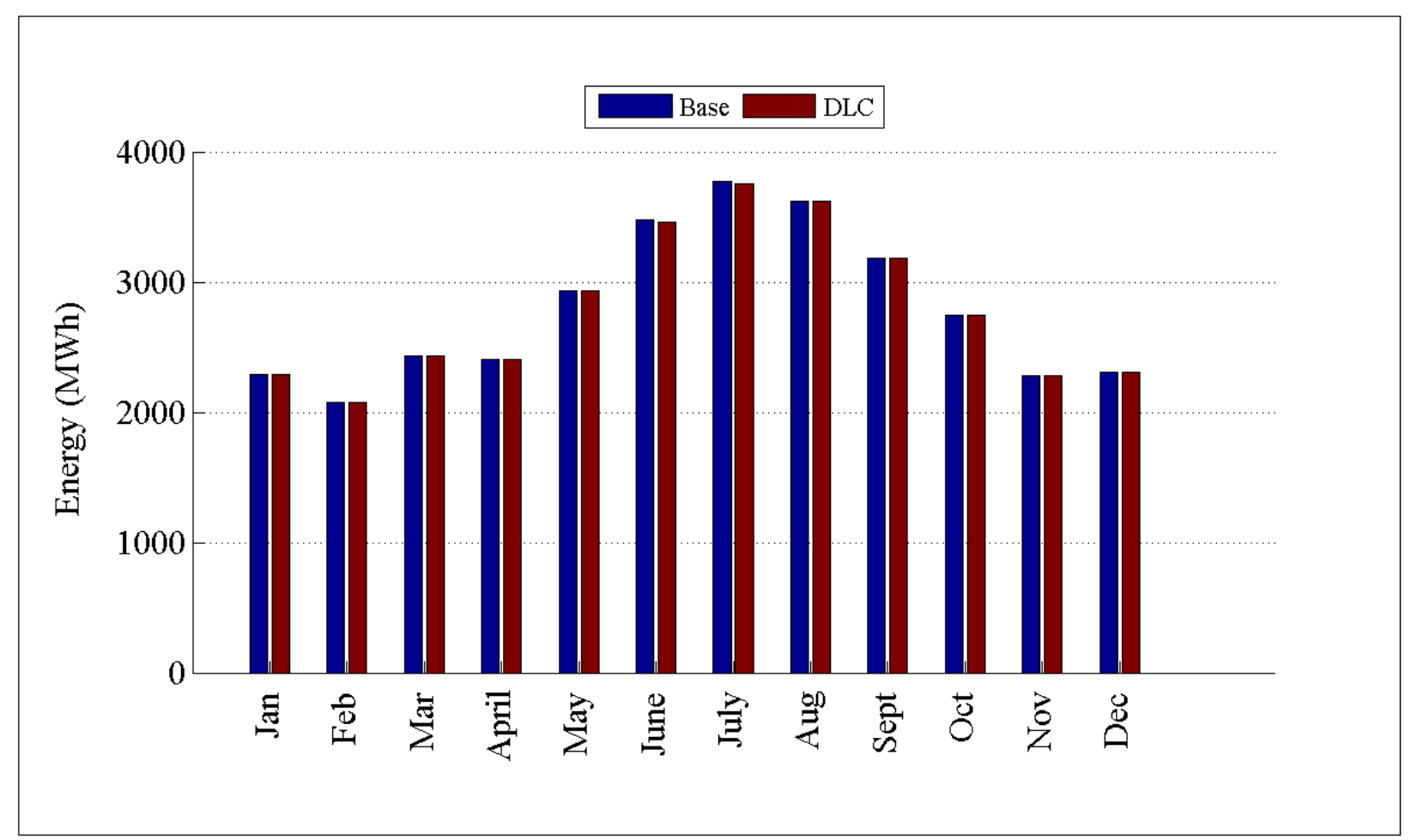

Figure D.174: Comparison of energy consumption by month for R3-12.47-3

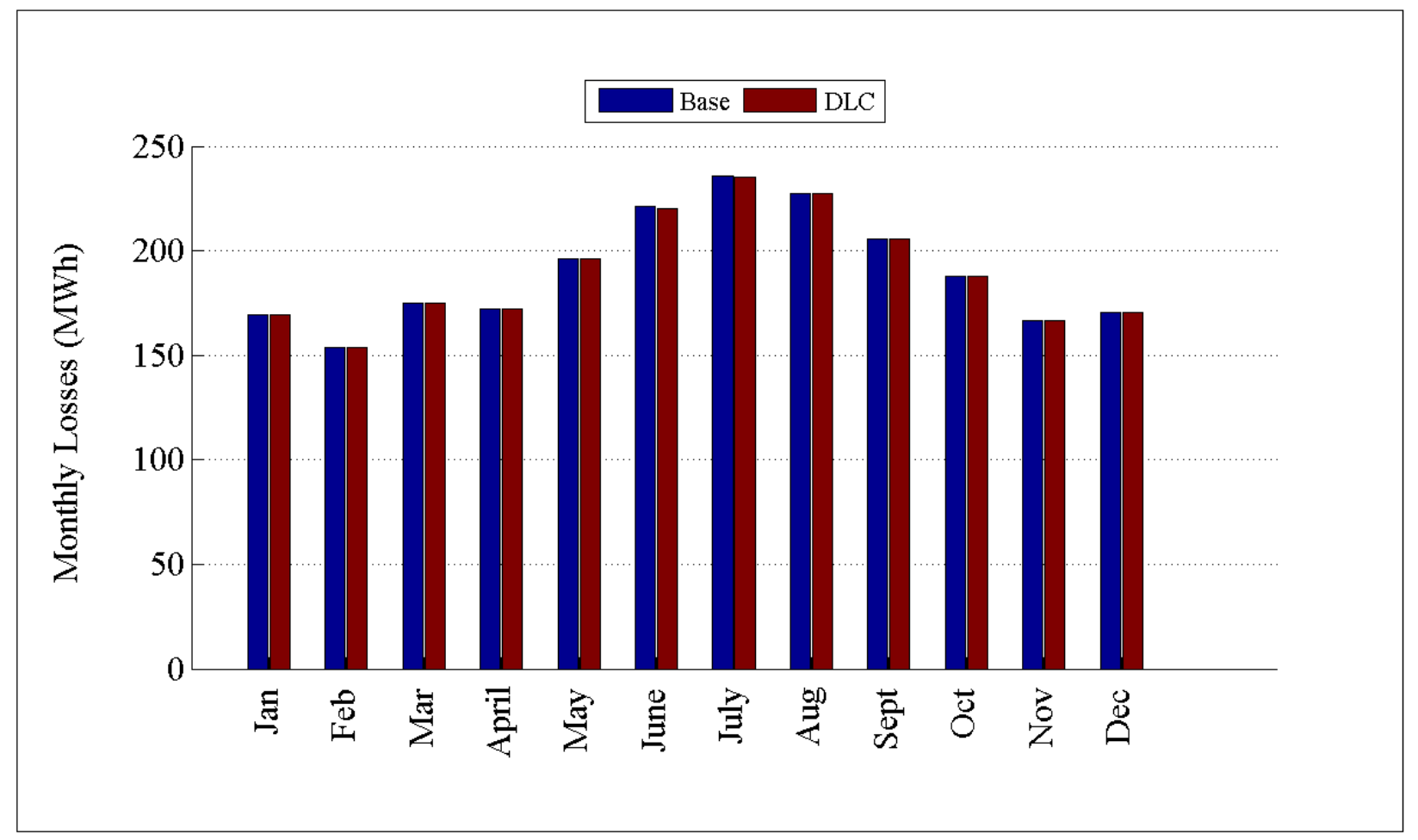

Figure D.175: Comparison of losses by month for R3-12.47-3 


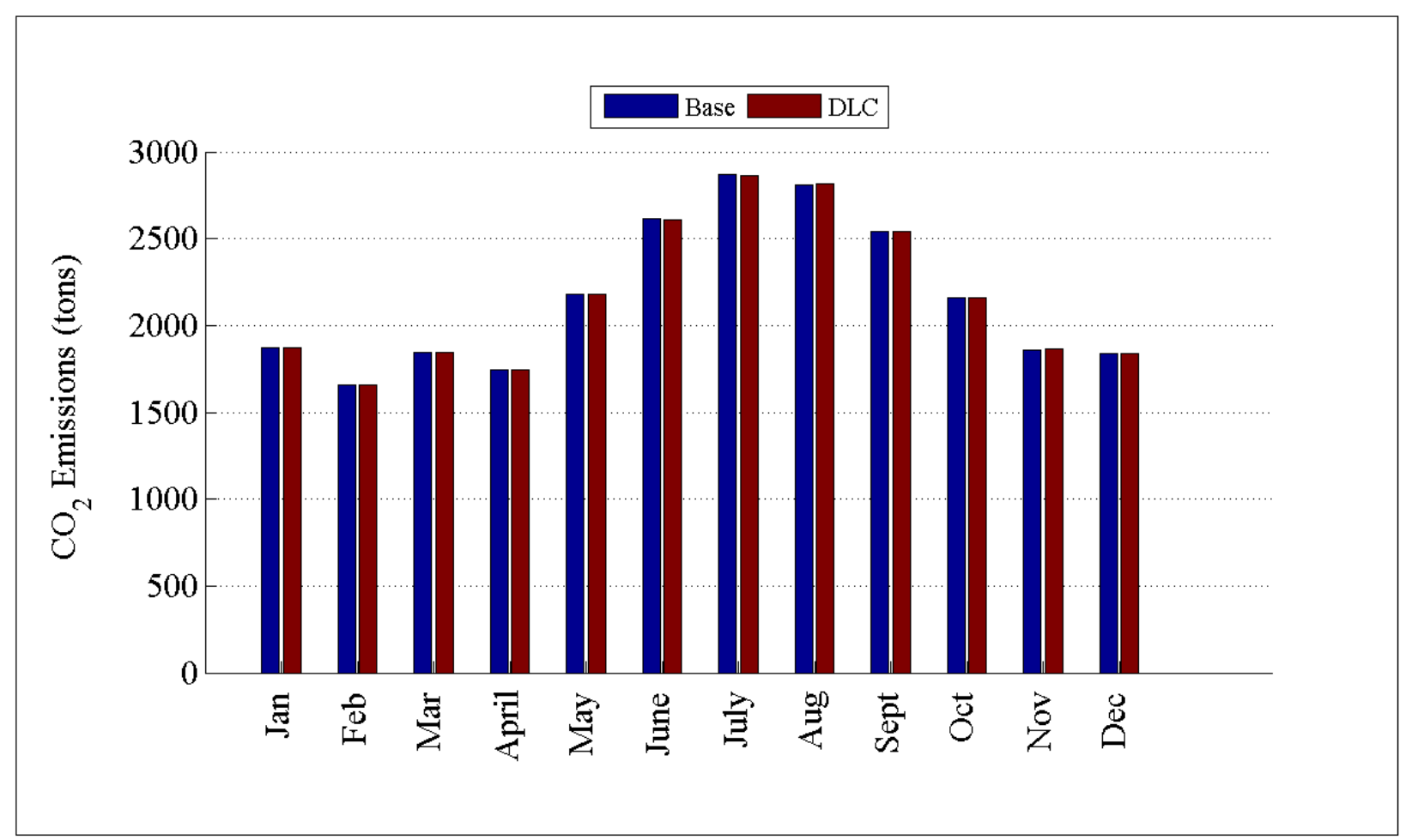

Figure D.176: Comparison of $\mathrm{CO}_{2}$ emissions by month for R3-12.47-3

D.2.17 Detailed DLC Plots for GC-12.47-1_R4 


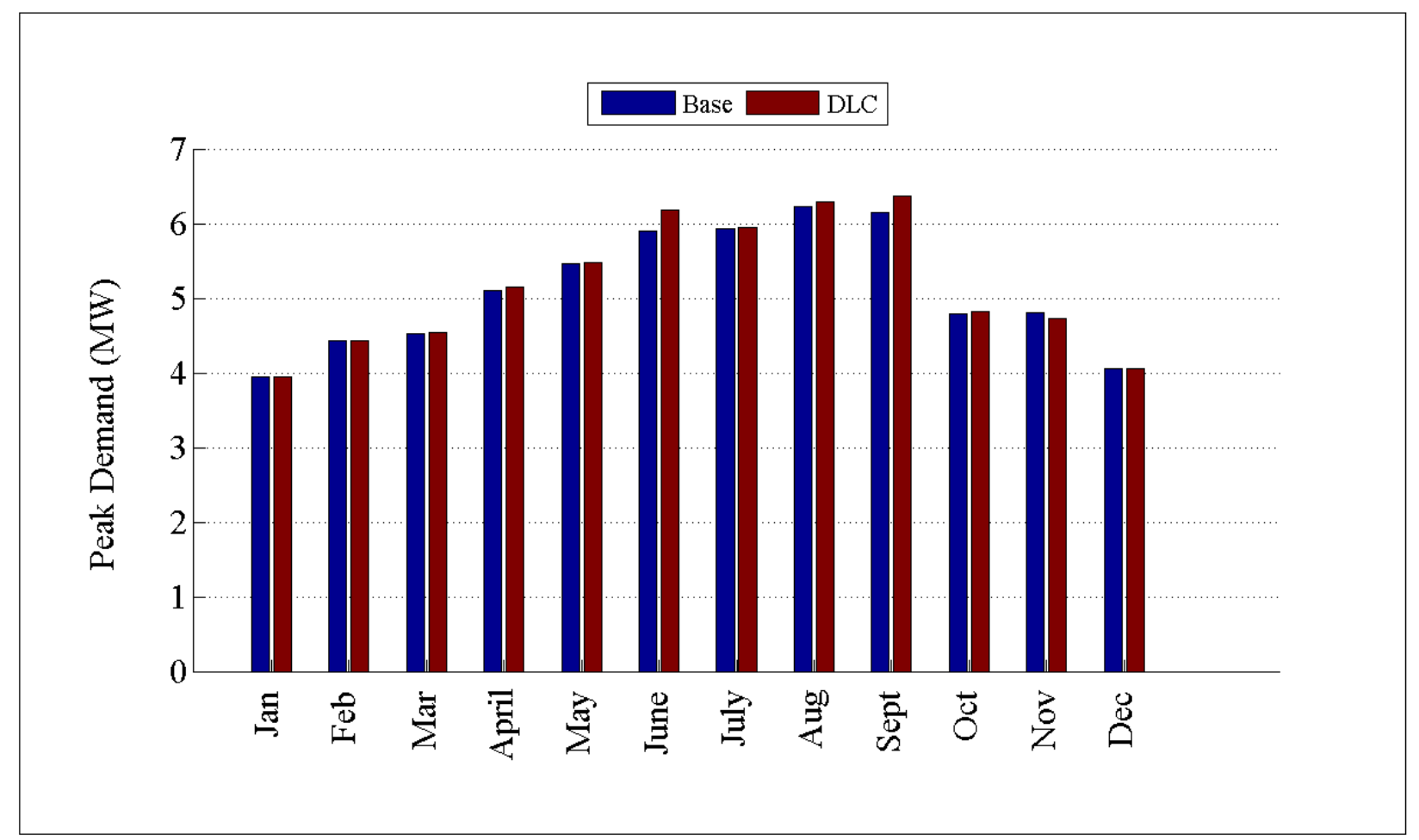

Figure D.177: Comparison of peak demand by month for GC-12.47-1_R4

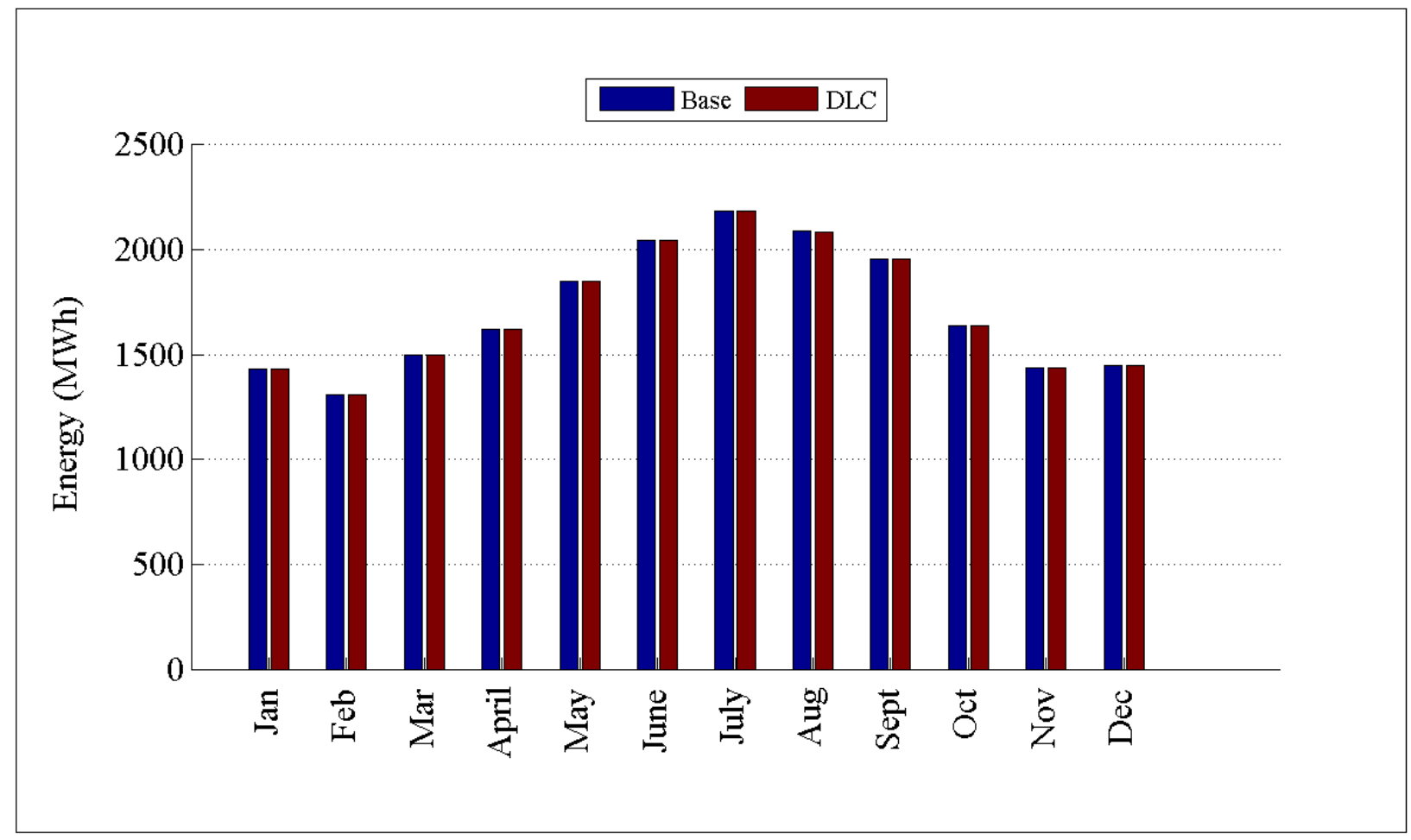

Figure D.178: Comparison of energy consumption by month for GC-12.47-1_R4 


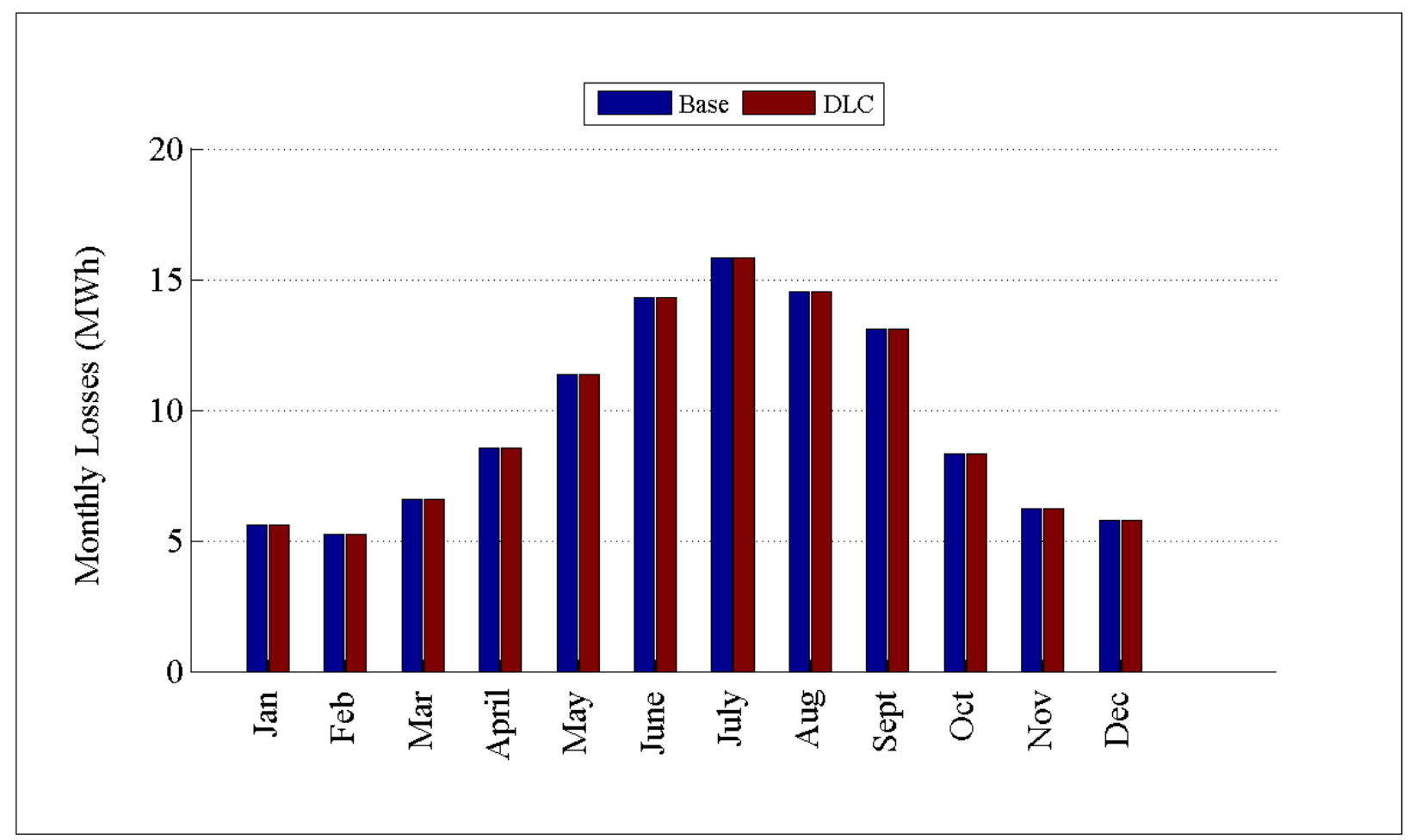

Figure D.179: Comparison of losses by month for GC-12.47-1_R4

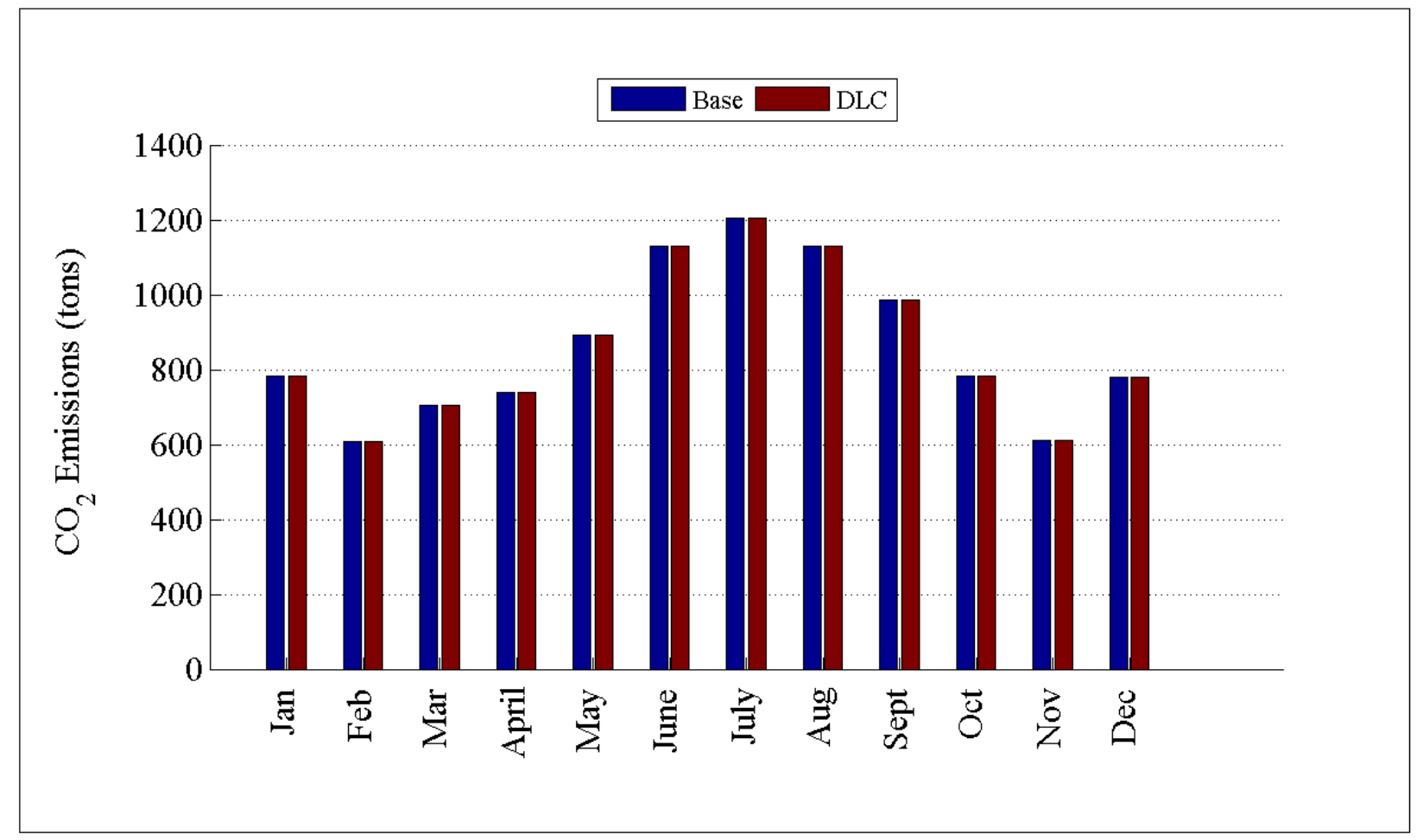

Figure D.180: Comparison of $\mathrm{CO}_{2}$ emissions by month for GC-12.47-1_R4 
D.2.18 Detailed DLC Plots for R4-12.47-1

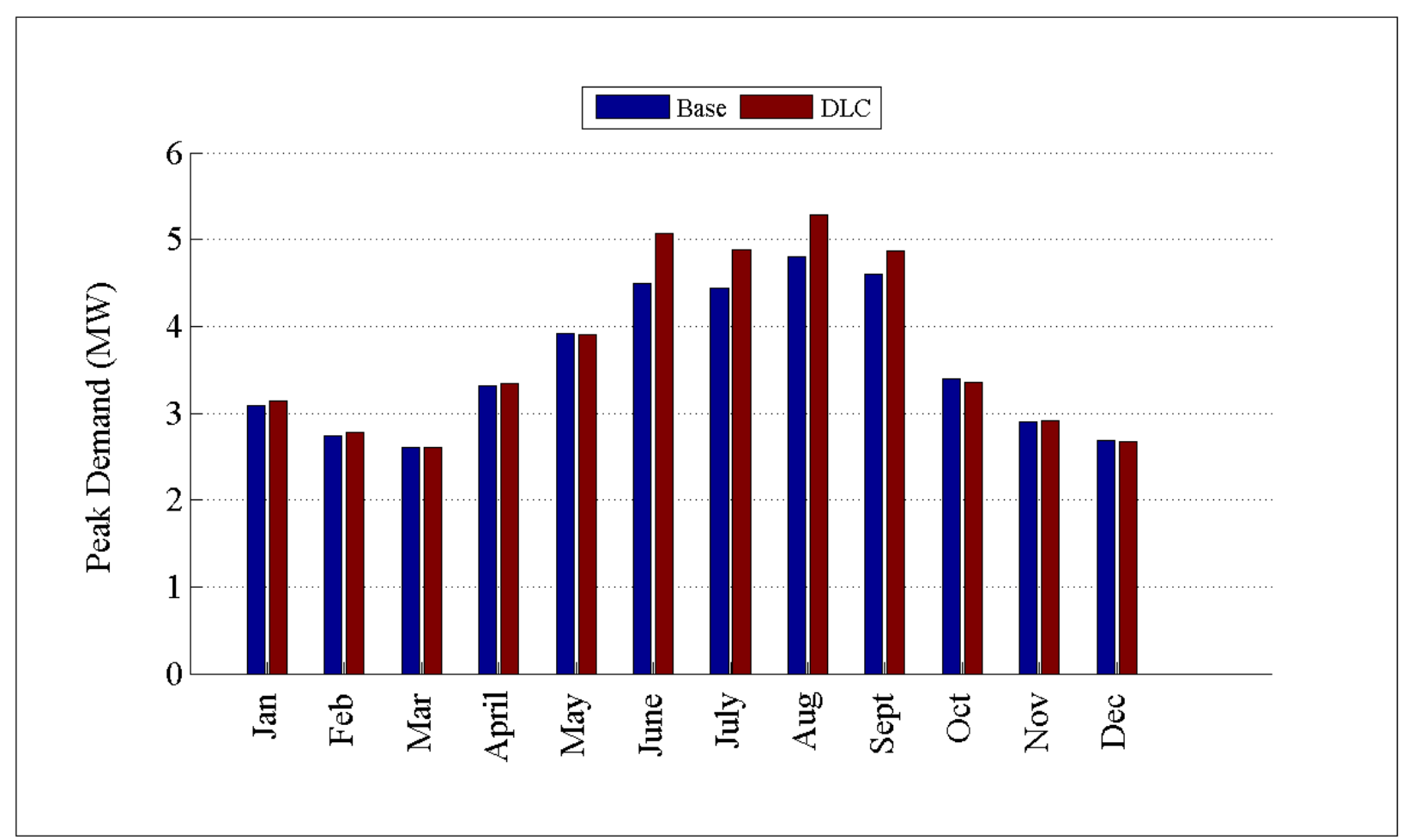

Figure D.181: Comparison of peak demand by month for R4-12.47-1 


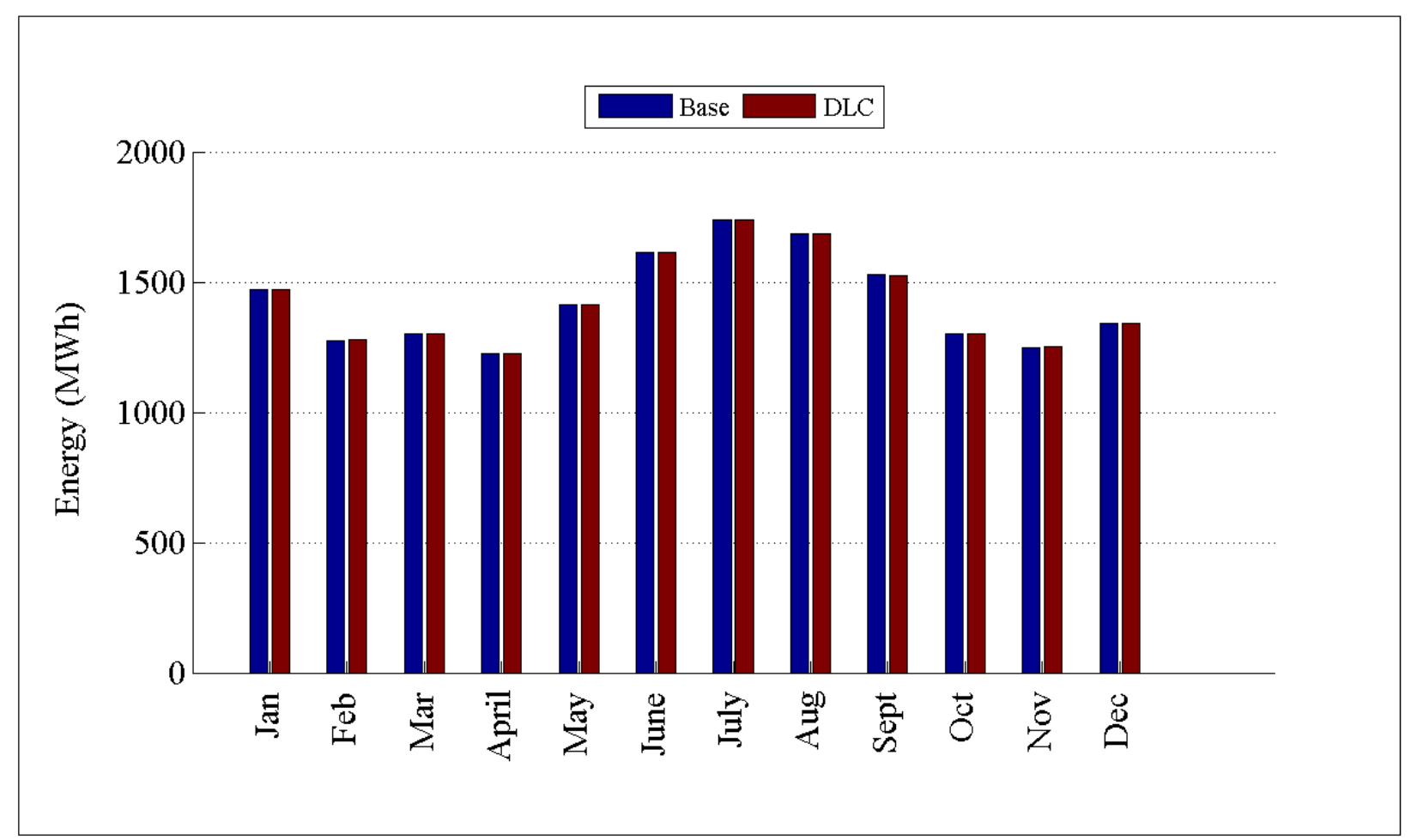

Figure D.182: Comparison of energy consumption by month for R4-12.47-1

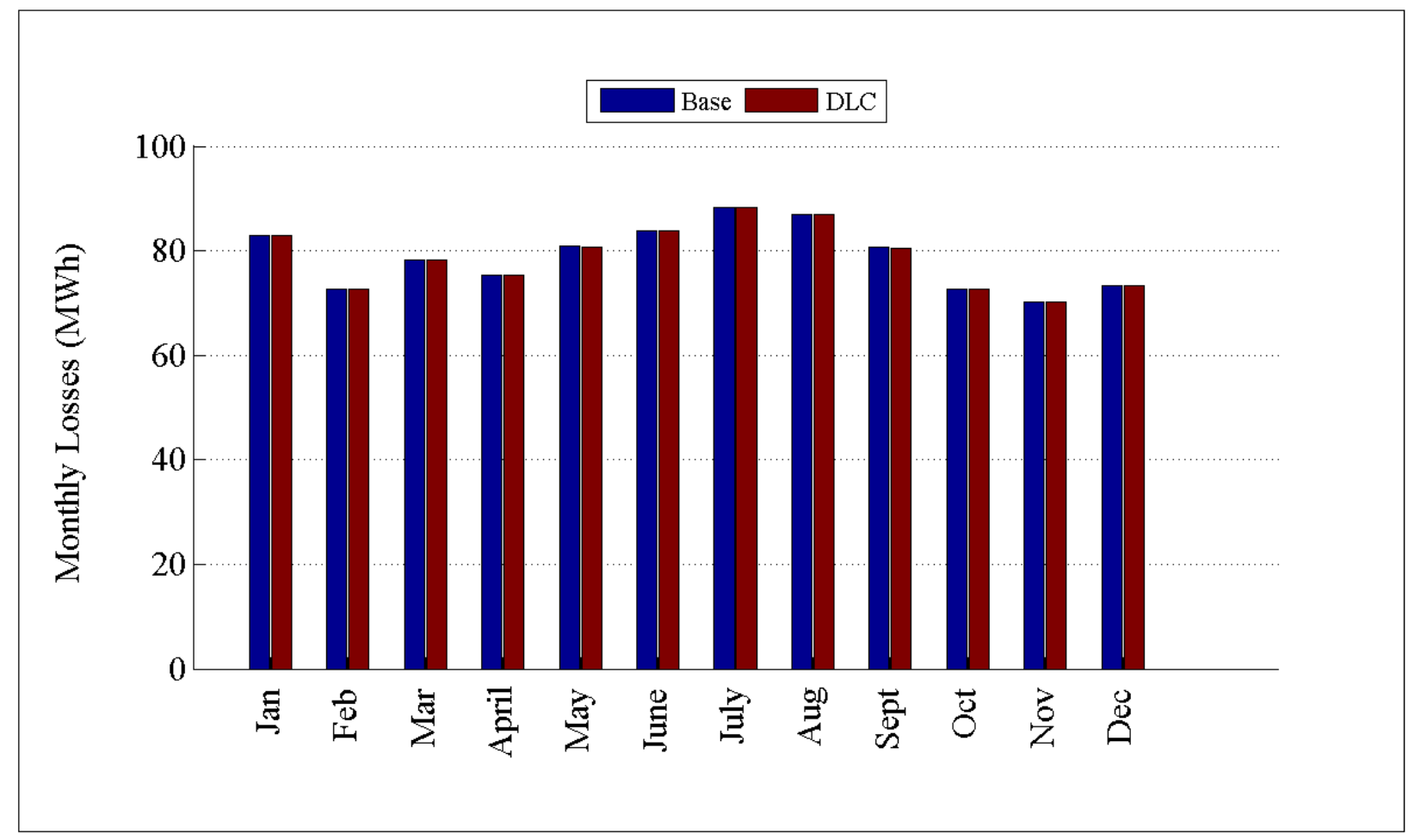

Figure D.183: Comparison of losses by month for R4-12.47-1 


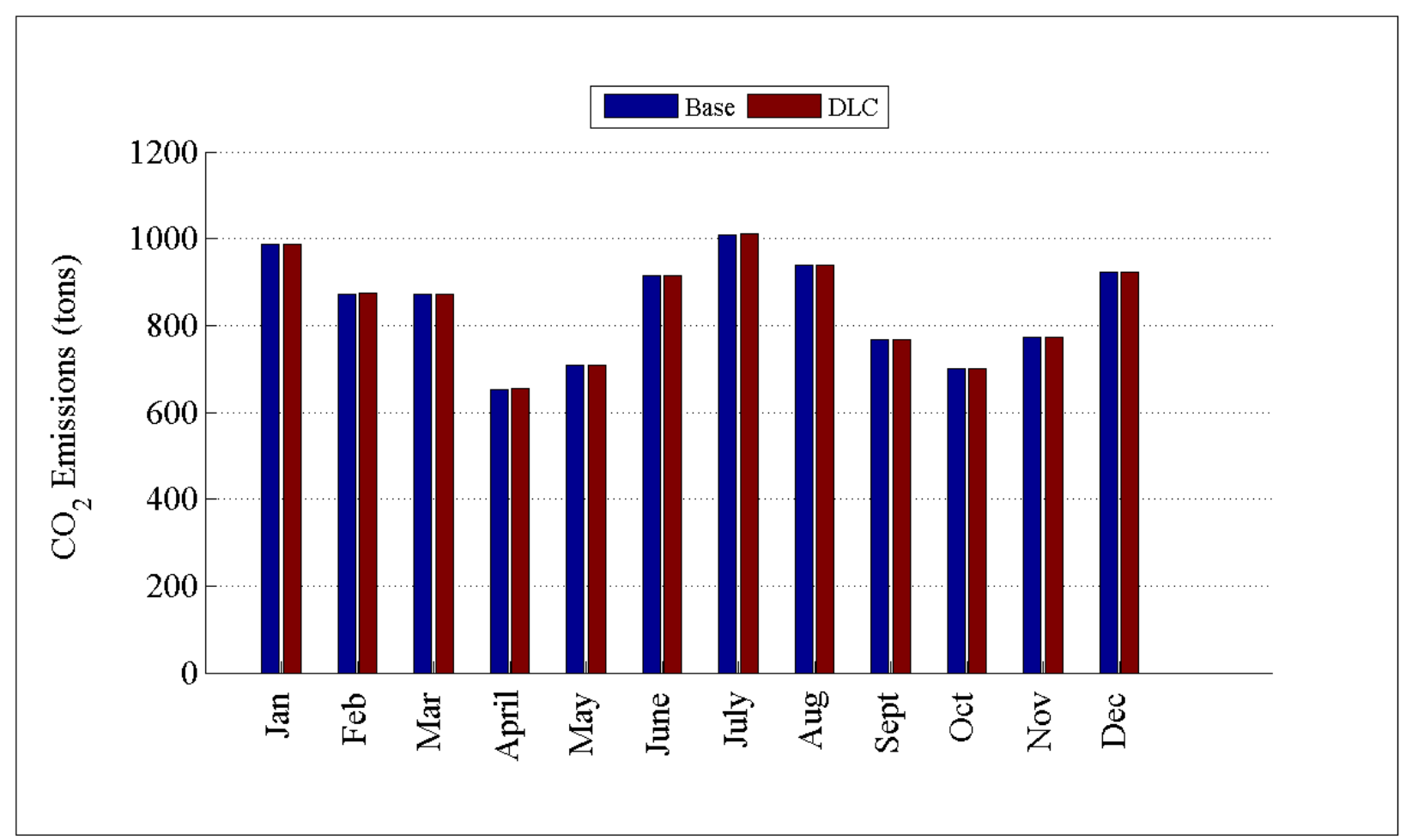

Figure D.184: Comparison of $\mathrm{CO}_{2}$ emissions by month for R4-12.47-1

D.2.19 Detailed DLC Plots for R4-12.47-2 


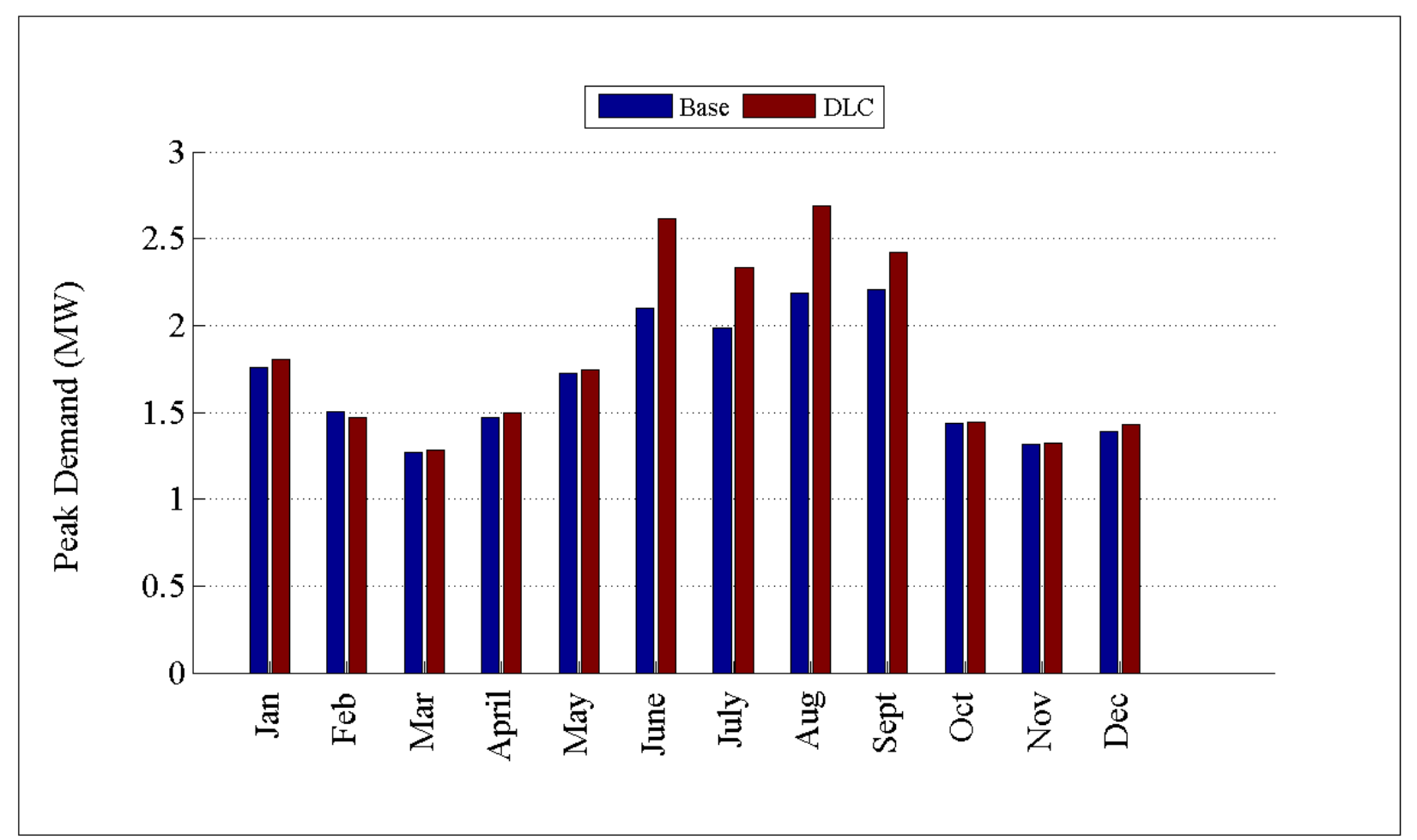

Figure D.185: Comparison of peak demand by month for R4-12.47-2

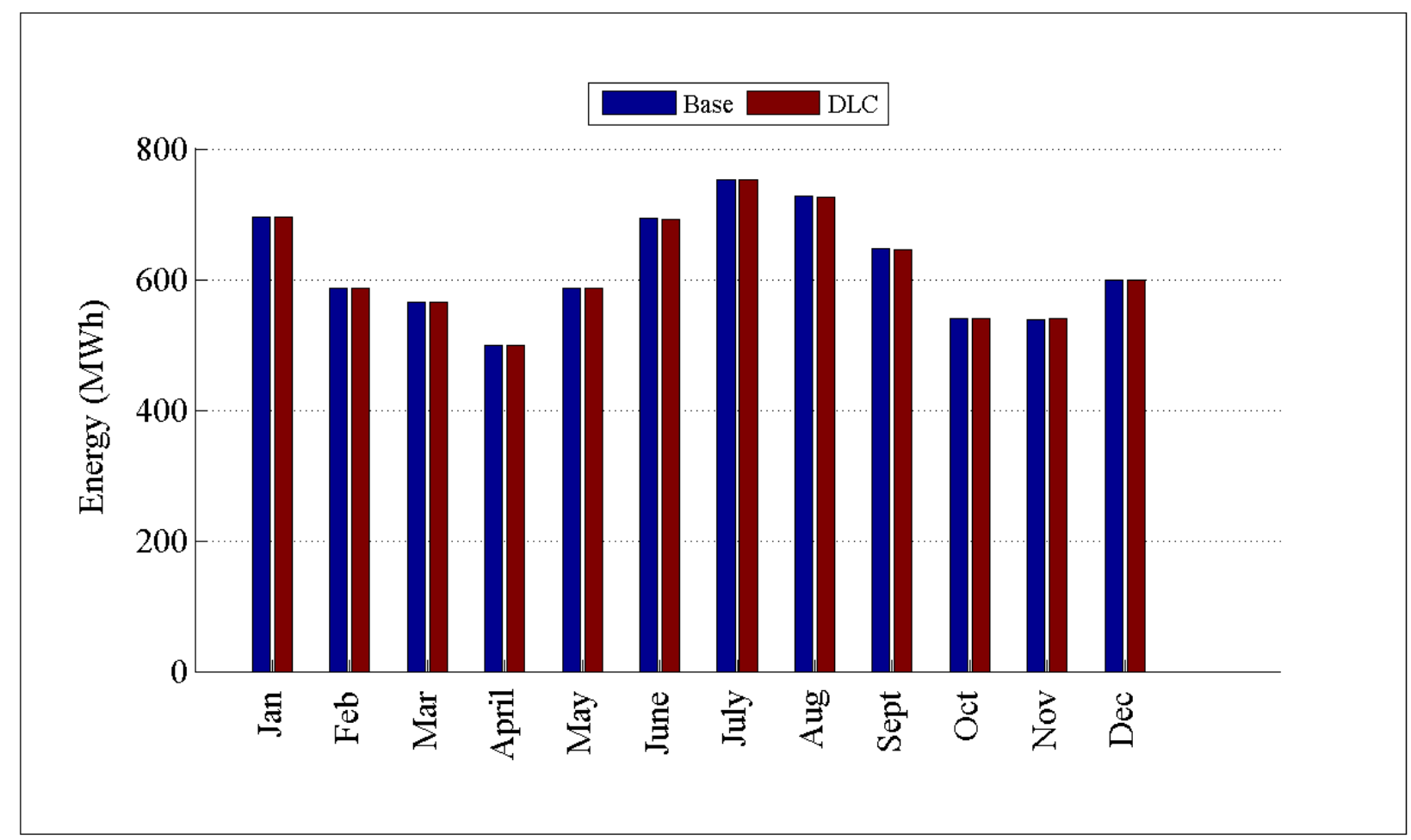

Figure D.186: Comparison of energy consumption by month for R4-12.47-2 


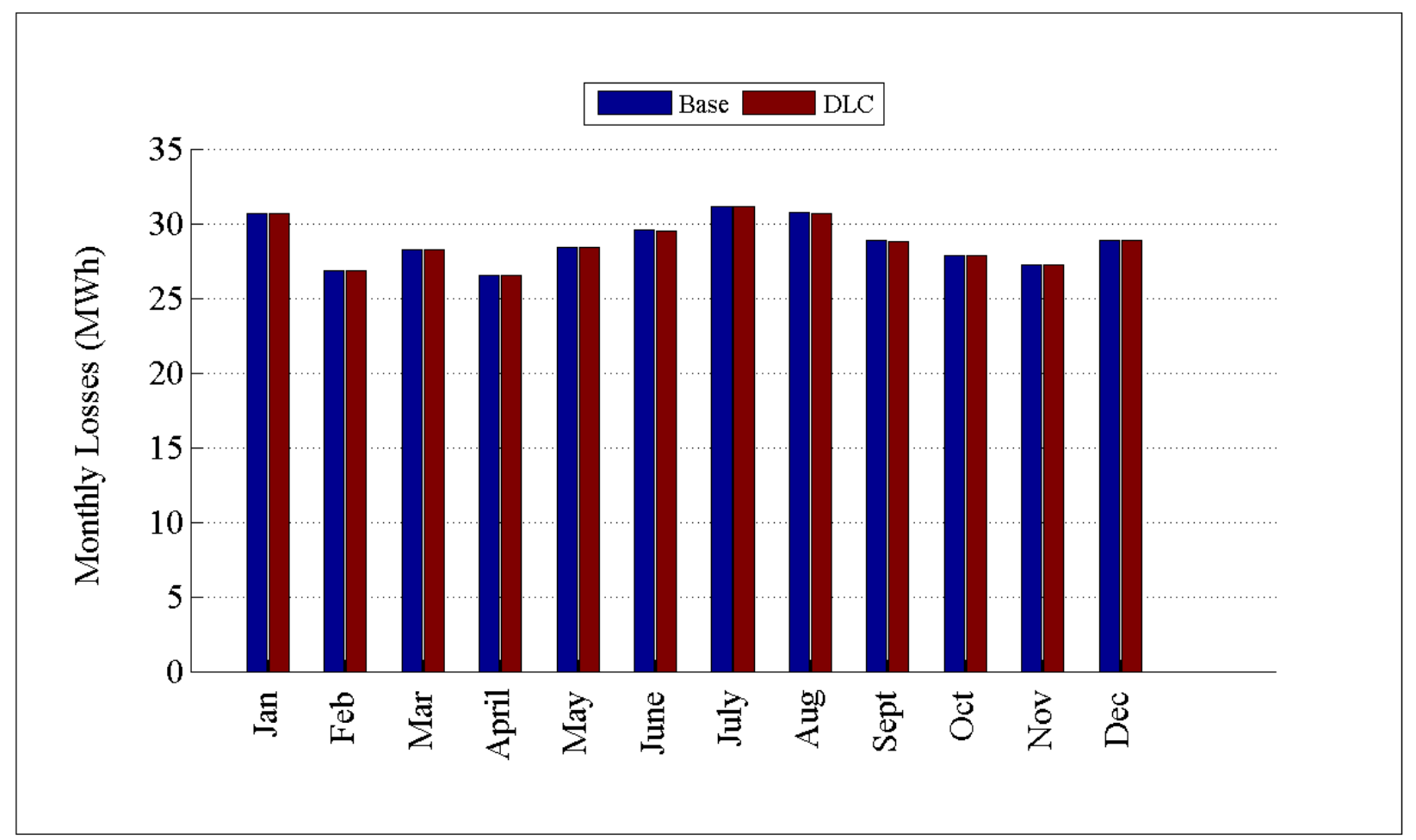

Figure D.187: Comparison of losses by month for R4-12.47-2

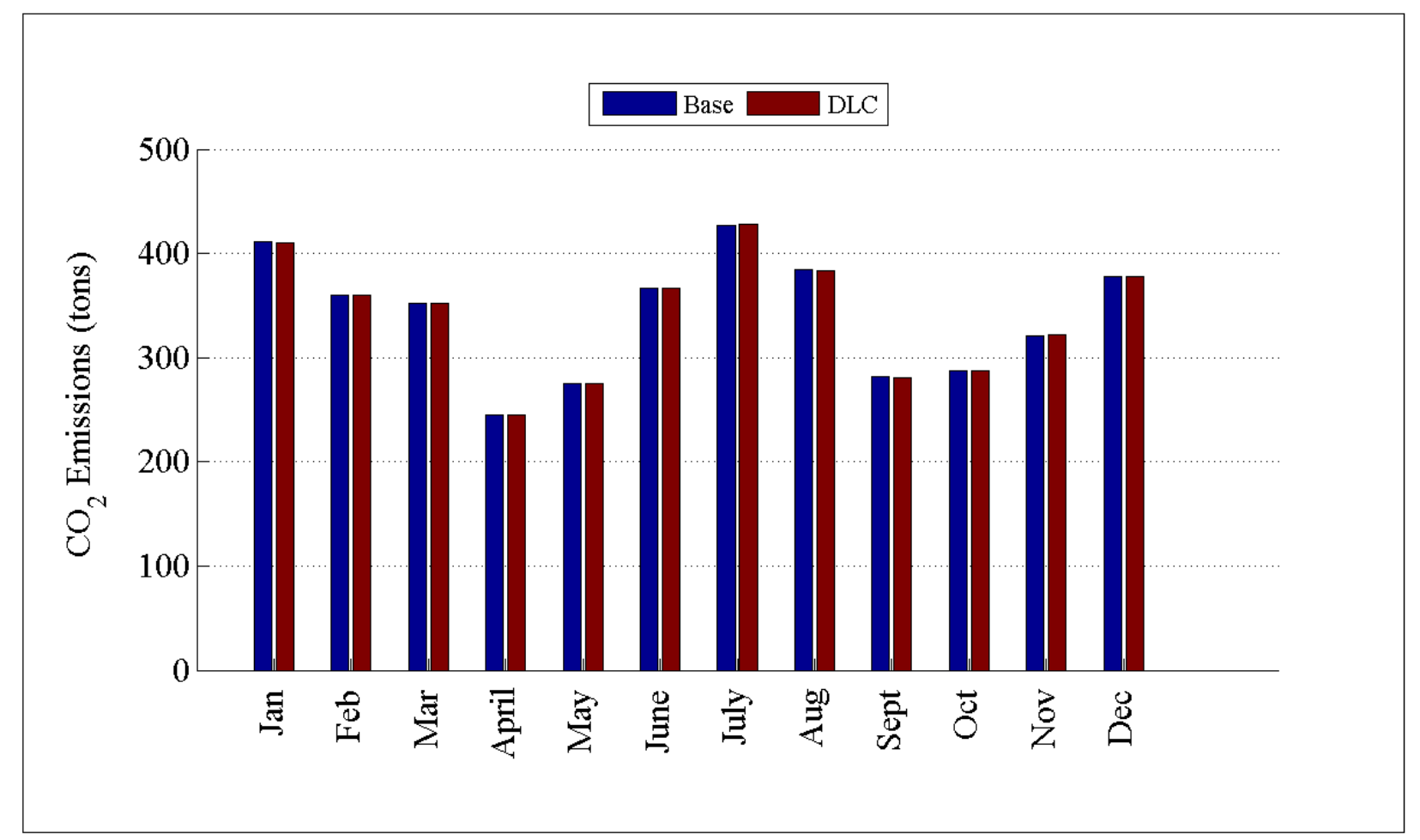

Figure D.188: Comparison of $\mathrm{CO}_{2}$ emissions by month for R4-12.47-2 
D.2.20 Detailed DLC Plots for R4-25.00-1

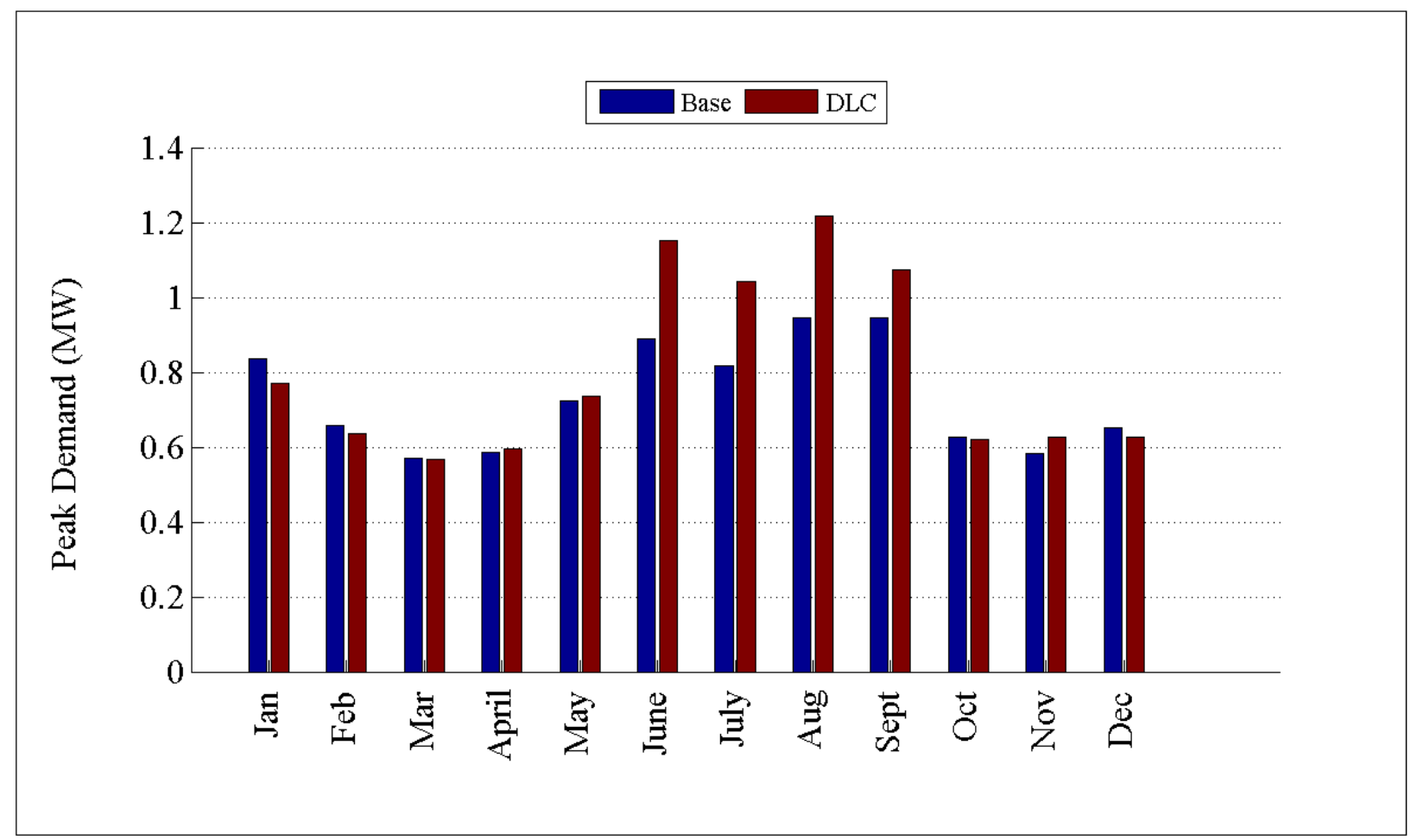

Figure D.189: Comparison of peak demand by month for R4-25.00-1 


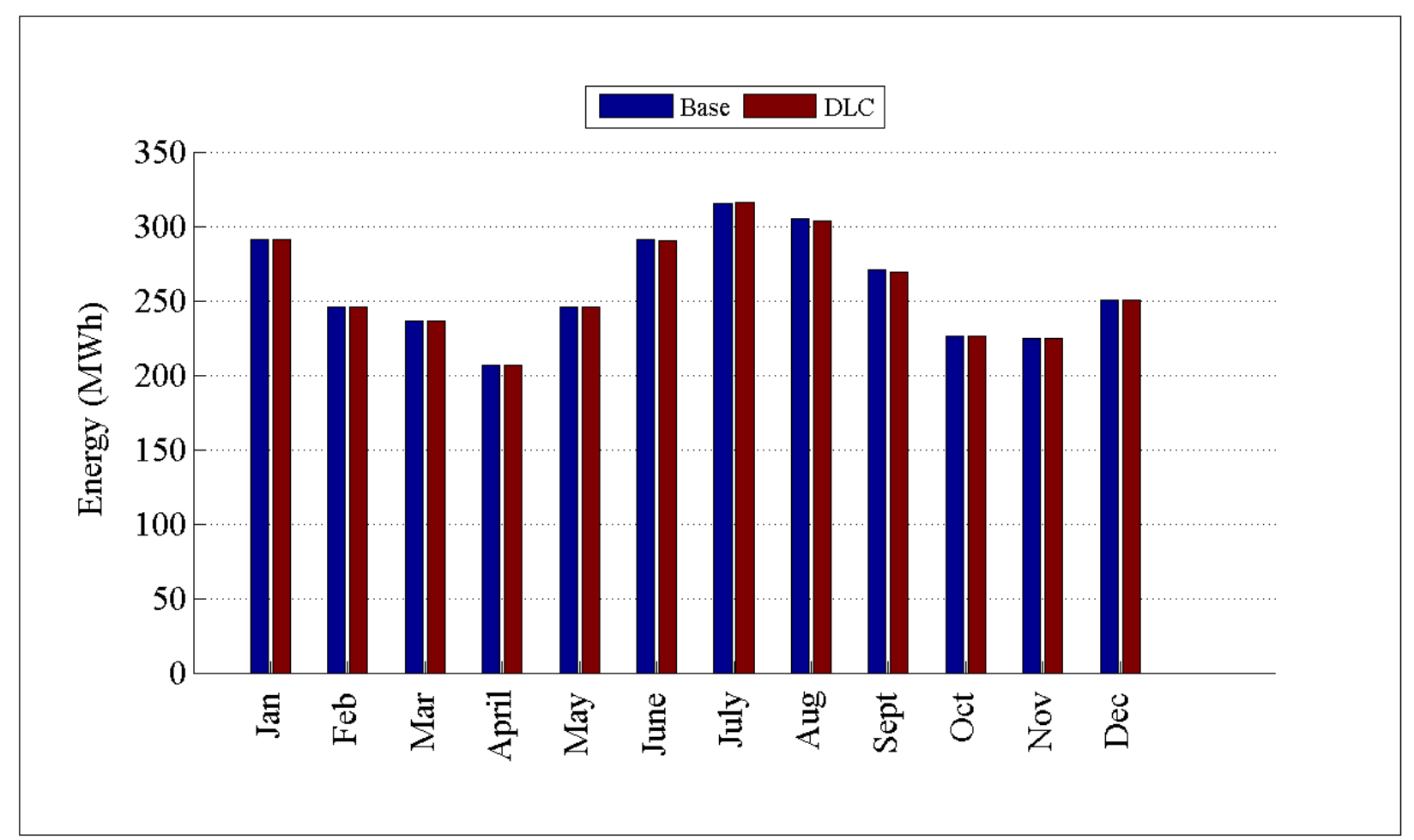

Figure D.190: Comparison of energy consumption by month for R4-25.00-1

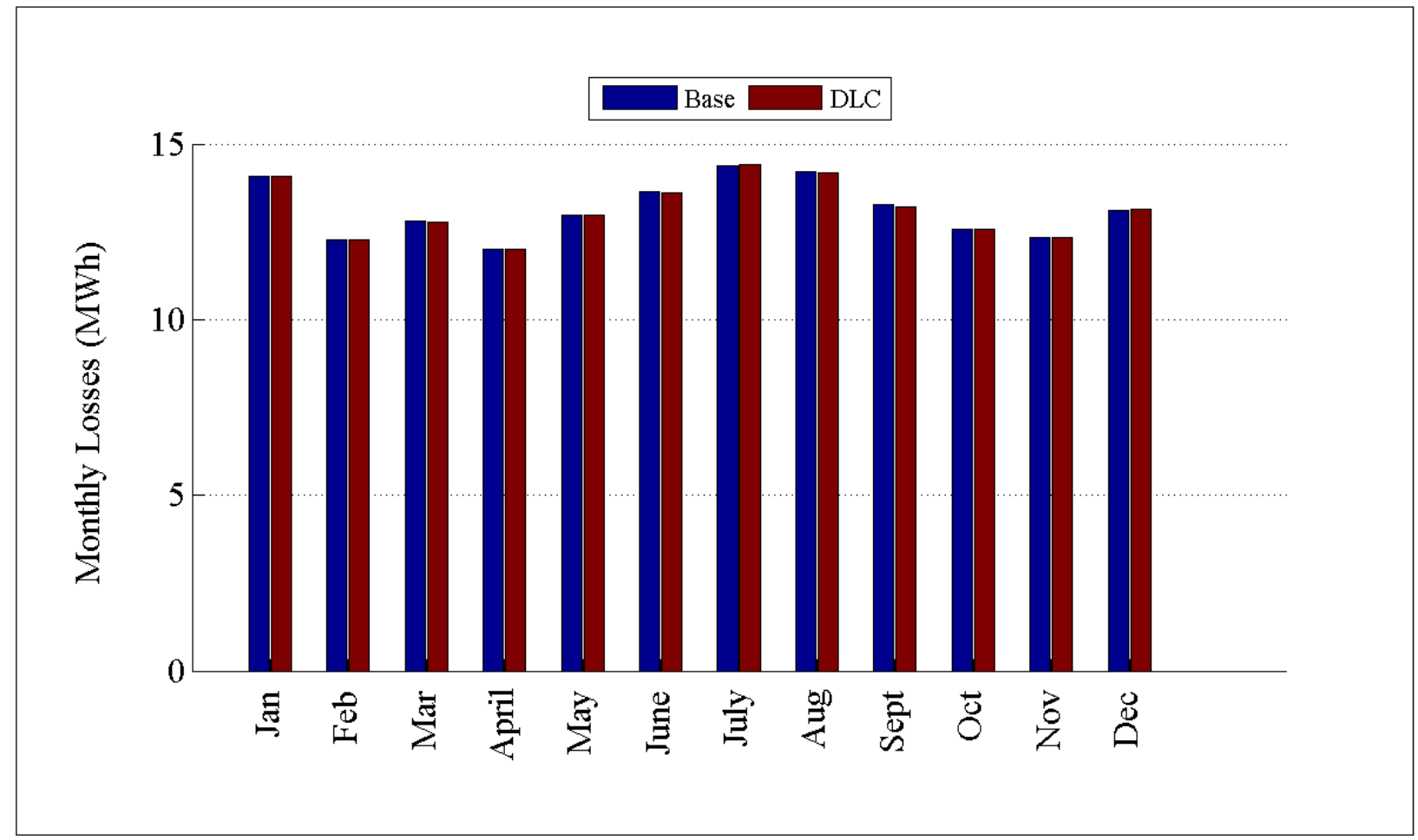

Figure D.191: Comparison of losses by month for R4-25.00-1 


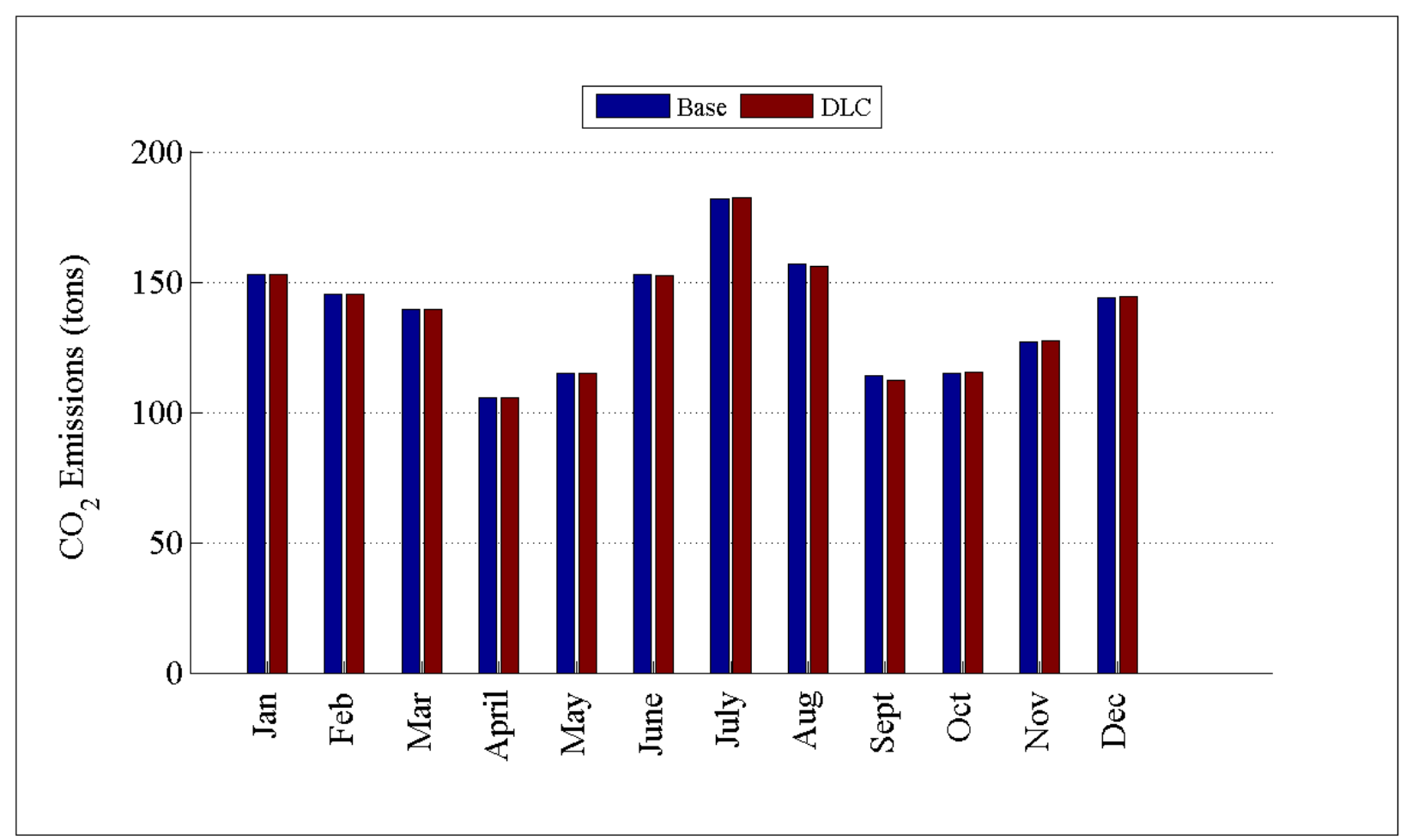

Figure D.192: Comparison of $\mathrm{CO}_{2}$ emissions by month for R4-25.00-1

D.2.21 Detailed DLC Plots for GC-12.47-1_R5 


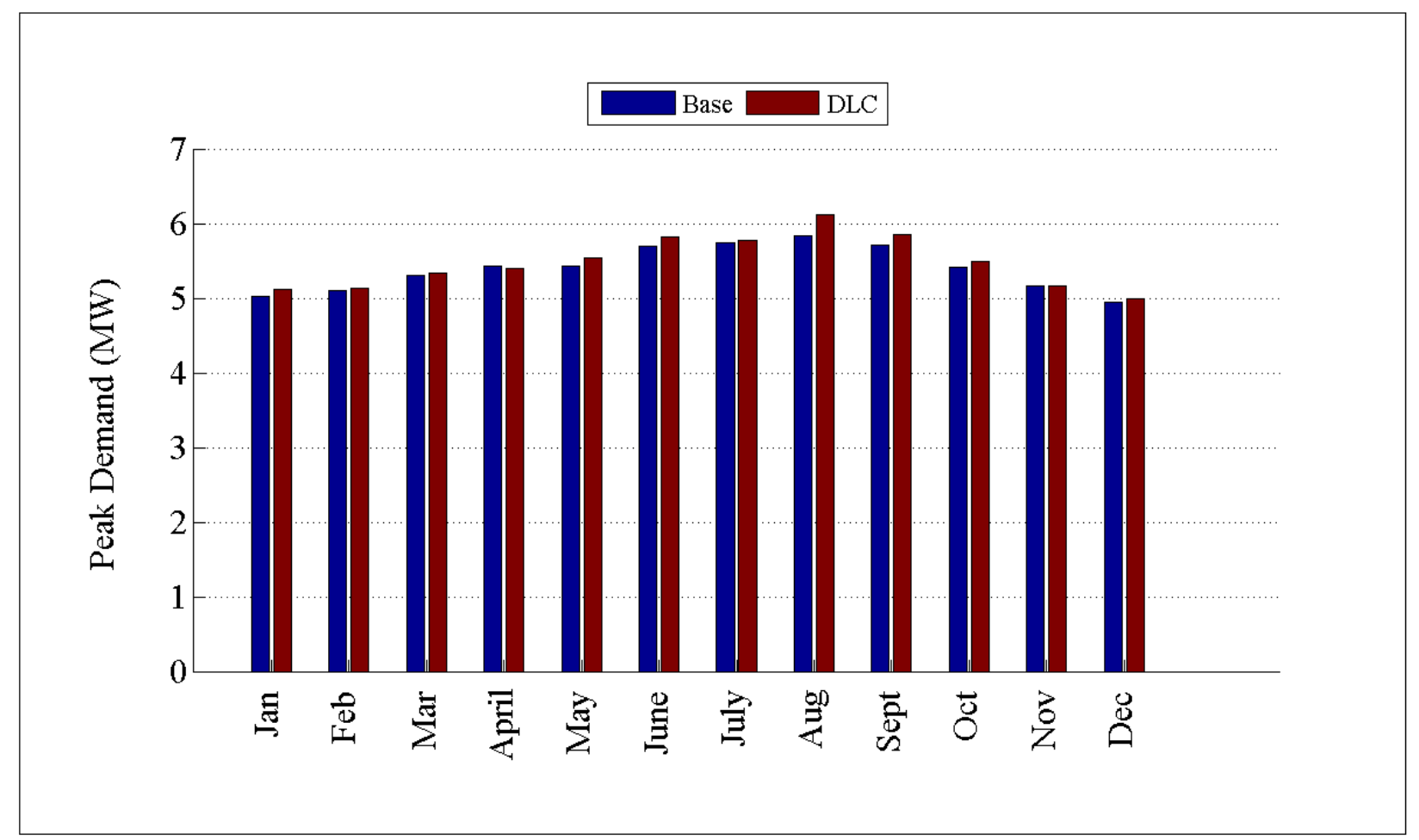

Figure D.193: Comparison of peak demand by month for GC-12.47-1_R5

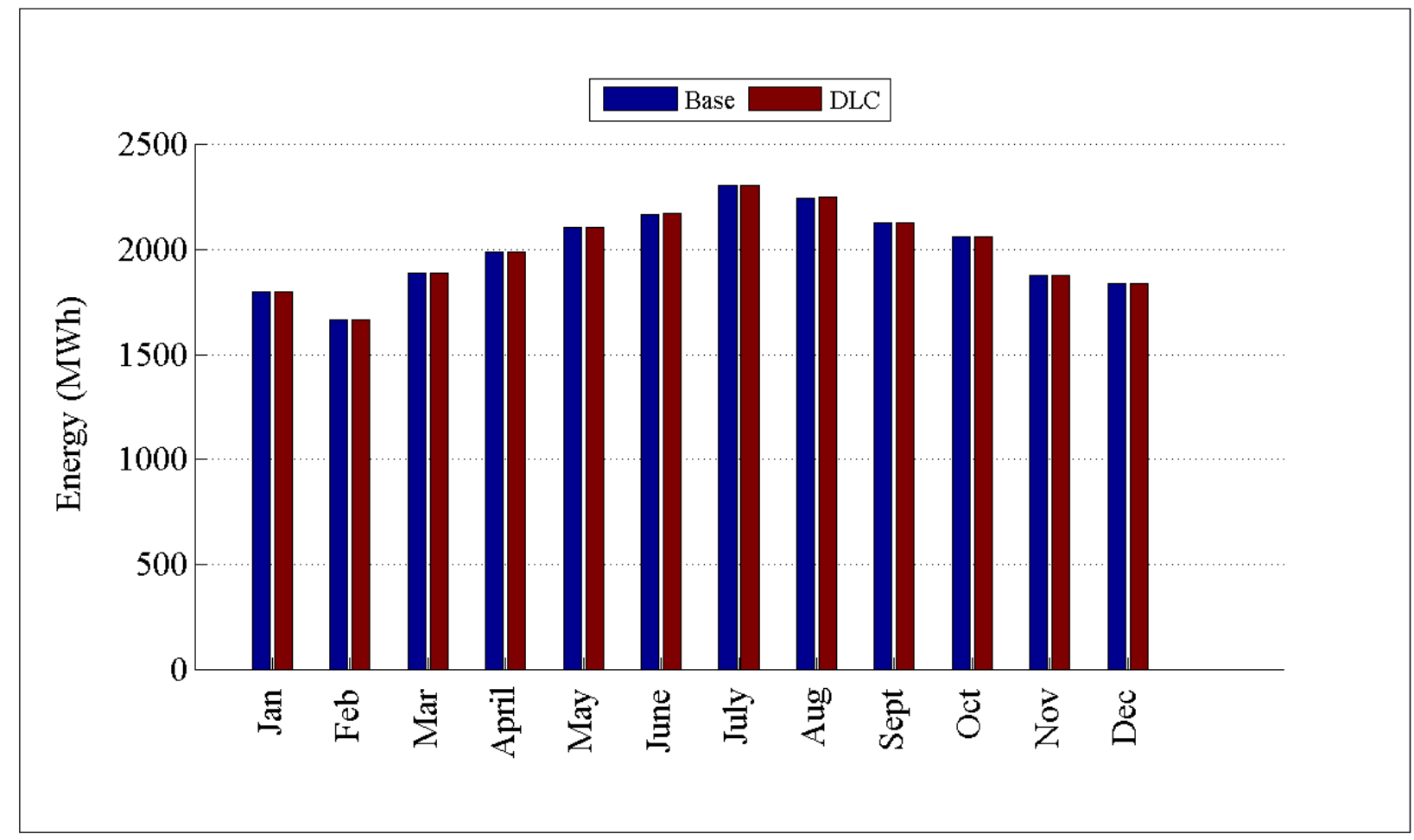

Figure D.194: Comparison of energy consumption by month for GC-12.47-1_R5 


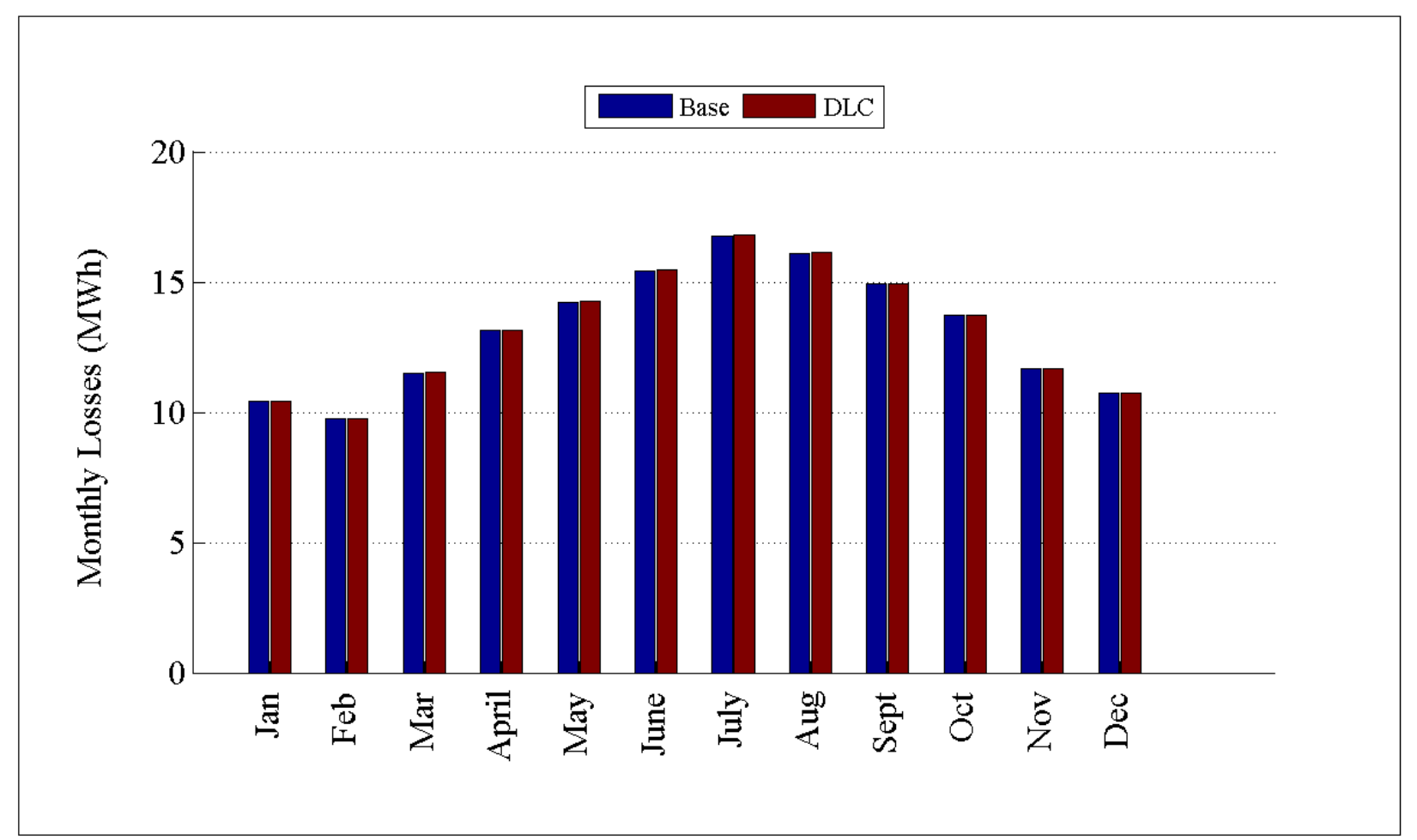

Figure D.195: Comparison of losses by month for GC-12.47-1_R5

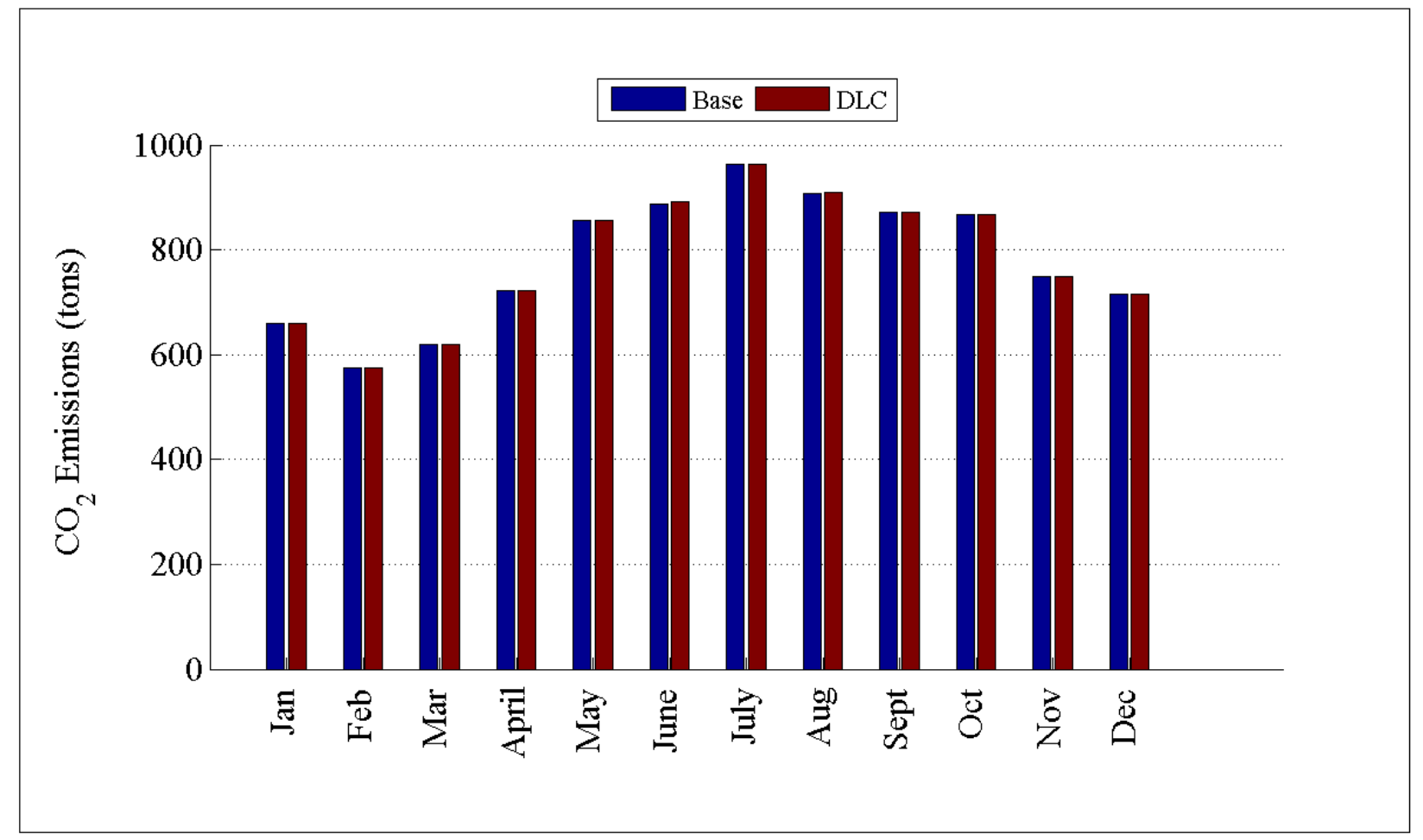

Figure D.196: Comparison of $\mathrm{CO}_{2}$ emissions by month for GC-12.47-1_R5 
D.2.22 Detailed DLC Plots for R5-12.47-1

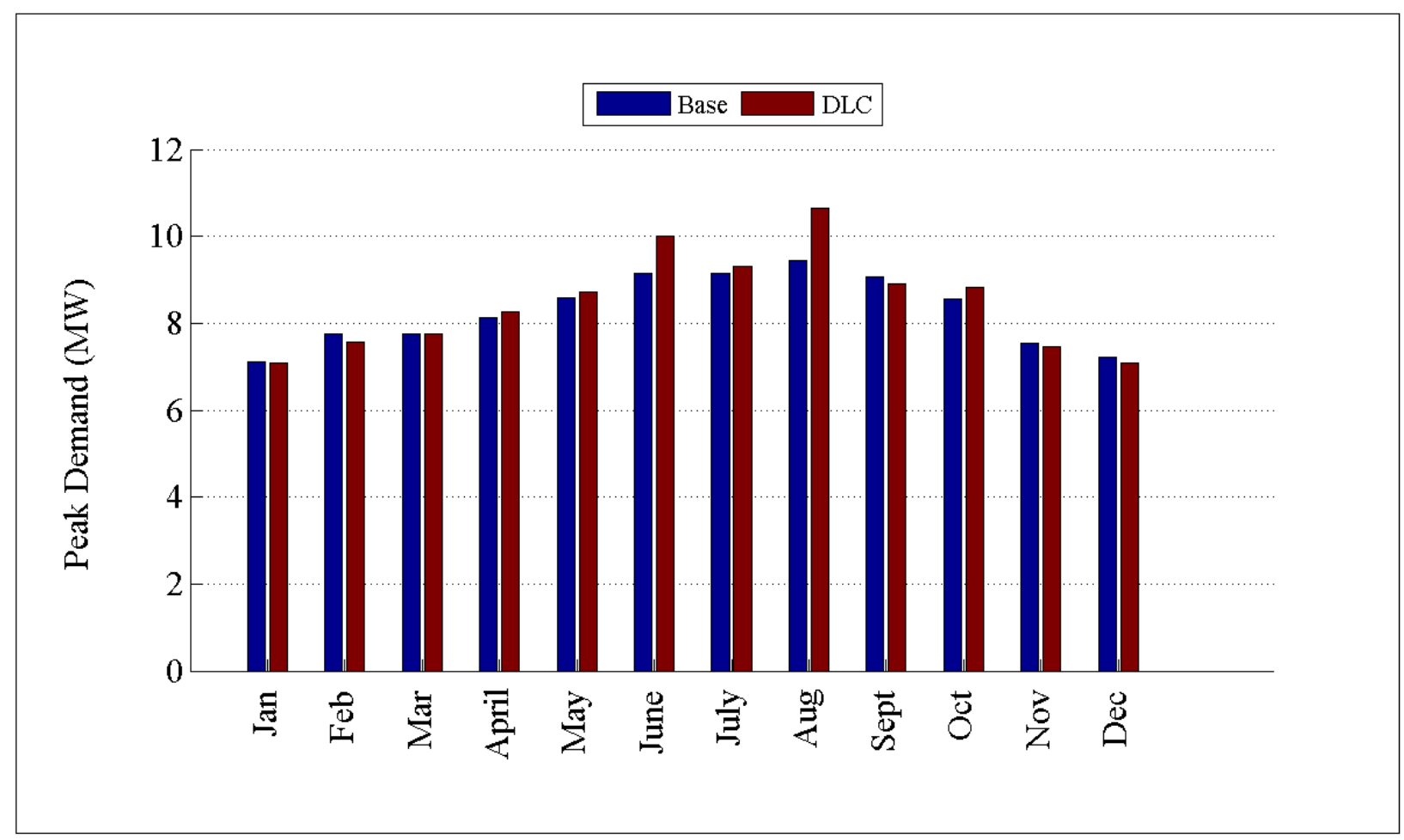

Figure D.197: Comparison of peak demand by month for R5-12.47-1 


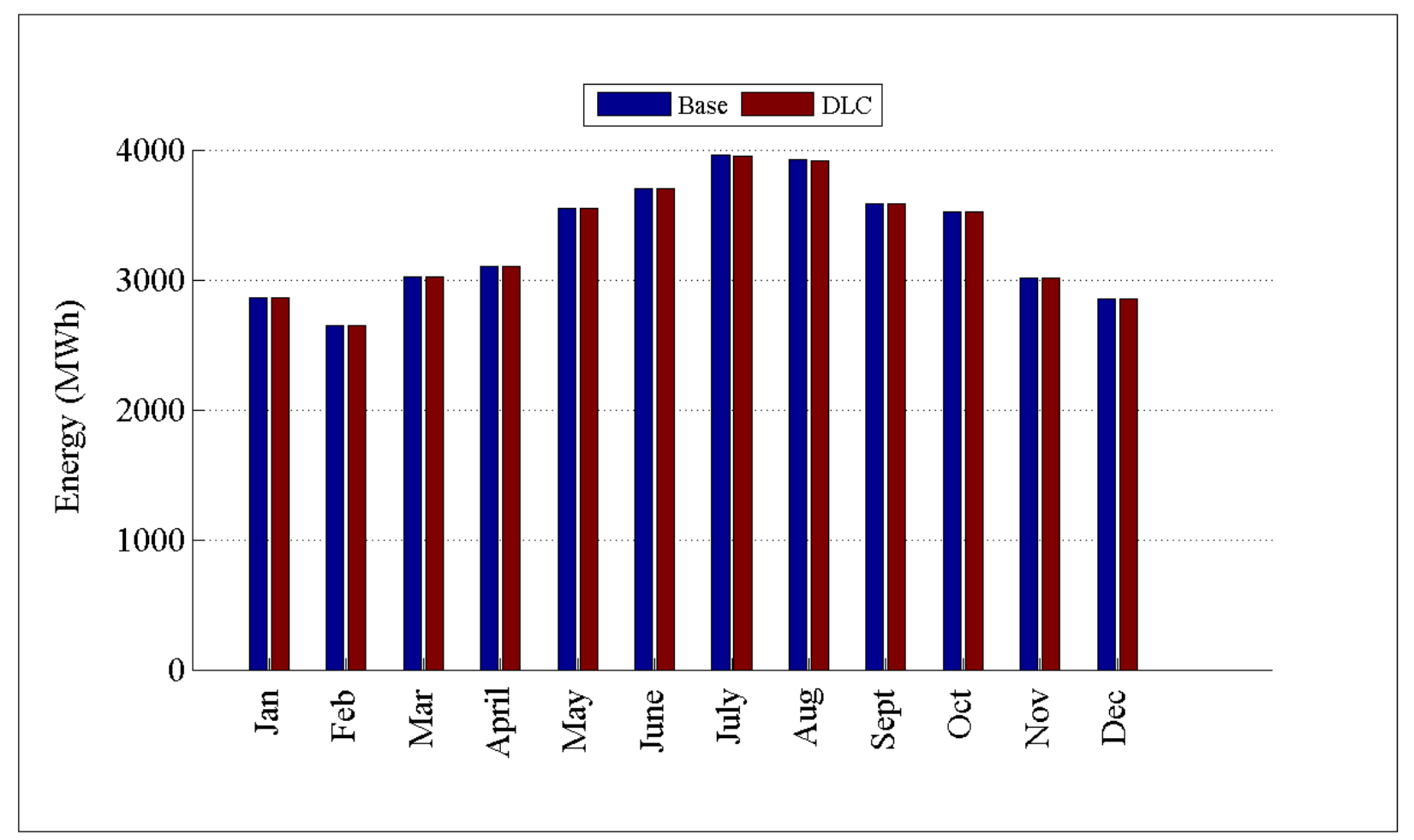

Figure D.198: Comparison of energy consumption by month for R5-12.47-1

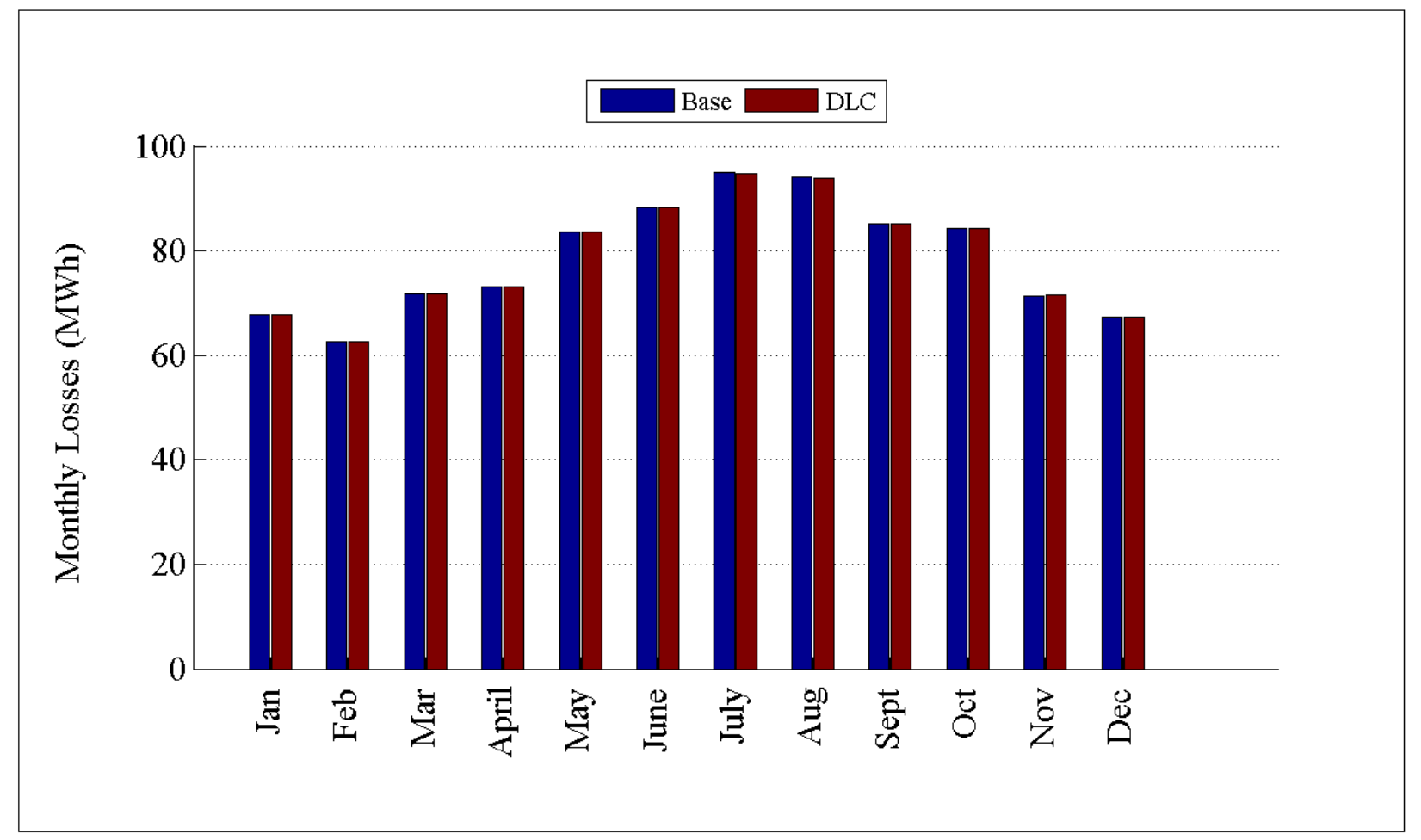

Figure D.199: Comparison of losses by month for R5-12.47-1 


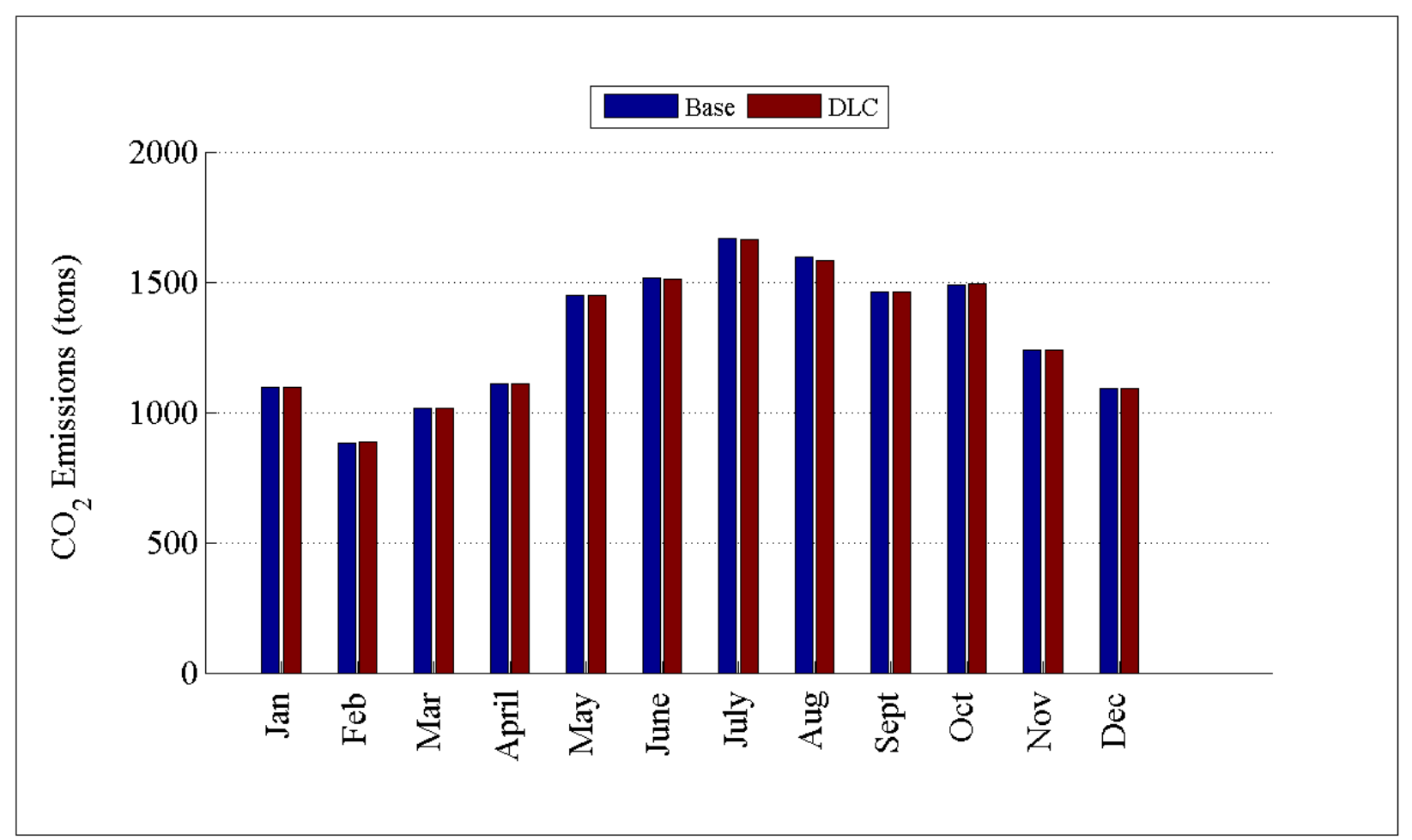

Figure D.200: Comparison of $\mathrm{CO}_{2}$ emissions by month for R5-12.47-1

D.2.23 Detailed DLC Plots for R5-12.47-2 


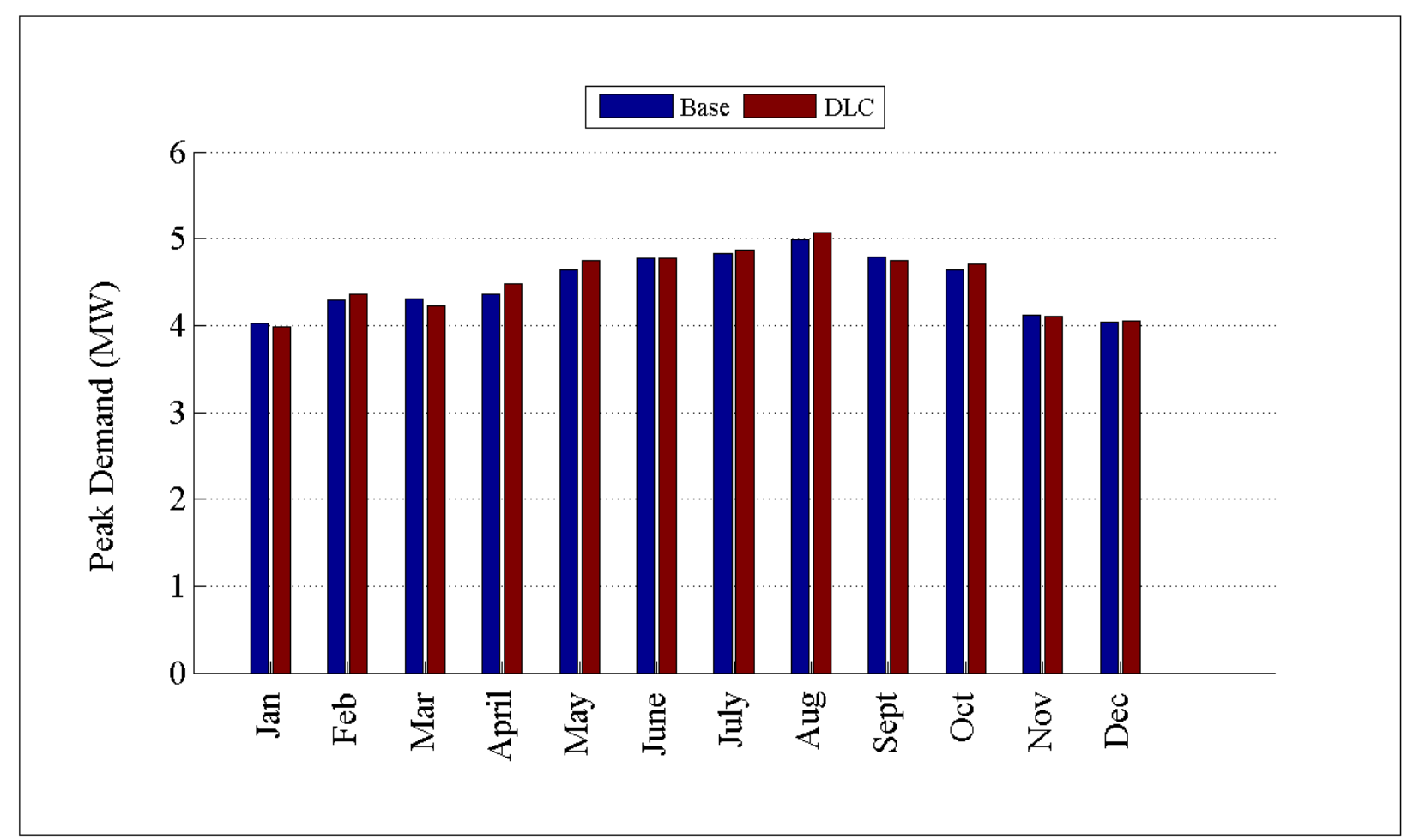

Figure D.201: Comparison of peak demand by month for R5-12.47-2

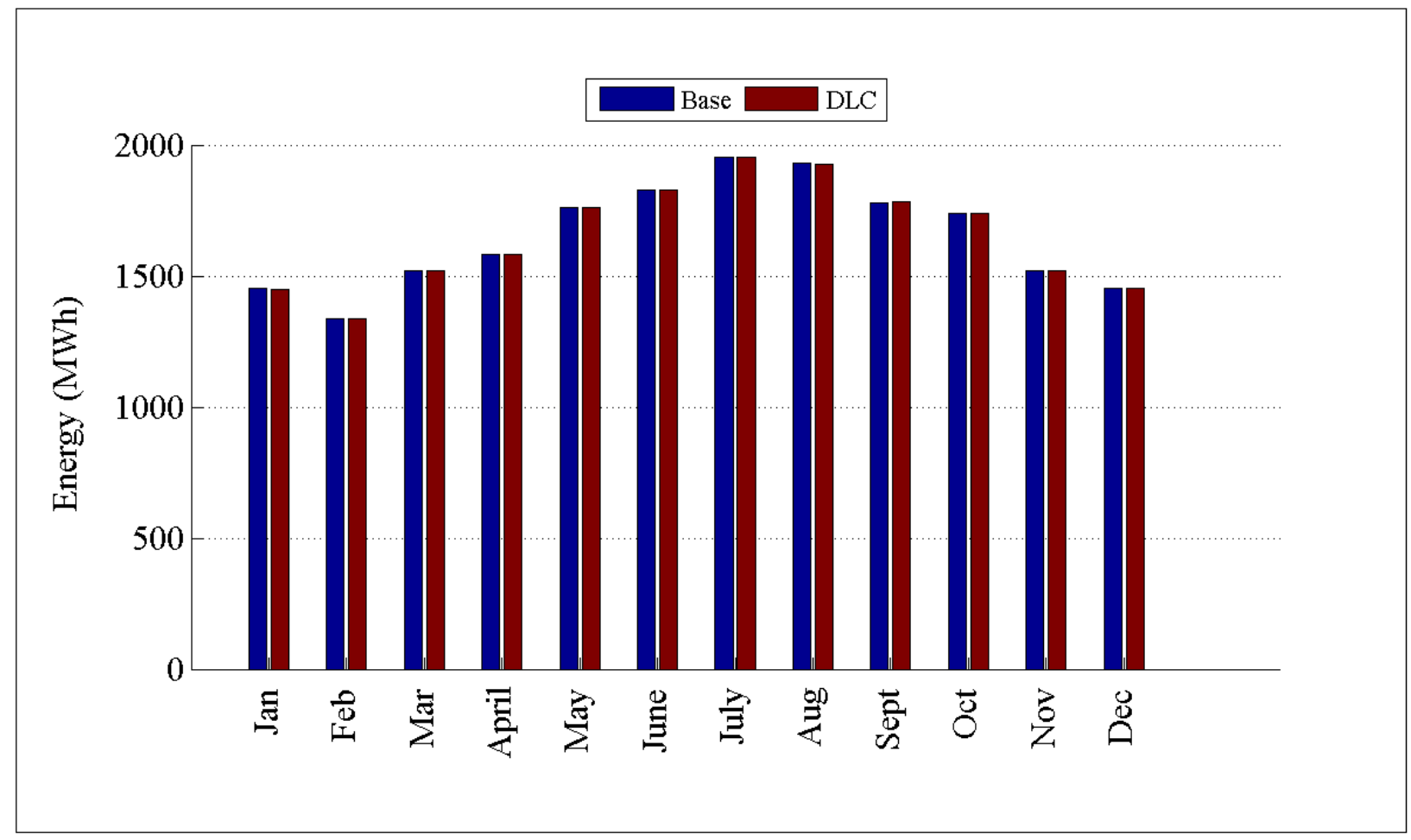

Figure D.202: Comparison of energy consumption by month for R5-12.47-2 


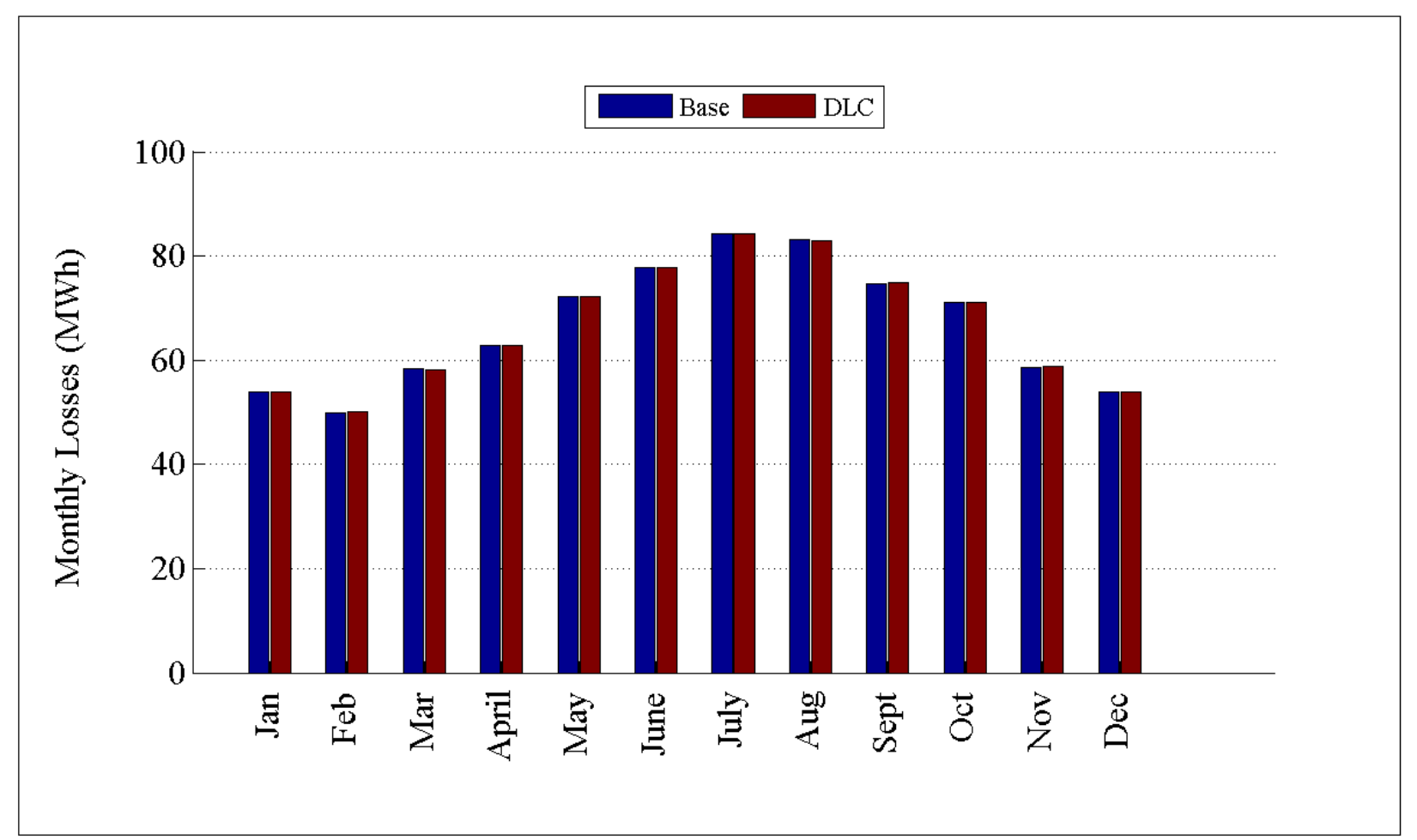

Figure D.203: Comparison of losses by month for R5-12.47-2

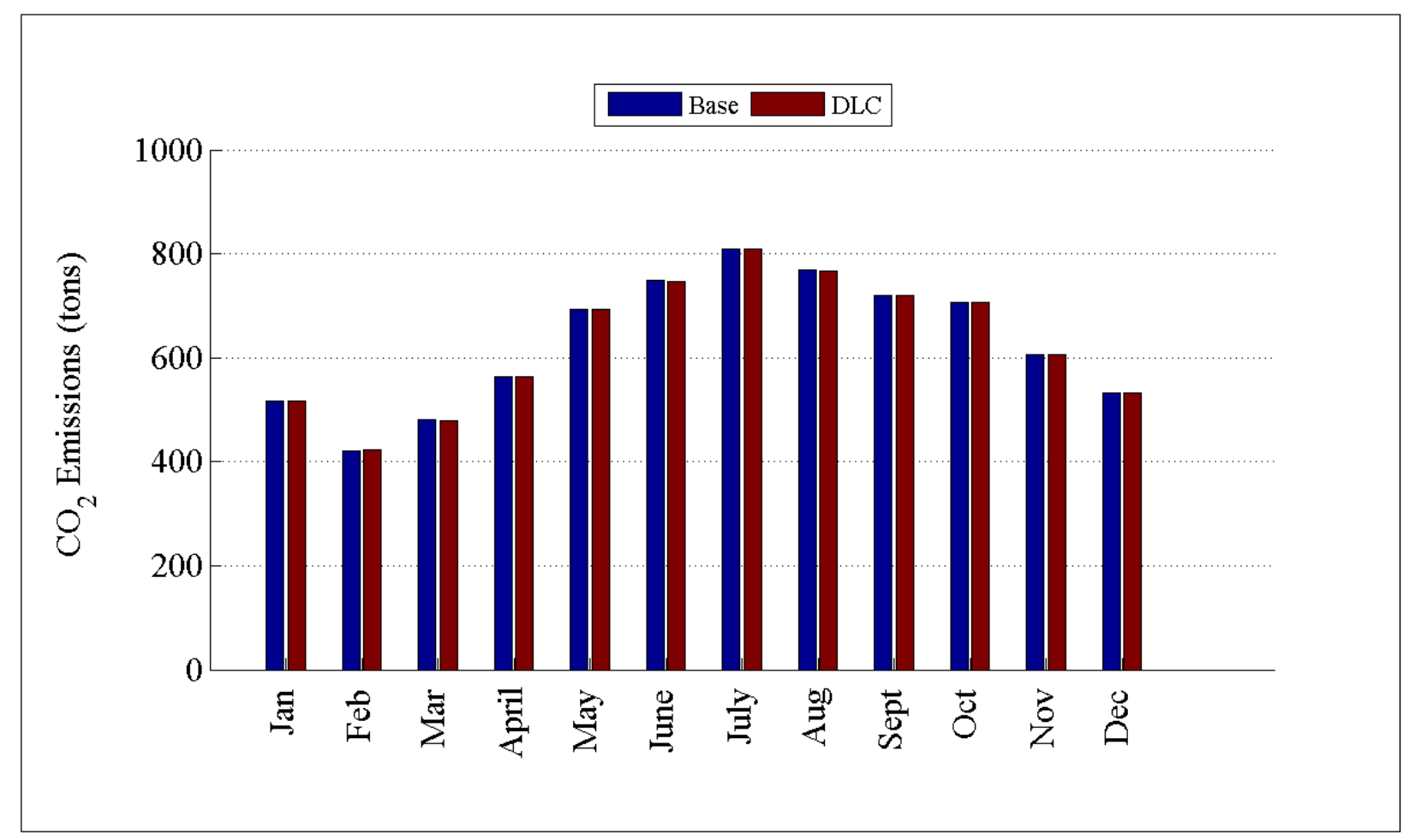

Figure D.204: Comparison of $\mathrm{CO}_{2}$ emissions by month for R5-12.47-2 
D.2.24 Detailed DLC Plots for R5-12.47-3

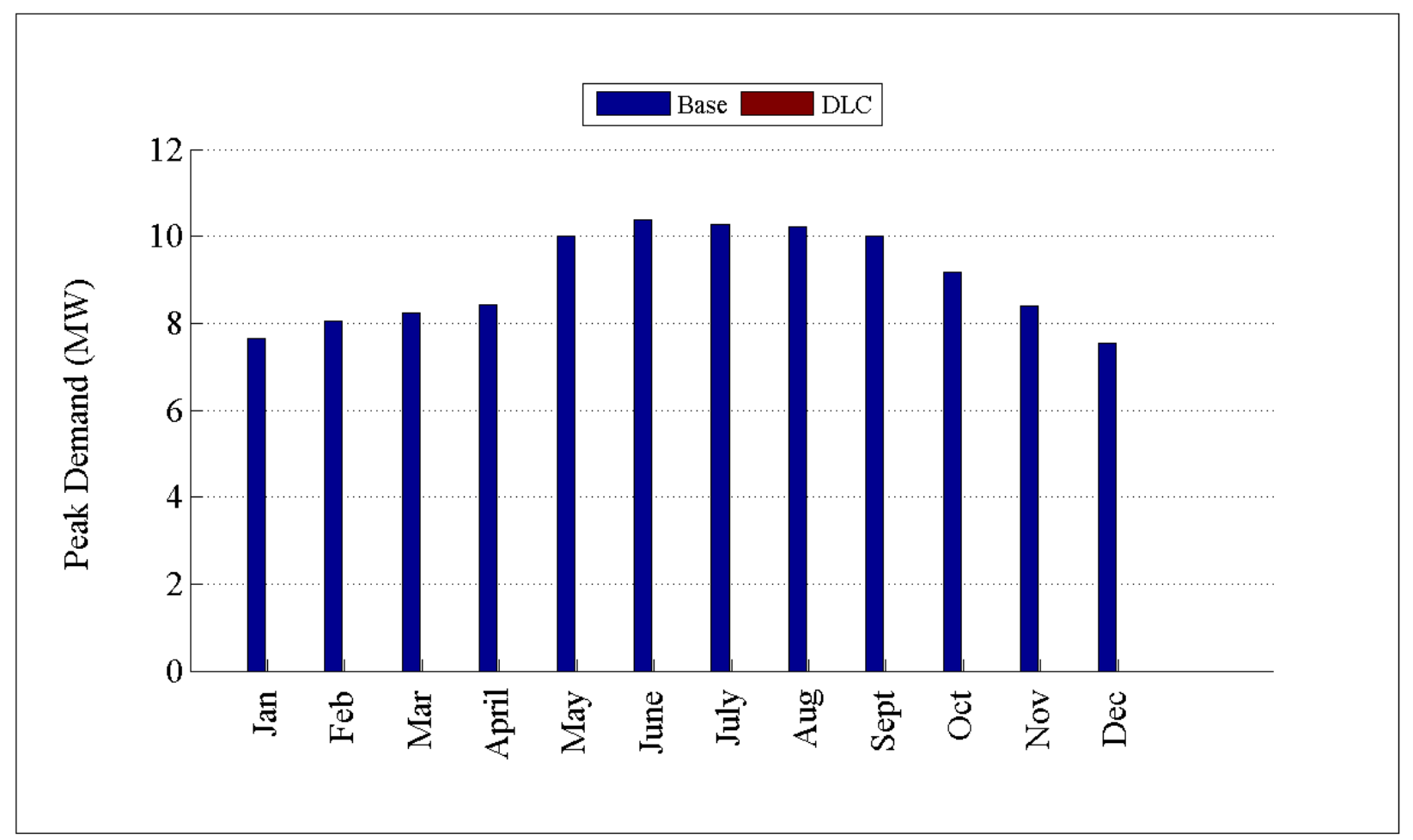

Figure D.205: Comparison of peak demand by month for R5-12.47-3 


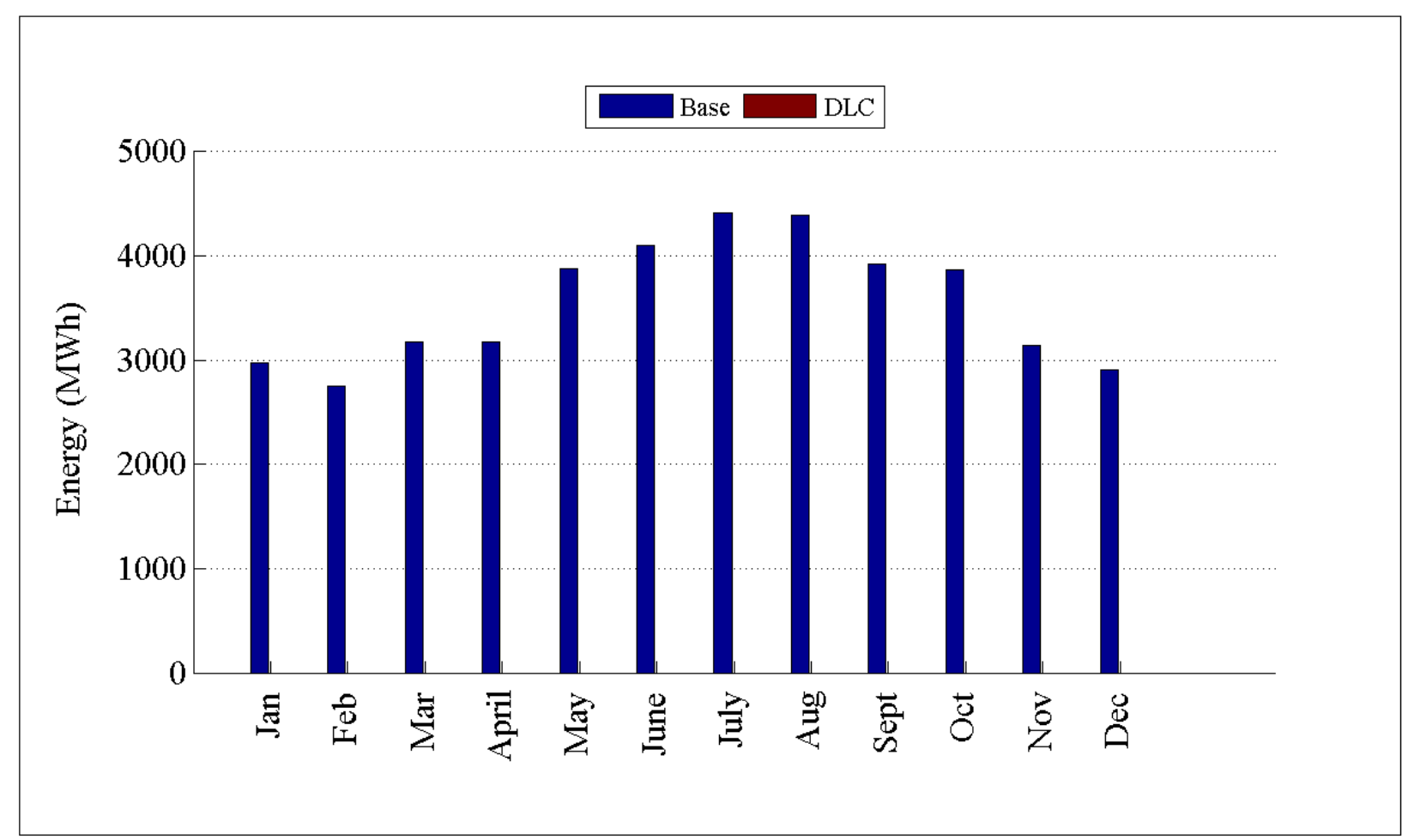

Figure D.206: Comparison of energy consumption by month for R5-12.47-3

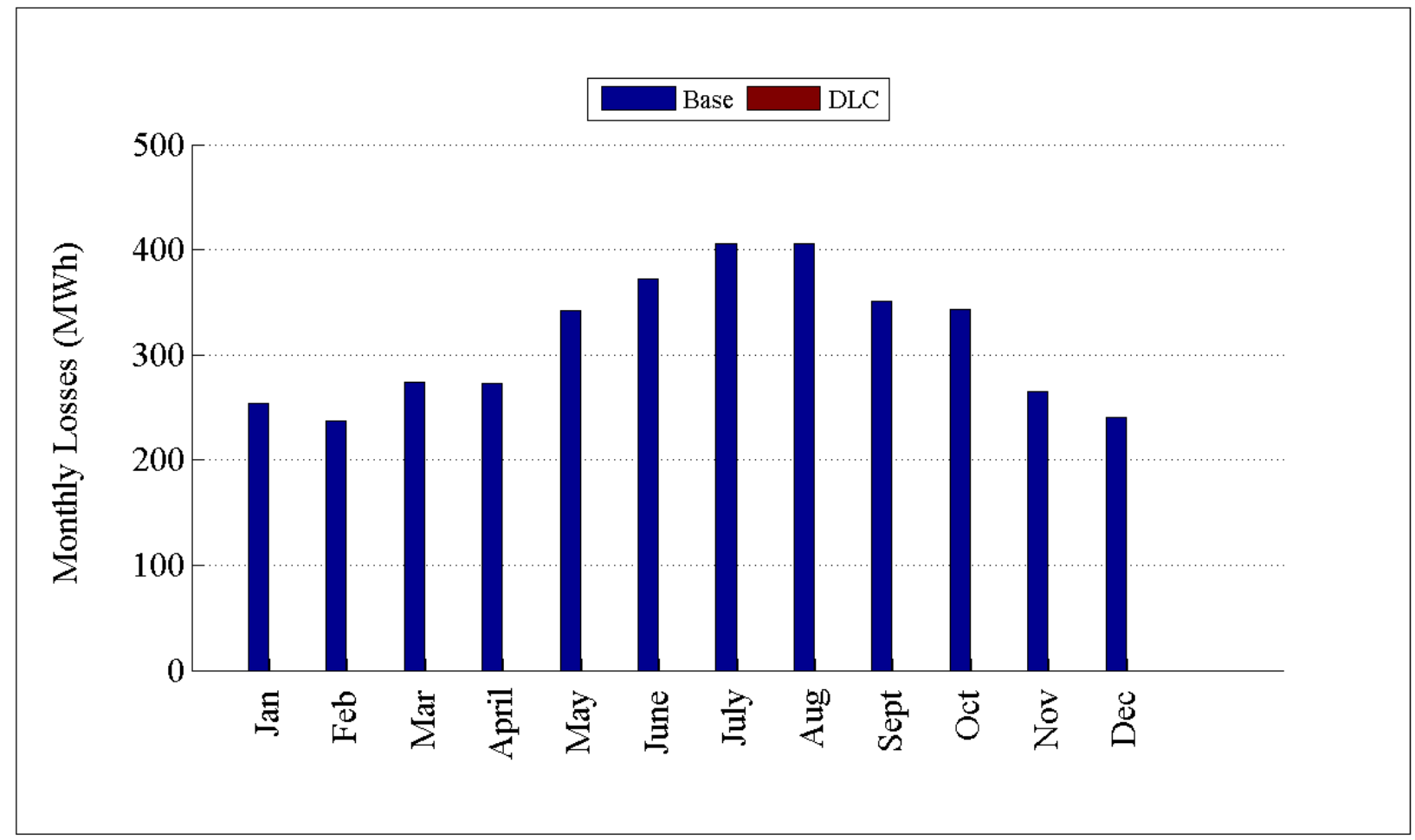

Figure D.207: Comparison of losses by month for R5-12.47-3 


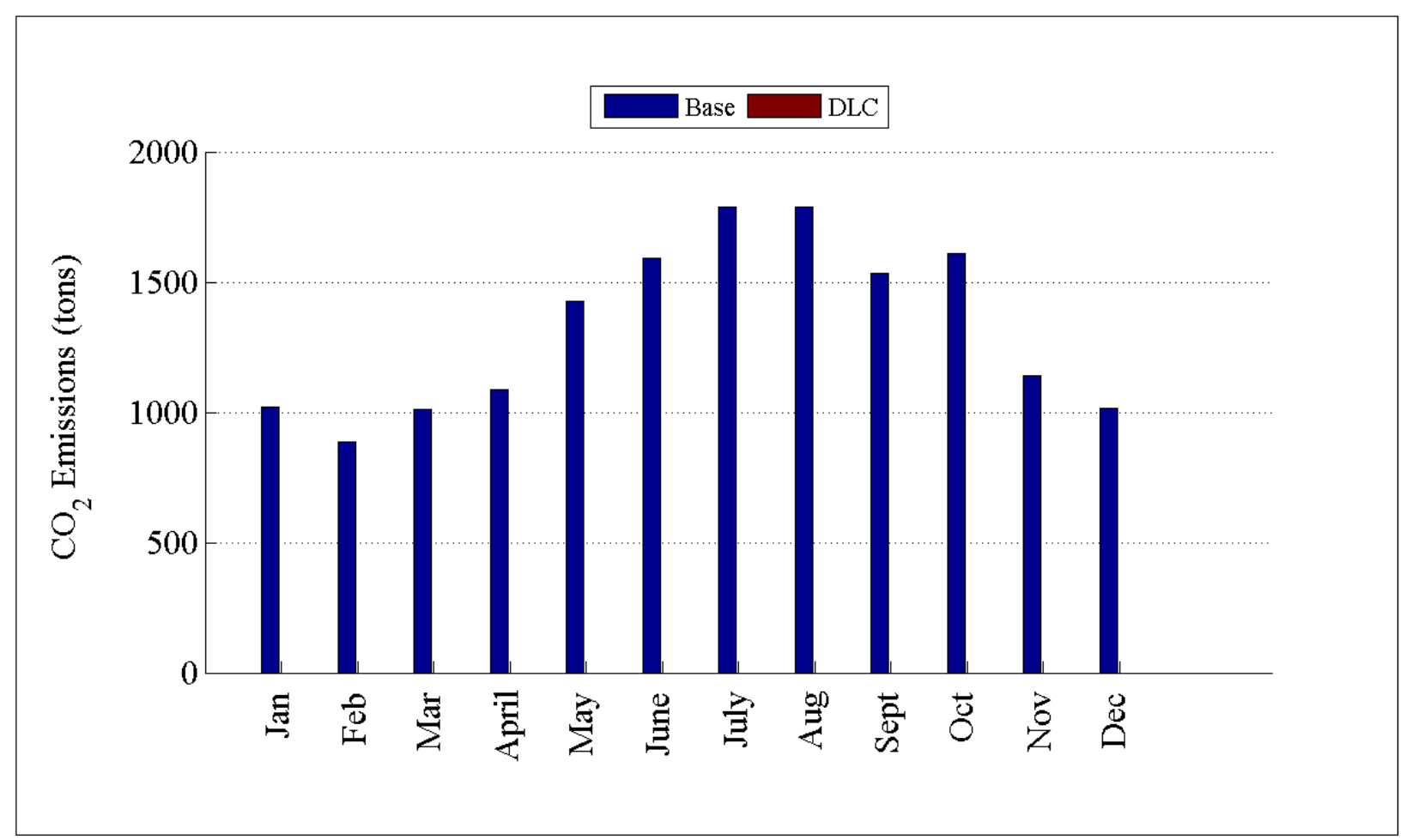

Figure D.208: Comparison of $\mathrm{CO}_{2}$ emissions by month for R5-12.47-3

D.2.25 Detailed DLC Plots for R5-12.47-4 


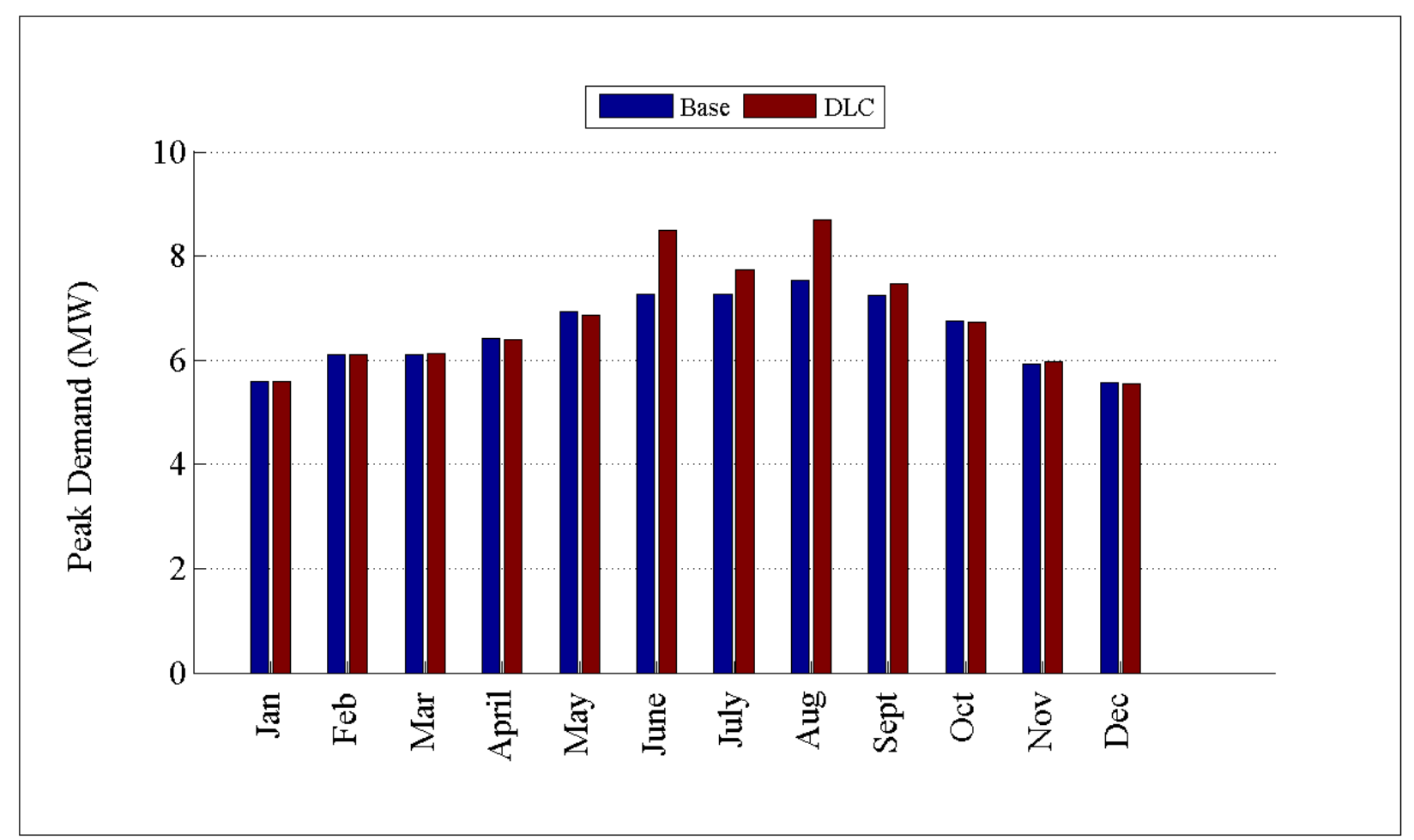

Figure D.209: Comparison of peak demand by month for R5-12.47-4

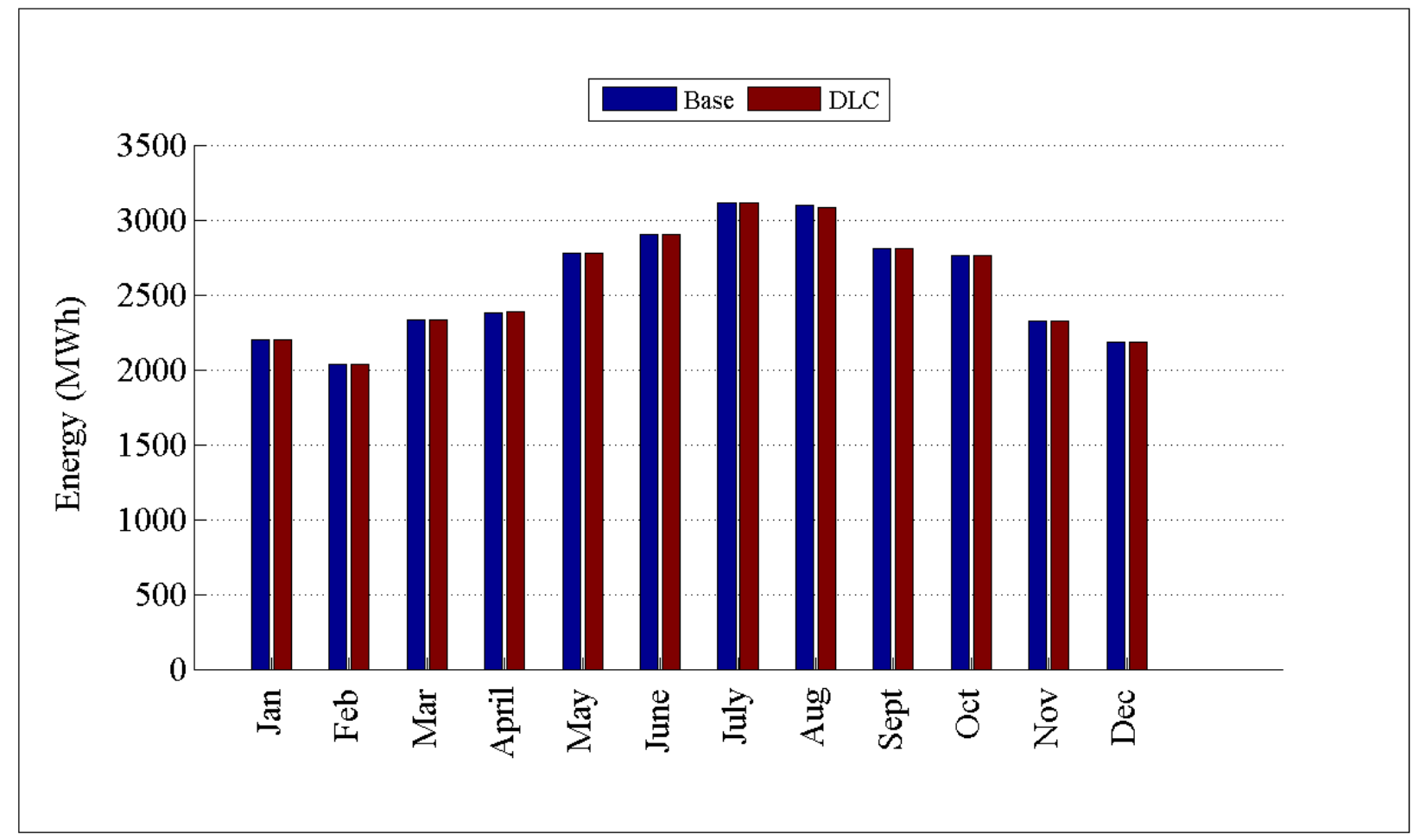

Figure D.210: Comparison of energy consumption by month for R5-12.47-4 


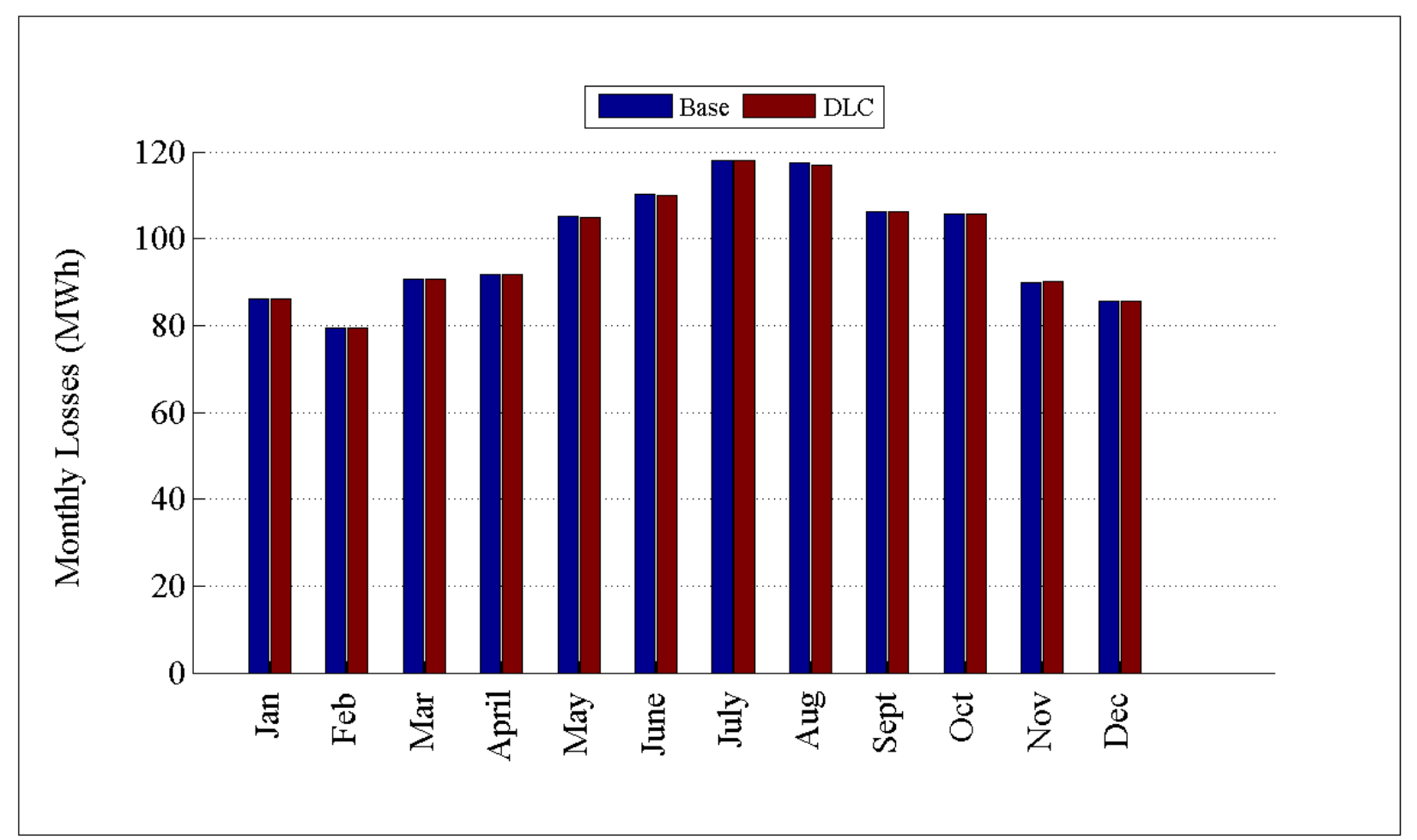

Figure D.211: Comparison of losses by month for R5-12.47-4

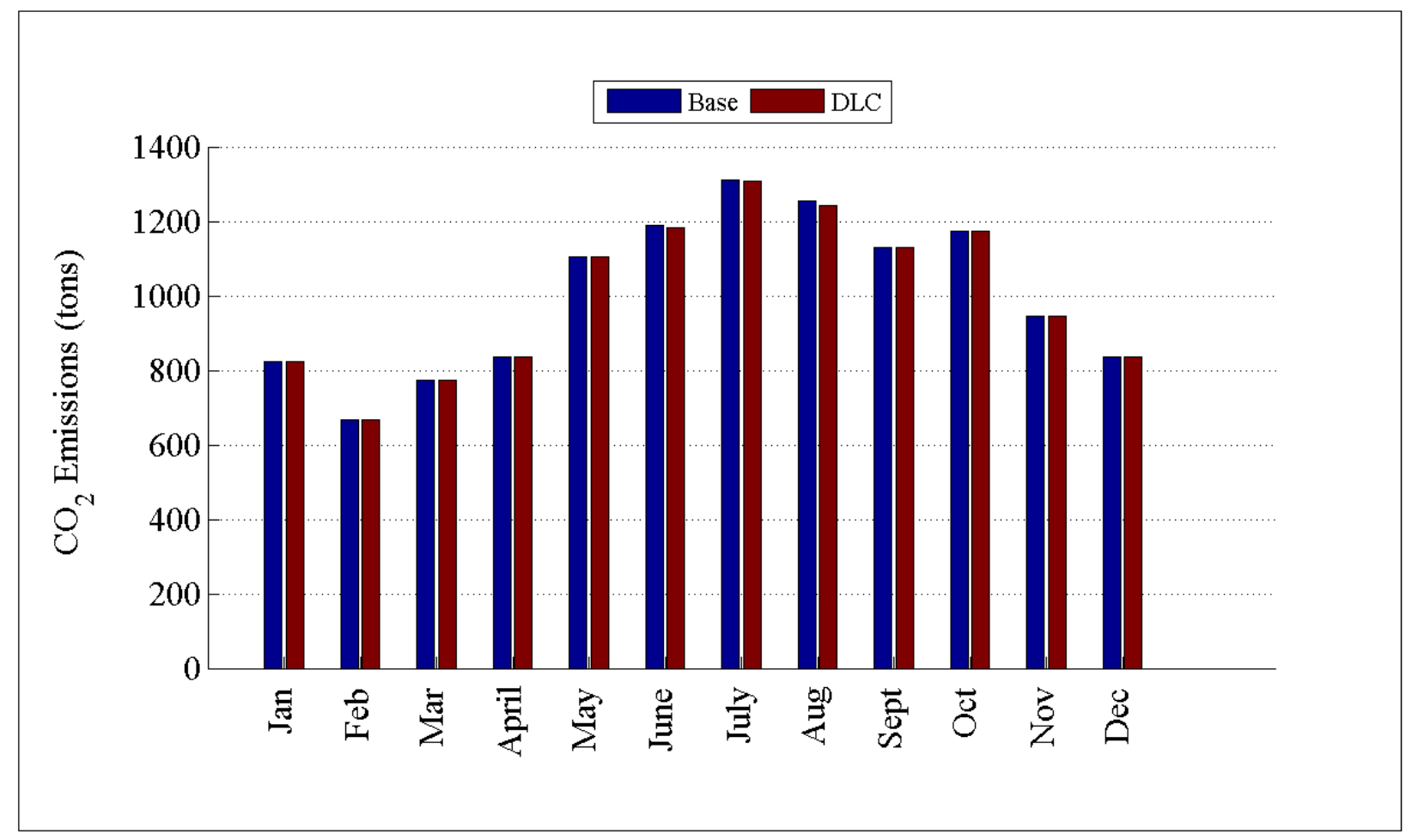

Figure D.212: Comparison of $\mathrm{CO}_{2}$ emissions by month for R5-12.47-4 
D.2.26 Detailed DLC Plots for R5-12.47-5

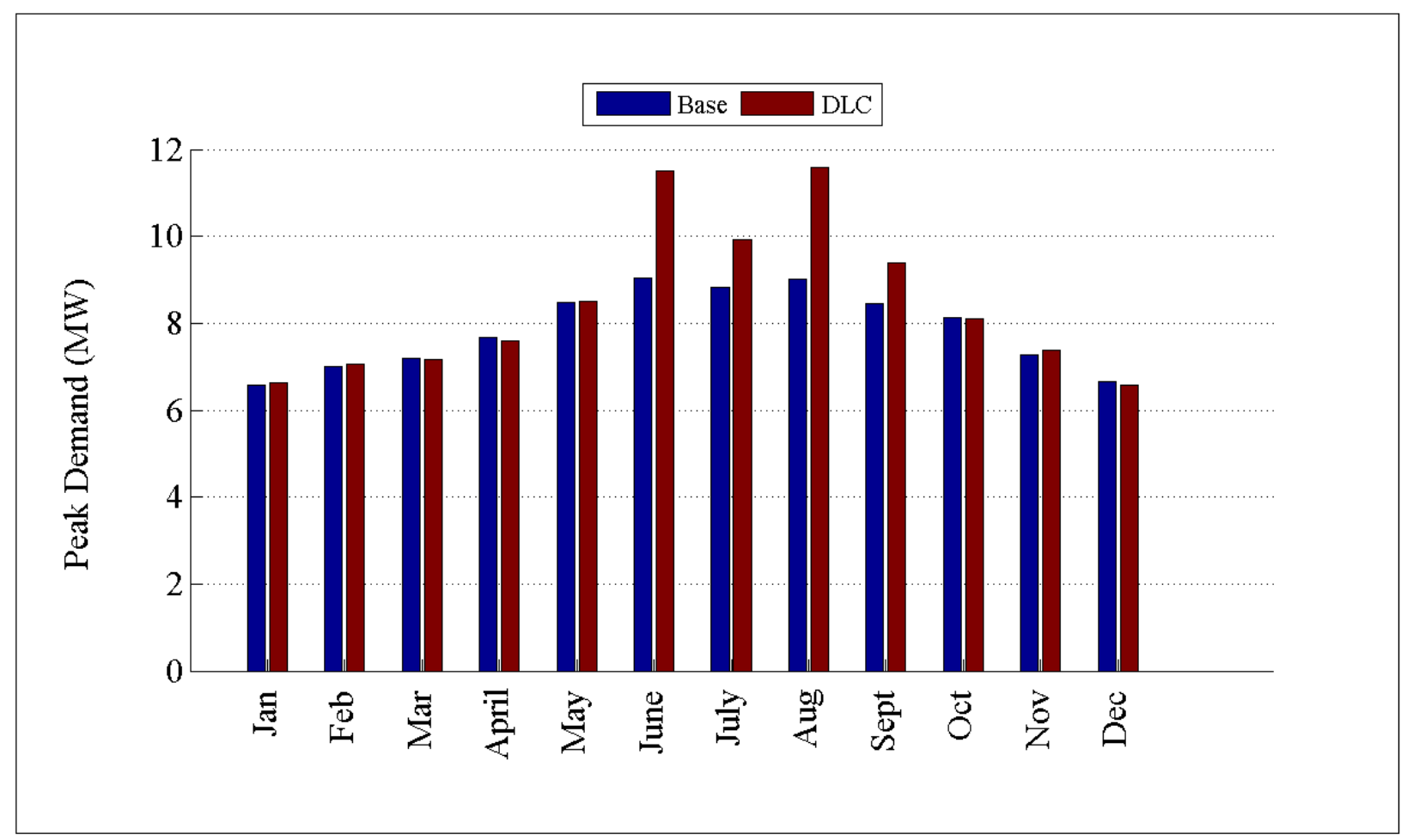

Figure D.213: Comparison of peak demand by month for R5-12.47-5 


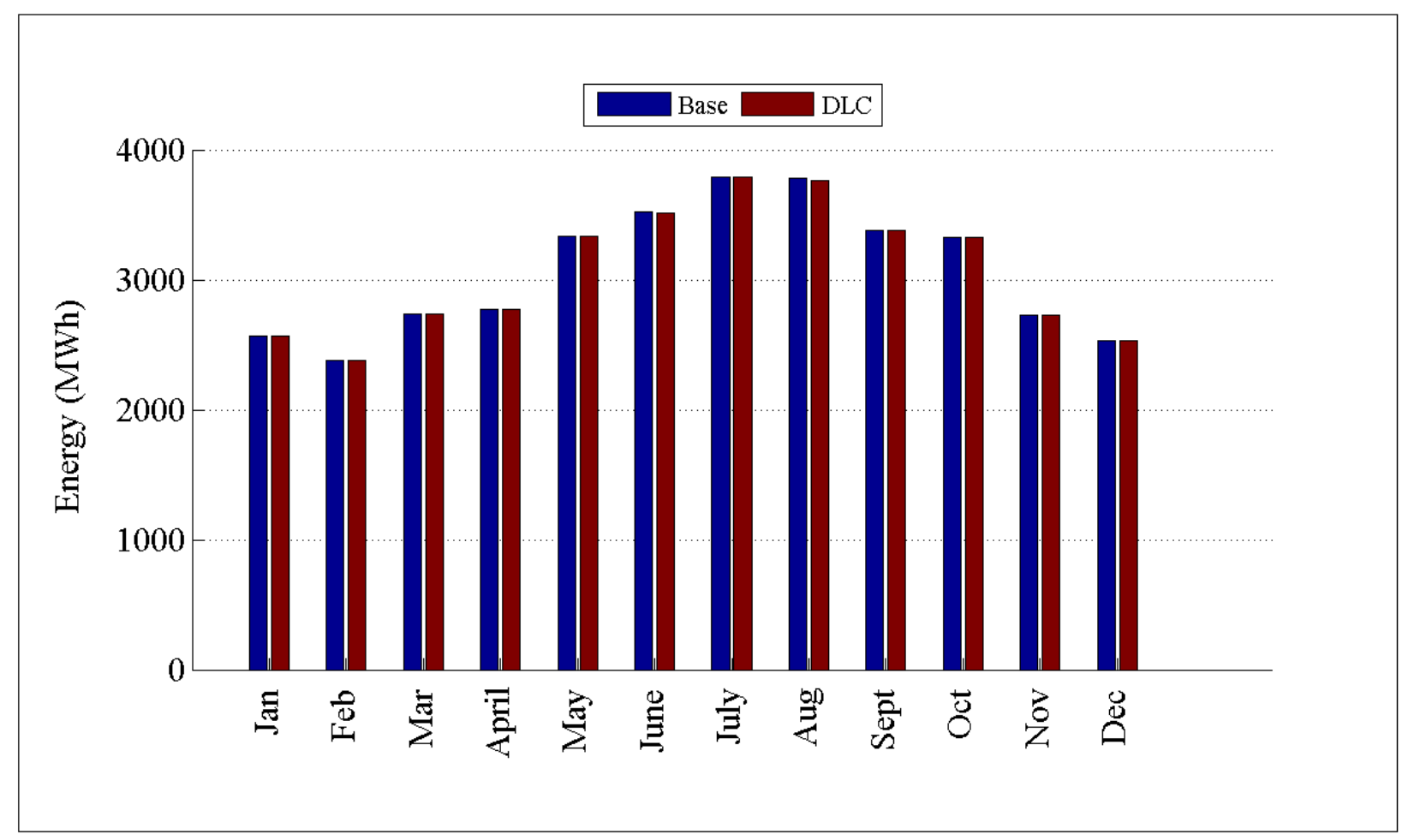

Figure D.214: Comparison of energy consumption by month for R5-12.47-5

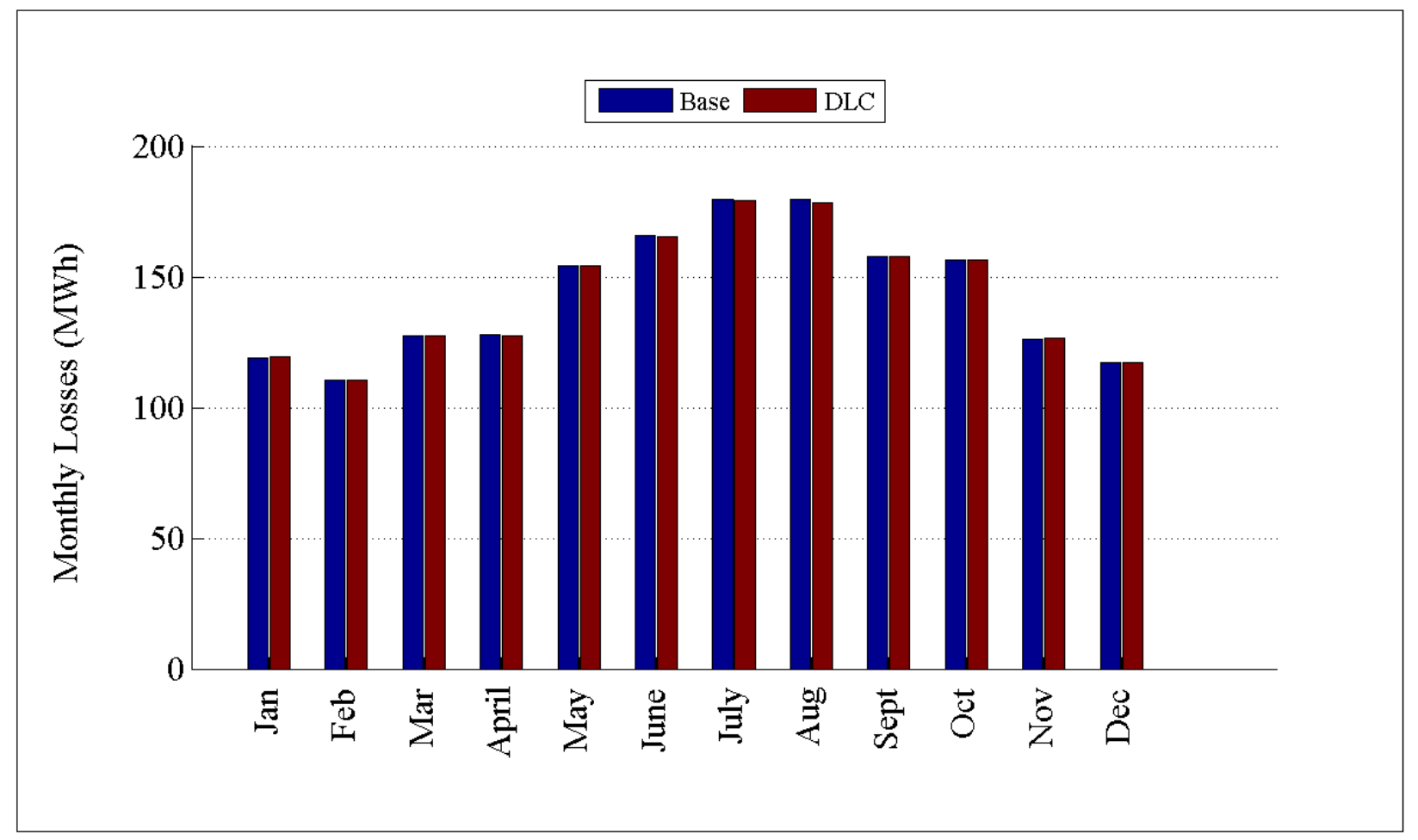

Figure D.215: Comparison of losses by month for R5-12.47-5 


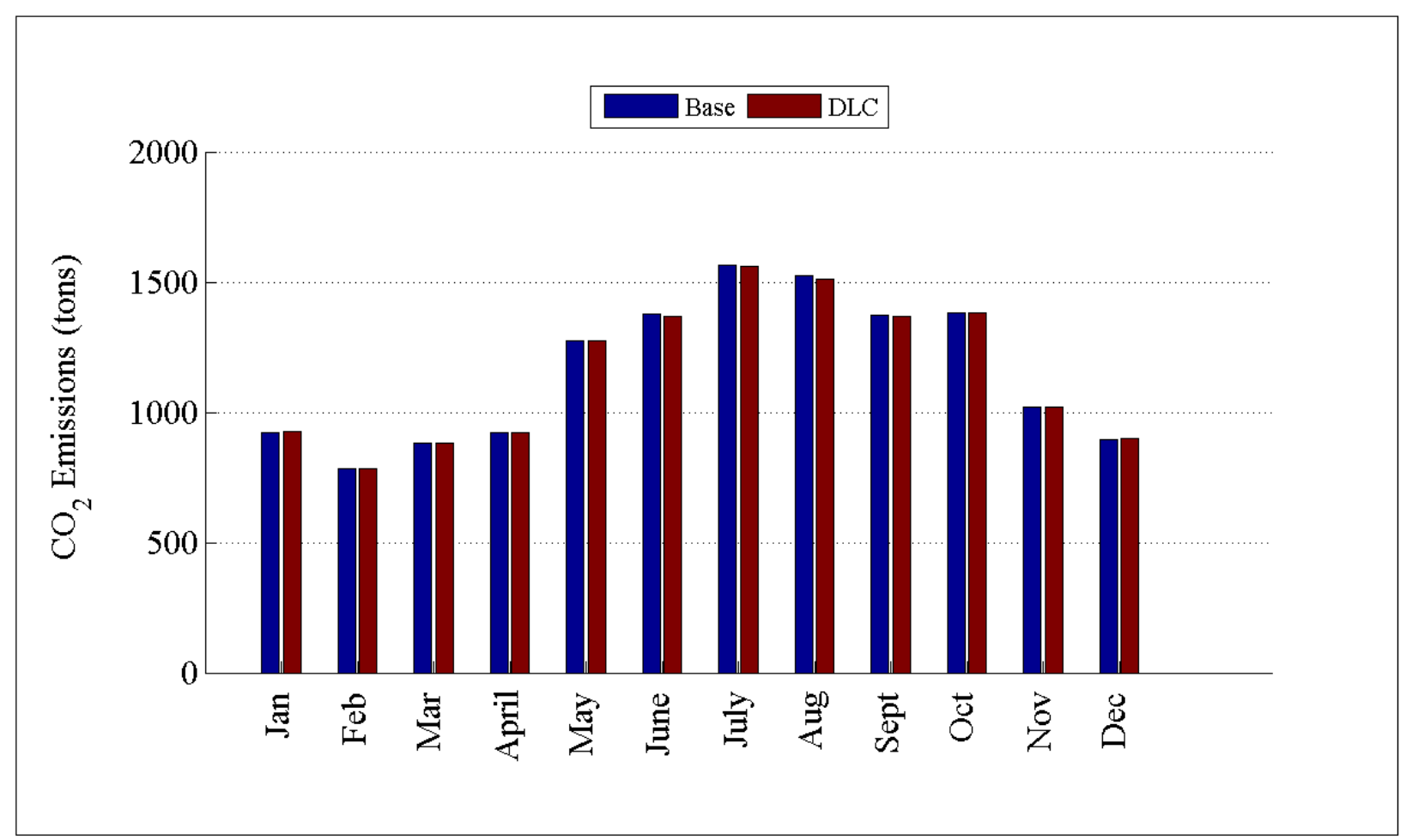

Figure D.216: Comparison of $\mathrm{CO}_{2}$ emissions by month for R5-12.47-5

D.2.27 Detailed DLC Plots for R5-25.00-1 


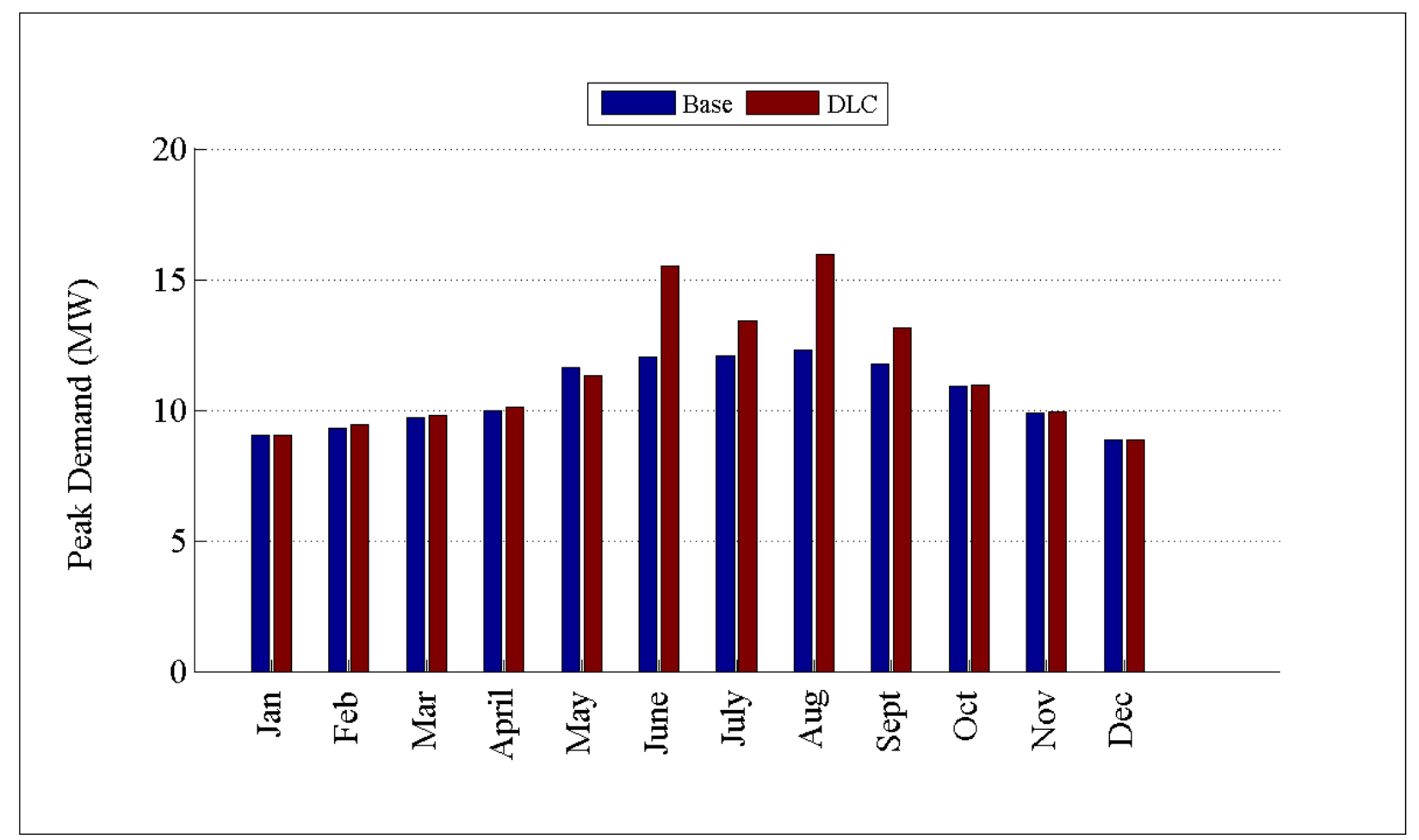

Figure D.217: Comparison of peak demand by month for R5-25.00-1

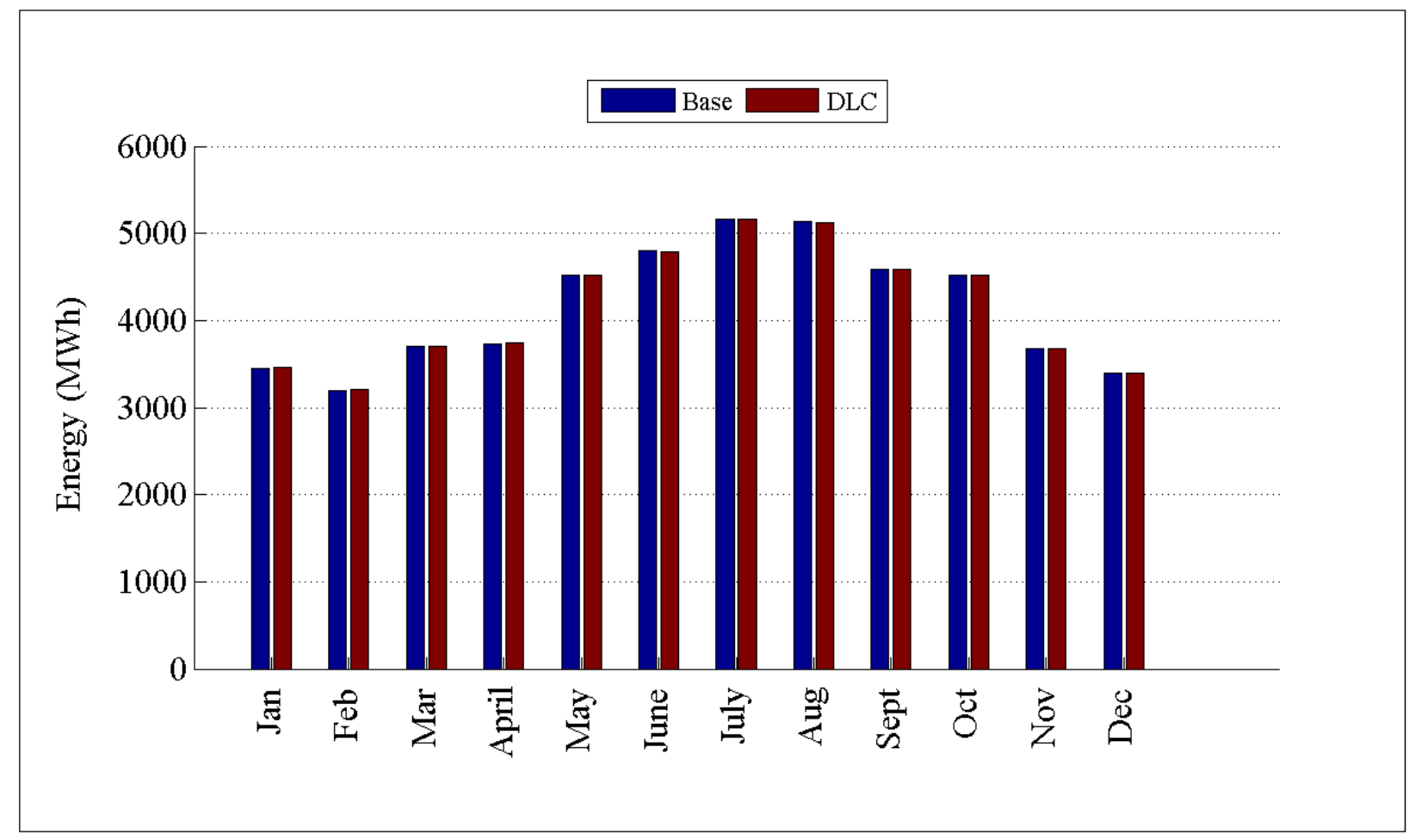

Figure D.218: Comparison of energy consumption by month for R5-25.00-1 


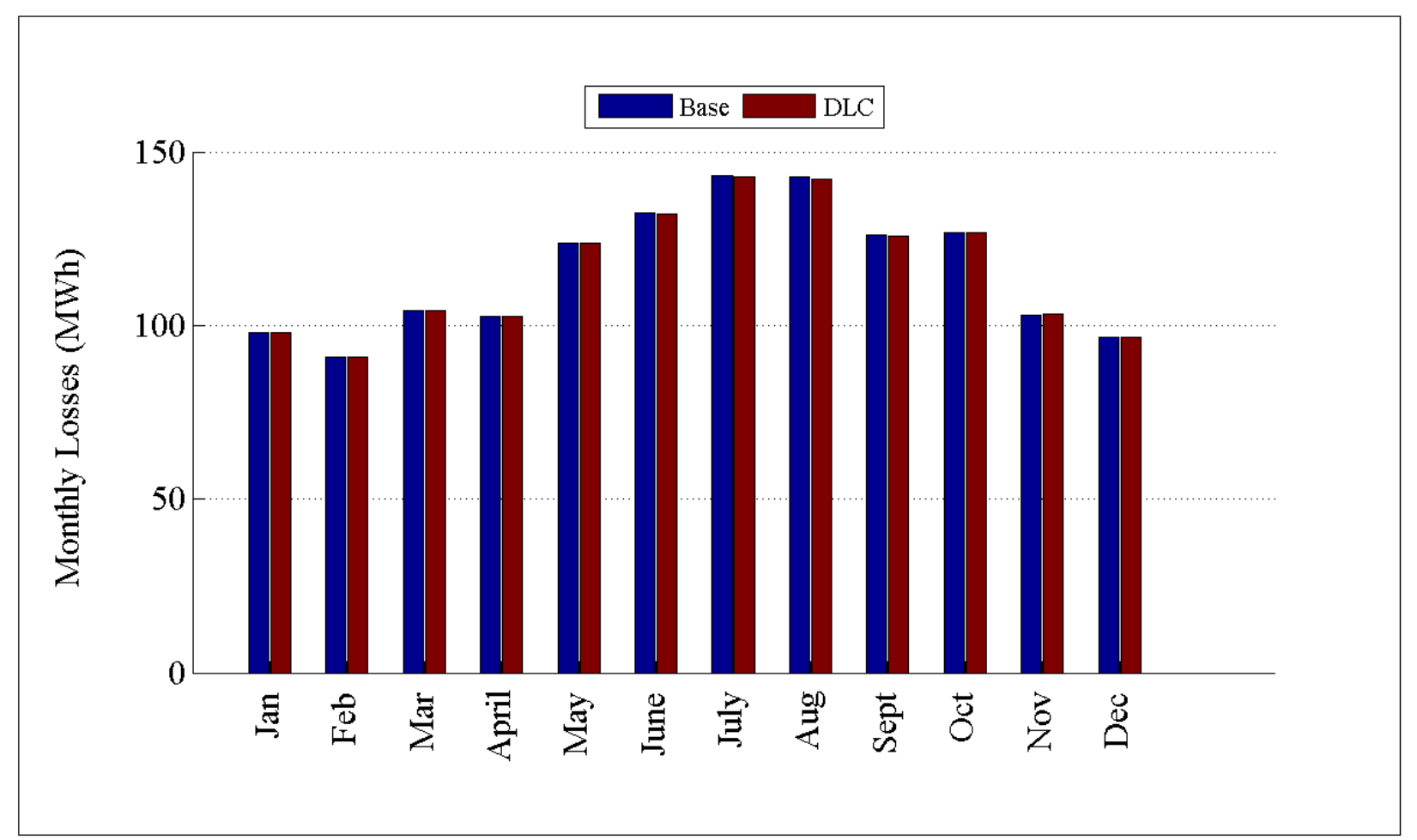

Figure D.219: Comparison of losses by month for R5-25.00-1

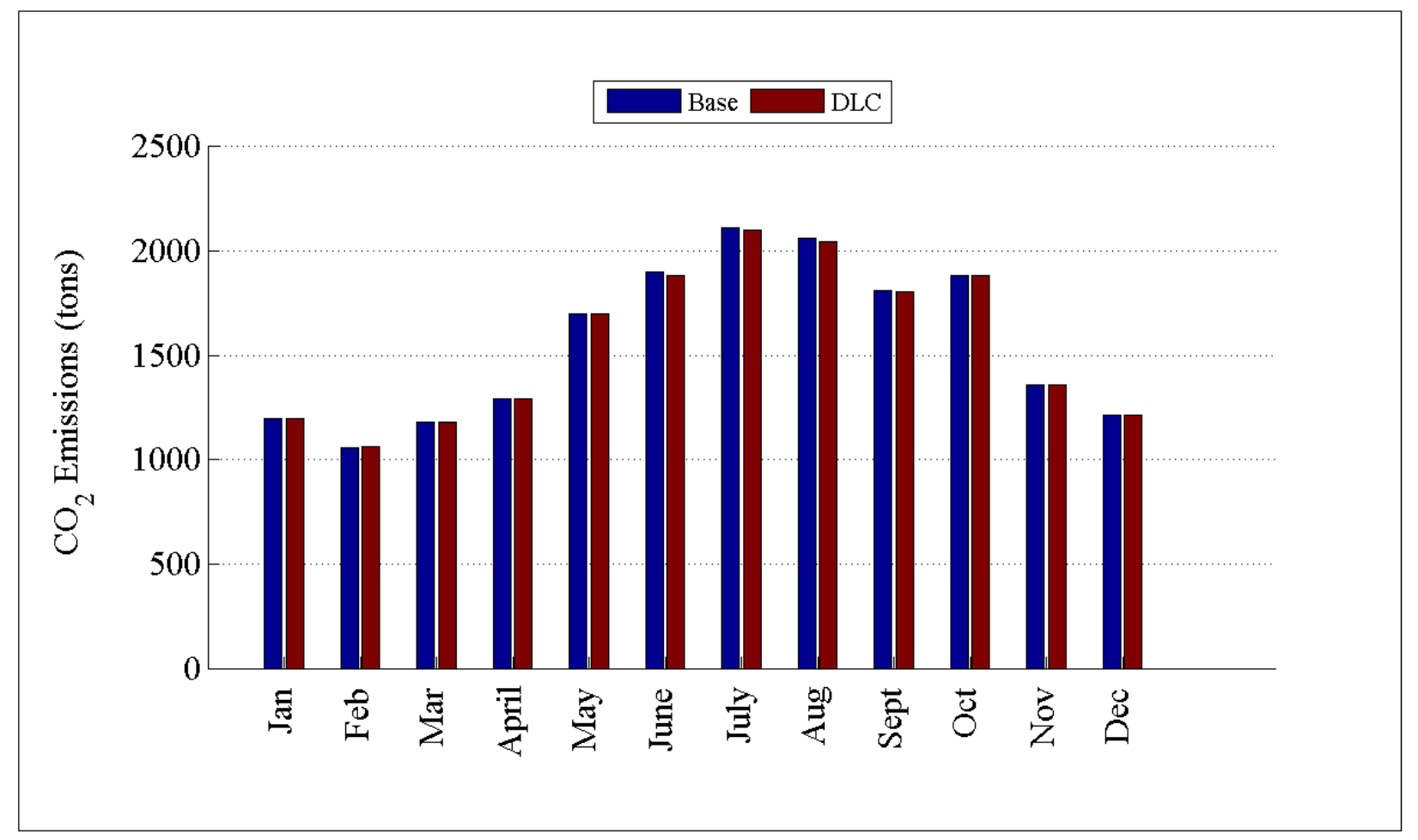

Figure D.220: Comparison of $\mathrm{CO}_{2}$ emissions by month for R5-25.00-1 
D.2.28 Detailed DLC Plots for R5-35.00-1

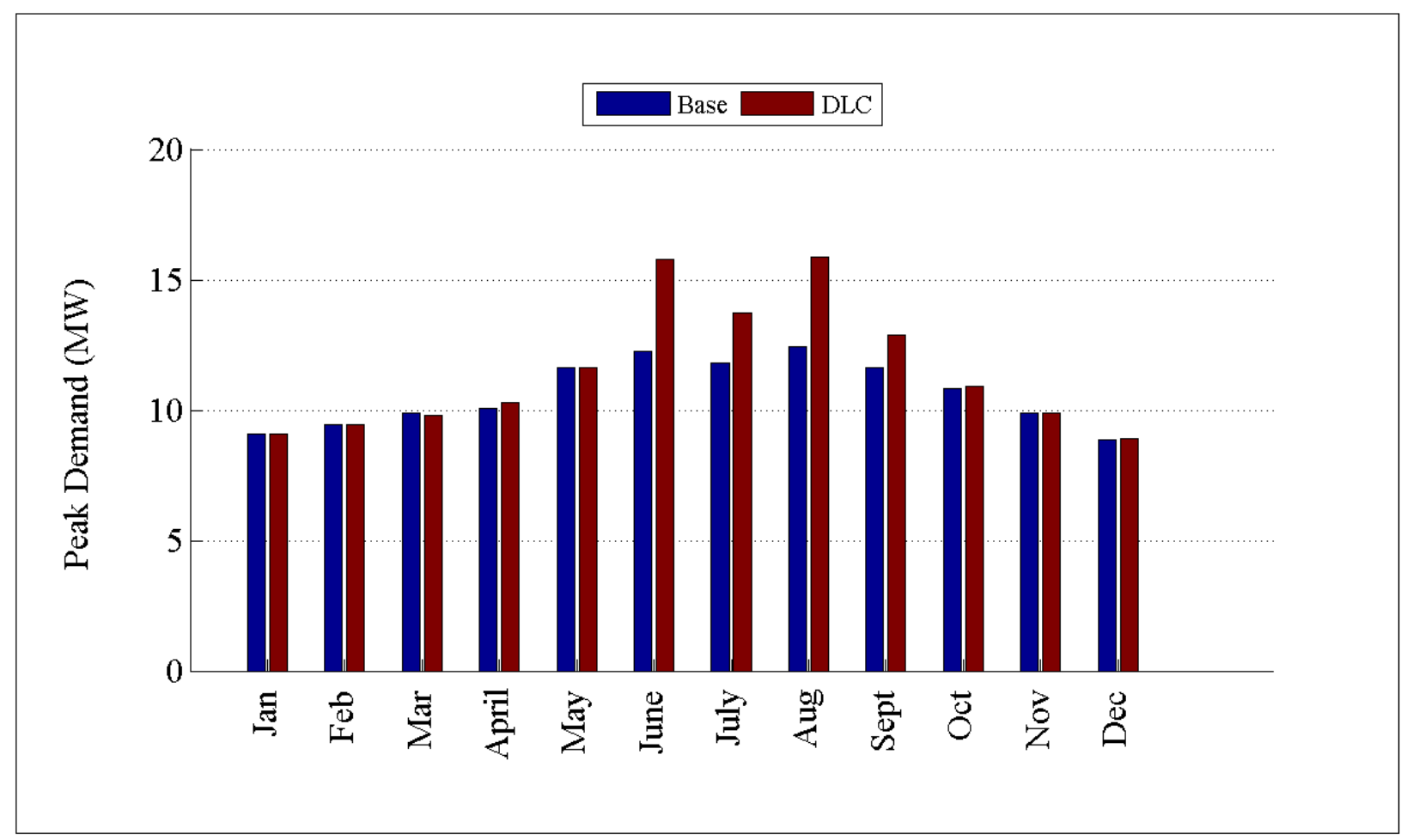

Figure D.221: Comparison of peak demand by month for R5-35.00-1 


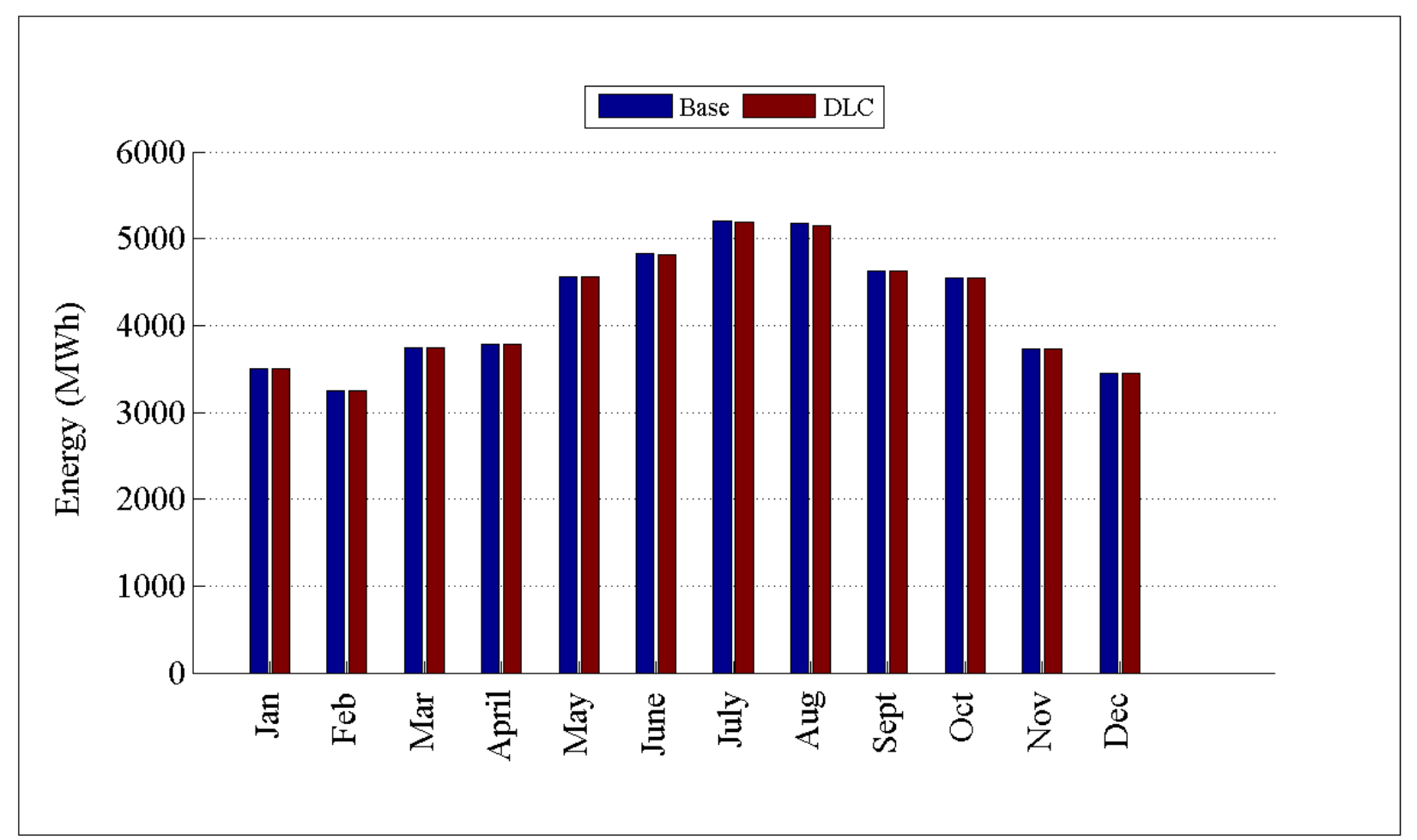

Figure D.222: Comparison of energy consumption by month for R5-35.00-1

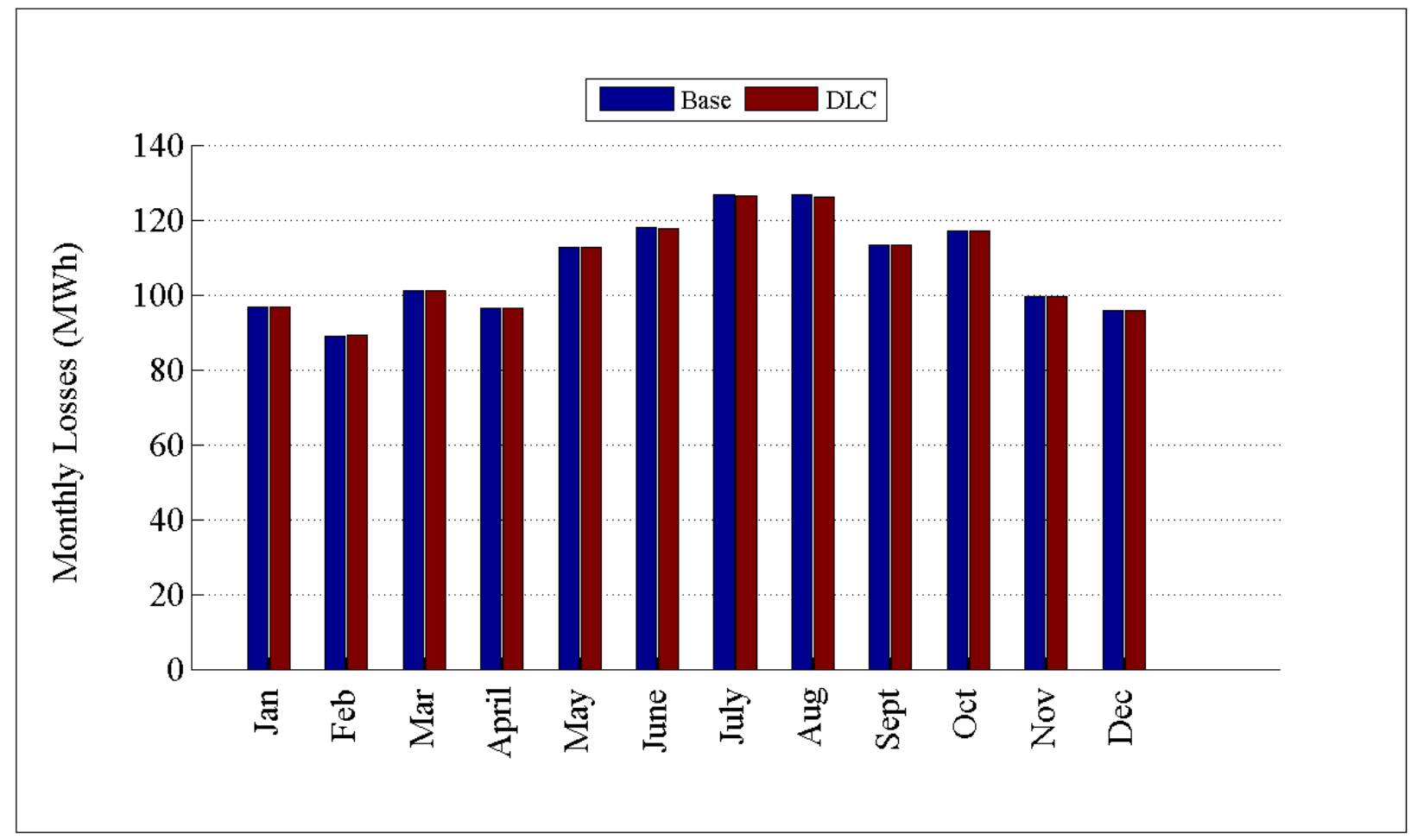

Figure D.223: Comparison of losses by month for R5-35.00-1 


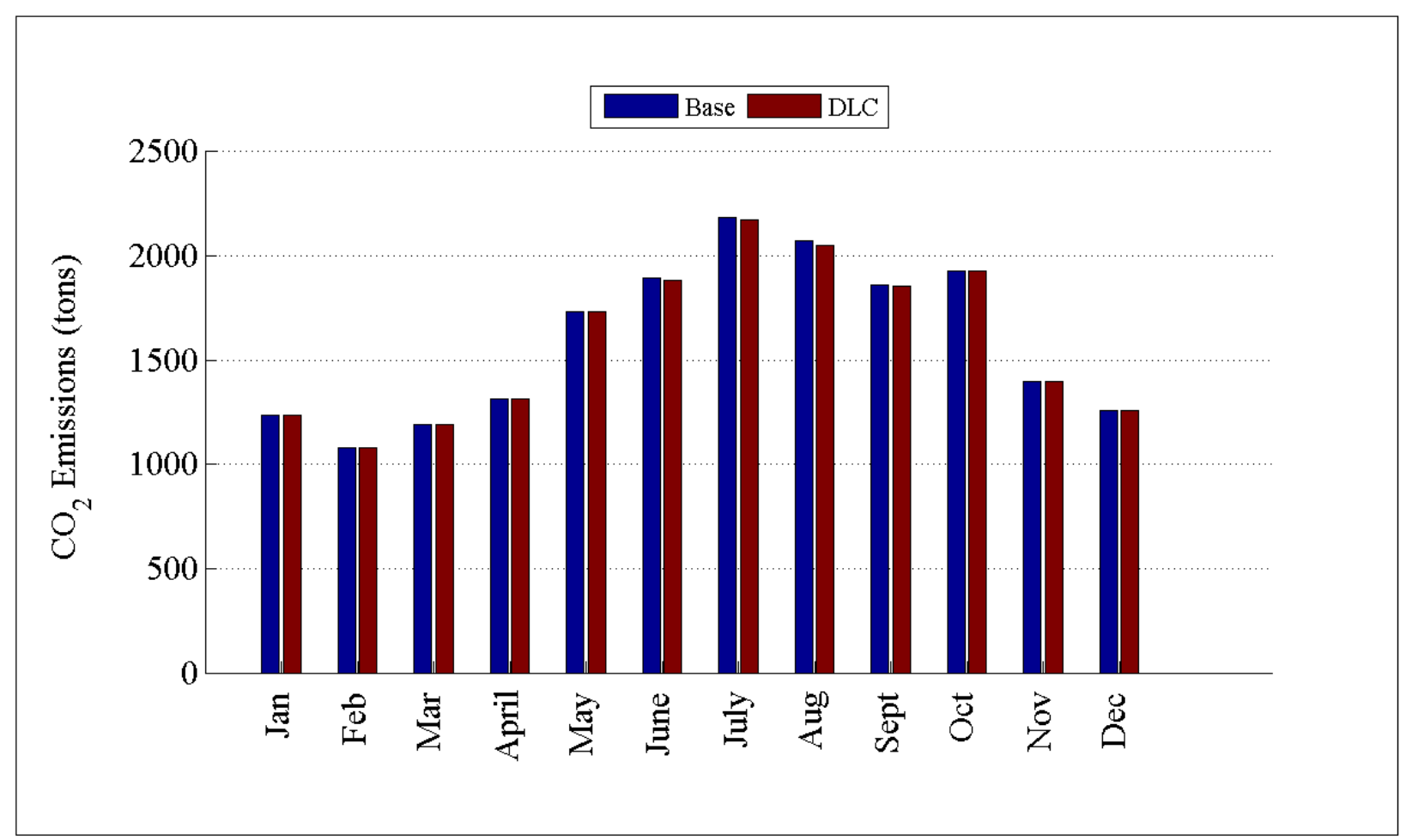

Figure D.224: Comparison of $\mathrm{CO}_{2}$ emissions by month for R5-35.00-1 


\section{Appendix E: Individual Feeder Impact Metrics}

This appendix contains the raw performance metric values for each technology on each of the

prototypical distribution feeders. The impact matrices in section 4.1, 4.2, and 4.3 are calculated from the raw values in this appendix. 


\section{E.1 Individual Performance Metrics for Base Case}

Table E.1: Base case performance metrics for region 1

\begin{tabular}{|c|c|c|c|c|c|c|c|c|}
\hline Index & Metric & Units & 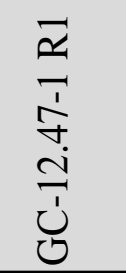 & 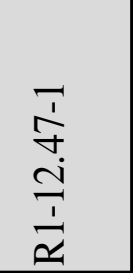 & $\begin{array}{l}\frac{T}{1} \\
\stackrel{+}{ \pm} \\
\frac{1}{\Delta} \\
\frac{1}{\simeq}\end{array}$ & $\begin{array}{l}\frac{1}{f} \\
\stackrel{+}{\sim} \\
\frac{1}{\Delta}\end{array}$ & 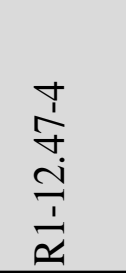 & 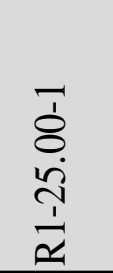 \\
\hline 1 & $\begin{array}{l}\text { Hourly Customer } \\
\text { Electricity Usage } \\
\end{array}$ & $\mathrm{kWh}$ & 2,083 & 2,692 & 992 & 435 & 1,948 & 875 \\
\hline 2 & $\begin{array}{l}\text { Monthly Customer } \\
\text { Electricity Usage } \\
\end{array}$ & MWh & 1,521 & 1,965 & 724 & 317 & 1,422 & 639 \\
\hline \multirow{10}{*}{3} & Peak Generation & $\mathrm{kW}$ & 5,313 & 7,329 & 2,675 & 1,261 & 5,050 & 2,317 \\
\hline & Nuclear & $\%$ & 10.68 & 10.68 & 10.68 & 10.68 & 10.09 & 10.68 \\
\hline & Solar & $\%$ & 0.25 & 0.25 & 0.25 & 0.25 & 0.21 & 0.25 \\
\hline & Bio & $\%$ & 0.67 & 0.67 & 0.67 & 0.67 & 0.72 & 0.67 \\
\hline & Wind & $\%$ & 4.07 & 4.07 & 4.07 & 4.07 & 3.55 & 4.07 \\
\hline & Coal & $\%$ & 2.88 & 2.88 & 2.88 & 2.88 & 4.38 & 2.88 \\
\hline & Hydroelectric & $\%$ & 36.88 & 36.88 & 36.88 & 36.88 & 26.32 & 36.88 \\
\hline & Natural Gas & $\%$ & 41.38 & 41.38 & 41.38 & 41.38 & 51.24 & 41.38 \\
\hline & Geothermal & $\%$ & 2.84 & 2.84 & 2.84 & 2.84 & 3.11 & 2.84 \\
\hline & Petroleum & $\%$ & 0.35 & 0.35 & 0.35 & 0.35 & 0.38 & 0.35 \\
\hline 4 & Peak Load & MW & 5,288 & 7,085 & 2,590 & 1,247 & 4,924 & 2,261 \\
\hline 7 & \begin{tabular}{|l} 
Annual Electricity \\
Production
\end{tabular} & MWh & 18,290 & 24,196 & 8,964 & 3,829 & 17,276 & 7,776 \\
\hline 12 & $\mathrm{CO} 2$ Emissions & Tons & 1,783 & 2,273 & 818 & 392 & 1,774 & 752 \\
\hline \multirow{3}{*}{13} & SOx Emis sions & Tons & 0.03 & 0.03 & 0.01 & 0.01 & 0.04 & 0.01 \\
\hline & NOx Emis sions & Tons & 0.24 & 0.28 & 0.10 & 0.05 & 0.22 & 0.10 \\
\hline & PM-10 Emis sions & Tons & 0.25 & 0.32 & 0.12 & 0.06 & 0.25 & 0.11 \\
\hline \multirow[b]{2}{*}{21} & Feeder Real Load & MW & 2,088 & 2,762 & 1,023 & 437 & 1,972 & 888 \\
\hline & $\begin{array}{l}\text { Feeder Reactive } \\
\text { Load } \\
\end{array}$ & MVAR & 68 & -284 & -200 & 11 & 62 & -70 \\
\hline 29 & Dis tribution Losses & $\%$ & 0.23 & 2.54 & 3.05 & 0.56 & 1.21 & 1.44 \\
\hline 30 & \begin{tabular}{|l} 
Distribution Power \\
Factor
\end{tabular} & $\mathrm{pf}$ & 0.9994 & 0.9925 & 0.9678 & 0.9997 & 0.9995 & 0.9666 \\
\hline 39 & $\mathrm{CO} 2$ Emissions & Tons & 1,787 & 2,332 & 844 & 394 & 1,796 & 763 \\
\hline \multirow{3}{*}{40} & SOx & Tons & 0.03 & 0.03 & 0.01 & 0.01 & 0.04 & 0.01 \\
\hline & NOx & Tons & 0.24 & 0.29 & 0.11 & 0.05 & 0.22 & 0.10 \\
\hline & PM-10 & Tons & 0.25 & 0.33 & 0.12 & 0.06 & 0.26 & 0.11 \\
\hline
\end{tabular}


Table E.2: Base case performance metrics for region 2

\begin{tabular}{|c|c|c|c|c|c|c|c|c|}
\hline Index & Metric & Units & 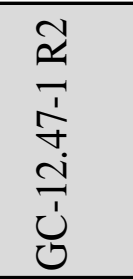 & 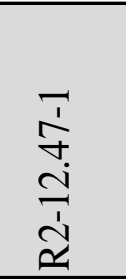 & 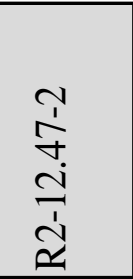 & 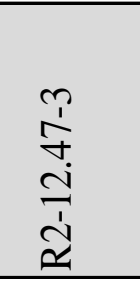 & 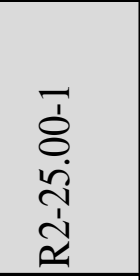 & $\begin{array}{l}\bar{\delta} \\
8 \\
\ddot{1} \\
\dot{1} \\
\tilde{d}\end{array}$ \\
\hline 1 & $\begin{array}{l}\text { Hourly Customer } \\
\text { Electricity Usage }\end{array}$ & $\mathrm{kWh}$ & 2,169 & 2,268 & 1,970 & 2,975 & 6,342 & 4,576 \\
\hline 2 & \begin{tabular}{|l|} 
Monthly Customer \\
Electricity Usage \\
\end{tabular} & MWh & 1,584 & 1,656 & 1,438 & 2,171 & 4,630 & 3,340 \\
\hline \multirow{10}{*}{3} & Peak Generation & $\mathrm{kW}$ & 5,749 & 6,287 & 5,777 & 8,555 & 16,840 & 12,676 \\
\hline & Nuclear & $\%$ & 26.33 & 26.33 & 26.33 & 27.95 & 26.33 & 26.33 \\
\hline & Solar & $\%$ & 0.01 & 0.01 & 0.01 & 0.01 & 0.01 & 0.01 \\
\hline & Bio & $\%$ & 0.82 & 0.82 & 0.82 & 0.84 & 0.82 & 0.82 \\
\hline & Wind & $\%$ & 1.41 & 1.41 & 1.41 & 1.70 & 1.41 & 1.41 \\
\hline & Coal & $\%$ & 47.18 & 47.18 & 47.18 & 45.54 & 47.18 & 47.18 \\
\hline & Hydroelectric & $\%$ & 7.42 & 7.42 & 7.42 & 9.05 & 7.42 & 7.42 \\
\hline & Natural Gas & $\%$ & 16.33 & 16.33 & 16.33 & 14.47 & 16.33 & 16.33 \\
\hline & Geothermal & $\%$ & 0.07 & 0.07 & 0.07 & 0.07 & 0.07 & 0.07 \\
\hline & Petroleum & $\%$ & 0.43 & 0.43 & 0.43 & 0.37 & 0.43 & 0.43 \\
\hline 4 & Peak Load & MW & 5,720 & 6,166 & 5,647 & 8,360 & 16,622 & 12,533 \\
\hline 7 & $\begin{array}{l}\text { Annual Electricity } \\
\text { Production }\end{array}$ & $\mathrm{MWh}$ & 19,050 & 20,128 & 17,588 & 26,686 & 56,091 & 40,417 \\
\hline 12 & $\mathrm{CO} 2$ Emissions & Tons & 8,419 & 9,246 & 8,417 & 12,627 & 26,866 & 17,434 \\
\hline \multirow{3}{*}{13} & SOx Emis sions & Tons & 3.81 & 4.21 & 3.88 & 5.82 & 12.33 & 7.86 \\
\hline & NOx Emissions & Tons & 2.43 & 2.67 & 2.46 & 3.69 & 7.81 & 5.02 \\
\hline & PM-10 Emis sions & Tons & 1.25 & 1.37 & 1.25 & 1.87 & 3.99 & 2.58 \\
\hline \multirow[b]{2}{*}{21} & Feeder Real Load & MW & 2,175 & 2,298 & 2,008 & 3,046 & 6,403 & 4,614 \\
\hline & \begin{tabular}{|l|} 
Feeder Reactive \\
Load \\
\end{tabular} & MVAR & 92 & 116 & 146 & -130 & 333 & 69 \\
\hline 29 & Distribution Losses & $\%$ & 0.25 & 1.27 & 1.87 & 2.36 & 0.96 & 0.82 \\
\hline 30 & $\begin{array}{l}\text { Distribution Power } \\
\text { Factor }\end{array}$ & $\mathrm{pf}$ & 0.9989 & 0.9987 & 0.9973 & 0.9973 & 0.9986 & 0.9996 \\
\hline 39 & $\mathrm{CO} 2$ Emis sions & Tons & 8,440 & 9,365 & 8,578 & 12,932 & 27,125 & 17,579 \\
\hline \multirow{3}{*}{40} & SOx & Tons & 3.82 & 4.26 & 3.95 & 5.96 & 12.45 & 7.93 \\
\hline & NOx & Tons & 2.44 & 2.71 & 2.51 & 3.78 & 7.88 & 5.06 \\
\hline & PM-10 & Tons & 1.25 & 1.39 & 1.27 & 1.92 & 4.03 & 2.61 \\
\hline
\end{tabular}


Table E.3: Base case performance metrics for region 3

\begin{tabular}{|c|c|c|c|c|c|c|}
\hline Index & Metric & Units & 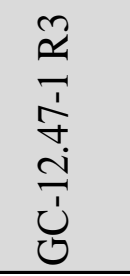 & 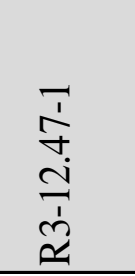 & 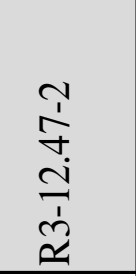 & 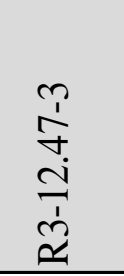 \\
\hline 1 & $\begin{array}{l}\text { Hourly Customer } \\
\text { Electricity Usage } \\
\end{array}$ & $\mathrm{kWh}$ & 2,635 & 3,661 & 1,642 & 3,705 \\
\hline 2 & $\begin{array}{l}\text { Monthly Customer } \\
\text { Electricity Usage }\end{array}$ & MWh & 1,924 & 2,673 & 1,199 & 2,705 \\
\hline \multirow{10}{*}{3} & Peak Generation & $\mathrm{kW}$ & 6,594 & 9,315 & 4,422 & 8,417 \\
\hline & Nuclear & $\%$ & 8.65 & 9.72 & 9.72 & 9.72 \\
\hline & Solar & $\%$ & 0.13 & 0.13 & 0.13 & 0.13 \\
\hline & Bio & $\%$ & 0.23 & 0.25 & 0.25 & 0.25 \\
\hline & Wind & $\%$ & 2.05 & 2.45 & 2.45 & 2.45 \\
\hline & Coal & $\%$ & 40.24 & 41.52 & 41.52 & 41.52 \\
\hline & Hydroelectric & $\%$ & 5.58 & 6.40 & 6.40 & 6.40 \\
\hline & Natural Gas & $\%$ & 41.67 & 37.88 & 37.88 & 37.88 \\
\hline & Geothermal & $\%$ & 1.25 & 1.40 & 1.40 & 1.40 \\
\hline & Petroleum & $\%$ & 0.20 & 0.25 & 0.25 & 0.25 \\
\hline 4 & Peak Load & MW & 6,554 & 9,122 & 4,364 & 8,157 \\
\hline 7 & $\begin{array}{l}\text { Annual Electricity } \\
\text { Production }\end{array}$ & MWh & 23,160 & 32,687 & 14,483 & 33,603 \\
\hline 12 & $\mathrm{CO} 2$ Emis s ions & Tons & 16,269 & 23,430 & 9,963 & 25,107 \\
\hline \multirow{3}{*}{13} & SOx Emis sions & Tons & 7.03 & 10.24 & 4.25 & 11.14 \\
\hline & NOx Emis s ions & Tons & 4.38 & 6.36 & 2.66 & 6.88 \\
\hline & PM-10 Emis sions & Tons & 2.42 & 3.49 & 1.48 & 3.74 \\
\hline \multirow[b]{2}{*}{21} & Feeder Real Load & MW & 2,644 & 3,731 & 1,653 & 3,836 \\
\hline & $\begin{array}{l}\text { Feeder Reactive } \\
\text { Load }\end{array}$ & MVAR & 219 & 484 & 143 & 547 \\
\hline 29 & Dis tribution Losses & $\%$ & 0.33 & 1.87 & 0.69 & 3.40 \\
\hline 30 & $\begin{array}{l}\text { Dis tribution Power } \\
\text { Factor }\end{array}$ & $\mathrm{pf}$ & 0.9969 & 0.9904 & 0.9968 & 0.9897 \\
\hline 39 & CO2 Emis s ions & Tons & 16,323 & 23,877 & 10,032 & 25,991 \\
\hline \multirow{3}{*}{40} & SOx & Tons & 7.05 & 10.44 & 4.28 & 11.53 \\
\hline & NOx & Tons & 4.39 & 6.48 & 2.67 & 7.12 \\
\hline & PM-10 & Tons & 2.43 & 3.56 & 1.49 & 3.87 \\
\hline
\end{tabular}


Table E.4: Base case performance metrics for region 4

\begin{tabular}{|c|c|c|c|c|c|c|}
\hline Index & Metric & Units & 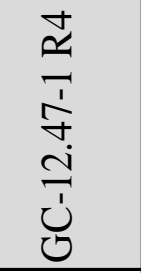 & 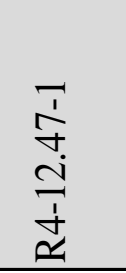 & 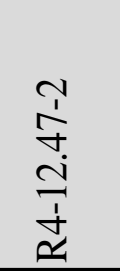 & 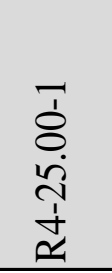 \\
\hline 1 & $\begin{array}{l}\text { Hourly Customer } \\
\text { Electricity Usage }\end{array}$ & $\mathrm{kWh}$ & 2,339 & 1,909 & 832 & 347 \\
\hline 2 & $\begin{array}{l}\text { Monthly Customer } \\
\text { Electricity Usage }\end{array}$ & MWh & 1,708 & 1,393 & 607 & 253 \\
\hline \multirow{10}{*}{3} & Peak Generation & $\mathrm{kW}$ & 6,221 & 4,798 & 2,205 & 945 \\
\hline & Nuclear & $\%$ & 21.91 & 21.91 & 23.58 & 23.58 \\
\hline & Solar & $\%$ & 0.00 & 0.00 & 0.00 & 0.00 \\
\hline & Bio & $\%$ & 0.18 & 0.18 & 0.21 & 0.21 \\
\hline & Wind & $\%$ & 0.60 & 0.60 & 0.59 & 0.59 \\
\hline & Coal & $\%$ & 57.14 & 57.14 & 56.06 & 56.06 \\
\hline & Hydroelectric & $\%$ & 2.20 & 2.20 & 3.09 & 3.09 \\
\hline & Natural Gas & $\%$ & 17.49 & 17.49 & 16.14 & 16.14 \\
\hline & Geothermal & $\%$ & 0.00 & 0.00 & 0.00 & 0.00 \\
\hline & Petroleum & $\%$ & 0.48 & 0.48 & 0.33 & 0.33 \\
\hline 4 & Peak Load & MW & 6,186 & 4,701 & 2,171 & 928 \\
\hline 7 & $\begin{array}{l}\text { Annual Electricity } \\
\text { Production }\end{array}$ & MWh & 20,550 & 17,195 & 7,457 & 3,118 \\
\hline 12 & $\mathrm{CO} 2$ Emis sions & Tons & 10,321 & 9,844 & 3,994 & 1,608 \\
\hline \multirow{3}{*}{13} & SOx Emis sions & Tons & 4.91 & 4.72 & 1.92 & 0.77 \\
\hline & NOx Emis sions & Tons & 3.00 & 2.87 & 1.17 & 0.47 \\
\hline & PM-10 Emissions & Tons & 1.54 & 1.47 & 0.60 & 0.24 \\
\hline \multirow[b]{2}{*}{21} & Feeder Real Load & MW & 2,346 & 1,963 & 851 & 356 \\
\hline & $\begin{array}{l}\text { Feeder Reactive } \\
\text { Load }\end{array}$ & MVAR & 138 & -413 & 98 & 45 \\
\hline 29 & Distribution Losses & $\%$ & 0.28 & 2.76 & 2.32 & 2.53 \\
\hline 30 & $\begin{array}{l}\text { Distribution Power } \\
\text { Factor }\end{array}$ & $\mathrm{pf}$ & 0.9982 & 0.9666 & 0.9934 & 0.9920 \\
\hline 39 & $\mathrm{CO} 2$ Emis sions & Tons & 10,350 & 10,123 & 4,089 & 1,650 \\
\hline \multirow{3}{*}{40} & SOx & Tons & 4.93 & 4.86 & 1.96 & 0.79 \\
\hline & NOx & Tons & 3.00 & 2.95 & 1.19 & 0.48 \\
\hline & PM-10 & Tons & 1.54 & 1.51 & 0.61 & 0.25 \\
\hline
\end{tabular}


Table E.5: Base case performance metrics for region 5

\begin{tabular}{|c|c|c|c|c|c|c|c|c|c|c|}
\hline Index & Metric & Units & 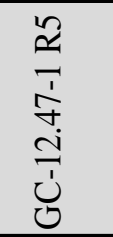 & 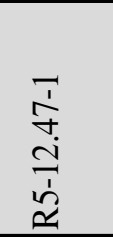 & 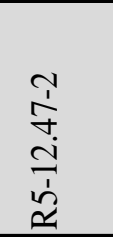 & 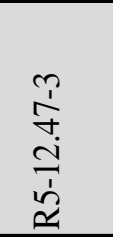 & 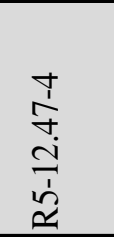 & 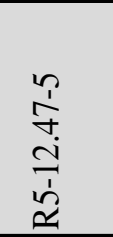 & $\begin{array}{l}7 \\
8 \\
8 \\
\\
1 \\
1 \\
\end{array}$ & 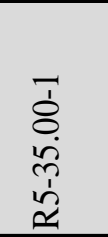 \\
\hline 1 & $\begin{array}{l}\text { Hourly Customer } \\
\text { Electricity Usage }\end{array}$ & $\mathrm{kWh}$ & 2,747 & 4,490 & 2,226 & 4,669 & 3,468 & 4,116 & 5,627 & 5,689 \\
\hline 2 & $\begin{array}{l}\text { Monthly Customer } \\
\text { Electricity Usage }\end{array}$ & MWh & 2,005 & 3,278 & 1,625 & 3,408 & 2,532 & 3,005 & 4,108 & 4,153 \\
\hline \multirow{10}{*}{3} & Peak Generation & $\mathrm{kW}$ & 5,841 & 9,451 & 4,992 & 10,384 & 7,531 & 9,041 & 12,282 & 12,428 \\
\hline & Nuclear & $\%$ & 13.85 & 13.85 & 13.85 & 13.53 & 13.85 & 13.53 & 13.85 & 13.85 \\
\hline & Solar & $\%$ & 0.00 & 0.00 & 0.00 & 0.00 & 0.00 & 0.00 & 0.00 & 0.00 \\
\hline & Bio & $\%$ & 0.33 & 0.33 & 0.33 & 0.31 & 0.33 & 0.31 & 0.33 & 0.33 \\
\hline & Wind & $\%$ & 1.48 & 1.48 & 1.48 & 1.74 & 1.48 & 1.74 & 1.48 & 1.48 \\
\hline & Coal & $\%$ & 30.17 & 30.17 & 30.17 & 30.37 & 30.17 & 30.37 & 30.17 & 30.17 \\
\hline & Hydroelectric & $\%$ & 0.63 & 0.63 & 0.63 & 0.78 & 0.63 & 0.78 & 0.63 & 0.63 \\
\hline & Natural Gas & $\%$ & 51.68 & 51.68 & 51.68 & 51.29 & 51.68 & 51.29 & 51.68 & 51.68 \\
\hline & Geothermal & $\%$ & 0.00 & 0.00 & 0.00 & 0.00 & 0.00 & 0.00 & 0.00 & 0.00 \\
\hline & Petroleum & $\%$ & 1.86 & 1.86 & 1.86 & 1.98 & 1.86 & 1.98 & 1.86 & 1.86 \\
\hline 4 & Peak Load & MW & 5,810 & 9,319 & 4,848 & 9,772 & 7,373 & 8,784 & 12,088 & 12,270 \\
\hline 7 & $\begin{array}{l}\text { Annual Electricity } \\
\text { Production }\end{array}$ & MWh & 24,144 & 39,806 & 19,900 & 42,781 & 30,976 & 36,921 & 49,992 & 50,486 \\
\hline 12 & $\mathrm{CO} 2$ Emis sions & Tons & 9,364 & 15,419 & 7,414 & 15,195 & 11,809 & 13,594 & 18,504 & 18,904 \\
\hline \multirow{3}{*}{13} & SOx Emis sions & Tons & 1.55 & 2.23 & 1.11 & 1.64 & 1.70 & 1.66 & 2.19 & 2.34 \\
\hline & NOx Emis sions & Tons & 1.38 & 2.11 & 1.04 & 1.82 & 1.61 & 1.72 & 2.31 & 2.41 \\
\hline & PM-10 Emis sions & Tons & 1.37 & 2.26 & 1.09 & 2.23 & 1.73 & 1.99 & 2.71 & 2.77 \\
\hline \multirow[b]{2}{*}{21} & Feeder Real Load & MW & 2,756 & 4,544 & 2,272 & 4,884 & 3,536 & 4,215 & 5,707 & 5,763 \\
\hline & $\begin{array}{l}\text { Feeder Reactive } \\
\text { Load }\end{array}$ & MVAR & 248 & 542 & 242 & -357 & 407 & 594 & 650 & 641 \\
\hline 29 & Distribution Losses & $\%$ & 0.33 & 1.19 & 2.02 & 4.41 & 1.92 & 2.34 & 1.39 & 1.28 \\
\hline 30 & \begin{tabular}{|l|} 
Distribution Power \\
Factor
\end{tabular} & $\mathrm{pf}$ & 0.9964 & 0.9937 & 0.9952 & 0.9779 & 0.9942 & 0.9913 & 0.9942 & 0.9944 \\
\hline 39 & $\mathrm{CO} 2$ Emis sions & Tons & 9,395 & 15,605 & 7,567 & 15,895 & 12,040 & 13,919 & 18,766 & 19,150 \\
\hline \multirow{3}{*}{40} & SOx & Tons & 1.55 & 2.26 & 1.14 & 1.72 & 1.73 & 1.70 & 2.22 & 2.37 \\
\hline & NOx & Tons & 1.39 & 2.14 & 1.06 & 1.91 & 1.65 & 1.76 & 2.34 & 2.44 \\
\hline & PM-10 & Tons & 1.38 & 2.29 & 1.11 & 2.33 & 1.77 & 2.04 & 2.75 & 2.81 \\
\hline
\end{tabular}




\section{E.2 Individual TOU and CPP Performance Metrics}

Table E.6: TOU without enabling technologies performance metrics for region 1

\begin{tabular}{|c|c|c|c|c|c|c|c|c|}
\hline Index & Metric & Units & 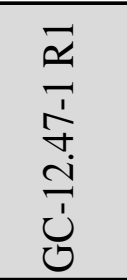 & $\begin{array}{l}\text { 京 } \\
\stackrel{+}{c} \\
\frac{1}{\Delta}\end{array}$ & $\begin{array}{l}\frac{N}{\sigma} \\
\stackrel{+}{\sim} \\
\frac{1}{\Delta}\end{array}$ & $\begin{array}{l}\frac{1}{1} \\
\stackrel{+}{d} \\
\frac{1}{\Delta}\end{array}$ & 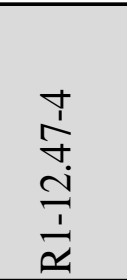 & $\begin{array}{l}\bar{\delta} \\
\text { o } \\
\stackrel{1}{1} \\
\frac{1}{\alpha}\end{array}$ \\
\hline 1 & $\begin{array}{l}\text { Hourly Customer } \\
\text { Electricity Usage }\end{array}$ & $\mathrm{kWh}$ & 2,083 & 2,691 & 990 & 435 & 1,947 & 875 \\
\hline 2 & $\begin{array}{l}\text { Monthly Customer } \\
\text { Electricity Usage } \\
\end{array}$ & MWh & 1,521 & 1,964 & 723 & 318 & 1,421 & 639 \\
\hline \multirow{10}{*}{3} & Peak Generation & $\mathrm{kW}$ & 5,414 & 7,256 & 2,676 & 1,251 & 4,894 & 2,304 \\
\hline & Nuclear & $\%$ & 10.68 & 10.68 & 10.68 & 10.68 & 10.68 & 10.68 \\
\hline & Solar & $\%$ & 0.25 & 0.25 & 0.25 & 0.25 & 0.25 & 0.25 \\
\hline & Bio & $\%$ & 0.67 & 0.67 & 0.67 & 0.67 & 0.67 & 0.67 \\
\hline & Wind & $\%$ & 4.07 & 4.07 & 4.07 & 4.07 & 4.07 & 4.07 \\
\hline & Coal & $\%$ & 2.88 & 2.88 & 2.88 & 2.88 & 2.88 & 2.88 \\
\hline & Hydroelectric & $\%$ & 36.88 & 36.88 & 36.88 & 36.88 & 36.88 & 36.88 \\
\hline & Natural Gas & $\%$ & 41.38 & 41.38 & 41.38 & 41.38 & 41.38 & 41.38 \\
\hline & Geothermal & $\%$ & 2.84 & 2.20 & 2.84 & 2.37 & 0.12 & 2.62 \\
\hline & Petroleum & $\%$ & 2.26 & 0.00 & 0.41 & 0.00 & 0.00 & 0.00 \\
\hline 4 & Peak Load & $\mathrm{kW}$ & 5,389 & 7,013 & 2,592 & 1,237 & 4,768 & 2,248 \\
\hline 7 & $\begin{array}{l}\text { Annual Electricity } \\
\text { Production }\end{array}$ & MWh & 18,293 & 24,181 & 8,949 & 3,832 & 17,261 & 7,777 \\
\hline 12 & $\mathrm{CO} 2$ Emissions & Tons & 1,784 & 2,239 & 801 & 392 & 1,743 & 750 \\
\hline \multirow{3}{*}{13} & SOx Emis sions & Tons & 0.03 & 0.03 & 0.01 & 0.01 & 0.03 & 0.01 \\
\hline & NOx Emis sions & Tons & 0.24 & 0.28 & 0.10 & 0.05 & 0.22 & 0.10 \\
\hline & PM-10 Emissions & Tons & 0.25 & 0.32 & 0.11 & 0.06 & 0.25 & 0.11 \\
\hline \multirow{2}{*}{2} & Feeder Real Load & $\mathrm{kW}$ & 2,088 & 2,760 & 1,022 & 437 & 1,970 & 888 \\
\hline & Feeder Reactive Load & kVAR & 68 & -279 & -198 & 11 & 64 & -70 \\
\hline 29 & Distribution Losses & $\%$ & 0.23 & 2.53 & 3.05 & 0.56 & 1.20 & 1.44 \\
\hline 30 & \begin{tabular}{|l|} 
Distribution Power \\
Factor
\end{tabular} & $\mathrm{pf}$ & 0.9994 & 0.9929 & 0.9687 & 0.9997 & 0.9994 & 0.9667 \\
\hline 39 & $\mathrm{CO} 2$ Emissions & Tons & 1,788 & 2,297 & 826 & 394 & 1,764 & 761 \\
\hline \multirow{3}{*}{40} & SOx Emis sions & Tons & 0.03 & 0.03 & 0.01 & 0.01 & 0.03 & 0.01 \\
\hline & NOx Emis sions & Tons & 0.24 & 0.29 & 0.10 & 0.05 & 0.22 & 0.10 \\
\hline & PM-10 Emis sions & Tons & 0.25 & 0.33 & 0.12 & 0.06 & 0.25 & 0.11 \\
\hline
\end{tabular}


Table E.7: TOU without enabling technologies performance metrics for region 2

\begin{tabular}{|c|c|c|c|c|c|c|c|c|}
\hline Index & Metric & Units & 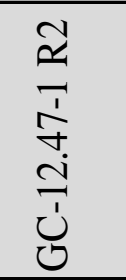 & 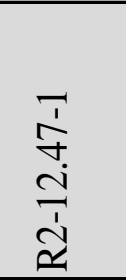 & 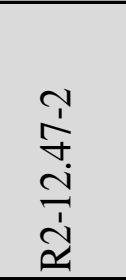 & 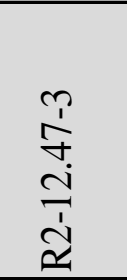 & 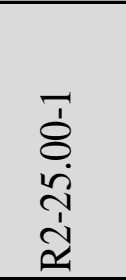 & $\begin{array}{l}\bar{\delta} \\
8 \\
\tilde{\delta} \\
\dot{1} \\
\tilde{d}\end{array}$ \\
\hline 1 & $\begin{array}{l}\text { Hourly Customer } \\
\text { Electricity Usage }\end{array}$ & $\mathrm{kWh}$ & 2,169 & 2,269 & 1,975 & 2,977 & 6,340 & 4,578 \\
\hline 2 & $\begin{array}{l}\text { Monthly Customer } \\
\text { Electricity Usage } \\
\end{array}$ & $\mathrm{MWh}$ & 1,584 & 1,656 & 1,442 & 2,173 & 4,628 & 3,342 \\
\hline \multirow{10}{*}{3} & Peak Generation & $\mathrm{kW}$ & 5,732 & 6,191 & 5,773 & 8,453 & 16,987 & 12,593 \\
\hline & Nuclear & $\%$ & 26.33 & 26.33 & 26.33 & 26.33 & 27.95 & 26.33 \\
\hline & Solar & $\%$ & 0.01 & 0.01 & 0.01 & 0.01 & 0.01 & 0.01 \\
\hline & Bio & $\%$ & 0.82 & 0.82 & 0.82 & 0.82 & 0.84 & 0.82 \\
\hline & Wind & $\%$ & 1.41 & 1.41 & 1.41 & 1.41 & 1.70 & 1.41 \\
\hline & Coal & $\%$ & 47.18 & 47.18 & 47.18 & 47.18 & 45.54 & 47.18 \\
\hline & Hydroelectric & $\%$ & 7.42 & 6.40 & 7.42 & 6.98 & 9.05 & 7.27 \\
\hline & Natural Gas & $\%$ & 16.33 & 16.33 & 16.33 & 16.33 & 14.47 & 16.33 \\
\hline & Geothermal & $\%$ & 0.07 & 0.00 & 0.07 & 0.00 & 0.07 & 0.00 \\
\hline & Petroleum & $\%$ & 0.13 & 0.00 & 0.37 & 0.00 & 1.89 & 0.00 \\
\hline 4 & Peak Load & $\mathrm{kW}$ & 5,703 & 6,071 & 5,643 & 8,259 & 16,769 & 12,450 \\
\hline 7 & $\begin{array}{l}\text { Annual Electricity } \\
\text { Production }\end{array}$ & MWh & 19,050 & 20,130 & 17,629 & 26,705 & 56,071 & 40,432 \\
\hline 12 & $\mathrm{CO} 2$ Emis sions & Tons & 8,419 & 9,245 & 8,455 & 12,639 & 26,858 & 17,444 \\
\hline \multirow{3}{*}{13} & SOx Emissions & Tons & 3.81 & 4.21 & 3.90 & 5.83 & 12.34 & 7.87 \\
\hline & NOx Emis sions & Tons & 2.43 & 2.67 & 2.47 & 3.70 & 7.81 & 5.02 \\
\hline & PM-10 Emis sions & Tons & 1.25 & 1.37 & 1.25 & 1.88 & 3.99 & 2.59 \\
\hline \multirow[b]{2}{*}{21} & Feeder Real Load & $\mathrm{kW}$ & 2,175 & 2,298 & 2,012 & 3,048 & 6,401 & 4,616 \\
\hline & $\begin{array}{l}\text { Feeder Reactive } \\
\text { Load } \\
\end{array}$ & kVAR & 92 & 117 & 148 & -128 & 335 & 71 \\
\hline 29 & Distribution Losses & $\%$ & 0.25 & 1.27 & 1.87 & 2.35 & 0.95 & 0.82 \\
\hline 30 & $\begin{array}{l}\text { Distribution Power } \\
\text { Factor }\end{array}$ & $\mathrm{pf}$ & 0.9989 & 0.9987 & 0.9972 & 0.9975 & 0.9986 & 0.9996 \\
\hline 39 & $\mathrm{CO} 2$ Emissions & Tons & 8,440 & 9,364 & 8,616 & 12,943 & 27,117 & 17,589 \\
\hline \multirow{3}{*}{40} & SOx Emis sions & Tons & 3.82 & 4.26 & 3.98 & 5.98 & 12.46 & 7.93 \\
\hline & NOx Emis sions & Tons & 2.44 & 2.71 & 2.52 & 3.79 & 7.89 & 5.06 \\
\hline & PM-10 Emissions & Tons & 1.25 & 1.39 & 1.28 & 1.92 & 4.02 & 2.61 \\
\hline
\end{tabular}


Table E.8: TOU without enabling technologies performance metrics for region 3

\begin{tabular}{|c|c|c|c|c|c|c|}
\hline Index & Metric & Units & 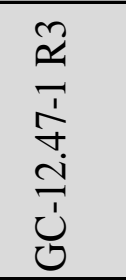 & 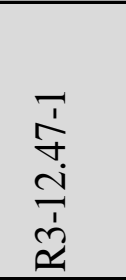 & 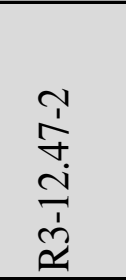 & 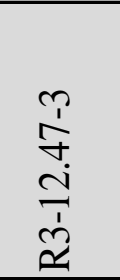 \\
\hline 1 & $\begin{array}{l}\text { Hourly Customer } \\
\text { Electricity Usage }\end{array}$ & $\mathrm{kWh}$ & 2,634 & 3,657 & 1,642 & 3,691 \\
\hline 2 & $\begin{array}{l}\text { Monthly Customer } \\
\text { Electricity Usage } \\
\end{array}$ & MWh & 1,923 & 2,670 & 1,199 & 2,695 \\
\hline \multirow{10}{*}{3} & Peak Generation & $\mathrm{kW}$ & 6,682 & 9,250 & 4,381 & 8,416 \\
\hline & Nuclear & $\%$ & 9.72 & 9.72 & 9.72 & 9.72 \\
\hline & Solar & $\%$ & 0.13 & 0.13 & 0.13 & 0.13 \\
\hline & Bio & $\%$ & 0.25 & 0.25 & 0.25 & 0.25 \\
\hline & Wind & $\%$ & 2.45 & 2.45 & 2.45 & 2.45 \\
\hline & Coal & $\%$ & 41.52 & 41.52 & 41.52 & 41.52 \\
\hline & Hydroelectric & $\%$ & 6.40 & 6.40 & 6.40 & 6.40 \\
\hline & Natural Gas & $\%$ & 37.88 & 37.88 & 37.88 & 37.88 \\
\hline & Geothermal & $\%$ & 1.40 & 0.95 & 0.74 & 1.40 \\
\hline & Petroleum & $\%$ & 1.68 & 0.00 & 0.00 & 0.24 \\
\hline 4 & Peak Load & $\mathrm{kW}$ & 6,643 & 9,056 & 4,324 & 8,155 \\
\hline 7 & $\begin{array}{l}\text { Annual Electricity } \\
\text { Production }\end{array}$ & MWh & 23,149 & 32,649 & 14,484 & 33,477 \\
\hline 12 & $\mathrm{CO} 2$ Emis sions & Tons & 16,265 & 23,441 & 9,963 & 25,076 \\
\hline \multirow{3}{*}{13} & SOx Emis sions & Tons & 7.03 & 10.27 & 4.25 & 11.16 \\
\hline & NOx Emis sions & Tons & 4.38 & 6.37 & 2.66 & 6.88 \\
\hline & PM-10 Emis sions & Tons & 2.42 & 3.49 & 1.48 & 3.74 \\
\hline \multirow[b]{2}{*}{21} & Feeder Real Load & $\mathrm{kW}$ & 2,643 & 3,727 & 1,653 & 3,822 \\
\hline & $\begin{array}{l}\text { Feeder Reactive } \\
\text { Load } \\
\end{array}$ & kVAR & 218 & 484 & 143 & 546 \\
\hline 29 & Distribution Losses & $\%$ & 0.33 & 1.87 & 0.69 & 3.40 \\
\hline 30 & $\begin{array}{l}\text { Distribution Power } \\
\text { Factor }\end{array}$ & $\mathrm{pf}$ & 0.9969 & 0.9904 & 0.9968 & 0.9897 \\
\hline 39 & $\mathrm{CO} 2$ Emissions & Tons & 16,318 & 23,888 & 10,033 & 25,959 \\
\hline \multirow{3}{*}{40} & SOx Emis sions & Tons & 7.05 & 10.46 & 4.28 & 11.56 \\
\hline & NOx Emis sions & Tons & 4.39 & 6.49 & 2.67 & 7.13 \\
\hline & PM-10 Emissions & Tons & 2.43 & 3.56 & 1.49 & 3.87 \\
\hline
\end{tabular}


Table E.9: TOU without enabling technologies performance metrics for region 4

\begin{tabular}{|c|c|c|c|c|c|c|}
\hline Index & Metric & Units & 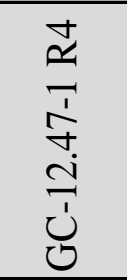 & 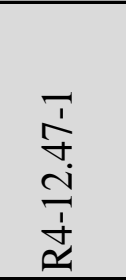 & $\begin{array}{l}\stackrel{1}{f} \\
\stackrel{+}{d} \\
\frac{1}{d}\end{array}$ & $\begin{array}{l}7 \\
8 \\
\text { d } \\
\text { i } \\
\dot{1}\end{array}$ \\
\hline 1 & $\begin{array}{l}\text { Hourly Customer } \\
\text { Electricity Usage }\end{array}$ & $\mathrm{kWh}$ & 2,339 & 1,905 & 828 & 345 \\
\hline 2 & $\begin{array}{l}\text { Monthly Customer } \\
\text { Electricity Usage }\end{array}$ & MWh & 1,708 & 1,391 & 604 & 252 \\
\hline \multirow{10}{*}{3} & Peak Generation & $\mathrm{kW}$ & 6,252 & 4,797 & 2,174 & 941 \\
\hline & Nuclear & $\%$ & 21.91 & 21.91 & 22.45 & 23.58 \\
\hline & Solar & $\%$ & 0.00 & 0.00 & 0.00 & 0.00 \\
\hline & Bio & $\%$ & 0.18 & 0.18 & 0.18 & 0.21 \\
\hline & Wind & $\%$ & 0.60 & 0.60 & 0.64 & 0.59 \\
\hline & Coal & $\%$ & 57.14 & 57.14 & 56.92 & 56.06 \\
\hline & Hydroelectric & $\%$ & 2.20 & 2.20 & 3.32 & 3.01 \\
\hline & Natural Gas & $\%$ & 17.49 & 17.49 & 16.04 & 16.14 \\
\hline & Geothermal & $\%$ & 0.00 & 0.00 & 0.00 & 0.00 \\
\hline & Petroleum & $\%$ & 0.98 & 0.47 & 4.10 & 0.00 \\
\hline 4 & Peak Load & $\mathrm{kW}$ & 6,217 & 4,701 & 2,140 & 924 \\
\hline 7 & $\begin{array}{l}\text { Annual Electricity } \\
\text { Production }\end{array}$ & MWh & 20,549 & 17,160 & 7,425 & 3,104 \\
\hline 12 & $\mathrm{CO} 2$ Emis sions & Tons & 10,322 & 9,820 & 3,964 & 1,594 \\
\hline \multirow{3}{*}{13} & SOx Emis sions & Tons & 4.92 & 4.72 & 1.90 & 0.77 \\
\hline & NOx Emis sions & Tons & 3.00 & 2.86 & 1.16 & 0.47 \\
\hline & PM-10 Emissions & Tons & 1.54 & 1.47 & 0.59 & 0.24 \\
\hline \multirow{2}{*}{21} & Feeder Real Load & $\mathrm{kW}$ & 2,346 & 1,959 & 848 & 354 \\
\hline & Feeder Reactive Load & kVAR & 138 & -413 & 98 & 45 \\
\hline 29 & Dis tribution Losses & $\%$ & 0.28 & 2.76 & 2.32 & 2.54 \\
\hline 30 & $\begin{array}{l}\text { Distribution Power } \\
\text { Factor }\end{array}$ & $\mathrm{pf}$ & 0.9982 & 0.9670 & 0.9933 & 0.9919 \\
\hline 39 & $\mathrm{CO} 2$ Emis sions & Tons & 10,351 & 10,098 & 4,059 & 1,635 \\
\hline \multirow{3}{*}{40} & SOx Emis sions & Tons & 4.93 & 4.85 & 1.95 & 0.79 \\
\hline & NOx Emis sions & Tons & 3.00 & 2.95 & 1.19 & 0.48 \\
\hline & PM-10 Emissions & Tons & 1.54 & 1.51 & 0.61 & 0.24 \\
\hline
\end{tabular}


Table E.10: TOU without enabling technologies performance metrics for region 5

\begin{tabular}{|c|c|c|c|c|c|c|c|c|c|c|}
\hline Index & Metric & Units & 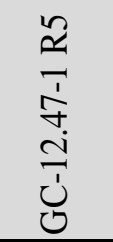 & 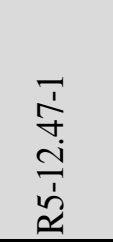 & 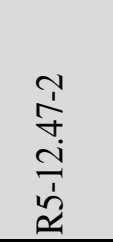 & 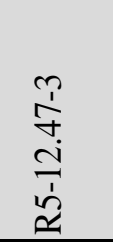 & 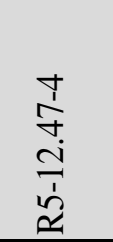 & 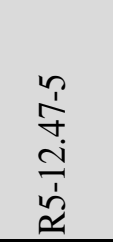 & 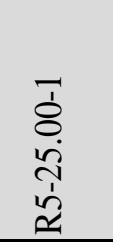 & 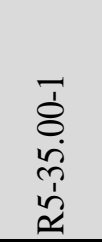 \\
\hline 1 & $\begin{array}{l}\text { Hourly Customer } \\
\text { Electricity Usage } \\
\end{array}$ & $\mathrm{kWh}$ & 2,747 & 4,451 & 2,214 & 4,593 & 3,428 & 4,054 & 5,532 & 5,593 \\
\hline 2 & $\begin{array}{l}\text { Monthly Customer } \\
\text { Electricity Usage } \\
\end{array}$ & MWh & 2,005 & 3,249 & 1,617 & 3,353 & 2,503 & 2,960 & 4,038 & 4,083 \\
\hline \multirow{10}{*}{3} & Peak Generation & $\mathrm{kW}$ & 5,813 & 9,265 & 4,929 & 10,268 & 7,519 & 8,965 & 11,915 & 12,268 \\
\hline & Nuclear & $\%$ & 13.53 & 13.85 & 13.85 & 13.53 & 13.85 & 13.53 & 13.53 & 13.85 \\
\hline & Solar & $\%$ & 0.00 & 0.00 & 0.00 & 0.00 & 0.00 & 0.00 & 0.00 & 0.00 \\
\hline & Bio & $\%$ & 0.31 & 0.33 & 0.33 & 0.31 & 0.33 & 0.31 & 0.31 & 0.33 \\
\hline & Wind & $\%$ & 1.74 & 1.48 & 1.48 & 1.74 & 1.48 & 1.74 & 1.74 & 1.48 \\
\hline & Coal & $\%$ & 30.37 & 30.17 & 30.17 & 30.37 & 30.17 & 30.37 & 30.37 & 30.17 \\
\hline & Hydroelectric & $\%$ & 0.78 & 0.52 & 0.63 & 0.78 & 0.63 & 0.78 & 0.78 & 0.63 \\
\hline & Natural Gas & $\%$ & 51.29 & 51.68 & 51.68 & 51.29 & 51.68 & 51.29 & 51.29 & 51.68 \\
\hline & Geothermal & $\%$ & 0.00 & 0.00 & 0.00 & 0.00 & 0.00 & 0.00 & 0.00 & 0.00 \\
\hline & Petroleum & $\%$ & 3.94 & 0.00 & 0.61 & 0.86 & 1.71 & 1.15 & 0.86 & 0.57 \\
\hline 4 & Peak Load & $\mathrm{kW}$ & 5,782 & 9,133 & 4,785 & 9,656 & 7,361 & 8,709 & 11,721 & 12,110 \\
\hline 7 & $\begin{array}{l}\text { Annual Electricity } \\
\text { Production }\end{array}$ & MWh & 24,144 & 39,454 & 19,795 & 42,070 & 30,619 & 36,360 & 49,138 & 49,633 \\
\hline 12 & $\mathrm{CO} 2$ Emis sions & Tons & 9,365 & 15,035 & 7,309 & 14,541 & 11,434 & 13,035 & 17,647 & 18,050 \\
\hline \multirow{3}{*}{13} & SOx Emis sions & Tons & 1.55 & 2.04 & 1.06 & 1.35 & 1.52 & 1.40 & 1.79 & 1.94 \\
\hline & NOx Emis sions & Tons & 1.38 & 2.00 & 1.01 & 1.64 & 1.50 & 1.56 & 2.07 & 2.17 \\
\hline & PM-10 Emis sions & Tons & 1.37 & 2.21 & 1.07 & 2.13 & 1.68 & 1.91 & 2.58 & 2.64 \\
\hline \multirow{2}{*}{21} & Feeder Real Load & $\mathrm{kW}$ & 2,756 & 4,504 & 2,260 & 4,802 & 3,495 & 4,151 & 5,609 & 5,666 \\
\hline & Feeder Reactive Load & kVAR & 248 & 533 & 239 & -386 & 397 & 577 & 630 & 622 \\
\hline 29 & Distribution Losses & $\%$ & 0.33 & 1.19 & 2.00 & 4.37 & 1.92 & 2.32 & 1.39 & 1.28 \\
\hline 30 & $\begin{array}{l}\text { Distribution Power } \\
\text { Factor }\end{array}$ & $\mathrm{pf}$ & 0.9964 & 0.9938 & 0.9952 & 0.9778 & 0.9943 & 0.9915 & 0.9943 & 0.9945 \\
\hline 39 & $\mathrm{CO} 2$ Emis sions & Tons & 9,396 & 15,215 & 7,458 & 15,205 & 11,657 & 13,345 & 17,896 & 18,285 \\
\hline \multirow{3}{*}{40} & SOx Emis sions & Tons & 1.56 & 2.06 & 1.09 & 1.41 & 1.54 & 1.43 & 1.81 & 1.97 \\
\hline & NOx Emis sions & Tons & 1.39 & 2.02 & 1.03 & 1.72 & 1.53 & 1.60 & 2.10 & 2.20 \\
\hline & PM-10 Emis sions & Tons & 1.38 & 2.23 & 1.09 & 2.23 & 1.71 & 1.95 & 2.62 & 2.68 \\
\hline
\end{tabular}


Table E.11: TOU with enabling technologies performance metrics for region 1

\begin{tabular}{|c|c|c|c|c|c|c|c|c|}
\hline Index & Metric & Units & 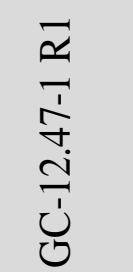 & 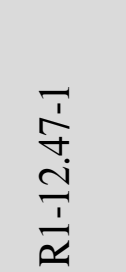 & 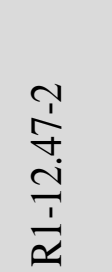 & $\begin{array}{l}\stackrel{1}{+} \\
\stackrel{+}{ \pm} \\
\stackrel{1}{a}\end{array}$ & 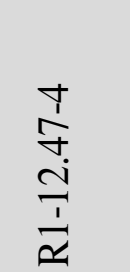 & $\begin{array}{l}\overline{1} \\
\delta \\
\dot{\sigma} \\
\stackrel{1}{a}\end{array}$ \\
\hline 1 & $\begin{array}{l}\text { Hourly Customer } \\
\text { Electricity Usage }\end{array}$ & $\mathrm{kWh}$ & 2,070 & 2,677 & 986 & 432 & 1,939 & 868 \\
\hline 2 & $\begin{array}{l}\text { Monthly Customer } \\
\text { Electricity Usage } \\
\end{array}$ & MWh & 1,511 & 1,954 & 719 & 315 & 1,416 & 634 \\
\hline \multirow{10}{*}{3} & Peak Generation & $\mathrm{kW}$ & 5,265 & 7,144 & 2,642 & 1,223 & 5,004 & 2,242 \\
\hline & Nuclear & $\%$ & 10.68 & 10.09 & 10.68 & 10.09 & 10.68 & 10.68 \\
\hline & Solar & $\%$ & 0.25 & 0.21 & 0.25 & 0.21 & 0.25 & 0.25 \\
\hline & Bio & $\%$ & 0.67 & 0.72 & 0.67 & 0.72 & 0.67 & 0.67 \\
\hline & Wind & $\%$ & 4.07 & 3.55 & 4.07 & 3.55 & 4.07 & 4.07 \\
\hline & Coal & $\%$ & 2.88 & 4.38 & 2.88 & 4.38 & 2.88 & 2.80 \\
\hline & Hydroelectric & $\%$ & 36.88 & 26.32 & 36.88 & 26.32 & 36.88 & 36.88 \\
\hline & Natural Gas & $\%$ & 41.38 & 51.24 & 41.38 & 51.24 & 41.38 & 41.38 \\
\hline & Geothermal & $\%$ & 2.29 & 3.11 & 1.98 & 3.11 & 2.30 & 0.00 \\
\hline & Petroleum & $\%$ & 0.00 & 1.57 & 0.00 & 1.50 & 0.00 & 0.00 \\
\hline 4 & Peak Load & $\mathrm{kW}$ & 5,240 & 6,900 & 2,558 & 1,209 & 4,878 & 2,186 \\
\hline 7 & $\begin{array}{l}\text { Annual Electricity } \\
\text { Production }\end{array}$ & MWh & 18,178 & 24,056 & 8,905 & 3,806 & 17,194 & 7,715 \\
\hline 12 & $\mathrm{CO} 2$ Emissions & Tons & 1,725 & 2,184 & 782 & 379 & 1,698 & 717 \\
\hline \multirow{3}{*}{13} & SOx Emis sions & Tons & 0.02 & 0.02 & 0.01 & 0.01 & 0.02 & 0.01 \\
\hline & NOx Emis sions & Tons & 0.23 & 0.27 & 0.10 & 0.05 & 0.21 & 0.10 \\
\hline & PM-10 Emis sions & Tons & 0.24 & 0.31 & 0.11 & 0.05 & 0.24 & 0.10 \\
\hline \multirow[b]{2}{*}{21} & Feeder Real Load & $\mathrm{kW}$ & 2,075 & 2,746 & 1,017 & 434 & 1,963 & 881 \\
\hline & $\begin{array}{l}\text { Feeder Reactive } \\
\text { Load } \\
\end{array}$ & kVAR & 64 & -279 & -198 & 10 & 63 & -72 \\
\hline 29 & Distribution Losses & $\%$ & 0.23 & 2.53 & 3.05 & 0.55 & 1.19 & 1.42 \\
\hline 30 & $\begin{array}{l}\text { Distribution Power } \\
\text { Factor }\end{array}$ & $\mathrm{pf}$ & 0.9995 & 0.9929 & 0.9687 & 0.9997 & 0.9994 & 0.9666 \\
\hline 39 & $\mathrm{CO} 2$ Emis sions & Tons & 1,729 & 2,241 & 806 & 381 & 1,719 & 728 \\
\hline \multirow{3}{*}{40} & SOx Emis sions & Tons & 0.02 & 0.02 & 0.01 & 0.01 & 0.02 & 0.01 \\
\hline & NOx Emis sions & Tons & 0.23 & 0.28 & 0.10 & 0.05 & 0.21 & 0.10 \\
\hline & PM-10 Emissions & Tons & 0.24 & 0.32 & 0.11 & 0.05 & 0.24 & 0.10 \\
\hline
\end{tabular}


Table E.12: TOU with enabling technologies performance metrics for region 2

\begin{tabular}{|c|c|c|c|c|c|c|c|c|}
\hline Index & Metric & Units & 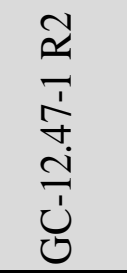 & 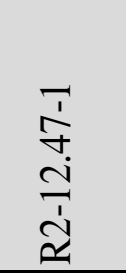 & 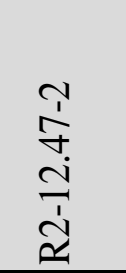 & 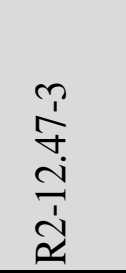 & 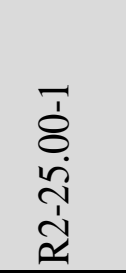 & $\begin{array}{l}\bar{\delta} \\
\delta \\
\ddot{1} \\
\tilde{1} \\
\tilde{d}\end{array}$ \\
\hline 1 & $\begin{array}{l}\text { Hourly Customer } \\
\text { Electricity Usage }\end{array}$ & $\mathrm{kWh}$ & 2,165 & 2,268 & 1,982 & 2,989 & 6,340 & 4,571 \\
\hline 2 & $\begin{array}{l}\text { Monthly Customer } \\
\text { Electricity Usage } \\
\end{array}$ & $\mathrm{MWh}$ & 1,580 & 1,656 & 1,447 & 2,182 & 4,628 & 3,336 \\
\hline \multirow{10}{*}{3} & Peak Generation & $\mathrm{kW}$ & 6,345 & 6,189 & 6,246 & 9,495 & 18,180 & 12,461 \\
\hline & Nuclear & $\%$ & 26.33 & 26.33 & 26.33 & 26.33 & 26.33 & 26.33 \\
\hline & Solar & $\%$ & 0.01 & 0.01 & 0.01 & 0.01 & 0.01 & 0.01 \\
\hline & Bio & $\%$ & 0.82 & 0.82 & 0.82 & 0.82 & 0.82 & 0.82 \\
\hline & Wind & $\%$ & 1.41 & 1.41 & 1.41 & 1.41 & 1.41 & 1.41 \\
\hline & Coal & $\%$ & 47.18 & 47.18 & 47.18 & 47.18 & 47.18 & 47.18 \\
\hline & Hydroelectric & $\%$ & 7.42 & 6.37 & 7.42 & 7.42 & 7.42 & 6.23 \\
\hline & Natural Gas & $\%$ & 16.33 & 16.33 & 16.33 & 16.33 & 16.33 & 16.33 \\
\hline & Geothermal & $\%$ & 0.07 & 0.00 & 0.07 & 0.07 & 0.07 & 0.00 \\
\hline & Petroleum & $\%$ & 10.80 & 0.00 & 8.55 & 11.70 & 8.38 & 0.00 \\
\hline 4 & Peak Load & $\mathrm{kW}$ & 6,316 & 6,068 & 6,116 & 9,301 & 17,962 & 12,319 \\
\hline 7 & $\begin{array}{l}\text { Annual Electricity } \\
\text { Production }\end{array}$ & $\mathrm{MWh}$ & 19,012 & 20,127 & 17,690 & 26,814 & 56,076 & 40,368 \\
\hline 12 & $\mathrm{CO} 2$ Emis sions & Tons & 8,387 & 9,251 & 8,522 & 12,756 & 26,864 & 17,415 \\
\hline \multirow{3}{*}{13} & SOx Emis sions & Tons & 3.80 & 4.21 & 3.94 & 5.90 & 12.34 & 7.86 \\
\hline & NOx Emis sions & Tons & 2.42 & 2.68 & 2.49 & 3.73 & 7.82 & 5.02 \\
\hline & PM-10 Emis sions & Tons & 1.24 & 1.37 & 1.26 & 1.89 & 3.98 & 2.58 \\
\hline \multirow[b]{2}{*}{21} & Feeder Real Load & $\mathrm{kW}$ & 2,170 & 2,298 & 2,019 & 3,061 & 6,401 & 4,608 \\
\hline & \begin{tabular}{|l|} 
Feeder Reactive \\
Load \\
\end{tabular} & kVAR & 91 & 117 & 151 & -121 & 335 & 69 \\
\hline 29 & Distribution Losses & $\%$ & 0.24 & 1.27 & 1.87 & 2.35 & 0.95 & 0.82 \\
\hline 30 & $\begin{array}{l}\text { Distribution Power } \\
\text { Factor }\end{array}$ & $\mathrm{pf}$ & 0.9989 & 0.9987 & 0.9971 & 0.9976 & 0.9986 & 0.9996 \\
\hline 39 & $\mathrm{CO} 2$ Emissions & Tons & 8,408 & 9,370 & 8,684 & 13,063 & 27,123 & 17,558 \\
\hline \multirow{3}{*}{40} & SOx Emis sions & Tons & 3.81 & 4.27 & 4.01 & 6.04 & 12.46 & 7.93 \\
\hline & NOx Emis sions & Tons & 2.43 & 2.71 & 2.54 & 3.82 & 7.89 & 5.06 \\
\hline & PM-10 Emissions & Tons & 1.25 & 1.39 & 1.29 & 1.94 & 4.02 & 2.60 \\
\hline
\end{tabular}


Table E.13: TOU with enabling technologies performance metrics for region 3

\begin{tabular}{|c|c|c|c|c|c|c|}
\hline Index & Metric & Units & 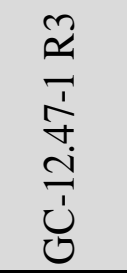 & 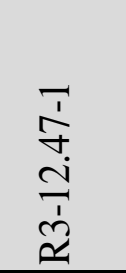 & 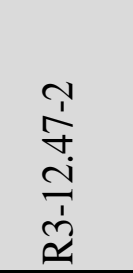 & 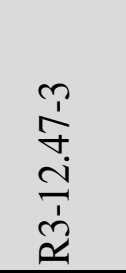 \\
\hline 1 & $\begin{array}{l}\text { Hourly Customer } \\
\text { Electricity Usage }\end{array}$ & $\mathrm{kWh}$ & 2,625 & 3,664 & 1,636 & 3,726 \\
\hline 2 & $\begin{array}{l}\text { Monthly Customer } \\
\text { Electricity Usage }\end{array}$ & MWh & 1,916 & 2,675 & 1,195 & 2,720 \\
\hline \multirow{10}{*}{3} & Peak Generation & $\mathrm{kW}$ & 6,700 & 9,198 & 4,333 & 8,285 \\
\hline & Nuclear & $\%$ & 8.65 & 9.72 & 9.72 & 9.72 \\
\hline & Solar & $\%$ & 0.13 & 0.13 & 0.13 & 0.13 \\
\hline & Bio & $\%$ & 0.23 & 0.25 & 0.25 & 0.25 \\
\hline & Wind & $\%$ & 2.05 & 2.45 & 2.45 & 2.45 \\
\hline & Coal & $\%$ & 40.24 & 41.52 & 41.52 & 41.52 \\
\hline & Hydroelectric & $\%$ & 5.58 & 6.40 & 6.06 & 6.40 \\
\hline & Natural Gas & $\%$ & 41.67 & 37.88 & 37.88 & 37.88 \\
\hline & Geothermal & $\%$ & 1.25 & 0.39 & 0.00 & 0.08 \\
\hline & Petroleum & $\%$ & 1.81 & 0.00 & 0.00 & 0.00 \\
\hline 4 & Peak Load & $\mathrm{kW}$ & 6,661 & 9,004 & 4,276 & 8,024 \\
\hline 7 & $\begin{array}{l}\text { Annual Electricity } \\
\text { Production }\end{array}$ & MWh & 23,071 & 32,707 & 14,433 & 33,786 \\
\hline 12 & $\mathrm{CO} 2$ Emis sions & Tons & 16,252 & 23,553 & 9,955 & 25,305 \\
\hline \multirow{3}{*}{13} & SOx Emis sions & Tons & 7.05 & 10.34 & 4.26 & 11.24 \\
\hline & NOx Emis sions & Tons & 4.39 & 6.41 & 2.66 & 6.93 \\
\hline & PM-10 Emis sions & Tons & 2.42 & 3.51 & 1.48 & 3.77 \\
\hline \multirow[b]{2}{*}{21} & Feeder Real Load & $\mathrm{kW}$ & 2,634 & 3,734 & 1,648 & 3,857 \\
\hline & \begin{tabular}{|l|} 
Feeder Reactive \\
Load \\
\end{tabular} & kVAR & 216 & 486 & 141 & 558 \\
\hline 29 & Dis tribution Losses & $\%$ & 0.32 & 1.87 & 0.69 & 3.39 \\
\hline 30 & $\begin{array}{l}\text { Distribution Power } \\
\text { Factor }\end{array}$ & $\mathrm{pf}$ & 0.9969 & 0.9904 & 0.9969 & 0.9896 \\
\hline 39 & $\mathrm{CO} 2$ Emissions & Tons & 16,305 & 24,001 & 10,024 & 26,194 \\
\hline \multirow{3}{*}{40} & SOx Emis sions & Tons & 7.07 & 10.54 & 4.29 & 11.64 \\
\hline & NOx Emis sions & Tons & 4.40 & 6.53 & 2.68 & 7.18 \\
\hline & PM-10 Emissions & Tons & 2.43 & 3.58 & 1.49 & 3.90 \\
\hline
\end{tabular}


Table E.14: TOU with enabling technologies performance metrics for region 4

\begin{tabular}{|c|c|c|c|c|c|c|}
\hline Index & Metric & Units & 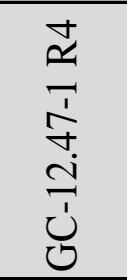 & 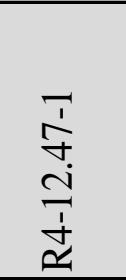 & $\begin{array}{l}\stackrel{1}{f} \\
\stackrel{+}{d} \\
\frac{1}{d}\end{array}$ & $\begin{array}{l}7 \\
8 \\
\text { d } \\
\text { i } \\
\dot{1}\end{array}$ \\
\hline 1 & $\begin{array}{l}\text { Hourly Customer } \\
\text { Electricity Usage }\end{array}$ & $\mathrm{kWh}$ & 2,326 & 1,913 & 836 & 349 \\
\hline 2 & $\begin{array}{l}\text { Monthly Customer } \\
\text { Electricity Usage }\end{array}$ & MWh & 1,698 & 1,396 & 610 & 255 \\
\hline \multirow{10}{*}{3} & Peak Generation & $\mathrm{kW}$ & 6,078 & 5,228 & 2,405 & 1,103 \\
\hline & Nuclear & $\%$ & 21.91 & 21.91 & 22.45 & 23.15 \\
\hline & Solar & $\%$ & 0.00 & 0.00 & 0.00 & 0.00 \\
\hline & Bio & $\%$ & 0.18 & 0.18 & 0.18 & 0.18 \\
\hline & Wind & $\%$ & 0.60 & 0.60 & 0.64 & 0.53 \\
\hline & Coal & $\%$ & 57.14 & 57.14 & 56.92 & 56.89 \\
\hline & Hydroelectric & $\%$ & 0.38 & 2.20 & 3.32 & 2.05 \\
\hline & Natural Gas & $\%$ & 17.49 & 17.49 & 16.04 & 16.75 \\
\hline & Geothermal & $\%$ & 0.00 & 0.00 & 0.00 & 0.00 \\
\hline & Petroleum & $\%$ & 0.00 & 9.45 & 15.08 & 35.30 \\
\hline 4 & Peak Load & $\mathrm{kW}$ & 6,043 & 5,131 & 2,371 & 1,086 \\
\hline 7 & $\begin{array}{l}\text { Annual Electricity } \\
\text { Production }\end{array}$ & MWh & 20,436 & 17,231 & 7,497 & 3,138 \\
\hline 12 & $\mathrm{CO} 2$ Emis sions & Tons & 10,224 & 9,898 & 4,037 & 1,628 \\
\hline \multirow{3}{*}{13} & SOx Emis sions & Tons & 4.88 & 4.75 & 1.94 & 0.78 \\
\hline & NOx Emis sions & Tons & 2.97 & 2.89 & 1.18 & 0.48 \\
\hline & PM-10 Emissions & Tons & 1.53 & 1.48 & 0.60 & 0.24 \\
\hline \multirow{2}{*}{21} & Feeder Real Load & $\mathrm{kW}$ & 2,333 & 1,967 & 856 & 358 \\
\hline & Feeder Reactive Load & kVAR & 135 & -410 & 101 & 46 \\
\hline 29 & Dis tribution Losses & $\%$ & 0.28 & 2.75 & 2.31 & 2.52 \\
\hline 30 & $\begin{array}{l}\text { Distribution Power } \\
\text { Factor }\end{array}$ & $\mathrm{pf}$ & 0.9982 & 0.9676 & 0.9932 & 0.9917 \\
\hline 39 & $\mathrm{CO} 2$ Emis sions & Tons & 10,252 & 10,177 & 4,132 & 1,670 \\
\hline \multirow{3}{*}{40} & SOx Emis sions & Tons & 4.89 & 4.89 & 1.98 & 0.80 \\
\hline & NOx Emis sions & Tons & 2.98 & 2.97 & 1.21 & 0.49 \\
\hline & PM-10 Emissions & Tons & 1.53 & 1.52 & 0.62 & 0.25 \\
\hline
\end{tabular}


Table E.15: TOU with enabling technologies performance metrics for region 5

\begin{tabular}{|c|c|c|c|c|c|c|c|c|c|c|}
\hline Index & Metric & Units & 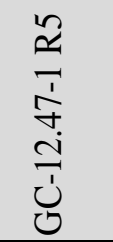 & 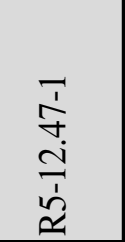 & 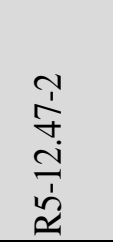 & 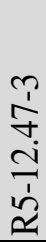 & 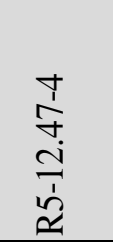 & 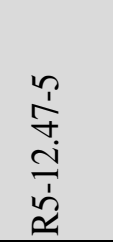 & 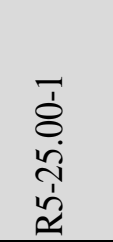 & 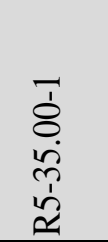 \\
\hline 1 & $\begin{array}{l}\text { Hourly Customer } \\
\text { Electricity Usage }\end{array}$ & $\mathrm{kWh}$ & 2,734 & 4,489 & 2,216 & - & 3,458 & 4,111 & 5,612 & 5,678 \\
\hline 2 & $\begin{array}{l}\text { Monthly Customer } \\
\text { Electricity Usage }\end{array}$ & MWh & 1,996 & 3,277 & 1,617 & - & 2,524 & 3,001 & 4,097 & 4,145 \\
\hline \multirow{10}{*}{3} & Peak Generation & $\mathrm{kW}$ & 6,359 & 9,456 & 4,928 & - & 8,370 & 10,456 & 14,917 & 14,617 \\
\hline & Nuclear & $\%$ & 13.53 & 12.70 & 13.85 & - & 12.70 & 12.70 & 12.70 & 12.7 \\
\hline & Solar & $\%$ & 0.00 & 0.00 & 0.00 & - & 0.00 & 0.00 & 0.00 & 0.00 \\
\hline & Bio & $\%$ & 0.31 & 0.39 & 0.33 & - & 0.39 & 0.39 & 0.39 & 0.39 \\
\hline & Wind & $\%$ & 1.74 & 2.52 & 1.48 & - & 2.52 & 2.52 & 2.52 & 2.52 \\
\hline & Coal & $\%$ & 30.37 & 33.46 & 30.17 & - & 33.46 & 33.46 & 33.46 & 33.46 \\
\hline & Hydroelectric & $\%$ & 0.78 & 1.75 & 0.63 & - & 1.75 & 1.75 & 1.75 & 1.75 \\
\hline & Natural Gas & $\%$ & 51.29 & 47.55 & 51.68 & - & 47.55 & 47.55 & 47.55 & 47.55 \\
\hline & Geothermal & $\%$ & 0.00 & 0.00 & 0.00 & - & 0.00 & 0.00 & 0.00 & 0.00 \\
\hline & Petroleum & $\%$ & 13.51 & 12.25 & 0.58 & - & 25.57 & 30.45 & 38.23 & 36.69 \\
\hline 4 & Peak Load & $\mathrm{kW}$ & 6,328 & 9,324 & 4,784 & - & 8,212 & 10,199 & 14,723 & 14,459 \\
\hline 7 & $\begin{array}{l}\text { Annual Electricity } \\
\text { Production }\end{array}$ & MWh & 24,025 & 39,792 & 19,802 & - & 30,882 & 36,870 & 49,852 & 50,381 \\
\hline 12 & $\mathrm{CO} 2$ Emis sions & Tons & 9,202 & 15,147 & 7,218 & - & 11,505 & 13,325 & 18,098 & 18,492 \\
\hline \multirow{3}{*}{13} & SOx Emissions & Tons & 1.46 & 2.00 & 0.98 & - & 1.47 & 1.44 & 1.87 & 2.01 \\
\hline & NOx Emis sions & Tons & 1.33 & 1.98 & 0.97 & - & 1.48 & 1.59 & 2.12 & 2.21 \\
\hline & PM-10 Emis sions & Tons & 1.35 & 2.22 & 1.06 & - & 1.68 & 1.93 & 2.62 & 2.68 \\
\hline \multirow[b]{2}{*}{21} & Feeder Real Load & $\mathrm{kW}$ & 2,743 & 4,542 & 2,261 & - & 3,525 & 4,209 & 5,691 & 5,751 \\
\hline & \begin{tabular}{|l} 
Feeder Reactive \\
Load
\end{tabular} & kVAR & 244 & 545 & 239 & - & 407 & 599 & 657 & 649 \\
\hline 29 & Distribution Losses & $\%$ & 0.33 & 1.18 & 1.99 & - & 1.91 & 2.33 & 1.39 & 1.28 \\
\hline 30 & $\begin{array}{l}\text { Distribution Power } \\
\text { Factor }\end{array}$ & $\mathrm{pf}$ & 0.9965 & 0.9935 & 0.9951 & - & 0.9941 & 0.9911 & 0.9940 & 0.9942 \\
\hline 39 & $\mathrm{CO} 2$ Emis sions & Tons & 9,232 & 15,328 & 7,365 & - & 11,728 & 13,643 & 18,354 & 18,732 \\
\hline \multirow{3}{*}{40} & SOx Emis sions & Tons & 1.46 & 2.02 & 1.00 & - & 1.50 & 1.47 & 1.90 & 2.04 \\
\hline & NOx Emis sions & Tons & 1.33 & 2.01 & 0.99 & - & 1.51 & 1.63 & 2.15 & 2.23 \\
\hline & PM-10 Emis sions & Tons & 1.35 & 2.25 & 1.08 & - & 1.71 & 1.98 & 2.65 & 2.71 \\
\hline
\end{tabular}


Table E.16: TOU/CPP without enabling technologies performance metrics for region 1

\begin{tabular}{|c|c|c|c|c|c|c|c|c|}
\hline Index & Metric & Units & 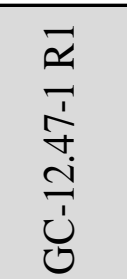 & $\begin{array}{l}\overline{1} \\
\stackrel{+}{+} \\
\stackrel{1}{a} \\
\stackrel{1}{a}\end{array}$ & 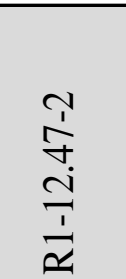 & 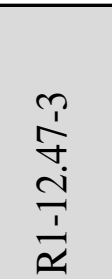 & 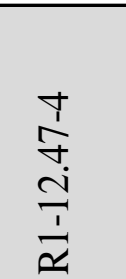 & 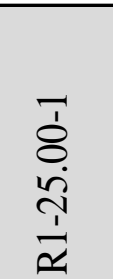 \\
\hline 1 & $\begin{array}{l}\text { Hourly Customer } \\
\text { Electricity Usage }\end{array}$ & $\mathrm{kWh}$ & 2,083 & 2,689 & 991 & 435 & 1,948 & 875 \\
\hline 2 & \begin{tabular}{|l|} 
Monthly Customer \\
Electricity Usage
\end{tabular} & MWh & 1,521 & 1,963 & 724 & 317 & 1,422 & 639 \\
\hline \multirow{10}{*}{3} & Peak Generation & $\mathrm{kW}$ & 5,414 & 6,814 & 2,523 & 1,204 & 4,807 & 2,280 \\
\hline & Nuclear & $\%$ & 10.68 & 10.68 & 10.68 & 10.68 & 10.68 & 10.68 \\
\hline & \begin{tabular}{|l} 
Solar \\
\end{tabular} & $\%$ & 0.25 & 0.25 & 0.25 & 0.25 & 0.25 & 0.25 \\
\hline & Bio & $\%$ & 0.67 & 0.67 & 0.67 & 0.67 & 0.67 & 0.67 \\
\hline & Wind & $\%$ & 4.07 & 4.07 & 4.07 & 4.07 & 4.07 & 4.07 \\
\hline & Coal & $\%$ & 2.88 & 0.00 & 0.39 & 1.53 & 1.26 & 2.88 \\
\hline & Hydroelectric & $\%$ & 36.88 & 36.88 & 36.88 & 36.88 & 36.88 & 36.88 \\
\hline & Natural Gas & $\%$ & 41.38 & 40.43 & 41.38 & 41.38 & 41.38 & 41.38 \\
\hline & Geothermal & $\%$ & 2.84 & 0.00 & 0.00 & 0.00 & 0.00 & 1.59 \\
\hline & Petroleum & $\%$ & 2.26 & 0.00 & 0.00 & 0.00 & 0.00 & 0.00 \\
\hline 4 & Peak Load & $\mathrm{kW}$ & 5,389 & 6,570 & 2,438 & 1,190 & 4,680 & 2,224 \\
\hline 7 & $\begin{array}{l}\text { Annual Electricity } \\
\text { Production }\end{array}$ & MWh & 18,293 & 24,170 & 8,957 & 3,831 & 17,270 & 7,778 \\
\hline 12 & $\mathrm{CO} 2$ Emissions & Tons & 1,784 & 2,234 & 802 & 392 & 1,745 & 750 \\
\hline \multirow{3}{*}{13} & SOx Emis sions & Tons & 0.03 & 0.03 & 0.01 & 0.01 & 0.03 & 0.01 \\
\hline & NOx Emis sions & Tons & 0.24 & 0.28 & 0.10 & 0.05 & 0.22 & 0.10 \\
\hline & PM-10 Emissions & Tons & 0.25 & 0.32 & 0.11 & 0.06 & 0.25 & 0.11 \\
\hline \multirow[b]{2}{*}{21} & Feeder Real Load & $\mathrm{kW}$ & 2,088 & 2,759 & 1,022 & 437 & 1,971 & 888 \\
\hline & \begin{tabular}{|l|} 
Feeder Reactive \\
Load \\
\end{tabular} & kVAR & 68 & -280 & -198 & 11 & 64 & -70 \\
\hline 29 & Distribution Losses & $\%$ & 0.23 & 2.53 & 3.05 & 0.56 & 1.20 & 1.44 \\
\hline 30 & \begin{tabular}{|l} 
Distribution Power \\
Factor
\end{tabular} & $\mathrm{pf}$ & 0.9994 & 0.9929 & 0.9688 & 0.9997 & 0.9994 & 0.9667 \\
\hline 39 & $\mathrm{CO} 2$ Emis sions & Tons & 1,788 & 2,292 & 828 & 394 & 1,766 & 761 \\
\hline \multirow{3}{*}{40} & SOx Emis sions & Tons & 0.03 & 0.03 & 0.01 & 0.01 & 0.03 & 0.01 \\
\hline & NOx Emis sions & Tons & 0.24 & 0.29 & 0.10 & 0.05 & 0.22 & 0.10 \\
\hline & PM-10 Emissions & Tons & 0.25 & 0.33 & 0.12 & 0.06 & 0.25 & 0.11 \\
\hline
\end{tabular}


Table E.17: TOU/CPP without enabling technologies performance metrics for region 2

\begin{tabular}{|c|c|c|c|c|c|c|c|c|}
\hline Index & Metric & Units & 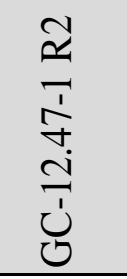 & 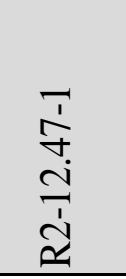 & 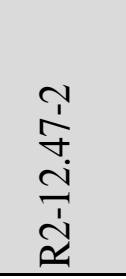 & 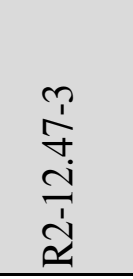 & 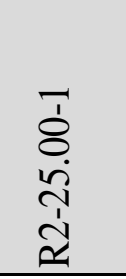 & $\begin{array}{l}7 \\
8 \\
\ddot{8} \\
\ddot{1} \\
\tilde{d}\end{array}$ \\
\hline 1 & $\begin{array}{l}\text { Hourly Customer } \\
\text { Electricity Usage }\end{array}$ & $\mathrm{kWh}$ & 2,169 & 2,269 & 1,976 & 2,982 & 6,342 & 4,578 \\
\hline 2 & $\begin{array}{l}\text { Monthly Customer } \\
\text { Electricity Usage } \\
\end{array}$ & $\mathrm{MWh}$ & 1,584 & 1,656 & 1,442 & 2,177 & 4,630 & 3,342 \\
\hline \multirow{10}{*}{3} & Peak Generation & $\mathrm{kW}$ & 5,732 & 6,274 & 5,606 & 8,246 & 16,673 & 12,528 \\
\hline & Nuclear & $\%$ & 26.33 & 26.33 & 27.95 & 26.33 & 26.33 & 26.33 \\
\hline & Solar & $\%$ & 0.01 & 0.01 & 0.01 & 0.01 & 0.01 & 0.01 \\
\hline & Bio & $\%$ & 0.82 & 0.82 & 0.84 & 0.82 & 0.82 & 0.82 \\
\hline & Wind & $\%$ & 1.41 & 1.41 & 1.70 & 1.41 & 1.41 & 1.41 \\
\hline & Coal & $\%$ & 47.18 & 47.18 & 45.54 & 47.18 & 47.18 & 47.18 \\
\hline & Hydroelectric & $\%$ & 7.42 & 7.42 & 9.05 & 4.56 & 6.92 & 6.76 \\
\hline & Natural Gas & $\%$ & 16.33 & 16.33 & 14.47 & 16.33 & 16.33 & 16.33 \\
\hline & Geothermal & $\%$ & 0.07 & 0.07 & 0.07 & 0.00 & 0.00 & 0.00 \\
\hline & Petroleum & $\%$ & 0.13 & 0.22 & 2.34 & 0.00 & 0.00 & 0.00 \\
\hline 4 & Peak Load & $\mathrm{kW}$ & 5,703 & 6,153 & 5,476 & 8,052 & 16,455 & 12,386 \\
\hline 7 & $\begin{array}{l}\text { Annual Electricity } \\
\text { Production }\end{array}$ & $\mathrm{MWh}$ & 19,050 & 20,134 & 17,635 & 26,751 & 56,090 & 40,433 \\
\hline 12 & $\mathrm{CO} 2$ Emis sions & Tons & 8,419 & 9,249 & 8,464 & 12,686 & 26,880 & 17,446 \\
\hline \multirow{3}{*}{13} & SOx Emis sions & Tons & 3.81 & 4.21 & 3.91 & 5.86 & 12.35 & 7.87 \\
\hline & NOx Emis sions & Tons & 2.43 & 2.67 & 2.48 & 3.71 & 7.82 & 5.02 \\
\hline & PM-10 Emis sions & Tons & 1.25 & 1.37 & 1.26 & 1.88 & 3.99 & 2.59 \\
\hline \multirow[b]{2}{*}{21} & Feeder Real Load & $\mathrm{kW}$ & 2,175 & 2,298 & 2,013 & 3,054 & 6,403 & 4,616 \\
\hline & \begin{tabular}{|l} 
Feeder Reactive \\
Load \\
\end{tabular} & kVAR & 92 & 117 & 148 & -128 & 335 & 71 \\
\hline 29 & Distribution Losses & $\%$ & 0.25 & 1.27 & 1.86 & 2.35 & 0.95 & 0.82 \\
\hline 30 & $\begin{array}{l}\text { Distribution Power } \\
\text { Factor }\end{array}$ & $\mathrm{pf}$ & 0.9989 & 0.9987 & 0.9972 & 0.9976 & 0.9986 & 0.9996 \\
\hline 39 & $\mathrm{CO} 2$ Emissions & Tons & 8,440 & 9,368 & 8,624 & 12,991 & 27,139 & 17,590 \\
\hline \multirow{3}{*}{40} & SOx Emis sions & Tons & 3.82 & 4.26 & 3.98 & 6.00 & 12.47 & 7.93 \\
\hline & NOx Emis sions & Tons & 2.44 & 2.71 & 2.52 & 3.80 & 7.89 & 5.06 \\
\hline & PM-10 Emis sions & Tons & 1.25 & 1.39 & 1.28 & 1.93 & 4.03 & 2.61 \\
\hline
\end{tabular}


Table E.18: TOU/CPP without enabling technologies performance metrics for region 3

\begin{tabular}{|c|c|c|c|c|c|c|}
\hline Index & Metric & Units & 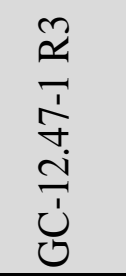 & 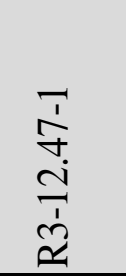 & 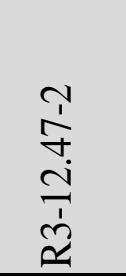 & 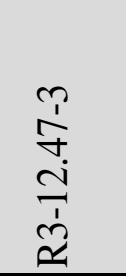 \\
\hline 1 & $\begin{array}{l}\text { Hourly Customer } \\
\text { Electricity Usage }\end{array}$ & $\mathrm{kWh}$ & 2,634 & 3,658 & 1,642 & 3,694 \\
\hline 2 & $\begin{array}{l}\text { Monthly Customer } \\
\text { Electricity Usage } \\
\end{array}$ & $\mathrm{MWh}$ & 1,923 & 2,670 & 1,199 & 2,697 \\
\hline \multirow{10}{*}{3} & Peak Generation & $\mathrm{kW}$ & 6,682 & 9,166 & 4,381 & 8,420 \\
\hline & Nuclear & $\%$ & 9.72 & 9.72 & 9.72 & 9.72 \\
\hline & Solar & $\%$ & 0.13 & 0.13 & 0.13 & 0.13 \\
\hline & Bio & $\%$ & 0.25 & 0.25 & 0.25 & 0.25 \\
\hline & Wind & $\%$ & 2.45 & 2.45 & 2.45 & 2.45 \\
\hline & Coal & $\%$ & 41.52 & 41.52 & 41.52 & 41.52 \\
\hline & Hydroelectric & $\%$ & 6.40 & 6.40 & 6.40 & 6.40 \\
\hline & Natural Gas & $\%$ & 37.88 & 37.88 & 37.88 & 37.88 \\
\hline & Geothermal & $\%$ & 1.40 & 0.05 & 0.74 & 1.40 \\
\hline & Petroleum & $\%$ & 1.68 & 0.00 & 0.00 & 0.29 \\
\hline 4 & Peak Load & $\mathrm{kW}$ & 6,643 & 8,972 & 4,324 & 8,160 \\
\hline 7 & $\begin{array}{l}\text { Annual Electricity } \\
\text { Production }\end{array}$ & $\mathrm{MWh}$ & 23,149 & 32,652 & 14,484 & 33,503 \\
\hline 12 & $\mathrm{CO} 2$ Emissions & Tons & 16,265 & 23,448 & 9,963 & 25,097 \\
\hline \multirow{3}{*}{13} & SOx Emis sions & Tons & 7.03 & 10.27 & 4.25 & 11.17 \\
\hline & NOx Emis sions & Tons & 4.38 & 6.37 & 2.66 & 6.89 \\
\hline & PM-10 Emis sions & Tons & 2.42 & 3.49 & 1.48 & 3.74 \\
\hline \multirow[b]{2}{*}{21} & Feeder Real Load & $\mathrm{kW}$ & 2,643 & 3,727 & 1,653 & 3,825 \\
\hline & $\begin{array}{l}\text { Feeder Reactive } \\
\text { Load }\end{array}$ & $\mathrm{kVAR}$ & 218 & 484 & 143 & 546 \\
\hline 29 & Distribution Losses & $\%$ & 0.33 & 1.87 & 0.69 & 3.40 \\
\hline 30 & $\begin{array}{l}\text { Distribution Power } \\
\text { Factor }\end{array}$ & $\mathrm{pf}$ & 0.9969 & 0.9904 & 0.9968 & 0.9897 \\
\hline 39 & $\mathrm{CO} 2$ Emis sions & Tons & 16,318 & 23,895 & 10,033 & 25,981 \\
\hline \multirow{3}{*}{40} & SOx Emis sions & Tons & 7.05 & 10.47 & 4.28 & 11.56 \\
\hline & NOx Emis sions & Tons & 4.39 & 6.49 & 2.67 & 7.13 \\
\hline & PM-10 Emis sions & Tons & 2.43 & 3.56 & 1.49 & 3.87 \\
\hline
\end{tabular}


Table E.19: TOU/CPP without enabling technologies performance metrics for region 4

\begin{tabular}{|c|c|c|c|c|c|c|}
\hline Index & Metric & Units & 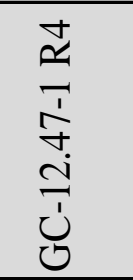 & 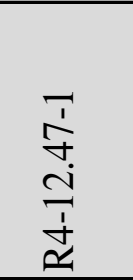 & 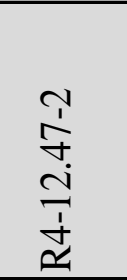 & 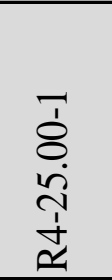 \\
\hline 1 & $\begin{array}{l}\text { Hourly Customer } \\
\text { Electricity Usage }\end{array}$ & $\mathrm{kWh}$ & 2,339 & 1,906 & 828 & 346 \\
\hline 2 & \begin{tabular}{|l|} 
Monthly Customer \\
Electricity Usage \\
\end{tabular} & MWh & 1,708 & 1,392 & 605 & 252 \\
\hline \multirow{10}{*}{3} & Peak Generation & $\mathrm{kW}$ & 6,252 & 4,612 & 2,075 & 905 \\
\hline & Nuclear & $\%$ & 21.91 & 21.91 & 21.91 & 23.58 \\
\hline & Solar & $\%$ & 0.00 & 0.00 & 0.00 & 0.00 \\
\hline & Bio & $\%$ & 0.18 & 0.18 & 0.18 & 0.21 \\
\hline & Wind & $\%$ & 0.60 & 0.60 & 0.60 & 0.59 \\
\hline & Coal & $\%$ & 57.14 & 57.14 & 57.14 & 56.06 \\
\hline & Hydroelectric & $\%$ & 2.20 & 0.00 & 0.00 & 0.00 \\
\hline & Natural Gas & $\%$ & 17.49 & 16.30 & 15.17 & 15.36 \\
\hline & Geothermal & $\%$ & 0.00 & 0.00 & 0.00 & 0.00 \\
\hline & Petroleum & $\%$ & 0.98 & 0.00 & 0.00 & 0.00 \\
\hline 4 & Peak Load & $\mathrm{kW}$ & 6,217 & 4,515 & 2,041 & 889 \\
\hline 7 & \begin{tabular}{|l|} 
Annual Electricity \\
Production \\
\end{tabular} & MWh & 20,549 & 17,172 & 7,430 & 3,107 \\
\hline 12 & $\mathrm{CO} 2$ Emis sions & Tons & 10,322 & 9,837 & 3,971 & 1,597 \\
\hline \multirow{3}{*}{13} & SOx Emis sions & \begin{tabular}{|l|} 
Tons \\
\end{tabular} & 4.92 & 4.73 & 1.91 & 0.77 \\
\hline & NOx Emis sions & Tons & 3.00 & 2.87 & 1.16 & 0.47 \\
\hline & PM-10 Emis sions & \begin{tabular}{|l|} 
Tons \\
\end{tabular} & 1.54 & 1.47 & 0.59 & 0.24 \\
\hline \multirow[b]{2}{*}{21} & Feeder Real Load & $\mathrm{kW}$ & 2,346 & 1,960 & 848 & 355 \\
\hline & $\begin{array}{l}\text { Feeder Reactive } \\
\text { Load } \\
\end{array}$ & kVAR & 138 & -413 & 98 & 45 \\
\hline 29 & Distribution Losses & $\%$ & 0.28 & 2.76 & 2.32 & 2.54 \\
\hline 30 & \begin{tabular}{|l|} 
Distribution Power \\
Factor
\end{tabular} & $\mathrm{pf}$ & 0.9982 & 0.9671 & 0.9933 & 0.9919 \\
\hline 39 & $\mathrm{CO} 2$ Emis sions & Tons & 10,351 & 10,116 & 4,066 & 1,639 \\
\hline \multirow{3}{*}{40} & SOx Emis sions & Tons & 4.93 & 4.86 & 1.95 & 0.79 \\
\hline & NOx Emis sions & Tons & 3.00 & 2.95 & 1.19 & 0.48 \\
\hline & PM-10 Emis sions & Tons & 1.54 & 1.51 & 0.61 & 0.24 \\
\hline
\end{tabular}


Table E.20: TOU/CPP without enabling technologies performance metrics for region 5

\begin{tabular}{|c|c|c|c|c|c|c|c|c|c|c|}
\hline Index & Metric & Units & 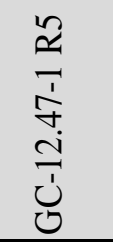 & 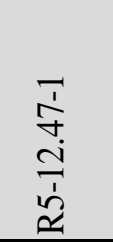 & 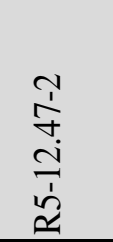 & 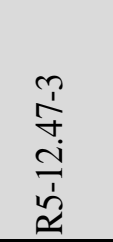 & 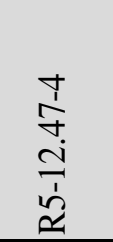 & 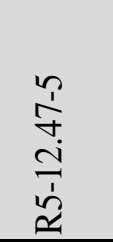 & 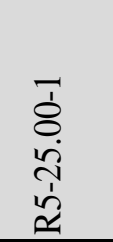 & 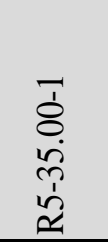 \\
\hline 1 & $\begin{array}{l}\text { Hourly Customer } \\
\text { Electricity Usage }\end{array}$ & $\mathrm{kWh}$ & 2,747 & 4,452 & 2,215 & 4,597 & 3,430 & 4,057 & 5,537 & 5,598 \\
\hline 2 & $\begin{array}{l}\text { Monthly Customer } \\
\text { Electricity Usage } \\
\end{array}$ & MWh & 2,005 & 3,250 & 1,617 & 3,356 & 2,504 & 2,962 & 4,042 & 4,087 \\
\hline \multirow{10}{*}{3} & Peak Generation & $\mathrm{kW}$ & 5,813 & 9,176 & 4,915 & 9,939 & 7,287 & 8,568 & 11,622 & 11,653 \\
\hline & Nuclear & $\%$ & 13.53 & 13.85 & 13.85 & 14.67 & 13.85 & 13.85 & 13.85 & 13.85 \\
\hline & Solar & $\%$ & 0.00 & 0.00 & 0.00 & 0.00 & 0.00 & 0.00 & 0.00 & 0.00 \\
\hline & Bio & $\%$ & 0.31 & 0.33 & 0.33 & 0.30 & 0.33 & 0.33 & 0.33 & 0.33 \\
\hline & Wind & $\%$ & 1.74 & 1.48 & 1.48 & 1.91 & 1.48 & 1.48 & 1.48 & 1.48 \\
\hline & Coal & $\%$ & 30.37 & 29.74 & 30.17 & 32.04 & 29.42 & 27.72 & 27.29 & 26.42 \\
\hline & Hydroelectric & $\%$ & 0.78 & 0.00 & 0.63 & 1.61 & 0.00 & 0.00 & 0.00 & 0.00 \\
\hline & Natural Gas & $\%$ & 51.29 & 51.68 & 51.68 & 47.26 & 51.68 & 51.68 & 51.68 & 51.68 \\
\hline & Geothermal & $\%$ & 0.00 & 0.00 & 0.00 & 0.00 & 0.00 & 0.00 & 0.00 & 0.00 \\
\hline & Petroleum & $\%$ & 3.94 & 0.00 & 0.33 & 1.59 & 0.00 & 0.00 & 0.00 & 0.00 \\
\hline 4 & Peak Load & $\mathrm{kW}$ & 5,782 & 9,043 & 4,771 & 9,327 & 7,129 & 8,311 & 11,428 & 11,495 \\
\hline 7 & $\begin{array}{l}\text { Annual Electricity } \\
\text { Production }\end{array}$ & MWh & 24,144 & 39,470 & 19,801 & 42,107 & 30,636 & 36,387 & 49,188 & 49,676 \\
\hline 12 & $\mathrm{CO} 2$ Emis sions & Tons & 9,365 & 15,040 & 7,311 & 14,552 & 11,440 & 13,045 & 17,668 & 18,066 \\
\hline \multirow{3}{*}{13} & SOx Emis sions & Tons & 1.55 & 2.04 & 1.06 & 1.34 & 1.51 & 1.40 & 1.79 & 1.94 \\
\hline & NOx Emis sions & Tons & 1.38 & 2.00 & 1.01 & 1.64 & 1.50 & 1.56 & 2.07 & 2.17 \\
\hline & PM-10 Emis sions & Tons & 1.37 & 2.21 & 1.07 & 2.13 & 1.68 & 1.91 & 2.59 & 2.65 \\
\hline \multirow[b]{2}{*}{21} & Feeder Real Load & $\mathrm{kW}$ & 2,756 & 4,506 & 2,260 & 4,807 & 3,497 & 4,154 & 5,615 & 5,671 \\
\hline & \begin{tabular}{|l|} 
Feeder Reactive \\
Load
\end{tabular} & kVAR & 248 & 533 & 239 & -386 & 397 & 577 & 630 & 622 \\
\hline 29 & Dis tribution Losses & $\%$ & 0.33 & 1.19 & 2.00 & 4.37 & 1.91 & 2.32 & 1.39 & 1.28 \\
\hline 30 & $\begin{array}{l}\text { Distribution Power } \\
\text { Factor }\end{array}$ & $\mathrm{pf}$ & 0.9964 & 0.9938 & 0.9952 & 0.9779 & 0.9943 & 0.9915 & 0.9943 & 0.9945 \\
\hline 39 & $\mathrm{CO} 2$ Emis sions & Tons & 9,396 & 15,220 & 7,460 & 15,216 & 11,663 & 13,355 & 17,916 & 18,301 \\
\hline \multirow{3}{*}{40} & SOx Emis sions & Tons & 1.56 & 2.06 & 1.09 & 1.40 & 1.54 & 1.43 & 1.81 & 1.97 \\
\hline & NOx Emis sions & Tons & 1.39 & 2.02 & 1.03 & 1.72 & 1.53 & 1.60 & 2.10 & 2.19 \\
\hline & PM-10 Emis sions & Tons & 1.38 & 2.23 & 1.09 & 2.23 & 1.71 & 1.96 & 2.62 & 2.68 \\
\hline
\end{tabular}


Table E.21: TOU/CPP with enabling technologies performance metrics for region 1

\begin{tabular}{|c|c|c|c|c|c|c|c|c|}
\hline Index & Metric & Units & 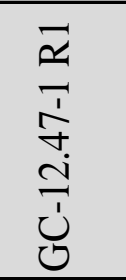 & 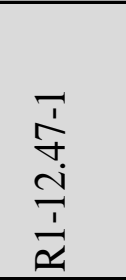 & $\begin{array}{l}\frac{N}{\sigma} \\
\frac{1}{\sim} \\
\frac{1}{a}\end{array}$ & $\begin{array}{l}\frac{1}{+} \\
\frac{1}{\sim} \\
\frac{1}{\Delta}\end{array}$ & 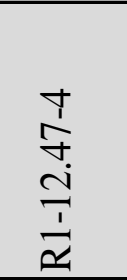 & $\begin{array}{l}\bar{\delta} \\
8 \\
\stackrel{1}{1} \\
\frac{1}{\alpha}\end{array}$ \\
\hline 1 & $\begin{array}{l}\text { Hourly Customer } \\
\text { Electricity Usage }\end{array}$ & $\mathrm{kWh}$ & 2,073 & 2,692 & 991 & 433 & 1,946 & 870 \\
\hline 2 & $\begin{array}{l}\text { Monthly Customer } \\
\text { Electricity Usage }\end{array}$ & MWh & 1,513 & 1,965 & 723 & 316 & 1,421 & 635 \\
\hline \multirow{10}{*}{3} & Peak Generation & $\mathrm{kW}$ & 6,229 & 7,441 & 2,692 & 1,333 & 5,246 & 2,607 \\
\hline & Nuclear & $\%$ & 10.68 & 10.68 & 10.68 & 10.68 & 10.68 & 10.68 \\
\hline & Solar & $\%$ & 0.25 & 0.25 & 0.25 & 0.25 & 0.25 & 0.25 \\
\hline & Bio & $\%$ & 0.67 & 0.67 & 0.67 & 0.67 & 0.67 & 0.67 \\
\hline & Wind & $\%$ & 4.07 & 4.07 & 4.07 & 4.07 & 4.07 & 4.07 \\
\hline & Coal & $\%$ & 2.88 & 2.88 & 2.88 & 2.88 & 2.88 & 2.88 \\
\hline & Hydroelectric & $\%$ & 36.88 & 36.88 & 36.88 & 36.88 & 36.88 & 36.88 \\
\hline & Natural Gas & $\%$ & 41.38 & 41.38 & 41.38 & 41.38 & 41.38 & 41.38 \\
\hline & Geothermal & $\%$ & 2.84 & 2.84 & 2.84 & 2.84 & 2.84 & 2.84 \\
\hline & Petroleum & $\%$ & 17.59 & 1.88 & 0.99 & 6.09 & 4.24 & 12.86 \\
\hline 4 & Peak Load & $\mathrm{kW}$ & 6,204 & 7,197 & 2,608 & 1,319 & 5,119 & 2,551 \\
\hline 7 & $\begin{array}{l}\text { Annual Electricity } \\
\text { Production }\end{array}$ & MWh & 18,199 & 24,190 & 8,952 & 3,812 & 17,256 & 7,730 \\
\hline 12 & $\mathrm{CO} 2$ Emis sions & Tons & 1,736 & 2,216 & 793 & 382 & 1,720 & 725 \\
\hline \multirow{3}{*}{13} & SOx Emis sions & Tons & 0.02 & 0.02 & 0.01 & 0.01 & 0.03 & 0.01 \\
\hline & NOx Emis sions & Tons & 0.23 & 0.28 & 0.10 & 0.05 & 0.21 & 0.10 \\
\hline & PM-10 Emis sions & Tons & 0.24 & 0.31 & 0.11 & 0.05 & 0.24 & 0.10 \\
\hline \multirow[b]{2}{*}{21} & Feeder Real Load & $\mathrm{kW}$ & 2,077 & 2,761 & 1,022 & 435 & 1,970 & 882 \\
\hline & $\begin{array}{l}\text { Feeder Reactive } \\
\text { Load }\end{array}$ & kVAR & 65 & -278 & -198 & 10 & 63 & -72 \\
\hline 29 & Distribution Losses & $\%$ & 0.23 & 2.53 & 3.05 & 0.56 & 1.20 & 1.43 \\
\hline 30 & $\begin{array}{l}\text { Distribution Power } \\
\text { Factor }\end{array}$ & $\mathrm{pf}$ & 0.9994 & 0.9930 & 0.9691 & 0.9997 & 0.9994 & 0.9666 \\
\hline 39 & $\mathrm{CO} 2$ Emis sions & Tons & 1,740 & 2,273 & 818 & 384 & 1,740 & 735 \\
\hline \multirow{3}{*}{40} & SOx Emis sions & Tons & 0.02 & 0.02 & 0.01 & 0.01 & 0.03 & 0.01 \\
\hline & NOx Emis sions & Tons & 0.23 & 0.28 & 0.10 & 0.05 & 0.21 & 0.10 \\
\hline & PM-10 Emissions & Tons & 0.24 & 0.32 & 0.12 & 0.05 & 0.25 & 0.10 \\
\hline
\end{tabular}


Table E.22: TOU/CPP with enabling technologies performance metrics for region 2

\begin{tabular}{|c|c|c|c|c|c|c|c|c|}
\hline Index & Metric & Units & 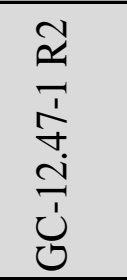 & 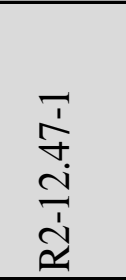 & 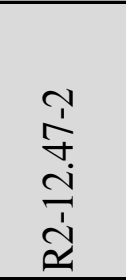 & 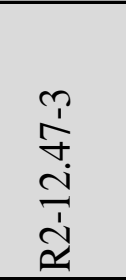 & 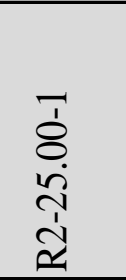 & $\begin{array}{l}\bar{\delta} \\
\delta \\
\tilde{\delta} \\
\tilde{1} \\
\tilde{d} \\
\tilde{c}\end{array}$ \\
\hline 1 & $\begin{array}{l}\text { Hourly Customer } \\
\text { Electricity Usage }\end{array}$ & $\mathrm{kWh}$ & 2,165 & 2,269 & 1,988 & 2,990 & 6,343 & 4,571 \\
\hline 2 & $\begin{array}{l}\text { Monthly Customer } \\
\text { Electricity Usage }\end{array}$ & MWh & 1,580 & 1,657 & 1,452 & 2,183 & 4,630 & 3,337 \\
\hline \multirow{10}{*}{3} & Peak Generation & $\mathrm{kW}$ & 6,231 & 6,236 & 6,315 & 9,430 & 18,692 & 12,754 \\
\hline & Nuclear & $\%$ & 26.33 & 26.33 & 26.33 & 26.33 & 26.33 & 26.33 \\
\hline & Solar & $\%$ & 0.01 & 0.01 & 0.01 & 0.01 & 0.01 & 0.01 \\
\hline & Bio & $\%$ & 0.82 & 0.82 & 0.82 & 0.82 & 0.82 & 0.82 \\
\hline & Wind & $\%$ & 1.41 & 1.41 & 1.41 & 1.41 & 1.41 & 1.41 \\
\hline & Coal & $\%$ & 47.18 & 47.18 & 47.18 & 47.18 & 47.18 & 47.18 \\
\hline & Hydroelectric & $\%$ & 7.42 & 7.12 & 7.42 & 7.42 & 7.42 & 7.42 \\
\hline & Natural Gas & $\%$ & 16.33 & 16.33 & 16.33 & 16.33 & 16.33 & 16.33 \\
\hline & Geothermal & $\%$ & 0.07 & 0.00 & 0.07 & 0.07 & 0.07 & 0.07 \\
\hline & Petroleum & $\%$ & 8.81 & 0.00 & 9.73 & 10.94 & 11.43 & 1.05 \\
\hline 4 & Peak Load & $\mathrm{kW}$ & 6,202 & 6,116 & 6,185 & 9,235 & 18,474 & 12,611 \\
\hline 7 & $\begin{array}{l}\text { Annual Electricity } \\
\text { Production }\end{array}$ & MWh & 19,012 & 20,133 & 17,750 & 26,826 & 56,100 & 40,373 \\
\hline 12 & $\mathrm{CO} 2$ Emis sions & Tons & 8,392 & 9,260 & 8,581 & 12,779 & 26,908 & 17,424 \\
\hline \multirow{3}{*}{13} & SOx Emis sions & Tons & 3.80 & 4.22 & 3.97 & 5.91 & 12.37 & 7.87 \\
\hline & NOx Emis sions & Tons & 2.43 & 2.68 & 2.51 & 3.74 & 7.83 & 5.02 \\
\hline & PM-10 Emis sions & Tons & 1.24 & 1.37 & 1.27 & 1.89 & 3.99 & 2.58 \\
\hline \multirow[b]{2}{*}{21} & Feeder Real Load & $\mathrm{kW}$ & 2,170 & 2,298 & 2,026 & 3,062 & 6,404 & 4,609 \\
\hline & \begin{tabular}{|l|} 
Feeder Reactive \\
Load \\
\end{tabular} & kVAR & 91 & 117 & 151 & -121 & 336 & 69 \\
\hline 29 & Dis tribution Losses & $\%$ & 0.24 & 1.27 & 1.86 & 2.35 & 0.95 & 0.82 \\
\hline 30 & $\begin{array}{l}\text { Distribution Power } \\
\text { Factor }\end{array}$ & $\mathrm{pf}$ & 0.9989 & 0.9987 & 0.9971 & 0.9976 & 0.9986 & 0.9996 \\
\hline 39 & $\mathrm{CO} 2$ Emissions & Tons & 8,413 & 9,379 & 8,744 & 13,086 & 27,168 & 17,568 \\
\hline \multirow{3}{*}{40} & SOx Emis sions & Tons & 3.81 & 4.27 & 4.04 & 6.05 & 12.49 & 7.93 \\
\hline & NOx Emis sions & Tons & 2.43 & 2.72 & 2.56 & 3.83 & 7.91 & 5.06 \\
\hline & PM-10 Emissions & Tons & 1.25 & 1.39 & 1.30 & 1.94 & 4.03 & 2.60 \\
\hline
\end{tabular}


Table E.23: TOU/CPP with enabling technologies performance metrics for region 3

\begin{tabular}{|c|c|c|c|c|c|c|}
\hline Index & Metric & Units & 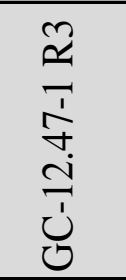 & 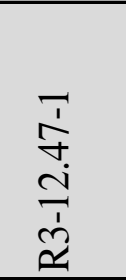 & $\begin{array}{l}\frac{1}{\sigma} \\
\stackrel{+}{\sim} \\
\frac{1}{2}\end{array}$ & $\begin{array}{l}\frac{r}{f} \\
\frac{\dot{J}}{\sim} \\
\frac{1}{\tilde{d}}\end{array}$ \\
\hline 1 & $\begin{array}{l}\text { Hourly Customer } \\
\text { Electricity Usage }\end{array}$ & $\mathrm{kWh}$ & 2,626 & 3,663 & 1,638 & 3,729 \\
\hline 2 & $\begin{array}{l}\text { Monthly Customer } \\
\text { Electricity Usage }\end{array}$ & MWh & 1,917 & 2,674 & 1,195 & 2,722 \\
\hline \multirow{10}{*}{3} & Peak Generation & $\mathrm{kW}$ & 7,032 & 9,028 & 4,186 & 8,261 \\
\hline & Nuclear & $\%$ & 9.72 & 9.72 & 8.65 & 8.65 \\
\hline & Solar & $\%$ & 0.13 & 0.13 & 0.13 & 0.13 \\
\hline & Bio & $\%$ & 0.25 & 0.25 & 0.23 & 0.23 \\
\hline & Wind & $\%$ & 2.45 & 2.45 & 2.05 & 2.05 \\
\hline & Coal & $\%$ & 41.52 & 41.52 & 40.24 & 40.24 \\
\hline & Hydroelectric & $\%$ & 6.40 & 4.96 & 5.58 & 5.58 \\
\hline & Natural Gas & $\%$ & 37.88 & 37.88 & 41.67 & 41.67 \\
\hline & Geothermal & $\%$ & 1.40 & 0.00 & 1.25 & 1.25 \\
\hline & Petroleum & $\%$ & 6.99 & 0.00 & 0.65 & 1.17 \\
\hline 4 & Peak Load & $\mathrm{kW}$ & 6,993 & 8,834 & 4,129 & 8,001 \\
\hline 7 & $\begin{array}{l}\text { Annual Electricity } \\
\text { Production }\end{array}$ & MWh & 23,080 & 32,696 & 14,445 & 33,816 \\
\hline 12 & $\mathrm{CO} 2$ Emis sions & Tons & 16,255 & 23,542 & 9,960 & 25,330 \\
\hline \multirow{3}{*}{13} & SOx Emis sions & Tons & 7.04 & 10.33 & 4.26 & 11.25 \\
\hline & NOx Emis sions & Tons & 4.39 & 6.41 & 2.66 & 6.94 \\
\hline & PM-10 Emis sions & Tons & 2.42 & 3.51 & 1.48 & 3.78 \\
\hline \multirow[b]{2}{*}{21} & Feeder Real Load & $\mathrm{kW}$ & 2,635 & 3,732 & 1,649 & 3,860 \\
\hline & $\begin{array}{l}\text { Feeder Reactive } \\
\text { Load } \\
\end{array}$ & kVAR & 216 & 486 & 142 & 558 \\
\hline 29 & Distribution Losses & $\%$ & 0.32 & 1.87 & 0.69 & 3.39 \\
\hline 30 & $\begin{array}{l}\text { Distribution Power } \\
\text { Factor }\end{array}$ & $\mathrm{pf}$ & 0.9969 & 0.9904 & 0.9968 & 0.9896 \\
\hline 39 & $\mathrm{CO} 2$ Emissions & Tons & 16,308 & 23,991 & 10,028 & 26,219 \\
\hline \multirow{3}{*}{40} & SOx Emis sions & Tons & 7.07 & 10.53 & 4.29 & 11.64 \\
\hline & NOx Emis sions & Tons & 4.40 & 6.53 & 2.68 & 7.18 \\
\hline & PM-10 Emissions & Tons & 2.43 & 3.57 & 1.49 & 3.91 \\
\hline
\end{tabular}


Table E.24: TOU/CPP with enabling technologies performance metrics for region 4

\begin{tabular}{|c|c|c|c|c|c|c|}
\hline Index & Metric & Units & 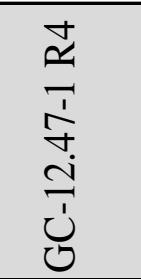 & 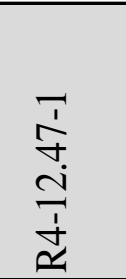 & 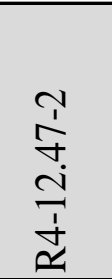 & $\begin{array}{l}7 \\
\delta \\
\dot{\delta} \\
\sim \\
\dot{1} \\
\dot{\alpha}\end{array}$ \\
\hline 1 & $\begin{array}{l}\text { Hourly Customer } \\
\text { Electricity Usage }\end{array}$ & $\mathrm{kWh}$ & 2,329 & 1,916 & 838 & 350 \\
\hline 2 & $\begin{array}{l}\text { Monthly Customer } \\
\text { Electricity Usage }\end{array}$ & MWh & 1,700 & 1,399 & 612 & 255 \\
\hline \multirow{10}{*}{3} & Peak Generation & $\mathrm{kW}$ & 7,221 & 5,712 & 2,636 & 1,122 \\
\hline & Nuclear & $\%$ & 21.91 & 23.58 & 21.91 & 22.45 \\
\hline & Solar & $\%$ & 0.00 & 0.00 & 0.00 & 0.00 \\
\hline & Bio & $\%$ & 0.18 & 0.21 & 0.18 & 0.18 \\
\hline & Wind & $\%$ & 0.60 & 0.59 & 0.60 & 0.64 \\
\hline & Coal & $\%$ & 57.14 & 56.06 & 57.14 & 56.92 \\
\hline & Hydroelectric & $\%$ & 2.20 & 3.09 & 2.20 & 3.32 \\
\hline & Natural Gas & $\%$ & 17.49 & 16.14 & 17.49 & 16.04 \\
\hline & Geothermal & $\%$ & 0.00 & 0.00 & 0.00 & 0.00 \\
\hline & Petroleum & $\%$ & 16.56 & 24.60 & 21.15 & 26.72 \\
\hline 4 & Peak Load & $\mathrm{kW}$ & 7,187 & 5,616 & 2,602 & 1,105 \\
\hline 7 & $\begin{array}{l}\text { Annual Electricity } \\
\text { Production }\end{array}$ & $\mathrm{MWh}$ & 20,458 & 17,259 & 7,516 & 3,144 \\
\hline 12 & $\mathrm{CO} 2$ Emissions & Tons & 10,245 & 9,933 & 4,059 & 1,635 \\
\hline \multirow{3}{*}{13} & SOx Emis sions & Tons & 4.89 & 4.77 & 1.95 & 0.79 \\
\hline & NOx Emis sions & Tons & 2.98 & 2.90 & 1.19 & 0.48 \\
\hline & PM-10 Emis sions & Tons & 1.53 & 1.48 & 0.60 & 0.24 \\
\hline \multirow[b]{2}{*}{21} & Feeder Real Load & $\mathrm{kW}$ & 2,335 & 1,970 & 858 & 359 \\
\hline & \begin{tabular}{|l} 
Feeder Reactive \\
Load \\
\end{tabular} & kVAR & 135 & -410 & 101 & 46 \\
\hline 29 & Distribution Losses & $\%$ & 0.28 & 2.75 & 2.30 & 2.52 \\
\hline 30 & $\begin{array}{l}\text { Distribution Power } \\
\text { Factor }\end{array}$ & $\mathrm{pf}$ & 0.9982 & 0.9677 & 0.9932 & 0.9917 \\
\hline 39 & $\mathrm{CO} 2$ Emissions & Tons & 10,273 & 10,214 & 4,154 & 1,677 \\
\hline \multirow{3}{*}{40} & SOx Emis sions & Tons & 4.90 & 4.91 & 2.00 & 0.81 \\
\hline & NOx Emis sions & Tons & 2.99 & 2.98 & 1.21 & 0.49 \\
\hline & PM-10 Emissions & Tons & 1.53 & 1.52 & 0.62 & 0.25 \\
\hline
\end{tabular}


Table E.25: TOU/CPP with enabling technologies performance metrics for region 5

\begin{tabular}{|c|c|c|c|c|c|c|c|c|c|c|}
\hline Index & Metric & Units & 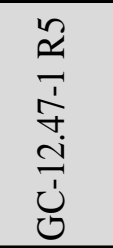 & 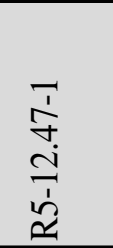 & 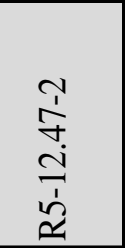 & 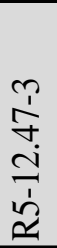 & 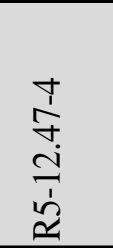 & 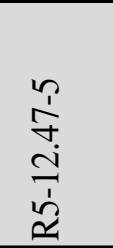 & 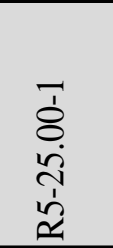 & 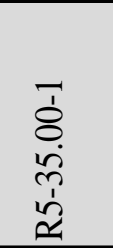 \\
\hline 1 & $\begin{array}{l}\text { Hourly Customer } \\
\text { Electricity Usage }\end{array}$ & $\mathrm{kWh}$ & 2,736 & 4,497 & 2,220 & - & 3,467 & 4,121 & 5,630 & 5,694 \\
\hline 2 & $\begin{array}{l}\text { Monthly Customer } \\
\text { Electricity Usage }\end{array}$ & MWh & 1,997 & 3,283 & 1,620 & - & 2,531 & 3,009 & 4,110 & 4,157 \\
\hline \multirow{10}{*}{3} & Peak Generation & $\mathrm{kW}$ & 6,824 & 11,210 & 5,905 & - & 9,132 & 11,211 & 15,301 & 15,662 \\
\hline & Nuclear & $\%$ & 13.85 & 13.85 & 13.85 & - & 13.85 & 13.85 & 13.85 & 13.85 \\
\hline & Solar & $\%$ & 0.00 & 0.00 & 0.00 & - & 0.00 & 0.00 & 0.00 & 0.00 \\
\hline & Bio & $\%$ & 0.33 & 0.33 & 0.33 & - & 0.33 & 0.33 & 0.33 & 0.33 \\
\hline & Wind & $\%$ & 1.48 & 1.48 & 1.48 & - & 1.48 & 1.48 & 1.48 & 1.48 \\
\hline & Coal & $\%$ & 30.17 & 30.17 & 30.17 & - & 30.17 & 30.17 & 30.17 & 30.17 \\
\hline & Hydroelectric & $\%$ & 0.63 & 0.63 & 0.63 & - & 0.63 & 0.63 & 0.63 & 0.63 \\
\hline & Natural Gas & $\%$ & 51.68 & 51.68 & 51.68 & - & 51.68 & 51.68 & 51.68 & 51.68 \\
\hline & Geothermal & $\%$ & 0.00 & 0.00 & 0.00 & - & 0.00 & 0.00 & 0.00 & 0.00 \\
\hline & Petroleum & $\%$ & 18.69 & 20.46 & 20.15 & - & 23.13 & 26.24 & 26.44 & 27.88 \\
\hline 4 & Peak Load & $\mathrm{kW}$ & 6,793 & 11,077 & 5,761 & - & 8,974 & 10,954 & 15,107 & 15,504 \\
\hline 7 & $\begin{array}{l}\text { Annual Electricity } \\
\text { Production }\end{array}$ & MWh & 24,046 & 39,865 & 19,839 & - & 30,959 & 36,963 & 50,018 & 50,529 \\
\hline 12 & $\mathrm{CO} 2$ Emis sions & Tons & 9,227 & 15,221 & 7,253 & - & 11,578 & 13,394 & 18,218 & 18,600 \\
\hline \multirow{3}{*}{13} & SOx Emis sions & Tons & 1.47 & 2.03 & 1.00 & - & 1.50 & 1.46 & 1.91 & 2.05 \\
\hline & NOx Emis sions & Tons & 1.33 & 2.01 & 0.98 & - & 1.50 & 1.61 & 2.14 & 2.23 \\
\hline & PM-10 Emis sions & Tons & 1.35 & 2.23 & 1.06 & - & 1.69 & 1.95 & 2.64 & 2.70 \\
\hline \multirow[b]{2}{*}{21} & Feeder Real Load & $\mathrm{kW}$ & 2,745 & 4,551 & 2,265 & - & 3,534 & 4,220 & 5,710 & 5,768 \\
\hline & $\begin{array}{l}\text { Feeder Reactive } \\
\text { Load }\end{array}$ & kVAR & 245 & 547 & 241 & - & 409 & 601 & 661 & 653 \\
\hline 29 & Distribution Losses & $\%$ & 0.33 & 1.18 & 2.00 & - & 1.91 & 2.33 & 1.39 & 1.28 \\
\hline 30 & $\begin{array}{l}\text { Distribution Power } \\
\text { Factor }\end{array}$ & $\mathrm{pf}$ & 0.9965 & 0.9935 & 0.9951 & - & 0.9940 & 0.9911 & 0.9939 & 0.9942 \\
\hline 39 & $\mathrm{CO} 2$ Emissions & Tons & 9,257 & 15,403 & 7,400 & - & 11,803 & 13,713 & 18,475 & 18,841 \\
\hline \multirow{3}{*}{40} & SOx Emis sions & Tons & 1.47 & 2.06 & 1.02 & - & 1.53 & 1.50 & 1.94 & 2.07 \\
\hline & NOx Emis sions & Tons & 1.34 & 2.03 & 1.00 & - & 1.53 & 1.65 & 2.17 & 2.26 \\
\hline & PM-10 Emis sions & Tons & 1.36 & 2.26 & 1.08 & - & 1.73 & 1.99 & 2.68 & 2.73 \\
\hline
\end{tabular}




\section{E.3 Individual DLC Performance Metrics}

Table E.26: DLC performance metrics for region 1

\begin{tabular}{|c|c|c|c|c|c|c|c|c|}
\hline Index & Metric & Units & 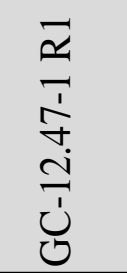 & $\begin{array}{l}\frac{1}{\Delta} \\
\stackrel{+}{d} \\
\frac{1}{\Delta}\end{array}$ & 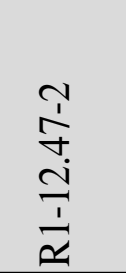 & $\begin{array}{l}\stackrel{r}{1} \\
\stackrel{+}{d} \\
\frac{1}{\Delta}\end{array}$ & 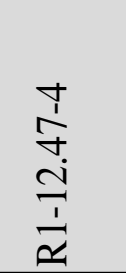 & 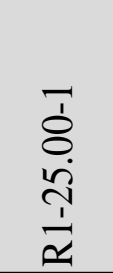 \\
\hline 1 & $\begin{array}{l}\text { Hourly Customer } \\
\text { Electricity Usage }\end{array}$ & $\mathrm{kWh}$ & 2,084 & 2,690 & 991 & 435 & 1,947 & 875 \\
\hline 2 & \begin{tabular}{|l|} 
Monthly Customer \\
Electricity Usage \\
\end{tabular} & MWh & 1,521 & 1,964 & 724 & 317 & 1,422 & 639 \\
\hline \multirow{10}{*}{3} & Peak Generation & $\mathrm{kW}$ & 5,439 & 11,925 & 4,230 & 1,211 & 6,736 & 2,332 \\
\hline & Nuclear & $\%$ & 10.68 & 10.68 & 10.68 & 10.68 & 10.68 & 10.68 \\
\hline & Solar & $\%$ & 0.25 & 0.25 & 0.25 & 0.25 & 0.25 & 0.25 \\
\hline & Bio & $\%$ & 0.67 & 0.67 & 0.67 & 0.67 & 0.67 & 0.67 \\
\hline & Wind & $\%$ & 4.07 & 4.07 & 4.07 & 4.07 & 4.07 & 4.07 \\
\hline & Coal & $\%$ & 2.88 & 2.88 & 2.88 & 2.12 & 2.88 & 2.88 \\
\hline & Hydroelectric & $\%$ & 36.88 & 36.88 & 36.88 & 36.88 & 36.88 & 36.88 \\
\hline & Natural Gas & $\%$ & 41.38 & 41.38 & 41.38 & 41.38 & 41.38 & 41.38 \\
\hline & Geothermal & $\%$ & 2.84 & 2.84 & 2.84 & 0.00 & 2.84 & 2.84 \\
\hline & Petroleum & $\%$ & 2.72 & 63.06 & 58.49 & 0.00 & 33.75 & 0.96 \\
\hline 4 & Peak Load & $\mathrm{kW}$ & 5,414 & 11,681 & 4,145 & 1,197 & 6,609 & 2,276 \\
\hline 7 & \begin{tabular}{|l|} 
Annual Electricity \\
Production
\end{tabular} & $\mathrm{MWh}$ & 18,294 & 24,179 & 8,957 & 3,829 & 17,268 & 7,776 \\
\hline 12 & $\mathrm{CO} 2$ Emis sions & Tons & 1,785 & 2,291 & 823 & 392 & 1,776 & 751 \\
\hline \multirow{3}{*}{13} & SOx Emis sions & Tons & 0.03 & 0.05 & 0.02 & 0.01 & 0.04 & 0.01 \\
\hline & NOx Emis sions & Tons & 0.24 & 0.29 & 0.10 & 0.05 & 0.22 & 0.10 \\
\hline & PM-10 Emissions & Tons & 0.25 & 0.32 & 0.11 & 0.06 & 0.25 & 0.11 \\
\hline \multirow[b]{2}{*}{21} & Feeder Real Load & $\mathrm{kW}$ & 2,088 & 2,760 & 1,023 & 437 & 1,971 & 888 \\
\hline & $\begin{array}{l}\text { Feeder Reactive } \\
\text { Load }\end{array}$ & kVAR & 68 & -278 & -197 & 11 & 64 & -70 \\
\hline 29 & Distribution Losses & $\%$ & 0.23 & 2.54 & 3.06 & 0.56 & 1.21 & 1.44 \\
\hline 30 & $\begin{array}{l}\text { Distribution Power } \\
\text { Factor }\end{array}$ & $\mathrm{pf}$ & 0.9994 & 0.9928 & 0.9683 & 0.9997 & 0.9994 & 0.9667 \\
\hline 39 & $\mathrm{CO} 2$ Emissions & Tons & 1,789 & 2,351 & 849 & 394 & 1,798 & 762 \\
\hline \multirow{3}{*}{40} & SOx Emis sions & Tons & 0.03 & 0.05 & 0.02 & 0.01 & 0.04 & 0.01 \\
\hline & NOx Emis sions & Tons & 0.24 & 0.29 & 0.11 & 0.05 & 0.22 & 0.10 \\
\hline & PM-10 Emissions & Tons & 0.25 & 0.33 & 0.12 & 0.06 & 0.25 & 0.11 \\
\hline
\end{tabular}


Table E.27: DLC performance metrics for region 2

\begin{tabular}{|c|c|c|c|c|c|c|c|c|}
\hline Index & Metric & Units & 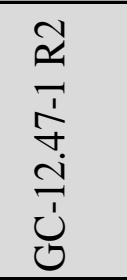 & 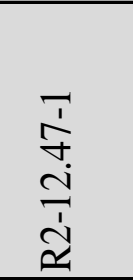 & 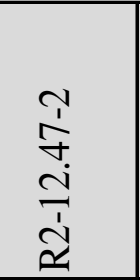 & $\begin{array}{l}\frac{1}{f} \\
\frac{+}{d} \\
\frac{1}{d}\end{array}$ & 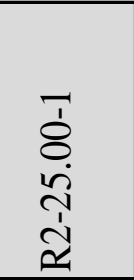 & $\begin{array}{l}F \\
\delta \\
\ddot{\delta} \\
\tilde{n} \\
\dot{1} \\
\tilde{\alpha}\end{array}$ \\
\hline 1 & $\begin{array}{l}\text { Hourly Customer } \\
\text { Electricity Usage }\end{array}$ & $\mathrm{kWh}$ & 2,170 & 2,269 & 1,969 & 2,972 & 6,341 & 4,577 \\
\hline 2 & \begin{tabular}{|l|} 
Monthly Customer \\
Electricity Usage \\
\end{tabular} & MWh & 1,584 & 1,656 & 1,437 & 2,169 & 4,629 & 3,341 \\
\hline \multirow{10}{*}{3} & Peak Generation & $\mathrm{kW}$ & 5,833 & 6,195 & 7,291 & 11,963 & 16,958 & 12,633 \\
\hline & Nuclear & $\%$ & 26.33 & 26.33 & 26.33 & 26.33 & 26.33 & 26.33 \\
\hline & Solar & $\%$ & 0.01 & 0.01 & 0.01 & 0.01 & 0.01 & 0.01 \\
\hline & Bio & $\%$ & 0.82 & 0.82 & 0.82 & 0.82 & 0.82 & 0.82 \\
\hline & Wind & $\%$ & 1.41 & 1.41 & 1.41 & 1.41 & 1.41 & 1.41 \\
\hline & Coal & $\%$ & 47.18 & 47.18 & 47.18 & 47.18 & 47.18 & 47.18 \\
\hline & Hydroelectric & $\%$ & 7.42 & 6.46 & 7.42 & 7.42 & 7.42 & 7.42 \\
\hline & Natural Gas & $\%$ & 16.33 & 16.33 & 16.33 & 16.33 & 16.33 & 16.33 \\
\hline & Geothermal & $\%$ & 0.07 & 0.00 & 0.07 & 0.07 & 0.07 & 0.07 \\
\hline & Petroleum & $\%$ & 1.89 & 0.00 & 26.63 & 40.63 & 1.13 & 0.09 \\
\hline 4 & Peak Load & $\mathrm{kW}$ & 5,804 & 6,074 & 7,161 & 11,769 & 16,740 & 12,490 \\
\hline 7 & $\begin{array}{l}\text { Annual Electricity } \\
\text { Production }\end{array}$ & MWh & 19,055 & 20,129 & 17,574 & 26,661 & 56,081 & 40,426 \\
\hline 12 & $\mathrm{CO} 2$ Emis sions & Tons & 8,422 & 9,253 & 8,415 & 12,621 & 26,883 & 17,446 \\
\hline \multirow{3}{*}{13} & SOx Emis sions & Tons & 3.81 & 4.21 & 3.88 & 5.82 & 12.34 & 7.87 \\
\hline & NOx Emis sions & Tons & 2.43 & 2.68 & 2.46 & 3.69 & 7.82 & 5.02 \\
\hline & PM-10 Emis sions & Tons & 1.25 & 1.37 & 1.25 & 1.87 & 3.99 & 2.59 \\
\hline \multirow{2}{*}{21} & Feeder Real Load & $\mathrm{kW}$ & 2,175 & 2,298 & 2,006 & 3,043 & 6,402 & 4,615 \\
\hline & Feeder Reactive Load & kVAR & 92 & 118 & 149 & -125 & 337 & 71 \\
\hline 29 & Distribution Losses & $\%$ & 0.25 & 1.27 & 1.87 & 2.36 & 0.96 & 0.82 \\
\hline 30 & $\begin{array}{l}\text { Distribution Power } \\
\text { Factor }\end{array}$ & $\mathrm{pf}$ & 0.9989 & 0.9987 & 0.9971 & 0.9975 & 0.9986 & 0.9996 \\
\hline 39 & $\mathrm{CO} 2$ Emis sions & Tons & 8,442 & 9,373 & 8,575 & 12,926 & 27,143 & 17,591 \\
\hline \multirow{3}{*}{40} & SOx Emis sions & Tons & 3.82 & 4.27 & 3.96 & 5.97 & 12.46 & 7.93 \\
\hline & NOx Emis sions & Tons & 2.44 & 2.71 & 2.51 & 3.78 & 7.89 & 5.06 \\
\hline & PM-10 Emis sions & Tons & 1.25 & 1.39 & 1.27 & 1.91 & 4.03 & 2.61 \\
\hline
\end{tabular}


Table E.28: DLC performance metrics for region 3

\begin{tabular}{|c|c|c|c|c|c|c|}
\hline Index & Metric & Units & 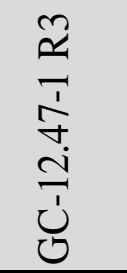 & 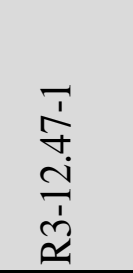 & 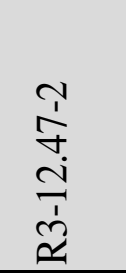 & $\begin{array}{l}\frac{r}{f} \\
\stackrel{+}{\sim} \\
\frac{1}{d} \\
\tilde{c}\end{array}$ \\
\hline 1 & $\begin{array}{l}\text { Hourly Customer } \\
\text { Electricity Usage }\end{array}$ & $\mathrm{kWh}$ & 2,635 & 3,661 & 1,643 & 3,704 \\
\hline 2 & $\begin{array}{l}\text { Monthly Customer } \\
\text { Electricity Usage } \\
\end{array}$ & MWh & 1,923 & 2,673 & 1,200 & 2,704 \\
\hline \multirow{10}{*}{3} & Peak Generation & $\mathrm{kW}$ & 6,727 & 8,892 & 4,461 & 10,704 \\
\hline & Nuclear & $\%$ & 9.72 & 9.72 & 9.72 & 9.72 \\
\hline & Solar & $\%$ & 0.13 & 0.13 & 0.13 & 0.13 \\
\hline & Bio & $\%$ & 0.25 & 0.25 & 0.25 & 0.25 \\
\hline & Wind & $\%$ & 2.45 & 2.45 & 2.45 & 2.45 \\
\hline & Coal & $\%$ & 41.52 & 41.52 & 41.52 & 41.52 \\
\hline & Hydroelectric & $\%$ & 6.40 & 3.51 & 6.40 & 6.40 \\
\hline & Natural Gas & $\%$ & 37.88 & 37.88 & 37.88 & 37.88 \\
\hline & Geothermal & $\%$ & 1.40 & 0.00 & 1.40 & 1.40 \\
\hline & Petroleum & $\%$ & 2.36 & 0.00 & 1.14 & 27.41 \\
\hline 4 & Peak Load & $\mathrm{kW}$ & 6,688 & 8,699 & 4,404 & 10,443 \\
\hline 7 & $\begin{array}{l}\text { Annual Electricity } \\
\text { Production }\end{array}$ & MWh & 23,154 & 32,685 & 14,497 & 33,587 \\
\hline 12 & $\mathrm{CO} 2$ Emis sions & Tons & 16,264 & 23,433 & 9,971 & 25,109 \\
\hline \multirow{3}{*}{13} & SOx Emis sions & Tons & 7.02 & 10.25 & 4.25 & 11.15 \\
\hline & NOx Emissions & Tons & 4.38 & 6.36 & 2.66 & 6.88 \\
\hline & PM-10 Emis sions & Tons & 2.42 & 3.49 & 1.48 & 3.74 \\
\hline \multirow[b]{2}{*}{21} & Feeder Real Load & $\mathrm{kW}$ & 2,643 & 3,731 & 1,655 & 3,834 \\
\hline & $\begin{array}{l}\text { Feeder Reactive } \\
\text { Load } \\
\end{array}$ & kVAR & 219 & 487 & 144 & 552 \\
\hline 29 & Distribution Losses & $\%$ & 0.33 & 1.87 & 0.69 & 3.40 \\
\hline 30 & $\begin{array}{l}\text { Distribution Power } \\
\text { Factor }\end{array}$ & $\mathrm{pf}$ & 0.9969 & 0.9903 & 0.9968 & 0.9895 \\
\hline 39 & $\mathrm{CO} 2$ Emissions & Tons & 16,317 & 23,881 & 10,040 & 25,994 \\
\hline \multirow{3}{*}{40} & SOx Emis sions & Tons & 7.05 & 10.44 & 4.28 & 11.55 \\
\hline & NOx Emis sions & Tons & 4.39 & 6.48 & 2.68 & 7.12 \\
\hline & PM-10 Emis sions & Tons & 2.43 & 3.56 & 1.49 & 3.87 \\
\hline
\end{tabular}


Table E.29: DLC performance metrics for region 4

\begin{tabular}{|c|c|c|c|c|c|c|}
\hline Index & Metric & Units & 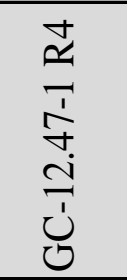 & 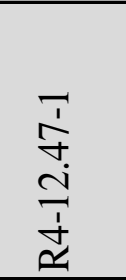 & 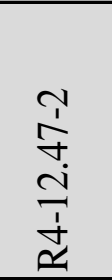 & 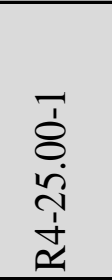 \\
\hline 1 & $\begin{array}{l}\text { Hourly Customer } \\
\text { Electricity Usage }\end{array}$ & $\mathrm{kWh}$ & 2,340 & 1,908 & 831 & 347 \\
\hline 2 & $\begin{array}{l}\text { Monthly Customer } \\
\text { Electricity Usage }\end{array}$ & MWh & 1,708 & 1,393 & 607 & 253 \\
\hline \multirow{10}{*}{3} & Peak Generation & $\mathrm{kW}$ & 6,364 & 5,281 & 2,690 & 1,217 \\
\hline & Nuclear & $\%$ & 23.58 & 21.91 & 21.91 & 21.91 \\
\hline & Solar & $\%$ & 0.00 & 0.00 & 0.00 & 0.00 \\
\hline & Bio & $\%$ & 0.21 & 0.18 & 0.18 & 0.18 \\
\hline & Wind & $\%$ & 0.59 & 0.60 & 0.60 & 0.60 \\
\hline & Coal & $\%$ & 56.06 & 57.14 & 57.14 & 57.14 \\
\hline & Hydroelectric & $\%$ & 3.09 & 2.20 & 2.20 & 2.20 \\
\hline & Natural Gas & $\%$ & 16.14 & 17.49 & 17.49 & 17.49 \\
\hline & Geothermal & $\%$ & 0.00 & 0.00 & 0.00 & 0.00 \\
\hline & Petroleum & $\%$ & 3.93 & 10.54 & 23.63 & 29.37 \\
\hline 4 & Peak Load & $\mathrm{kW}$ & 6,330 & 5,184 & 2,656 & 1,201 \\
\hline 7 & $\begin{array}{l}\text { Annual Electricity } \\
\text { Production }\end{array}$ & MWh & 20,552 & 17,190 & 7,453 & 3,116 \\
\hline 12 & $\mathrm{CO} 2$ Emissions & Tons & 10,324 & 9,850 & 3,993 & 1,606 \\
\hline \multirow{3}{*}{13} & SOx Emis sions & Tons & 4.92 & 4.73 & 1.92 & 0.77 \\
\hline & NOx Emis sions & Tons & 3.00 & 2.87 & 1.17 & 0.47 \\
\hline & PM-10 Emis sions & Tons & 1.54 & 1.47 & 0.60 & 0.24 \\
\hline \multirow[b]{2}{*}{21} & Feeder Real Load & $\mathrm{kW}$ & 2,346 & 1,962 & 851 & 356 \\
\hline & $\begin{array}{l}\text { Feeder Reactive } \\
\text { Load }\end{array}$ & kVAR & 138 & -411 & 99 & 45 \\
\hline 29 & Distribution Losses & $\%$ & 0.28 & 2.76 & 2.32 & 2.54 \\
\hline 30 & $\begin{array}{l}\text { Distribution Power } \\
\text { Factor }\end{array}$ & $\mathrm{pf}$ & 0.9982 & 0.9670 & 0.9932 & 0.9918 \\
\hline 39 & $\mathrm{CO} 2$ Emissions & Tons & 10,353 & 10,130 & 4,088 & 1,648 \\
\hline \multirow{3}{*}{40} & SOx Emis sions & Tons & 4.93 & 4.86 & 1.96 & 0.79 \\
\hline & NOx Emis sions & Tons & 3.00 & 2.95 & 1.19 & 0.48 \\
\hline & PM-10 Emissions & Tons & 1.54 & 1.51 & 0.61 & 0.25 \\
\hline
\end{tabular}


Table E.30: DLC performance metrics for region 5

\begin{tabular}{|c|c|c|c|c|c|c|c|c|c|c|}
\hline Index & Metric & Units & 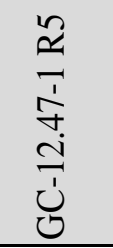 & 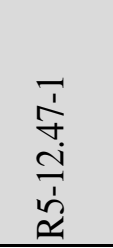 & 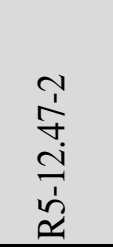 & 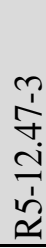 & 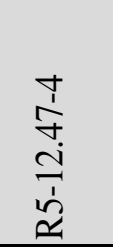 & 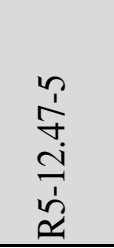 & 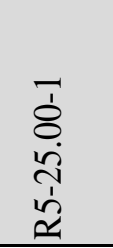 & 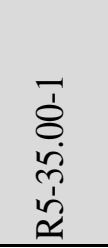 \\
\hline 1 & $\begin{array}{l}\text { Hourly Customer } \\
\text { Electricity Usage }\end{array}$ & $\mathrm{kWh}$ & 2,748 & 4,489 & 2,226 & - & 3,467 & 4,114 & 5,624 & 5,686 \\
\hline 2 & $\begin{array}{l}\text { Monthly Customer } \\
\text { Electricity Usage }\end{array}$ & MWh & 2,006 & 3,277 & 1,625 & - & 2,531 & 3,003 & 4,106 & 4,151 \\
\hline \multirow{10}{*}{3} & Peak Generation & $\mathrm{kW}$ & 6,116 & 10,659 & 5,065 & - & 8,694 & 11,579 & 15,960 & 15,864 \\
\hline & Nuclear & $\%$ & 13.85 & 13.85 & 13.85 & - & 13.85 & 13.85 & 13.85 & 13.85 \\
\hline & Solar & $\%$ & 0.00 & 0.00 & 0.00 & - & 0.00 & 0.00 & 0.00 & 0.00 \\
\hline & Bio & $\%$ & 0.33 & 0.33 & 0.33 & - & 0.33 & 0.33 & 0.33 & 0.33 \\
\hline & Wind & $\%$ & 1.48 & 1.48 & 1.48 & - & 1.48 & 1.48 & 1.48 & 1.48 \\
\hline & Coal & $\%$ & 30.17 & 30.17 & 30.17 & - & 30.17 & 30.17 & 30.17 & 30.17 \\
\hline & Hydroelectric & $\%$ & 0.63 & 0.63 & 0.63 & - & 0.63 & 0.63 & 0.63 & 0.63 \\
\hline & Natural Gas & $\%$ & 51.68 & 51.68 & 51.68 & - & 51.68 & 51.68 & 51.68 & 51.68 \\
\hline & Geothermal & $\%$ & 0.00 & 0.00 & 0.00 & - & 0.00 & 0.00 & 0.00 & 0.00 \\
\hline & Petroleum & $\%$ & 6.58 & 14.64 & 3.32 & - & 17.31 & 30.33 & 31.81 & 29.50 \\
\hline 4 & Peak Load & $\mathrm{kW}$ & 6,085 & 10,527 & 4,921 & - & 8,537 & 11,323 & 15,766 & 15,706 \\
\hline 7 & $\begin{array}{l}\text { Annual Electricity } \\
\text { Production }\end{array}$ & MWh & 24,149 & 39,798 & 19,900 & - & 30,967 & 36,901 & 49,965 & 50,459 \\
\hline 12 & $\mathrm{CO} 2$ Emis sions & Tons & 9,369 & 15,405 & 7,412 & - & 11,794 & 13,567 & 18,465 & 18,864 \\
\hline \multirow{3}{*}{13} & SOx Emis sions & Tons & 1.55 & 2.22 & 1.11 & - & 1.69 & 1.65 & 2.17 & 2.32 \\
\hline & NOx Emis sions & Tons & 1.38 & 2.11 & 1.04 & - & 1.61 & 1.71 & 2.30 & 2.39 \\
\hline & PM-10 Emis sions & Tons & 1.38 & 2.26 & 1.09 & - & 1.73 & 1.99 & 2.70 & 2.76 \\
\hline \multirow[b]{2}{*}{21} & Feeder Real Load & $\mathrm{kW}$ & 2,757 & 4,543 & 2,272 & - & 3,535 & 4,212 & 5,704 & 5,760 \\
\hline & $\begin{array}{l}\text { Feeder Reactive } \\
\text { Load }\end{array}$ & kVAR & 248 & 546 & 243 & - & 410 & 599 & 658 & 649 \\
\hline 29 & Distribution Losses & $\%$ & 0.33 & 1.19 & 2.02 & - & 1.92 & 2.34 & 1.39 & 1.28 \\
\hline 30 & $\begin{array}{l}\text { Distribution Power } \\
\text { Factor }\end{array}$ & $\mathrm{pf}$ & 0.9964 & 0.9936 & 0.9951 & - & 0.9941 & 0.9912 & 0.9940 & 0.9943 \\
\hline 39 & $\mathrm{CO} 2$ Emis sions & Tons & 9,400 & 15,590 & 7,565 & - & 12,024 & 13,891 & 18,726 & 19,110 \\
\hline \multirow{3}{*}{40} & SOx Emis sions & Tons & 1.56 & 2.25 & 1.14 & - & 1.72 & 1.69 & 2.20 & 2.35 \\
\hline & NOx Emis sions & Tons & 1.39 & 2.13 & 1.06 & - & 1.64 & 1.75 & 2.33 & 2.42 \\
\hline & PM-10 Emis sions & Tons & 1.38 & 2.29 & 1.11 & - & 1.76 & 2.03 & 2.74 & 2.80 \\
\hline
\end{tabular}




\section{References}

[1] http://www.oe.energy.gov/american_recovery_reinvestment_act.htm

[2] http://www.smartgrid.gov/sites/default/files/pdfs/metrics_guidebook.pdf

[3] http://sourceforge.net/projects/gridlab-d/

[4] J.H. Chamberlin, "Pricing and Incentives," Proceedings of the IEEE, Vol. 73, Issue 10, pp. 1513-1518, Oct. 1985.

[5] K. Schneider, Y. Chen, D. Chassin, R. Pratt, D. Engel, and S. Thompson, "Modern Grid Initiative Distribution Taxonomy Final Report", PNNL-18035, Pacific Northwest National Laboratory, Richland, Washington, 2008

[6] http://www.eia.gov

[7] D. J. Hammerstrom, et. al, "Pacific Northwest GridWise Testbed Demonstration Projects: Part I. Olympic Peninsula Project," Technical Report PNNL-17167, Pacific Northwest National Laboratories, WA, 2007.

[8] K. P. Schneider, J. C. Fuller, and D. Chassin, "Analysis of Distribution Level Residential Demand Response,” in Proc. of 2011 IEEE PSCE, Mar. 2011.

[9] J. C. Fuller, K. P. Schneider, and D. Chassin, "Analysis of Residential Demand Response and Double-Auction Markets," in Proc. of 2011 IEEE PES General Meeting, July 2011.

[10] S. D. Allen, "Energy Savings through Automatic Seasonal Run-Time Adjustment of Pool Filter Pumps," available at: http://www.tightwatt.com/learn-about-digitaltimers/white_paper.pdf.

[11] Davis Energy Group, "Codes and Standard Enhancement Initiative for PY2004: Title 20 Standards Development - Analysis of Standards Options for Residential Pool Pumps, Motors, and Controls," prepared for Pacific Gas and Electric Company, May 12, 2004.

[12] A. Jongejan, B. Katzman, T. Leahy, and M. Michelin, "Dynamic Pricing Tariffs for DTE's Residential Electricity Customers", Report No. CSS10-04, Center for Sustainable Studies, University of Michigan, April 2010.

[13] A. Faruqui and S. Sergici, "Household Response to Dynamic Pricing of Electricity - A Survey of the Empirical Evidence", February 2010.

[14] A. Faruqui and L. Wood, "Quantifying the Benefits of Dynamic Pricing in the Mass Market”, The Brattle Group, Prepared for Edison Electric Institute, January 2008.

[15] Charles River Associates, "Impact Evaluation of the California Statewide Pricing Pilot", March 2005.

[16] http://www.brattle.com/Publications/

[17] "Guidebook for ARRA Smart Grid Program Metrics and Benefits", June 2010, 331 
http://www.smartgrid.gov/federal_initiatives/featured_initiatives/smart-grid-metrics.

[18] R. S. Briggs, R. G. Lucas, Z. T. Taylor, "Climate Classification for Building Energy Codes and Standards", ASHRAE Winter Meeting, Chicago, IL, January, 2003

[19] K. Schneider, J. Fuller, F. Tuffner, and R. Singh, "Evaluation of Conservation Voltage Reduction (CVR) on a National Level), PNNL-19596, Pacific Northwest National Laboratory, Oct. 2010.

[20] W. H. Kersting, "Distribution System Modeling and Analysis, 2nd Edition", CRC Press, New York, 2007.

[21] K. Schneider, J. Fuller, and D. Chassin, "Multi-State Load Models for Distribution System Analysis", Accepted IEEE Transactions on Power Systems.

[22] Available online: http://www.energycodes.gov/implement/pdfs/climate_paper_review_draft_rev.pdf.

[23] R. G. Pratt, et. al., "Description of Electric Energy Use in Single Family Residences in the Pacific Northwest," DOE/BP 13795 21, Bonneville Power Administration, Portland, OR, 1989.

[24] IEC 2003, International Energy Conservation Code, 2003, International Code Council, Washington D.C.

[25] IEC 2001, International Energy Conservation Code, 2001, International Code Council, Washington D.C.

[26] Z. T. Taylor and R. G. Pratt, "Summary of Electrical Energy Use in the Commercial Sector,” DOE/BP 13795 22, Bonneville Power Administration, Portland, OR, 1989. 